\title{
Metalworkers and Smelting Precincts: Technological Reconstructions of Second Millennium Copper Production around Phalaborwa, Northern Lowveld of South Africa
}
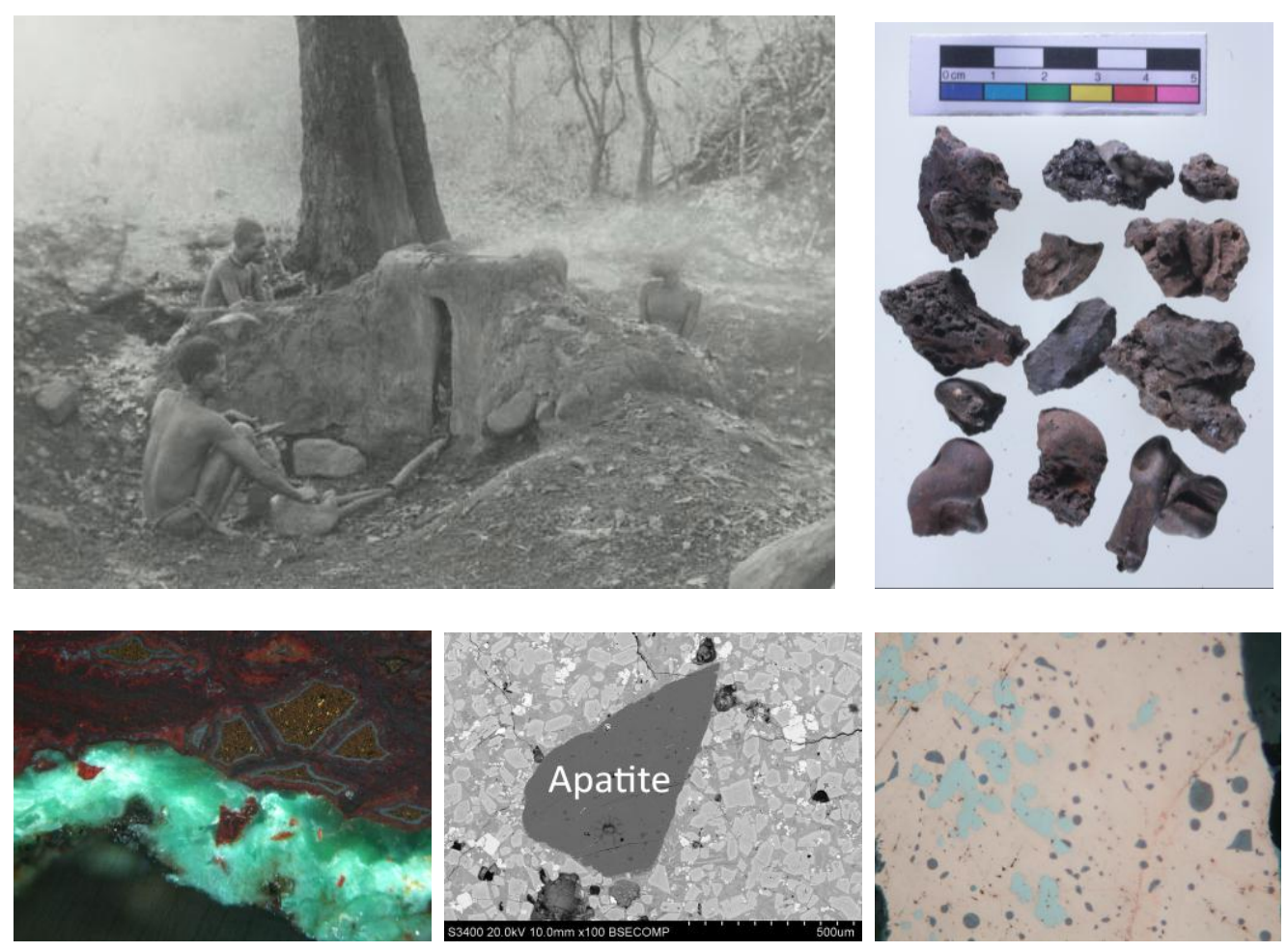

Thomas Panganayi Thondhlana

Thesis submitted for the degree of Doctor of Philosophy (PhD)

UNIVERSITY COLLEGE LONDON

Institute of Archaeology

December 2012 


\section{Declaration}

I, Thomas Panganayi Thondhlana, confirm that the work presented in this thesis is my own. Where information has been derived from other sources, I confirm that it is indicated in the thesis.

Signed:

Date: 


\begin{abstract}
This thesis examines metal production debris with the aim of reconstructing extractive metal technologies employed around Phalaborwa during the second millennium AD. Mining and metallurgy were previously identified as exclusive pulling factors for Iron Age human settlement in this agropastoral marginal area. Several Iron Age settlements with extensive metal production evidence were previously documented. This thesis places emphasis on extractive copper metallurgy previously neglected for several reasons. The early second millennium AD site of Shankare is used as the main case study. Whilst previously excavated metallurgical assemblages from late second millennium AD sites are re-investigated to explore diachronic changes in smelting technologies. The thesis is inspired by contemporary theoretical developments by the Francophone school of thought known as the 'Anthropology of Technology'.
\end{abstract}

Standard archaeological fieldwork procedures together with post-fieldwork laboratory studies were employed. Separation of copper from iron production debris visually was impossible but a combination of field observations and archaeometric approaches offered the answer. Archaeological ores, slags, technical ceramics and metal artefacts were subjected to optical microscopy, energy dispersive x-ray fluorescence spectrometry (XRF), scanning electron microscopy energy dispersive spectrometry (SEM-EDS).

Copper smelting slags differ significantly from iron smelting slags in their chemistry and microstructure. There are subtle differences in copper slags from different archaeological sites. Earlier copper slags are heterogeneous with notable unreacted minerals fragments. Despite these differences both copper and iron slags are linked to the same ore deposit known as the Palabora Igneous Complex.

The metallurgical chaînes opératoires employed in the research area are reconstructed. At Shankare copper production is represented by crushed furnace slags and secondary refining ceramic crucibles. Iron slags are confined to dedicated metallurgical middens whereas copper production debris is present at low density scatters and domestic middens. This spatial configuration confirms recent observations by other archaeologists in Southern Africa. The archaeological and analytical results permit preliminary discussions of sociotechnical systems of Iron Age metal producers in the Northern Lowveld. 


\section{Table of contents}

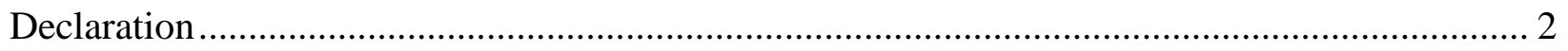

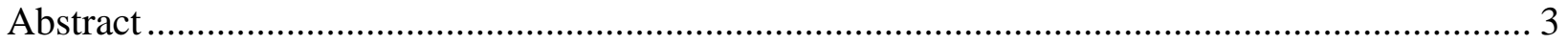

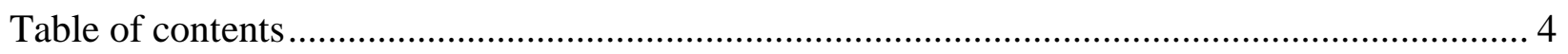

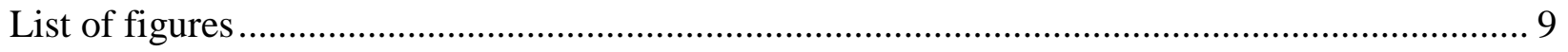

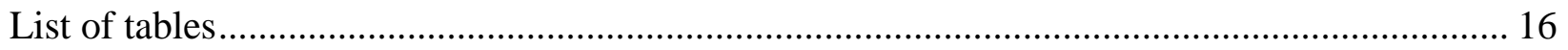

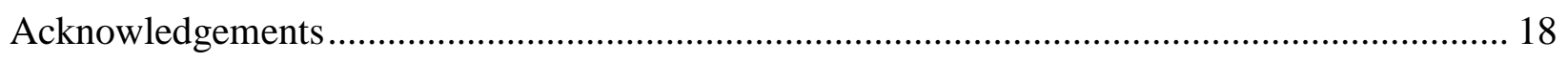

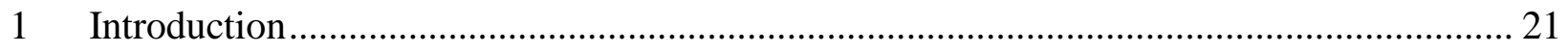

1.1 Copper-based mining and metallurgy in pre-colonial Africa.......................................... 25

1.1.1 Copper and tin deposits: pre-colonial mines.......................................................... 26

1.1.2 Extractive copper metallurgy: the missing link ................................................... 31

1.1.3 Alloying and fabrication technology .................................................................. 35

1.1.4 Trade, exchange and consumption...................................................................... 44

1.2 Research questions, aims and objectives....................................................................... 46

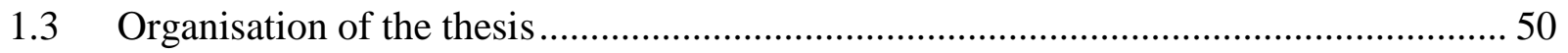

2 Theories and approaches to ancient technologies, with specific reference to African

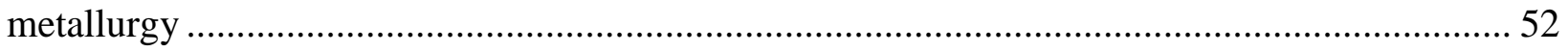

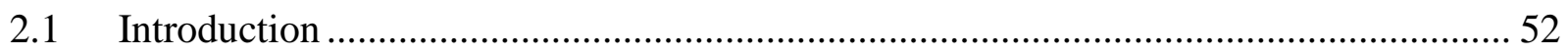

2.2 Exploring the notion of 'technology': field of study, object of study or concept? ........ 55

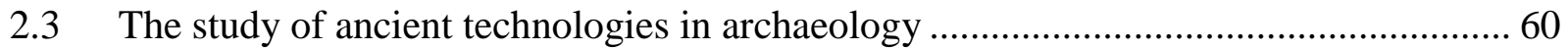

2.4 Science-based archaeological approaches and archaeometallurgy ................................ 63

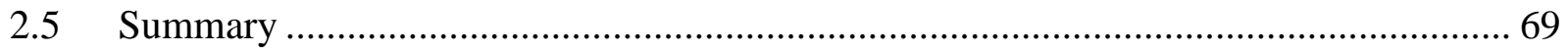

3 The research area: Phalaborwa and the Northern Lowveld, South Africa ........................... 71

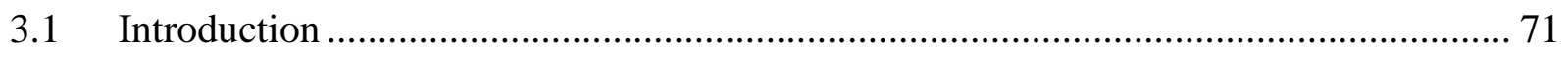

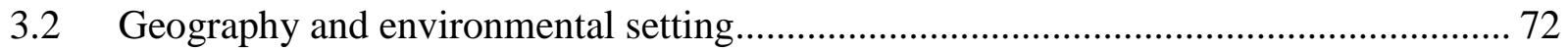

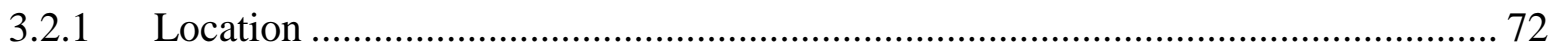

3.2.2 The current perceptions: physiography, climate, fauna and flora ............................ 74 
3.2.3 Geology, soils and mineral resources ........................................................ 79

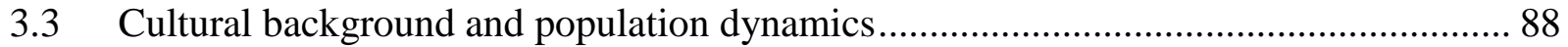

3.3.1 Archaeology: From the Early Iron Age to the $19^{\text {th }}$ century ................................ 88

3.3.2 Recent history and ethnohistory .............................................................. 91

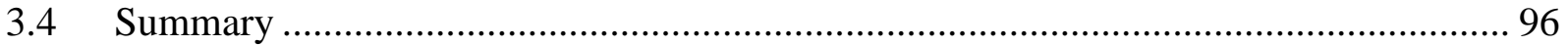

4 An overview of previous studies on Iron Age mining and metallurgy of the Northern

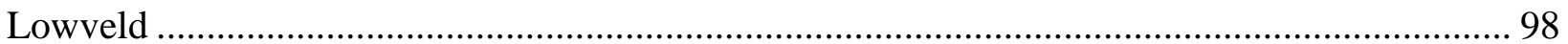

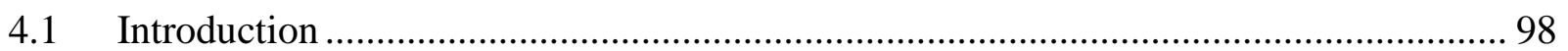

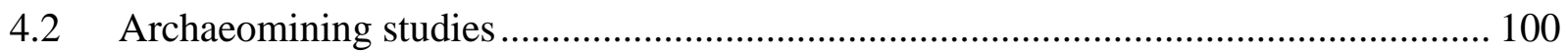

4.3 Extractive metallurgy studies: furnace designs, technical ceramics and slags ........... 107

4.4 Studies of metal artefacts .................................................................................. 123

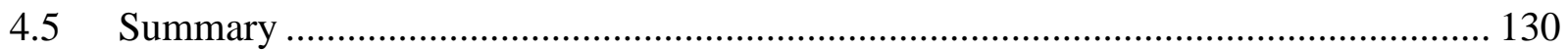

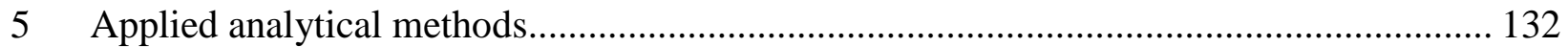

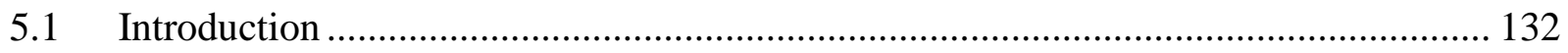

5.2 Macroscopic examination, classification and sample selection .............................. 135

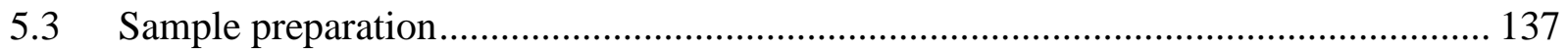

5.3.1 Polished blocks for optical microscopy and SEM-EDS ................................. 137

5.3.2 Pressed powder pellets for (P)ED-XRF .................................................. 138

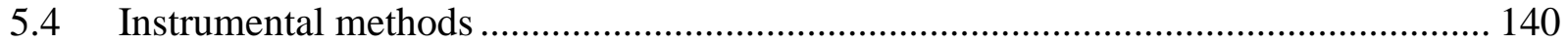

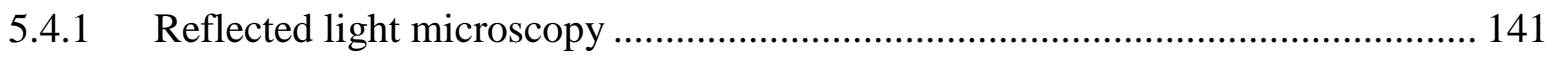

5.4.2 Scanning electron microscopy with energy dispersive $\mathrm{x}$-ray spectrometry (SEMEDS) $\quad 142$

5.4.3 Energy Dispersive X-ray fluorescence spectrometry (ED-XRF) ...................... 149

5.5 Estimation of operation parameters in archaeometallurgy .................................... 152

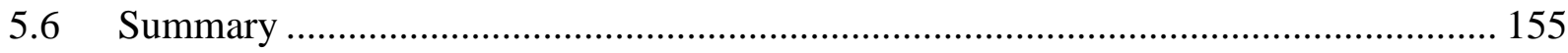

6 Shankare Hill: The archaeology and extractive copper metallurgy ................................ 156

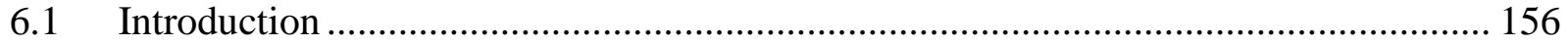

6.2 Previous investigations at Shankare Hill.......................................................... 161

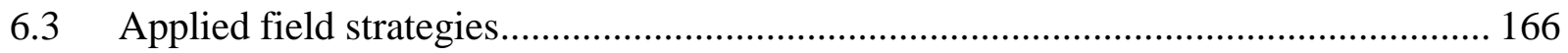

6.3.1 The survey design, implementation and results ........................................... 166

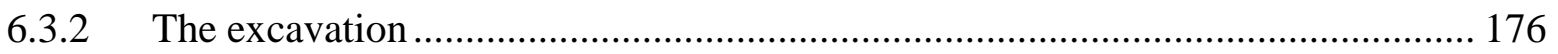


6.3.3 Overview of the archaeology of Shankare Hill............................................ 193

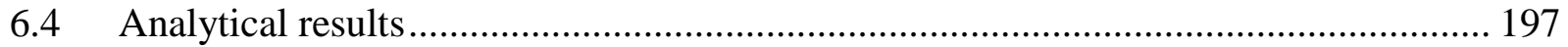

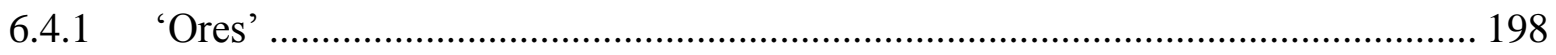

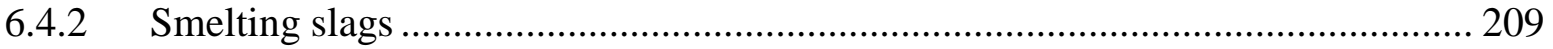

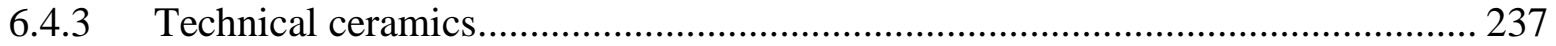

6.4.4 Metals: copper artefacts, prills and fragments ............................................. 257

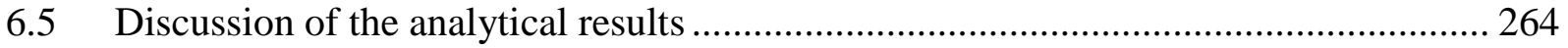

6.5.1 Establishing the nature of the smelting charge .............................................. 264

6.5.2 Establishing the temperature and redox parameters ...................................... 268

6.5.3 Quality of the copper products: raw copper vs. finished products .................... 272

6.6 Proposed extractive copper metallurgy chaîne opératoire at Shankare...................... 274

7 Collection-based investigations: Archaeology and extractive metallurgy processes at Kgopolwe, Molotho, Serotwe, Phutwane and Maranda ...................................................... 279

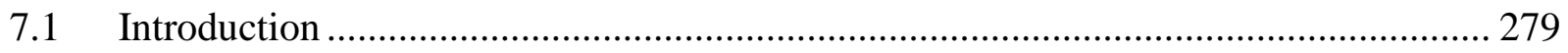

7.2 The Phalaborwa archaeometallurgical collection at UCT...................................... 283

7.3 Kgopolwe (SPK): c. $11^{\text {th }}-19^{\text {th }}$ century AD ......................................................... 285

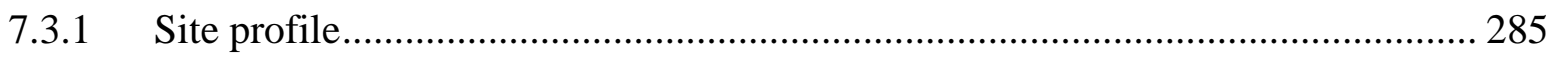

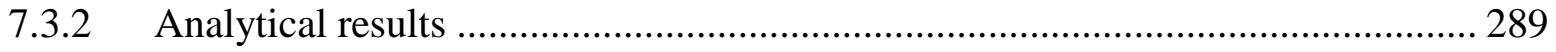

7.3.3 Brief discussion of Kgopolwe analytical results............................................ 307

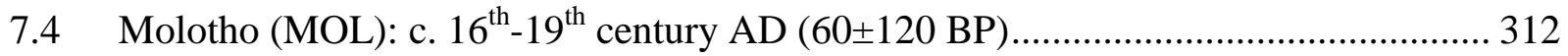

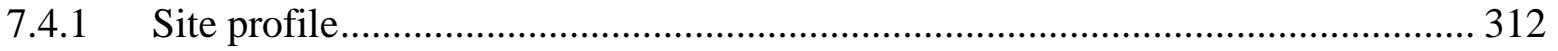

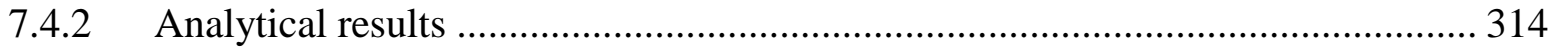

7.4.3 Brief discussion of Molotho analytical results............................................... 319

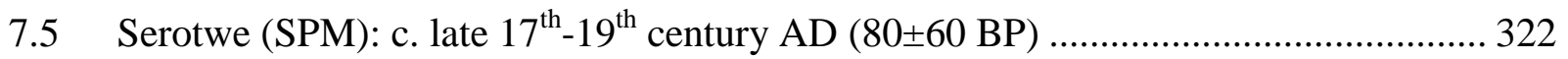

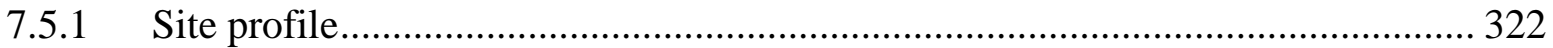

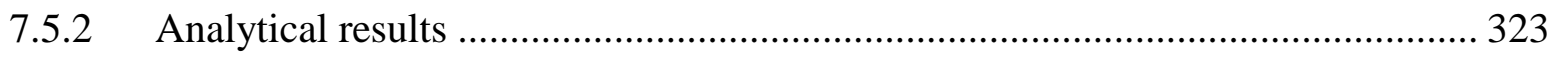

7.5.3 Brief discussion of Serotwe analytical results ............................................... 329

7.6 Phutwane (PHU): Undated ............................................................................. 331

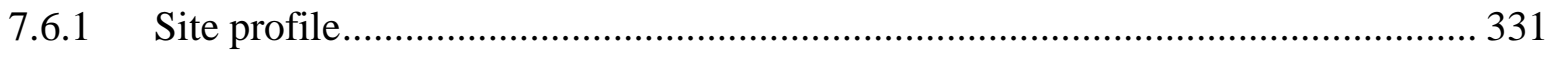

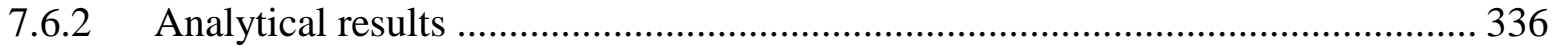


7.6.3 Brief discussion of Phutwane analytical results........................................... 345

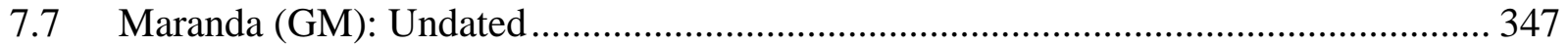

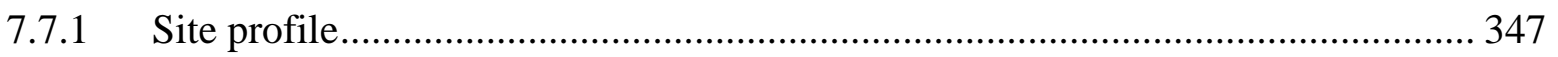

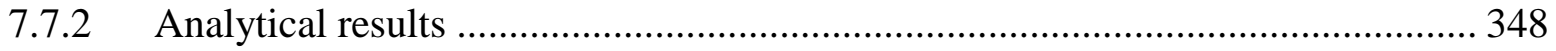

7.7.3 Brief discussion of Maranda analytical results .............................................. 351

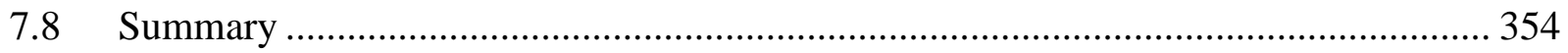

8 Second millennium AD extractive copper metallurgy: Inter-site comparisons and wider

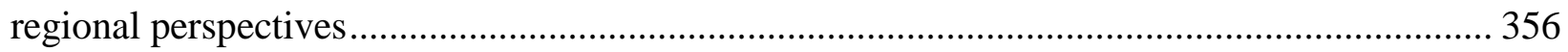

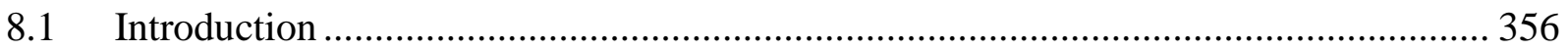

8.2 Copper and iron metallurgy: technological and regional comparisons ....................... 360

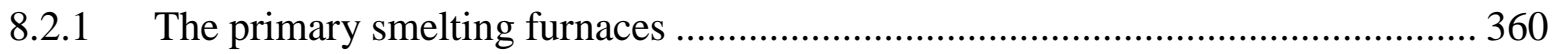

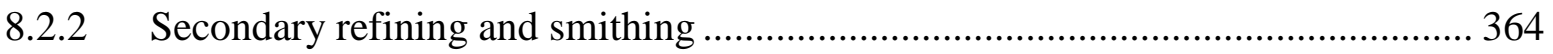

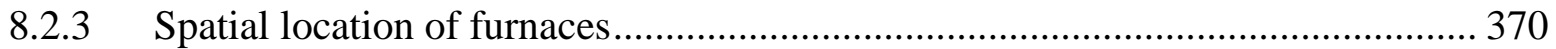

8.2.4 Archaeological visibility: slag heaps and slag appearance ............................... 371

8.3 Variability and efficiency in copper production technology .................................... 374

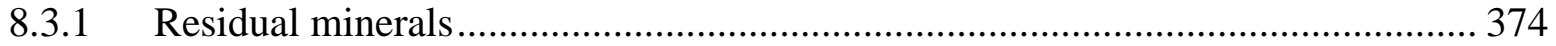

8.3.2 Diachronic variation and regional comparisons ............................................ 380

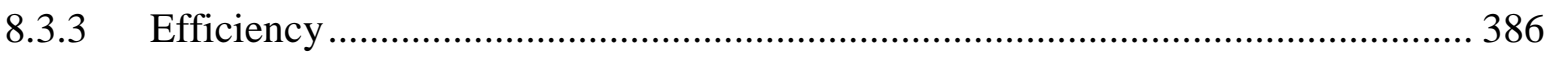

8.4 Copper-base products: a general commentary on cultural preferences..................... 387

8.5 Phalaborwa metallurgists: Their socio-cultural and economic roles and status........... 389

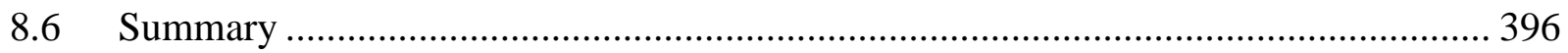

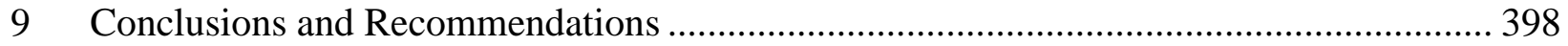

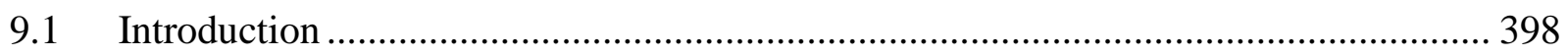

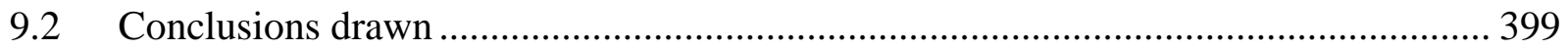

9.3 Lessons and directions for future research ........................................................ 406

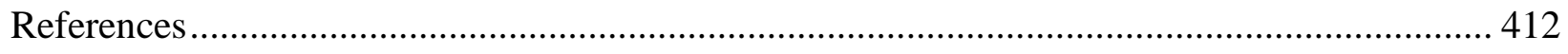

Appendix 1: Precision and accuracy of instrumental methods ............................................. 440

Appendix 2: Inventory of samples subjected to analytical work ......................................... 447

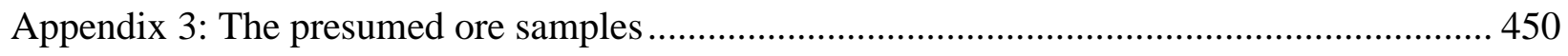

Appendix 4: The slagged crucible fragments from Shankare Hill ...................................... 471 


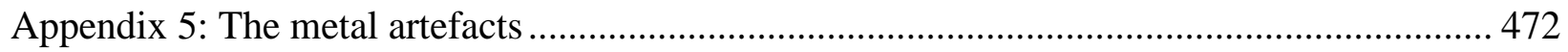

Appendix 6: Full (P)ED-XRF bulk composition data of slag samples from Shankare Hill ...... 480 


\section{List of figures}

Figure 1.1: Map of Africa showing the location of the twenty well known pre-colonial copper mines (Adopted from Bisson 1997).1(Akjoujt), 2 (Nioro-Siracoro), 3 (Azelik and Afunfun), 4 (Agadez), 5 (Hufrat en-Nahas), 6 (Kilembe), 7(Niari),8 (Bembe), 9 (Kolwezi), 10 (Benguela), 11 (Kansanshi), 12 (Lubumbashi), 13 (Ndola), 14 (Tsumeb), 15 (Umkondo), 16 (Rehoboth), 17 (Tati), 18 (Messina/Musina), 19 (Phalaborwa), 20 (O’Okiep).

Figure 1.2: A $9^{\text {th }}-10^{\text {th }}$ century roped leaded copper pot from Igbo Isaiah (Igbo-Ukwu), Nigeria (Image: courtesy of http://www.nairaland.com/618904/igbo-ukwu-ca-9th-century)................. 39

Figure 1.3: A cast brass plaque from Benin City, Nigeria. This $16^{\text {th }}$ century cast is on display at the British Museum, London (Image: Author). 39

Figure 1.4: The Queen mother bronze head from Benin City, Nigeria. This cast dating between the $15^{\text {th }}-16^{\text {th }}$ century is also on display at the British Museum, London (Image: Author). 40

Figure 2.1: Extract of a newspaper article by David Bullard (The Times, South Africa, 06 April 2008). 56

Figure 3.1: Map of the Northern Lowveld showing the location of Phalaborwa (Map: Adapted from Klapwijk 1986b). 73

Figure 3.2: Landscape view of the Northern Lowveld showing the typical bushveld and vast plains with isolated koppies (View from Shankare Hill in August 2010). 76

Figure 3.3: Generalised map of Southern Africa showing the position of the Kaapvaal Craton within the major geological events of the sub-continent (Adopted from Groves \& Vielreicher 2001). 80

Figure 3.4: The detailed geology of the Palabora Igneous Complex showing the major lobes and position of the current PMC copper mining open pit. (Map: Adapted from Viljoen \& Reimold 1999). 82

Figure 3.5: Typical Iron Age hoes from Phalaborwa that were widely traded and used as bride wealth. The hoes are on display at Masorini Archaeological Site Museum (Image: Author)..... 95 Figure 4.1: Satellite image showing the open pit where Lolwe Hill used to be situated (Image: Courtesy of Google Earth, modified by the author). 106

Figure 4.2: Floor/base plans of three furnace designs documented in the Northern Lowveld. (a) Venda Furnace with a circular plan and three tuyère port entrances, (b) Phalaborwa Furnace with a triangular plan also accompanied by three tuyère port entrances, (c) Lolwe Furnace with one tuyère port entrance. Note that central circle represent the position of the 'medicine hole'. (Image: Author but not drawn to scale). 111

Figure 4.3: Lolwe furnace on display at Foskor Museum excavated by Julius Pistorius presumably at Shankare Hill in the late 1980s. The red arrow shows the location of the tuyère port entrance and the circle shows the shaft used to charge the furnace. (Image: Author)....... 112 
Figure 4.4: Sketch diagrams of Iron Age furnace designs of the Northern Lowveld showing the position of the 'medicine hole'. (Image: Adapted from Schwellnus 1937, 910). 113

Figure 4.5: Tuyères manufactured with the 'pressure method' showing the longitudinal marks left by narrow sticks that were wrapped around the wet clay paste. (Image: Reproduced from Klapwijk 1986b, 19). 118

Figure 4.6: Tuyères from archaeological sites around Phalaborwa on display at Foskor Museum. Note that some of them are trumpet-shaped (Image: Author).

Figure 4.7: A cast form of a plano-convex ingot that was recovered from Kgopolwe (SPK III), Phalaborwa. This ingot is in the teaching collection at the University of Cape Town (UCT) (Image: Author). 128

Figure 4.8: Golf club-shaped ingots known as 'marale' typically manufactured around Phalaborwa during the Iron Age. These ingots are displayed at Foskor Museum (Image: Author). 129

Figure 6.1: An example of unwanted guests, in this particular instance an elephant, that frequently disrupted the surveys and excavations at Shankare Hill in the 2010 fieldwork season (Image: Author).

Figure 6.2: Satellite image of the twin koppies of Shankare, circled in red, dissected by an access road. (Image: Courtesy of Google Earth, modified by the author). 160

Figure 6.3: Site plan of Shankare produced by Mason based on his fieldwork at the site during the 1960s (Adapted from Mason 1986, 117). 162

Figure 6.4: View of Shankare Hill from the vantage point of the mining tailing dump in the north, August 2010 (Image: Author). 173

Figure 6.5: Terraced platforms on the northern hillside slopes of Shankare (Image: Author).. 173 Figure 6.6: Rock boulders with dolly holes together with dimpled hammer stones (Image: Author). 174

Figure 6.7: Example of rocks with dolly holes documented at Shankare during the surveys (Image: Author). 174

Figure 6.8: Sketch plan of the activity areas and excavation trenches (Map compiled by GEMScience from GPS coordinates gathered during the final season fieldwork). 175

Figure 6.9: Impressive quantity of slag from the SHASH1 trench, Unit B2. Scale of excavation unit is $1 \times 1 \mathrm{~m}$ (Image: Author).

Figure 6.10: Part of the tuyère fragments recovered from SHASH1 trench (Image: Author). . 179 Figure 6.11: Excavation in progress at SHAM1 domestic midden (Image: Louisa Hutten)..... 181 Figure 6.12: Section illustrations from trench SHAM1 showing the stratigraphic units (Image: Author).

Figure 6.13: North-western section of SHAM1 (Unit A1) at Shankare domestic midden with in situ tuyères (Image: Louisa Hutten). 183

Figure 6.14: Typical glass beads from late second millennium AD contexts at Masorini in the Kruger National Park (Image: Abigail Moffett). 185 
Figure 6.15: Typical Kgopolwe pottery with necked jars from midden SHAM1 presumably dating to the 10th-13th century (Drawing by Foreman Bandama). 186

Figure 6.16: Necked jars decorated with fine line incision presumably related to the 10th-13th Kgopolwe pottery from midden SHAM1 (Drawing by Foreman Bandama). 187

Figure 6.17: Profiles of undecorated spherical jars retrieved from midden SHAM1 (Drawing by Foreman Bandama). 188

Figure 6.18: Examples of bowl fragments from SHAM1 midden decorated with red ochre and graphite burnishing a later occurrence around Phalaborwa (Drawing by Foreman Bandama). 189 Figure 6.19: Undecorated bowl fragments from the SHAM1 midden excavation (Drawing by Foreman Bandama). 190

Figure 6.20: Human burial accidentally exposed during the excavation of Unit B8 Trench SHAM1 (Image: Louisa Hutten). .................................................................................. 192

Figure 6.21: Copper carbonate mineral samples from Shankare (Group 1)........................... 199

Figure 6.22: Magnetite fragment with adhering malachite on the surface (Group 3)............. 199 Figure 6.23: Photomicrographs of presumed ore sample SHA13NEL showing brassy chalcopyrite surrounded by thin light blue rims of chalcocite enclosed together in a copper ironbearing red matrix. The green matrix is malachite. Left photomicrograph under cross polarised light. Right photomicrograph taken under plane polarized light (200x magnification)............ 204 Figure 6.24: SEM-BSE image of presumed ore sample SHA13NEL showing the composition of the isolated residual chalcopyrite. Results are presented in atom \% and normalised to 100\% . 204 Figure 6.25: SEM-EDS image of sample SHA13NEL. Results presented in atom \%............. 204 Figure 6.26: SEM-BSE image of presumed ore sample SHA13NEL showing the composition of the oxidised matrix surrounding the residual sulphides. Results are presented in wt\% and not normalised to $100 \%$. 205

Figure 6.27: Example of "flow-type" slags which solidified from fully molten state inside the furnace (Image: Author). 211

Figure 6.28: Examples of "crushed-type" slags with notable residual minerals suggesting they were not fully molten (Image: Author). 211

Figure 6.29: SEM-BSE image of sample SHA2NEL showing the dominant blocky olivines and ulvospinels. Microstructure of iron smelting slags in Group 1. 216 Figure 6.30: SEM-BSE image of sample SHA8NEL showing the dominant wüstite dendrites and olivines. Typical microstructure of Group 2 iron smelting slags. 216 Figure 6.31: SEM-BSE image of copper slag SHA9NWL showing fully crystallised olivines and pseudomorphs of natural magnetite. 220

Figure 6.32: Photomicrograph of sample SHAMK27(3) showing magnetite band. Under plane polarised light $(100 \mathrm{x})$. 221

Figure 6.33: SEM-BSE image of sample SHAMK18(2) also showing magnetite bands. ....... 221 Figure 6.34: Photomicrographs of copper prills trapped inside slag samples SHA7NWL (Top) showing Fe-O phases in copper prill. SHAMK18(3) (Bottom) showing copper sulphide 'rims' surrounding copper prills. Under plane polarised light (500x) 224 
Figure 6.35: Photomicrographs of copper prills trapped inside slag samples SHA8NWL (Top) and SHAMK18(3) (Bottom). Both showing exsolved iron (light blue) and copper sulphide inclusions (dark green). Under plane polarised light (200x). 225

Figure 6.36: SEM-BSE image showing undissolved minerals embedded in the slag matrix of sample SHA8NWL. 228

Figure 6.37: Macroscopic residual magnetite fragments in the polished blocks of copper smelting slags from Shankare. 228

Figure 6.38: Photomicrographs of residual chalcopyrite entrapped in sample SHAMK7(1) (Top) and secondary copper compounds resulting from post-depositional corrosion in sample SHAMK18(1)(Bottom). Under plane and cross polarised light respectively.

Figure 6.39: SEM-BSE images of slag sample SHA1NWL. Image (A) is showing phosphoric iron prills surrounding the slag matrix. Image (B) is showing the micrometric copper and matte prills in the slag matrix. 233

Figure 6.40: Plot of titania against phosphorous pentoxide showing the distinction between $\mathrm{TiO}_{2}$ rich iron slags from $\mathrm{P}_{2} \mathrm{O}_{5}$ rich copper slags. Data based on 'bulk' SEM-EDS area scans. ........ 235 Figure 6.41: Tuyère fragment (nozzle) from trench SHASH1 (Image: Author)....................... 243 Figure 6.42: SEM-BSE image of the non-vitrified part of tuyère sample SHA25NEL showing the well rounded, unshattered mineral inclusions and bright ilmenite inclusions. 243

Figure 6.43: Images comparing the slagged and vitrified interiors with the unvitrified exteriors of crucible fragments from Shankare (Image: Author). 253

Figure 6.44: Iron Age clay-based crucibles from Phalaborwa on display at Foskor Museum. Please note that the impression given on the museum label is that these crucibles were used for primary copper smelting (Image: Author). 254

Figure 6.45: Mounted polished blocks of crucible fragments from Shankare Hill (Image:

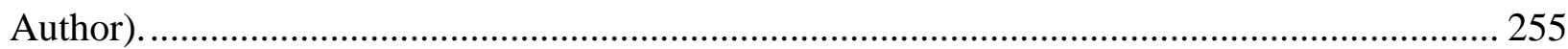

Figure 6.46: SEM-BSE images showing non-shattered quartz inclusion and slag temper in crucible sample SMB21(3). 256

Figure 6.47: Photomicrograph of metal prills adhering to crucible SMB21(3) showing the effects of oxidation during the melting process which resulted in the formation of cuprite. Top left: under plane polarised light (500x), Top right: under cross polarised light (500x), Bottom left: under plane polarised light (500x), Bottom right: under cross polarised light (500x)..... 256 Figure 6.48: Part of the copper metal artefacts recovered from Shankare between 2009 and 2010 (Image: Author). 260

Figure 6.49: Rigid copper bangles from Iron Age sites in the research area. These bangles are on display at Foskor Museum, Phalaborwa (Image: Author). 261

Figure 6.50: Photomicrographs of sample SMB81 showing the copper dendrites together with the network of copper/cuprite eutectic. All images taken under plane polarised light and polished section is not etched (Image: Author). 262

Figure 6.51: Plot of 'bulk' SEM-EDS results of Shankare smelting slag samples on a $\mathbf{F e O}-\mathbf{S i O}_{\mathbf{2}}$ $\left(\mathrm{TiO}_{2}+\mathrm{Al}_{2} \mathrm{O}_{3}\right)-\mathbf{C a O}\left(+\mathrm{MgO}+\mathrm{P}_{2} \mathrm{O}_{5}\right)$. (Phase diagram adapted from Kowalski et al. 1995, 126). 270 
Figure 6.52: Schematic representation of the proposed chaîne opératoire of copper production reconstructed from Shankare metallurgical debris (Image: Author). 278

Figure 7.1: Map showing the location of archaeological sites discussed in this chapter (Map adapted from South Africa Map Sheets, 2431AA Grietjie and 2331CC Phalaborwa of 1987). Maranda is further afield, about $60 \mathrm{~km} \mathrm{NW}$ of Phalaborwa (Image: Author). 282

Figure 7.2: Presumed ore samples from Kgopolwe SPK III. Sample SPK3 1 is in the bottom right corner and SPK3 2 is situated in the centre bottom row (Image: Author). 290

Figure 7.3: (a) Resin mounted section of ore sample SPK3 1 two matrices. (b) Photomicrograph of the outer blue matrix of SPK3 1 presumably azurite. Photomicrograph under cross polarised light (200x magnification) (Image: Author). 294

Figure 7.4: (Top) Photomicrograph of sample SPK 31 showing dominant golden coloured chalcopyrite inside an iron-copper secondary mineral matrix. Photomicrograph under plane polarized light at 50x magnification. (Bottom) SEM-BSE image of sample SPK3 1 showing the chemistry of chalcopyrite inclusions and surrounding secondary iron-copper matrix (Image: Author). 295

Figure 7.5: SEM-BSE image showing chemistry of the blue-green outer matrix sample SPK3 1(Image: Author). 296

Figure 7.6: Photomicrographs of ore sample SPK3 2, (a) showing an outer thin layer of green copper mineralisation (b) showing the dominant inner secondary iron copper member. Both photomicrographs under cross polarised light (Image: Author).

Figure 7.7: SEM-BSE image of sample SPK3 2 showing the chemistry of chalcopyrite inclusions and the surrounding secondary iron-copper matrix (Image: Author). 297

Figure 7.8: Five selected copper slags from Kgopolwe that are notably very porous (Image: Author). 299

Figure 7.9: Photomicrographs showing magnetite-rich slags (SPK6 1F) against olivine dominated slags (SPK6 4F). Photomicrographs taken under plane polarized light (100x magnification)... .. 304

Figure 7.10: SEM-BSE images of sample SPK6 3F showing some unreacted magnetite and fluorapatite mineral grains embedded in the slag matrix. 305

Figure 7.11: Photomicrograph (Top) and SEM-BSE image (Bottom) of one of the several 'black copper' prills entrapped in slag sample SPK6 4F. 306

Figure 7.12: Ternary phase diagram showing system $\mathrm{FeO}-\mathrm{SiO}_{2} \quad\left(+\mathrm{TiO}_{2}+\mathrm{Al}_{2} \mathrm{O}_{3}\right)-\mathrm{CaO}$ $\left(\mathrm{MgO}+\mathrm{P}_{2} \mathrm{O}_{5}\right)$, with plots of copper slags and ores from Kgopolwe (phase diagram adapted from Kowalski et al. 1995, 126). Data used in this diagram is present in Table 7.2, Table 7.5 and Table 7.6. 311

Figure 7.13: Photograph of the Lolwe type furnace at Molotho taken by C. E. More during the 1960s (Image: Reproduced from van der Merwe 1980, 484).

Figure 7.14: Irregular copper slags from Molotho with notable charcoal impressions (Image: Author). 314 
Figure 7.15: Reflected light photomicrographs of copper smelting slags from Molotho. Showing the dominant magnetite spinels embedded in blocky olivines and pyroxenes. Photomicrographs captured under plane polarized light (200x magnification)........................ 318

Figure 7.16: Ternary phase diagram showing system $\mathrm{FeO}-\mathrm{SiO}_{2} \quad\left(+\mathrm{TiO}_{2}+\mathrm{Al}_{2} \mathrm{O}_{3}\right)-\mathrm{CaO}$ $\left(\mathrm{MgO}+\mathrm{P}_{2} \mathrm{O}_{5}\right)$, with plots of copper slags from Molotho (Phase diagram adapted from Kowalski et al. 1995, 126). Data used in this diagram is present in Table 7.8 ....................................... 321

Figure 7.17: Photomicrograph and SEM-BSE image of the wüstite dominated iron slag SPM3C(1) from Serotwe (Image: Author) ..................................................................... 324

Figure 7.18: Serotwe slag samples SPM1(1) showing charcoal impressions and SPM1(4) with embedded charcoal fragments.................................................................................. 328

Figure 7.19: Reflected light photomicrographs of copper slags from Serotwe illustrating the presence of blocky olivines and/or pyroxenes, magnetite spinels and copper prills. Under plane

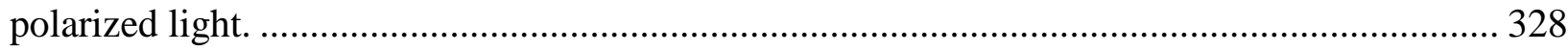

Figure 7.20: Ternary phase diagram showing system $\mathrm{FeO}-\mathrm{SiO}_{2} \quad\left(+\mathrm{TiO}_{2}+\mathrm{Al}_{2} \mathrm{O}_{3}\right)-\mathrm{CaO}$ $\left(\mathrm{MgO}+\mathrm{P}_{2} \mathrm{O}_{5}\right)$, with plots of copper and iron slags from Serotwe (Phase diagram adapted from Kowalski et al. 1995, 126). Data used in this diagram is present in Table 7.10 and Table 7.11.330 Figure 7.21: Satellite image of the cluster of koppies of Phutwane showing the location of metallurgical debris. The red square shows the location of the forge and the blue triangle represents the dedicated slag scatters (Image: courtesy of Google Earth). 334

Figure 7.22: The forge site with large hammer stones and few tuyère fragments under large rock boulders at Phutwane Hills (Image: Author). 335

Figure 7.23: A large hammer stone and anvil documented at the forge area at Phutwane Hills (Image: Author).

Figure 7.24: Microstructure of iron slags in Group 1. Photomirograph of sample PHU1NL showing blocky olivines, pinkish angular ulvospines and isolated iron particles. .................... 338 Figure 7.25: Microstructure of iron slag samples in Group 2. Photomicrograph of iron slag sample PHU1SM showing the dominant wüstite dendrites surrounded by olivines with isolated metallic iron particles. 338

Figure 7.26: Plot of iron oxide against silica showing the silica-rich slags (Group 1) and ironrich slags (Group 2). Data taken from bulk SEM-EDS results in Table 7.13. 339 Figure 7.27: Scatter plots of $\mathrm{TiO}_{2}$ against $\mathrm{P}_{2} \mathrm{O}_{5}$ and $\mathrm{FeO}$ against $\mathrm{CaO}$. The scatter plots show differences in the bulk chemistry of copper and iron slags from Phutwane. 343 Figure 7.28: SEM-BSE image of copper slags PHU2SM and PHU5SM showing the dominant blocky olivines (midgrey) and sparse magnetite spinels (bright). ........................................ 344 Figure 7.29: Ternary phase diagram showing system $\mathrm{FeO}-\mathrm{SiO}_{2} \quad\left(+\mathrm{TiO}_{2}+\mathrm{Al}_{2} \mathrm{O}_{3}\right)-\mathrm{CaO}$ $\left(\mathrm{MgO}+\mathrm{P}_{2} \mathrm{O}_{5}\right)$, with plots of copper and iron slags from Phutwane (phase diagram adapted from Kowalski et al. 1995, 126). Data used in this diagram is present in Table 7.13 and Table 7.15.346 Figure 7.30: Left: BSE image of copper slag sample GM10M showing spinifex textured fayalite crystals. Right: Photomicrograph of copper slag sample GM10M showing a bluish matte prill together with red copper prills. Under plane polarised light (500x magnifications)................ 350 
Figure 7.31: Ternary phase diagram showing system $\mathrm{SiO}_{2}-\mathrm{FeO}-\mathrm{Al}_{2} \mathrm{O}_{3}$, with plots of a copper slag from Maranda (Phase diagram adapted from Kowalski et al. 1995, 111). Data used in this diagram is present in Table 7.16.

Figure 8.1: Map of some Southern African countries showing the location of relevant archaeological sites mentioned in this chapter (Image: Adapted from Miller 2002, 1084). ...... 359

Figure 8.2: Kaonde copper refining furnace with a cooking pot used as a crucible inside (Image: Adapted from Bisson 1997, 129). 369

Figure 8.3: Plot of 'bulk' SEM-EDS results of copper smelting slag samples from Phalaborwa on a $\mathrm{FeO}-\mathrm{SiO}_{2}\left(\mathrm{TiO}_{2}+\mathrm{Al}_{2} \mathrm{O}_{3}\right)-\mathrm{CaO}\left(+\mathrm{MgO}+\mathrm{P}_{2} \mathrm{O}_{5}\right)$. (Phase diagram adapted from Kowalski et al. 1995, 126). 382

Figure 8.4: Scatter plots showing the relationship between $\mathrm{FeO}, \mathrm{SiO}_{2}$ and $\mathrm{CaO}$ in the copper smelting slags from various sites around Phalaborwa 383

Figure 8.5: Scatter plot showing concentration of $\mathrm{P}_{2} \mathrm{O}_{5}$ against $\mathrm{Al}_{2} \mathrm{O}_{3}$ of copper smelting slags from Molotho and Shankare. 384

Figure 8.6: Comparisons of the averages major oxides of bulk chemistry of copper slags from Southern African archaeological sites. For the Marothodi data see Hall et al. 2006; Kleinfontein data see Miller et al. 1995 or Miller \& Killick 2004; Rehoboth data see Sandelowsky \& Miller 1999. 385

Figure 8.7: Part of the personal adornments from Shankare (SHAM1) made from locally available shell and a single East African coast conus shell. 394 


\section{List of tables}

Table 4.1: Radiocarbon dates of Iron Age copper mining activities in the Northern Lowveld. The dates were calibrated with Oxcal 4.1 and IntCal 09 by the author. 102

Table 4.2: Available published radiocarbon dates of three tuyère port furnaces documented in the Northern Lowveld. The dates were calibrated with Oxcal 4.1 and IntCal 09 by the author. 114 Table 4.3: Available published radiocarbon dates of single tuyère port furnaces in the Northern Lowveld. The dates were calibrated with Oxcal 4.1 and IntCal 09 by the author. 115

Table 6.1: Available analytical results of slags from Shankare in Pistorius $(1989,564)$......... 166 Table 6.2: Radiocarbon dates from midden SHAM1 excavation unit B2. These dates were calibrated by Beta Analytic Inc. with IntCal04. 185

Table 6.3: Average SEM-EDS results of at least five area scans of the presumed ore samples recovered from Shankare (wt\%). Results not normalised due to the presence of structural water and carbonates prevalent in secondary ores. 206

Table 6.4: Average SEM-EDS 'bulk' chemical results of iron production slags from Shankare. The results presented are in wt\% and normalised to $100 \%$. The last column shows the silica to alumina ratio. 217

Table 6.5: Average ED-XRF bulk chemical results of iron production slags from Shankare. Results presented in wt\% and not normalised. The last column shows the silica to alumina ratio.

Table 6.6: Data showing the presence $(\boldsymbol{})$ and absence of unreacted and partially reduced minerals embedded in the copper smelting slags. 227

Table 6.7: Average SEM-EDS 'bulk' chemical results of copper slags. The results are normalised to $100 \&$ presented in $\mathrm{wt} \%$. 231

Table 6.8: Average SEM-EDS results of five area scans of the ceramic fabrics of Shankare tuyères. Reported results in wt \% and normalised to $100 \%$. 244

Table 6.9: Average SEM-EDS results of at least five area scans on the ceramic fabrics of each crucible fragment. Results in wt $\%$ and normalised to $100 \%$.

Table 6.10: Average SEM-EDS results of five area scans of metallurgical debris attached to Shankare crucible fragments. Results in wt\% and normalised to $100 \%$. 250

Table 6.11: SEM-EDS results of the polished copper artefacts together with their inclusion chemistry. Results are normalised and presented as wt $\%$. 263

Table 7.1: Inventory of metallurgical debris by weight (g) from selected archaeological sites housed at UCT. 284

Table 7.2: Average SEM-EDS results of at least five area scans of the presumed ore samples from Kgopolwe (SPK III) in wt\%. Results are not normalised due to the presence of structural water and carbonates prevalent in these ores. 298 
Table 7.3: Average of five SEM-EDS analysis of the dominant olivines in the Kgopolwe copper slags. The results are presented in atomic $\%$ and normalised............................................ 301

Table 7.4: Chemistry of some unreduced fluorapatite minerals in the copper slags from Kgopolwe. The results are presented in wt $\%$ and normalised........................................... 301

Table 7.5: Average SEM-EDS 'bulk' chemical results of copper smelting slags from Kgopolwe SPK VI. The results are presented in wt\% and normalised to $100 \%$. The last column is showing the silica to alumina ratio.

303

Table 7.6: Previously published SEM-EDS bulk chemical results of copper smelting slags from Kgopolwe SPK III (Miller \& Killick 2004, 41). 303

Table 7.7: SEM-EDS results of the analysed olivines and pyroxenes associated with copper slags from Molotho. The results are presented in atomic $\%$ and normalised. 316

Table 7.8: Average SEM-EDS 'bulk' chemical results of copper smelting slags from Molotho. The results are presented in wt $\%$ and normalised to $100 \%$. The last column is showing the silica to alumina ratio.

Table 7.9: SEM-EDS results obtained from the analysis of olivines and pyroxenes documented in Serotwe copper slags. The results are presented in atomic $\%$ and normalised. 325

Table 7.10: Average SEM-EDS 'bulk' chemical results of iron smelting slag SPM3C(1) from Serotwe. The results are presented in wt\% and normalised to $100 \%$. The last column is showing the silica to alumina ratio. 327

Table 7.11: Average SEM-EDS 'bulk' chemical results of copper smelting slags from Serotwe. The results are presented in wt $\%$ and normalised to $100 \%$. The last column is showing the silica to alumina ratio. 327

Table 7.12: Distribution of major oxides in the iron slag phases. All the remaining oxides are present in the interstitial glass. X: present as a major oxide. -: absent. 337

Table 7.13: Average SEM-EDS 'bulk' chemical results of iron slags from Phutwane. The results are presented in $\mathrm{wt} \%$ and normalised to $100 \%$. The last column is showing the silica to alumina ratio. 340

Table 7.14: Average of five SEM-EDS analysis of silicate crystals in the Phutwane copper slags. Results in wt\% and normalised to $100 \%$. 342

Table 7.15: Average SEM-EDS 'bulk' chemical results of copper slags from Phutwane. The results are presented in wt $\%$ and normalised to $100 \%$. The last column is showing the silica to alumina ratio. 342

Table 7.16: Averaged SEM-EDS 'bulk' chemical results of copper slag GM10M1. The results are presented in wt $\%$ and normalised to $100 \%$. The last column is showing the silica to alumina ratio. 350

Table 8.1: Compositional results of river bed sands from the local river systems that were analysed by David Killick (Killick \& Miller, in press). Sand A was collected from a stream bed near Matsepe (Serotwe) Hill and Sand B from the bed of the Ga-Selati River. 380 


\section{Acknowledgements}

"If I have seen further, it is by standing on the shoulders of giants" Isaac Newton 1642-1727.

Many individuals and organisations deserve to be mentioned here for their invaluable assistance and passion that saw the completion of this thesis. First I would like to thank my sponsors UCL Dorothy Hodgkin Postgraduate Award (DHPA) and the Institute of Archaeo-Metallurgical Studies (IAMS) who assisted me financially to pursue this research programme. UCL Graduate School also provided financial assistance for the several fieldwork trips and conference meetings abroad. IAMS also provided a grant which allowed me to come back to London to revise and submit this thesis. I would also like to thank the South African Heritage Resources Agency (SAHRA) who issued permits for archaeological fieldwork to be carried out around Phalaborwa (Permit No. 80/09/08/015/50). SAHRA also issued export permits which allowed analytical and invasive sampling to be undertaken in London (Permit No. 80/08/08/012/52). Access granted by the Palabora Mining Company (PMC) and Palabora Heritage Committee to conduct archaeological surveys at Shankare Hill and Phutwane Hills situated in their Cleveland Private Game Park is also gratefully acknowledged. It would have not been possible to commence with this research without the support of the Department of Archaeology, University of Cape Town (UCT) who initiated me into South African archaeology for a whole academic year between September 2007 and September 2008.

Various individuals assisted in their own capacity to ensure that this project was at least finished before the deadline. In Phalaborwa, 1 would like to thank the management of PMC in particular Mr J van Dyk, who gave us permission to work on their property and provided several facilities that enabled us to carry out the fieldwork. The assistance, logistical support together with information from Mr Tim Paxton and Mr Johannes Malatji of Palabora Heritage Committee which operates under PMC is gratefully acknowledged. 
I would like to thank Professor David Killick, Dr Julius Pistorius, Dr Duncan Miller and Professor Nikolaas van der Merwe who provided the goodwill and access to their previously excavated materials, surface-collected materials and unpublished works on archaeology and archaeometallurgy of the Northern Lowveld.

In Cape Town, 1 would like to say thank you to Dr Shadreck Chirikure, Dr Simon Hall and Professor Judith Sealy for accommodating me at their institution whenever 1 was around. I also extend my thank you to Louisa Hutten, Foreman Bandama, Ndivhuwo Eric Mathobo, Abigail Moffett, Guy Thomas, Emil Krupandan and Nicholas Zachariou from the Department of Archaeology UCT who accompanied me during the different fieldwork campaigns. Foreman Bandama also produced the excellent illustrations of pottery presented in this thesis. Dr Munyaradzi Manyanga and Mr Joseph Chikumbirike of the University of Witwatersrand also contributed significantly to the logistics and the latter accompanied me too during the last fieldwork at Shankare Hill. Professor Innocent Pikirayi and $\mathrm{Dr}$ Munyaradzi Manyanga also assisted me to get access to some important unpublished documents in the Library at the University of Pretoria. However, the greatest debt of gratitude goes to Dr Chirikure for being one of my mentors since my undergraduate days. $\mathrm{He}$ also facilitated this research in many ways and he provided free accommodation during my frequent visits to Cape Town.

In London at the UCL, Institute of Archaeology 1 would like to thank Dr Marcos Martinón-Torres, Dr Andrew Reid, Dr Jane Hatton, Professor Kevin MacDonald, Professor Cyprian Broodbank and Professor Thilo Rehren who have constructively criticised some of my earlier drafts of this thesis. To my three academic supervisors namely, Dr Marcos Martinón-Torres, Professor Thilo Rehren and Dr Shadreck Chirikure, I say thank you for the steadfast support and patience. This supervisory team of three did not only mould me academically but constantly shaped my personality and helped me to deal with the various challenges of life beyond the $\mathrm{PhD}$. Over the years this great team has slowly transformed a science terrified student into an archaeologist cum material scientist. However, without the technical assistance from Kelvin Reeves, Simon Groom and Philip Connolly of the Wolfson Archaeological Science Laboratories the analytical work would have been a mission impossible. Still at UCL Institute of Archaeology, I would like to thank Lisa Daniel 
and Fiona McLean who frequently attended to several requests that 1 had during the course of the programme. I am also grateful to my colleagues at UCL Institute of Archaeology (especially my B53 roommates) who created the favourable environment and provided moral support throughout these years. Not in any particular order they include Edwinus Lyaya, Fernanda Kalazich, Kristina Franke, Loïc Boscher, Min Yin, Wenli Zhou, Piran Venunan, Qiyan Hong, Siran Liu and Carmen Ting. Min Yin and Siran Liu helped me to get started with the Origin 8 software used to create diagrams presented in this thesis. To Kristina Franke thank you for borrowing your priced laptop when mine decided to give up just weeks before submitting the thesis.

In Harare at the University of Zimbabwe (UZ), I would like to acknowledge the debt of gratitude which I owe to Professor Gilbert Pwiti and Dr Robert Soper for their guidance from the time that 1 was an undergraduate student until now. It was Dr Robert Soper who suggested 'copper beads' as the topic for my honours dissertation at a time when 1 had no idea what 1 was going to do for my project. What started as a typological analysis of archaeological copper beads from the Zimbabwe Museum of Human Science collections eventually developed into my fixation with copper production in pre-colonial Africa. Several years on, 1 am still trying to find answers about this "red gold of Africa".

To my parents and siblings 1 say thank you for sustaining my efforts together with the financial support that you provided at the most crucial time of my thesis writing up. I would like to thank my wife Susan for coping with my absence from home for all these years. I hope that the completion of this thesis will make up for those unfulfilled plans and promises. To her I say, I will share whatever spoils that will come with the successful completion of this $\mathrm{PhD}$. I finally would like to thank God for giving me good health and providing the breakthroughs whenever 1 thought there was no way out. However, despite the efforts made by these numerous organisations and individuals, the shortcomings and misinterpretation of information in this thesis remain my sole responsibility. 


\section{Introduction}

"Red gold of Africa" (Herbert 1984).

The application of pyrotechnology by humanity to transform the natural into cultural objects together with the social, economic and political changes that supposedly accompanied this ability have always captured the fascination of scholars from diverse academic backgrounds. This interest has resulted in diverging views about the origins, development and impact of metallurgy in different parts of the World. In sub-Saharan Africa the inception or practice of metallurgy which started during the 'Iron Age' ${ }^{1}$ has often been associated with some important technological, sociopolitical and economic transformations (Calabrase 2000; Childs \& Herbert 2005; Chirikure 2007; Herbert 1996). According to these views, heavy duty iron tools such as hoes and axes were instrumental in the slash-and-burn agriculture practices that were typical during this period (Chirikure \& Rehren 2004). The efficiency of iron tools resulted in high agricultural harvests which most likely promoted human population growth. One of the effects of population growth would be the development of much more complex socio-political systems. Some metals were also used in the "expressive sphere" as symbols of wealth, authority or royal insignia to materialise and perpetuate ideologies of the ruling elites (Calabrase 2000; Childs 1991). The control of metal production and its subsequent distribution was one of the several factors that possibly promoted the development of early states such as those

\footnotetext{
${ }^{1}$ The 'Iron Age' has been considered an outdated concept in the Southern African context where some communities exclusively used stone tools up to the twentieth century (Lane et al. 1998, 18; Mitchell 2002, 257). This term is used in this thesis because of lack of better terminology, rather for convenience sake, to refer to the period beginning from the first millennium AD to the nineteenth century AD in Southern Africa. The 'Iron Age' is further subdivided into 'Early Iron Age' c. 1 to 900 AD, 'Middle Iron Age' c. 900 to 1300 AD, and 'Late Iron Age' c. 1300 to 1900 AD (Huffman 2007).
} 
once based at Mapungubwe and Great Zimbabwe (Calabrase 2000; Herbert 1996). The manufacturing of efficient agricultural tools and metal weapons thus helped to shape the political and cultural landscape of sub-Saharan Africa. It is against this backdrop that Miller $(2002,1083)$ contends that the study of metal production forms a key element in our comprehension of this subcontinent's history.

At least four metals with distinct histories and roles were produced in sub-Saharan Africa during the Iron Age. They include iron, copper, gold, tin and their alloys. During the first millennium $\mathrm{AD}$ the metallurgical repertoire included modest amounts of iron and copper, mostly jewelry (Miller 2001b). Gold, tin, and copper alloys, namely bronze and brass, were only introduced at the beginning of the second millennium $\mathrm{AD}$, several centuries after the inception of iron and copper metallurgy (Miller 2002; Miller 2003; Thondhlana \& Martinón-Torres 2009). By this period, iron was mainly used to manufacture heavy duty utilitarian items (agricultural tools and weaponry) such as spears, hoes and axes. Gold was largely mined for export markets in Asia and Europe (Nixon et al. 2011; Summers 1969; Swan 1994). Copper on the other hand was used to manufacture some forms of currency (medium of exchange) and personal adornments (Bisson 1975; Bisson 2000). However, the simplified dichotomy of associating iron exclusively with utilitarian purposes and non-ferrous metals with non-utilitarian purposes is not applicable in all cases. Some ethnographic studies have shown that iron implements can be equally used for utilitarian purposes as agricultural implements and for non-utilitarian purposes as symbols of wealth and status (Childs 1991; Childs \& Dewey 1996). This thesis begins by acknowledging the indispensable role of iron tools to Iron Age 
agriculturalists in the region, but it also highlights the importance of non-ferrous metals, particularly copper and its alloys.

Previous studies have demostrated that copper and its alloys occupied a unique position in the traditional value systems of many societies in sub-Saharan Africa (Bisson 2000; Herbert 1984). The demand for copper was in some cases so high that it outstripped local supply in some regions. West African societies, for example, were more eager to trade most of their gold with North Africans in return for copper and copper alloys at the peak of the Iron Age trans-Saharan commerce (Fenn 2006; Herbert 1973; Nixon et al. 2011). In Southern Africa, most of the mined gold dust was exported whilst copper was retained for the production of jewellery (Summers 1969; Swan 1994). The demand for copper alloys in Southern Africa was also high, such that exotic copper alloys had to supplement this demand. It is this apparent disregard of noble metals and high demand of both unalloyed and alloyed copper in sub-Saharan Africa that led Herbert (1984) to surmise that copper was the "red gold of Africa". The use of gold by some Iron Age elites in sub-Saharan Africa has largely been seen as the adoption of alien value systems from the Indian merchants, Swahili merchants, Muslim and Christian worlds (Herbert 1984; Killick 2009b, 410). This interpretation is based on the observation that gold was only produced by societies who interacted directly or indirectly with Arabs and/or Europeans.

The current thesis is largely concerned with the reconstruction of extractive metallurgy of this "red gold of Africa" by renowned metallurgists of Phalaborwa, Northern Lowveld, South Africa. Phalaborwa is often cited as one of the major copper-mining areas in Southern Africa (Evers 1974, 33), and holds the earliest secure dates for copper mining, with a metallurgical intention, in South Africa 
(Stuiver \& van der Merwe 1968, 57-58). Archaeologists have previously suggested that mining and metallurgy were the pillars of economy of societies who occupied Phalaborwa during the Iron Age (Miller et al. 2001; Plug \& Pistorius 1999). This is also supported by early twentieth-century oral traditions collected from people who resided far from Phalaborwa (see Mamadi 1940). However, very little information is available about the extractive copper technologies which lasted over several centuries around Phalaborwa.

Before outlining the more specific aims and objectives of this thesis it is pertinent to give a broad overview of African copper mining and metallurgy during the Iron Age period. Detailed accounts of the inception, development and chronology of African metallurgy have been published previously (see Herbert 1984; Killick 2009b; van der Merwe 1980). The next section of this chapter provides an abridged version of these publications in order to highlight general gaps in our knowledge of copper production in sub-Saharan Africa. The unique position of copper and its alloys in sub-Saharan Africa is further discussed with specific examples from West Africa, Central Africa and Southern Africa. The chapter also outlines current topical issues in South African archaeometallurgy, together with a justification for the focus on copper production in this thesis. The chapter outlines the broad aims and objectives of the current thesis, which will be narrowed down to more specific research problems after the review of relevant archaeometallurgical work in Chapter 4. This chapter concludes with a thesis outline which summarises the salient points to be expected in each of the following chapters. 


\subsection{Copper-based mining and metallurgy in pre-colonial ${ }^{2}$ Africa}

Chronologically, sub-Saharan extractive metallurgy begins in West Africa, where uncontested dates of at least the mid-first millennium $\mathrm{BC}$ have been obtained, and reaches Southern Africa in the early first millennium AD (Miller \& van der Merwe 1994a; Miller 1995). However, the Eurasian-based model that prescribes a standard technological progression of human societies from 'Stone Age' through the intermediary 'Copper Age/ Bronze Age' before the 'Iron Age' is difficult to apply in sub-Saharan Africa ${ }^{3}$. The prevailing school of thought is that sub-Saharan Africa experienced a leap in technology from the 'Stone Age' direct to the 'Iron Age' in West Africa (Woodhouse 1998). Copper and iron production appear to be coeval in archaeological contexts of Central Africa and Southern Africa (occurring between c. $500 \mathrm{BC}$ to $\mathrm{AD} 500)$. This unprecedented technological leap has been the subject of a debate which started six decades ago about the origins of metallurgy in sub-Saharan Africa (for recent views on this debate see: Alpern 2005; Holl 2009; Killick 2004b; Pringle 2009; Zangato \& Holl 2010). At the centre of this debate is the question, 'Did they or didn't they invent it (iron)?' (Alpern 2005). The source of contention is that copper metallurgy practice was deemed a necessary apprenticeship phase prior to any systematic production of iron, just like in Eurasia. This has led to the search for evidence of systematic copper production prior to iron production in sub-Saharan Africa. The idea of 'Copper Age(s)' occurring prior to the 'Iron Age' was once

\footnotetext{
${ }^{2}$ The presence of Portuguese and Dutch settlements along the coasts of Africa from the fifteenth century and Arabs prior to this is acknowledged; however, the term pre-colonial as employed in this thesis refers to the period before the nineteenth century when Africa was formally partitioned and colonised by European settlers.

${ }^{3}$ Sub-Saharan Africa in geographical terms is the vast area south of the Sahara that is historically treated as a separate cultural entity from the Mediterranean North Africa. This region is also known as 'Black Africa'. Traditionally archaeometallurgists have considered the Mediterranean North Africa, Nile Valley and Red Sea Coast as very different entities from sub-Saharan Africa culturally and technologically, and this will be maintained in this thesis (Miller \& van der Merwe 1994a, 6).
} 
proposed in the Agadez region of Niger in West Africa (Grébénart 1987) but this idea was quickly rebutted by archaeometallurgists (see Killick et al. 1988). The search for earliest the evidence for copper production prior to iron production, critical to the origins of African metallurgy debate, remains a research priority in West Africa (see Holl 2009). However, some scholars view the preoccupation with the origins debate as an obstruction to other issues of historical and anthropological importance in African metallurgy (Herbert 2001, 42). Irrespective of this apparent lack of an early 'Copper Age/ Bronze Age', in the greater part of sub-Saharan Africa copper and its alloys were extensively produced and used during the Iron Age. To appreciate this it is important to discuss the evidence of copper mining, smelting, trade and consuption during the pre-colonial period.

\subsubsection{Copper and tin deposits: pre-colonial mines}

Mining and metallurgy go hand in hand; usually the main limiting factors include the availability of viable mineral deposits and limits of technical knowledge. The distribution of ore resources is always crucial in any discussion of mining and metallurgy. Naturally copper and tin ores are not as ubiquitous as iron ores. Tin deposits are hereby considered together with copper deposits because tin played a vital role in bronze technology during the Iron Age. Although zinc is crucial in brassmaking and brasses have been found in Iron Age contexts, zinc deposits were not exploited in sub-Saharan Africa prior to the nineteenth century (Maggs \& Miller 1995), and as such they will not be discussed here.

Geologically, copper ores are scarce in West Africa beyond the Sahara, but extensive Iron Age copper mines have been documented at Akjoujt and Agadez, in Mauritania and Niger respectively. The richest copper ore deposits in sub-Saharan Africa, indeed 
the largest copper mineralisation in the World, are present in the Lufilian Arc (Central African Copper Belt) in modern day Democratic Republic of Congo (DRC) and Zambia (Bowen \& Gunatilaka 1977, 129). Iron Age copper mines were documented all over the Lufilian Arc (Bisson 1976). Copper deposits are rare in East Africa; as such, not much information is available on pre-colonial copper mining in this region. In Southern Africa important copper deposits are present on the Zimbabwe Plateau, eastern Botswana and the Limpopo Province of South Africa. Hundreds of Iron Age copper mines have been documented across sub-Saharan Africa (Bisson 1976; Summers 1969). Figure 1.1 illustrates the distribution of a small fraction of these mines. In South Africa, the majority of copper deposits situated in the summer rainfall zone were extensively exploited during the precolonial period (Friede 1980; Mason 1982). The most important pre-colonial mines were documented at Musina (Messina), Phalaborwa and Harmony (Evers 1974, 33; Hanisch 1974); these will be further discussed in Chapter 4. Evidence of pre-colonial copper mining and production at a lower scale has also been encountered in other parts of the Limpopo Province and North West Province (formerly Transvaal) of South Africa (Mason 1982). Iron Age tin mines were rare in sub-Saharan Africa and only two tin-fields have positive evidence of exploitation during the pre-colonial era; they are Rooiberg in South Africa and Jos Plateau of Nigeria (Baumann 1919; Sutton 1983).

Most pre-colonial copper mines have been obliterated by large-scale commercial mining activities that started in the early twentieth century. However, some important information about their chronology and techniques of mining was recorded by the early mining engineers and geologists of European descent. Few pre-colonial copper 
mines were spared from obliteration because their exploitation was considered uneconomic by modern standards. Detailed archaeological (archaeomining) investigations of these have been carried out in Central and Southern Africa (Bisson 1974; Bisson 1976; Evers \& van der Berg 1974; Swan 2002). These investigations have addressed issues such as mining techniques, chronology of mining activities and identity of miners.

Iron Age mining techniques have been comprehensively discussed previously (see Friede 1980; Hammel et al. 2000; Huffman et al. 1995; Summers 1969). These mines can be classified into three groups, namely open stopes, shafts and alluvial workings (Summers 1969, 19). Fire setting was a widely used technique to detach ores from the parent rocks. Radiocarbon dating of charcoal samples from fire setting processes provides invaluable clues about the antiquity of mining activities. Archaeological evidence of safety precautions in underground mines includes timbering and curving of rock pillars (Evers \& van der Berg 1974). It is widely thought that the mining activities were presumably limited to the exploitation of secondary copper minerals in the form of malachite and azurite (Hammel et al. 2000). It has been argued that several reasons will have prevented the miners from exploiting ore bodies beyond the oxidised zone. Firstly, the miners had no means to pump underground water; as such, mining stopped at the water table. Secondly, sulphidic ores usually require more complex extractive metallurgical techniques which appear to have been beyond the limits of technical knowledge or need of precolonial African metallurgists. Sulphidic ores require roasting prior to smelting or complex matte smelting (Craddock 1995, 122-153), processes that have not yet been indisputably documented in pre-colonial Africa. The ores were subjected to the 
process of beneficiation, represented archaeologically in the copper mining areas by ubiquitous dolly holes on rock boulders and portable anvils (Swan 1994, 64).

The issue of the identity of pre-colonial copper and tin miners was once a topical issue and still remains unresolved in some regions. Sustained academic interest in the gender makeup, age and status of the miners has generated important information. Foreign influences were initially invoked whenever discussions of initial gold, copper and tin mining activities were made. Fantasies with Biblical connections to the Queen of Sheba and King Solomon's mines were propagated (Friede 1980, 164; Hammel et al. 2000, 50; Herbert 1984, 29-32). As such, some argued that the earliest miners were foreigners or at least natives managed by foreign people like the Sumerians, Phoenicians, Egyptians, Arabs and Indians (e.g. Summers 1969). However, these suggestions have never been laid on solid archaeological and historical evidence. Human skeletal remains have been the primary evidence in the discussion of the identity of the miners. Human skeletal remains, mostly women, have been found in underground copper mines on the Zimbabwe Plateau (Summers 1969, 217). However, Hanisch $(1974,251)$ correctly suggests that caution has to be exercised because these mines were also convenient burial grounds, hence not every human skeleton should necessarily be associated with mining activities. The narrow width of some mine gallery shafts has been used as evidence indicating that children also worked in these pre-colonial mines (Bisson 1974; van der Merwe \& Scully 1971). While many questions remain open, there is little doubt that copper and its alloys were culturally and economically important across the subcontinent's landscape. The large-scale Iron Age copper mines of Central Africa and Southern Africa bear witness to this. 


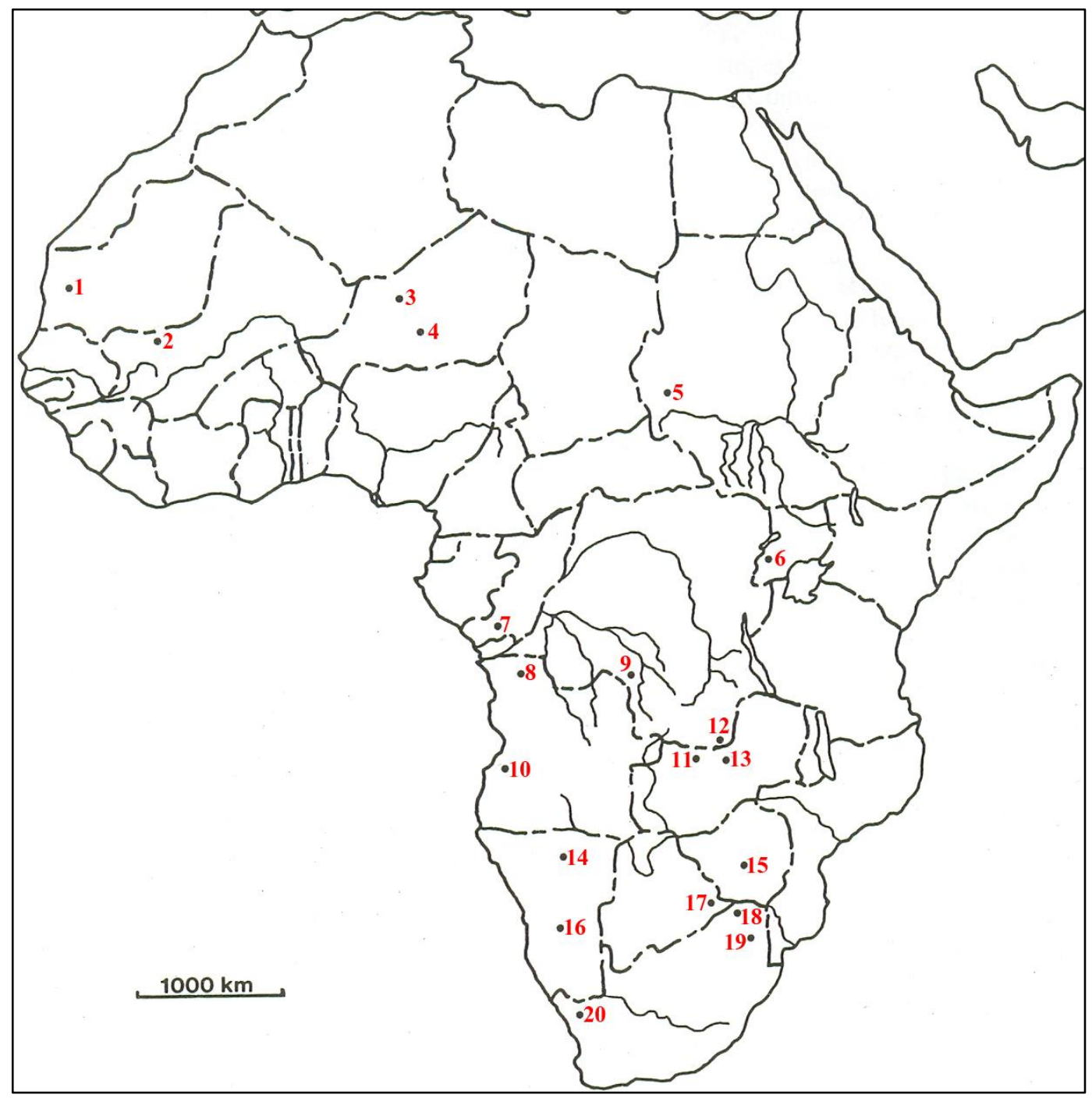

Figure 1.1: Map of Africa showing the location of the twenty well known precolonial copper mines (Adopted from Bisson 1997).1(Akjoujt), 2 (Nioro-Siracoro), 3 (Azelik and Afunfun), 4 (Agadez), 5 (Hufrat en-Nahas), 6 (Kilembe), 7(Niari),8 (Bembe), 9 (Kolwezi), 10 (Benguela), 11 (Kansanshi), 12 (Lubumbashi), 13 (Ndola), 14 (Tsumeb), 15 (Umkondo), 16 (Rehoboth), 17 (Tati), 18 (Messina/Musina), 19 (Phalaborwa), 20 (O’Okiep). 


\subsubsection{Extractive copper metallurgy: the missing link}

Although there is overwhelming evidence of pre-colonial copper mining in subSaharan Africa, the evidence of copper smelting is rather limited and very little is known about the techniques that were used to extract copper from its ores. Almost 40 years ago, Küsel (1974a, 247) estimated that in the Limpopo Province of South Africa alone, thousands of tonnes of copper ore were mined during the pre-colonial period and yet evidence for copper smelting was very scarce. The same observation is also true for Iron Age copper mining areas on the Zimbabwe Plateau, where extensive evidence of copper mining is made perplexing by lack of copper smelting evidence (Summers 1969, 105; Herbert 1984, 26). In West Africa, copper production installations or debris have not been documented in spite of the abundance of artefactual evidence at Igbo Ukwu (Craddock et al. 1997). There is thus a missing link between the copper mines and the abundant copper artefacts that have been documented both in the archaeological and ethnographic records. The evidence of copper smelting is also dwarfed by the evidence of iron smelting that has been documented in the sub-Saharan Africa.

Several hypotheses, which are yet to be substantiated, have been put forward to account for this scarcity of copper smelting evidence or information in sub-Saharan Africa. For example it has been suggested that fundamental differences in between copper and iron smelting favour the obtrusive nature of iron production evidence in the archaeological record. This hypothesis is based on the ethnographic information which suggests that most copper furnaces were broken down after every smelting episode to retrieve bun copper ingots (Küsel 1974a, 247; Bisson 1997, 129). Herbert (1984, 51) 
also suggests that copper smelting furnaces were less solid compared to their iron smelting counterparts; as such, they were prone to fast natural degradation after their use. Other scholars have suggested that field archaeologists erroneously identify copper slags as iron slags or vice versa in the Iron Age contexts (van der Merwe 1978, 102; Herbert 1984, 51; Miller \& Killick 2004, 34; Severin et al. 2011), thus creating this uneven picture in the database of copper production against iron production sites. Elsewhere, in NW Europe, the 'slagless' extractive metallurgy associated with the use of high grade ores has been used to account for the scarce nature copper production evidence during the Early Bronze Age (Craddock \& Craddock 1996; Craddock 2009). Küsel (1974a, 247) once proposed the same idea by claiming that copper carbonate ores employed in sub-Saharan Africa produced very little in terms of slag. These various hypotheses are yet to be tested systematically in specific contexts in subSaharan Africa. This is a gap in the field of African metallurgy that this thesis will aim to contribute using both field and laboratory evidence of copper production from Phalaborwa.

The few copper smelting furnaces that have been documented by archaeologists and ethnographers in sub-Saharan Africa illustrate notable diversity in design and size (Miller \& van der Merwe 1994a, 20). Slag tapping tall shaft furnaces, reaching a height of 1.75 metres equipped with at least four tuyère ports, were documented ethnographically in Central Africa amongst Sanga people, who produced copper at a large-scale until the nineteenth century (Bisson 1997). Non-slag tapping, short shaft furnaces with a single tuyère port entrance were employed in the northern parts of South Africa (van der Merwe \& Scully 1971; Grant \& Huffman 2007). Simple bowl furnaces without clay superstructures were used for copper smelting during the 
seventeenth century AD in eastern Botswana (Huffman et al. 1995). The number and form of the tuyères varied, from flared clay pipes to hollowed out anthills and tubes fashioned out of stone (Miller \& van der Merwe 1994a).

The paucity of published archaeometallurgical analyses of debris associated with nonferrous extractive metallurgy in sub-Saharan Africa is notable. Very little is known about pre-colonial extractive technologies of copper and tin in the region. Over the last three decades scholars have continuously lamented that pre-colonial extractive copper technology is poorly understood compared to iron production (Friede \& Steel 1975; Miller 1992; Miller 2003, 104). There are several factors contributing to this situation. Firstly, archaeometry in general and archaeometallurgy in particular remain peripheral in archaeological research. The few trained archaeometallurgy specialists rarely participate in archaeological fieldwork excursions (Miller 2001a, 99). On the other hand most archaeologists in the region lack infrastructure and expertise in archaeological science which is much needed in the analyses of metallurgical debris (Killick \& Young 1997, 519; Killick 2004b). Due to the above mentioned factors, literature entirely dedicated to the technological reconstruction of copper production remains scarce. Consequently, information on the technical innovations and diversity in pre-colonial copper smelting technologies in sub-Saharan Africa largely remains a grey area. Recent archaeometallurgical investigations of tin slags from Rooiberg have given insights into the technological aspects of pre-colonial extractive tin metallurgy (Chirikure et al. 2010; Heimann et al. 2010), but there is still a long way to go. This thesis will thus contribute to redressing this scarcity of information on copper smelting. 
The socio-cultural aspects of copper production in pre-colonial Africa are not as well documented as is the case of iron production because ethnographic information about the former is limited. According to Bisson $(2000,84)$, by the period of formal European colonisation, copper production operations had almost ceased in subSaharan Africa, resulting in scanty written ethnographic information about the craft. In few exceptional cases where the craft continued into the contact or colonial period it has been observed that craftsmen kept their copper smelting activities secret from European settlers and foreign observers (Bisson 2000, 84; Hall et al. 2006, 31). In the absence of ethnographic information, scholars have had to rely on the archaeological evidence to establish the social context of production. Extrapolating from ethnographic models on iron smelting, archaeologists have noted the importance of spatial patterning of metal smelting precincts as indicators of cultural aspects of metal craft production. The spatial separation of iron smelting activities from habitation sites widespread across sub-Saharan Africa has largely been interpreted as a response to ritual requirements of the craft (Childs \& Killick 1993; Miller \& van der Merwe 1994a). Iron smelting was usually associated with human reproductive symbolism and taboos; as such, iron production was carried out in secluded areas away from women and children. It is not yet clear if the same sociotechnical principles applied to copper production during the same period. Contrasting spatial arrangements of copper smelting activities are beginning to emerge (see Anderson 2009; Hall et al. 2006). It has been established that copper smelting and refining furnaces were usually located inside the settlements. These notable differences suggest important variations in the organisation of production and other cultural aspects that shaped copper and iron metallurgies (see Anderson 2009; Grant \& Huffman 2007). The spatial arrangement of 
copper production activities around Phalaborwa is thus considered an important aspect warranting further investigations in this thesis.

\subsubsection{Alloying and fabrication technology}

In the absence of primary copper smelting evidence, routine metallographic studies of copper-based artefacts have been the major source of information on African copper metallurgy (e.g. Garenne-Marot et al. 1994; Miller \& van der Merwe 1994b; Miller 1996; Miller 2002; Stanley 1929a; Stanley 1929b; Thondhlana \& Martinón-Torres 2009). Copper and copper alloy artefacts are much more ubiquitous in the archaeological record and in museum or private collections. The reasons for this scenario are twofold. First, copper-based artefacts tend to survive well, compared to iron artefacts, in the acidic soils that make up most of the archaeological deposits of sub-Saharan Africa. Secondly, as Miller $(2002,1129)$ rightfully notes, until recently most Iron Age archaeologists in the region concetrated on the excavation of settlements and the recovery of finished artefacts, rather than the systematic recovery of metal production waste. The metal assemblages from these excavations are currently curated in various university, museum and private collections. Archaeometallurgists who concentrate only on post-fieldwork analytical work, as pointed above, are thus likely to find only finished metal artefacts rather than production debris in these collections. This might also account for the prevelance of published metallographic analytical work on copper artefacts and comparatively little analytical work on metal production debris. To overcome this limitation, fieldwork and analytical work were viewed as equally important avenues in the reconstruction of extractive copper metallurgy in the research area. However, this section of the chapter 
establishes the information that has been gathered from metallographic studies of copper-based artefacts, in the process highlighting the scarcity of copper smelting evidence across the sub-continent.

The quantity of metal artefacts in the 'Early Iron Age' contexts suggests that the introduction of metallurgy was not suddenly accompanied by large scale production. The scarcity and small size of the metal items during the first millennium AD also likely results from metal recycling (Miller 2001b). In Southern Africa, the earliest securely dated metal artefacts were recovered from Broederstroom (South Africa) and Tsodilo (Botswana) (Miller 1992; Miller \& van der Merwe 1994b). These metal assemblages were dated between the fourth and seventh centuries AD. Towards the end of the first millennium $\mathrm{AD}$, the metal assemblages become ubiquitous and diverse. For the first time, large iron agricultural implements and weapons were manufactured whilst unalloyed copper continued to be used for the manufacture of jewellery and ornaments. Large-scale metal production from the beginning of the second millennium onwards (Miller 2001b), coincides with major population and political dynamics such as urbanisation and the development of more complex political structures.

During the second millennium AD cuprous alloys begin to appear in sub-Saharan Africa. Alloying is a significant technological innovation that allowed metallurgists to manipulate several properties of copper including hardness, sonority, colour and malleability. The alloying of copper with other metals during the 'Early Bronze Age' in Eurasia was largely a technological response resulting from the need for hard and durable metals for the manufacture of heavy duty tools prior to iron metallurgy. In subSaharan Africa, cuprous alloying innovations took place way after the region was 
systematically producing iron. According to Chirikure et al. $(2007,112)$ copper alloys, whether local or imported, were thus appreciated for the aesthetic appeal associated with their colours rather than superior hardness properties in sub-Saharan Africa.

African tin bronze metallurgy has provided some important research questions. As mentioned before only two tin-fields have positively been identified as the source of the tin used during the pre-colonial period in sub-Saharan Africa (Baumann 1919; Friede \& Steel 1976; Sutton 1983, 184). Despite the extensive Iron Age exploitation of tin ore deposits around Rooiberg and the Jos Plateau, archaeological tin artefacts are very rare in the region. As a result, it was once believed that most of the tin was exported to other continents; however, recent metallographic analyses have documented the preponderance of tin bronzes in West and South Africa during second millennium AD that might account for the missing tin (Miller 2001, Miller 2003).

The onset of tin mining and bronze metallurgy has evoked questions about the role of foreigners (Medieval Europeans, Arabs and Indian merchants) in metallurgical innovations that took place in sub-Saharan Africa. The sudden appearance, during the terminal first millennium $\mathrm{AD}$, of sophisticated Igbo-Ukwu cast bronze objects using techniques without precedence in the region has puzzled many scholars (Chikwendu et al. 1989; Craddock 1985; Craddock \& Picton 1986). Over a hundred leaded bronze castings, with up to $12 \%$ lead, were found at Igbo-Ukwu. It was initially thought that West Africa was devoid of copper resources as such Igbo-Ukwu bronzes were viewed as imports that were obtained from Arabs or Europeans (Shaw 1969, 88). The lost-wax techniques employed in these early castings were also supposedly too complicated to have been mastered by people without prior long experience with copper metallurgy 
(Figure 1.2). According to Chikwendu et al. (1989) the Igbo-Ukwu bronzes lack antecedents, contemporaries or direct successors in Africa and abroad. However, subsequent analytical work on the Igbo-Ukwu objects demonstrated that they were actually indigenous in both raw materials and design. The copper and lead deposits of the Benue Rift of Nigeria were identified as the unequivocal source of Igbo-Ukwu leaded bronzes (Chikwendu et al. 1989; Craddock et al. 1997). In spite of positively identifying the source of the ores, the lack of early copper and lead production debris in the Benue Rift remains a puzzle to be solved. A substantial scale of copper and lead production was required to produce Igbo-Ukwu castings. However, systematic search for copper and lead smelting evidence around the Benue Rift has proved fruitless (Craddock et al. 1997, 425). As such, the earliest smelting technology used to extract copper and lead in Nigeria remains unknown.

Equally sophisticated pre-colonial cuprous alloy castings were found at Benin City, Ife and Sintiou Bara in West Africa. These objects include bells, heads, plaques and statuettes that show an impressive execution of the lost-wax technique to produce relief or free-standing human and animal figures (Figure 1.3 \& Figure 1.4). However, there is no doubt that the raw metal that was used to manufacture cuprous alloys castings, mostly brasses, was obtained from Arab and European sources (Craddock 1985; Garenne-Marot et al. 1994). Several sourcing investigations of these brasses over the years have shown that they were actually manufactured with raw materials from different Eurasian sources (see Goucher et al. 1976; Chikwendu et al. 1989; Joel et al. 1995; Craddock et al. 1997; Willett \& Sayre 2006). 


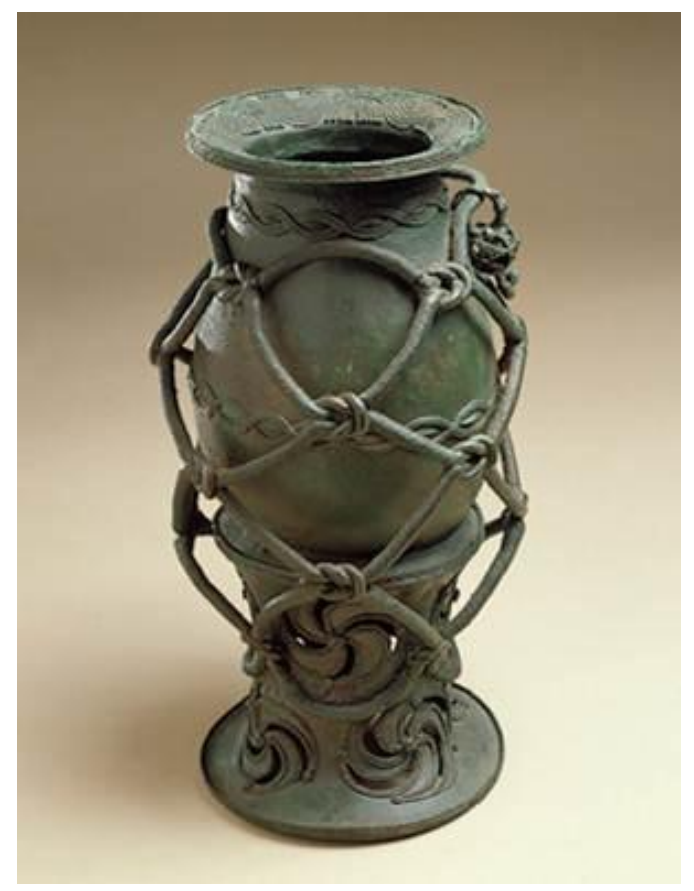

Figure 1.2: $A 9^{\text {th }}-10^{\text {th }}$ century roped leaded copper pot from Igbo Isaiah (IgboUkwu), Nigeria (Image: courtesy of http://www.nairaland.com/618904/igbo-ukwuca-9th-century).

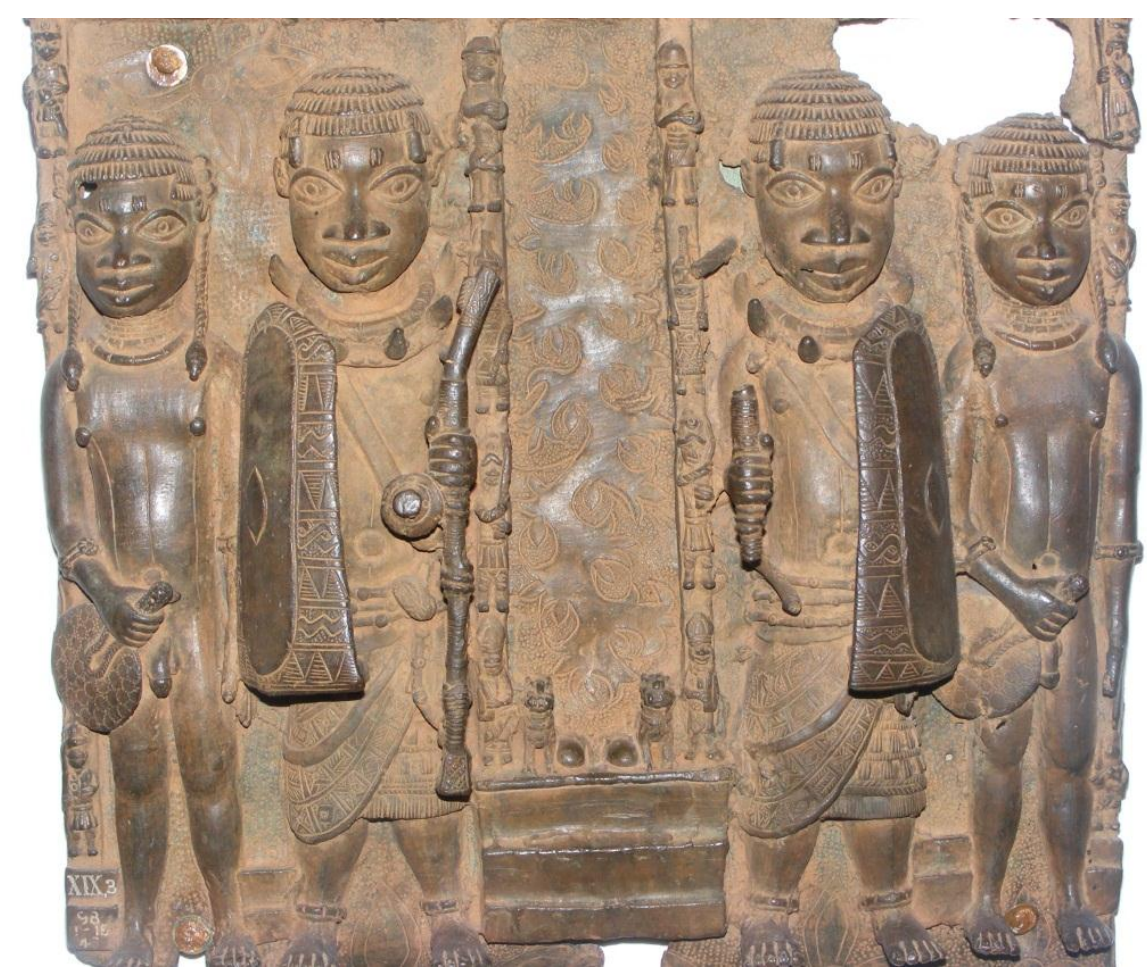

Figure 1.3: A cast brass plaque from Benin City, Nigeria. This $16^{\text {th }}$ century cast is on display at the British Museum, London (Image: Author). 


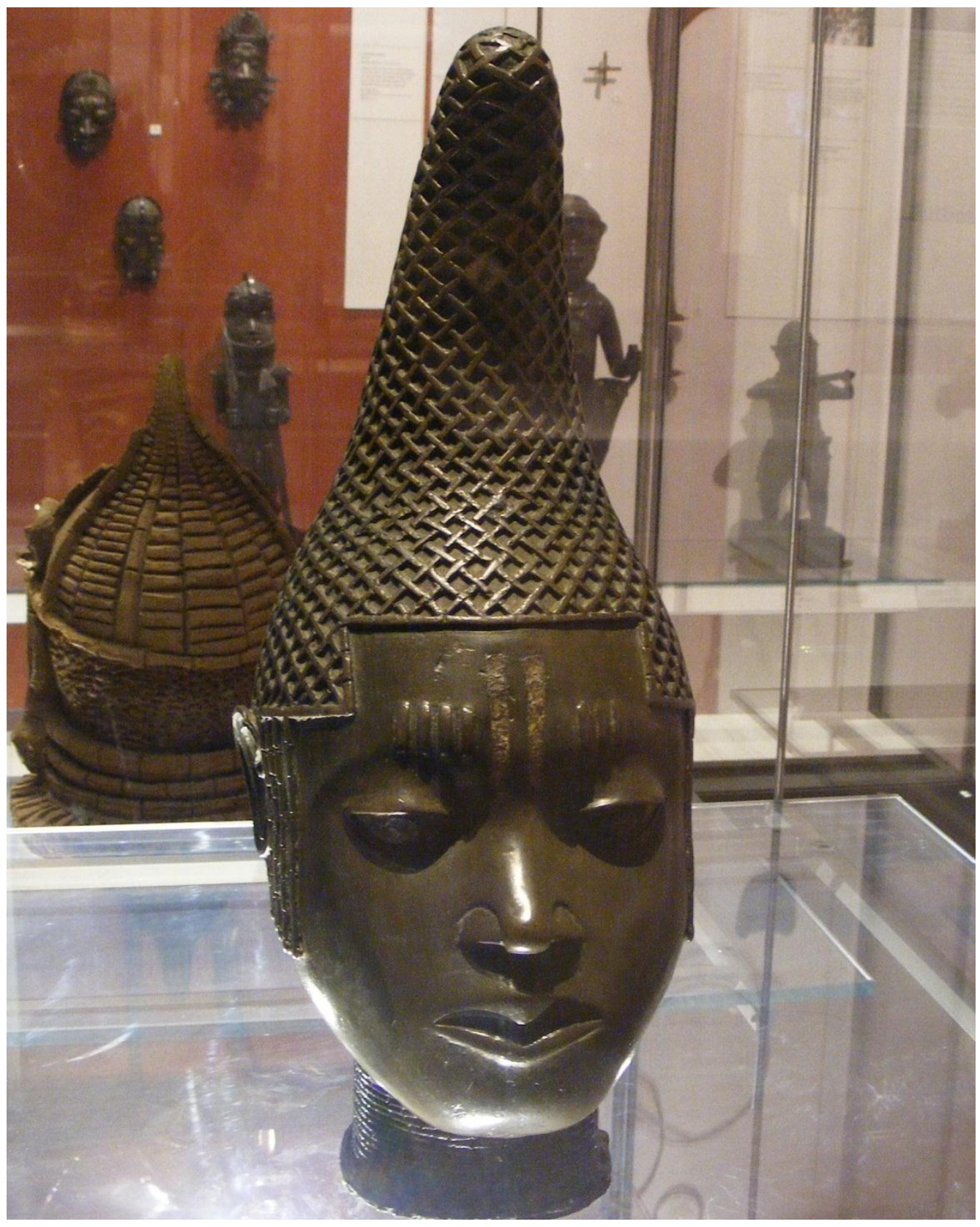

Figure 1.4: The Queen mother bronze head from Benin City, Nigeria. This cast dating between the $15^{\text {th }}-16^{\text {th }}$ century is also on display at the British Museum, London (Image: Author). 
Pre-colonial copper and copper alloy objects in Southern Africa are not as impressive in the execution of skills as their West African counterparts. The lost-wax technique prevalent in West African was not among the technological skills of metalworkers of Southern Africa, who fabricated most of their copper objects by cold working and annealing (Miller 2002, Miller 2010). The cuprous items in this region are limited to items of personal adornment and ingots. However, the timing of the appearence of tin bronzes in Southern Africa has recently generated academic interest since the earliest examples seem to predate the onset of tin mining at Rooiberg (Chirikure et al. 2007; Miller 2002, 1102, 1124-1125). Previously it was thought that tin mining and smelting activities around the Rooiberg tin fields did not predate the fifteenth century AD (Grant 1990), but the earliest tin bronzes in Southern Africa predate tin mining at Rooiberg by at least two centuries (Miller 2002). The source of the tin for these earliest bronzes has been a subject of speculation. Traditionally it was thought that either this early tin came from overseas and was alloyed with African copper in the region, or readymade bronzes were imported from overseas (Caton-Thompson 1931, 64). However, recent archaeometric studies of the earliest tin and tin bronzes in Southern Africa point to Rooiberg as the source thus extending the antiquity of tin mining in the region (Molofsky 2009). There have been previous suggestions that alluvial tin deposits on the Zimbabwe Plateau were also exploited during the precolonial period (Prendergast 1979), but systematic archaeometallurgical investigations are yet to be carried out to establish the veracity of the claims. Chirikure et al. (2007) have shown that there is still a lot of scope to research into the origins and development of bronze metallurgy in sub-Saharan Africa. Conversely, in Central Africa the alloying of copper with tin or other metals was not practised in the precolonial period. 
As mentioned earlier, brass metal artefacts begin to appear during second millennium AD both in West Africa and Southern Africa. They end up being the preferred alloy during the late second millennium AD (Garenne-Marot et al. 1994; Miller 2001a; Miller 2002; Thondhlana \& Martinón-Torres 2009). Zinc and brassmaking technology presented serious practical challenges that require specific skills not yet documented in the pre-colonial metallurgical record of sub-Saharan Africa. Suggestions of indigenous 'brass' production from complex the copper-zinc blende deposit from the Murchison Schist were once put forward (More 1974, 230) and will be discussed later in this thesis. Apart from this possible exception, the exploitation of zinc ores remained unknown until the nineteenth century; hence earlier brasses were obtained through contacts with other regions (Bisson 1997, 130; Herbert 1984, 97). From late second millennium AD contexts, brasses with characteristic high zinc content above $30 \%$ have been documented (Thondhlana \& Martinón-Torres 2009). The plausible source of the brasses is India, where zinc was produced by distillation from the early second millennium AD onwards (Craddock et al. 1998). Strong trading connections existed between Southern Africa and India from the terminal first millennium AD, but these exotic brass articles are mostly confined to the recent contexts dating from the seventeenth century onwards. Evidence of reworking and recycling of imported brass has been identified in Southern Africa (Maggs \& Miller 1995).

Arsenical copper artefacts, some with high arsenic values of up to 19 per cent, have also been documented in Iron Age contexts of sub-Saharan Africa (Friede 1975; Grant et al. 1994; Thondhlana \& Martinón-Torres 2009). It is not yet clear if there was systematic production of arsenical copper at any given time in sub-Saharan 
Africa. Occasional arsenical coppers that have been analysed to date were interpreted as unintentional products of using copper ores with significant levels of arsenic (Friede 1975, 188). However, systematic metallographic investigations are yet to be carried out to assess if there are any trends in the production and use of arsenic coppers in the region. This exercise might indicate conscious and purposeful production of arsenical copper in parts of sub-Saharan Africa.

The fabrication techniques utilized in the production of copper-based artefacts have been established using standard metallographic techniques (Miller 1996; Miller 2002), even though it has been noted that curators are sometimes reluctant to submit unique metal artefacts for invasive metallographic analysis (Miller 1992, 3; Miller \& van der Merwe 1994a, 5). The fabrication technology has been viewed as conservative throughout the Iron Age in Southern Africa (Miller 2002, Miller 2010). Most copperbased artefacts were subjected to annealing and some wire drawing but somewhat more complex techniques such as soldering and lost-wax casting were absent in the greater part of the region (Herbert 1984). It has been established in this section that some copper alloys were produced in the region although others were actually exported from other regions. There are still gaps in our knowledge of copper alloying and fabrication techniques although the research priorities tend to vary with regions. In West Africa some outstanding questions include: how did the Igbo-Ukwu metal workers achieve highest levels of copper casting without precedence in the region? Where is the evidence of copper production debris in Nigeria? What techniques were used to extract copper in West Africa? In Southern Africa, bronze metallurgy offers several avenues of research, some of which have been summarised by Chirikure et al. (2007). This thesis tries to establish answers to some of these questions which include: 
Was copper and tin alloyed around Phalaborwa? If the answer is yes, was this a systematic process? What paraphernalia was required for copper alloying?

\subsubsection{Trade, exchange and consumption}

Several factors would have constrained the production of copper-based metals in many parts of sub-Saharan Africa. Chief among them is the restricted nature of copper and tin ore deposits as discussed earlier on. The lack of firewood to produce charcoal, the principal fuel in ancient extractive metallurgy, also constrained metal production (see Chirikure et al. 2008). However, copper and copper alloy artefacts have been found in regions devoid of the much needed raw materials, attesting the importance of copper and cuprous alloys in pre-colonial trade systems (Bisson 1976). Copper-based artefacts can be useful in the reconstruction of pre-colonial trade and cultural contacts. Several forms of copper ingots used for trade purposes have been identified in different parts of sub-Saharan Africa. However, the organisation of trade and exchange between copper producing and non-producing areas has not been investigated systematically in many cases.

Historical documents have been used to establish the trade of Eurasian copper into West Africa from as early as the tenth century (Herbert 1973, 179). This trans-Saharan trade network saw the movement of copper and copper alloys from North Africa and Europe into West Africa. Lead isotope studies have been prioritized in West Africa, were they have been used to reconstruct trans-Saharan metal trade (see Chikwendu et al. 1989; Craddock et al. 1997; Fenn 2006; Willett \& Sayre 2006). In other parts of sub-Saharan Africa investigations of pre-colonial trade or exchange of copper have been based on typological studies of peculiar ingot forms known from different copper 
producing areas (Bisson 1975; Swan 2007). Unfortunately, little considerations have been made to complement these typological studies with standard analytical approaches such as lead isotope analysis (LIA). Stylistic similarities in metallic assemblages of different regions can result from imitations rather than trade. Fingerprinting or sourcing studies of metal artefacts in Central and Southern Africa remain very limited (see Grant 1999; Grigorova et al. 1998; Molofsky 2009). Without a comprehensive data base of lead isotope signatures and chemistry of the potential ore deposits it will still be difficult to establish the sources of any artefacts. Characterisation of potential ores as undertaken in this thesis is one way of establishing general geochemical differences that will be useful in the future.

The economic role copper ingots and objects in sub-Saharan Africa have been discussed in great detail elsewhere (see Bisson 1975; Herbert 1984; Swan 2007). Various forms of copper ingots were used during the pre-colonial period as a medium of exchange and measure of wealth (Bisson 1975; de Maret 1999; Haddon 1908; Hemsworth 1908). In Central Africa the control of copper production and distribution, or possession of copper, became synonymous with wealth (Bisson 1976). According to Herbert $(1973,193)$ since wealth is commonly equated to power in some societies, it was natural that copper was used in emblems of rank and regalia of kingship. However, the large corpus of archaeological and ethnographic copper and copper-alloy artefacts from pre-colonial sub-Saharan Africa was not only important in the economic sense. It has already been pointed out at the beginning of this chapter that copper was a metal of choice for the manufacture of ornaments that were likely loaded with cultural and symbolic value. Copper bangles, anklets, armlets and beads are a common place in second millennium AD archaeological sites in sub-Saharan Africa. They were symbols 
of wealth and status but simultaneously acted as amulets to wade off evil against the wearer (Herbert 1973, 189; Herbert 1984). Copper also played an important social role in rites of passages. Archaeological examples in Central Africa show that copper formed part of ruling class investiture regalia, accompanying high social status people in their burials (Bisson 1975, 279). To summarise, some pre-colonial sub-Saharan African societies did not only perceive the value of copper in purely economic terms.

\subsection{Research questions, aims and objectives}

The previous pages were inevitably generalizing in trying to highlight common threads, questions, approaches and problems in African archaeometallurgy. At the same time, some emphasis was placed on the regional variability documented ethnographically and archaeologically that responded to both specific natural and cultural stimuli. As a matter of fact, metallurgy was as diverse as the societies that made and used metals. This means that, while not losing sight of the big picture, our research approaches should be tailored for the particular region of interest. This section takes a limited geographical focus to establish the research avenues and questions concerning pre-colonial copper production in the Northern Lowveld of South Africa.

This thesis aims to build a high-resolution reconstruction of copper production stages, from the raw material procurement to final product, with the aid of field and analytical work of metallurgical debris from archaeological sites around Phalaborwa. The research area was chosen because it has been identified as one of the important sources of copper during the pre-colonial period in South Africa (Evers 1974) and pioneering archaeological studies there documented extensive evidence of metal production (van der Merwe \& Scully 1971). Our knowledge of copper production in this research area 
is affected by lack of written documents. In South Africa documents became available only with the Portuguese and Dutch maritime expansion from the fifteenth century, and most of these reports are limited to the encounters that took place on the coastal areas. It took some centuries for the Europeans to penetrate into the interior of South Africa. Reports about European encounters in the interior only became prevalent in the nineteenth-century (Mitchell 2002, 4). Even when available, these reports should be used with caution because some of them are laden with racial prejudice, usually exhibiting a lack of understanding of the Africans and their technologies. By the time of European penetration into the South African interior most indigenous copper production activities had ceased; as such, ethnographic information on the practice is not available for the Northern Lowveld. Reconstructions of South Africa's pre-colonial past have relied on oral traditions that are notably selective, concentrating mostly on political or mythical events to validate present day political arrangements (Mitchell $2002,3)$. These oral traditions rarely furnish us with information on the technological processes and generally have a notably limited time depth. For a deeper time-resolved insight of metal production around Phalaborwa, just like other parts of Southern Africa, we have to rely on archaeology and archaeometallurgical techniques as the most robust research avenue (Chirikure 2005).

It is unfortunate that archaeological research has to date paid less attention to metal production. Like elsewhere, initial Iron Age archaeological enquiry in South Africa was geared towards the establishment of sound chronologies largely based on ceramic typologies, prior to the development of radiometric dating methods. Ceramic typologies continue to be prioritised in most archaeological investigations in Southern Africa (Mitchell 2002, 272). On the other hand, typology or stylistic analyses of metal 
production debris usually provide little information about the chronology of archaeological sites (Rehren \& Pernicka 2008, 235), but with proper approaches can provide vital information in the reconstruction of extinct technologies.

This thesis was carried out principally to reconstruct copper production activities around Phalaborwa. Research questions for this project were formulated within the framework of the chaîne opératoire approach (see Chapter 2 for more on the theoretical framework). This approach seeks to establish how raw materials were procured and processed into artefacts in specific socio-cultural settings. This project therefore seeks to address the following basic questions: What raw materials were exploited to produce copper? Which smelting techniques were used to extract copper from its ores? How efficient were the methods that were used to extract copper? What was the quality of the metal that was produced? Did the copper production techniques change through time? To answer these basic questions an archaeometallurgical examination of the possible ores, production debris and technical ceramics was deemed necessary. It was hoped that by focusing on the detailed reconstruction of the production sequence, answers could also be established about the apparent lack of copper smelting evidence in most copper producing areas. In order to address this anomaly the following questions were also asked: How visible is the evidence of copper production in the archaeological record? What differences or similarities can be expected in debris produced during copper smelting and iron smelting? These questions provided the platform to break the cycle of concentrating on post hoc studies of excavated metallurgical assemblages by archaeometallurgists (Miller 2001a, 99), with very little concern for archeological fieldwork. This project is thus unique in that 
the fieldwork was regarded an important aspect of the project as much as the analytical work.

The reconstruction of the chaîne opératoire of extractive copper metallurgy with the aid of analytical work was not the ultimate goal, since this falls short of addressing questions of broader archaeological or historical interest. Iron Age copper production like any other technical systems should be investigated as a set of commonly used materials, sources of energy, types of labour, social organizations, tools and techniques, outputs of goods and services together with other aspects of society such as culture, politics and demography (Austen \& Headrick 1983, 168). Ultimately, since the "materials, products, agents, historical conditions and value systems are analytically indivisible", the reconstruction of the chaînes opératoires of copper production should provide more information about the relevant societies (MartinónTorres 2008, 23). Archaeological data, ethnohistoric sources and oral traditions were used in this thesis to place copper production activities in their social and historical context. The thesis attempts to establish the position of Phalaborwa as a major metal producing region in the broad economy of Southern African region during the precolonial period.

Comparatively little archaeological fieldwork has been conducted around Phalaborwa since the 1980s (see Chapter 4). Given changes in the theoretical outlook and advances that have been made in South African Iron Age archaeology and archaeometallurgy it was high time to revisit the area. To address the issues outlined above archaeometallurgical surveys and excavations were carried out at Shankare Hill, a site with extensive metallurgical debris, whilst previously surface collected materials from nearby sites were used for comparative purposes. 


\subsection{Organisation of the thesis}

This introductory chapter has highlighted the importance of copper and cuprous alloys in pre-colonial sub-Saharan Africa traditional value system. It was shown that very little is known about copper-based extractive metallurgy due to lack of archaeological evidence of smelting. Broad questions and gaps in our knowledge of copper-based metallurgy have been outlined in an attempt to situate the aims and objectives of the current project into the broader scope.

Chapter Two discusses the 'Anthropology of Technology' as a theoretical framework from which this thesis gets its inspiration. The concept of technology is explored and its application to archaeology is discussed. The application of the chaîne opératoire approach to African archaeology in general and archaeometallurgy in particular is appraised. The role of archaeometallurgy in the investigation of African metallurgy is discussed.

Chapter Three is devoted to the presentation of background information on the Northern Lowveld such as the geographical and environmental setting, archaeological and historical chronology.

Chapter Four presents previous findings of relevant archaeological studies and analytical work carried out around Phalaborwa since the 1960s. The existing knowledge on pre-colonial copper mining and metallurgy in the Northern Lowveld is outlined as a way of identifying further gaps and research questions that are specific to the research area.

Chapter Five outlines the technical details of the archaeometric methods that were applied to study metal production debris from the research area. 
Chapter Six provides the archaeological and archaeometallurgical evidence documented during two fieldwork seasons at the early second millennium AD site of Shankare. Analytical results of ores, slags, technical ceramics and metal objects from this site are presented and discussed. The chapter ends with the reconstruction of a chaîne opératoire of copper production activities represented at the site.

Chapter Seven presents the analytical results of metal production debris that was previously surface collected from Kgopolwe, Molotho, Matsepe, Phutwane and Maranda. Assemblages from Molotho and Matsepe date to the late second millennium $\mathrm{AD}$; as such, their comparison to Shankare assemblages provides the diachronic perspective of copper production activities from the early to the late second millennium AD.

Chapter Eight, having presented and discussed the analytical results in the two preceding chapters this chapter, compares the extractive copper technologies from the different archaeological sites. Finally an attempt is made to compare analytical data from Phalaborwa with other sites around South Africa. The chapter also places pre-colonial copper production around Phalaborwa within the regional framework of Southern Africa.

Chapter Nine sums up the conclusions of the thesis and suggests some avenues that future research can pursue around Phalaborwa and Southern Africa in general. 


\section{Theories and approaches to ancient technologies, with specific reference to African metallurgy}

"To state my case in the strongest possible terms: there is no such thing as technology in so-called primitive societies.” (Ingold 1990, 6)

"Technology, even in its original meaning as the science of the arts, was applicable to prehistoric human beings as to MIT graduates." (Schatzberg 2006, 500)

\subsection{Introduction}

Contemporary archaeological practice requires sound conceptual and theoretical armoury to justify research questions, methodology, results and data interpretation. This chapter outlines and critically assesses theoretical approaches that inspire the current thesis together with some previous studies on African metallurgy and ancient technologies in general. Conceptual approaches that inspire these studies were first developed and applied in 'Western' academic discourses other than archaeology itself. For example the 'sociotechnical system' concept was initially developed by social scientists specifically for modern industrial societies but was subsqently applied by anthropologists to study pre-industrial societies (Marx 2010, 567-572; Pfaffenberger 1992, 492). Several challenges have been encountered previously as a result of uncritical application of models developed for Eurasian prehistory to African archaeology. For example, C.J. Thomsen's “Three Age System”, which broadly divided European prehistory into the 'Stone Age', 'Bronze Age' and 'Iron Age' (Renfrew \& Bahn 2004, 27), proved irrelevant in the chronological signposting of the African prehistorical period as pointed out in Chapter 1. It is thus necessary to briefly trace the origins and development of theoretical frameworks and concepts which informed the approaches employed in the current thesis. 
The scope of the current thesis fits well within the broad field of technology studies. However, the term technology is understood differently depending on each scholar's theoretical orientation (Eglash 2006, 330). Interest in the relationship between technology and human societies has resulted in fully-fledged academic discourses and proliferation of innovative theories and approaches (Küchler 2006). Since the 1970s technology has been at the heart of inquiry of academic fields such as science and technology studies (STS) and history of technology, together with dedicated journals on the subject such as Technology and Culture, Techniques et Cultures or History and Technology to mention just a few. Although several strides have been made in the various academic fields, some compelling questions about technology are yet to be answered unanimously including: What is technology? Is technology a human universal? (Pfaffenberger 1992, 492; Salomon 1984). Is there any basis to discuss technology in pre-colonial contexts of sub-Saharan Africa? Sub-Saharan Africa has often been portrayed as a recipient of technology or a region in a permanent state of technological inertia (see Figure 2.1). To dispel some of these negative perceptions, the connotations and baggage carried in the present-day use of the term technology had to be unpacked first before any discussion of the conceptual framework that guided this thesis.

Some innovative approaches in the field of technology studies were developed by anthropologists and archaeologists. Of particular significance to this thesis is the chaîne opératoire approach, which functions both as an analytical tool and interpretive framework. The historical origins and tenets of this approach to ancient technology studies were discussed by other scholars in great depth (see Edmonds 1990; Martinón-Torres 2002), as such, they will only be summarised in this chapter. 
In this chapter the application of the chaîne opératoire approach in African archaeology and metallurgy studies is discussed.

The step-by-step reconstruction of the production process, a core tenet of chaîne opératoire studies, often requires the use of archaeometric approaches. The challenges of employing scientific approaches in archaeological studies and the supposed conceptual incompatibility of archaeometry and mainstream archaeology noted elsewhere (Jones 2004; Knapp 2000; Pollard \& Bray 2007; Sillar \& Tite 2000) will be discussed in the context of studies in African metallurgy. This chapter begins by exploring the meaning of the term technology followed by an outline of theoretical and archaeological approaches relevant to this thesis. The chapter concludes with a discussion of the role of science-based archaeology to this thesis in particular and mainstream archaeology in general. 


\subsection{Exploring the notion of 'technology': field of study, object of study or concept?}

Sub-Saharan Africa is usually viewed as a technologically conservative region; as such, routes of technological transfer are always sought to account for its past technological changes or achievements (Austen \& Headrick 1983; Killick 2009a). These views were deeply entrenched and fostered in the ideology of minority white settlers who once colonised Africa in the recent past (Mitchell 2005, 1). However, it will be argued in subsequent paragraphs that the adoption and semantic shift of the term technology in the English language perpetuates the same views. Barndon (2004, 26) has noted that few archaeologists have critically analysed the content and historical background of technology as a term or phenomenon. In African archaeology it is necessary to do this because it exposes weakness of the 'Standard View of technology' resulting from modernism, allowing us to reconsider the ways that we investigate past technologies. 


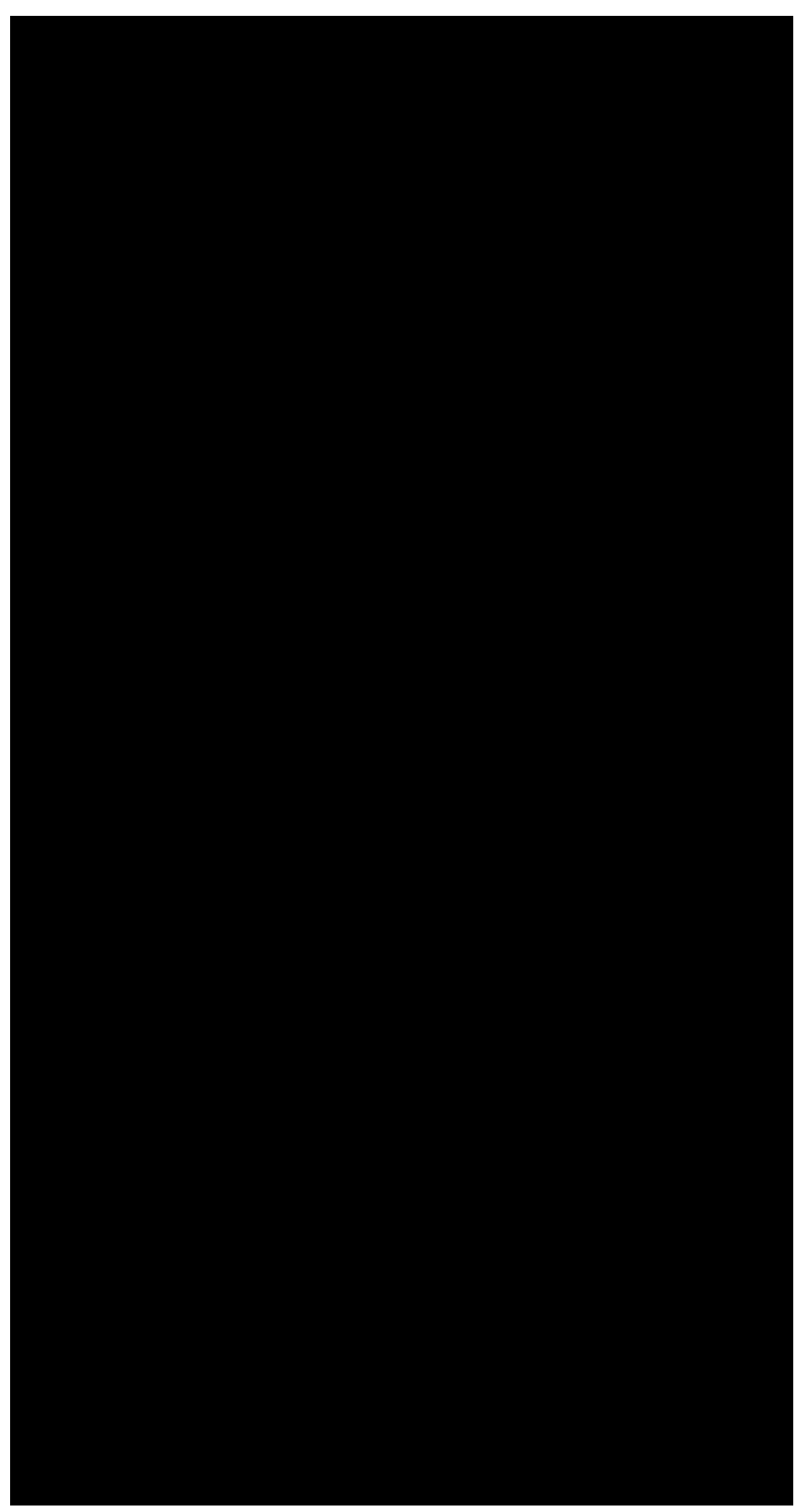

Figure 2.1: Extract of a newspaper article by David Bullard (The Times, South Africa, 06 April 2008). 
The meaning of the term technology has been subject to changes in everyday use and in the academic discourses as a result of varying theoretical vantage points. Epistemologically the term technology was coined from the Greek term "technologia", a combination of the terms "tekhne" denoting a "craft" "skill" and "logia" or "logos" which denotes "saying" or "discourse" (Dobres 2000, 47-95; Ingold 2001, 17). The initial use of the Greek term "technologia" can be traced back to the work of Aristotle (see Barndon 2004, 25-26). With the rapid changes following the 'Industrial Revolution' the term technology gained prominence in Englishspeaking countries. When the term entered the English language in the seventeenth century it meant a branch of learning that was concerned with practical and mechanic arts (Marx 2010). Once the term technology was adopted in English there was a semantic shift. By the early twentieth century, technology in the American discourse became firmly associated with modern engineering, industrial processes and their associated artefacts (Schatzberg 2006). As a result, Sigaut $(1994,422)$ notes that in the modern day Anglo-American contexts the term technology has come to refer to some kind of refined or sophisticated technique associated only with modern engineering. This rather narrow view of the term excludes traditional handicrafts and tools typically used in production processes in pre-colonial Africa and prehistoric contexts elsewhere, since these are usually perceived as employing primitive and simple techniques. However, it has been argued that human technological activities, whether "primitive" or "pre-industrial" are enormously much more complex than often perceived (Pfaffenberger 1992, 509). The misconception that Africans did not open their technological chapter before the arrival of foreigners from other continents as advocated by the newspaper extract inserted above (Figure 2.1) stems from prejudice and the limited scope in the modern use of the term technology. This thesis 
seeks to dispel such perceptions by demonstrating that extractive metallurgical activities around Phalaborwa involved careful planning, complex organisation and required in-depth understanding of material properties of the raw materials in addition to a wealth of sociocultural factors that cannot be separated from technological activities.

The criticism of modern-day usage of the term technology takes us to other 'Western' perspectives on the subject that have come to be known under the umbrella phrase 'Standard View of technology' (Pfaffenberger 1992). The 'Standard View of technology' has propagated the three main myths about technology; such as, 'necessity is the mother of invention', 'form follows function' and 'unilinear progression...from simple tools to complex machines' (Pfaffenberger 1992). Enshrined in these myths is the notion of technological determinism which assumes that technology is the driving force of all social changes making human beings passive respondents to technology. The role of human agency and other social aspects on technological activities is thus not acknowledged. These myths also promote 'internalist approaches' that desocialise or, put in simple terms, isolate technology from society (Austen \& Headrick 1983; Pfaffenberger 1992).

Having established the baggage carried with modern-day views and use of the term technology, we can now turn to its application in ancient technology studies. What is technology to contemporary archaeologists and related professionals? Several archaeologists and anthropologists have explicitly defined the term technology. A scan through some of these definitions shows that use of the term remains ambiguous. Caple $(2006,16)$ defines technology as "a culture-wide level of knowledge and expertise". Ingold $(1990,7)$ concurs by simply defining technology as a body of 
generalised and objective knowledge applicable in practical situations. Following on the work of Marcel Mauss, Sigaut $(1994,422)$ explicitly defines technology as a branch of anthropology devoted to the scientific study of techniques. This places techniques or skills at the centre of technology studies (Küchler 2006, 325). However, Ingold (1990) sees no apparent link between techniques and technology. He vehemently questions the assumptions that the use of techniques by human suggests the presence of technology (Ingold 1990, 8). Pfaffenberger (1992, 497) views technology as a system of material resources, tools, operational sequences and skills, verbal and nonverbal knowledge and specific modes of work coordination that come into play during the fabrication of material artefacts. Technology as understood by many archaeologists is limited to the production processes only. In fact, some tend to employ technology and production as interchangeable terms. However, Miller (2007, 4) define technology as a nested set of actions and relationships: from production, organization of the production process, to the entire cultural system of processes and practises associated with production and consumption. From the above perspectives from archaeologists and anthropologists it can be surmised that technology cannot be restricted to modern industrial contexts. However, some view technology as a field of study whilst others are comfortable with viewing technology as an object of study. In this thesis the view of technology that is adapted is the one that incorporates techniques together with the context and social dimension. 


\subsection{The study of ancient technologies in archaeology}

There has been an ambivalent attitude towards the study of ancient technology in the disciplines of archaeology, anthropology and history. Some theorists have emphasised the repressive, destructive and authoritarian nature of technology upon human societies (Eglash 2006, 332). Jack Goody (1971) describes how military technology represented a means of both destruction and production in pre-colonial West Africa. Some authorities have argued that technology studies tend to place excessive emphasis on the role of technology in human history, conjuring up notions of technological determinism. Technological determinist approaches attributing profound social transformations to technological changes i.e. "technology-driven progress" have been heavily criticised (Austen \& Headrick 1983). As such, chronological referents implying some sort of technological stage like 'Stone Age', 'Bronze Age', 'Iron Age' and 'Industrial Revolution' have been challenged by archaeologists working in Southern Africa as too technicist (Maggs \& Whitelaw 1991; Pwiti 1996, 17; Walker 1995, 13-14). At the same time, continued criticism of ancient technology studies by archaeologists and anthropologists has resulted in major theoretical and methodological developments in the last three decades (Dobres 2000; Lemonnier 1986; Miller 2007; Pfaffenberger 1988; Pfaffenberger 1992). A wide range of themes and topics like gender and technology (Bray 2007; Dobres 1995), mode or organisation of production (Costin 1991; Hall 1987) and technological choices (Sillar \& Tite 2000), only to mention a few, have been addressed by archaeologists interested in technology. Several approaches have been employed to explore these themes. Of particular interest to the current thesis is the chaîne opératoire concept when applied to ancient metallurgical studies. 
The unwavering interest in the subject of technology by French anthropologists since the mid-twentieth century gave rise to the 'Anthropology of Techniques' or 'Anthropology of Technology' (Pfaffenberger 1992). One of the prominent theoretical concepts from this school of thought is the chaîne opératoire. The concept was first developed in the work of the French anthropologist Marcel Mauss in the early twentieth century. The concept was subsequently developed and introduced to Palaeolithic studies by the French archaeologist André Leroi-Gourhan. Translated loosely to English, chaîne opératoire refers to the repetitive operation sequence. This approach has close similarities to the so-called object production and use sequence (OPUS) approach prominent in material culture studies (Caple 2006, 13). These approaches focus on the observation and systematic description of technical sequences employed during the production of material culture. In archaeology, this usually involves detailed reconstructions of technical sequences using production debris or artefacts. Over the decades this concept has become prominent in studies by archaeologists interested in lithics, pottery and more recently metallurgy (see Edmonds 1990; Martinón-Torres 2002; Martinón-Torres 2008, 24).

There are several advantages of employing the chaîne opératoire approach in ancient technology studies and archaeology in general. The approach provides the impetus for step-by-step description and reconstruction of production processes rather than simple description of end products or artefacts (Martinón-Torres 2002, 30). The chaîne opératoire approach thus shifts emphasis from description of finished products, as is the case with typological studies of ceramics prevalent in Southern Africa (Mitchell 2002, 257), and places emphasis in their production thus allowing several themes to be explored. In this thesis, the chaîne opératoire concept allows 
close attention to be paid to production debris rather than finished objects. By employing this concept archaeologists will start to shift focus from metal consuming areas to consider systematic recovery of metal production waste. The approach thus provides the necessary framework for technology studies to flourish in archaeology.

The reconstruction of metal production processes using archaeological evidence alone is easier said than done. Different stages of metal production leave varying amounts of archaeological evidence. Some stages of the operation sequence are obtrusive whilst others remain invisible in the archaeological record. Thus in reality reconstructions of the entire metallurgical chaîne opératoire from mining, smelting, distribution, use, reuse to disposal are not feasible. Within the limited scope of this thesis only copper smelting and refining will be considered. Edmonds (1990) also notes that it is notoriously difficult to move from description of the technical sequences to a broad understanding of the involved societies. It is essential in chaîne opératoire studies to explain production processes with specific reference to the human agents and their societies. Detailed descriptions of chaîne opératoire alone promote the alienation of technology from its cultural context. According to Martinón-Torres (2008, 23) there is an inextricable relationship between technological practice and social aspects; as such, it is no longer acceptable to simply end with the reconstruction of a technical sequence. We thus cannot fully comprehend technology without the understanding of social and historical conditions of the extant societies. Even if this thesis focuses on a relatively small section of the chaîne of copper production around Phalaborwa, it will also endeavour to engage with broader themes of archaeological interest. 


\section{archaeometallurgy}

"..., I find it increasingly difficult to define what separates archeometallurgy from archaeology proper." (Rehren 2000, 964)

Several approaches have been used to explore past African metallurgical practices; these include ethnoarchaeology, film making, field and laboratory experiments and archaeological science (Childs 1994; Killick 1991b). Some ethnoarchaeologists have been able to observe metal production activities unfolding in their social setting, enabling them to give detailed descriptions of these activities in the process and asking participating craftsmen relevant questions (e.g. David 2001; Haaland 2004). It is not always possible to get such first-hand experience with traditional craft production since many crafts have ceased and the responsible craftsmen have long gone. There are risks of extrapolating present day experiences into the deeper past in cases where some of these traditional crafts have survived up to this day. Archaeological approaches are therefore best suited to study extinct technologies without parallel in the present day circumstances. This is indeed the case with metallurgical technologies practiced in the Northern Lowveld during the Iron Age. To reconstruct operational sequences of these extinct crafts therefore standard archaeological approaches together with a range of analytical approaches from hard sciences are required. Material science approaches play an indispensible role in investigations of ancient technologies employing the chaine opératoire approach (Sillar \& Tite 2000; Martinón-Torres 2002). This section assesses the role of sciencebased approaches in the study of past African metallurgical technologies. This thesis employs science-based approaches to reconstruct extractive copper metallurgies around Phalaborwa and therefore this project fits in the scope of archaeometallurgy 
research. Conceptual frameworks that inform current archaeometallurgical practice are briefly discussed to situate archaeometallurgy in contemporary archaeological theory and practice. Paradigm shifts in archaeometallurgy during the past three decades are presented to establish the current prevailing conceptual approaches.

Archaeometallurgy contributes enormously to archaeometric research which applies science-based approaches (archaeometry) to address cultural-historical questions (Killick \& Fenn 2012; Rehren \& Pernicka 2008). Science-based archaeology is vital in ancient technology studies; however, it is not always easy to reconcile sciencebased archeological approaches with mainstream archaeological theory (see Jones 2004; Knapp 2000; Pollard \& Bray 2007). Reasons for this lack of conceptual coherence between science-based archaeology and mainstream archaeology are varied. Firstly, vanguard science-based archaeological investigations are usually carried out by experts from physical sciences with little concern for archaeological theory. Studies by these experts are usually problem-rooted in hard sciences rather than anthropology or social theory (Doonan \& Day 2007, 3). As a result most initial science-based archaeological investigations develop in a 'social theory vaccum' (Pollard \& Bray 2007, 253). Secondly, science-based archaeology flourished with the emergence of 'New Archaeology' during the 1960s (Jones 2004; Knapp 2000), thus some scholars regarded science-based archaeology as processual in outlook (e.g. Dunnel 1993). Archaeometallurgy, as a major sub-discipline of archaeometry, was recently labelled as an outdated branch of 'New Archaeology' which should be abolished (see Doonan \& Day 2007).

Because of an apparent lack of social theory, experts with a physical science background often stop with the reconstruction of ancient technologies and limit their 
explanations to functional interpretations notably avoiding any social interpretations (Sillar \& Tite 2000, 15). However, in non-industrial contexts, as is the case with precolonial African metallurgy, experience has constantly shown that functional interpretations are not always useful (cf. Childs \& Killick 1993; Killick 1991b). Barndon $(2004,28)$ suggests that studies of pre-industrial technological activities can be an important entry point into belief systems and other social aspects of societies in question. A major challenge of archaeometry-based investigations in the field of ancient technological studies therefore is to go beyond the identification and reconstruction of production processes to provide socially meaningful interpretations. In archaeometallurgy social interpretations which pay attention to cultural choices and social beliefs of the craftsmen are now viewed as equally important as purely technical or functional explanations (e.g. Rehren et al. 2007). According to Miller (2007) whenever possible the ultimate goal of ancient technology studies is to put forward a social interpretation of technology. It is against these views that the study of Iron Age extractive copper technologies around Phalaborwa should be investigated. However, the author concurs with Killick (2004a) that it is difficult to come up with a social interpretation of technology based on archaeological evidence alone.

Despite the inevitable challenges faced by science-based archaeologists they have contributed immersely to mainstream archaeology. Sillar \& Tite (2000) correctly point out that in some cases material science approaches are the only avenue to reconstruct past technologies. This is especially true for extractive metallurgical debris from archaeological contexts. It can be very difficult to positively assign a metallurgical assemblage to a particular production stage without employing 
archaeometric approaches. Archaeological slags, for example, were produced at various stages of metal production namely smelting, refining and forging. There are also cases when visual evidence alone will not be adequate to distinguish between ferrous and cuprous metallurgical evidence in the field without employing sciencebased approaches (see Miller \& Killick 2004; Severin et al. 2011), as will be pointed out later in this thesis (Chapter 6).

It is incorrect to suggest that science-based archaeology or archaeometallurgy are outdated branches of 'New Archaeology'(see Doonan \& Day 2007; Dunnel 1993). A brief history of the emergence and development of archaeometallurgy in general, and within the context of Southern Africa in particular, will highlight paradigm shifts that have occured in the specialism in keeping with theoretical changes in mainstream archaeology. In South Africa as already highlighted in Chapter 1, notable metallographic studies of archeological metal artefacts were carried out by G.H. Stanley, the first Professor of Metallurgy and Assaying at the South African School of Mines (Stanley 1929a; Stanley 1929b). These metal artefacts were submitted by various archaeologists for laboratory studies (e.g. Caton-Thompson 1931). Understandably only metal products rather than production debris were submitted for further investigations by archaeologists. Be that as it may, this initial interaction between archaeologists and research metallurgists created the necessary foundations for archaeometallurgy. The initial focus on finished metal artefacts by research metallurgists was eventually followed by systematic investigations of metal production installations, tools and debris between the 1970s and 80s (Espelund 1997; Goodway 1991; Thornton 2009). Further collaboration between archaeologists and research metallurgists resulted in joint archaeological field expenditions. It was the 
continued interaction between these professionals that resulted in the development of archeometallurgy. But what exactly is archaeometallurgy? How has it contributed to the investigation of African metallurgy?

Etymologically the term archaeometallurgy is a combination of two Greek words "arkhaios" meaning "ancient" and "metallourgos" denoting a "worker in metal". The term was coined to accommodate specialists with an applied science background interested in investigating metals used in antiquity. This specialist sub-discipline of archeology was christianed 'archaeo-metallurgy' in 1973 by Beno Rothenberg during the formation of the Institute for Archaeo-Metallurgical Studies (IAMS) in London (Cleere 1993; Goodway 1991, 705). However, the term only gained prominence in Europe during the 1980 s with the publication of newsletters and monographs of IAMS. During the last three decades archaeometallurgy has developed into a fullyfledged area of specialisation in Europe and the United States of America (Espelund 1997; Killick \& Young 1997). Archaeometallurgy is now a branch of archaeometry notable for applying analytical techniques from physics, chemistry and engineering to address archaeological questions (Rehren \& Pernicka 2008). As a result Rehren (2000, 967) suggests that purely archaeological or historical approaches lacking instrumental analyses of metals in antiquity only qualify as 'archaeology of a metal' rather than 'archeometallurgy'. However, emphasis on laboratory practice at the expense of thorough fieldwork studies of production contexts can have limitations on the social interpretation of archaeometallurgical results as was pointed out in Chapter 1. Fieldwork was considered an important aspect of archaeometallurgy in this thesis. The term 'archaeo-metallurgy' was first introduced to the Southern African audience in the early 1980s by an archaeologist with primary interests in ancient mining and 
metallurgy (Friede 1980). Friede simply defined 'archaeo-metallurgy' as the prehistory of mining and metalworking (Friede 1980, 156). Throughout the 1980s the term 'archaeo-metallurgy' appeared in leading academic journals on archaeology or mining and metallurgy in South Africa (e.g. Friede et al. 1982; Friede \& Steel 1986; Kiriama 1987). By 1987, the growing interest on pre-colonial mining and metallurgy saw the first "Archaeometallurgical Workshop" being held in Pretoria, South Africa under the auscipices of the Southern African Association of Archaeologists (SAAA). By the mid 1990s the scope of archaeometallurgy as the investigation of metal processing waste and metal products to establish technological skills, choices and decisions that influenced production of metals was well established in Southern Africa (Miller \& van der Merwe 1994a, 33). Noteworthy, in this new scope is the omission of 'mining', initially recognised as part of archaeometallurgy by Friede (1980) and the emphasis on production debris together with the role of human agents. Recently the term 'archaeo-mining' or 'archaeomining' has been coined to denote investigations that exclusively focus on prehistoric mining or mining archaeology (Rapp 2002). The brief history of archaeometallurgy outlined above shows that the sub-discipline has not been a static field of study that continues draw inspiration from outdated 'New Archaeology' tenets. Archaeometallurgists have constantly reevaluated the scope of their field, incorporating new ideas and analytical approaches in their investigations. Archaeometallurgy is no longer limited to the study of finished artefacts and it has embraced both functional and social interpretations of metallurgical technologies.

The tendency to define archaeometallurgy based on the technical paraphernalia employed or the academic background of investigators involved is deplorable. It is 
the position of the current author that archaeometallurgists should be unified by common interests in the study of production and use of metals in antiquity rather than paying attention to "outdated disciplinary boundaries" (see Pollard \& Bray 2007). Science-free publications have for a long time provided vital information concerning the social aspects of African metal technologies (e.g. Haaland 2004; Reid \& MacLean 1995). However, calls to abandon 'archaeometallurgy' as a separate subdiscipline (e.g. Doonan \& Day 2007) are tantamount to throwing the baby with the bathwater. Archaeology as a discipline has come of age, in essence, specialisation should be welcome because it encourages division of labour so long as communication and overarching paradigms are shared, hence the need for theoretical frameworks discussed in this chapter. Archaeometallurgy as envisaged in this thesis should include the use of standard archaeological field methods together with ethnographic observations where applicable, supplemented by laboratory approaches that help to understand the production, distribution and use of metals in antiquity.

\subsection{Summary}

Although at the beginning of this chapter the risks entailed by the use of theoretical perspectives developed in other disciplines and contexts were noted, this thesis does not put forth any new or ground-breaking theoretical approaches, nor does it claim that it is the first to employ such concepts in the study of African metallurgies. As Childs $(1994,7)$ envisaged, Africanists interested in metallurgy have benefitted a lot from general theories developed and applied first outside the continent by nonAfricanists. The key is to do so critically, and with an awareness of the different archaeological and social contexts, past and present. Studies of ancient technologies in general have undergone profound changes in the disciplines of anthropology and 
archaeology. The study of ancient technology, neglected by many, can be a fruitful venture in Southern African archaeology. Archaeological inquiry should therefore take technology seriously so as to dispel wrong assumptions that Africa has played no part in humanity's technological history.

The current thesis is an attempt to utilise approaches developed in ancient technology studies to investigate copper production around Phalaborwa in the Northern Lowveld of South Africa. The chaîne opératoire approach has been identified as an appropriate analytical concept to investigate the copper production technologies in the research area. The approach places operation sequences at the core of investigation and thus redirects the focus of the current thesis away from traditional archaeological typological methods. A number of research projects on past African metallurgies have successfully implemented the chaîne opératoire approach (e.g. Chirikure 2005; Humphris 2010). It has also been argued that a combination of fieldwork and archaeometric methods provides the best way to establish the chaînes opératoires of pre-colonial copper extractive technologies. This thesis employs material science-based approaches to investigate archaeological ores, production debris and technical ceramics to reconstruct metal production sequences. However, it is no longer adequate to give mere descriptions of techniques and catalogues of hardware used in ancient technologies, a practice previously labelled "dry discussion of techniques" (Tilley et al. 2006, 2). The ultimate goal of this thesis is to come up with a social interpretation of reconstructed technologies whenever it is possible. Since technologies are embedded in social, economic, political and ideological systems, the study has to start by establishing these dimensions of Iron Age societies who occupied the research area, as presented in the next chapter. 


\section{The research area: Phalaborwa and the Northern Lowveld, South Africa}

"...to understand our subject and to penetrate its background we have to consider all sorts of geological, climatic, geographical data but especially consider cultural factors..." (Summers 1969, 150).

\subsection{Introduction}

Archaeometallurgical investigations of this nature at least require some appreciation of the region's geology with a particular focus on the distribution of ore resources. This chapter will outline the major geological events that took place in the research area. Other aspects of the physiographic setting that include the present and past climate, pedology and vegetation also provide the much needed background information to contextualise the metal production activities reconstructed in this thesis. Although the current research is largely limited to Phalaborwa and its immediate environs, it is necessary to discuss the broader Northern Lowveld region as a geographic unit. Perceptions of the Northern Lowveld as an unhealthy and useless vast land where human and animal diseases are prevalent together with poor climatic conditions are assessed. The distribution of mineral resources in the immediate vicinity of Phalaborwa is discussed based on the information provided in the geological literature. The chapter concludes with a discussion of the cultural context outlining the archaeological framework, recent ethnohistorical background which includes twentieth-century population dynamics associated with the Sotho, Venda, Tsonga and settlers of European descent. The current landholding and land utilisation patterns around Phalaborwa are highlighted to show contemporary 
economic pillars and logistical constraints that were faced during fieldwork data collection.

\subsection{Geography and environmental setting}

\subsubsection{Location}

Phalaborwa is situated in the current administrative district of Mopani in the Limpopo Province (formerly Transvaal). Physiographically, it is located right in the middle of an extensive undulating plain better known as the Northern Lowveld, in the extreme north-eastern part of South Africa (Figure 3.1). The Olifants River marks the southernmost limit of the Northern Lowveld, whilst the west boundary is marked by the Great Drakensberg Escarpment, with the Lebombo Mountains forming the natural boundary in the east. Some scholars identify the Great (Groot) Letaba River as the northern natural boundary (Evers1975, 71); however, some extend the northern frontier up to the Soutpansberg Range (Klapwijk 1986b, 17). The current thesis is concerned with archaeological sites within the immediate vicinity of the modern day town of Phalaborwa, with particular focus on the Iron Age sites inside the Cleveland Game Reserve, privately owned by Palabora Mining Company (PMC). The actual research area is thus limited but the understanding of the Northern Lowveld as a geographic unit is necessary. Geologically, this area is well known for its mineral wealth; archaeologically, several settlement sites, ancient mining galleries, smelting precincts and metal working remains have been documented. 


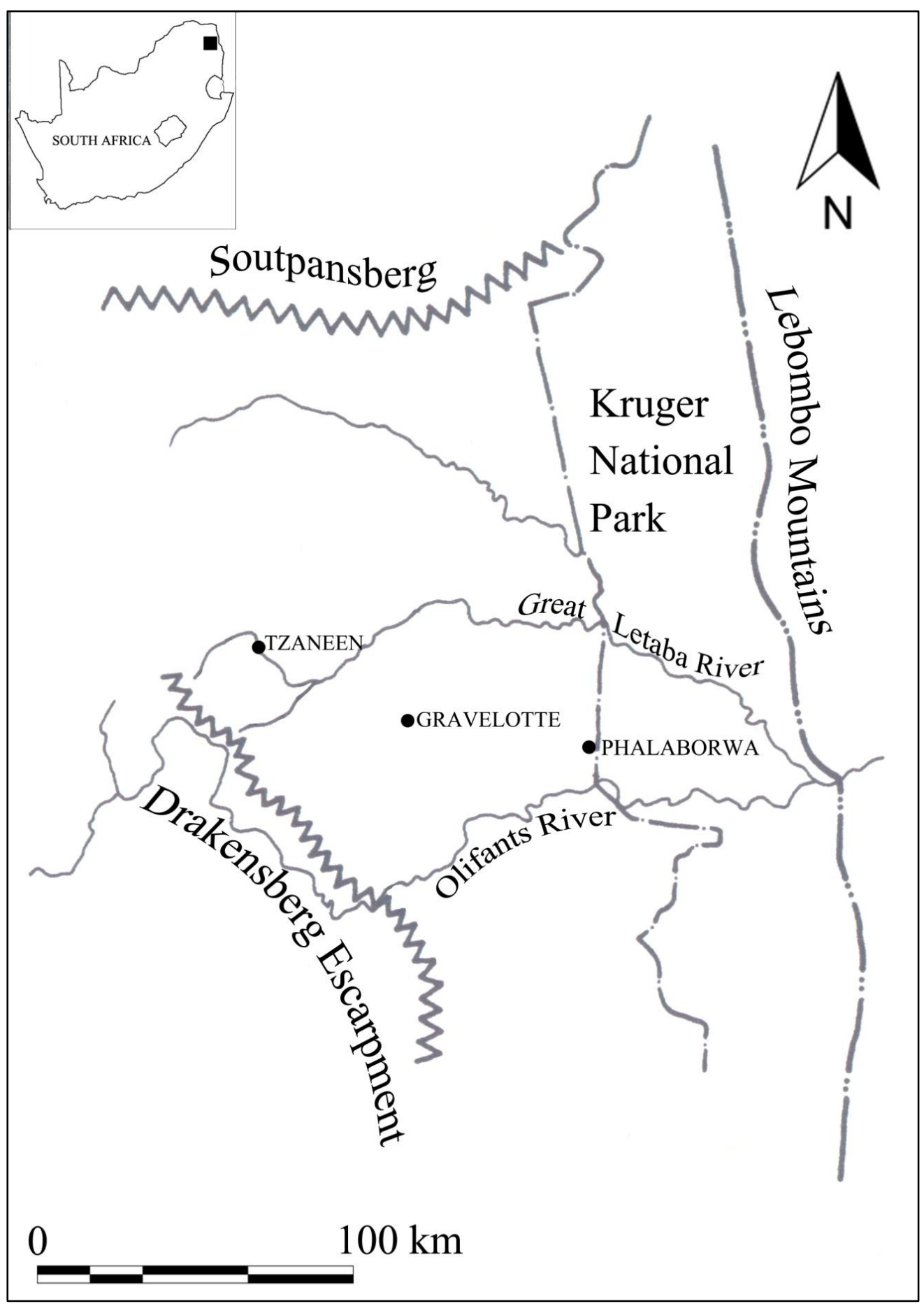

Figure 3.1: Map of the Northern Lowveld showing the location of Phalaborwa (Map: Adapted from Klapwijk 1986b). 


\subsubsection{The current perceptions: physiography, climate, fauna and flora}

Topographically, the Northern Lowveld, as the name implies, is a vast low-lying area with an altitude ranging just between 300 to $400 \mathrm{~m}$ above sea level. The vast plain that characterises this region slopes gently eastwards occasionally being interrupted by isolated syenite hills, further discussed in the geology section below (Figure 3.1). Apart from the isolated hills, this low-lying landscape is bisected by the Murchison Range that stretches from Gravelotte to Phalaborwa. The region is drained by two perennial rivers, namely Great Letaba and Olifants, flowing from west to east as tributaries of the Limpopo River. These major rivers have their headwaters in the Great Drakensberg Escarpment. Much closer to Phalaborwa is the Ga-Selati River which flows to the south eventually joining the Olifants River.

Published narratives concerning the Northern Lowveld from the nineteenth-century hunting parties, explorers, mineral prospectors, missionaries and settlers of European descent portray the region as hot, and severely unhealthy for both humans and domestic stock due to the prevalence of tsetse flies (Glossina sp.), mosquitoes and other vectors responsible for diseases such as sleeping sickness, malaria, black water fever, tick fever and bilharzia (Cartwright 1974, 146-152; Kriege E. J. 1937; Stevenson-Hamilton 1974). Due to the prevalence of diseases during the nineteenth century, the region was known by different names associated with unhealthy conditions including 'Fever Coast', 'Fever Flats', 'Death Valley', 'White Man's Grave' (Cartwright 1974; Stevenson-Hamilton 1974; van der Merwe \& Scully 1971). The legacy of the devastating conditions of the nineteenth century is still present in the Northern Lowveld. One of the earliest settlements to be established by people of European descent was named Gravelotte in Afrikaans, which literally means 'a plot 
of graves' thus highlighting the stigma of death attached to this region (Thorne 1974, 129). Pack animals used by European pioneers, including horses and cattle, were not spared by the unhealthy conditions of the Northern Lowveld. Most of their livestock succumbed to nagana, which is caused by the tsetse flies.

This is the background against which the Northern Lowveld region has been viewed as nothing but a death trap for both human beings and animals. Archaeologists, anthropologists and historians have also projected these hostile conditions into the further past concluding that the area was unpleasant for typical Iron Age agropastoral pursuits (Evers 1981; Miller et al. 2002; Plug \& Pistorius 1999; van der Merwe \& Scully 1971). Iron Age communities occupying the Northern Lowveld are thus portrayed as people who did not engage in any form of crop cultivation or livestock rearing. However, previous results of the analyses of faunal assemblages from archaeological sites situated in the Kruger National Park and around Phalaborwa suggest that the region was relatively free of tsetse flies before the nineteenth century, potentially making it possible for some livestock to thrive (Plug 1989; Plug \& Skelton 1991). Proper paleoclimatic studies dedicated to the Northern Lowveld are yet to be carried out to substantiate claims that harsh climatic conditions prevailed throughout the Iron Age period. Archaeological investigations, elsewhere in semiarid regions of Southern Africa, have shown the resilience and innovations of communities who occupied these perceived 'uninhabitable' landscapes on a permanent basis (Manyanga 2006). The availability of drought resistant crops and innovative agricultural practices like floodplain crop cultivation used by other Iron Age communities in marginal agricultural areas were possibly employed around the Northern Lowveld. It is, however, beyond the scope of this thesis to establish the 
veracity of the claims that the region experienced equally harsh conditions throughout the Iron Age period.

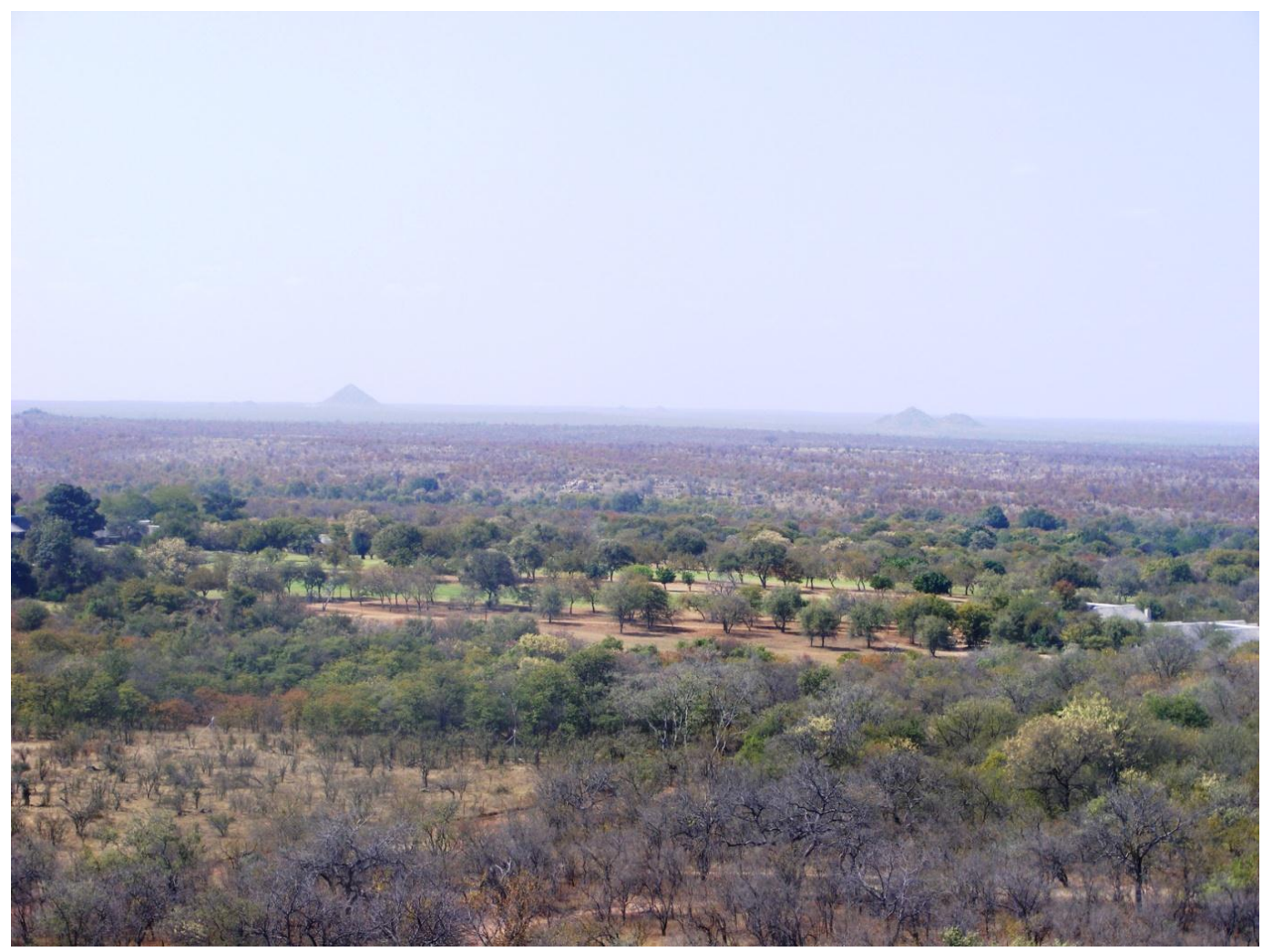

Figure 3.2: Landscape view of the Northern Lowveld showing the typical bushveld and vast plains with isolated koppies (View from Shankare Hill in August 2010).

In terms of climate, today the Northern Lowveld experiences two distinct seasons, namely summer starting from mid-September to May, and winter, occurring between June and mid-September. December, January and February are usually the wettest and hottest months, whilst the months July and August are the driest and coldest (Gertenbach 1980). During the winter season, temperatures are relatively cool but the area never experiences any snow, except for frost, which normally occurs during the morning. The average temperatures during the winter season are usually around $25{ }^{\circ} \mathrm{C}$ with a minimum of $8{ }^{\circ} \mathrm{C}$ in rare occasions. The average $450 \mathrm{~mm}$ of rainfall per year, combined with extremely hot conditions with daytime temperatures exceeding 
$40{ }^{\circ} \mathrm{C}$, makes this region drought prone. This has been the basis for the speculation that rain-fed agriculture was not viable in the past. However, it has to be noted that traditional cultigens of Southern Africa, namely sorghum and millets, are droughtresistant crops requiring only a $400 \mathrm{~mm}$ rainfall threshold per year, making it possible to practice some agriculture albeit at a lower scale (Manyanga 2006, 38). These rainfall patterns are largely dictated by the altitude, where the Highveld experiences more favourable climatic conditions than the Lowveld. Compared to the Great Drakensberg Escarpment, which receives an average of $2000 \mathrm{~mm}$ of rainfall per year, the Northern Lowveld receives relatively low rainfall.

The Northern Lowveld is endowed abundantly with fauna; as a result, large tracts of land in the region have been designated either as sanctuaries for wildlife and nature reserves (Carruthers 1995). The most famous of these game reserves is the Kruger National Park, covering an area of more than 19000 square kilometres, located to the immediate eastern boundary of the town of Phalaborwa. The archaeological sites that were investigated for this thesis are also located within a private game reserve known as the Cleveland Game Reserve, belonging to PMC. The area is home to Africa's Big Five dangerous wildlife game in the form of elephants, lions, buffalos, rhinoceros and leopards. Today tourism resulting from the ubiquitous wildlife is ranked one of the most important economic sectors around Phalaborwa, second only to mining. In the past, this diverse faunal community would have given an endless source of ivory and skins, which eventually found their way to the East African Coast bound for Asia where there was a lucrative market for such items during the Iron Age. The exploitation of these wild animals as a major source of protein through meat 
consumption during the Iron Age has also been reported by archaeologists (Plug 1989; Plug \& Skelton 1991; Plug \& Pistorius 1999).

Directly related to the central theme of this thesis is the availability of certain floral communities to support smelting processes in the research area (Figure 3.2). We should acknowledge the fact that extractive metallurgical process in the past required an enormous supply of charcoal from suitable species of trees (Hoffman 1997). Trees used to produce the much needed charcoal for the fuel in the furnaces are present in the Northern Lowveld. The vegetation in the greater part of the Lowveld is classified as semi-arid savannah, mainly dominated by indigenous tress in the form of Colophospermum mopane, Combretum apiculatum and Combretum imberbe, which are drought-tolerant. Mopani District is actually named after the most dominant Colophospermum mopane trees, famously known for mopani worms, larvae of the moth Imbrasia belina, considered a delicacy by many people in Southern Africa (Makhado et al. 2009, 921). Today the drought tolerant Colophospermum mopane is the major source of fuel wood used for cooking and heating in households without electricity supply across the Northern Lowveld (Makhado et al. 2009). Recent studies suggest that hardwood tree species like Colophospermum mopane and Combretum are strongly prefered sources of firewood in the greater part of the research area (Makhado et al. 2009). According to Prior \& Culter (1992) today mopane produces the best firewood in Africa because it has superior burning qualities that make it burn slowly. Other resources notwithstanding, many scholars view the presence of mineral resources in the form of iron and copper as the sole explanation for the occupation of the unhealthy Lowveld region (Miller et al. 2001; 
Plug \& Pistorius 1999). As such, the next section of this chapter discusses the major geological events and associated mineral deposits.

\subsubsection{Geology, soils and mineral resources}

\subsubsection{The Kaapvaal Craton}

Geologically, Phalaborwa is situated in the eastern margins of the Kaapvaal Craton (Figure 3.3). This Craton is composed of the oldest rocks, mainly granites and gneisses, formed during the Archaean eon (Viljoen \& Reimold 1999). These Achaean rocks are said to have intruded older volcanic and sedimentary rocks known geologically as 'Greenstone Belts'. Collectively the granite-greenstone rocks form the 'Basement Complex' or simply the Kaapvaal Craton; a continental crust that has been around since 3500-2500 million years ago (Viljoen \& Reimold 1999). This older granite-greenstones belt has been susceptible to erosion since the Karoo times, resulting in the vast monotonous low land known as the Northern Lowveld. These underlying basement granitoids have given rise to shallow, coarse, sandy soils identified as Glenrosa and Hutton, which are notably poor in retaining moisture and nutrients (Fraser et al. 1987, 24; Plug \& Pistorius 1999, 163). The combination of poor soils, climatic harshness and unhealthy conditions discussed above has influenced the way the region's past has been reconstructed and interpreted. 


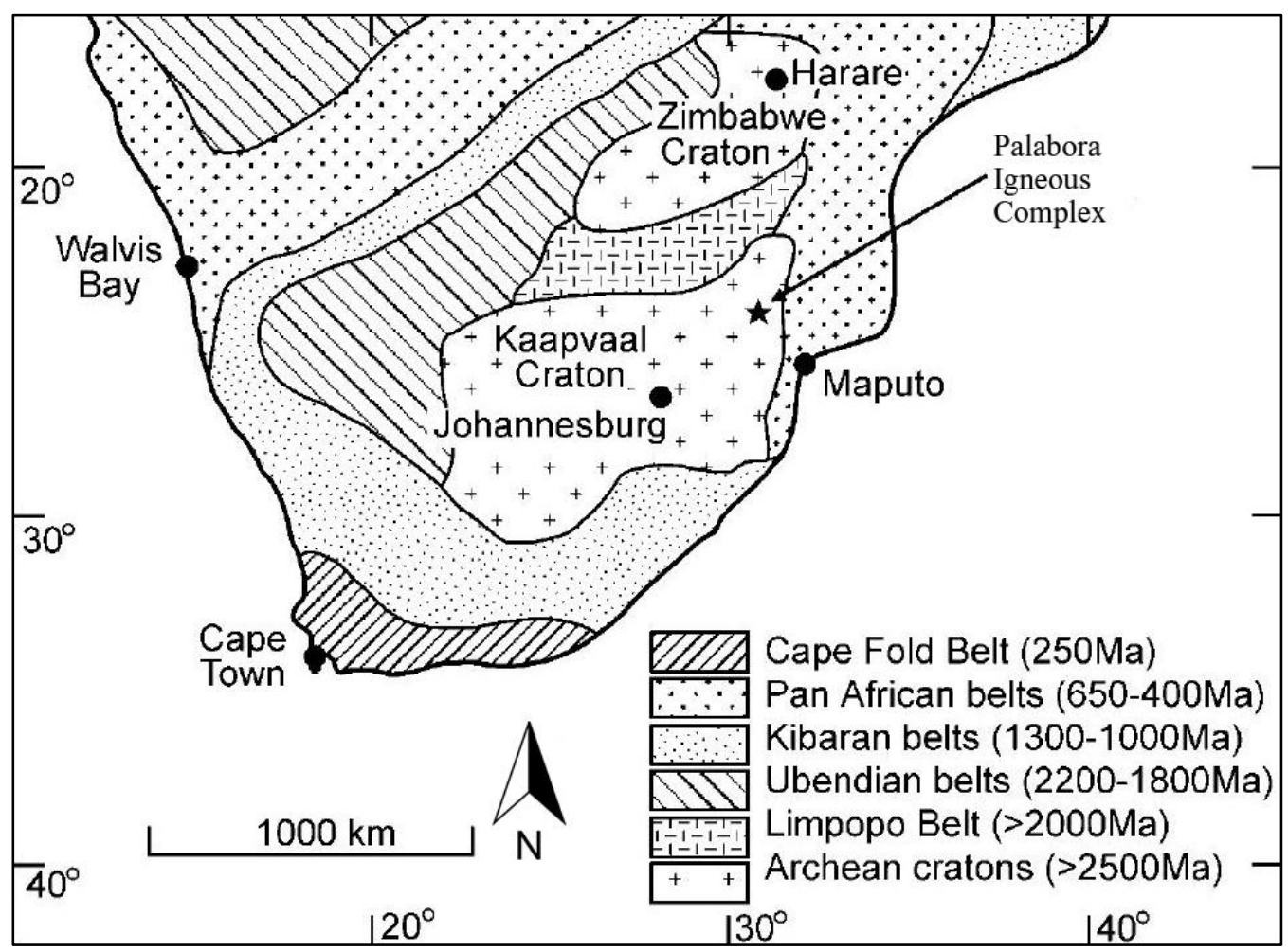

Figure 3.3: Generalised map of Southern Africa showing the position of the Kaapvaal Craton within the major geological events of the sub-continent (Adopted from Groves \& Vielreicher 2001).

\subsubsection{Palabora Igneous Complex}

Phalaborwa has one of the extensively studied geological deposits in the form of the Palabora (sic) Igneous Complex, whose epicentre is located just to the south of

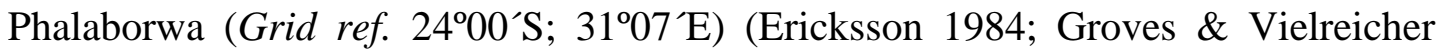
2001; Hall 1912; Heirich 1970; Kuschke \& Tonking 1971; Palabora Mining Company Limited Mine Geological and Mineralogical Staff 1976; Roux et al. 1989; Russell et al. 1954; Shand 1931). The Palabora Igneous Complex is a result of successive geological events dating from at least 2025-2070 million years ago (Ericksson 1984). Proterozoic rocks of magmatic origin that make up the Palabora Igneous Complex are believed to have intruded vertically into the Basement 
Complex discussed above. Over the years, the differential denudation of more resistant rocks making up the Palabora Igneous Complex against erosion-susceptible granite-greenstone rocks of the Basement Complex has resulted in the formation of occasional prominent koppies $^{4}$ around Phalaborwa.

The Palabora Igneous Complex has been described as a kidney-shaped geological deposit that covers an estimated area of about $8 \mathrm{~km}$ by $4 \mathrm{~km}$. Geologists have divided this complex into three zoned lobes, namely the Northern Pyroxenite Lobe, Loolekop Lobe and Southern Pyroxenite Lobe (Figure 3.4). The first magmatic rocks to be deposited during the formation of this unique geological feature were pyroxenite rocks, followed by syenite plugs, then foskorite rocks ending with the deposition of the central carbonatite. The results of these successive geological events were large deposits of apatite, iron, uranoan thorianite, vermiculite and copper. It is estimated that the complex contains copper ore reserve of more than three hundred million tons with an average of $0.7 \%$ copper (Palabora Mining Company Limited Mine Geological and Mineralogical Staff 1976). Modern mining at this unique geological deposit dates back to the 1930s, with small-scale mining of apatite. To date, the deposit has been exploited for vermiculite, uranoan thorianite and copper on a large commercial scale. The epicentre of this geological deposit was Lolwe Hill (Lulukop/Loolekop) that used to stand at a height of 90 metres above the surrounding low veld. By the late 1990s this hill was an open pit mine with a depth of more than 760 metres (Viljoen \& Reimold 1999). The following paragraphs give more information on the mineralogical makeup of the Palabora Igneous Complex.

\footnotetext{
${ }^{4}$ Koppies (singular: koppie) is the preferred term for small hills protruding from the surrounding open veld in Southern Africa. It is derived from Afrikaans.
} 


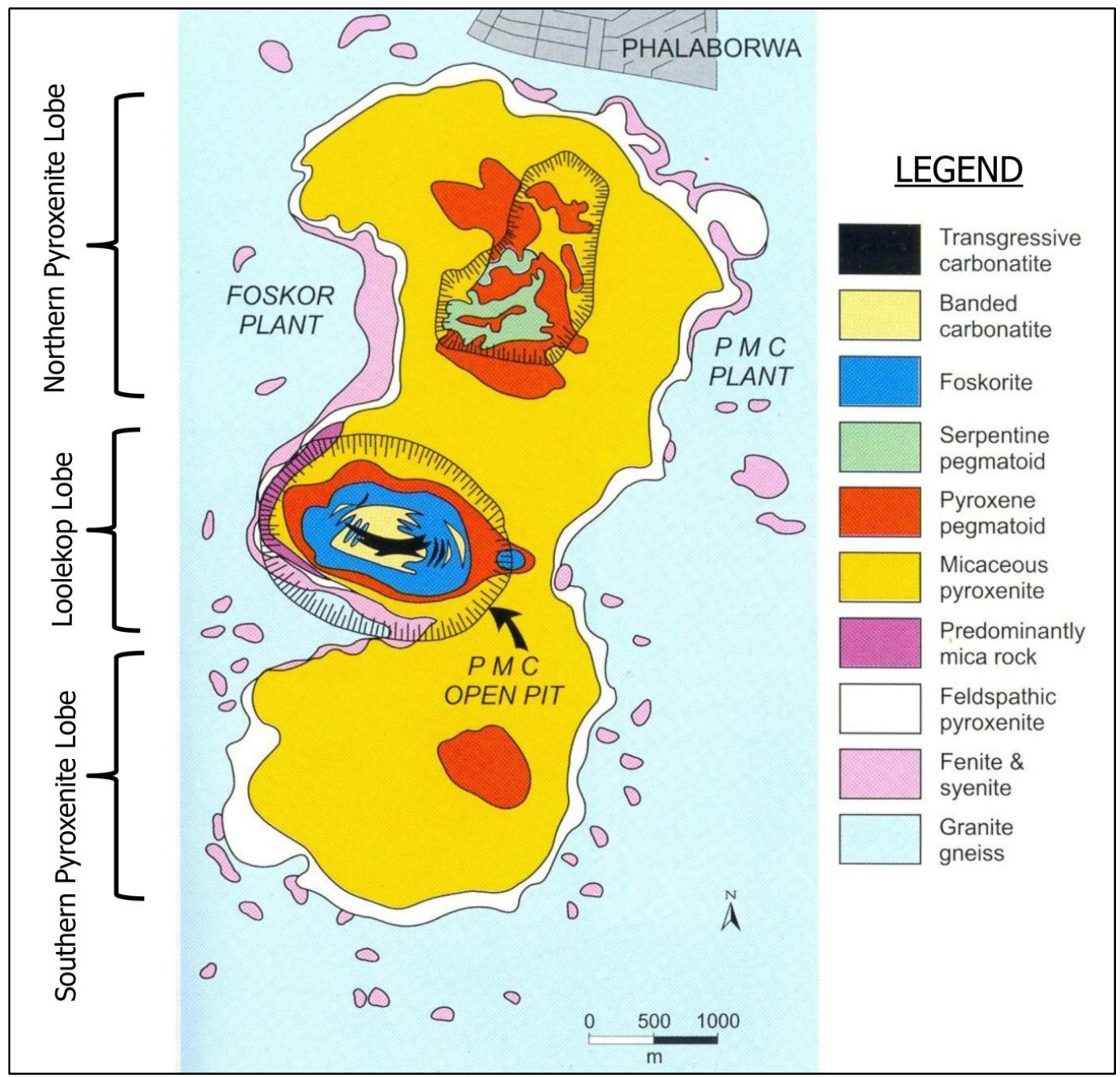

Figure 3.4: The detailed geology of the Palabora Igneous Complex showing the major lobes and position of the current PMC copper mining open pit. (Map: Adapted from Viljoen \& Reimold 1999).

The pyroxenite rocks were the first ones to be deposited in the initial stages of the formation of the Palabora Igneous Complex. The pyroxenite member dominates other members in the complex. The rocks in the pyroxenite member are dark green in colour and they cover the flat area surrounding what used to be Lolwe Hill. This member is the host rock to apatite, which makes between 15 and $19 \%$. Enclosed in the massive pyroxenite member is the foskorite (phoscorite) member. The term foskorite is a mnemonic term derived from Foskor, the name of the mining company 
exploiting this member for phosphates (Russell et al. 1954). The foskorite member is made up of magnetite-apatite-olivine with some late stage copper mineralisations. These copper mineralisations occur mainly as patches of sulphides (Kuschke \& Tonking 1971). The foskorite member has a reserve of more than 200 million tonnes of magnetite iron ore (Viljoen \& Reimold 1999). Important to note at this juncture is the observation that the magnetite ores in the foskorite member are titaniferous, with up to $8.0 \mathrm{wt} \% \mathrm{TiO}_{2}$. The foskorite has the highest concentration of apatite, mainly in the form of fluorapatite with subordinate amounts of hydroapatite and chlorapatite currently exploited for phophate by Foskor mining company (Roux et al. 1989).

Located right in the centre of the Palabora Igneous Complex is the carbonatite deposit which is the youngest in the complex. Geologists have identified two generations of carbonatite deposits, namely the banded carbonatite and the transgressive carbonatite. The banded carbonatite is the older of the two, and contains iron oxides in the form of magnetite with intermediate $\mathrm{TiO}_{2}$ values in comparison to magnetite present in the foskorite member discussed above. The $\mathrm{TiO}_{2}$ values in the magnetite ores tend to decrease with the age of the host rock in the Palabora Igneous Complex (Heirich 1970). As such magnetite ores associated with the foskorite member are titaniferous, whereas titanium is lower in the banded carbonatite and virtually absent in the young transgressive carbonatite. The magnetite associated with the transgressive carbonatite, discussed below, has an average of less than $0.5 \mathrm{wt} \% \mathrm{TiO}_{2}$; this should be compared to the high $\mathrm{TiO}_{2}$ in magnetite from the foskorite member, discussed above (Kuschke \& Tonking 1971). The systematic variation in the $\mathrm{TiO}_{2}$ values of the magnetite ores from the Palabora Igneous Complex has previously proved useful to archaeologists interested in sourcing 
studies of ores, slags and metal artefacts from archaeological contexts around and beyond Phalaborwa (e.g. Gordon \& van der Merwe 1984; Killick 1977; van der Merwe \& Killick 1979). The banded carbonitite rocks are also associated with grey to greyish-green apatite rocks (Russell et al. 1954).

The transgressive carbonatite emplaced after the banded carbonatite is a very important source of copper ores. This member is located right at the centre of the Palabora Igneous Complex (Loolekop lobe). Subsequent to the deposition of the transgressive carbonatite, there was extensive fracturing of the Palabora Igneous Complex. These fractures created channels for the copper-bearing mineralising solutions to permeate both the carbonatite and foskorite members of the complex (Palabora Mining Company Limited Geological and Mineralogical Staff 1976). Copper mineralisations that took place in the postcarbonatite formation period were largely copper sulfides, of which chalcopyrite is the most abundant, followed by bornite and, to a lesser extent, chalcocite, vallerite, cubanite, and pyrrhotite. The copper sulphides occur as disseminated grains, parallel strings, coarse irregular masses and veinlets. The weathered surfaces of carbonatite member observed at Lolwe Hill had visible stains, pockets and specks of green malachite (Shand 1931). Early twentienth-century prospectors and geologists noted extensive 'ancient' adits with depths of up to 12 meters, together with quarries of the Iron Age miners at Lolwe Hill (Hall 1912; Schwellnus 1937; More 1974). It was observed that Iron Age miners meticulous removed copper minerals but discarded magnetite in the tailings within the immediate vicinity of Lolwe Hill (More 1974; van der Merwe \& Scully 1971, 182). The current research will seek to establish through slag analyses and other forms of archaeological evidence of whether these old assumptions were true. 
Literally, thousands of tonnes of magnetite pebbles, a residual product of actively eroding Northern Lowveld coastal shelf, were available on the talus slopes of Lolwe Hill (Miller et al. 2001, 405). Thus apart from the copper sulphides mentioned above, the carbonatite members also contain magnetite and uranoan thorianite (Russell et al. 1954). Mineralogical and petrologic studies of the carbonatite rocks of the Palabora Igneous Complex revealed that the main constituents are $\mathrm{CaO}, \mathrm{MgO}, \mathrm{FeO}, \mathrm{P}_{2} \mathrm{O}_{5}$ and $\mathrm{CO}_{2}$ (Russell et al. 1954). Also very relevant to this thesis is the observation that rocks/ minerals from the central carbonatite are under saturated (i.e. silica free) (Groves \& Vielreicher 2001; Russell et al. 1954).

\subsubsection{Phalaborwa and beyond: other copper ore deposits}

Thus far we have established that viable copper mineralisations are available in abundance in the Palabora Igneous Complex, particularly in the central carbonatite member. Two more copper deposits close to Lolwe Hill were exploited during the Iron Age period. Early geological reports mention the occurrence of 'ancient mines' around the Old Guide Copper Mine and April Kop (Hall 1912; Schwellnus 1937). The Old Guide Copper Mine is located about $6.4 \mathrm{~km} \mathrm{NW}$ of the Lolwe Hill, on a flat area in the Schiettocht Farm. Geologically the deposit at this mine is described as a feldspathic pyroxenite (shonkinite) pipe that is geochemically related to the Palabora Igneous Complex (Eriksson 1985; Shand 1931). At Old Guide Copper Mine, copper ores are characterised as bornite and pyrites deposited mainly within the veins of the feldspathic pyroxenite (Shand 1931). The copper mineralisation also occurs as little pockets, specks and streaks but without any continuous lobe, thereby making it difficult to mine. The copper ores in the zone of weathering, with a depth of $6 \mathrm{~m}$, were copper carbonates identified as malachite and azurite (Hall 1912). Below this 
zone, copper ore minerals occur mainly as bornite and chalcopyrite. It is important to note that just like in the deposits in the main Palabora Igneous Complex, apatite also occurs at the Old Guide Copper Mine deposit as an accessory mineral (Eriksson 1985). Ancient workings were also noted in the deep green pyroxene east of the April Kop, which is southwest of Lolwe Hill. Not much is known about the nature of this deposit but the geological literature indicates that the pyroxene rocks at this location contained streaks and specks of malachite (Hall 1912; Schwellnus 1937).

Having attempted to give a detailed description of the local geology of the research area there is no doubt that the area is endowed with mineral resources. Today large commercial mining activities are going on around the Palabora Igneous Complex with the exploitation of copper, vermiculite, phosphates, zirconium, mica and gold. It has been established that magnetite for iron smelting was abundant at Lolwe Hill in both the foskorite and carbonatite members. Copper mineralisations were also present in a matrix of calcite, apatite and magnetite in the same deposit. Further afield, approximately $60 \mathrm{~km} \mathrm{SW}$ of Phalaborwa, copper deposits have been identified at Harmony Mine (Grid ref. 24 $4^{\circ} 10^{\prime} \mathrm{S} ; 30^{\circ} 36^{\prime} \mathrm{E}$ ). Also more than $60 \mathrm{~km} \mathrm{NW}$ of Phalaborwa there is copper deposit at Maranda Mine which contains significant

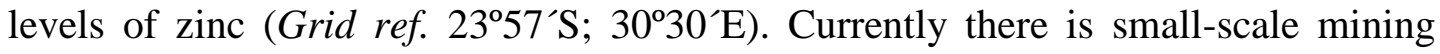
operation of zinc-copper from sulphide deposits at Maranda (Viljoen \& Reimold 1999, 109-111). Small-scale copper mining is reported to have taken place at Harmony Mine and Maranda during the pre-colonial period (see Chapter 4). 


\subsubsection{The syenite plugs}

The Northern Lowveld landscape is occasionally relieved by koppies that are very important from a geological point of view. Occasional syenite plugs found around Phalaborwa have resulted in the formation of these koppies. These plugs are related to successive geological events that formed the Palabora Igneous Complex. They represent the forcible injection of magma into the country rock of granitegreenstones (i.e. Basement Complex). As pointed out earlier, the granitic rocks have since been weathered and eroded leaving the resistant syenite plugs standing out as prominent koppies (Frick 1986). No occurrence of copper or iron ores has been reported at any of these isolate syenite plugs. Mineralogical and petrological studies of the rocks of these syenite plugs show that they contain $\mathrm{SiO}_{2}$ and $\mathrm{Al}_{2} \mathrm{O}_{3}$ as their major constituents, with traces of iron and copper oxides (Shand 1931). The isolated syenite koppies form a crucial part of the cultural landscape of Phalaborwa. Archaeological studies have revealed that these isolated koppies were preferred locations for Iron Age settlements (Plug \& Pistorius 1999; van der Merwe \& Scully 1971). This takes us to the discussion of the cultural background in the research area from the Early Iron Age. 


\subsection{Cultural background and population dynamics}

\subsubsection{Archaeology: From the Early Iron Age to the $19^{\text {th }}$ century}

Our knowledge of early human settlement history in the research area remains sketchy. Late Stone Age sites have been reported inside the Kruger National Park (Plug 1989); however, since this research primarily focuses on metal production, this section will consider briefly the settlement history during the Iron Age period. Archaeologists generally accept that groups of people with different modes of subsistence occupied the South African landscape from the first millennium AD. The drier and winter rainfall western part was occupied by pastoralist communities, whereas the more humid and summer rainfall eastern part was home to agriculturalists (Maggs \& Whitelaw 1991, 3). The Northern Lowveld is situated in the summer rainfall region. It is believed that the occupation of the eastern summer rainfall regions from the early first millennium $\mathrm{AD}$ was a result of separate waves of migrations (Huffman 2007; Huffman \& Herbert 1994-1995; Maggs \& Whitelaw 1991; Mitchell 2002). The Iron Age cultural sequence of the Northern Lowveld has been developed using ceramic typologies combined with stratigraphic information and radiocarbon dates (Evers 1981; Evers \& van der Merwe 1987). Different ceramics groups have been identified and linked to various linguistic groups and population movements (see Huffman 2007). However, the interpretation of ceramic typologies and stratigraphic data is as always subject to criticism; as such, caution is required. The Iron Age cultural sequence of Phalaborwa outlined here only provides the archaeological framework crucial for comprehending past metal production activities. 
The 'Early Iron Age' settlement history and cultural sequence of Phalaborwa remains vague. As result we have to rely on information from surrounding archaeological sites in the Northern Lowveld. The vanguards of the first millennium Iron Age migrations into other parts of the Northern Lowveld have been associated with Matola ceramics. These ceramics have been dated from the first to the fourth century AD (Evers 1981, 68; Maggs \& Whitelaw 1991, 13). Subsequent groups have been associated with Matakoma and Eiland ceramics. These two ceramic phases have been radiocarbon dated from the fourth to the sixth century, and tenth to twelfth centuries, respectively (Evers 1981, 68). Unfortunately, information regarding the metal production activities of these 'Early Iron Age' vanguards around Phalaborwa remains circumstantial; neither do we know much about other aspects of these groups. This is true for the broader Southern African region where metals and evidence of metal production remain scarce.

The 'Middle Iron Age' and 'Late Iron Age' sequence of Phalaborwa are better understood because they are represented archaeologically by large ceramic assemblages, habitation sites and metal production sites (Evers \& van der Merwe 1987; van der Merwe \& Scully 1971). Three second millennium AD ceramic groups, namely Kgopolwe, Moloko and Letaba have been identified. Kgopolwe ceramics, named after the type site excavated by Nikolaas van der Merwe in the 1970s, have been radiocarbon dated by association to between AD 1000 and AD 1300 (for more on Kgopolwe the site see Chapter 7). The Kgopolwe phase (AD 1000-1300) is associated with unequivocal evidence of mining, metal production and large habitation sites that are usually located in the lowlands adjacent to syenite koppies described above. 
Archaeologists seem to concur that there is a temporal occupation hiatus in the Phalaborwa sequence from about AD 1300 to AD 1500 (Evers \& van der Merwe 1987; Miller et al. 2001; Plug \& Pistorius 1999). The reasons for this hiatus have not yet been established, therefore potential links between this hiatus and demand or markets for metal objects are difficult to explore. Elsewhere in the Northern Lowveld, ceramics known as Moloko begin to appear in the late thirteenth century (Huffman 2007; Huffman \& Herbert 1994-1995). These ceramics have been linked to ancestral Sotho-Tswana speakers who continue to occupy most parts of the Northern Lowveld to this day. The temporal hiatus around Phalaborwa ends with the appearance of Letaba ceramics (AD 1600-1900). Letaba ceramics are believed to be a hybrid outcome of the interaction between manufacturers of Khami ceramics and manufactures of Moloko ceramics (Loubser 1989; Maggs \& Whitelaw 1991). The late second millennium is associated with many settlements that were located on terraced platforms of syenite koppies and smelting furnaces.

The settlement patterns of second millennium $\mathrm{AD}$ communities of Phalaborwa remain poorly understood. Conversely, considerable advances have been made in Iron Age settlement pattern studies in other parts of Southern Africa. The identification of cattle enclosures at the centre of Iron Age settlements, a model better known as the Central Cattle Pattern (CCP), highlights the significance of cattle amongst most Iron Age societies in the region (Huffman 1986a; Huffman 1986b). The CCP has not yet been documented around Phalaborwa. The absence of the CCP is possibly in line with the view that cattle played a less significant role in the Northern Lowveld (Plug \& Pistorius 1999). Vudogwe is the only Iron Age site where 
livestock enclosures have been documented in the research area (van der Merwe \& Scully 1971,183$)$.

The nature of socio-political organization of the second millennium AD societies in the research area has not yet been explored in great depth from an archaeological perspective. It is not known if the individual settlements associated with the isolated koppies were autonomous or if there was a centralised authority. Based on faunal evidence it has been argued that archaeological sites in the research area were peripheral to main centres of power during the Iron Age (Meyer and Plug cited Maggs \& Whitelaw 1991, 16).

\subsubsection{Recent history and ethnohistory}

The Northern Lowveld is presently home to people of diverse ethnic and linguistic backgrounds, namely Sotho, Venda and Tsonga. Ethnohistorical information of these diverse groups in the form of genealogies, accounts of major events, migration and interaction have been published (Kriege E. J. 1937; Kriege E. J. 1938; Kriege J. D. 1937; Scully 1979). These accounts have been of great value to archaeologists interested in the more recent past of Phalaborwa (e.g. Loubser 1989; Plug \& Pistorius 1999; van der Merwe \& Scully 1971). The Sotho groups are believed to have a much greater antiquity in the area when compared to other groups. The Venda people, mostly occupying the Soutpansberg Range and adjacent Lowveld areas, have a history going back to the early eighteenth century (Loubser 1989), and the Tsonga (Tonga) people are early nineteenth-century immigrants from Mozambique. The late nineteenth to early twentieth century saw the influx and settlement of immigrants of 
European descent in response to the discovery of gold fields and the establishment of the Kruger National Park (Carruthers 1995; Cartwright 1974; Stevenson-Hamilton 1974).

The late second millennium AD history of Phalaborwa is dominated by the Northern Lowveld Sotho people known as Ba-Phalaborwa or Ba-Malatji (Kriege J. D. 1937; Scully, 1979; Plug \& Pistorius 1999). They are recalled in the oral traditions as renowned metal workers who supplied both iron and copper implements to other groups in the Northern Lowveld and Drakensberg Escarpment. By the nineteenth century, the Ba-Phalaborwa people sub-divided themselves into different clans, namely Maseke-Malatji (formed c. 1830), then Makusane (formed c.1860) and finally the Selwane-Malatji or Majaji-Malatji (established 1900). Each clan was ruled by a Kgoshi. The clan-based histories identify Sealeng Hill as the royal residence and place of burial for the Malatji rulers (Scully 1979). Pistorius (1989) who used these clan histories, oral traditions together with archaeological evidence concluded that there was notable economic specialisation amongst the various clans. He concluded that the Makusane and Majaji-Malatji clans were exclusive producers of iron whilst the Maseke-Malatji clans were predominantly copper producers. The Majaji-Malatji iron producers occupied the area to the north of the modern day town of Phalaborwa. The copper-working Maseke-Malatji occupied the area around Lolwe Hill with a sphere of influence that covered the settlements presented in this thesis. These various clans were dispossessed of their territories to make way for the game reserves, mines and farms.

The importance of metal production to Iron Age societies of Phalaborwa is well summed up in one of the early twentieth century praise poems of the Musina people, 
who occupied the Lowveld between Soutpansberg and Limpopo River about $200 \mathrm{~km}$ north of Phalaborwa. Musina people, renowned copper and iron workers in their own right, acknowledge the importance of metal production around Phalaborwa. This praise poem suggests that Phalaborwa was the land of specialised metal producers who were not involved in any cattle rearing activities. This praise poem says:

\section{"Phalaborwa where the hammer is heard,}

The lowing of the cattle is not there,

The hammer resounds...?...” (Mamadi 1940, 81)

Metals from Phalaborwa were an important medium of exchange in social transactions such as marriages. The metal inventory included the well-known distinctive copper or tin ingots locally referred to as marale (singular: lerale) (see Chapter 4). The function of these golf club-shaped ingots has been subject to speculation but the view that they were used to pay bride price seems to have gained currency (Haddon 1908; Hemsworth 1908; Killick 1991a; Lindblom 1926). Amongst most Bantu groups of Southern Africa, transactions of bride price during marriages usually involve cattle (Huffman 1998; Kuper 1982). The practice involves the payment of a certain number of cattle by the groom to the family of the bride. This practice is locally known as lobola. It has been argued that since cattle-keeping was not viable in the Northern Lowveld metal objects such as marale and iron hoes were widely used as a form of bride price instead of cattle (Klapwijk 1974; Plug \& Pistorius 1999, 181; van der Merwe \& Scully 1971, 190). This unusual practice has further been used to support the perceptions of a hostile climate and unhealthy region that could not support pastoral activities. It is important to note that although the area around Phalaborwa has been regarded as unsuitable for agriculture, hoes and axes 
that play a crucial role in the economic activities of agriculturalists are ubiquitous in the archaeological record (Klapwijk 1974). Agricultural hoes (Figure 3.5) are historically known to have been exchanged for agricultural produce with neighbouring groups like the Balobedu, Bakgaga and Monareng, who occupied the fertile foothills of the Great Drakensberg Escarpment (Miller et al. 2002). 


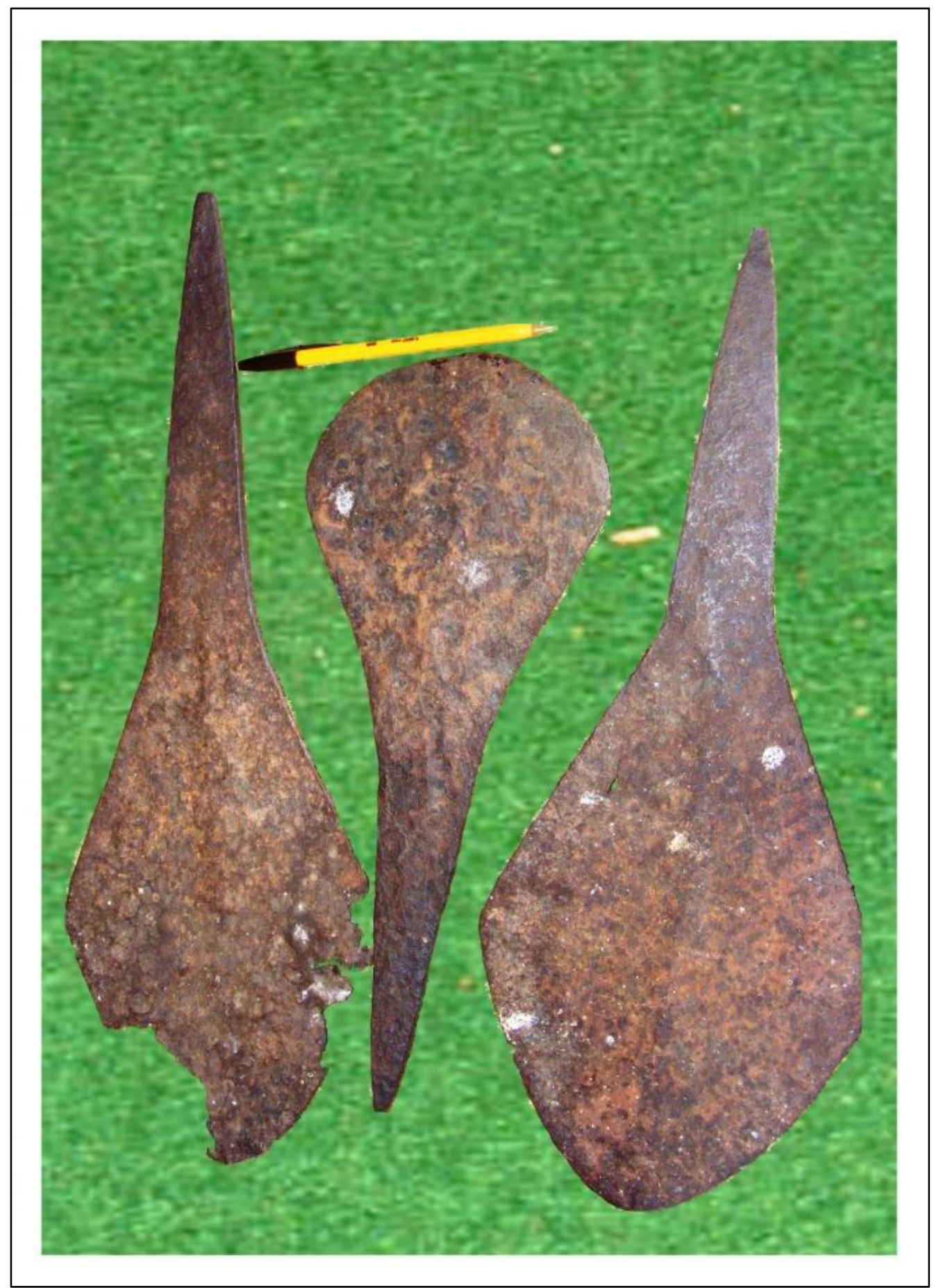

Figure 3.5: Typical Iron Age hoes from Phalaborwa that were widely traded and used as bride wealth. The hoes are on display at Masorini Archaeological Site Museum (Image: Author). 


\subsection{Summary}

Twentieth-century perceptions of the Northern Lowveld that dominate in the narratives of the first European explorers have long viewed the region as an unhealthy area for human habitation and livestock rearing. Environmentally, the research area is also perceived as an agropastoral marginal area with erratic rainfall and poor soils. Typical agropastoral practices characterising other Iron Age societies around Southern Africa were probably difficult to pursue in the Northern Lowveld. However, archaeological work has revealed that the region was occupied on permanent bases by different groups of people during the past two millennia (van der Merwe \& Scully 1971). However marginal as the Lowveld is perceived, it is very hard to subscribe to the view these Iron Age communities never practised any form of agriculture. Be that as it may, the nature of agricultural practices adapted by these Iron Age communities is beyond the scope of this thesis largely focusing on metal production. This issue might warrant some further research in the future by archaeologists and scholars from related disciplines.

One of the facts that can be substantiated is that the Northern Lowveld provided unique opportunities for metal producing communities because it had the much needed resources in the form of abundant ores and trees for charcoal production. The geological literature surveyed in this chapter has highlighted significant variations in the ore deposits around Phalaborwa. High grade iron ores in the form of magnetite are found in abundance, not only at the centre of the Palabora Igneous Complex but also at Schiel Igneous Complex and Rooiwater Igneous Complex (Miller et al. 2001). Copper ores are also available at different locations in the Northern Lowveld and some of them had evidence for exploitation during the Iron Age period (Evers \& van 
der Berg 1974). The research area is also endowed with trees suitable for charcoal production that are needed for the production of metals unlike some of the regions of South Africa that have been studied previously. 'Treeless' grasslands of the Free State Province of South Africa are a good example of an area that lacked trees to make charcoal. Iron Age societies of the Free State Province had to rely on dung as fuel for domestic use and imported metals from neighbouring resource rich regions (Chirikure et al. 2008). Mining remains the major economic pillar in the modern day town of Phalaborwa, together with tourism based on the availability of wildlife. It is not clear how the modern day sole importance of mining has influenced the historical and archaeological interpretations. The next chapter presents the archaeological evidence relating to metal production around Phalaborwa, providing an appraisal of previous research, identifying gaps and further clarifying the objectives of the current thesis. 


\section{An overview of previous studies on Iron Age mining and metallurgy of the Northern Lowveld}

"It is often impossible to reconstruct the technology from chemical data alone." (Killick et al. 1988, 392).

\subsection{Introduction}

Systematic archaeological research into the Iron Age period of the Northern Lowveld, and Phalaborwa in particular, started in the 1960s with the work of Revil Mason and Nikolaas van der Merwe (Mason 1965; van der Merwe \& Scully 1971). With the exception of archaeological investigations carried out at Mapungubwe in the 1930s to 1940s by amateur archaeologists (Fouché 1937; Gardner 1963), the Phalaborwa studies were the pioneering investigations by professionally trained archaeologists into the Iron Age of South Africa during the apartheid era. Iron Age studies were largely neglected in favour of investigations of earliest hominids and their associated material culture. Iron Age studies which openly challenged the apartheid version of history that blacks and whites had arrived simultaneously south of the Limpopo were considered inappropriate (see Mitchell 2002, 36, 414; Shepherd 2003). This is the background against which we have to judge initial studies around Phalaborwa as ground breaking studies.

Initial extensive archaeological surveys within the $30 \mathrm{~km}$ radius of Phalaborwa resulted in the location of an impressive number of Iron Age smelting sites (van der Merwe \& Scully 1971). The geographical coverage of Iron Age research was extended by Evers who investigated mines and smelting furnaces at Harmony, situated about $60 \mathrm{~km} \mathrm{SW}$ of Phalaborwa (Evers 1975; Evers \& van der Berg 1974). 
Prior to the current project, the last systematic fieldwork of Iron Age sites around Phalaborwa was carried out in the 1980s by Julius Pistorius, who excavated several iron and copper metal production remains for his doctoral thesis (Pistorius 1989).

Initial analytical work of metallurgical debris and artefacts that began some three decades ago highlighted some important aspects of pre-colonial iron metallurgy around Phalaborwa (Gordon \& van der Merwe 1984; van der Merwe \& Killick 1979). During the last decade, metallurgical debris and products from the earlier surveys and excavations have been revisited and subjected to further analytical work (Miller 2010; Miller et al. 2001; Miller \& Killick 2004). However, our understanding of extractive copper metallurgy remains sketchy with some conflicting views that remain unsolved as a result of less dedicated fieldwork and analytical work. Hitherto, analytical studies of extractive copper metallurgical debris have rather been sporadic, based on limited analytical approaches and relatively small numbers of samples. The available analytical data is largely based on bulk chemical studies with notable limitations when it comes to detailed reconstruction of pyrotechnologies. Thus there occurs a large scope to have high resolution reconstruction of Iron Age metal technologies together with their associated social aspects in the research area.

The investigations of Iron Age mining and metallurgy in the Northern Lowveld conducted by Revil Mason, Nikolaas van der Merwe, Mike Evers, David Killick, Duncan Miller and Julius Pistorius will be evaluated in this chapter. To achieve this, a thematic approach is employed to summarise, review and further identify gaps that have only been briefly outlined in Chapter 1. In line with the chaîne opératoire approach, this review of previous studies covers the following aspects: mining, smelting, metal alloying and fabrication, trade and use of metals. This chapter 
concludes with an outline of outstanding issues on extractive copper metallurgy that this thesis seeks to address.

\subsection{Archaeomining studies}

The earliest reports on Iron Age mining activities in the research area were produced by European explorers, mining engineers and geologists who encountered the region from the late nineteenth century. The most notable explorers to report these mining activities include the German explorer and geologist Karl Mauch, who passed through Phalaborwa and witnessed mining activities at Lolwe Hill in 1868. Edward Button also reported copper production activities at Mashishimale, near Lolwe Hill, the following year. It is interesting to note that Button, as a foreigner, was refused access to see copper mining operations at Lolwe Hill (More 1974, 227). Abandoned mining galleries around Phalaborwa were subsequently documented and described by government geologists and inspectors of mines in the early twentieth century (Hall 1912; Schwellnus 1937; Trevor 1912). Their descriptions were also accompanied by pictorial evidence. Although some of the ancient workings at Lolwe Hill had been deliberately backfilled, some of them had a depth of up to $15 \mathrm{~m}$ (Trevor 1912). Besides these 'ancient mines' early geologists and mine inspectors also noted the occurrence of metal smelting precincts around Phalaborwa. Since these ancient workings had been abandoned by the twentieth century, speculations were made regarding their antiquity, the ores that were sought by pre-colonial miners and the identity of miners. Hall $(1912,167)$ suggested that the reef working prevalent at Lolwe Hill was not the work of indigenous African tribes of Phalaborwa. Schwellnus $(1937,904)$ doubted if copper was actually mined at Lolwe Hill, since he was unable to identify any definite lode of copper mineralisation. 
Unfortunately, interest in these ancient workings remained in the hands of Phalaborwa white residents cum amateur archaeologists (e.g. More 1974). By the late 1950s commercial mining activities had commenced at Lolwe Hill, as a result archaeological sites around this koppie were in imminent danger of destruction (Figure 4.1). This triggered rescue archaeological investigations by Revil Mason and Nikolaas van der Merwe (van der Merwe 1971; van der Merwe \& Scully 1971). These professional archaeologists managed to salvage some important information although systematic archaeomining studies were never carried out. Mason $(1965,264)$ managed to produce the first sketch plans of the ancient shafts and dumps at Lolwe Hill. It was also noted that these ancient shafts were exclusively located on the carbonatite member of the Palabora Igneous Complex (Miller et al. 2001, 406). Precolonial copper mining evidence was also documented at Old Guide Copper Mine, less than $7 \mathrm{~km} \mathrm{NW}$ of Lolwe Hill, but unfortunately no further archaeological work was also carried out at this mine. Systematic archaeological excavations were only carried out at Harmony, $60 \mathrm{~km} \mathrm{SW}$ of Phalaborwa, where some pre-colonial copper mines were spared from destruction because they were uneconomical to exploit by modern standards (Evers 1975; Evers \& van der Berg 1974).

The mining techniques that were employed at these mines have been synthesised in several publications (see Chirikure 2010; Friede 1980; Hammel et al. 2000; Mason 1982 More 1974; Trevor 1912). It is estimated that well over 10, 000 tonnes of rock containing copper ore were removed from Lolwe Hill during the pre-colonial period (van der Merwe \& Scully 1971, 179). The mining tool kit that was used included dolomite hammer stones, iron gads and chisels. There was also archaeological evidence of fire setting at Lolwe Hill and Harmony (More 1974; van der Merwe \& 
Scully 1971, 181-182). Nikolaas van der Merwe managed to collect some charcoal samples to determine the antiquity of mining activities at Lolwe whilst the koppie was being blasted to commence open pit mining. Radiocarbon dating of these charcoal samples produced the earliest acceptable dates of mining activities with metallurgical intentions in South Africa (see Table 4.1). Iron Age copper mining operations in the Lowveld presumably ended in the second half of the nineteenth century presumably as a result of easy access to imported European metals and the regional unrest that characterised this period.

Table 4.1: Radiocarbon dates of Iron Age copper mining activities in the Northern Lowveld. The dates were calibrated with Oxcal 4.1 and IntCal 09 by the author.

\begin{tabular}{|l|l|r|r|l|}
\hline Sites & Lab. Ref & ${ }^{14}$ C age BP & Calibrated AD @ 2 6 (95.4\%) & References \\
\hline Lolwe Hill & Y-1636 & $1180 \pm 80$ & 674AD (95.4\%) 993AD & (van der Merwe \& Scully 1971) \\
\hline Lolwe Hill & Y-1635 & $950 \pm 60$ & 990AD (95.4\%) 1214AD & (van der Merwe \& Scully 1971) \\
\hline Lolwe Hill & GrN-4215 & $160 \pm 30$ & $1664 \mathrm{AD}(16.9 \%) 1706 \mathrm{AD}$ & (van der Merwe \& Scully 1971) \\
& & & $1720 \mathrm{AD}(47.6 \%) 1826 \mathrm{AD}$ & \\
& & & $1832 \mathrm{AD}(12.8 \%) 1884 \mathrm{AD}$ & \\
& & & $1914 \mathrm{AD}(18.1 \%)$ 1953AD & \\
\hline Harmony Mine & RL-2070 & $690 \pm 90$ & $1164 \mathrm{AD}(95.4 \%)$ 1424AD & (Evers \& van der Berg 1974) \\
\hline
\end{tabular}

Theories of foreign miners being involved in mining activities during the Iron Age mooted by early geologists have never been substantiated by subsequent archaeological research. These mines were worked by different groups, as suggested by the cultural sequence of the region outlined in the previous chapter. Ethnographic information of copper mining activities available in Central Africa has highlighted important aspects about the organisation of mining activities and issues of access, ownership and political control of mineral resources (Bisson 1976). However, this information is not available in the research area since copper mining activities had long ceased when Europeans started to settle permanently in the region. It is 
therefore not possible to comment on the makeup of the mining crews or seasonality of their mining activities. Archaeologists have tried to infer some of these aspects from the limited evidence gathered from the abandoned mining galleries. Firstly, narrow shafts of only $40 \mathrm{~cm}$ in width and up to $15 \mathrm{~m}$ depth documented at Lolwe Hill have been interpreted as evidence of the use of child labour (More 1974; van der Merwe \& Scully 1971). Hammel et al. (2000) suggest that underground mining activities such as the ones documented at Lolwe Hill and Harmony entail increased organisation complexity or presence of specialists. Archaeologists have also suggested that the miners would have worked as full-time specialists because the region had no agropastoral potential as discussed in Chapter 3 (Plug \& Pistorius 1999).

The prevailing wisdom is that only copper carbonate ores such as malachite and azurite were exploited during the Iron Age period throughout sub-Saharan Africa (Miller \& van der Merwe 1994a). However, it should be noted that there are some reports of the deliberate exploitation of sulphidic ores for smelting purposes during the Iron Age period at Musina (Messina), Old Guide Copper Mine and Wagon Drift in the Limpopo Province in South Africa (Cline 1937, 72; Trevor 1930). The veracity of these claims has never been refuted with analytical work of copper production debris from these ancient mines. There is thus need for analytical work on archaeological copper ores from the Northern Lowveld. However, caution is required with data from presumed ores since they are prone to undergo chemical decomposition resulting from weathering after their deposition in the archaeological record (Friede 1980,160). Another problem is that catches of ores left at smelting sites may have been intentionally abandoned, thus sometimes they are not 
representative of the smelted ore. The current literature on Iron Age extractive copper metallurgy has given the impression that the copper ores available across the sub-continent are homogenous and high grade ores. Most investigators are content to identify green or blue minerals as malachite and azurite respectively. Usually these potential ores are not subjected to any chemical, mineralogical or petrographic analysis. As such variations in the copper ores that can dictate differences in extractive copper technologies or provide insights about variations in artefact composition have been overlooked. Exceptions include investigations at Harmony, where Evers (an archaeologist) collaborated with van der Berg (the geologist) to conduct chemical and microscopic studies on 26 potential ore samples (Evers \& van der Berg 1974). They concluded that the Harmony copper carbonate mineralisations were low grade with up to $5 \%$ copper.

It is understandable that the concern of the initial studies on pre-colonial copper mines were geared towards the establishment of their chronology and identity of the miners. However, it is now high time for archaeometallurgists to pay more attention to the mineralogy and compositional analysis of potential ores that are usually found in the same context with metallurgical debris. The nature of the ores has an influence on the extractive technologies that were adopted; as such, some attention should be given to potential ore samples.

Iron Age mining galleries at Lolwe Hill and Old Guide Copper Mine are no longer available for detailed archaeomining studies; however, the meticulous analytical work of geologists as presented in Chapter 3 provides some important insight into the nature of mineral resources available in the research area. However, geologists are usually interested in ore deposits that are of economic value by modern standards; as 
such, they sometimes neglect small deposits that were actually exploited in the past.

Their data thus needs to be corroborated by archaeometallurgical work. 


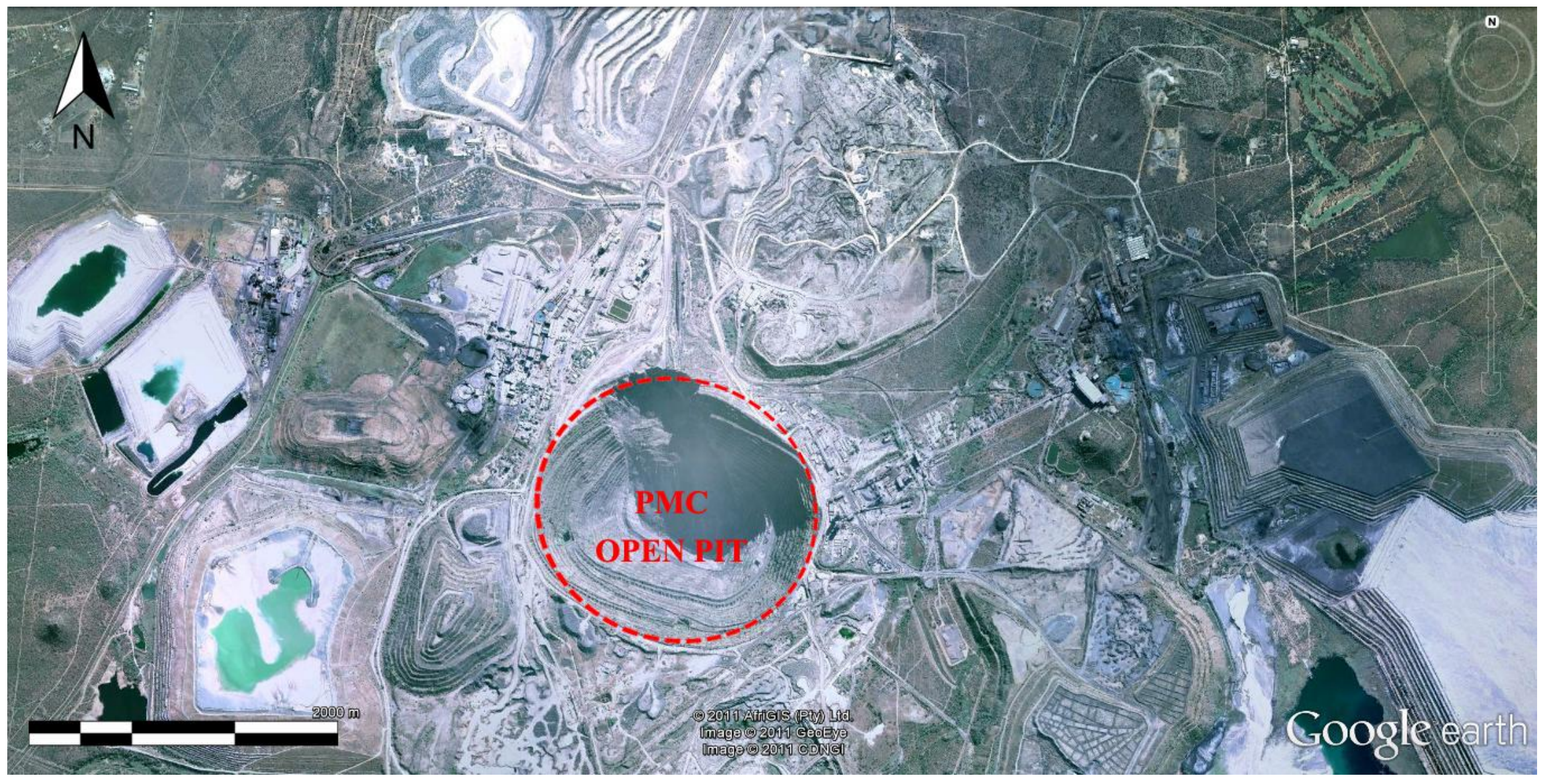

Figure 4.1: Satellite image showing the open pit where Lolwe Hill used to be situated (Image: Courtesy of Google Earth, modified by the author). 


\subsection{Extractive metallurgy studies: furnace designs, technical ceramics and slags}

The reduction of ores to metals during the Iron Age period in the Northern Lowveld, like elsewhere, involved complex physico-chemical reactions in charcoal fuelled clay-based installations. Previous archaeological surveys in the region resulted in the location and excavation of a significant number of well-preserved clay-built smelting furnaces with peculiar features (Klapwijk 1986a; Mason 1965; Pistorius 1989; van der Merwe \& Killick 1979; van der Merwe \& Scully 1971). During the 1960s surveys, Nikolaas van der Merwe and his team located close to 50 archaeological sites associated with furnaces within the $30 \mathrm{~km}$ radius of Phalaborwa. Klapwijk (1986a) also documented more than 50 furnaces within a radius of $15 \mathrm{~km}$ of the modern town of Tzaneen on the foothill of the Drakensberg Escarpment. The furnaces and associated slag heaps attest the importance of metal production in the region during the Iron Age period. This section establishes the various furnace designs that were employed together with the associated accessories and analytical work carried out to date.

Three basic furnace designs have been documented in the Northern Lowveld region: these include Venda furnaces, Phalaborwa furnaces and Lolwe furnaces (Figure 4.2). For detailed descriptions and nomenclature of these different furnace types, the reader is directed to Thorne (1974, 38-42) and Klapwijk (1986a). Venda furnaces have a circular plan with three tuyère port entrances. Phalaborwa furnaces resemble the Venda furnaces in many respects, specifically the three tuyère openings, but they have a sub-triangular plan. The Phalaborwa and Venda furnaces have an internal 
diameter of between $60-100 \mathrm{~cm}$, with a superstructure height ranging from 80-120 cm (Miller et al. 2001, 406). Lolwe furnaces have a small domed superstructure with a circular or oval plan and a single tuyère entrance (Figure 4.3). The Lolwe furnaces were much smaller, compared to the three tuyère port furnaces, with an average superstructure height of between 40 and $50 \mathrm{~cm}$. The bases of these furnaces usually contained small central holes without any apparent metallurgical function (Figure 4.4). These holes have previously been interpreted as receptacles of medicines used by smelters which included occasionally human finger bones and other charms (Plug \& Pistorius 1999, 179). The explicit genderisation of smelting furnaces with elaborate female anatomy representing fertility symbols prevalent in Iron Age subSaharan Africa has not been documented in the Northern Lowveld (see Bernhard 1962; Chirikure \& Rehren 2004; Cooke 1959; Ndoro 1991).

The antiquity of the various furnace designs in the research area was previously established (Table 4.2 \& Table 4.3). Three tuyère port furnaces outnumber single tuyère port furnaces. It was previously suggested that sub-triangular three tuyère port furnaces are restricted to the Phalaborwa area. Iron Age settlements around this area are usually accompanied by a group of furnaces of the Phalaborwa type. The most impressive evidence of these furnaces was documented at the farm of Square, a site $25 \mathrm{~km} \mathrm{SW}$ of Phalaborwa, where seven well preserved Phalaborwa furnaces associated with about 180 tonnes of slag were found (van der Merwe \& Killick 1979). Venda furnaces have a much wider geographic coverage that extends from the foothills of the Drakensberg Range to the Soutpansberg in the north. Radiocarbon dates of the Phalaborwa and Venda type furnaces range from the early second millennium AD to the late nineteenth century AD (Miller et al. 2001, 405). Venda 
and Phalaborwa furnaces were last used to smelt iron in 1893, when iron smelting was banned by the then white minority Transvaal Government after the metalworkers were accused of manufacturing weapons to fuel unrest (Klapwijk 1986a, 25). The Lolwe furnaces are much rare and geographically limited to the area around Lolwe Hill and Harmony Mine. The earliest Lolwe furnace to be excavated in situ was dated to the early second millennium AD (Pistorius 1989) and this design also survived until the nineteenth century AD (Miller et al. 2001).

The respective functions of these various furnace types has been a subject of speculation and heated debate (Küsel 1974b; Thorne 1974). Earlier speculations were that three tuyère port furnaces were used for primary smelting whilst single tuyère port furnaces were exclusively used for refining purposes (Schwellnus 1937). Subsequent analytical work of metallurgical debris associated with the different furnace designs established that they were all used for primary smelting however conflicting interpretations emerged. Küsel (1974b), who carried out bulk chemical analyses of slags from one of the Lolwe furnaces, concluded that single port furnaces were used for iron smelting. These findings were challenged because it was difficult to separate iron from copper smelting slags with the aid of bulk chemical analysis alone (van der Merwe 1978; see Chapter 6 of this thesis). The current prevailing interpretation is that three tuyère port furnaces of the Venda and Phalaborwa type were exclusively used for iron smelting whilst single tuyère port furnaces of the Lolwe type were reserved for copper smelting (Miller et al. 2001; van der Merwe \& Scully 1971). It has been argued that the design of the furnaces tends to vary due to cultural choice, nature of the ores and scale of production among other complex factors (see Chirikure 2006). In the case of the Northern Lowveld, variations in 
furnace designs have previously been discussed as resulting from differences in metallurgical function of individual designs. Miller et al. $(2001,414)$ proposed that single tuyère furnaces with limited air input and thus lower operating temperatures were exclusively used for copper smelting to avoid the co-smelting of copper and iron. They also proposed that multiple tuyère furnaces had the capacity to generate great air flow and higher temperatures together with more reducing conditions that were required for iron smelting purposes rather than copper smelting. Despite the variations in designs it should be noted that these furnaces belong to the same class of forced draft low-shafts furnaces without slag and metal-tapping capabilities. This thesis thus sought to contribute to this debate by focusing on metallurgical debris associated with the different designs. 


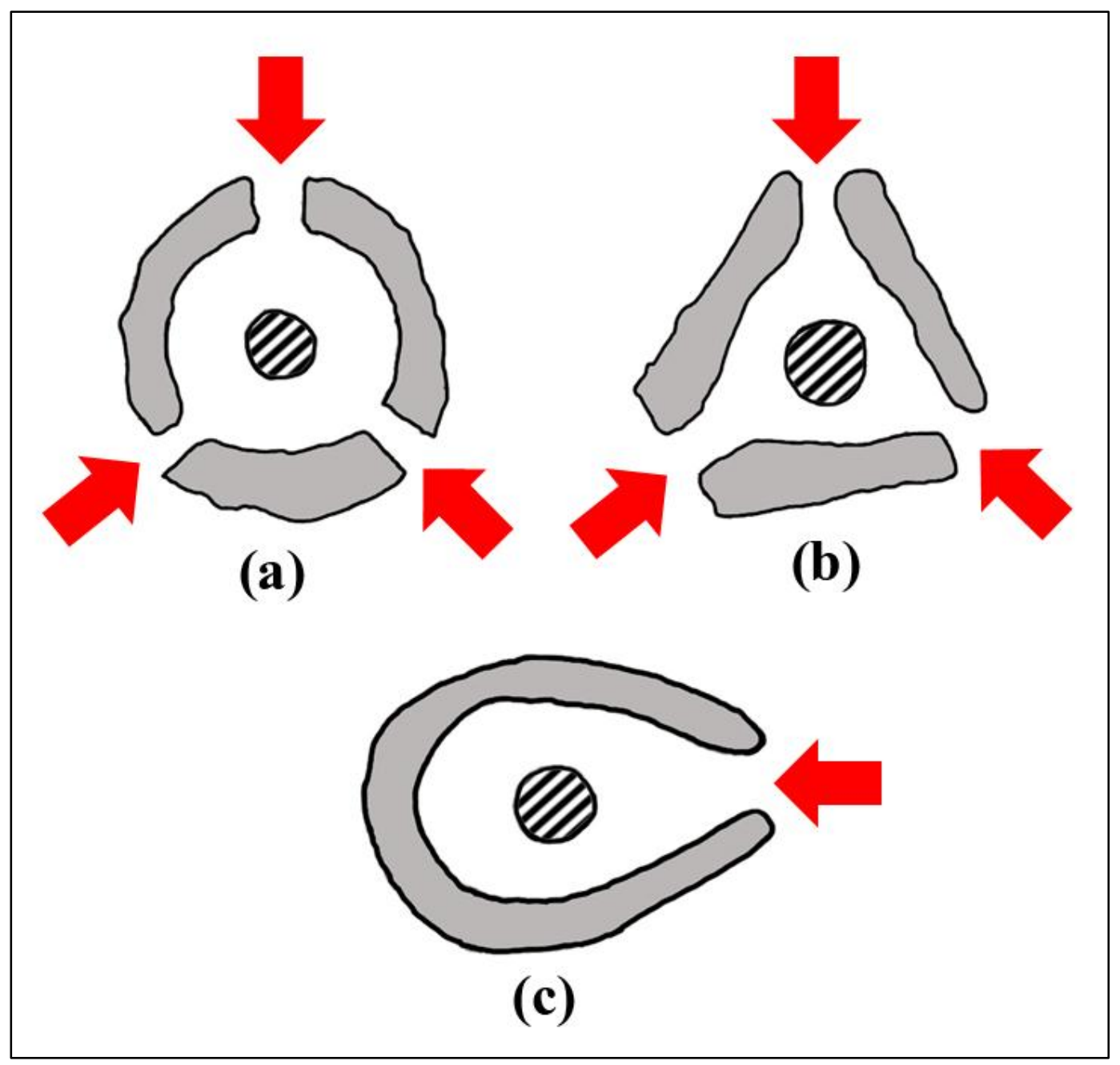

Figure 4.2: Floor/base plans of three furnace designs documented in the Northern Lowveld. (a) Venda Furnace with a circular plan and three tuyère port entrances, (b) Phalaborwa Furnace with a triangular plan also accompanied by three tuyère port entrances, (c) Lolwe Furnace with one tuyère port entrance. Note that central circle represent the position of the 'medicine hole'. (Image: Author but not drawn to scale). 


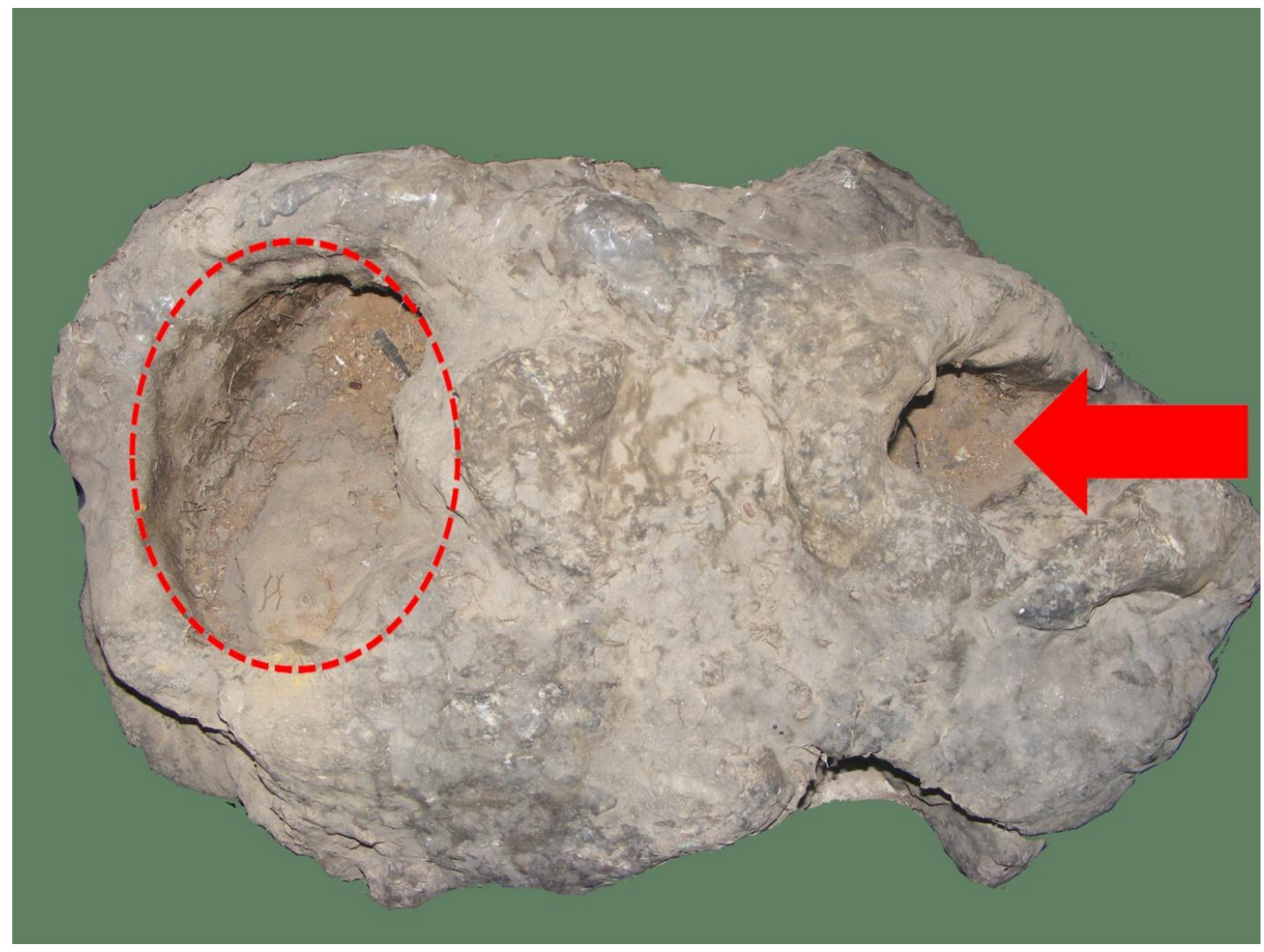

Figure 4.3: Lolwe furnace on display at Foskor Museum excavated by Julius Pistorius presumably at Shankare Hill in the late 1980s. The red arrow shows the location of the tuyère port entrance and the circle shows the shaft used to charge the furnace. (Image: Author). 


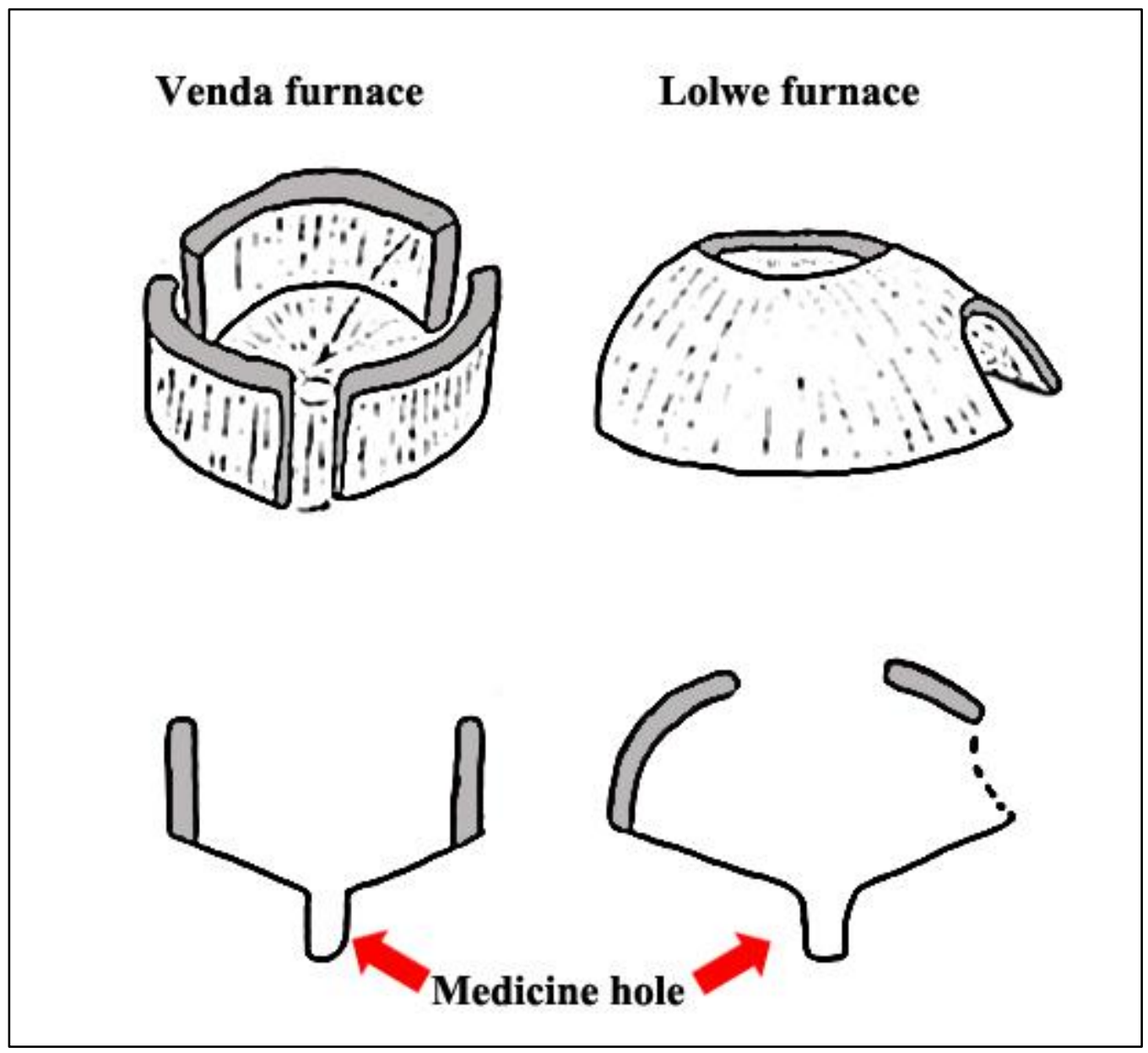

Figure 4.4: Sketch diagrams of Iron Age furnace designs of the Northern Lowveld showing the position of the 'medicine hole'. (Image: Adapted from Schwellnus 1937, 910). 
Table 4.2: Available published radiocarbon dates of three tuyère port furnaces documented in the Northern Lowveld. The dates were calibrated with Oxcal 4.1 and IntCal 09 by the author.

\begin{tabular}{|c|c|c|c|c|c|c|}
\hline Sites & Lab. Ref & ${ }^{14} \mathrm{C}$ age $\mathrm{BP}$ & $\begin{array}{l}\text { Calibrated AD dates @ } 26 \\
(95.4 \%)\end{array}$ & Furnace Types & $\begin{array}{l}\text { No. of } \\
\text { furnaces }\end{array}$ & References \\
\hline Kgopolwe (SPK4) & $\mathrm{Y}-1657$ & $520 \pm 60$ & 1296AD (95.4\%) 1466AD & $\begin{array}{l}\text { Phalaborwa } \\
\text { (Slag Heap) }\end{array}$ & One & (Miller et al. 2001) \\
\hline Shankare & Y-1766 & $290 \pm 80$ & $\begin{array}{l}\text { 1439AD }(78.5 \%) \text { 1694AD } \\
\text { 1727AD }(12.6 \%) \text { 1812AD } \\
\text { 1918AD }(4.3 \%) \text { 1954AD }\end{array}$ & Phalaborwa & Eight & (Mason 1986) \\
\hline Kgopolwe (SPK4) & $\mathrm{Y}-1658$ & $280 \pm 60$ & $\begin{array}{l}1454 \mathrm{AD}(82.6 \%) 1682 \mathrm{AD} \\
1738 \mathrm{AD}(1.7 \%) 1756 \mathrm{AD} \\
1762 \mathrm{AD}(8.4 \%) 1803 \mathrm{AD} \\
1936 \mathrm{AD}(2.8 \%) 1954 \mathrm{AD}\end{array}$ & Phalaborwa & One & (Stuiver \& van der Merwe 1968) \\
\hline Mabete & Pta-1525 & $270 \pm 50$ & 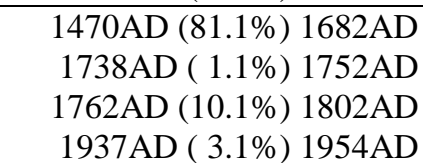 & Phalaborwa & One & (Evers 1982) \\
\hline Nareng & $\mathrm{Y}-1767$ & $160 \pm 60$ & $\begin{array}{l}\text { 1654AD (78.9\%) 1894AD } \\
1904 \mathrm{AD}(16.5 \%) \text { 1952AD }\end{array}$ & Phalaborwa & Two & (Mason 1986) \\
\hline Shankare & Y-1769 & $90 \pm 60$ & $\begin{array}{l}\text { 1671AD }(34.9 \%) \text { 1778AD } \\
1798 \mathrm{AD}(60.5 \%) 1942 \mathrm{AD}\end{array}$ & Phalaborwa & Eight & (Mason 1986) \\
\hline Kgopolwe (SPK5) & Pta-339 & $80 \pm 45$ & $\begin{array}{l}\text { 1680AD }(29.3 \%) \text { 1764AD } \\
\text { 1800AD }(66.1 \%) \text { 1939AD }\end{array}$ & Phalaborwa & One & (Stuiver \& van der Merwe 1968) \\
\hline Longridge & Pta-1713 & $230 \pm 50$ & 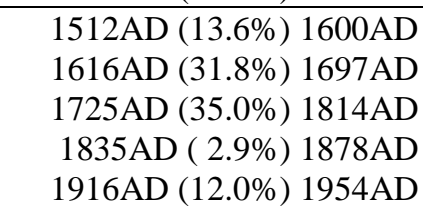 & Venda & One & (Klapwijk 1986a) \\
\hline
\end{tabular}


Table 4.3: Available published radiocarbon dates of single tuyère port furnaces in the Northern Lowveld. The dates were calibrated with Oxcal 4.1 and IntCal 09 by the author.

\begin{tabular}{|c|c|c|c|c|c|c|}
\hline Sites & Lab. Ref & ${ }^{14} \mathrm{C}$ age $\mathrm{BP}$ & $\begin{array}{l}\text { Calibrated dates AD @2 6 } \\
(95.4 \%)\end{array}$ & Furnace Types & $\begin{array}{l}\text { No. of } \\
\text { furnaces }\end{array}$ & References \\
\hline Shankare & Pta-4443 & $890 \pm 50$ & $\begin{array}{l}\text { 1027AD (94.8\%) 1226AD } \\
1234 \mathrm{AD}(0.6 \%) 1238 \mathrm{AD}\end{array}$ & Lolwe & One & (Pistorius 1989) \\
\hline Marupale & Pta-4436 & $300 \pm 40$ & 1474AD (95.4\%) 1662AD & Lolwe & Four & (Pistorius 1989) \\
\hline Ghoenkop (Hill X) & Pta-4427 & $220 \pm 50$ & $\begin{array}{l}\text { 1520AD ( 8.2\%) 1593AD } \\
\text { 1619AD (29.6\%) 1706AD } \\
\text { 1720AD (39.3\%) 1818AD } \\
\text { 1832AD }(4.5 \%) \text { 1880AD } \\
\text { 1915AD }(13.8 \%) \text { 1954AD }\end{array}$ & Lolwe & One & (Pistorius 1989) \\
\hline Selongwe & Pta-4662 & $170 \pm 35$ & $\begin{array}{l}\text { 1656AD (18.3\%) 1706AD } \\
\text { 1720AD }(48.2 \%) \text { 1825AD } \\
\text { 1832AD (10.8\%) 1883AD } \\
\text { 1914AD }(18.2 \%) \text { 1954AD }\end{array}$ & Lolwe & One & (Pistorius 1989) \\
\hline Eskom Hill & Pta-4442 & $130 \pm 45$ & $\begin{array}{l}\text { 1669AD (40.0\%) 1780AD } \\
\text { 1798AD }(55.4 \%) \text { 1944AD }\end{array}$ & Lolwe & One & (Pistorius 1989) \\
\hline Pjene & Pta-4428 & $110 \pm 45$ & $\begin{array}{l}\text { 1675AD (34.8\%) 1778AD } \\
\text { 1799AD (60.6\%) 1942AD }\end{array}$ & Lolwe & One & (Pistorius 1989) \\
\hline Nagome (MN1) & Pta-567 & $110 \pm 40$ & $\begin{array}{l}\text { 1678AD (32.1\%) 1765AD } \\
\text { 1772AD (0.8\%) 1776AD } \\
\text { 1800AD (62.5\%) 1940AD }\end{array}$ & Lolwe & Two & (Stuiver \& van der Merwe 1968) \\
\hline Matsepe (SPM1) & Y-1660 & $80 \pm 60$ & $\begin{array}{l}\text { 1675AD (33.4\%) 1778AD } \\
\text { 1799AD }(62.0 \%) \text { 1942AD }\end{array}$ & Lolwe & One & (Stuiver \& van der Merwe 1968) \\
\hline Molotho & Y-1661 & $60 \pm 120$ & $\begin{array}{l}\text { 1529AD ( } 0.6 \%) \text { 1542AD } \\
\text { 1634AD }(94.8 \%) 1950 \mathrm{AD}\end{array}$ & Lolwe & One & (Stuiver \& van der Merwe 1968) \\
\hline
\end{tabular}


Artificial air provisions were required for low shaft furnaces like the ones described above (Chirikure et al. 2009); as such, bellows and tuyères presumably played a vital role. Unfortunately, only tuyères usually survive in the archaeological record whilst bellows manufactured from perishable materials like animal skins and wood rarely survive. The above discussed furnaces are usually associated with cylindrical ceramic tuyères, with notable variations in the method of manufacture and size. These tuyères can provide vital information about type of bellows employed and other furnace operation parameters.

The method used to manufacture some of the tuyères documented around the Northern Lowveld has been described as the 'pressure method' (Klapwijk 1986b). This method involved the use of a wet clay paste wrapped around a cylindrical smooth stick that was subsequently covered with narrow sticks running along the long axis on the outside and pressed against the central stick. The resulting tuyères have pronounced external longitudinal impressions that are described in other publications as decorations (Figure 4.5) (Klapwijk 1986b; Mason 1986, 116). The majority of tuyères documented in the research area had one flared end resulting in a trumpet shape without any longitudinal impressions (Figure 4.6). Preliminary typological analysis of tuyères from smelting sites around Tzaneen suggests that tuyères from older smelting sites were much larger, with an inside diameter of between 36-46 mm, whilst tuyères from younger smelting sites are smaller, with an inside diameter of $25-33 \mathrm{~mm}$ (Klapwijk 1986b). Klapwijk proposed that these variations in size could provide important chronological information and also reflected changes in the type of bellows through time. He proposed that larger tuyères from earlier periods were used with drum bellows whereas the smaller ones 
were used with bag bellows (Klapwijk 1986b, 19). However, there is no direct evidence of the use of drum bellows in the archaeological, ethnographic and historic record of the region in question (Chirikure et al. 2009).

Notable differences were also documented in the size of tuyères associated with different furnace designs around Phalaborwa. Tuyères associated with the Lolwe furnaces are usually larger, with an average internal diameter of $50 \mathrm{~mm}$, compared to tuyères from the three port furnaces of the Venda or Phalaborwa type which have an average internal diameter of $25 \mathrm{~mm}$ (van der Merwe \& Scully 1971, 182). The reason for such variation in size of tuyères is not easily discernible.

It is now appreciated that in some cases technical ceramics contributed to the slagging process, some smelting technologies actually encouraged the melting of technical ceramics to help in the formation of slag (Childs 1989; David et al. 1989). As such it has become standard to subject technical ceramics to routine analysis together with slags in archaeometallurgical investigations. Hitherto, no analytical work was carried out on technical ceramics that were used during the production of metals in the research area. The analysis of technical ceramics was also deemed important in this thesis as a way to complement previous typological studies. 


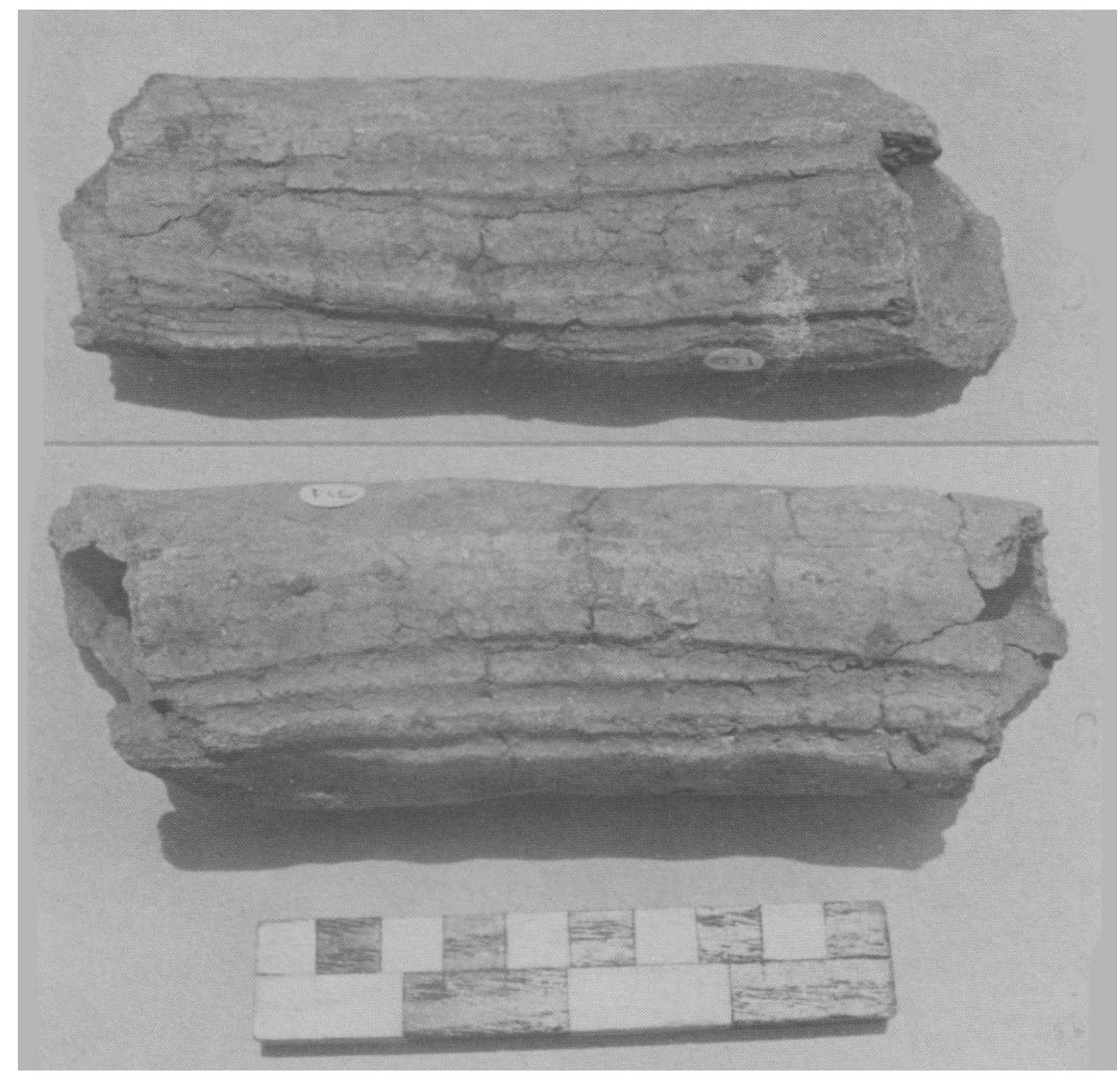

Figure 4.5: Tuyères manufactured with the 'pressure method' showing the longitudinal marks left by narrow sticks that were wrapped around the wet clay paste. (Image: Reproduced from Klapwijk 1986b, 19). 


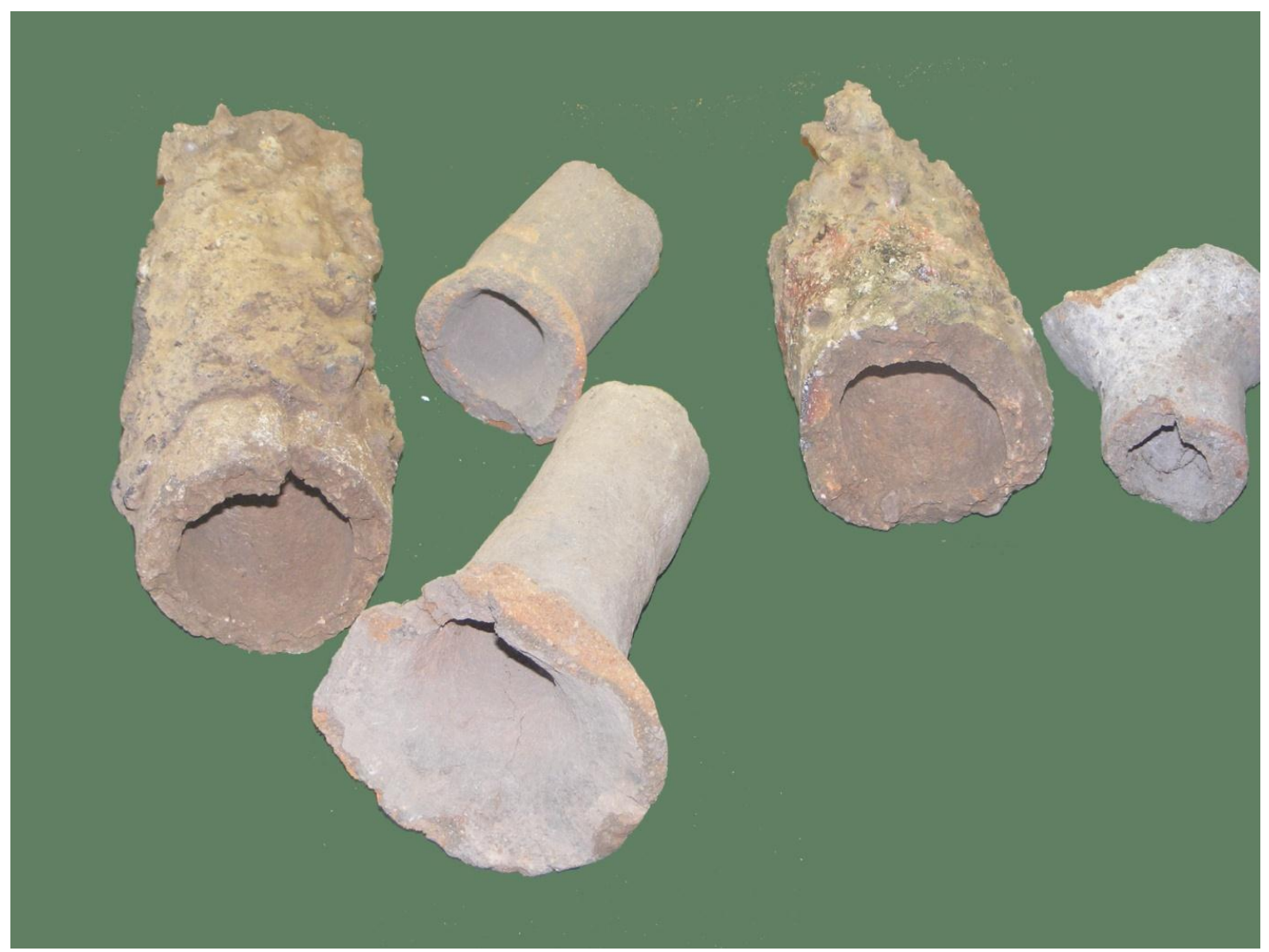

Figure 4.6: Tuyères from archaeological sites around Phalaborwa on display at Foskor Museum. Note that some of them are trumpet-shaped (Image: Author).

Archaeological slags from the Northern Lowveld were previously subjected to analytical investigations for various purposes. Pilot chemical studies of archaeological slags from the research area were conducted by David Killick for his Honours dissertation at the University of Cape Town (Killick 1977). The prime aim of this pilot study was to identify the source of iron ores used at different smelting sites around the Northern Lowveld during the Iron Age period. This project relied on the known systematic chemical variations of high grade magnetite ore deposits found at Lolwe Hill, Schiel and Rooiwater. Iron smelting slag samples from more than twenty archaeological sites dotted around the Northern Lowveld were surfacecollected and subjected to semi-quantitative bulk chemical analysis. A criterion to 
identify the sources of iron ores that were used at these twenty sites was developed from this exercise. This criterion relies on the known differences in $\mathrm{TiO}_{2}$ levels in high grade magnetite at three major deposits in the research area. This pilot study was largely successful, it highlighted that iron smelting slags in this region could be linked to specific ore deposits with great confidence.

A follow up to this pilot study was carried out on surface-collected iron smelting slags from the site of Square (van der Merwe \& Killick 1979). This time analytical work aimed not only to establish the source of iron ores used at Square but also to reconstruct the smelting technology. Based on the unusually high $\mathrm{TiO}_{2}$ levels in the iron smelting slags from Square, the Lolwe Hill magnetite ore body was identified as the source. This investigation thus established that ores were sometimes carried for fairly substantial distances to the smelting furnaces. Magnetite ores had to be transported for more than $25 \mathrm{~km}$ before the final smelting processing. The use of silica-rich fluxes to extract iron from high grade magnetite ores was also documented at Square.

Several archaeological slag samples were also submitted for bulk chemical analyses by Julius Pistorius for his doctoral thesis (Pistorius 1989). These results were subsequently presented in the appendices without much technical discussion of the results or documentation of analytical procedures employed. Although the appendices provided separate iron from copper smelting slags, it is rather difficult to come up with these categories on the basis of bulk chemical compositions alone. Differences in the bulk composition of copper and iron smelting slags can be very subtle thus their identification requires phase determination. 
The extractive technologies used for both iron and copper production in the Northern Lowveld were summarised for non-specialist and non-technical readership (Miller et al. 2001). This publication understandably omitted information about the chemical and mineralogy of archaeological slags that the authors used to reconstruct the extractive technologies discussed therein. As a result, it is impossible to evaluate the analytical methods or sample size that were utilised to draw conclusions in this publication. The authors of this paper are notable archaeologists with vast experience in archaeometry and archaeometallurgy; however, some concerns should possibly be raised about the size and representativeness of the sample that was analysed. The amount of copper production debris from Phalaborwa that has hitherto been analysed and published remains small. Limited bulk compositional data of copper smelting slags are provided in the seminal paper by Miller \& Killick (2004) on proper methods of identifying and classifying slag from archaeological sites. This publication seeks to inform archaeologists about useful analytical methods to separate slags from non-slag vitrified material frequently encountered in the archaeological record; as such, it is not concerned with the reconstruction of smelting technology. This particular publication was necessary because, frequently, archaeologists erroneously identify non-metallurgical vitrified samples from archaeological contexts as metallurgical slags. A total of six bulk chemical results of copper slags from the archaeological sites of Matsepe and Kgopolwe, located in Phalaborwa, were presented as examples. These analytical results remain the only published data of copper smelting slags from the Iron Age period of Phalaborwa. The same chemical results together with some mineralogical observations were utilised, in a paper that is yet to be published by the same authors, to reconstruct copper smelting technologies at the two sites (Killick \& Miller, in press). 
From this brief survey of slag studies the following remarks can be made. The majority of the analytical work was carried out on iron production slags at the expense of copper production slags. Only six analytical results of copper slags have been published to date, these results have been use to reconstruct copper production activities that lasted close to a millennium. As a result of the limited analytical work, the possible diachronic changes that presumably took place in technologies of smelting copper during the second millennium AD have been masked. The previous analytical work on archaeological slags from the research area was largely based on bulk chemical analytical methods, with notable limitations especially when it comes to non-tapped furnace slags (Miller \& Killick 2004, 30; see Chapter 5). Bulk chemical results of archaeological slags are important but they also need to be corroborated by mineralogical data to reconstruct extractive processes (see Killick et al. 1988). This is the approach that has been implemented in the current thesis.

Virtually no information is available about further copper refining technologies that presumably took place after primary smelting in the research area. Slagged technical ceramics with visible slag layers and copper prills frequently excavated around Phalaborwa have been interpreted as evidence of copper refining (Evers \& van der Merwe 1987). Unfortunately, to date no analytical work has been conducted on these technical ceramics to determine where they fit exactly in the chaîne opératoire of copper production. In the absence of appropriate archaeometallurgical investigations it is impossible to say with absolute confidence how these ceramics were utilised. Their role in metallurgical processes remains shrouded with speculations; as such, it was hoped that further analytical work of such technical ceramics would address 
sticking questions; such as, were these ceramics used for copper refining, alloying or simply melting?

Some aspects of the organisation of iron production in the research area have been established from the ethnographic information recorded by early settlers of European descent in the late nineteenth century AD (Miller et al. 2002). However, by that period copper production had ceased as a result of the influx of copper and copper alloys from other continents that commenced in the early second millennium AD (Miller et al. 2001, 401). As a result of this, combined with the lack of more socially grounded archaeometallurgical research, the information concerning the social aspects of copper production is not available in the Northern Lowveld region.

\subsection{Studies of metal artefacts}

Archaeological investigations around the Northern Lowveld over the years have yielded iron, tin, tin bronze, brass and copper artefacts. Noteworthy is the absence of gold artefacts from the archaeological contexts of the region. Gold artefacts were documented at several second millennium AD zimbabwe culture sites not very far from the Northern Lowveld. The ruling class elites of Thulamela, about $140 \mathrm{~km}$ north of Phalaborwa, were buried with their gold ornaments (Küsel 1992; Steyn et al. 1998). The metal inventory from the archaeological contexts in the research area includes mostly hoes and axes exclusively made from iron. Non-ferrous metals are restricted to beads, ingots, bangles and anklets, like elsewhere in Southern Africa. The copper-based artefacts represent different stages of manufacture, from primary smelting to finished products. However, finished copper-based artefacts are not as elaborate; neither were they manufactured with complex casting methods employed 
in West Africa (Chapter 1). These artefacts have been subjected to a number of examinations that include typological, compositional and metallographic studies.

The survival of iron artefacts as was discussed in previous chapters is inhibited by the highly acidic nature of the soils. As a result, iron artefact assemblages from the research area come from relatively recent periods. The majority of the iron artefacts are either surface finds from archaeological sites or were collected from the ethnographic record. To date only six archaeological iron objects (Gordon \& van der Merwe 1984) and almost six hundred ethnographic iron artefacts were subjected to investigations (Klapwijk 1974). The objectives of these studies were similar they aimed to establish the source of metal used to manufacture these heavy duty iron implements from nineteenth century contexts. Historical documents suggest that iron was amongst the staple imports from Europe into Southern Africa from the eighteenth century onwards (Gordon \& van der Merwe 1984, 109). The imported European iron implements significantly differed from the locally smelted products in smelting technology and thus mechanical properties, composition and microstructure. Based on typological grounds, Klapwijk concluded that about one third of six hundred iron implements from the Tzaneen area were manufactured using African designs (Klapwijk 1974). However, it should be appreciated that traditional typological approaches have their limitations since stylistic similarities can result from imitations. As a matter of fact, Gordon \& van der Merwe (1984, 109) established that during the 1870 s a French company introduced more than a million iron hoes of traditional African design into the Northern Lowveld in exchange for ivory. 
Metallographic analyses were subsequently carried out on a few iron implements from the Northern Lowveld to resolve the above noted limitations of the typological approaches (Gordon \& van der Merwe 1984; Klapwijk 1974). A single hoe with a typical African design from the Tzaneen collection was submitted by Klapwijk for metallographic and microprobe analyses. It was concluded that this hoe was manufactured using bloomery iron presumably smelted locally. Detailed metallographic analyses of six surface-collected iron artefacts from archaeological sites of Sekgopo, Thlaro and Shivulani, in the Kruger National Park also proved that the implements were manufactured using locally smelted iron (Gordon \& van der Merwe 1984). These iron objects contained slag inclusions and pearlite structures suggesting that quenching and tempering employed in the treatment of iron in contemporary industrial Europe were not utilised in these particular implements. Using the criteria developed in the pioneer slag studies in the region (Killick 1977; van der Merwe \& Killick 1979), it was also concluded that the high titanium levels in the slag inclusions documented in these iron artefacts indicated that ores from the Palabora Igneous Complex and Rooiwater Igneous Complex were used (Gordon \& van der Merwe 1984). Despite their limited number of samples these studies demonstrate that metallographic and chemical data can complement typological approaches to address issues relating to trade, exchange and manufacturing technology.

Analytical work was also carried out on archaeological and ethnographic non-ferrous metal artefacts from the Northern Lowveld over the years (Friede 1975; Killick 1991a; Killick \& Miller, in press; Miller et al. 2001; Miller 2002; Miller 2010; Stanley 1929a; Stanley 1929b). Copper artefacts from the archaeological sites around 
Phalaborwa included ingots and finished products. The copper ingots included several plano-convex (bun or dish-shaped) ingots recovered from second millennium AD contexts (Figure 4.7). Some scholars have suggested that these ingots resulted from the secondary melting of copper inside clay pots or hemispherical potsherds (Friede 1975, 185). Others have suggested that these ingots are crude products of primary copper smelting processes (Miller et al. 2001, 408; Miller 2010, 47). Secondary refined copper ingots in the form of marale ingots have also been documented (Figure 4.8). The finished copper products include bangles, anklets and beads. Initial compositional investigations of finished copper objects showed remarkable levels of purity, viewed as representing fairly low smelting temperatures (van der Merwe \& Scully 1971, 182).

Metallographic studies of copper-based metals from archaeological sites around the Phalaborwa area established the presence of brass articles from the early second millennium AD (Miller 2002). Earlier publications had suggested that brasses were locally smelted from mixed copper-zinc ore deposits located in the Murchison Range to the NW of Phalaborwa (More 1974, 230; Stanley 1929b, 740). Subsequent quantitative compositional investigations of the brass articles and available information on ancient brassmaking do not support the earlier suggestions (Miller 2002). Phalaborwa brass articles have high zinc levels (35 wt\%) suggesting that they were not products of simple co-smelting of copper-zinc polymetallic ores. Such highzinc brasses would have required the use of distilled zinc (Martinón-Torres \& Rehren 2002). Since zinc production was not practised in Southern Africa during the Iron Age period, these high-zinc brasses represent imports from extant brassmaking regions namely, India or China (Maggs \& Miller 1995). To date no reports mention 
the occurrence of archaeological zinc ingots in the Northern Lowveld; as such, we can safely presume that the brass was imported readymade into the region.

Tin and tin bronze artefacts in the form of ingots and beads were also recovered from the Northern Lowveld. Archaeological tin artefacts, like elsewhere in Southern Africa, are very rare; the known archaeological tin artefacts in the research area do not exceed five objects. One remarkable tin ingot was recovered from the Soutpansberg (Killick 1991a). Typologically this tin ingot falls into the class of marale copper ingots illustrated in Figure 4.8. All the other known marale ingots were manufactured from remarkably pure copper (Friede 1975). The Soutpansberg lerale tin ingot was probably cast in the Northern Lowveld. Another tin ingot with a different design was also recovered in the Gravelotte area to the west of Phalaborwa (Miller et al. 2001). The occurrence of these ingots raises some significant archaeological questions concerning tin production, trade and bronze making in Southern Africa. Analytical work on the Soutpansberg lerale ingot pointed to Rooiberg tin fields as the source of the tin (Killick 1991a). Tin bronze seem to be exclusively represented by beads with up to $10 \mathrm{wt} \%$ tin around Phalaborwa (Killick \& Miller, in press; Miller et al. 2001, 409). It remains unclear whether the art of bronze-making was ever practiced in the Northern Lowveld during the Iron Age period. The analysis of slagged ceramic potsherds often encountered in archaeological contexts of the region with proper archaeometric approaches will possibly give a clear picture about this issue. 


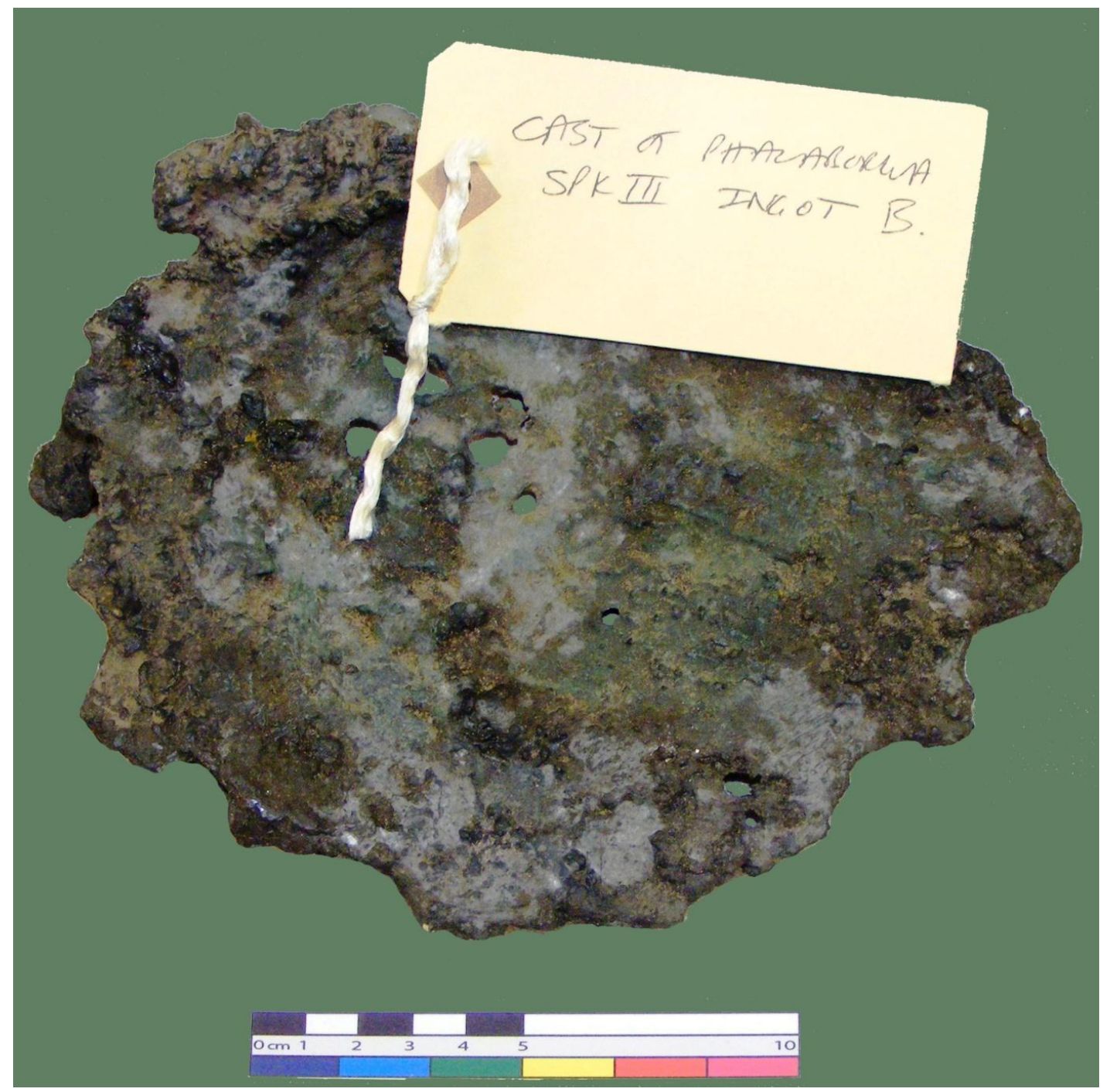

Figure 4.7: A cast form of a plano-convex ingot that was recovered from Kgopolwe (SPK III), Phalaborwa. This ingot is in the teaching collection at the University of Cape Town (UCT) (Image: Author). 


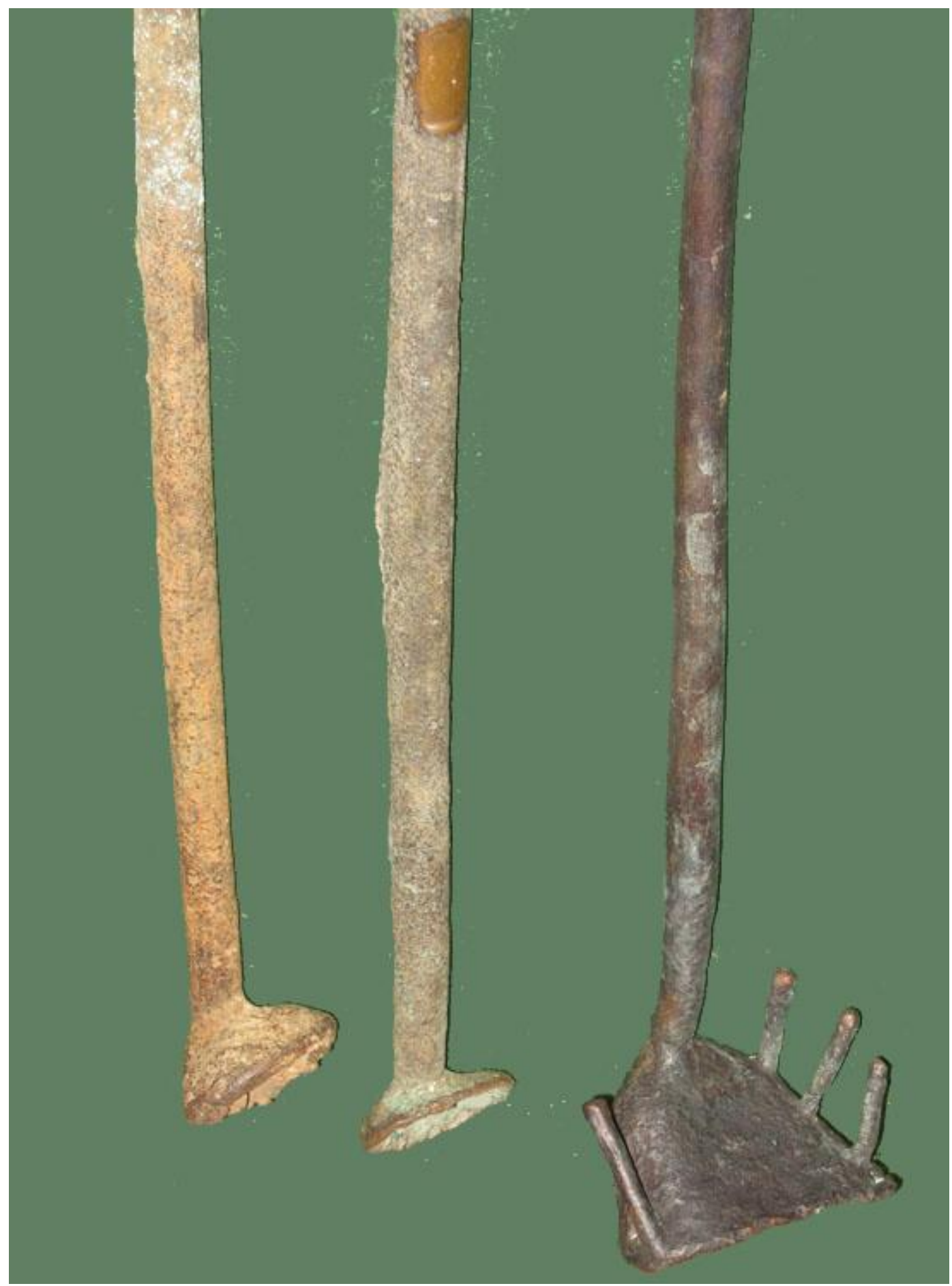

Figure 4.8: Golf club-shaped ingots known as 'marale' typically manufactured around Phalaborwa during the Iron Age. These ingots are displayed at Foskor Museum (Image: Author). 


\subsection{Summary}

The preceding review of literature on Iron Age mining and metallurgy in the Northern Lowveld shows that a significant body of information has been accumulated over the years. However, it has also been highlighted that there are notable discrepancies and gaps that need further work. The pioneering archaeological investigations in the region managed to establish a basic chronology of mining and metal smelting activities. Successive archaeologists working in the research area have highlighted the importance of mining and metal production to pre-colonial societies of the Northern Lowveld. Detailed archaeomining investigations were not carried out around Phalaborwa but important information about mining activities at Lolwe Hill was established. Since the ancient mining galleries are no longer available, analytical work on the presumed ore samples from metal production and archaeological contexts is of necessity.

Analytical work has been previously carried out to reconstruct metal production technologies that were employed in the Northern Lowveld. The analytical work has largely focused on iron production at the expense of other metals or production debris like ores and technical ceramics. The reconstruction of the metal production processes have also been based exclusively on bulk chemical analytical approaches. However, chemical data alone will only provide limited technological information; they need to be supported by other analytical methods. It is also not easy to separate iron from copper production slags using chemical data alone; as such, alternative archaeometric approaches ought to complement the bulk chemical analyses.

Phalaborwa has been cited as an important source of copper during the Iron Age period in South Africa. Previous studies laid the foundation for further analytical 
work; however, the information on extractive copper metallurgy in this region remains scanty. Hitherto, the reconstruction of extractive copper metallurgical activities spanning over a period of almost a millennium has been based on analytical work of a handful of slag samples (Killick \& Miller, in press). There remains a large opportunity to conduct high resolution investigations to reconstruct extractive copper metallurgical processes with a large analytical sample and diverse analytical approaches with the hope to develop our understanding of spatial and temporal variability plus sociocultural aspects through contextualisation.

Some of the questions that remain unanswered concerning Iron Age copper metallurgy in the Northern Lowveld were previously outlined (Miller et al. 2001, 415). The questions are as follows: Firstly, was copper ever alloyed in the region? Secondly, what was the origin of the tin metal and tin bronzes found in the northern archaeological record? Third, when did copper alloys enter this region? The topical issue concerning the archaeological copper alloy artefacts in the Northern Lowveld therefore is whether they were imported or produced locally. Detailed analytical work on the metal production debris from archaeological sites in the region has the potential to address these questions. The geographical extent to which copper from the Northern Lowveld was traded remains obscure. This requires more analytical work on potential copper ore samples from deposits in the region together with detailed characterisation of archaeological copper objects. The potential of lead isotope analyses to address this issue in the Northern Lowveld region was previously put forward (Miller et al. 2001, 415), but this is beyond the scope of the current thesis. The next chapter discusses the analytical methods that were employed to reconstruct the Iron Age metallurgical processes in the research area. 


\section{Applied analytical methods}

"Technological practices are obviously constrained by the laws of physics and chemistry..." (Killick 2004a, 572).

\subsection{Introduction}

The metallurgical debris from archaeological sites around Phalaborwa, whether surface-collected, excavated or selected from the collections housed at the University of Cape Town, was subjected to a wide range of analytical techniques in this thesis. Extractive metallurgical processes are to a large extent constrained by physicochemical parameters. Proxies of how these parameters were handled by past metallurgists are often retained in the metallurgical debris from archaeological sites and they can be revealed with meticulous material science investigations. Archaeometallurgical investigations usually require analytical work to be carried out on a number of products and by-products such as ores, slags, technical ceramics and metal artefacts. Bulk chemical results of slag samples, for example, when used in conjunction with phase diagrams, can provide reliable estimates of the temperature which was attained during the extractive process (see Bachmann 1982; Morton \& Wingrove 1969; Morton \& Wingrove 1972). Characterisation of ore samples from metal production contexts together with residual ores embedded in the slags can enable mass balance calculations to be done to estimate output (e.g. Joosten 2004). Technical ceramics can also provide valuable information about clay selection and preparation; as well as the potential chemical contribution of the ceramics to the slagging process and their ability to withstand high temperatures. Numerous analytical techniques have been tried and tested on metallurgical debris from archaeological sites resulting in some standard procedures in archaeometallurgy. 
These standard procedures have been outlined in several seminal works which focus on various categories of metallurgical debris ranging from ores, slags, technical ceramics and metal products (e.g. Bachmann 1982; Garrison 2003; Miller \& Killick 2004; Rapp 2002; Scott 1991). However, the biggest challenge is always to translate these microscopic observations, phase and bulk chemical compositions into an account of the craftsmen behaviour and the societies where the technology was practised (Rehren et al. 2007). Pollard et al. (2007, 9) correctly envisage that the use of these archaeometric techniques should be more than a decriptive exercise which simply documents the composition of materials but should address current problems in archaeology and articulate with modern archaeological theories. The use of the chaîne opératoire approach, which involves the detailed reconstruction and explanation of raw material procurement strategies through to the production and use, in their specific contexts has been one way of dealing with this challenge as was discussed in Chapter 2.

After fieldwork surveys and excavations at selected archaeological sites (see Chapters $6 \& 7$ ) initial analytical work of samples presented in this thesis was carried out at the Archaeological Materials Laboratory, University of Cape Town (UCT), which specialises on the analysis of archaeometallurgical materials. This initial phase, described in detail in the next section, involved visual inspection, morphological description, classification and quantification of the materials. This documentation phase formed the basis for subsequent sample selection strategy and preparation. The selected samples were transported to London for further examination at the Wolfson Archaeological Science Laboratories at the UCL Institute of Archaeology. These laboratories specialise in the analyses of a wide range of archaeological materials 
including metallurgical debris and technical ceramics. Standard protocols to prepare and analyse archaeometallurgical materials have been developed over the years at these laboratories. Permission to export and conduct invasive sampling of metallurgical debris and artefacts was granted by the South African Heritage Resources Agency (hereafter SAHRA) in permit number 80/08/08/012/52.

The theoretical foundations of archaeometric methods employed in this thesis will be dealt with at an introductory level in this chapter; for more detailed discussions the reader is referred to other publications (e.g. Garrison 2003; Moens et al. 2000; Pollard et al. 2007; Pollard \& Heron 2008; Ponting 2004; Tite 1972) and others noted in relevant sections of this chapter. More emphasis will be given to the discussion of practicalities and justification of procedures followed in this particular investigation. The choice of archaeometric techniques was guided by their analytical capability to produce data relevant to answer research questions outlined in Chapters 1 and 4. The level of accuracy and precision required also played a crucial role in the choice of the analytical methods and instruments that were employed. However, it has to be acknowledged that to some extent the choice of analytical techniques was influenced and affected by the personal expertise of the researcher and their availability. This chapter outlines the procedures of sample documentation and preparation, and briefly discusses the analytical methods in each case highlighting the information which was gathered and the specific research question which was to be addressed. 


\subsection{Macroscopic examination, classification and sample selection}

The initial laboratory analysis involved the creation of an inventory of all surface finds, excavated samples and relevant samples that were present in the UCT Phalaborwa collection. The inventory included artefacts and ecofacts, some not necessarily related to metallurgical activities but helpful to situate the technology into its social context. The finds were cleaned under running tap water and left to dry. Obvious metallurgy related finds were separated from the other finds and sorted according to their context of recovery. More attention was then paid to the pottery fragments which were thoroughly inspected for evidence of metal production such as adhering slag and metal.

Subsequently the metallurgical debris was classified into four broad groups, namely mineral samples, slags, technical ceramics and metal artefacts. The groups were further divided into sub-groups based on their macroscopic features. The mineral or potential ore samples were classified based on their colour into copper ores for the green and bluish minerals, and iron ores, which were mainly black chunks of magnetite. Based on their morphology the slags were divided into two types, namely 'flow slags' and 'crushed slags'. Following the suggestions of Bachmann (1982), the attributes recorded during the macroscopic analysis of slags included shape, flow texture, layering, colour of corrosion products, colour of the fresh surface, porosity, and metrical attributes such as size and weight. Technical ceramics were subdivided into three subtypes, namely tuyères, furnace linings and crucibles or ceramic slag skimmers ${ }^{5}$. The metallic finds were subdivided into two main groups, namely

\footnotetext{
${ }^{5}$ Not all slagged pottery were used as crucibles; some were used to skim dross during the refining of non-ferrous metals (Calabrese 2000; Miller 2010). These ceramic fragments, better known as slag skimmers, exhibit little vitrification because they were not exposed to high temperatures for a long time and can be distinguished from crucibles with microscopy (see Chapter 6).
} 
primary raw metal and finished objects. An inventory which established the distribution and quantity of the classes and sub-groups in each context of retrieval was created. The diverse nature of the metallurgical debris subjected to analysis meant that the attributes of interest also varied. The macroscopic examination of the assemblages was considered an equally important step in the understanding of the metallurgical processes that were represented at the archaeological sites presented in this thesis.

The macroscopic examination and classification processes were followed by the selection of samples to be subjected to detailed analytical work, using sampling strategies suggested by Orton $(2000,177-190)$ on the selection samples for microscopic and chemical analysis. Orton suggests a two-stage sampling strategy which starts with macroscopic grouping of artefacts followed by sub-sampling from these categories. The sampling process thus consisted of two stages, first involving the selection of 'typical' samples of each category identified macroscopically, followed by sectioning of specimens. Several considerations were taken into account: firstly, the condition of the samples determined if the sample could be subjected to further analytical work or not. Taking heed of warnings from previous researchers, it is known that archaeometallurgical materials including the supposedly durable slag and crucibles samples are prone to post-depositional alteration from prolonged exposure to atmospheric and bacteriological influences (Bachmann 1982, 18; Morton \& Wingrove 1969, 1555; Rehren, 2009). The analysis of materials largely altered by these post-depositional processes was therefore deemed less informative; thus they were excluded from further analysis. Secondly, the analytical procedures also imposed their own requirements therefore influencing the sampling strategy. For 
example, pressed pellets required samples weighing at least $15 \mathrm{~g}$; as such, any smaller samples could not be used for (P)ED-XRF analysis. The selected samples were photographed before they were invasive sampled for polished blocks and pressed pellets. The next section of this chapter describes the procedures that were followed in the preparation of selected samples prior to further analyses.

\subsection{Sample preparation}

\subsubsection{Polished blocks for optical microscopy and SEM-EDS}

Microscopy investigations of materials of geologic origin, including the ones which are transformed by high temperature process, usually require the samples to be prepared either as thin sections or polished blocks. Thin sections are samples prepared to a thinness of $30 \mu \mathrm{m}$ which are mounted and polished on glass slides. These sections are conventionally used for transmitted light microscopy. The use of thin sections is common in the analysis of archaeological ceramics and has sometimes been used for metallurgical slag samples (e.g. Chirikure et al. 2010). Polished blocks, on the other hand, are usually thick samples which are mounted in resin and are given a mirror polish on one flat surface. These polished blocks are used for reflected light microscopy. In this project, polished blocks were preferred over thin sections mainly because some of the samples were metallic or contained metallic prills and other opaque phases that could not be examined with transmitted light microscopy. The same polished blocks were subsequently used for SEM-EDS analysis. The preparation of polished blocks was also considered less laborious compared to thin sections.

The preparation of polished blocks followed the standard procedures outlined in Scott $(1991,61-68)$ for the invasive sampling and preparation of metallographic 
samples. The samples were once again cleaned under running tap water, then sectioned with a tile cutter and left to dry at room temperature overnight. The dry samples together with paper labels with inventory numbers were then embedded in epoxy resin and hardener, both from MetPrep Ltd, inside dedicated plastic moulds. The epoxy resin embedding the specimens was then cured at room temperature for 24 hrs. Further preparation of the set blocks involved grinding through progressively fine grades of silicon carbide papers to produce a flat surface of the specimen. The grinding process was followed by polishing with dedicated cloths using diamond paste and lubricant to a fineness of $1 \mu \mathrm{m}$. After polishing at $1 \mu \mathrm{m}$ grade the samples were placed in the ultra-sonic bath to remove diamond paste and lubricant, ready for analyses.

\subsubsection{Pressed powder pellets for (P)ED-XRF}

The matrix of the sample can have a great effect on the accuracy and precision of analytical chemical results obtained by XRF (Revenko 2009). Unprepared samples or polished blocks can be used for routine qualitative XRF analytical work. However, for a project which require quantitative data with a high degree of accuracy and precision, samples have to be homogenised. Samples for quantitative bulk chemical $\mathrm{XRF}$ analysis can be prepared in several forms, primarily as fused glass discs and pressed pellets. At the Wolfson Archaeological Science Laboratories XRF samples are usually prepared as pressed pellets. The preparation of pressed pellets is an invasive procedure which requires the crushing and milling of the samples.

The choice to prepare samples as polished blocks or pressed pellets was also influenced by the nature of the material. Some samples of slags were prepared as pressed pellets and polished blocks of these were mounted as well. However, none of 
the crucibles or slag skimmers and tuyères with adhering slags was crushed into pressed pellets because these were complex samples, made up of different layers, which could be better examined with optical and electron microscopy; for these, only polished blocks were prepared.

The preparation of pressed pellets involved the sectioning of the samples, crushing and subsequent milling into a fine analytical powder. The samples were washed and the corrosion products on the surface were manually removed by cutting or grinding to remain with the sound part, especially for the slags. At least $15 \mathrm{~g}$ were removed from each sample although approximately $8 \mathrm{~g}$ were needed to prepare the pressed pellets with the remainder being lost during the process of crushing and milling. The samples were cut into small fragments of about $5 \mathrm{~mm}$ using a tile saw and once again washed followed by drying at room temperature for $24 \mathrm{hrs}$. The fragments were subsequently crushed inside steel sample crushers and milled. The stages of crushing and milling can pose serious challenges of cross sample contamination; to prevent this, high levels of cleanliness and other quality control measures were taken. After each sample was crushed or milled the containers were meticulously cleaned with sand and industrial methylated spirit (IMS). For milling purposes the crushed fragments of the samples were placed inside tightly sealed steel pots which contained tungsten carbide balls. The steel pots were placed inside a fast rotating PM100 planetary ball mill. The resulting product was an analytical powder with a fineness of less than $50 \mu \mathrm{m}$ which was placed in glass vials for storage. The glass vials with the powder were then covered with clinical tissue to avoid cross contamination and placed in an oven at $105{ }^{\circ} \mathrm{C}$ over night to remove moisture. Chirikure et al. (2010) have noted with some concern that most practising archaeometallurgists do not 
quantify the loss of moistore and loss-on-ignition for their XRF data. However, of the few published slag results in Southern Africa there seems to be negligible losson-ignition, with some actually gaining on ignition, as a result of oxidation (e.g. Chirikure et al. 2010; Friede \& Steel 1975). According to Morton \& Wingrove (1969, 1559) any moisture and loss-on-igniton documented in ancient slags result from physical and chemical changes due to exposure to atmospheric conditions in the archaeological context. Therefore, in this investigation the loss-on-ignition was tested only on a few samples since high organic matter is not expected in sound byproducts of high temperature processes such as slags. However, the calculation of the loss-on-ignition should be encouraged in XRF analytical work which involve ore samples.

After drying, the analytical powder was mixed thoroughly with industrial wax binding agent at a ratio of 7:1 in an agate mortar and pestle. Using a very sensitive scale the weight of the powder and industrial wax was measured to keep the ratio constant. Subsequently the homogenised mixture was placed inside dedicated aluminium caps and pressed at 15 tonnes for 2.5 minutes. The aluminium caps were then labelled with a marker pen with information such as the inventory number among others.

\subsection{Instrumental methods}

As pointed out earlier, the archaeometric techniques employed in this thesis have been utilised in archaeometallurgy for some time now, and their application and general limitations are well understood. However, each project has its own unique challenges or practicalities that influence procedures that will be followed during the analysis; more over procedures may differ with laboratories. Therefore it is necessary 
to establish the procedures, challenges and attempts that were made to produce the credible analytical results. We are reminded that it can be "... tempting to believe that if a figure comes from a piece of expensive equipment, probably via a computer, it must be 'true'." (Orton 2000, 181). Archaeometric methods are not immune to errors, be they random or systematic. The following sections of this chapter briefly discuss the three methods used to gather the data, namely reflected light microscopy, scanning electron microscopy with energy dispersive spectrometry (SEM-EDS) and energy dispersive X-ray fluorescence spectrometry (ED-XRF).

\subsubsection{Reflected light microscopy}

The microstructure of metallurgical debris can reveal several aspects about the conditions which prevailed during the extractive process. By studying the optical properties, morphology and relative abundance of phases and minerals present in polished specimens it is possible to characterise inorganic materials of geological or artificial origin (Garrison 2003; Nesse 2004). For example in the slag samples, the relative abundance and morphology of phases is used to estimate redox conditions and rates of cooling. In cases where rounded free iron oxides (wüstite, $\mathrm{Fe}_{1-\mathrm{x}} \mathrm{O}$ ) are abundant these are proxies of strongly reducing conditions, whereas angular free iron oxides (magnetite spinels, $\mathrm{Fe}_{3} \mathrm{O}_{4}$ ) are proxies of moderately reducing conditions (Miller \& Killick 2004). However, it must be pointed out that spinels of different compositions can appear similar optically, which makes it difficult to distinguish them by reflected light microscopy without further phase chemical studies. The cooling rate of pyrotechnological products and by-products influences the size and morphology of their microscopic phases, with slow cooling resulting in more developed crystals. In order to establish the prevailing conditions which shaped the 
metallurgical debris from Phalaborwa, several aspects of their microstructure were therefore recorded. These attributes ranged from crystal colour, size, heterogeneity, and distribution of porosity in the potential ores, slags, technical ceramics and metals. The art to identify relevant microscopic features with petrological and metallographic microscopy in this project was developed with more experience throughout the whole process of laboratory work. Credit also is to be given to my supervisors who assisted me with the explanation and interpretation of some complex microstructures that I was encountering.

A Leica optical microscope which utilised plane polarised light (PPL) and cross polarised light (XPL) was employed to examine the polished blocks. This method proved particularly useful in the identification of non-metallic inclusions such copper sulphide and cuprite which were prevalent inside the metallic copper. The optical microscope also enabled the field of view of the polished samples to be reduced at the magnifications ranging from 50x, 100x, 200x, 500x to 1000x. The microscope was also equipped with a digital camera to capture important attributes of the polished specimens in the form of photomicrographs. Each photomicrograph was accompanied by notes of magnification and polarising position.

\subsubsection{Scanning electron microscopy with energy dispersive $x$-ray spectrometry (SEM-EDS)}

Scanning electron microscopy (SEM) occupies an important place in the routine analyses of a wide range of geological and archaeological materials (Ponting 2004; Pollard et al. 2007; Pollard \& Heron 2008; Reed 1996; Tite 1972). Designed primarily as an imaging instrument, the scanning electron microscope was used in this thesis to complement the information gathered during the optical microscopy 
sessions. The SEM is capable of generating images with a better resolution at higher magnification than an optical microscope. It uses a beam of electrons (as opposed to visible light used in optical microscopy) to capture the subtle microstructural and microtopographical details of a sample. To achieve this, the polished blocks subsequent to carbon coating are scanned over with an incident beam of electrons from an electron gun (heated cathode). The primary electrons in turn trigger the emission of secondary electrons (SE) or the backscattered electrons (BSE) from the sample which can be converted into an image using dedicated detectors. The SE detector is used to capture important microtopographic details which include porosity in technical ceramics. On the other hand the BSE detector is used to view the compositional differences in the polished samples. The intensity of the BSE signal increases with the increase in average atomic number of the phase upon which the primary electrons are incident. Viewed under the BSE detector, the heavier phases (i.e. elements with high atomic numbers in the periodic table) appear as brighter shades with the lighter elements showing up as darker shades. These greyscale SEM images are best interpreted together with the colourful photomicrographs from optical microscopy. In this investigation, both SEM and reflected light optical microscopy were therefore regarded as equally crucial stages in the visual documentation and description of the samples at microscopic level.

The SEM was further employed in this project to perform analytical work. Besides being a very powerful imaging technique, once the SEM is fitted with an energy dispersive X-ray spectrometer (EDS) it is a very useful instrument for chemical analysis. To conduct analytical work, the EDS utilises secondary X-rays which are emitted by the sample upon being excited by the primary electron beam to identify 
and quantify elements present. Since X-ray spectrometry forms the basis of understanding both analytical SEM-EDS and (P)ED-XRF techniques utilised in this project some basic concepts about spectroscopy, X-rays and their production will be considered briefly here. For detailed explanations several archaeological science publications can be consulted (e.g. Pollard et al. 2007; Pollard \& Heron 2008; Tite 1972).

X-rays are a form of electromagnetic radiation with very short wavelengths ranging from 0.01 to $10 \mathrm{~nm}$ with a high energy range of between $120 \mathrm{eV}$ to $120 \mathrm{keV}$ (Pollard et al. 2007, 93). These X-rays are produced by the transition of electrons between the orbitals or energy levels (K, L, M and $\mathrm{N}$ ) of an atom. This transition of electrons takes place when a vacancy is created in the low energy levels of the electronic structure of an atom. This process, termed excitation, makes the atom unstable and triggers the process of de-excitation which is the movement of electrons from higher energy orbits to fill the vacancy. The processes of excitation and de-excitation of atoms in turn can result in either of the following two processes: X-ray process or auger process. In the case of the X-ray process, the de-excitation of the atom will result in the emmission of X-rays, whilst the auger process results in a raditionless transition which sees the ejection of electrons from the higher energy orbitals of an atom (Pollard et al. 2007, 94). Not all elements are capable of producing secondary X-rays upon being excited; particularly some lighter elements result in the ionization or auger process. Unfortunately some of these light elements, carbon and oxygen, are important in the study of archaeometallurgy but they are not easy to quantify with Xray methods. For the X-ray techniques the most important process is the one which produces secondary X-rays. These secondary X-rays have wavelengths and energies 
characteristic of the elements which produce them, which allows the identification and quantification of the elements present in a sample or phases.

The X-ray techniques used in this project differ mainly in the way in which samples are initially exicited. To create the initial electron vacancies in the low energy levels of atoms the samples can either be bombarded by primary X-rays, electrons or kinetic energy. In the case of the SEM, this is accomplished by bombarding the sample with primary beam of electrons. Secondary X-rays that will be produced are prone to absorption by the air therefore samples are usually analysed under vaccuum. Another challenge which is inherent in SEM analysis is that the electron beam is electrically charged; as such, materials electrically insulating such as ceramics and slags will result in the build-up of the charge (Pollard et al. 2007, 111). To overcome this problem, after optical microscopy all the polished block samples were coated with a thin layer of carbon prior to analytical electron microscopy.

The spectrometers used to identify and quantify secondary X-rays are broadly divided into two types, namely energy dispersive spectrometers (EDS) and wavelength dispersive spectrometers (WDS), which have their inherent pros and cons not discussed further in this thesis. As implied by its name, the EDS measures energy released by the secondary X-rays as they strike crystals in the detector. The EDS is a much faster method of analysis and has detection limits sufficient for general material characterisation, down to approximately $0.1-0.3 \%$. Hence it was the detector employed for this research.

The SEM-EDS in this project was primarily used to chemically characterise minerals or phases which were identified during optical microscopy. The technique was particularly useful for microanalysis because of its ability to focus the incident 
electron beam on small parts of the polished samples. The SEM-EDS was also employed to obtain an approximation to the 'bulk' composition of polished blocks, by scanning over various areas of the sample. Conventionally, as discussed below, $\mathrm{XRF}$ is used to establish the bulk chemical composition of metallurgical samples like ores, slags and ceramics; as discussed above these have to be homogenised before analysis. However, two main reasons worked against the use of XRF for bulk chemical composition for some of the samples analysed in this project. Firstly, the existence of unreacted mineral residues inside slag samples meant that XRF analysis was only useful to assess charge composition, but the data was less useful to estimate operating temperatures on phase diagrams, as discussed further below. Secondly, not all metallurgical materials were big enough to produce enough powdered analyte for the pressed pellets and specimens for the polished blocks. Since all samples had to be analysed by reflected light microscopy and SEM-EDS to facilitate comparison, it was decided not to prepare pressed pellets for samples which weighed less than $15 \mathrm{~g}$. Because of these two major reasons a decision was made to utilise SEM-EDS to establish the 'bulk' chemical composition. In order to establish this 'bulk' chemical composition with the SEM-EDS, area scans were conducted on the polished samples excluding large inclusions (i.e. unreacted ores residues, metal prills for slag samples and large mineral inclusions for technical ceramics), porosity and corrosion products. The 'bulk' SEM-EDS results presented in this thesis are averages of analytical results of at least five area scans per sample. For purposes of easy comparison between the samples, the working distance was kept constant at $10 \mathrm{~mm}$ and the magnification at $200 x$ corresponding to a 605 by $415 \mu \mathrm{m}$ area for slags. As such a minimum of $1.26 \mathrm{~mm}^{2}$ was analysed per sample to come up with 'bulk' chemical composition. The magnification was much lower, at 40x, for ores because they were 
considered too heterogeneous to analyse small areas while acknowledging the risks of lower accuracy given the higher likelihood of poor geometry and porosity being analysed when scanning large areas. Similar multiple SEM-EDS area scans were considered sufficient for bulk chemical analyses in previous archaeometallurgy projects (e.g. Bassiakos \& Catapotis 2006).

SEM-EDS is capable of identifying elements present in a sample but unable to identify the chemical compounds. For the identification of the phases and minerals, their optical properties under the optical microscope were therefore very important, again confirming the complementary role which SEM-EDS and optical microscopy played in this thesis. Although the SEM which was used can detect presence of oxygen, it cannot quantify this element very accurately; therefore oxygen was calculated by stoichiometry in most instances. Except for some phases; such as, cuprite inclusions inside metals prills were some attempt was made to quantify oxygen content. The composition of non-metallic phases and minerals is expressed as oxides in weight per cent, whilst metallic phases and primary sulphidic minerals; such as chalcopyrite, are reported as elements in weight per cent.

SEM-EDS work was carried out using a Hitachi S-3400N instrument which was equipped with an INCA Oxford X-ray energy dispersive spectrometer. The instrument was operated at the following working conditions: working distance 10 $\mathrm{mm}$; accelerating voltage potential of $20 \mathrm{kV}$; probe current ranging from 45.8-72.6 and a detector dead time of between $35-40 \%$. The secondary X-ray spectra were evaluated and quantified by the INCA software. To establish accuracy and precision of the analytical instrument, a number of certified reference materials (hereafter CRMs) were also analysed. The full description and detailed SEM-EDS results of 
these CRMs are given in Appendix 1. Apart from the standards mentioned above, drift in the analytical instrument during each SEM-EDS session was monitored at regular intervals using cobalt as an optimising element.

The control materials analysed together with the unknown materials, in this case archaeometallurgical debris, during the SEM-EDS included mostly the silica-rich basalts namely BIR-1, BHVO-2 and BCR-2. These CRMs also contain a wide range of other important oxides that are expected in slags and technical ceramics. Both technical ceramics and slag samples were primarily silicates, however, slags also contain high levels of iron oxide. It is unfortunate that these CRMs are not iron-rich and they do not contain significant copper quantifiable by SEM-EDS, but none-theless they provided the much needed materials to test instrument accuracy and precision. Concerns were also raised when it was noticed that the analytical totals of the CRMs results varied with each SEM-EDS session. Sometimes these analytical totals were way above 100 whilst in some cases they were very low, reaching as low as $81.2 \mathrm{wt} \%$ (see Appendix 1: Tables 1, $3 \&$ 5). Analytical totals are primarily determined by the nature of the sample matrix and variations in beam intensity. Porosity usually accounts for low analytical totals but in this case the control materials which were utilised were homogeneous polished specimens. This suggests that the incident electron beam of the Hitachi machine was prone to intensity drift and the machine was not stable. Regardless of the varying analytical totals that were produced during the analyses of CRMs it was encouraging to note that the normalised (100\%) results from this machine compared very well to the given CRM values (Appendix 1: Tables 2, 4 \& 6). For this reason the SEM-EDS chemical results quoted in this thesis are normalised to $100 \%$, except in few occasions where it was 
not necessary to present normalised results. Normalisation also allowed comparisons of the compositional results of the different samples to be possible. The coefficient variations (CVs) of major oxides range from 0 to $6 \%$, whilst for minor oxides $\mathrm{CVs}$ of up to $50 \%$ were noted. These results show that the level of precision of the Hitachi machine was acceptable over the period of analytical work. In terms of accuracy tests it should be noted that all oxides were slightly underestimated except for $\mathrm{SiO}_{2}$ which was always overestimated by $5 \%$. However, numerical adjustments of SEM-EDS results were avoided because the error margins are acceptable. For example, $\mathrm{SiO}_{2}$ was only overestimated by a factor of 0.95 (i.e. $(100-5) \div 100$ ); as such, the adjusted value of let us say $10 \% \mathrm{SiO}_{2}$ would have been $9.5 \%$.

\subsubsection{Energy Dispersive X-ray fluorescence spectrometry (ED-XRF)}

Suitable samples were subjected to bulk chemical composition analysis using X-ray fluorescence spectrometry (XRF). There were several reasons for utilizing XRF in conjunction with SEM-EDS for chemical characterisation. Firstly, the XRF analysis works well with heterogeneous samples, once they are homogenised and prepared as pressed pellets reliable results will be obtained. Thus XRF results can be regarded both as quantitative and representative of the sample. Secondly, bulk XRF results were also used to establish the degree of confidence in the 'bulk' chemical results gathered using SEM-EDS. Thirdly, the ability of the XRF to quantify trace elements apart from major and minor elements was also useful in identifying the range of composition groups that were available in the assemblage. The XRF method was also considered a faster way of getting bulk chemical results once the pressed pellets were prepared. The following paragraphs will discuss briefly the foundations of ED-XRF 
analysis concluding with the instrument specifications, measurement settings and calibration methods which were used to interpret the X-ray spectra in this project.

The foundations of XRF analysis are similar to the ones which were discussed for the SEM-EDS analysis. Therefore there is no need to repeat them in great detail again. In brief, like any other X-ray technique, XRF involves the excitation of atoms which make up the sample followed by de-excitation and emission of secondary X-rays (fluorescent) (Pollard et al. 2007; Veldhuijzen 2003). These secondary X-rays are characteristic of the atoms present and their intensity is used to establish the relative abundance of the different elements. The most notable difference of this technique with the SEM is that it uses (primary) X-rays to create the initial vacancies in the inner orbital energy levels of the atoms. The primary X-rays are generated in the Xray tube composed of a heated filament which emits electrons towards a cooled anode. Upon being bombarded with sufficient electrons the anode will produce $\mathrm{X}$ rays which will be directed to the sample through a beryllium window. In some cases secondary targets will be used to filter the primary X-rays to reduce the background noise in the spectrum. The (secondary) X-rays which are emitted by the sample after excitation will be directed to the X-ray spectrometer which in turn will identify and quantify them against known values (Pollard et al. 2007, 101). The X-ray spectrometer will produce a spectrum which will be evaluated by computer software which identifies and quantifies peaks enabling the elements to be identified and quantified. The spectrometer used for XRF analysis in this project was an energy dispersive (ED), which is based on the same principles as the spectrometer discussed under the SEM-EDS section. 
To conduct XRF analysis a Spectro X-Lab Pro 2000 instrument with secondary targets to polarise the primary X-rays was used. This method is thus referred to as polarising energy dispersive X-ray fluorescence spectrometry (P)ED-XRF. Similar to SEM-EDS the analytical work was carried out under a vacuum to reduce the loss of secondary X-ray by absorption. The higher excitation energy potential of $50 \mathrm{kV}$ (compared to SEM-EDS 20kV) which could be achieved by the (P)ED-XRF meant that it had lower detection limits allowing concentrations as low as approximately 20 ppm $(0.002 \%)$ to be established. The 'Slag_Fun' calibration method, designed to handle both iron-rich and silica-rich materials, was utilised to evaluate the secondary X-ray counts (Veldhuijzen, 2003). The bulk (P)ED-XRF chemical results reported in this thesis represent major and minor oxides which were normalised $100 \%$ to allow comparisons between the samples. The same basalt standards used for SEM-EDS were again analysed together with the metallurgical samples in order to monitor accuracy, precision and instrument drifts. In addition the iron-rich Swedish slag W25: R, a common reference material among archaeometallurgists, was also analysed together with the archaeological materials of unknown composition. The CRMs were prepared as pressed pellets following the same procedures which were used to prepare the archaeometallurgical samples. Details and results of the analyses which were carried out on the CRMs are given in full in Appendix 1 (Tables 7, 8 and 9). In terms of precision the CVs of major oxides ranged from 2 to 16 , comparatively higher than CVs of major oxides reported for the Hitachi machine used for SEMEDS. The accuracy of the instrument as determined in absolute and relative terms shows that four major oxides namely $\mathrm{Al}_{2} \mathrm{O}_{3}, \mathrm{SiO}_{2}, \mathrm{CaO}$ and $\mathrm{FeO}$ were usually overestimated. These oxides were overestimated by more than $15 \%$. It should be pointed out that some technical problems were experienced with the XRF machine 
from August 2010 onwards thus results gathered during this period are less precise and accuracy was compromised. These results are not presented in this thesis.

\subsection{Estimation of operation parameters in archaeometallurgy}

Investigations of operating parameters attained during the various stages of metal production can give vital information. These parameters include among others operating temperatures, atmospheric conditions (redox) and slag viscosities. By studying the physicochemical properties of products and by-products of past metal production episodes some of these parameters can be established. For example, it is now appreciated that the control of slag properties, such as composition together with melting point and viscosity, was essential for the efficient separation of metal from slag (Rehren et al. 2007). Metallurgists would have aimed to produce slags with a lower melting temperature, low viscosity and ideally a composition approaching the fayalitic region. The study of these properties and parameters does not only help in the reconstruction of ancient pyrotechnologies, but can help us to appreciate more the skills of ancient metallurgists. This section briefly discusses approaches that have been employed by archaeometallurgists to establish these parameters. The limitations of these approaches will be acknowledged whilst some justification will be given for their application in this thesis.

Some of the approaches that have been used to estimate operating temperatures of ancient extractive metallurgies include phase diagrams, hot-stage microscopy and experimental work (Bachmann 1982; Friede et al. 1982; Morton \& Wingrove 1969; Morton \& Wingrove 1972; Tylecote et al. 1977; Tylecote \& Boydell 1978; Whiteman \& Okafor 2003). Direct methods of establishing melting points of slags 
like hot stage microscopy or experimental smelts aided by thermocouple measurements require "considerable expertise and capital equipment expenditure" (Freestone 1988, 50), yet they can still produce doubtful values (e.g. Friede et al. 1982). For the purposes of the current thesis, empirical methods of calculating liquidus temperatures using bulk chemical data of archaeological slags subsequently plotted on phase diagrams was the chosen approach. The procedures to establish furnace working temperatures using phase diagrams for archaeological slags were initially developed in the seminal papers by Morton \& Wingrove $(1969 ; 1972)$.

The use of phase diagrams to estimate furnace operating temperatures in archaeometallurgy has been criticised before for various reasons (Kresten 1986; Pryce 2008, 111-118). In essence, the use of phase diagrams is based on several assumptions; one of them is that the slags were fully molten, free-flowing and are homogenous. However, it has so often been discovered that archaeological slags can contain partly decomposed ores and gangue material that can compromise the application of phase diagrams. Indeed archaeological slags from the non-slag tapping furnaces such as the ones found around Phalaborwa can contain conspicuous unreacted minerals (Chapters $6 \& 7$ ). As a result some reservations have been made regarding use of phase diagrams to obtain temperature estimates using archaeological slags in Southern Africa (Miller \& Killick 2004). Pryce (2008, 114) also notes that most phase diagrams are modelled for modern day industrial materials and production process, not for archaeological application. For this reason, Bassiakos \& Catapotis $(2006,347)$ envisage that phase diagrams which are applied are only suitable for strongly reducing conditions that were not necessary during the extraction of copper in the past. Phase diagrams thus represent one of the several 
techniques borrowed from metallurgy and chemistry that archaeologists should apply with a lot of caution. Another challenge in the use of phase diagrams arises when one is confronted with materials with complex compositions and mineralogy, for example slag samples with more than three principal oxides (see Iles \& MartinonTorres 2009). As will be established in the following chapters, Phalaborwa slags have at least seven major oxides, including very high $\mathrm{CaO}$ levels which make it unfeasible to use the anorthite-wüstite-silica phase diagram employed in most archaeometallurgy projects. $\mathrm{CaO}$ will thus combine with $\mathrm{SiO}_{2}$ and $\mathrm{FeO}$ to form complex pyroxenes and olivines, not anorthite as was proposed by Morton \& Wingrove (1969) for the Roman period bloomery slags. Research over the decades has shown that ancient slags have a wide range of composititions and phase structures; as such, they do not always fit in the models that were developed by Morton and Wingrove in the 1970s. Some of the challenges established above can be overcomed. For example the use of multiple area scans, avoiding large unreacted minerals, can be used to overcome problems of collecting bulk chemical readings that are not usefull on phase diagrams. Viscosity indexes $\left(\mathrm{K}_{\mathrm{v}}\right)$ of slag samples can be calculated using the ratio of basic oxides $\left(\Sigma \mathrm{CaO}+\mathrm{MgO}+\mathrm{FeO}+\mathrm{MnO}+\mathrm{K}_{2} \mathrm{O}\right)$ against acidic oxides $\left(\Sigma \mathrm{SiO}_{2}+\mathrm{Al}_{2} \mathrm{O}_{3}\right)$ as outlined by Bachmann $(1982,19)$. This approach has been criticised before by Kresten (1986) but still remains the best way to estimate viscosity of archaeological slags. All being said, the quid pro quo of using these hard science approaches in archaeology should be measured against their ability to generate meaningful data that will help archaeologists to understand past human societies. 


\subsection{Summary}

The combination of archaeometric approaches discussed above in this study was considered an effective way to reconstruct extractive metallurgies that were employed during the pre-colonial period around Phalaborwa. Multi-analytical approaches previously proved effective; as such, have been encouraged by several archaeometallurgists (e.g. Miller \& Killick 2004; Morton \& Wingrove 1972). Morphological analyses formed the bases for carrying out classification and sample selection. The microstructure of selected samples was described and documented with optical and electron microscopy. The chemical characterisation at microstructural and bulk chemical levels was carried out with SEM-EDS and (P)EDXRF. The choice of the archaeometric techniques was guided by their availability at the UCL Wolfson Archaeological Science Laboratories but most importantly by their ability to address specific research questions outlined in the previous chapters. The basic characterisation of the metallurgical debris made it possible to establish the technology used to produce copper and also suggest possible sources of the raw materials. The next chapter goes a step back to describe the fieldwork that was carried out at Shankare Hill before presenting results that were gathered using archaeometric approaches outlined in this chapter. 


\section{Shankare Hill: The archaeology and extractive copper metallurgy}

\subsection{Introduction}

Shankare was the first site to be targeted for proper investigations and excavations by Revil Mason between 1964 and 1967 around Phalaborwa (Mason 1965; Mason 1986; Mason et al. 1983). He publicised the site as Shangaankop which is the Afrikaanised combination of the term Shangaan, refering to one of the ethnic groups of the Tsonga speaking people, and kop, shortened form of the term koppie. The term Shangaankop therefore literally means "Hill of the Shangaan" because the site was last occupied by Tsonga migrant groups prior to their removal to make way for the private game park (Plug \& Pistorius 1999, 160). However, in this thesis I will maintain the Sotho name, "Shankare", that was given by the guides who led us to the site. Shankare is also used in the recent archaeological publications of this site (Plug \& Pistorius 1999).

Shankare (Map Sheet: South Africa 1:50 000 Sheet 2331CC Phalaborwa: Grid Ref: Latitude: $23^{\circ} 58^{\prime} \mathrm{S}$ Longitude: $31^{\circ} 09^{\prime} \mathrm{E}$ ) is composed of two prominent syenite outcrops situated in the extreme north-eastern part of Cleveland Game Park, privately owned by the PMC. The game park hosts a wide variety of wild animals; the most visible ones are elephants and buffalos that frequently interrupted our fieldwork (Figure 6.1). Neither copper nor iron ore deposits are known to be present at Shankare. The closest sources of copper ore are located $4.2 \mathrm{~km}$ (Lolwe Hill: now PMC open pit) and 7.1 km (Old Guide Copper Mine) westwards of Shankare. The site can only be accessed via the eastern bound private gravel road inside the PMC premises. The koppies are currently dissected by the mining company access road and separated by an electric fence. The construction of the access road which goes 
through the 'neck' of the koppies resulted in the destruction of metal production evidence and cultural materials previously reported by Mason (1986). Apart from the disturbances resulting from the construction of the access road, the archaeological deposits at Shankare remain fairly well preserved. About $100 \mathrm{~m}$ from the foothill of Shankare in the northern direction, the PMC has created a man-made plateau of tailings from on-going mining activities (Figure 6.2).

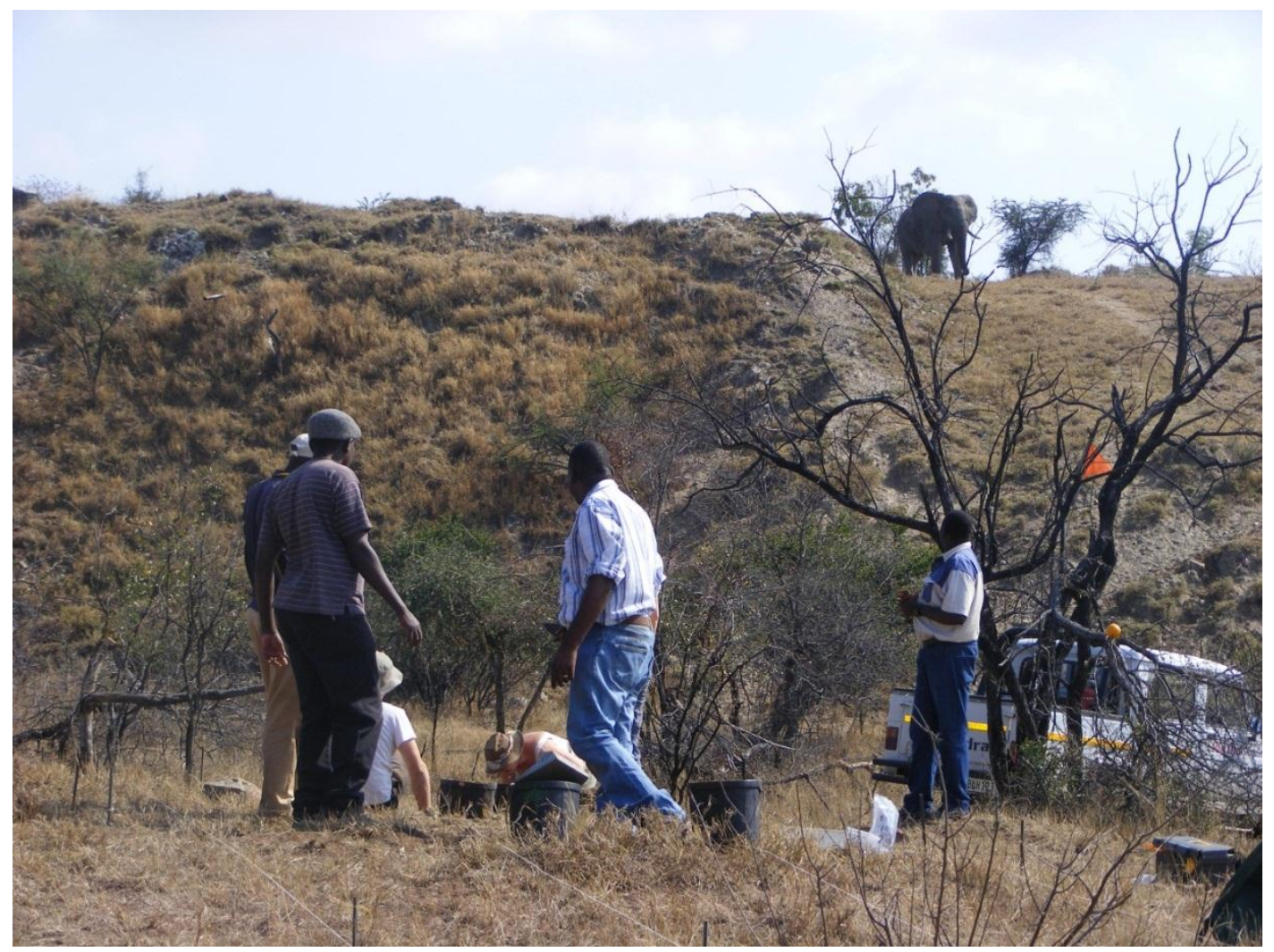

Figure 6.1: An example of unwanted guests, in this particular instance an elephant, that frequently disrupted the surveys and excavations at Shankare Hill in the 2010 fieldwork season (Image: Author). 
In this chapter, the archaeology of Shankare is presented based on both previous and current research findings. In the process, previous interpretations of the site as a metal production centre are highlighted. The choice of Shankare Hill as the core case study of archaeometallurgical investigation in this thesis, together with the survey and excavation strategies, are explained and justified. A brief account of the fieldwork approaches employed in the current project is also given. An overview of archaeological evidence as it was observed in the field is then presented, archaeological features and activity areas are discussed, but special attention is given to the evidence of metal production. This is followed by an archaeological interpretation of cultural material documented on the surface and exploratory excavation trenches that were dug on the site. The last half of the chapter is dedicated to the presentation of laboratory results of presumed ores, slag, technical ceramic and metal samples that were selected for further investigations. Combined together, archaeological interpretations and archaeometric results are then used to postulate extractive metallurgical processes represented at Shankare Hill. Although this thesis is devoted to extractive copper metallurgy, for the purposes of clarity and contrast, iron production debris found in abundance at the site is also briefly presented and discussed.

Shankare Hill was chosen for detailed archaeometallurgical investigations for a wide range of reasons. Firstly, previous studies had suggested the presence of impressive archaeometallurgical debris at the site. Secondly, the site remains one of the few archaeological sites within the PMC premises that have been spared from destruction during the ongoing commercial mining activities. Other sites with potential Iron Age copper production remains in the PMC premises have since been destroyed or buried 
under the mine tailings (Plug \& Pistorius 1999). These sites include Lolwe, Nagome, Ghoenkop, Eskom and Molotho. Thirdly, it was easier to get access to the site of Shankare because of the working relationship that was forged between our fieldwork team and staff at PMC and their Palabora Heritage Committee. Private property rights together with the dangers of animal attack in the game farm dominated region made it difficult to access other sites in the research area. As a result of limited access, health and safety reasons it was not practical to employ statistical probability sampling theories in the survey design and selection of sites that were finally investigated. However, this limitation was compensated by the availability of several published and unpublished literature of the archaeological sites in the research area. Our fieldwork in the Cleveland Game Park was therefore limited to visits to two previously documented sites namely, Shankare and Phutwane (Mason 1986; Pistorius 1989; Thorne 1974). This site selection strategy, although paying little attention to statistical rigour, was deemed cost-effective because the project actually aimed to obtain high-resolution technological reconstructions rather than document cursorily more sites; as a result, focus on a few known sites was a priority. 


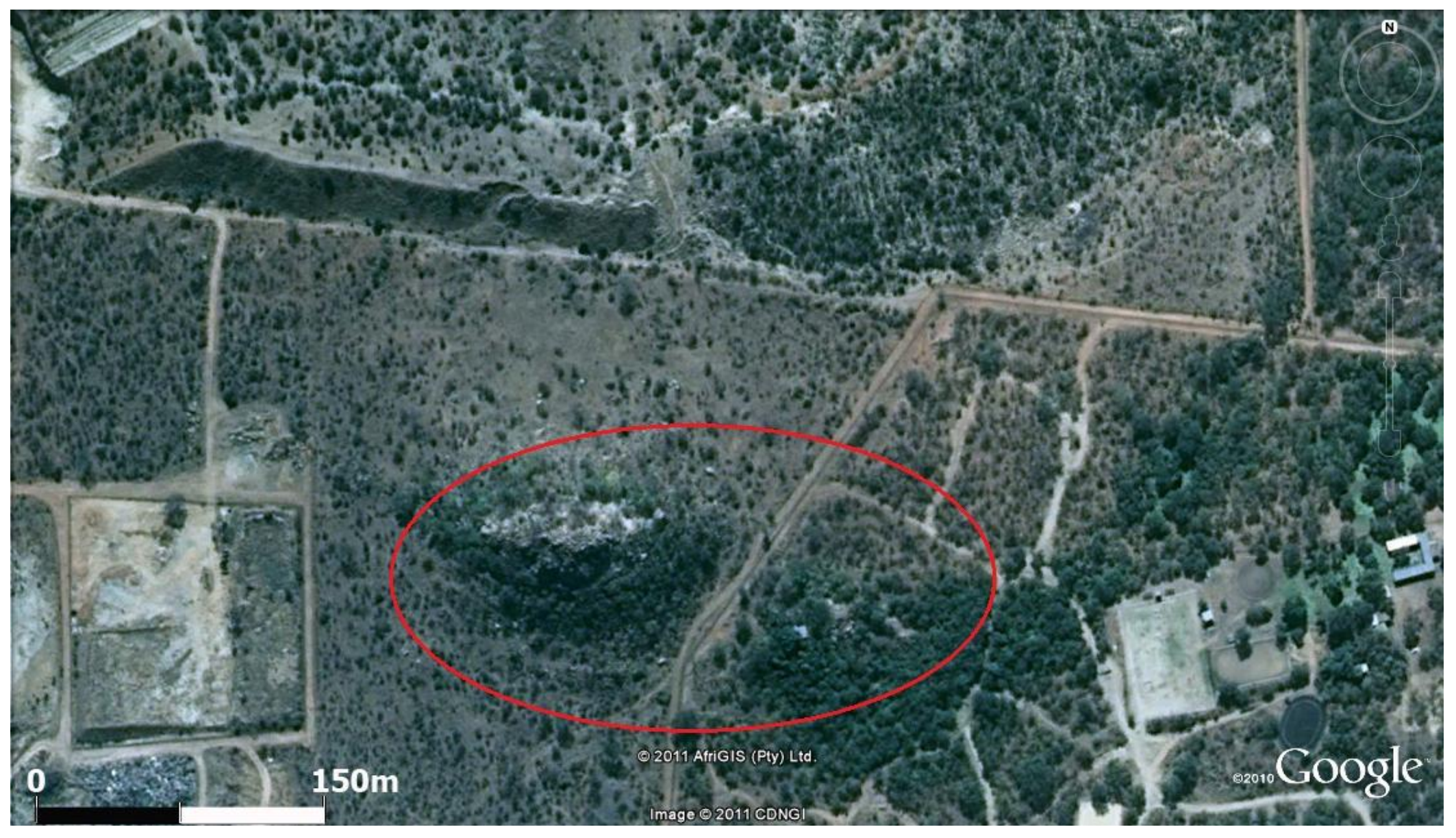

Figure 6.2: Satellite image of the twin koppies of Shankare, circled in red, dissected by an access road. (Image: Courtesy of Google Earth, modified by the author). 


\subsection{Previous investigations at Shankare Hill}

During the 1960s Revil Mason targeted four main features for excavation, namely a three tuyère port furnace on the north-western side (Site 10/64), two ash middens on the terraced platforms (Sites 11/64 \& 12/64) and an iron forge (Site 3/67) on the 'neck' between the two koppies (Mason 1986, 112-124). Two uncalibrated radiocarbon dates ranging from $290 \pm 80 \mathrm{BP}(\mathrm{Y}-1766)$ to $90 \pm 60 \mathrm{BP}(\mathrm{Y}-1769)$ were obtained from charcoal samples that came from the forge area and an ash midden respectively (Mason 1986, 133). Based on these radiocarbon dates and the typology of glass beads, Mason concluded that Shankare was occupied between the seventeenth and nineteenth century AD. Mason also concluded that the site was a specialised metal production centre rather than some of the metal consuming sites that he had previously excavated in South Africa (Mason 1986, 115). The site plan accompaning the report of Shankare that was eventually published shows the location of eight metal production furnaces that Mason documented at Shankare in the 1960s (Figure 6.3). Mason also mapped several ash mounds of varying sizes that were used as repositories of domestic refuse. Even though typical Iron Age hut floor remains were not documented at Shankare, Mason was convinced that the sheer number of ash mounds represented a much longer time depth of occupation. Be that as it may, the point to be emphasised here is that the first investigations indicated that metal production was the main economic activity of the Iron Age inhabitants of Shankare. 


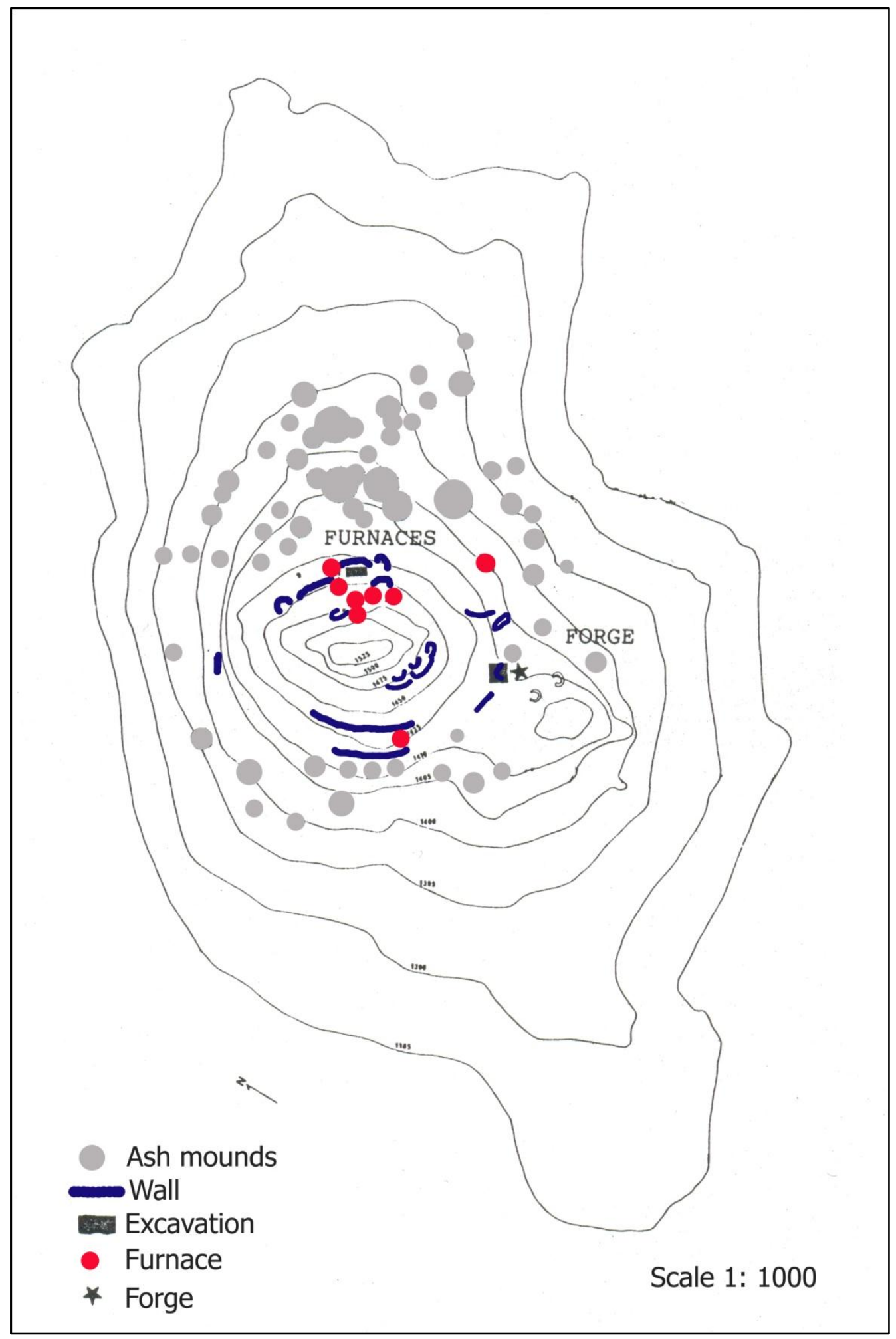

Figure 6.3: Site plan of Shankare produced by Mason based on his fieldwork at the site during the 1960s (Adapted from Mason 1986, 117). 
More than two decades later, Julius Pistorius conducted further archaeological work at Shankare Hill for his doctoral thesis at the University of Pretoria (Pistorius, 1989). Pistorius also excavated four main areas at the site, namely two terraced platforms (SHA1T8 and SHA1T18), a domestic midden (SHA3) and a copper smelting furnace (SHA2M1). The furnace was radiocarbon dated using associated charcoal samples to 890 \pm 50 BP (Pta-4443) (Pistorius 1989), with calibrated dates ranging between 1027 and $1238 \mathrm{AD}$ at two sigma (see Table 4.2). This remains the earliest known in situ evidence of extractive metallurgy around Phalaborwa. As will be established in Chapter 7, copper ingots and slags within the same age range were found in secondary contexts under a hut foundation at Kgopolwe by Nikolaas van der Merwe. Other positively identified copper smelting furnaces in the research area are much more recent, these will also be discussed in the next chapter.

Pistorius' work therefore extended the period of occupation and metal production activities at Shankare Hill back to the early second millennium AD. Shankare thus became one of the few sites (only three) with an early second millennium AD occupation and metallurgical deposits around Phalaborwa (Plug \& Pistorius 1999). Early second millennium AD occupation and metallurgical debris were also reported at Kgopolwe and Nagome (van der Merwe \& Scully 1971). Nagome has since been buried under the tailings of the PMC whilst Kgopolwe was granted a national monument status thus remains well preserved. Pistorius identified at least two occupational phases that are separated by a temporary hiatus at Shankare (Pistorius 1989; Plug \& Pistorius 1999). The occurence of earliest copper production debris at Shankare made it an ideal candidate for tracing possible diachronic changes in the extractive metallurgical techniques around Phalaborwa in this thesis. 
The recent occupation history of the site has been established using ethnohistorical sources. Oral tradition suggests that Shankare Hill was once used the as residence of the ruling Maseke-Malatji lineages (c. 1830 AD), who were renowed copper smelters and smiths (Pistorius 1989; Plug \& Pistorius 1999, $160 \& 164$ ). As pointed out at the beginning of this chapter, recent settlement history identifies the last inhabitants (c. 1900 AD) of the Shankare as Tsonga, immigrants from Mozambique. Unfortunately, the research findings in Pistorius' doctoral thesis largely remain unpublished and are in Afrikaans, therefore his work is not yet available to a wider readership. To date, the only published data from Pistorius' work at Shankare are results of the faunal analyses which highlighted that hunted animals outnumbered significantly domestic stock (Plug \& Pistorius 1999).

Previous investigators at Shankare concluded that the major economic activity was metal production and they concur that agropastoralism did not play a major economic role. However, they do not agree about the metal that was actually produced. Mason suggested that iron production was the most important activity at the site, whereas Pistorius concluded that the site was occupied by predominantly copper producers. In the absence of proper archaeometallurgical studies it was not possible to evaluate the veracity of these competing claims. Analytical work on metallurgical debris recovered from Shankare has been very restricted, with much work focusing on furnace descriptions. Both Phalaborwa and Lolwe type furnaces described in Chapter 4 were documented at the site. To date, only two analytical results of slag samples submitted to Mr J.G. Goodey of Foskor for routine analysis have been reported (Pistorius 1989, Table 17 reproduced here in Table 6.1). The analytical method employed by Goodey is unclear. No mineralogy or microscopic 
investigations were carried out on previously excavated metallurgical assemblages from Shankare, while the few samples that have been analysed are less informative about extractive metallurgical techniques that were employed at the site. However, it is important that previous investigators highlighted the impressive quantities of metallurgical debris with great archaeometallurgical potential to build on.

It was this limited nature of analytical work on metal production debris from the site that prompted the search for archaeometallurgical materials from the previous excavators and their affiliate institutions. Unfortunately, none of these materials could be located since they were deposited with the now dysfunctional museum that was once based in Phalaborwa. In the absence of previously excavated materials, it was necessary to conduct fieldwork in the form of both fresh surveys and excavations with some archaeometallurgical questions in mind. The objective of the fieldwork was to collect a wide range of metallurgical debris and datable materials that could be used in the reconstruction of extractive copper metallurgical processes at the site. Another objective of further fieldwork was to establish the spatial layout of activity areas that are related to metal production. The field approach was to focus on both obtrusive metallurgical activity areas and less obtrusive metallurgical scatters. The project also sought to broaden the scope of analytical work by increasing the sample size of slags together with new categories of metallurgical debris which had hitherto not received analytical attention; such as, ores, technical ceramics and metal objects. Before presenting the analytical results the next section will consider the fieldwork techniques that were employed at the site in the current project. 
Table 6.1: Available analytical results of slags from Shankare in Pistorius (1989, 564).

\begin{tabular}{lrrrrrrrr}
\hline Context & $\mathbf{N a}_{2} \mathbf{O}$ & $\mathbf{M g O}$ & $\mathbf{A l}_{2} \mathbf{O}_{3}$ & $\mathbf{S i O}_{2}$ & $\mathbf{K}_{2} \mathbf{O}$ & $\mathbf{C a O}$ & $\mathbf{F e}_{2} \mathbf{O}_{3}$ & $\mathbf{C u}$ \\
\hline Copper furnace (SHA2M1) & 0.6 & 4.1 & 5.3 & 50.2 & 1.8 & 15.0 & 18.5 & 1.07 \\
Terraced platform (SHA1T18) & 0.8 & 4.2 & 6.4 & 56.4 & 2.5 & 13.2 & 11.5 & 0.68 \\
\hline
\end{tabular}

\subsection{Applied field strategies}

\subsubsection{The survey design, implementation and results}

The overarching aim of fieldwork at Shankare was to gather baseline information, i.e. general archaeology. This baseline information includes chronology, subsistence and trade connections among other issues (Redman 1987, 258). As prescribed in standard literature concerning intra-site fieldwork techniques, a multi-stage approach was employed in conducting the archaeological surveys reported in this thesis (see Banning 2002; Orton 2000; Redman 1987; Schiffer et al. 1978). At Shankare Hill two main stages of archaeological surveys were carried out. Firstly, a reconnaissance survey was conducted between August and September 2009. The second phase, involving the intensive archaeological survey, was conducted in August 2010. The timing of both fieldwork campaigns coincided with the dry winter season to take advantage of low precipitation, sparse vegetation cover and better visibility of surface deposited material culture. The objectives of the first reconnaissance survey were to check the veracity of previous claims and observations of enormous quantities of metallurgical evidence at the site. The reconnaissance survey was also intended to locate, record and collect surface materials not only relating to metal production but the general archaeology of the site. The survey team also sought to understand the spatial distribution of activity areas and demarcate the site boundaries. 
The chief aim of this phase was to assess the potential of conducting further archaeometallurgical work focusing specifically on copper smelting and/or working remains. The reconnaissance survey was an opportunity to assess site-formation processes which affected the distribution of cultural material. Redman (1987) posits that, in some cases, controlled surface collections are effective in the establishment of site boundaries but also identifying behavioural meaningful units. The focus in this study was on activity areas which are hereby given a working definition as discrete clusters of surface artefacts or certain features where specific craft production stages can be assigned. Based on the nature of the metallurgical debris, where possible, the activity areas were categorised as smelting, smithing, crushing or refining precincts pending laboratory investigations. This pilot phase also saw the initial assessment of surface-collected materials with standard archaeometallurgical procedures discussed in Chapter 5. These activity areas became the units of investigation in the quest to establish the chaîne opératoire of extractive copper metallurgy at Shankare Hill.

The reconnaissance survey involved the systematic visual inspection and pedestrian traversing across Shankare Hill and the adjacent lowland covering an estimated 6.25 ha. The same pedestrian inspections had proved effective for metal production sites during the previous archaeological surveys around Phalaborwa (c.f. Thorne 1974). The survey team was composed of four archaeologists from the University of Cape Town, a PMC game warden and the current author. The survey team benefited a lot from Mr Malatji, the game warden, who doubles as the tour guide for archaeological sites located inside the Cleveland Game Park. As a descendant of the Ba-Malatji identified in ethnohistorical sources as the earliest inhabitants of these sites, he 
possessed great knowledge of the landscape and oral traditions. Information of archaeological features and metal production-related activity areas was captured on specially designed record sheets, and a handheld GPS system was employed to establish their coordinates. The survey team was interested in identifying spatial patterns of a wide range of material culture, not just scatters of metallurgical debris. Unfortunately, the survey was limited to the western koppie located inside the Cleveland Game Park because it was impossible to access the eastern koppie on the other side of the electric fence. The upper part of this hill is characterised by large steep boulders, making systematic survey challenging (Figure 6.4). Systematic coverage of the rugged parts of the hill was impossible. None-the-less, the survey team managed to reach the summit of the hill with the conclusion that cultural material was largely concentrated on the northern hillside and foothill areas.

The evidence of past cultural activities at Shankare Hill included terraced platforms, some stone walls and clusters of baked clay mostly concentrated on the northern talus slope (Figure 6.5). The baked clay structures were not associated with metallurgical debris and as such they cannot be linked to metal production. They were located inside restricted rock crevices and are therefore unlikely to represent hut remains. Pole-impressed baked clay was found in association with large potsherds, and presumably represented collapsed "grain bins" documented elsewhere in Southern Africa (Manyanga 2006, 113). Circular foundations of adobe structures, which usually represent hut foundations in Iron Age context in Southern Africa, were not documented on the surface at Shankare. The isolated stone walling on the northern and southern parts of the hill was constructed using undressed rocks of different sizes without any systematic coursing. The function of these stone walls 
was not established because no apparent cultural material was recorded in their vicinity. Metallurgical debris was scarce in these terraced platforms and limited to occasional potential ores and a few tuyère fragments. However, the picture was different in the adjacent lowland, particularly to the north of the hill. Systematic surface coverage of the adjacent lowland up to the northern PMC tailings was carried out. This gently undulating plain on the northern part of Shankare Hill is dotted with large ash middens, rock boulders with dolly holes, stone cairns, and several scatters of metallurgical debris. The evidence of metal production in the northern lowland included tuyères, slag, portable stone anvils, large rock boulders with dolly holes and hammer stones together with potential copper and iron ores. The survey results reinforced previous observations that the density of cultural material was largely concentrated on the northern talus slope together with the adjacent undulating plain of Shankare Hill (Plug \& Pistorius 1999, 164). However, our efforts to locate in situ smelting furnaces documented by Mason during the 1960s fieldwork were fruitless. Unfortunately, advanced subsurface detection methods, invasive or non-invasive, could not be employed at Shankare Hill because of time and budget constraints. Instead limited surface collections were conducted on the metallurgical debris scatters that were located during the reconnaissance survey. The preliminary field observations combined with pilot analytical results of surface collected materials encouraged further intensive surveys and excavations at Shankare Hill.

Archaeologists working around Phalaborwa suggest some varying topographical preferences for settlement locations through time during the Iron Age (see Chapter 3). Earlier settlements are usually situated in lowlands adjacent to syenite hills whereas later settlements tend to be located on the steep slopes with terraced platforms on the 
same syenite outcrops (see Chapter 3, Section 3.2.4.1). Unfortunately, with the surface evidence at Shankare Hill it is impossible to establish settlement patterns due to the lack of obtrusive house foundations. This makes it rather difficult to establish the spatial relationship between the metal production activity areas and the residential areas. Variations in the categories of artefacts at individual metal debris scatters in the lowland were observed. Some scatters contained a wide range of debris like tuyères, slags and ores whilst others contained only hammerstones and slags. Several hypotheses were therefore formulated about these scatters. First, the presence of slag scatters associated with some hammerstones and anvils but without technical ceramics possibly indicated iron smithing processes rather than smelting. Slags inevitably cling to iron blooms and are usually knocked off and discarded next to forges or smithing hearths (Miller 2001, 96). The second hypothesis was that these scatters represented deliberate slag crushing to retrieve whatever metal was entrapped. Several rock boulders with dolly holes representing either ore and/or slag crushing are present around Shankare Hill (Figure 6.6 \& Figure 6.7). Thirdly, it is possible that the varying proportions of metallurgical debris were a function of noncultural post-depositional site formation processes. Based on field experience van der Merwe $(1978,101)$ suggests small slag pieces easily gets waterborne whereas ceramics resist travel; as such, the possibility that slags were separated from tuyère due to post-depositional activities should be pointed out. Unfortunately, most of these scatters appeared to be shallow, only warranting controlled surface-collecting and analytical work to test the above mentioned hypotheses.

Following on from the reconnaissance survey and pilot analytical results, the site of Shankare was revisited again in the dry winter season of 2010. The aim of the second 
phase was to conduct more intensive archaeological surveys to broaden the sample size and obtain datable materials. It was difficult to establish the temporal perspective of the different activity areas based on surface collections only. The second survey was also conducted to determine the position to locate exploratory excavation units to test the depth of the deposits. For logistical purposes, the intensive site survey was also necessary since the fieldwork team included new members who required orientation to the site and its material culture. The intensive survey also encompassed previously uncovered parts of the site, including the summit and the southern side and adjacent lowland. The activity areas were once again located and recorded using a handheld GPS receiver and photographs. The GPS points were crucial in the production of the site plan and spatial representation of metallurgical debris located in the northern undulating plain (Figure 6.8). Further materials were collected from the low density metal production debris scatters, mainly situated in the lowland, which were deemed too shallow to warrant proper excavations.

The observations made during the intensive survey together with the principal objectives of targeting copper production debris and obtaining datable materials eventually informed the excavation strategies that were employed. Horizontal excavations have been encouraged for archaeometallurgical projects which aim to demarcate activity areas (Killick 2009b, 401); however, they are not always feasible. For this thesis, surface observations and controlled surface collections were sufficient to understand the spatial arrangement of metallurgical activities at Shankare. As such, our excavation strategy was aimed at the establishment of the vertical perspective of the cultural deposit. Exploratory excavations were also conducted to verify 
effectiveness of surface observations and interpretations. The location of excavation units by previous scholars at the site were also considered in the selection of areas that were eventually excavated. It was noted that previous excavators had only concentrated on the features on the terraced platforms with little work on the surrounding lowland (Mason 1986; Pistorius 1989). Since the northern foot of Shankare Hill contains the majority of the metal production-related materials, the exploratory archaeological trenches were sunk in this lowland. The next section describes in brief the excavation procedures and outcome of the process as a whole. 


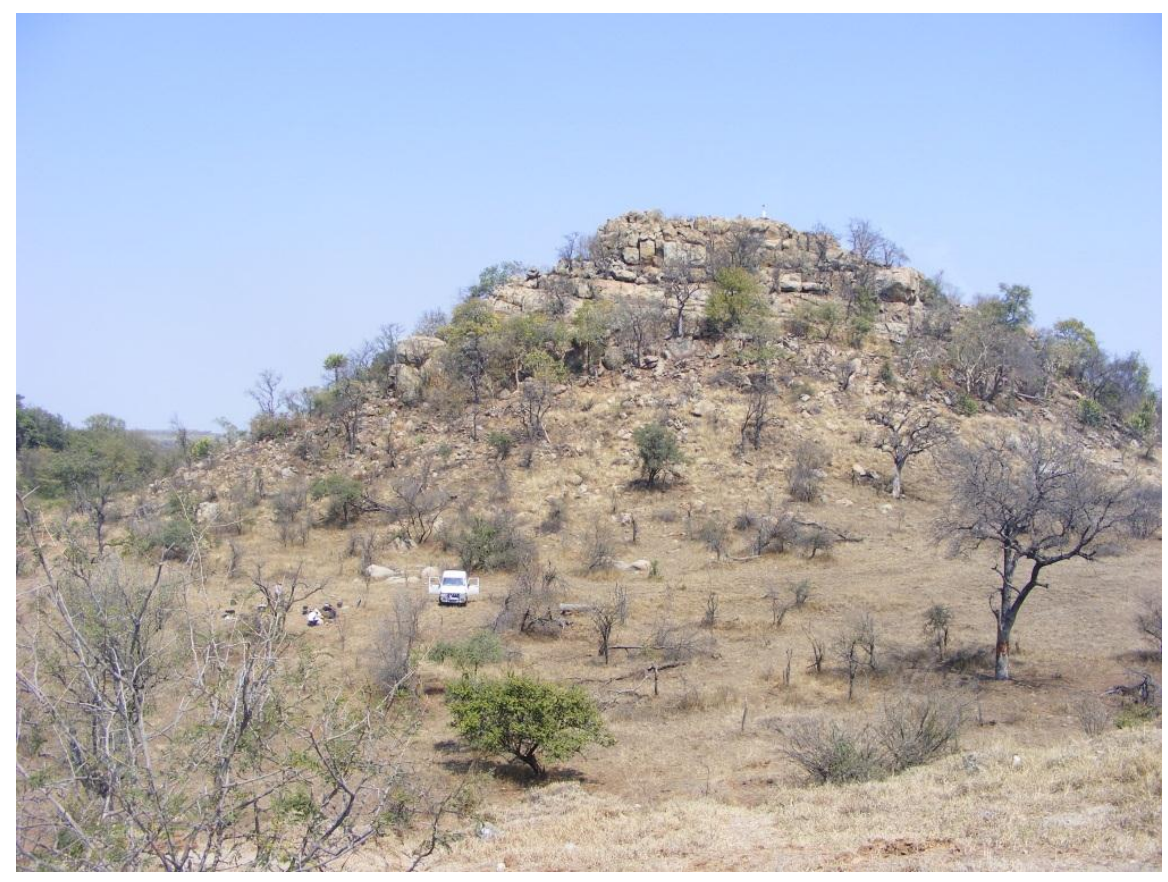

Figure 6.4: View of Shankare Hill from the vantage point of the mining tailing dump in the north, August 2010 (Image: Author).

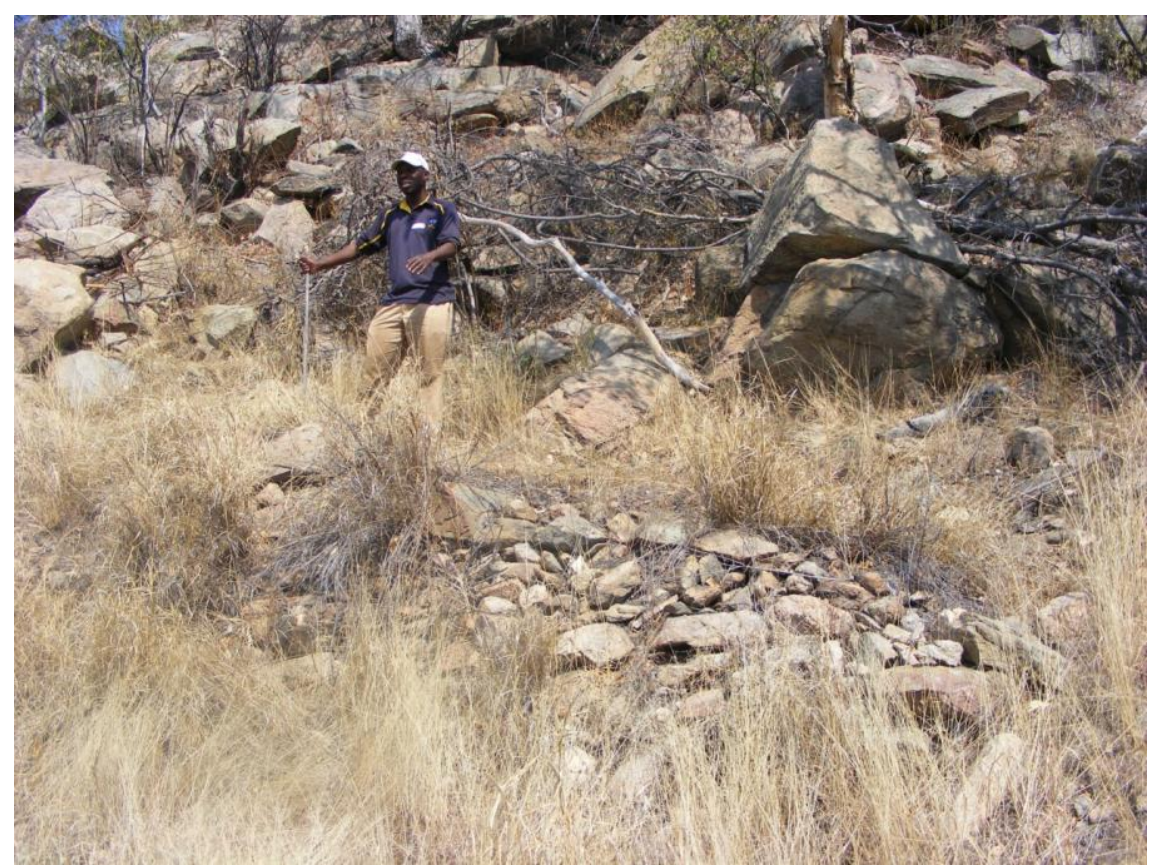

Figure 6.5: Terraced platforms on the northern hillside slopes of Shankare (Image: Author). 


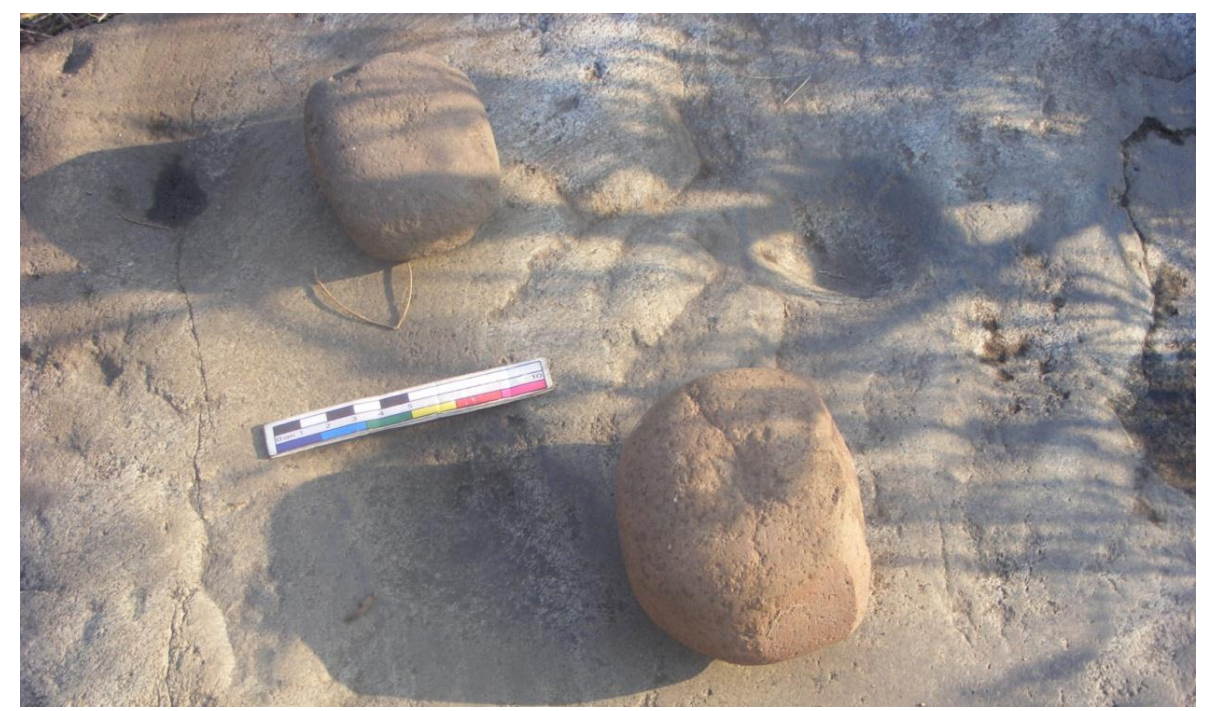

Figure 6.6: Rock boulders with dolly holes together with dimpled hammer stones (Image: Author).

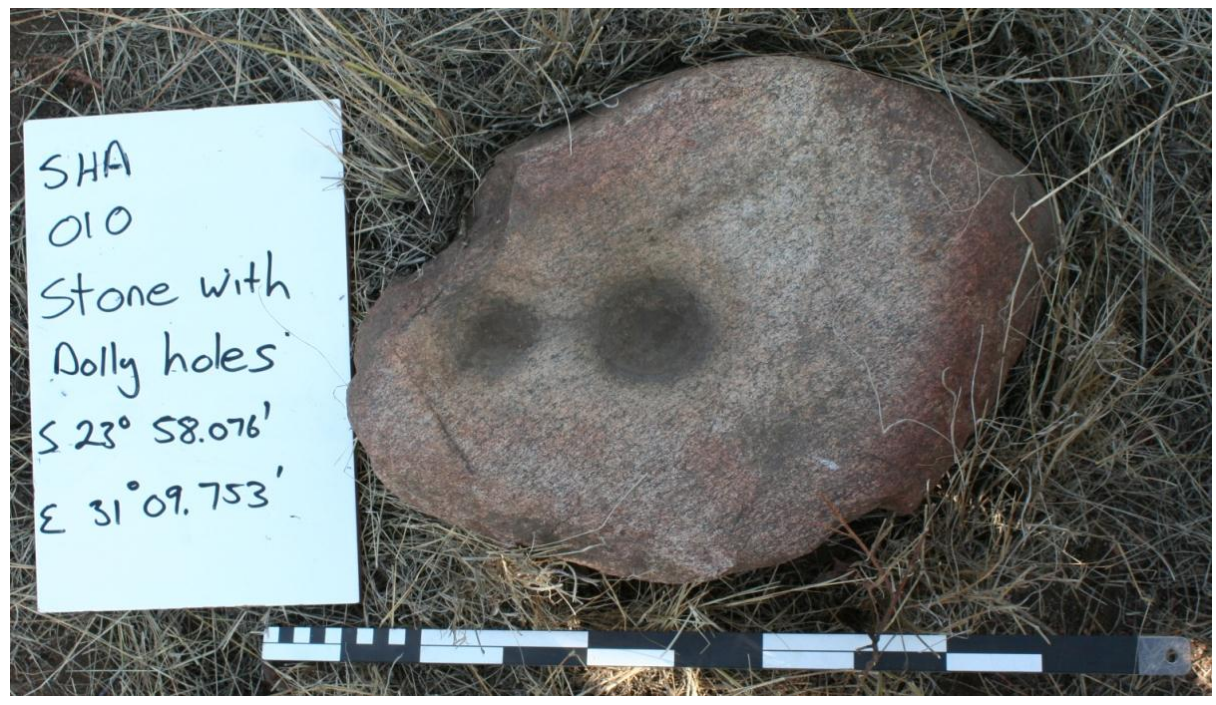

Figure 6.7: Example of rocks with dolly holes documented at Shankare during the surveys (Image: Author). 


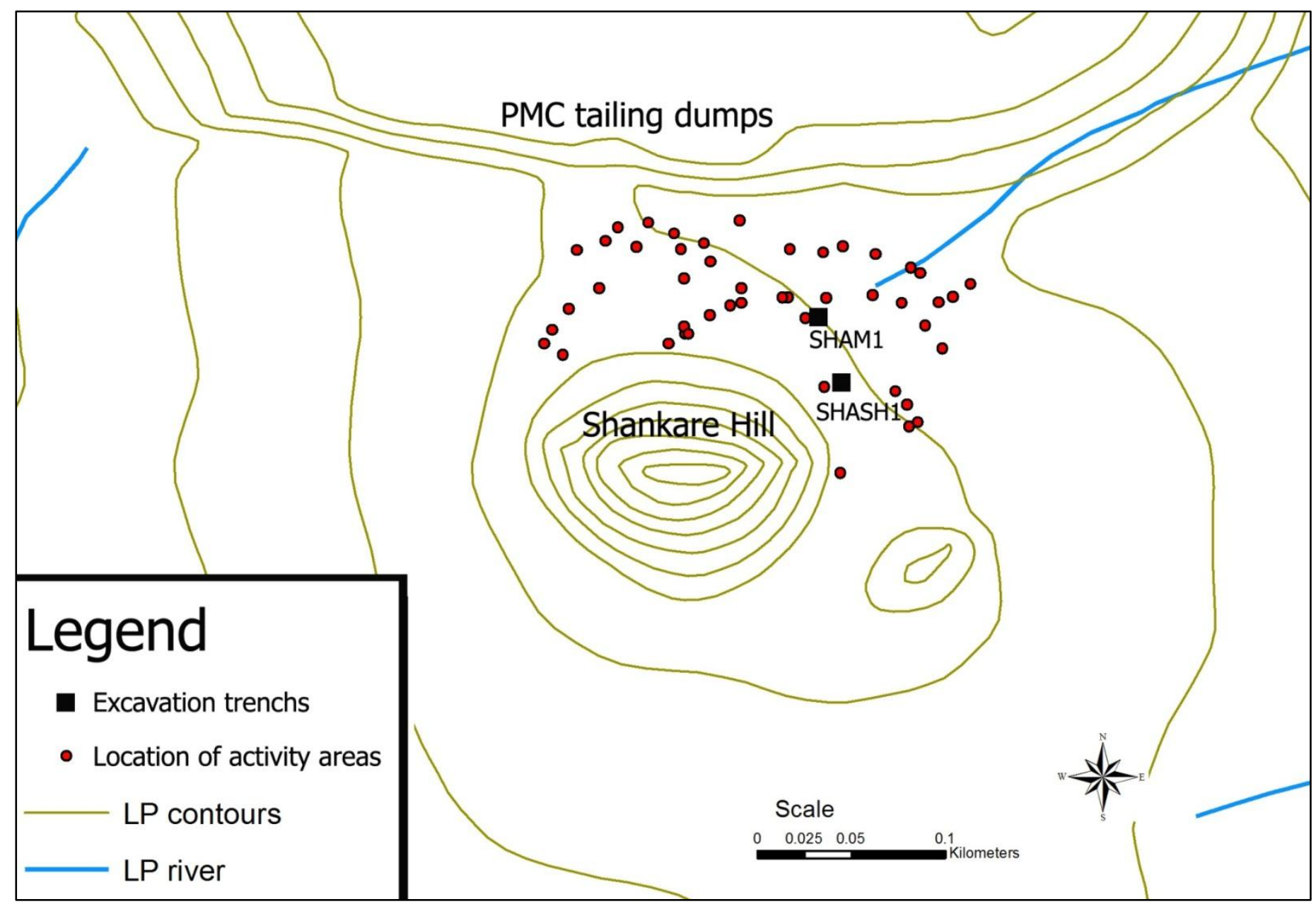

Figure 6.8: Sketch plan of the activity areas and excavation trenches (Map compiled by GEM-Science from GPS coordinates gathered during the final season fieldwork). 


\subsubsection{The excavation}

Two trenches (SHASH1 and SHAM1) were sunk on a high concentration slag scatter and a domestic midden with limited surface metallurgical debris, respectively. The trenches were subdivided into one by one metre excavation units. Each of these was assigned an individual who excavated the deposit with trowels using $10 \mathrm{~cm}$ spits levels from the surface. Progress during excavation process was monitored by trench supervisors who were also responsible for recording, sorting and labelling artefact bags. The excavations were also documented in field notes, as well as photographs and illustrations. In order to retrieve small finds, in particular metal prills and beads, the deposit from each unit was thoroughly sieved. The finds were sorted and bagged in plastic bags according to context and artefact category in the field. Charcoal samples were collected for radiocarbon dating process with trowels and stored in tin foil to avoid contamination. The finds were further cleaned at the Materials Laboratory, Department of Archaeology at UCT. Subsequently ceramic fragments were inspected for evidence of metal production residues and vitrification. A finds register of materials eventually transported to UCT was created, from which attempts were made to select enough samples for further archaeometric analysis in London (see Chapter 5). 


\subsubsection{Trench SHASH1 (Grid Ref: $\left.23^{\circ} 58,108^{\prime} S ; 31^{\circ} 09,7^{\prime} 3^{\prime} \mathrm{)}\right)$}

Trench SHASH1 was placed on top of a high concentration of metallurgical debris located near the north-eastern foothill of Shankare Hill. The assemblage at this hot spot was comprised of slag, tuyère fragments and other technical ceramics. A trench measuring 2 by $2 \mathrm{~m}$ was laid but only two units measuring 1 by $1 \mathrm{~m}$ each were excavated. The depth of the deposit at this trench was $30 \mathrm{~cm}$, below which a sterile layer of soil was reached. The deposit at this trench was comprised of dark grey soil firmly compact, resulting in difficulties during trowelling.

The stratification based on the artificial spits in excavation unit A1 revealed the following: Level $1(0-10 \mathrm{~cm})$ is mainly comprised of slag, tuyère pieces and baked clay. Some isolated artefacts in the same layer included a single hammer stone, a few pieces of metallic iron and potsherds. The level below $(10-20 \mathrm{~cm})$ contained more pottery compared to the upper spit with the volume of slag thinning out to a depth of $30 \mathrm{~cm}$. Below this depth the soil becomes light brown and granular with a notable absence of cultural material. The stratigraphy observed in excavation unit A1 is duplicated in excavation unit B2. The upper most spit $(0-10 \mathrm{~cm})$ of unit B2 has a high concentration of slag and tuyère pieces (Figure 6.9 \& Figure 6.10). Slag and tuyère pieces continue to dominate in the lower levels $(10-20 \mathrm{~cm}, 20-30 \mathrm{~cm})$ with occasional pottery, faunal material and slagged potsherds. A total of five crucible fragments were retrieved from the lower levels of excavation unit A1. Combined together, the two excavation units at this trench produced $45 \mathrm{~kg}$ of slag with a potential excavation density score of $75 \mathrm{~kg} / \mathrm{m}^{3}$. The presence of furnace slag as revealed by charcoal impressions and heavily bloated tuyère tips are strong indications that the metallurgical debris from this trench represents smelting 
activities. Unfortunately, during the two fieldwork seasons the team was unable to locate features or debris useful in the reconstruction of furnace designs. Due to the quantity of metallurgical debris from this trench it was impossible to implement a $100 \%$ collection policy. As such only a reasonable number of tuyères and slag samples were selected from the field, with the rest being backfilled after the excavation. Whilst the other rare remains, such as slagged ceramics, domestic pottery and metal artefacts were collected for further examination. This midden did not yield enough charcoal samples for radiometric dating. Luminescence dating of technical ceramics was prohibitively expensive to be carried out with the limited funds that were available for this project. 


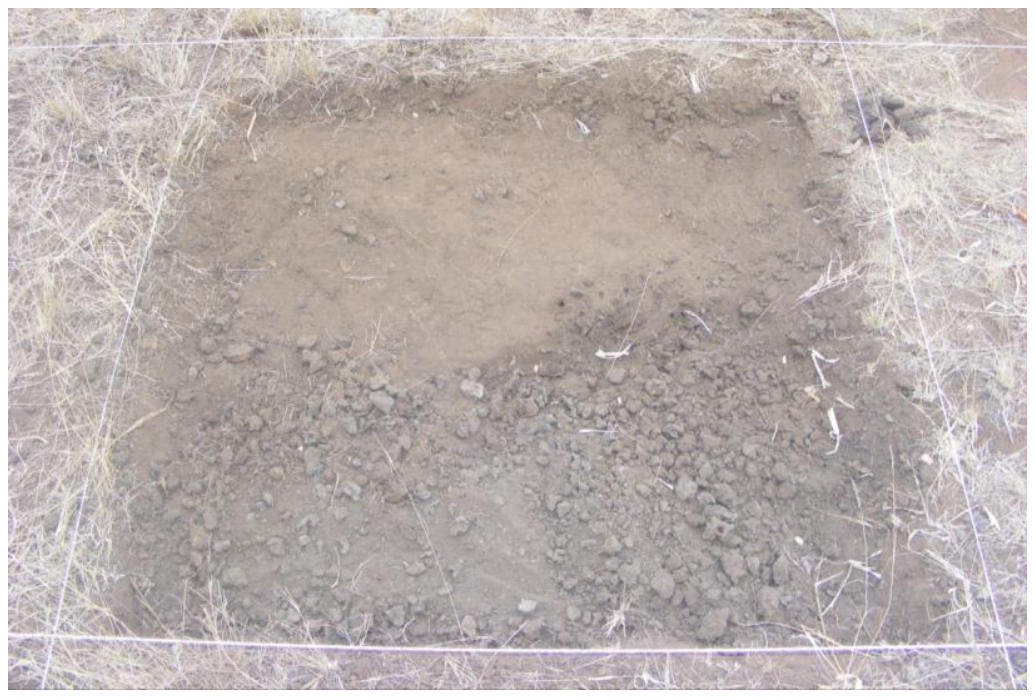

Figure 6.9: Impressive quantity of slag from the SHASH1 trench, Unit B2. Scale of excavation unit is $1 x \operatorname{lm}$ (Image: Author).

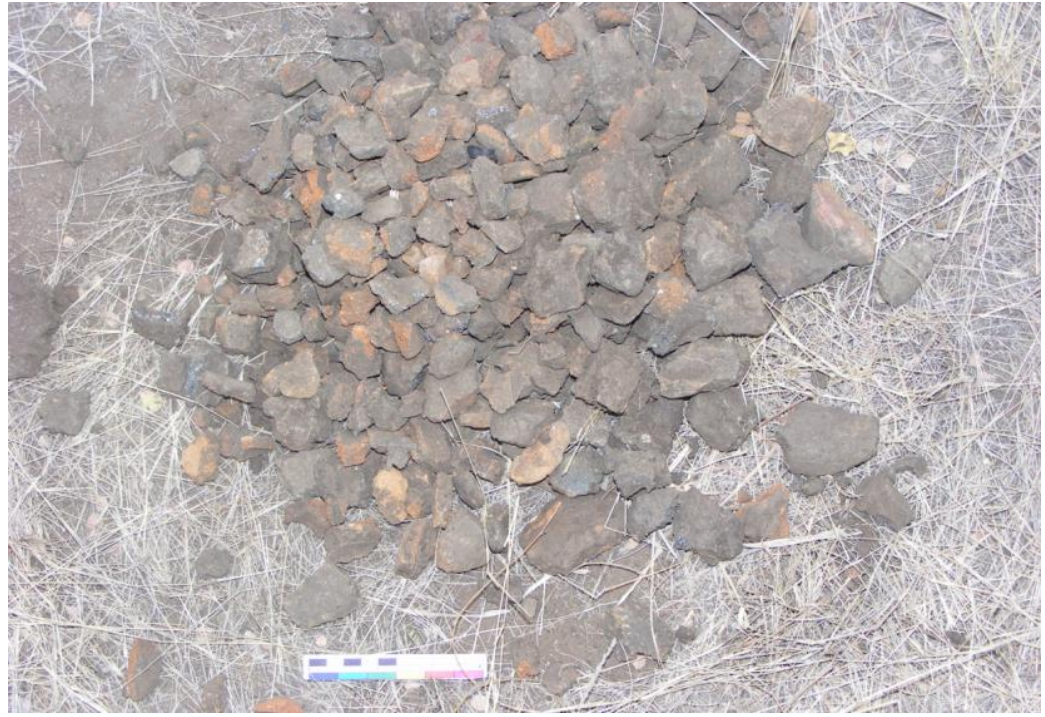

Figure 6.10: Part of the tuyère fragments recovered from SHASH1 trench (Image: Author). 


\subsubsection{Trench SHAM1 (Grid Ref: $23^{\circ} 58,084^{\prime} S ; 31^{\circ} 09$, $716^{\prime} E$ )}

Besides several scatters of metallurgical debris present in the gently undulating plain north of Shankare Hill, large middens are dotted around the koppie. Previous investigations were confined to the middens on the terraced platforms; therefore the decision was made to extend the scope with excavations in the undulating lowland (Figure 6.11). The midden was specifically targeted to provide more baseline information necessary to situate the metal production craft within the social context. The midden was also targeted because it offered insights of the general archaeology. Located approximately $50 \mathrm{~m}$ north of trench SHASH1, another exploratory trench (SHAM1) was sunk on a large domestic midden with limited metallurgical debris on its surface. The midden offered the excavation team the much needed vertical perspective of the archaeological deposits and complemented the controlled surface collection efforts on other scatters. Even though it was not targeted as a metallurgical feature, the midden offered the opportunity to recover metal production debris together with diagnostic ceramics and other datable materials. Six units (A1, B2, B3, B4, B8 and C4) were also excavated using artificial levels of $10 \mathrm{~cm}$ spits from the surface at trench SHAM1. The stratigraphy at trench SHAM1 was as follows: (1) The upper level contained dark brown-greyish fine humic topsoil. (2) The level below was characterised by grey and granular soil. (3) The layer below contained brown granular soil with isolated rocks below which a hut foundation was encountered. (4) In units B2 and A1 there was an ashy-grey anthropic soil which overlaid (5) a sterile layer with orange to red coarse soil. This sterile layer was encountered at the depth of $70 \mathrm{~cm}$ from the surface (Figure 6.12). 


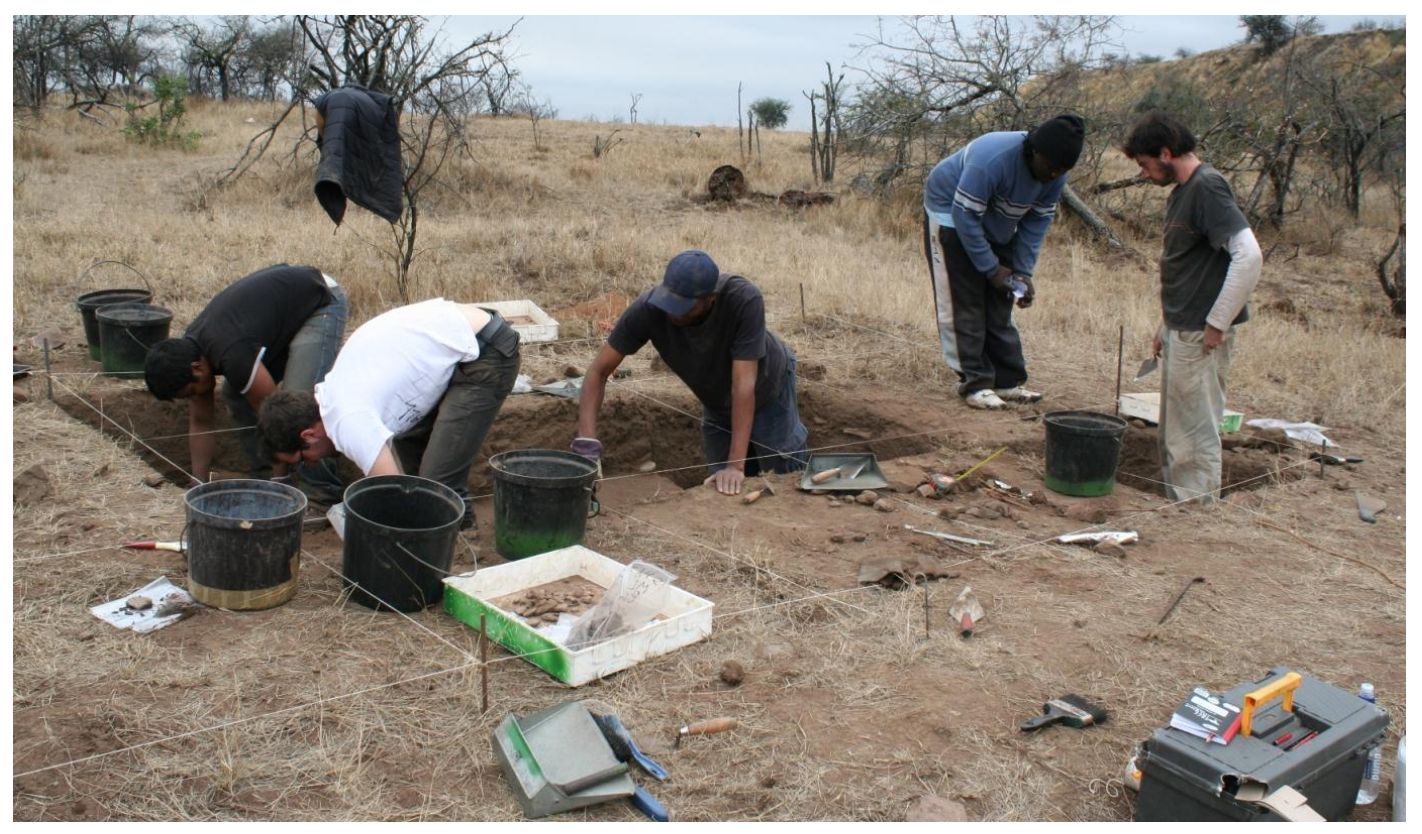

Figure 6.11: Excavation in progress at SHAM1 domestic midden (Image: Louisa Hutten). 


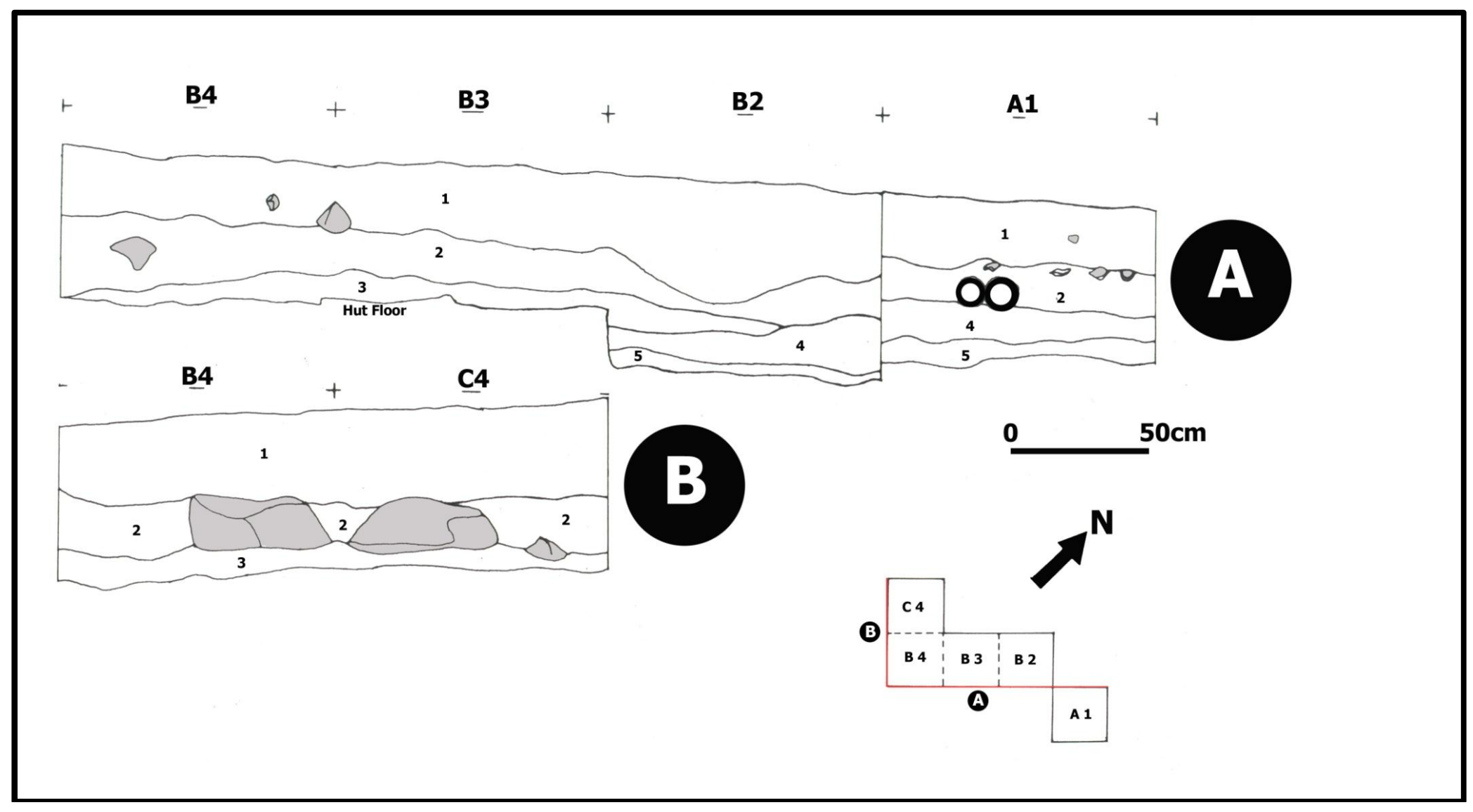

Figure 6.12: Section illustrations from trench SHAM1 showing the stratigraphic units (Image: Author). 


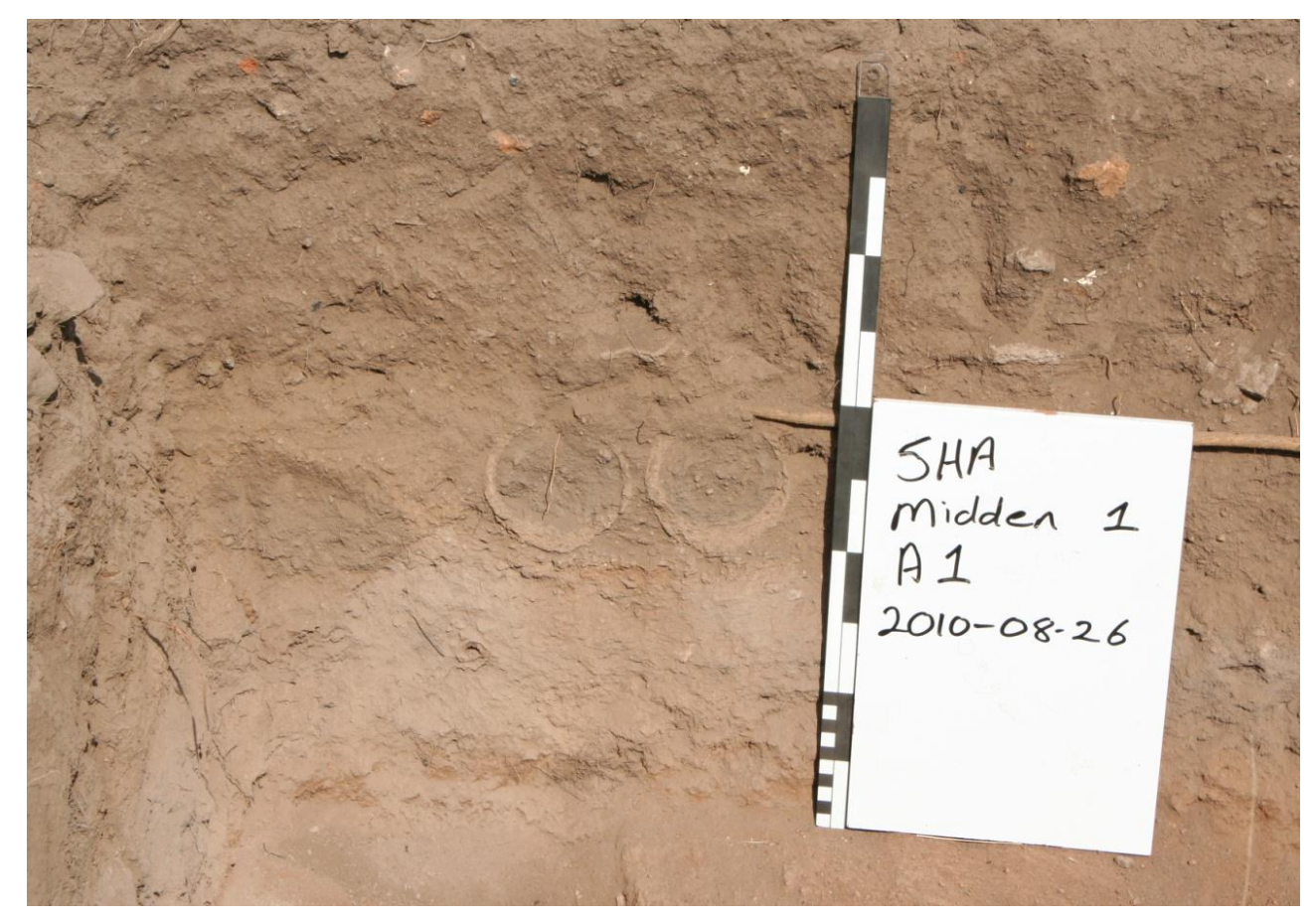

Figure 6.13: North-western section of SHAMI (Unit A1) at Shankare domestic midden with in situ tuyères (Image: Louisa Hutten).

Domestic ceramics were by far the most ubiquitous artefact category to be recovered from SHAM1 midden. The diagnostic ceramics from this midden included necked jars with herringbone, punctates and cross-hatched incision motifs (Figure 6.15). At other archaeological sites within the vicinity of Shankare Hill, these necked jars are exclusive to early Eiland and Kgopolwe pottery styles dating between the $10^{\text {th }}$ and $13^{\text {th }}$ century AD (Evers \& van der Merwe 1987; Huffman 2007; Simon Hall, pers. comm. 2010). Other domestic ceramic fragments with spherical/globular profiles can be assigned to Letaba pottery with dates ranging from $17^{\text {th }}$ and $19^{\text {th }}$ centuries (Evers \& van der Merwe 1987). During the excavations no clear stratigraphic break or changes in the ceramic designs with depth were noted at this midden. It is hoped that a quantitative typological analysis of the ceramics from the midden, which is yet to 
be carried out, will help to understand the stratigraphy better. Typological investigations of Phalaborwa ceramics have proved challenging due to the persistence of some decorative motifs over long periods (Schryver 1970; Stuiver \& van der Merwe 1968, 54). Despite previous attempts to appraise the region's ceramic sequence it remains a daunting task to use ceramics for convincing relative dating purposes (Evers \& van der Merwe 1987).

The midden yielded a wide range of organic material that could be used for radiometric dating, mostly in the form of charcoal. Three charcoal samples from different levels of the midden were submitted to Beta Analytic Inc. Two age determinations (Beta-306714 \& Beta-306715) were done by standard ${ }^{14} \mathrm{C}$ dating whilst the last date (Beta-306716) was obtained by accelerator mass spectrometry (AMS). Funding constraints determined the number of samples that were dated together with methods that were used for age determination. The challenges of using charcoal samples in radiocarbon of cultural events noted in other archaeological contexts were well appreciated. Charcoal samples can produce older dates relating to the age of trees which they were produced from, not necessarily related to cultural events that are of interest to archaeologists and archaeometallurgists (Killick 1987; Killick 2004b; Schiffer 1986). However, the dates that were obtained (Table 6.2) agree with the expected regional chronology of early settlements located on lowlands adjacent syenite hills excavated around Phalaborwa (Evers \& van der Merwe 1987). These dates are consistent with the lack of nineteenth century glass beads in the midden in contrast with those documented at other sites linked to Phalaborwa metallurgists (Figure 6.14). These early second millennium AD dates also agree well with previously obtained dates for copper smelting activities at Shankare Hill 
(Pistorius 1989). However, it has to be stated that Shankare Hill is a multicomponent site with successive human settlement which lasted until the early twentieth century. Evidence of presumed Letaba pottery at the site bears testimony of occupation in the second half of the second millennium AD (Figure 6.17).

Table 6.2: Radiocarbon dates from midden SHAM1 excavation unit B2. These dates were calibrated by Beta Analytic Inc. with IntCal04.

\begin{tabular}{|lc|l|r|r|r|}
\hline Level & & Lab. Ref & $\begin{array}{l}\mathbf{1 4}^{\mathbf{1 4}} \mathbf{C} \text { age } \\
\text { BP }\end{array}$ & $\begin{array}{r}\text { Calibrated AD } \\
\text { @ 2 6 (95.4\%) }\end{array}$ & $\begin{array}{r}\text { Calibrated AD } \\
\text { @ 1 6 (68\%) }\end{array}$ \\
\hline $\begin{array}{l}\text { L3 } \\
30 \mathrm{~cm})\end{array}$ & $(20-$ & $\begin{array}{l}\text { Beta- } \\
306714\end{array}$ & $830 \pm 30$ & 1160 to 1260 & 1200 to 1240 \\
\hline $\begin{array}{l}\text { L6 } \\
60 \mathrm{~cm})\end{array}$ & $(50-$ & $\begin{array}{l}\text { Beta- } \\
306715\end{array}$ & $840 \pm 30$ & 1160 to 1260 & 1170 to 1230 \\
\hline $\begin{array}{l}\text { L7 } \\
70 \mathrm{~cm})\end{array}$ & $(60-$ & $\begin{array}{l}\text { Beta- } \\
306716\end{array}$ & $1010 \pm 30$ & 980 to 1040 & 1010 to 1030 \\
\hline
\end{tabular}

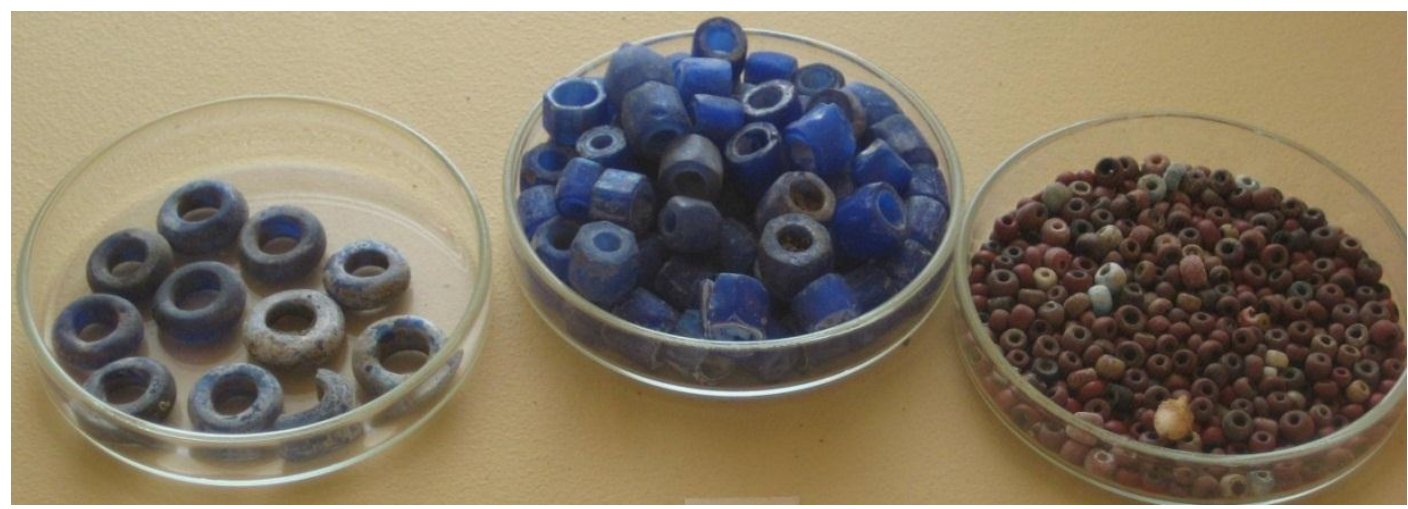

Figure 6.14: Typical glass beads from late second millennium AD contexts at Masorini in the Kruger National Park (Image: Abigail Moffett). 


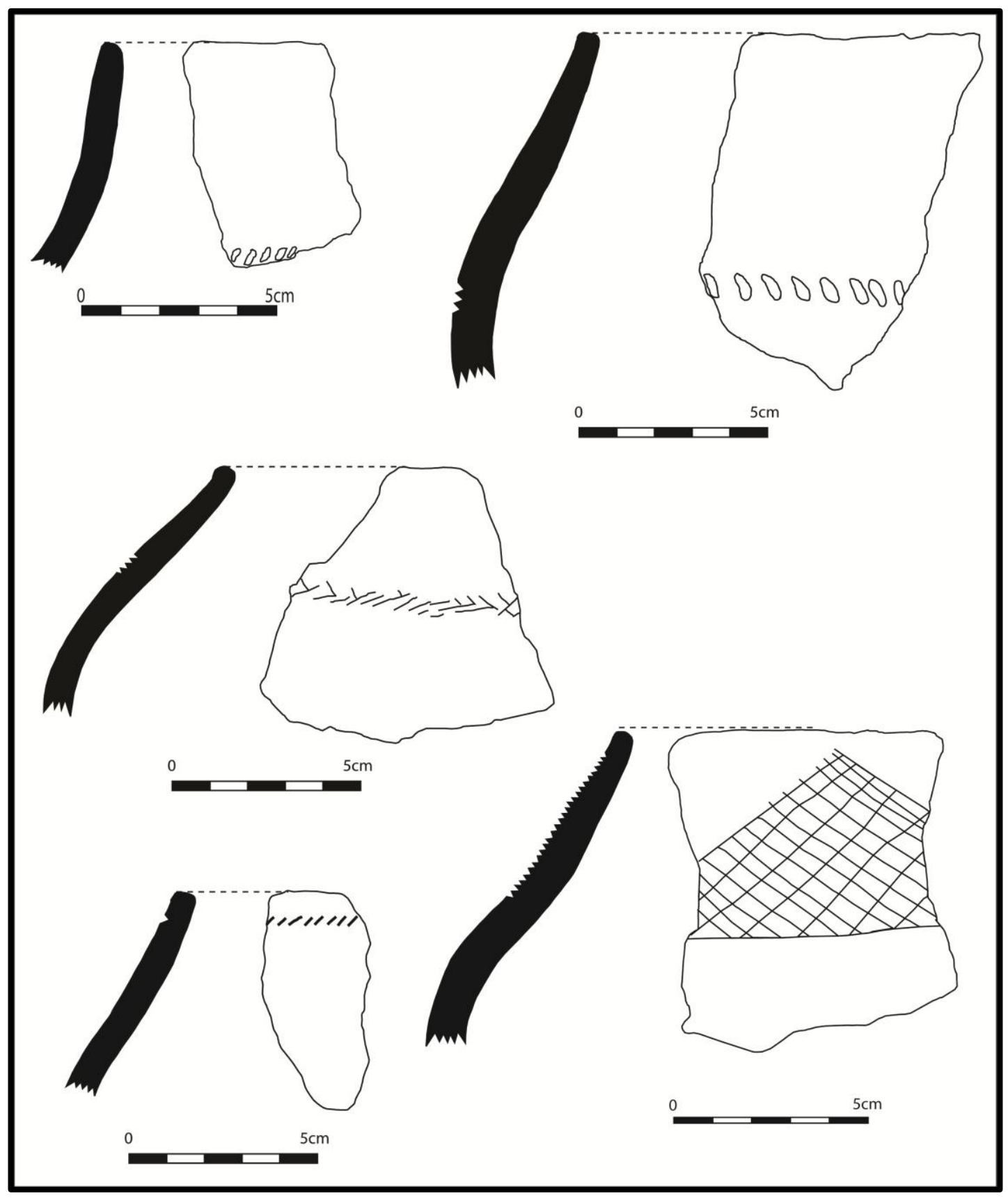

Figure 6.15: Typical Kgopolwe pottery with necked jars from midden SHAM1 presumably dating to the 10th-13th century (Drawing by Foreman Bandama). 


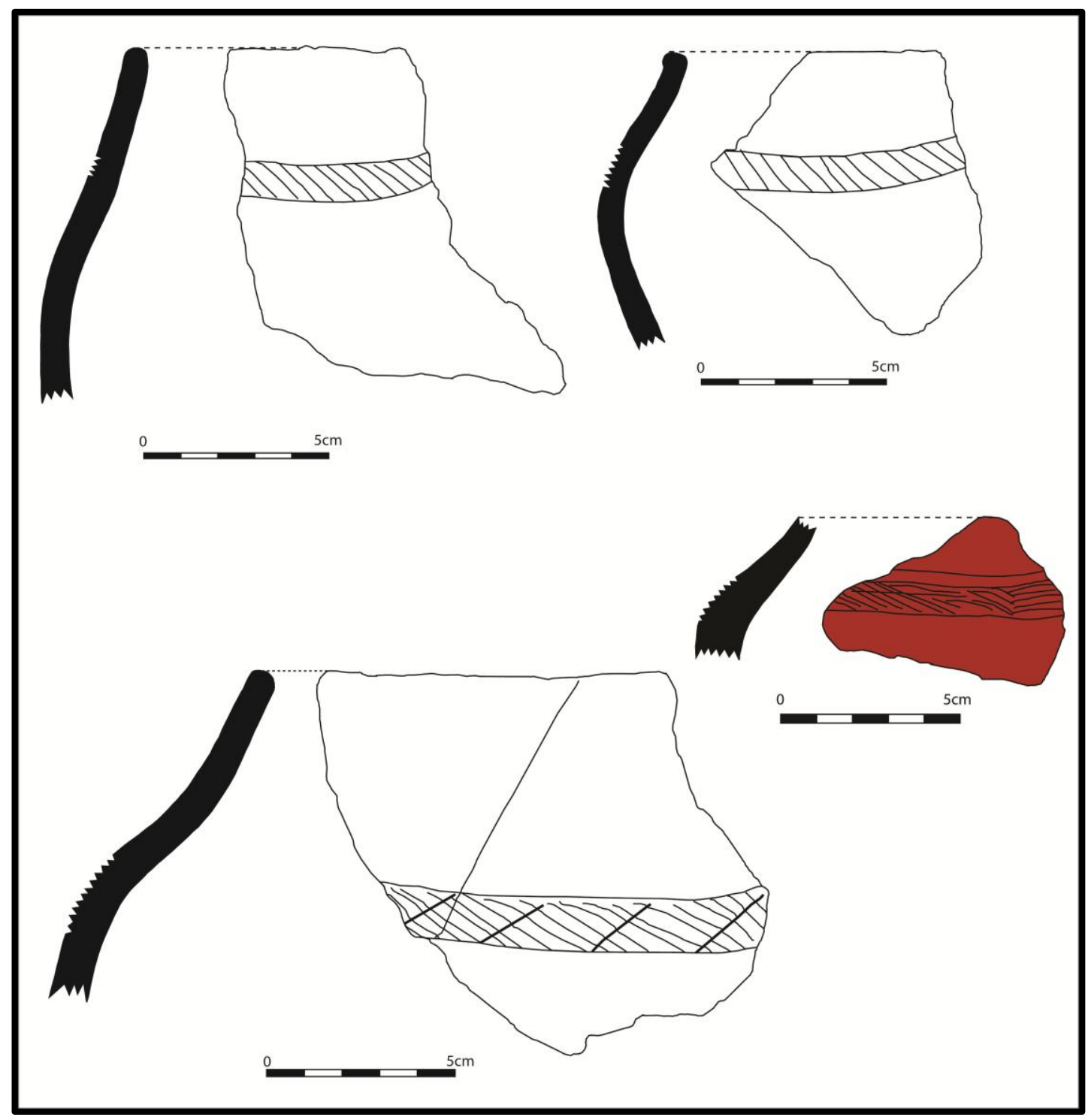

Figure 6.16: Necked jars decorated with fine line incision presumably related to the 10th-13th Kgopolwe pottery from midden SHAM1 (Drawing by Foreman Bandama). 


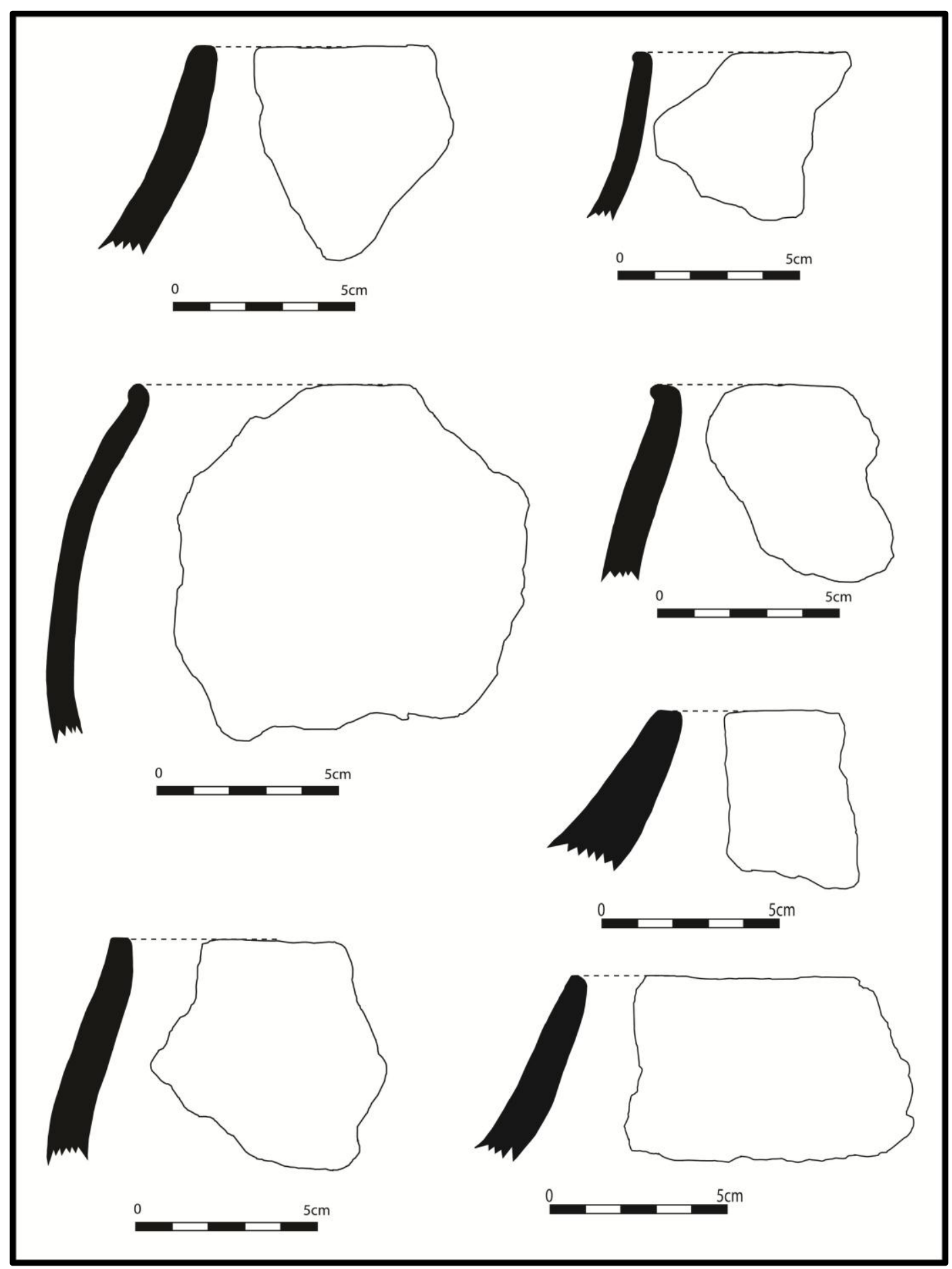

Figure 6.17: Profiles of undecorated spherical jars retrieved from midden SHAMI (Drawing by Foreman Bandama). 


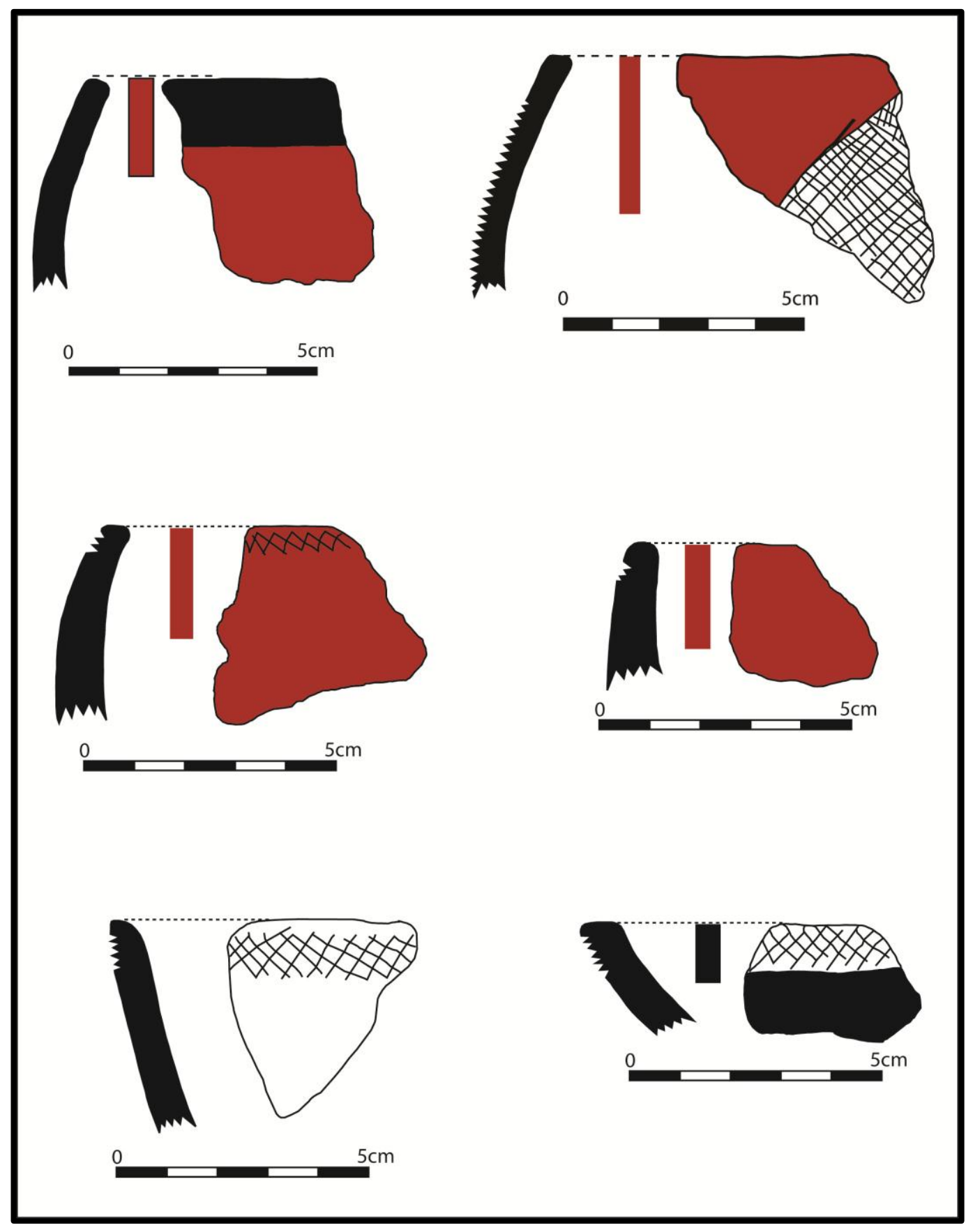

Figure 6.18: Examples of bowl fragments from SHAM1 midden decorated with red ochre and graphite burnishing a later occurrence around Phalaborwa (Drawing by Foreman Bandama). 


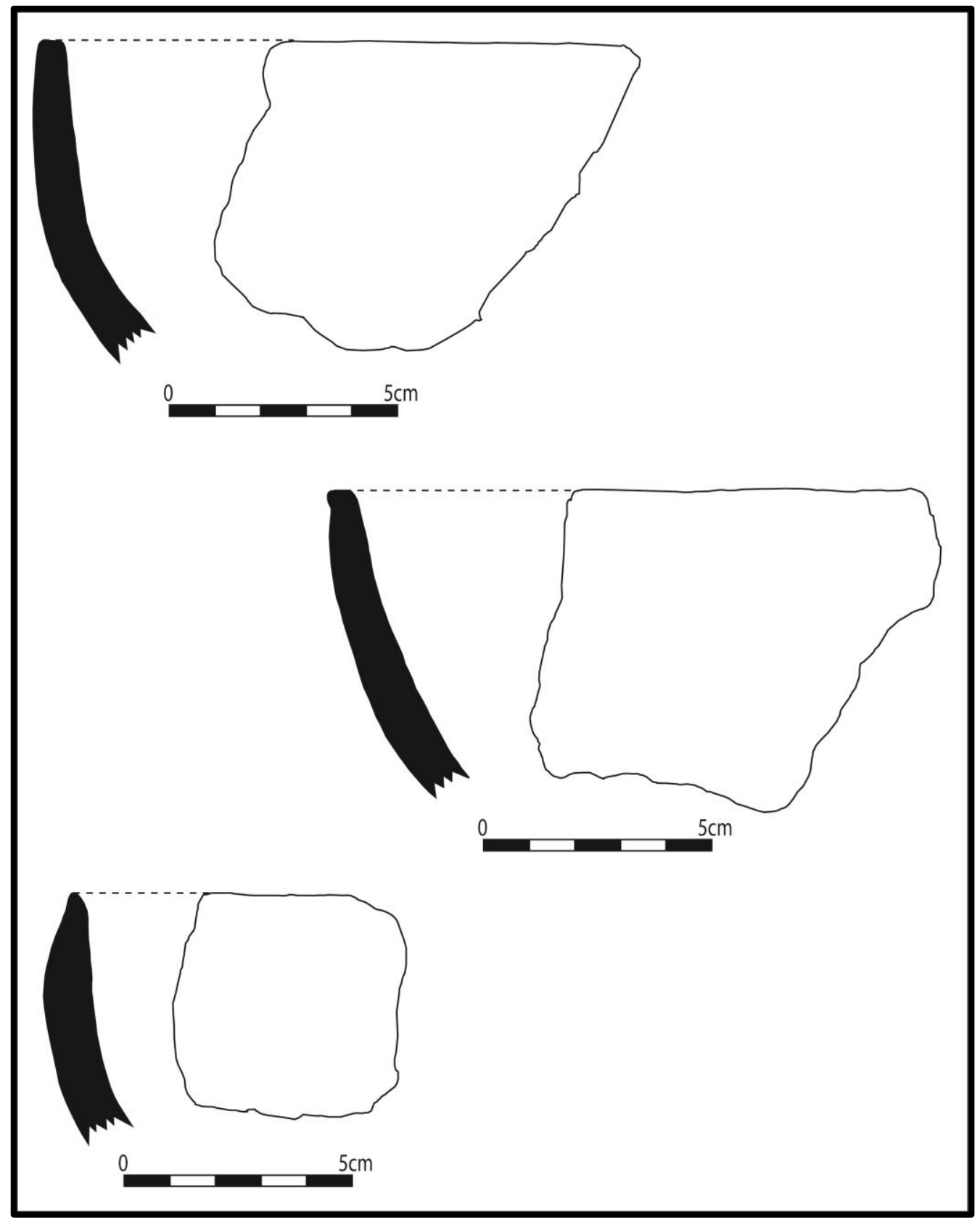

Figure 6.19: Undecorated bowl fragments from the SHAMI midden excavation (Drawing by Foreman Bandama). 
Apart from the domestic ceramics, the SHAM1 trench assemblage has large quantities of faunal remains. The midden excavations also yielded invaluable evidence of metal production albeit in smaller quantities compared to the SHASH1 trench. The evidence of metal production activities is found throughout the stratigraphy from the lowest levels to the surface, these included slag fragments, crucible fragments, tuyère fragments, copper prills and unfinished copper objects. Ninety-four presumed ore samples, which included magnetite and green copper minerals, were part of the assemblage recovered from this midden, together with ten copper artefacts in the form of bangle fragments, wires, prills and sheets. Thirty-three slagged and vitrified ceramic fragments (crucibles) were recovered from the midden across the stratigraphic units. The total weight of the slag from the five excavation units at SHAM1 was only $2.44 \mathrm{~kg}$ resulting in an excavation density score of approximately $1 \mathrm{~kg} / \mathrm{m}^{3}$. Ornaments from the midden included 108 beads manufactured from shell, presumably of local origin. Imports represented in the same midden included four tiny glass beads and two conus shell presumably obtained from the Indian Ocean merchants. The ceramics assemblage also included a few clay spindle whorls presumably used for spinning textiles. Noteworthy is the presence of cotton producing shrubs, possibly connected to previous spinning processes, which still grow on the terraced platforms of Shankare Hill.

An unmarked human burial (Grid ref: $23^{\circ} 58,090^{\prime} \mathrm{S} ; 31^{\circ} 09,7^{\prime} \mathrm{E}$ ) was encountered during the excavation unit B8 at trench SHAM1. Located at a depth of $12 \mathrm{~cm}$ from the current surface, the excavation team unexpectedly exposed a skull, tibia and fibula of a buried individual. This particular individual was laid to rest on its back with the head facing to the southeast (Figure 6.20). Unfortunately it was not possible 
to determine the age or gender of this individual. No obvious grave goods were apparent on the partially exposed parts of the burial, although some shell beads and pottery remains were found in the excavation unit. The excavation permit obtained from SAHRA did not cover the removal of human remains; therefore the excavation in this unit was prematurely terminated following proper documentation and it was backfilled with earth material and large stones were used to mark the location of the burial.

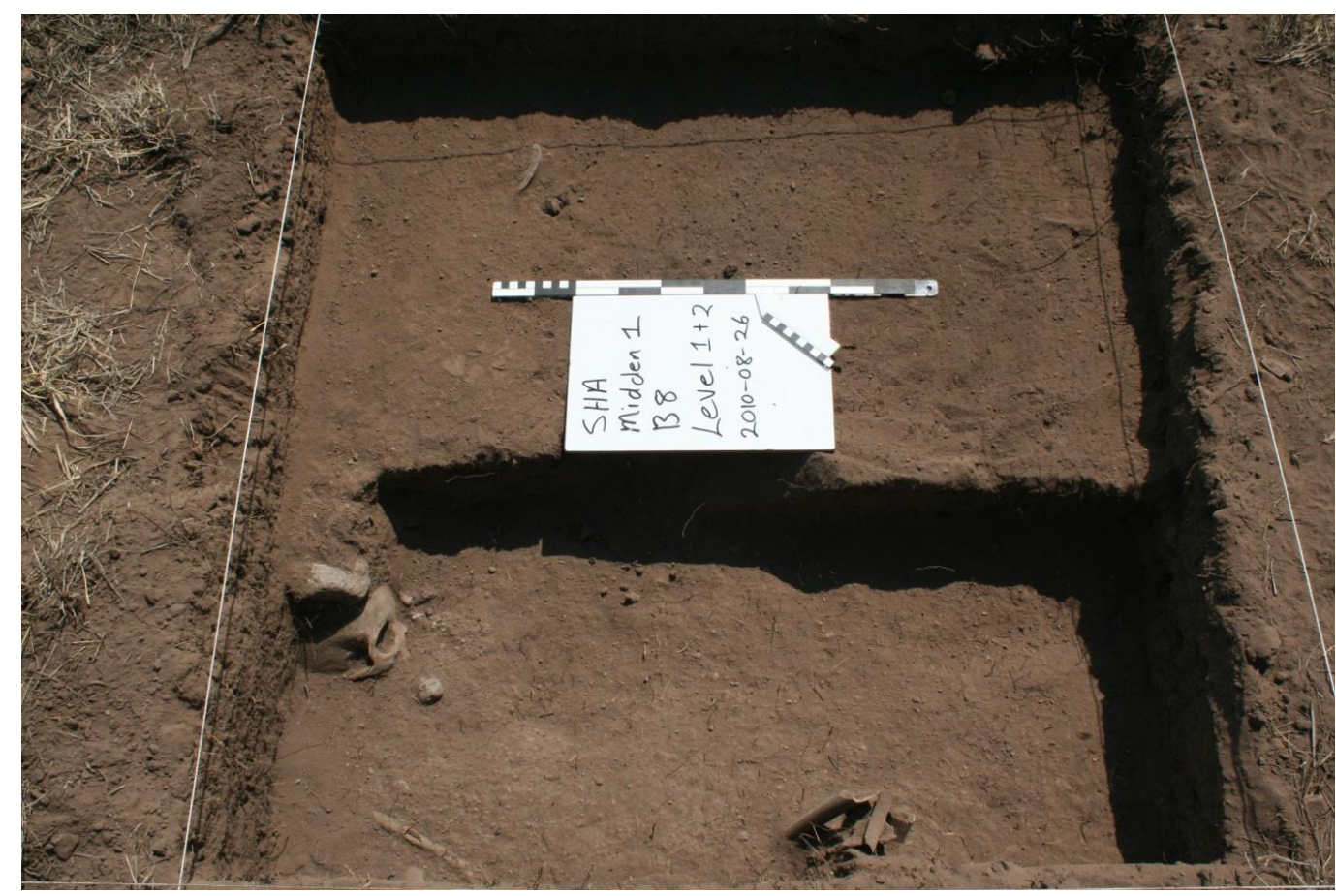

Figure 6.20: Human burial accidentally exposed during the excavation of Unit B8 Trench SHAMI (Image: Louisa Hutten). 


\subsubsection{Overview of the archaeology of Shankare Hill}

Previous studies combining archaeological and ethnohistorical approaches have highlighted the complex settlement history spanning at least a millennium at Shankare Hill (Mason 1986; Pistorius 1989). However, the absence of unequivocal evidence of house remains has forced scholars to rely on the impressive number of domestic middens to substantiate their claims that this site was indeed occupied on a permanent basis. 'Work camps' with evidence of metal production residues only have been reported around Phalaborwa but Shankare does not fit within that group (Plug \& Pistorius 1999). In the absence of horizontal excavations to identify more residential remains and information about their dimensions, it is not possible at this stage to estimate population size and dynamics at Shankare Hill. Only a small part of a house foundation was documented at the bottom of trench SHAM1 during the 2010 fieldwork campaign. Revisiting the site during the current project highlighted the mundane activities that took place at the site over this supposedly long period of occupation. The archaeological assemblage confirms that the major economic preoccupations of the residents of the site included metal and probably pottery production. However, in the absence of proper faunal analysis it is impossible to establish the contribution of hunting and pastoralism from the bones that were recovered during the course of the current project. For this we have to rely on previous findings which concluded that animal husbandry was only a minor activity at Shankare (Plug \& Pistorius 1999). Other activities at the site included cloth production, as represented by few spindle whorls, and possibly shell bead production although no shell waste or unfinished beads were found. 
Based on this evidence we can surmise that Shankare Hill functioned as a residence for a community whose economy was tied to metal production but also engaging presumably in hunting or animal husbandry. Metal production and working activities at Shankare are represented by both modest and substantial scatters of presumed ores, slag, tuyères, technical ceramics, dimpled hammer stones and boulders with dolly holes. Few metal artefacts were actually recovered from Shankare, testifying the fact that this was a metal production site and consumption of the products is likely to have taken place elsewhere. Unfortunately, the efforts to locate furnaces document during Mason's initial investigations were not successful. It is rather difficult to explain the absence of the furnaces remains, which seem to have been missed also by Julius Pistorius during the 1980s fieldwork. None of the possible furnace wall lumps that we excavated was large enough to reconstruct curvature, furnace height or number of tuyère ports. The findings of Pistorius, based on ethnohistorical and limited analytical results, seemed to contradict the findings by Mason who concluded that iron was the only metal produced at Shankare. Conclusions based on field observations alone for complex ore deposits like the ones found around Phalaborwa should be treated with caution if they are not substantiated with mineralogical and chemical data. The metallurgical debris at Shankare testifies to the practice of metal production but given the contradicting conclusions by previous investigators further comprehensive technological investigations were required.

The period of occupation of Shankare Hill has always been important in the conventional archaeological reconstructions in Southern Africa because it coincides with the region's intensified interaction with the Islamic world and Europeans (Killick 2009a). This interaction brought with it many imports to Southern Africa, of 
which only sea shells, ceramics and glass beads have been encountered in the archaeological record. During the 1960s excavations in the terraced platforms at Shankare Hill seventy-nine glass beads were recovered from the domestic middens (Mason 1986, 116). Noteworthy is the scarcity of glass beads during the 2010 excavations; the whole excavation season resulted in only four beads. This discrepancy can have several explanations: Firstly, this observed variation can signal a temporal variability between middens in the terraced steep slopes and the ones located in the adjacent lowland of Shankare Hill. Shifts in Iron Age village location of this nature have indeed been documented at several syenite hills across Phalaborwa (see Evers \& van der Merwe 1987). The midden excavated in 2010, with its early radiocarbon dates belongs to an earlier occupation phase at Shankare a period when access to exotic materials was also restricted, thus small volumes of exotic materials. Alternatively if the settlements on the terraces are contemporary to the ones in the lowland, this will be highlighting different social classes with varying access to imported items. It is unlikely that this discrepancy resulted from differences in the methods of recovery during the excavation process because the blue beads that were available later were relatively large in size; as such, they could not be missed during excavations. The period that Shankare was occupied is also associated with the initial development of highly complex socio-political systems known as states and urbanisation in Southern Africa (Huffman 2007). However, archaeologists working in Phalaborwa have not yet identified evidence suggesting that these second millennium societies attained the statehood level of socio-political organization. This issue has implications on the role of craft production, metallurgy and trade on the development of complex socio-political systems, revisited later in this thesis. 
Having highlighted the intra-site variation in imports at Shankare it is important to highlight some crucial inter-site variations. Comparatively, the number of imports recovered since the 1960s at Shankare Hill remains significantly low when other contemporary archaeological sites are put into perspective. Sites like Mapungubwe and $\mathrm{K} 2$, situated further into the interior from the Indian Ocean coast than Phalaborwa, have yielded a variety and large quantities of Oriental imports. Glass beads and imported ceramics have been recovered in their thousands at these sites (Huffman 2005). At Shankare Hill, not a single sherd of imported ceramics was recovered whilst glass beads are present in very small quantities. Four beads and two conus shells from the SHAM1 midden excavations are the only positively identified exotic artefacts that were recovered at the site. The excavations at Shankare remain limited in terms of area covered; however, with the available evidence it can be suggested that the residents at this site did not partake in direct maritime commerce. Metallurgy was one of the important economic activities represented at Shankare Hill. Having attempted to put the archaeology of Shankare into perspective, the remaining sections of this chapter are devoted to the archaeometric results of samples of ore, metals, technical ceramics and slags together with a discussion of the analytical results. 


\subsection{Analytical results}

This section of the chapter presents the results based on the laboratory work carried out with optical microscopy, phase and bulk composition analytical approaches. The surveys and excavations at Shankare provided the much needed baseline information to place the technological reconstruction of metal production in the socio-economic context. Such information can hardly be provided by archaeometric approaches no matter their level of sophistication. The field methods allow the reconstruction of important socio-economic aspects likely to impact on craft production. However, fieldwork strategies and observation alone are not enough to address the wide range of questions posed at the beginning of this thesis. Limitations of fieldwork data were much apparent when some activity areas or metallurgical debris proved difficult to assign to particular stages of the metallurgical chaîne opératoire. Previous conflicting conclusions presented by Mason and Pistorius concerning the type of metal smelted at Shankare could not be resolved using field-based strategies alone. The questions posed in this thesis required the use of archaeometric-based studies; therefore, using the chaîne opératoire approach, the relation between the potential ores, slags, technical ceramics and metal artefacts recovered from Shankare is explored in this section. 


\subsection{1 'Ores'}

Two fieldwork seasons at Shankare yielded a total number of 125 potential copper and iron ore samples. However, during the surveys at the site and its immediate environs no geological deposits or outcrops of copper or iron mineralisations were documented. This observation is also supported by the geological literature, which is silent about the occurrence of copper or iron deposits within the immediate vicinity of the site. The presumed ore samples must have been brought to Shankare from the ore deposits identified by the early geologists and mining engineers in the research area, discussed in depth in the geology section of this thesis (see Chapter 3). Obvious ore spoil heaps or scatters were absent at Shankare, with the majority of the presumed ores occurring on the surface and in excavated units together with other metallurgical debris. The hand-specimens of the potential ore samples fall into three major groups based on their external appearance. The first group is composed of non-magnetic small chips of soft, light green and blue copper carbonates (Figure 6.21). The second group is macroscopically represented by highly magnetic, irregular chunks of hard and black magnetite occasionally tarnished rusty red on the surface. These magnetite lumps are notably dense without any macroscopic porosity. The third group is represented by complex magnetite hand-specimens that are visibly stained by thick specks and veinlets of green copper compounds (Figure 6.22). This highlights the unique geological co-existence of copper and iron deposits noted in both geological and archaeological literature on the Phalaborwa region (Miller \& Killick 2004, 29). In terms of proportions, in weight, the Shankare mineral assemblage is composed of copper minerals accounting for $47.2 \%$, magnetite contributed $42.4 \%$ and complex magnetite-copper ores accounted for $10.4 \%$. 


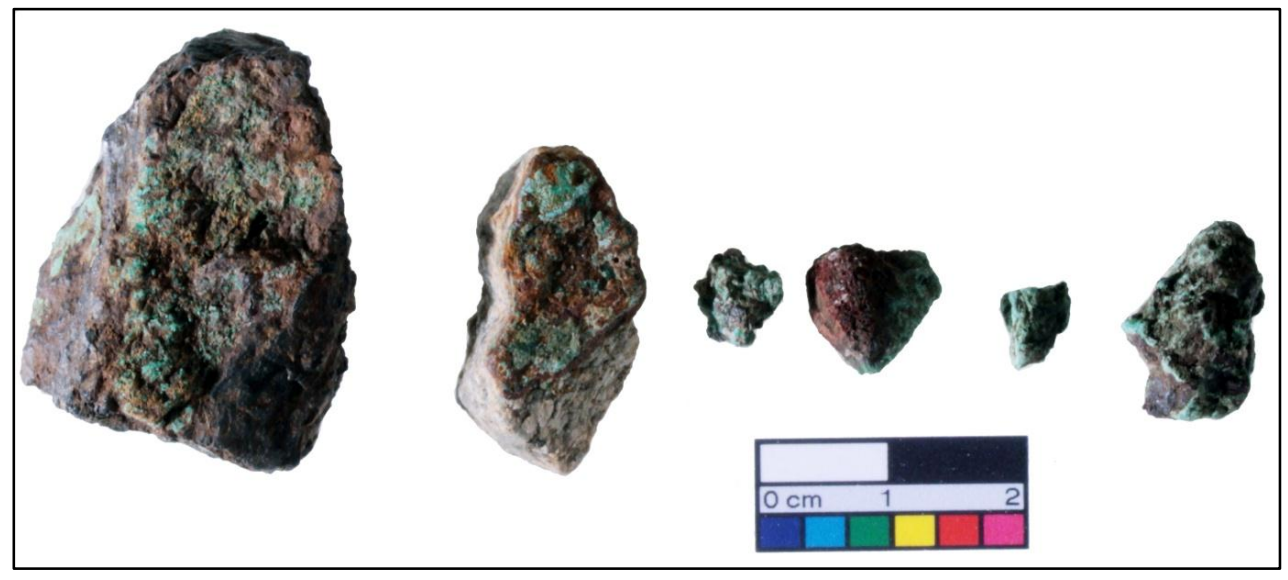

Figure 6.21: Copper carbonate mineral samples from Shankare (Group 1).

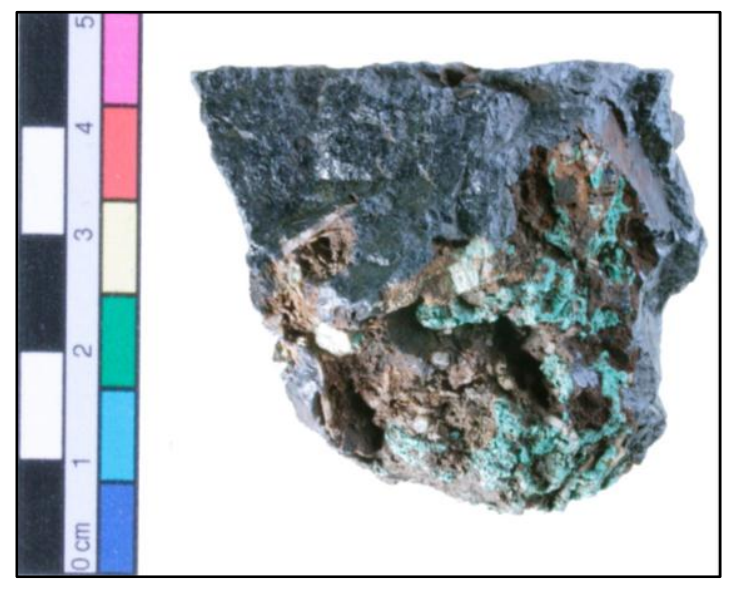

Figure 6.22: Magnetite fragment with adhering malachite on the surface (Group 3).

The presence of magnetite at Shankare is not conclusive evidence that iron was smelted and the same is also true for copper ores; either of them could represent gangue discarded, given their close geological association. In other words, copper minerals recovered at the site can equally represent beneficiated gangue of magnetite ores that were used for iron smelting. On the other hand magnetite could equally represent discarded gangue material resulting from the beneficiation of copper ores. The picture is also made complex by the role of iron oxide as a potential flux agent in extractive copper metallurgy; but the same cannot be said for copper oxides, whose 
negative impact in iron smelting is known. In the worst case scenario, the presumed ore samples recovered from Shankare are possibly not related to any metallurgical activities. The aesthetic nature of raw minerals has promoted their exploitation for non-metallurgical purposes as cosmetic powders and in the manufacturing of mineral jewellery (e.g. Miller 2001, 87; Radivojevic et al. 2010). Cline (1937, 62) actually came across information concerning the use of malachite as body paint during initiation and circumcision ceremonies by the Bomvana of Katanga in Central Africa. Caution is therefore required in the interpretation of minerals from archaeological context, since may not be related to metallurgical processes. Non-metallurgical functions of both copper and iron minerals during the Iron Age around Phalaborwa are yet to be established. Some of the pottery from Shankare is red ochre burnished, but haematite deposits are not known in the area but it is possible that haematite was produced by calcining magnetite in oxidising environment. It is thus not easy to link archaeological mineral samples to metallurgical process based only on field observations alone. Given these potentially complex scenarios, it was necessary to conduct further analytical work on these potential ores samples to ascertain whether their mineralogy was consistent with the chemistry of smelting slags recovered at Shankare.

The suite of potential ores was subjected to further archaeometric analysis to address several questions. Firstly, these minerals were analysed to establish if there was a link between these mineral samples and slags as well as the final metal products. The ore signature is usually expected to be reflected in the slag and metal chemistry. Mineralogical examination of potential ores together with the slags is crucial in the reconstruction of smelting technologies that were employed. The archaeometric 
approaches were used to determine if these potential ores required additional flux agents or not. Secondly, it was also important to establish the mineralogy of these presumed ores since the geological literature suggests that copper mineralisation at Lolwe are predominantly chalcopyrite (see Chapter 3). This is contrary to the received archaeological wisdom that only oxidic ores were exploited for metallurgical purposes during the Iron Age period in Africa. It was necessary to establish if the copper ores were primary sulphidic or secondary ores. Thirdly, presumed ores were analysed to establish if their copper content made them viable copper ores. Fourth, it was necessary to establish the level of tin, arsenic and zinc in these potential ore samples. Some copper alloy artefacts were previously documented around the research area as a result it was important to establish if they were actually produced in Phalaborwa. Fifth, although proper sourcing investigations of these potential ore samples require other analytical methods, an attempt was made to link these potential ores to the known ore sources based on the peculiar nature of some ore deposits reported in the geological literature. This project is primarily concerned with the processes involved in the winning of copper metal from ores rather than identifying ore sources, none the less this issue was considered important. Prior to the current project no comprehensive mineralogical investigations of copper ores from archaeological contexts was carried out around Phalaborwa (see Chapter 4).

Fourteen minerals with visible external signs of copper staining and mineralisations were targeted for detailed mineralogical, phase and bulk compositional analysis. The complete analytical results of individual samples are provided in Appendix 3, whilst their major characteristics are given here. Like the hand specimens, the polished blocks of these presumed ore samples do not show apparent signs of exposure to 
pyrotechnology processes, since they retained their geological structure. Microscopically, these copper minerals have outer layers of green malachite, usually surrounding a red inner matrix of iron-copper minerals in their oxide, carbonate and hydroxide forms. The microstructure of these potential ores is thus dominated by secondary oxidized minerals. However, residual sulphide inclusions with peculiar brassy to golden yellow colours identified as chalcopyrite $\left(\mathrm{CuFeS}_{2}\right)$, bluish chalcocite $\left(\mathrm{Cu}_{2} \mathrm{~S}\right)$ and barite $\left(\mathrm{BaSO}_{4}\right)$ are often enclosed in the weathered copper-iron hydroxide and carbonate matrices (Figure 6.23; Figure 6.24; Figure 6.26), although only in small amounts only visible under the microscope. The polished samples of some presumed ores (SHA11NEL, SHA13NEL, SHA15NEL) also contain isolated rare earth oxides and phosphates inclusions $\left(\mathrm{La}_{2} \mathrm{O}_{3}, \mathrm{Ce}_{2} \mathrm{O}_{3}, \mathrm{Pr}_{2} \mathrm{O}_{3}\right.$ and $\left.\mathrm{Nd}_{2} \mathrm{O}_{3}\right)$ that appear very bright under the SEM-BSE detector (Appendix 3). These copper minerals are also associated with magnetite $\left(\mathrm{Fe}_{3} \mathrm{O}_{4}\right)$, fluorapatite $\left(\mathrm{Ca}\left(\mathrm{PO}_{4}\right)_{3} \mathrm{~F}\right)$, calcium carbonate $\left(\mathrm{CaCO}_{3}\right)$ and occasionally siliceous $\left(\mathrm{SiO}_{2}\right)$ minerals.

Bulk chemical characterisation of the polished blocks was conducted with SEM-EDS due to the small size nature of mineral samples, which meant they could not be prepared as pressed pellets. The shortfalls of using SEM-EDS to conduct bulk chemical composition studies for these heterogeneous samples was fully appreciated in the course of the analytical programme and enough measures were put in place to produce credible results (see Chapter 5). Bulk chemical characterisation was obtained systematically using multiple area scans with SEM-EDS. The average composition of at least five area scans of each mineral sample is hereby presented as the 'bulk' composition (Table 6.3). It is important to note that the results in this case are not normalised to $100 \%$ to highlight the presence of carbonates, oxides and 
hydroxides (structural water) in the samples. The copper oxide content in the presumed ores samples ranged from 8 to $60 \mathrm{wt} \%$. FeO was another important oxide in the presumed ores ranging from as little as 0.3 to $63 \mathrm{wt} \%$. The composition of the presumed ores varied but it is important to highlight at this point that silica $\left(\mathrm{SiO}_{2}\right)$, a major slag former during smelting processes, is not well represented in most of these minerals. Only two samples SHA2NWL and SMB26(2) contain remarkable high levels of silica as gangue and potential flux. Whilst the majority of the copper minerals subjected to composition analyses are significantly undersaturated (silica free). Noteworthy also is the low levels of $\mathrm{TiO}_{2}$ in the suite of presumed copper minerals from Shankare. 

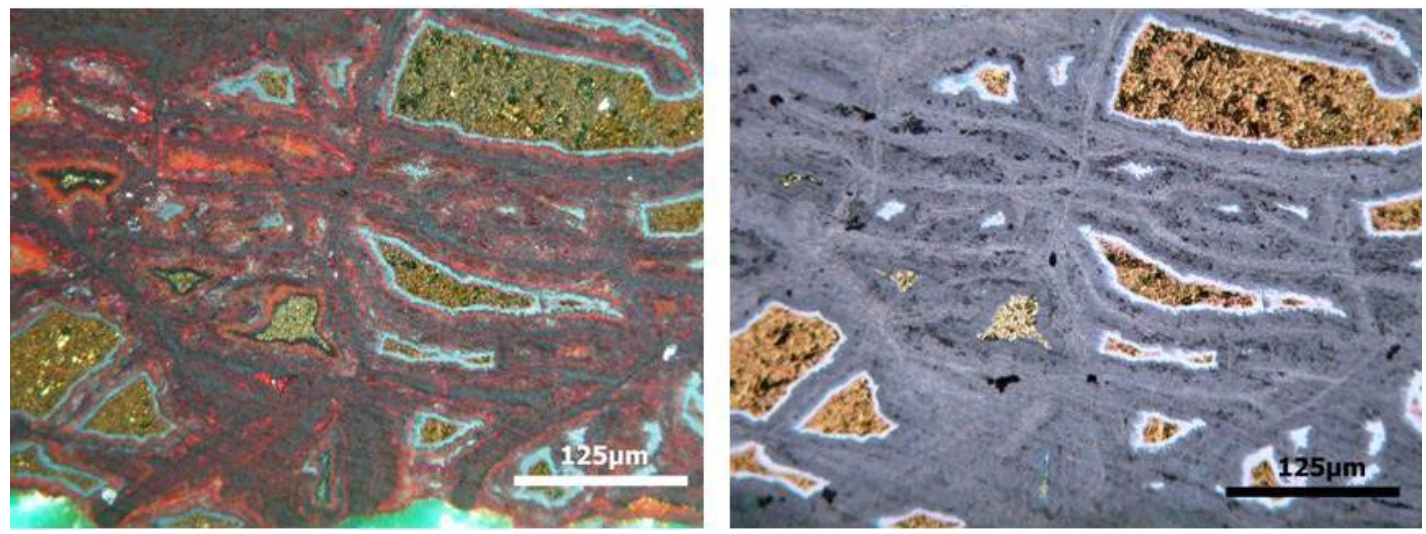

Figure 6.23: Photomicrographs of presumed ore sample SHA13NEL showing brassy chalcopyrite surrounded by thin light blue rims of chalcocite enclosed together in a copper iron-bearing red matrix. The green matrix is malachite. Left photomicrograph under cross polarised light. Right photomicrograph taken under plane polarized light (200x magnification).

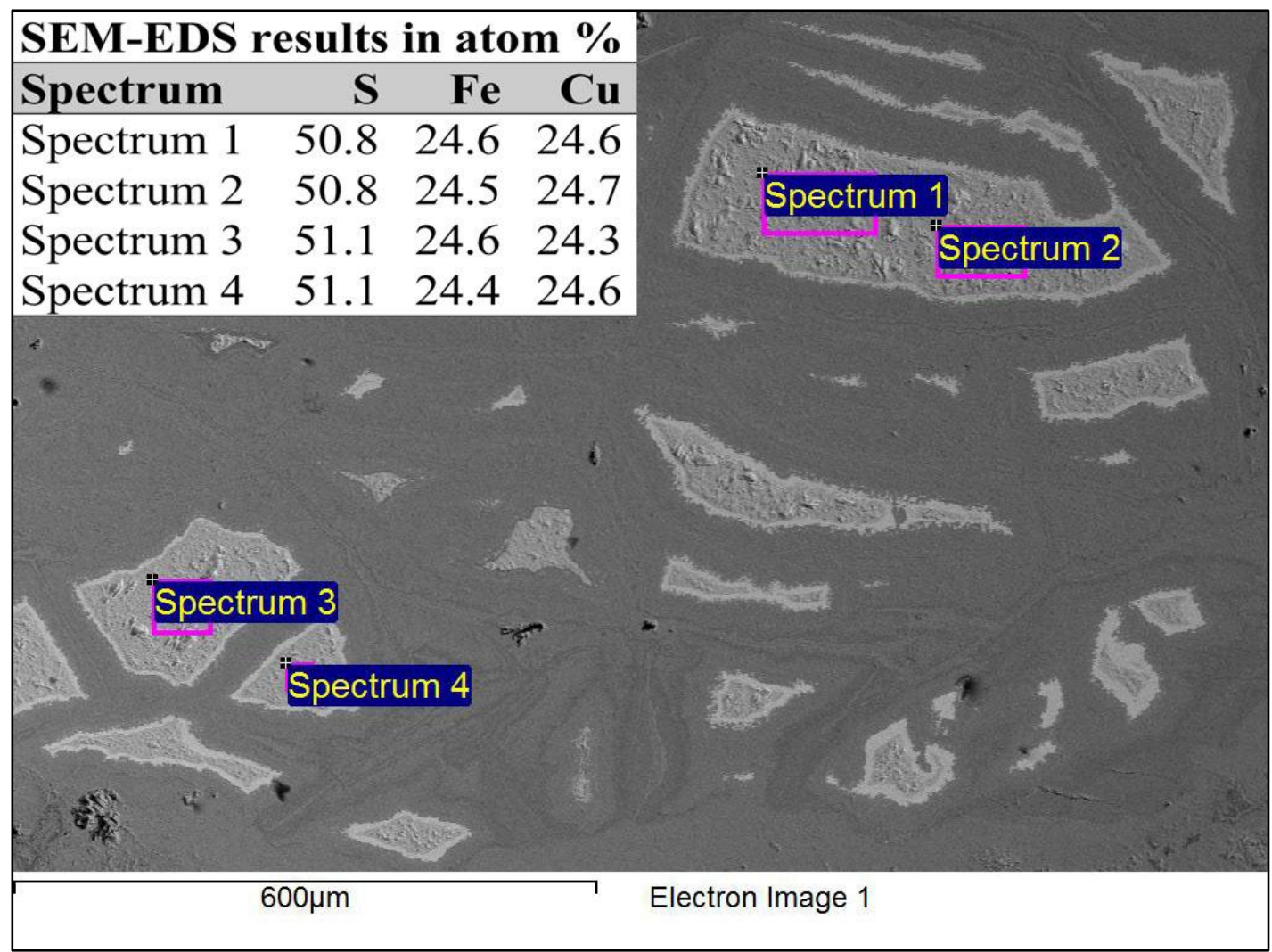

Figure 6.24: SEM-BSE image of presumed ore sample SHA13NEL showing the composition of the isolated residual chalcopyrite. Results are presented in atom \% and normalised to $100 \%$. 


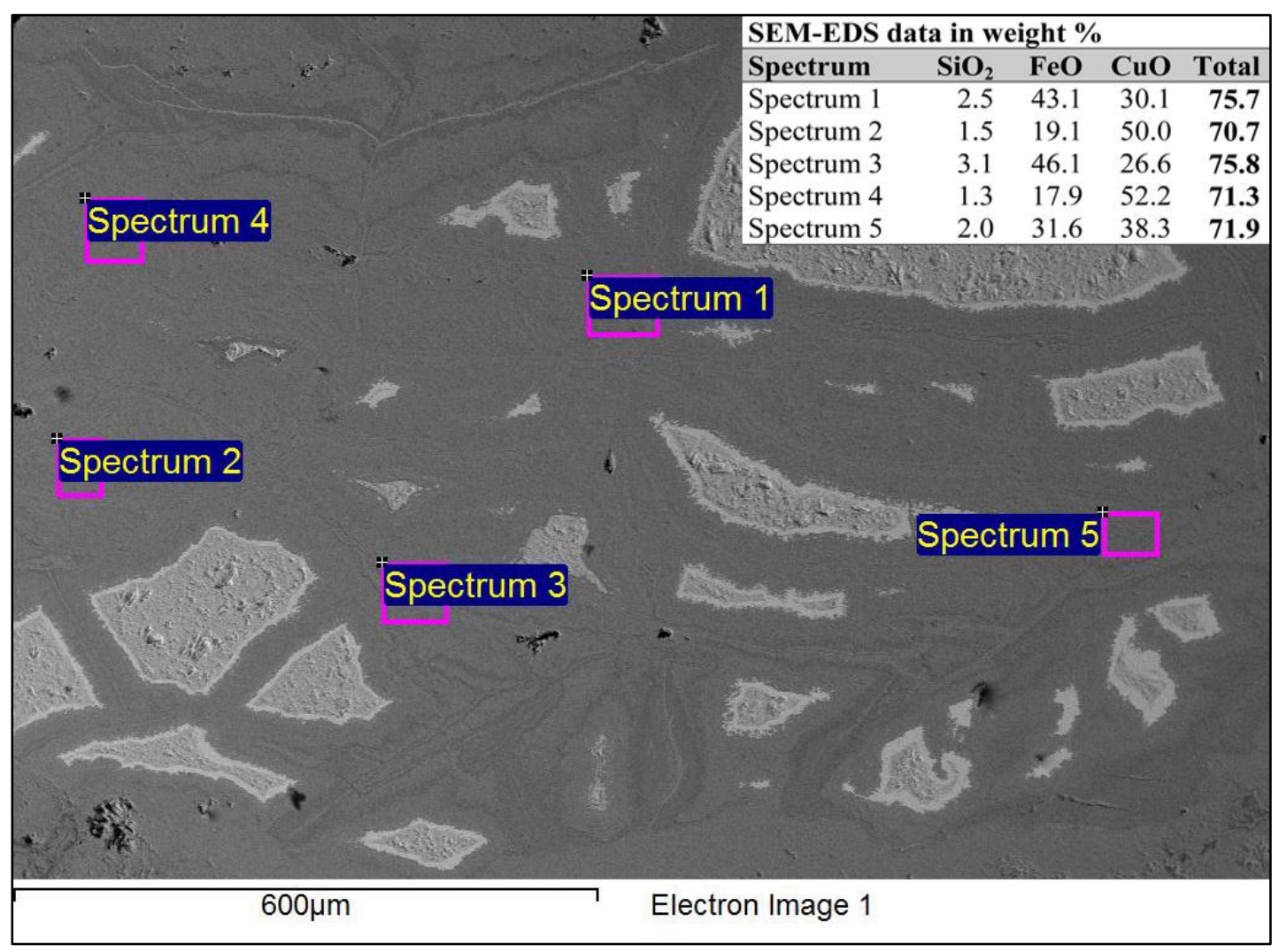

Figure 6.26: SEM-BSE image of presumed ore sample SHA13NEL showing the composition of the oxidised matrix surrounding the residual sulphides. Results are presented in wt\% and not normalised to $100 \%$. 
Table 6.3: Average SEM-EDS results of at least five area scans of the presumed ore samples recovered from Shankare (wt\%). Results not normalised due to the presence of structural water and carbonates prevalent in secondary ores.

\begin{tabular}{llllrrrrrrrrrrrrr}
\hline SAMPLE & Context & Group & $\mathbf{N a}_{2} \mathbf{O}$ & $\mathbf{M g O}$ & $\mathbf{A l}_{2} \mathbf{O}_{3}$ & $\mathbf{S i O}_{2}$ & $\mathbf{P}_{2} \mathbf{O}_{5}$ & $\mathbf{S O}_{3}$ & $\mathbf{K}_{2} \mathbf{O}$ & $\mathbf{C a O}$ & $\mathbf{T i O}_{2}$ & $\mathbf{M n O}$ & $\mathbf{F e O}$ & $\mathbf{C u O}$ & $\mathbf{B a O}$ & $\mathbf{S U M}$ \\
\hline SHA1T & Surface & MX & 0.0 & 0.3 & 0.1 & 1.3 & 6.0 & 0.1 & 0.0 & 18.3 & 0.0 & 0.1 & 16.7 & 12.7 & 0.0 & $\mathbf{5 5 . 7}$ \\
SHA2NWL & Surface & ML & 0.0 & 10.5 & 0.0 & 42.8 & 0.7 & 1.2 & 0.1 & 13.5 & 0.1 & 0.1 & 4.5 & 22.2 & 1.9 & $\mathbf{9 7 . 7}$ \\
SHA11NEL & Surface & ML & 0.0 & 0.1 & 0.1 & 2.3 & 0.5 & 1.1 & 0.0 & 2.4 & 0.0 & 0.0 & 34.1 & 35.9 & 0.1 & $\mathbf{7 6 . 7}$ \\
SHA12NEL & Surface & ML & 0.0 & 0.2 & 0.1 & 1.5 & 0.3 & 0.2 & 0.0 & 16.4 & 0.0 & 0.1 & 20.4 & 29.7 & 0.0 & $\mathbf{6 9 . 0}$ \\
SHA13NEL & Surface & ML & 0.0 & 0.2 & 0.2 & 0.7 & 0.3 & 0.1 & 0.0 & 0.1 & 0.1 & 0.0 & 8.3 & 59.6 & 0.0 & $\mathbf{6 9 . 5}$ \\
SHA14NEL & Surface & ML & 0.0 & 0.1 & 0.1 & 0.8 & 0.2 & 0.1 & 0.0 & 9.8 & 0.1 & 0.0 & 11.0 & 45.6 & 0.0 & $\mathbf{6 7 . 9}$ \\
SHA15NEL & Surface & ML & 0.0 & 0.4 & 0.6 & 2.1 & 0.3 & 0.0 & 0.0 & 1.0 & 0.0 & 0.1 & 0.3 & 57.9 & 0.1 & $\mathbf{6 2 . 7}$ \\
SHA16NEL & Surface & ML & 0.0 & 0.3 & 0.1 & 1.3 & 0.2 & 4.5 & 0.0 & 0.2 & 0.1 & 0.1 & 4.4 & 54.7 & 0.1 & $\mathbf{6 6 . 0}$ \\
SMB22(4) & SHAM1 & MX & 0.0 & 1.4 & 1.3 & 1.2 & 0.3 & 0.0 & 0.0 & 0.4 & 0.0 & 0.1 & 62.8 & 7.5 & 0.0 & $\mathbf{7 5 . 2}$ \\
SMB22(5) & SHAM1 & ML & 0.0 & 2.4 & 0.1 & 7.1 & 0.8 & 1.6 & 0.0 & 2.8 & 0.0 & 0.1 & 25.4 & 29.9 & 0.0 & $\mathbf{7 0 . 1}$ \\
SMB26(2) & SHAM1 & MX & 0.0 & 0.1 & 0.0 & 45.0 & 0.1 & 0.1 & 0.0 & 0.6 & 0.0 & 0.0 & 14.5 & 28.0 & 0.0 & $\mathbf{8 8 . 5}$ \\
SMB26(3) & SHAM1 & ML & 0.0 & 0.2 & 0.1 & 3.1 & 0.0 & 0.2 & 0.0 & 0.2 & 0.0 & 0.1 & 27.9 & 27.2 & 0.0 & $\mathbf{5 9 . 0}$ \\
SMB26(4) & SHAM1 & ML & 0.0 & 6.0 & 2.1 & 6.4 & 0.2 & 0.0 & 0.0 & 0.7 & 0.0 & 0.0 & 1.1 & 56.2 & 0.0 & $\mathbf{7 2 . 7}$ \\
SMB27(1) & SHAM1 & ML & 0.0 & 0.3 & 0.2 & 1.2 & 0.1 & 2.5 & 0.0 & 4.4 & 0.0 & 0.0 & 6.2 & 52.7 & 0.0 & $\mathbf{6 7 . 6}$ \\
\hline
\end{tabular}

For the group section: MX is mixed malachite and magnetite samples and ML represent malachite dominated samples. Groups based on macroscopic features. 
Based on the analytical results presented in the previous page it is possible to highlight some important characteristics of these potential ore samples. The 'ore' samples recovered from Shankare are copper carbonates, namely malachite and azurite, which are sometimes attached to magnetite. It is difficult to establish if these secondary copper compounds represent the 'as mined' ore samples or if they were weathered after mining. In other words, the challenge is to determine when the sulphidic to oxidic ore transformation took place. Did this take place in the geological context or archaeological context? The potential ore samples analysed in this thesis were small fragments, and some of them recovered from the surface, therefore exposed to natural weathering processes. This issue will be fully addressed after the presentation of results on slags, technical ceramics and metal artefacts. Chalcopyrite is the dominant residual sulphide in these copper carbonates ore samples. This is in agreement with the geological literature, which identifies chalcopyrite as the principal sulphide ore from Lolwe Hill (Palabora Mining Company Limited Mine Geological and Mineralogical Staff 1976). The variation in the copper content together with the mineralogy of the presumed copper ores is likely to indicate diverse ores sources or simply the heterogonous nature of same deposit. None of the Shankare ores subjected to compositional analysis contains tin, arsenic or zinc as major oxides. With minerals of this composition it would be impossible to produce intentionally or unintentionally arsenical copper, brass and tin bronze alloys.

To sum up, the majority of the mineral samples collected from Shankare are secondary mineralisation in the form of malachite, magnetite and occasionally azurite. Some of them are bimetallic ores comprising of soft green copper minerals adhering to hard magnetite. The copper compounds occur as thin veins and thick 
specks on host rocks identified as magnetite, apatite and calcium carbonate, but in rare cases quartz. The occurrence of isolated residual sulphides was noted in most of the secondary copper minerals from Shankare. Based on the presence of residual chalcopyrite in most of these secondary copper minerals, it can be surmised that the primary ore was chalcopyrite, as indicated in the geological literature. Such Beyschlag nodules with sulphidic cores enclosed in oxidic ores have been reported in some geological and archaeological contexts (see Rostoker et al. 1989, 84). The analytical results indicating that copper mineralisations were undersaturated are also consistent with information provided in the geological literature. Few self-fluxing samples were available in the suite of presumed ore samples that were analysed; the majority would have required addition of flux, be it intentionally or through other contribution such as the melting of technical ceramics. The contribution of these presumed ores to extractive metallurgy can only be discussed after the presentation of analytical results of slag from the same site. The next section presents the analytical results of slag samples in an attempt to establish their link to the presumed ore samples presented above. 


\subsubsection{Smelting slags}

Slags formed the major category of extractive metallurgy debris recovered from Shankare. The exterior colours of these slags range from rusty red, brown and grey to green, whilst the fresh sectioned interior is mostly black and porous. These slags are comparatively small, with an average weight of only $15 \mathrm{~g}$ each. The exceptionally large slag pieces from Shankare weigh around $60 \mathrm{~g}$ each. In terms of dimensions, the majority of these slags are less than $3 \mathrm{~cm}^{3}$ making them significantly smaller than smelting slags documented from other archaeological contexts in Africa. For example, extremely large iron bloomery slag blocks weighing up to $100 \mathrm{~kg}$ each have been documented in Uganda (Humphris et al. 2009). Slag typologies based on diagnostic external apperances have been developed to classify iron production slags in Southern Africa (Chirikure \& Rehren 2004; Chirikure \& Rehren 2006; Friede et al. 1982; Greenfield \& Miller 2004; Miller \& Killick 2004). Iron slags have been visually classified into tap slag, flow slag, furnace slag and smithing slags, although in practice this is not always an easy task. Furnaces with slag tapping provisions have not yet been documented in South Africa; as such, tap slags were not expected in the Shankare slag assemblage (Miller \& Killick 2004, 24). However, typologies of copper slags from archaeological contexts have not yet been developed in Southern Africa.

Based on their external appearance, some slag samples from Shankare are irregular shaped pieces with a flow-like morphology therefore are classified in this thesis as "flow-type" slag. These flow-type slags were not necessarily tapped outside the furnace because their surfaces are also frequently charcoal impressed. The charcoal impressions indicate that these slags solidified inside the furnace therefore are hereby 
also referred to as "furnace slags". Noteworthy is the observation that some furnace slags were deliberately crushed after smelting as shown by their small size and fractured edges. Several dimpled hammer stones and rock surfaces with peculiar dolly holes were found together close to scatters of fragmented slags (see Section 6.3.1). Macroscopically, therefore furnace smelting slags from Shankare can be divided into two categories namely "flow-type" and "crushed-type" (Figure $6.27 \&$ Figure 6.28). The crushed slags have macroscopic residual magnetite and copper prills. Besides the furnace smelting slags, there are slags attached to ceramic crucible fragments. These "crucible slags" are significantly different from furnace slags thus they will be presented together with associated crucible fragments in the next sections. Although the primary focus of this project is on extractive copper metallurgy, some iron bloomery smelting slags were documented in the Shankare assemblage. At macroscopic level it was not easy to separate these iron smelting slags from copper smelting slags. Analytical data collected during the investigation of these iron smelting slags is presented alongside copper smelting slags in this section for comparative purposes and for the benefit of future slag investigations in the research area. 


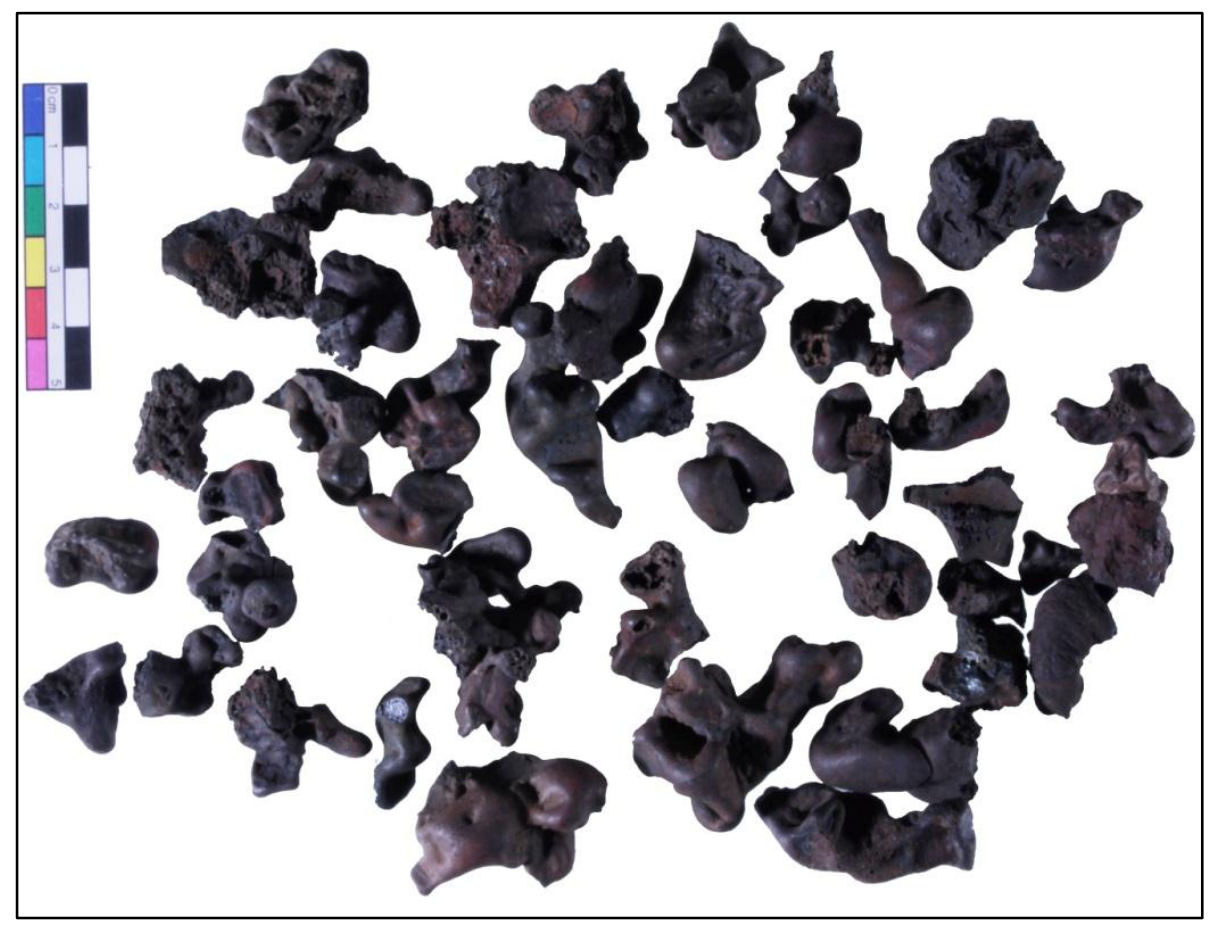

Figure 6.27: Example of "flow-type" slags which solidified from fully molten state inside the furnace (Image: Author).

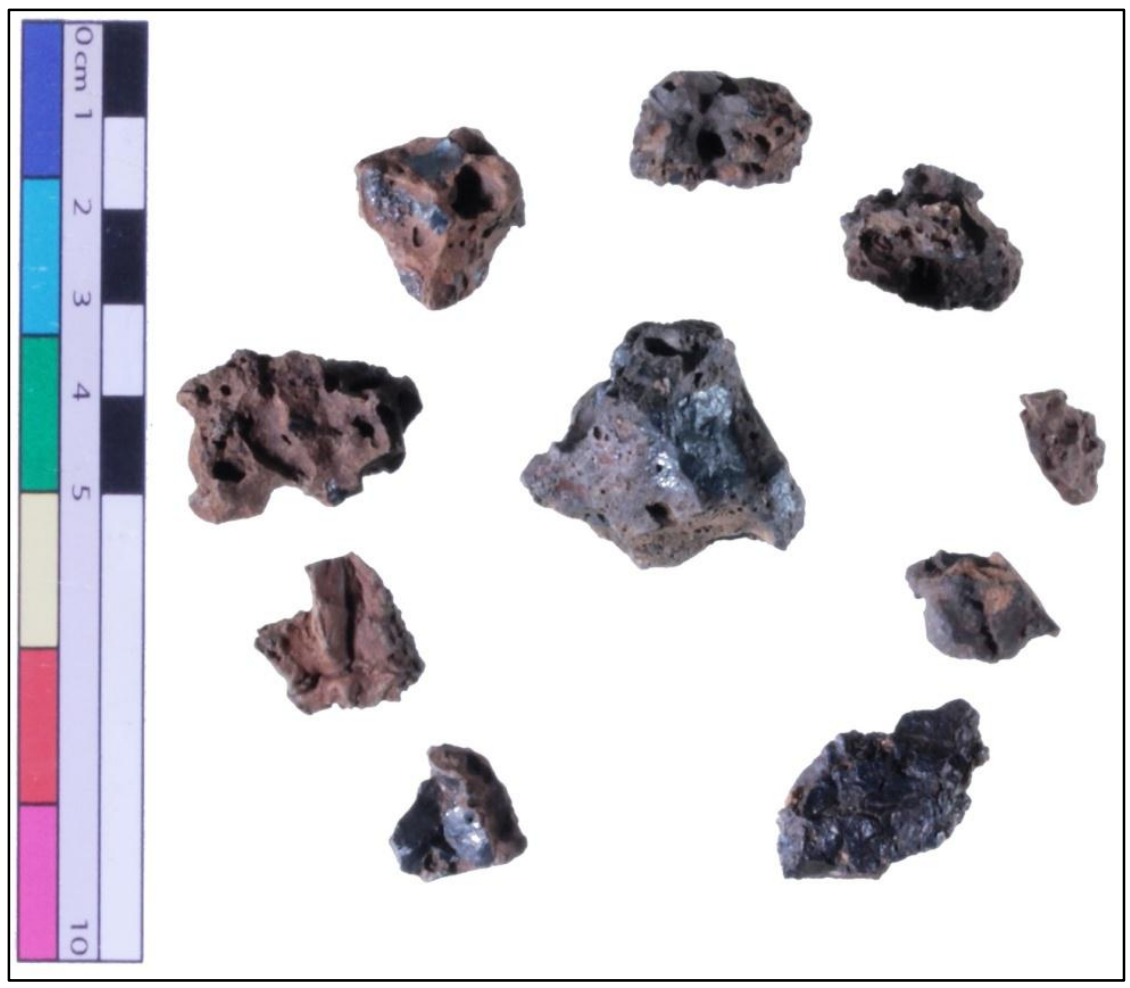

Figure 6.28: Examples of "crushed-type" slags with notable residual minerals suggesting they were not fully molten (Image: Author). 
Thirty-nine slag pieces recovered from different slag scatters were sampled for detailed analytical work with approaches outlined in Chapter 5. These samples included the once fully molten slag pieces of the "flow-type" and coarse fragmented slag samples with macroscopic copper prills of the "crushed-type". The relatively small size of individual slag pieces together with the presence of visibly unreacted minerals meant that most of these specimens were only suitable for optical microscopy and SEM-EDS analyses. A few relatively large sized slags were also prepared as polished blocks for microscopy and SEM-EDS as well as pressed pellets for (P)ED-XRF analysis. The following analytical results put emphasis first on the significant mineralogical differences between iron and copper smelting slags. The differences in the spatial context of recovery associated with copper and iron metallurgical debris at the site of Shankare are also highlighted.

\subsubsection{Shankare iron smelting slags}

Macroscopically, the iron smelting slags from Shankare fit within the category of "flow-type" slags that do not have any visible relict minerals. These slags have a typical rusty red tarnish together with charcoal impressions and they respond very weakly to magnetic tests. Twelve iron smelting slags mostly from trench SHASH1 were subjected to analytical work. Microscopically, these slags fall into two subgroups although these are likely to represent variability within the same technological system. Slag samples in the first microscopic group [SHA12(2), SHA22(2), SHA1NEL, SHA2NEL, SHA3NEL, SHA4NEL, SHA6NEL \& SHA7NEL] are dominated by blocky olivines, ulvospinels $\left(\mathrm{Fe}_{2} \mathrm{TiO}_{2}\right)$ with occasional wüstite dendrites/ globules $\left(\mathrm{Fe}_{1-\mathrm{x}} \mathrm{O}\right)$ and metallic iron particles (Figure 6.29). The 
dominant blocky olivines documented in these iron slags have the following ratio of ions: $0.8(\mathrm{MgO}), 2.1\left(\mathrm{SiO}_{2}\right), 1.6(\mathrm{CaO}), \mathrm{FeO}(1.5)$. These blocky olivines do not fall within the typical fayalitic bloomery slags known from Africa (see Rehren et al. 2007); instead, their composition approaches magnesian kirschsteinite. The angular ulvospinel crystals in these iron production slags contain on average $60 \% \mathrm{FeO}$ and $30 \% \mathrm{TiO}_{2}$ with magnesia and alumina as additional oxides. The second microscopic group is represented by four iron slag samples [SHA11(2), SHA22(1), SHA5NEL, SHA8NEL] mineralogically dominated by wüstite dendrites with occasional interstitial glass and metallic iron particles (Figure 6.30). Their microstructure is consistent with their slightly higher FeO content. The iron particles $(<20 \mu \mathrm{m}$ in size $)$ embedded in the Shankare iron slags were reduced in their solid state because they are not rounded in shape. Judging from the macroscopic evidence of charcoal impressions, microscopic blocky primary phases together with the absence of magnetite skins $\left(\mathrm{Fe}_{3} \mathrm{O}_{4}\right)$ that often form between layers in tap slag (Morton \& Wingrove 1969), it can be inferred that these iron slags solidified inside the furnace. The iron smelting slags that were subjected to microscopic and phase analyses have homogenous microstructures. They do not contain unreacted residual minerals documented in slag samples of the "crushed-type" presented below.

The 'bulk' SEM-EDS area scans show that the three principal oxides contributing to the composition of Shankare iron slags are $\mathrm{FeO}(33-49 \mathrm{wt} \%), \mathrm{SiO}_{2}(27-30 \mathrm{wt} \%)$, and $\mathrm{CaO}(10-15$ wt\%) (Table 6.4). The wüstite dominated samples in Group 2 have the highest $\mathrm{FeO}$ content. In theory these slags can be assigned to the $\mathrm{FeO}-\mathrm{CaO}-\mathrm{SiO}_{2}$ ternary system. However, these iron slags also contain additional major oxides, namely $\mathrm{TiO}_{2}$ (4-9 wt\%), $\mathrm{Al}_{2} \mathrm{O}_{3}(5-6 \mathrm{wt} \%), \mathrm{MgO}(4-5 \mathrm{wt} \%)$ and $\mathrm{K}_{2} \mathrm{O}$ (2-3 wt $\%$ ), 
which affect temperature estimates that rely on ternary phase diagrams. Analysis of four samples by $(\mathrm{P}) \mathrm{ED}-\mathrm{XRF}$ yielded marginally different results, most notably in the slightly higher $\mathrm{FeO}$ values, but the trend remained the same (Table 6.5). The bulk composition of iron smelting slags from Shankare shows some notable differences with contemporary bloomery slags in Africa. The notable peculiarities include high $\mathrm{CaO}$ and $\mathrm{TiO}_{2}$ levels. The elevated levels of $\mathrm{TiO}_{2}$ of these iron slags are consistent with dominant ulvospinels in their microstructure. High $\mathrm{TiO}_{2}$ levels in iron smelting slags have been linked to extraction technologies which employed high grade ilmenite-rich black sands (Iles \& Martinon-Torres 2009; Ige \& Rehren 2003). The use of titanium-rich magnetite ores for iron smelting around the Northern Lowveld was documented at several smelting sites before (van der Merwe \& Killick 1979; also see Chapter 4). The closest source of high grade and titanium-rich magnetite ores in the case of Shankare Hill was Lolwe Hill (see Figure 7.1). The iron smelting slags at Shankare thus have the ore signature of Lolwe magnetite; however, high levels of $\mathrm{CaO}$ presumably resulted from high fuel ash contribution (Iles \& MartinonTorres 2009).

The predominance of wüstite in some samples together with occasional metallic iron particles is indicative of strongly reducing conditions consistent with iron production rather than copper smelting (Morton \& Wingrove 1969; Morton \& Wingrove 1972). The viscosity of slag samples from Shankare were calculated using the formula outlined by Bachmann $(1982,19)$, provided in Chapter 5. However, the omission of titania, a major oxide in the Shankare iron slags, during the calculation of viscosity indexes might have compromised the viscosity results presented in this thesis. Based 
on the both the ED-XRF and SEM-EDS bulk composition, viscosity indices of Shankare iron slags range from 1.6-2.4 with an average of 1.9. 


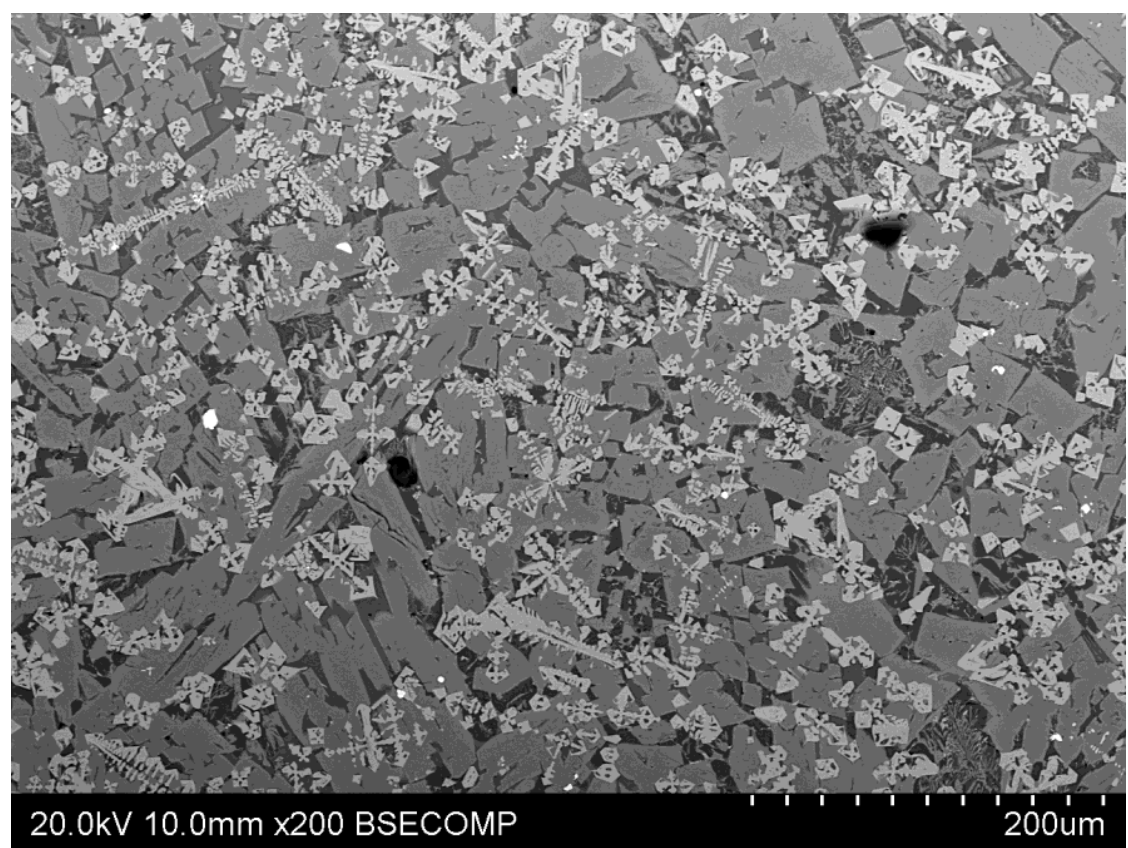

Figure 6.29: SEM-BSE image of sample SHA2NEL showing the dominant blocky olivines and ulvospinels. Microstructure of iron smelting slags in Group 1.

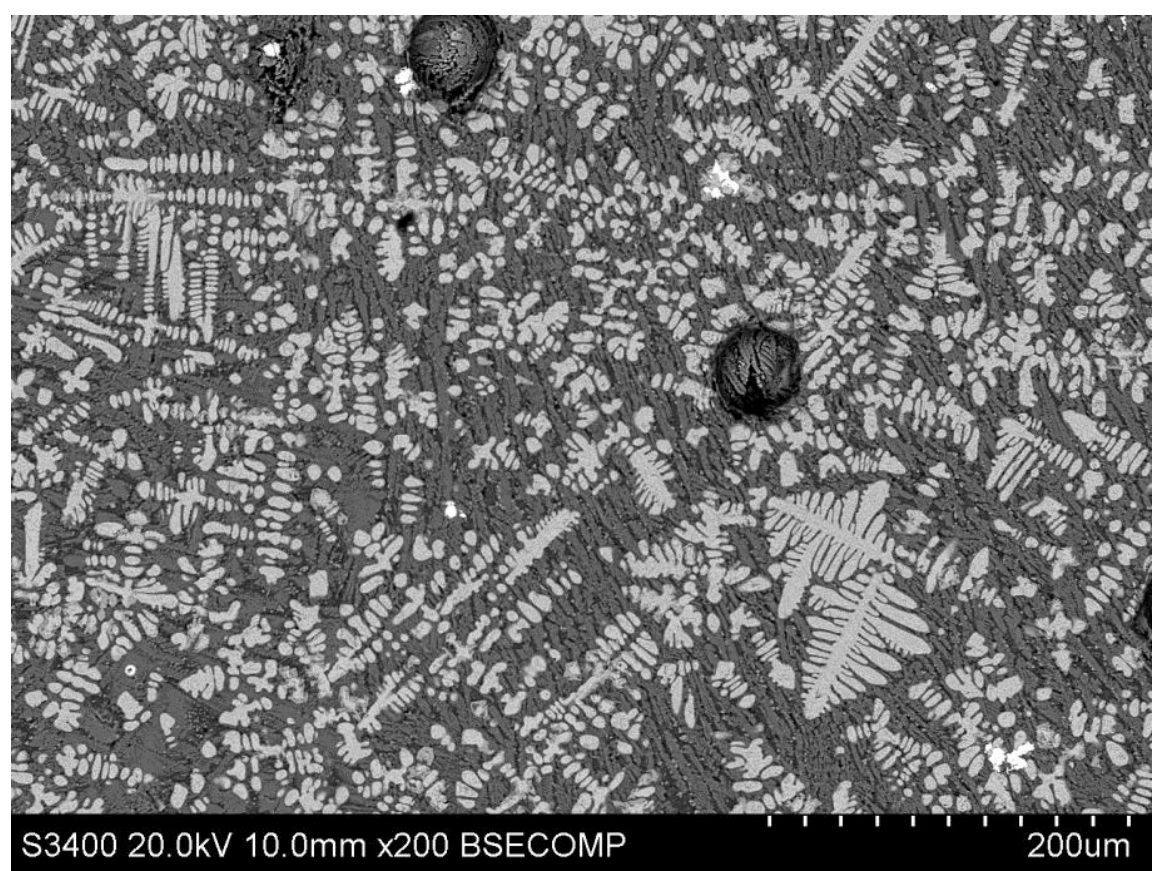

Figure 6.30: SEM-BSE image of sample SHA8NEL showing the dominant wüstite dendrites and olivines. Typical microstructure of Group 2 iron smelting slags. 
Table 6.4: Average SEM-EDS 'bulk' chemical results of iron production slags from Shankare. The results presented are in wt\% and normalised to $100 \%$. The last column shows the silica to alumina ratio.

\begin{tabular}{|c|c|c|c|c|c|c|c|c|c|c|c|c|c|c|}
\hline Sample & Context & $\mathrm{Na}_{2} \mathrm{O}$ & MgO & $\mathrm{Al}_{2} \mathrm{O}_{2}$ & $\mathrm{SiO}_{2}$ & $\mathbf{P}_{2} \mathbf{O}_{5}$ & $\mathrm{SO}_{3}$ & $\mathrm{~K}_{2} \mathrm{O}$ & $\mathrm{CaO}$ & $\mathrm{TiO}_{2}$ & MnO & $\mathrm{FeO}$ & $\mathrm{CuO}$ & $\mathrm{SiO}_{2}: \mathrm{Al}_{2} \mathrm{O}_{3}$ \\
\hline SSHA11(2) & Slag Midden & 0.7 & 5.3 & 4.6 & 24.4 & 0.7 & 0.1 & 2.2 & 10.2 & 4.2 & 0.3 & 47.3 & 0.1 & 5 \\
\hline SSHA12(2) & Slag Midden & 0.8 & 6.2 & 7.0 & 35.0 & 1.0 & 0.1 & 3.0 & 18.3 & 9.6 & 0.6 & 18.4 & 0.1 & 5 \\
\hline SSHA22(1) & Slag Midden & 0.4 & 4.4 & 3.6 & 19.8 & 1.0 & 0.1 & 2.1 & 10.5 & 7.7 & 0.3 & 50.0 & 0.1 & 5 \\
\hline SSHA22(2) & Slag Midden & 0.7 & 5.3 & 5.1 & 26.4 & 0.9 & 0.1 & 2.4 & 13.0 & 7.2 & 0.4 & 38.5 & 0.1 & 5 \\
\hline SHA1NEL & Surface SM & 0.7 & 4.4 & 4.6 & 24.3 & 0.7 & 0.1 & 2.2 & 13.6 & 7.8 & 0.4 & 41.4 & 0.0 & 5 \\
\hline SHA2NEL & Surface SM & 0.9 & 4.2 & 5.6 & 29.2 & 0.8 & 0.1 & 2.3 & 14.2 & 7.4 & 0.3 & 34.9 & 0.1 & 5 \\
\hline SHA3NEL & Surface SM & 0.7 & 5.1 & 4.8 & 27.8 & 1.0 & 0.1 & 3.1 & 12.9 & 6.4 & 0.4 & 37.5 & 0.1 & 6 \\
\hline SHA4NEL & Surface SM & 0.9 & 4.8 & 6.0 & 30.4 & 1.0 & 0.1 & 2.7 & 14.2 & 6.1 & 0.3 & 33.7 & 0.0 & 5 \\
\hline SHA5NEL & Surface SM & 0.4 & 4.6 & 4.7 & 23.9 & 0.6 & 0.2 & 1.7 & 9.8 & 6.9 & 0.3 & 46.7 & 0.2 & 5 \\
\hline SHA6NEL & Surface SM & 0.8 & 4.3 & 5.6 & 28.0 & 1.1 & 0.1 & 2.9 & 10.7 & 6.0 & 0.3 & 40.2 & 0.0 & 5 \\
\hline SHA7NEL & Surface SM & 0.8 & 4.7 & 5.4 & 28.7 & 0.7 & 0.1 & 2.3 & 15.1 & 8.9 & 0.4 & 32.8 & 0.0 & 5 \\
\hline SHA8NEL & Surface SM & 0.7 & 4.0 & 4.5 & 23.6 & 1.0 & 0.1 & 2.5 & 10.0 & 4.1 & 0.3 & 49.1 & 0.1 & 5 \\
\hline
\end{tabular}

Table 6.5: Average ED-XRF bulk chemical results of iron production slags from Shankare. Results presented in wt\% and not normalised. The last column shows the silica to alumina ratio.

\begin{tabular}{llrrrrrrrrrrrrr} 
Sample & Context & $\mathbf{N a}_{2} \mathbf{O}$ & $\mathbf{M g O}$ & $\mathbf{A l}_{\mathbf{2}} \mathbf{O}_{\mathbf{3}}$ & $\mathbf{S i O}_{\mathbf{2}}$ & $\mathbf{P}_{\mathbf{2}} \mathbf{O}_{\mathbf{5}}$ & $\mathbf{S O}_{\mathbf{3}}$ & $\mathbf{K}_{\mathbf{2}} \mathbf{O}$ & $\mathbf{C a O}$ & $\mathbf{T i O}_{\mathbf{2}}$ & $\mathbf{M n O}$ & $\mathbf{F e O}$ & $\mathbf{C u O}$ & $\mathbf{S i O}_{2}: \mathbf{A l}_{\mathbf{2}} \mathbf{O}_{\mathbf{3}}$ \\
\hline SHA4NEL & Surface & 0.49 & 3.82 & 4.78 & 30.25 & 0.81 & 0.16 & 2.39 & 13.70 & 6.32 & 0.35 & 36.81 & 0.02 & $\mathbf{6}$ \\
SHA6NEL & Surface & 0.58 & 3.51 & 4.48 & 29.04 & 0.90 & 0.17 & 2.51 & 11.21 & 5.89 & 0.31 & 41.28 & 0.01 & $\mathbf{6}$ \\
SHA7NEL & Surface & 0.59 & 3.48 & 4.21 & 27.60 & 0.50 & 0.11 & 1.81 & 12.94 & 8.41 & 0.34 & 39.91 & 0.01 & $\mathbf{7}$ \\
SHA8NEL & Surface & 0.47 & 3.08 & 3.45 & 24.25 & 0.81 & 0.19 & 2.14 & 9.29 & 3.79 & 0.30 & 52.11 & 0.02 & $\mathbf{7}$ \\
\hline
\end{tabular}




\subsubsection{Shankare copper smelting slags}

Copper smelting slags were recovered from the domestic midden (SHAM1) and six low density slag scatters (SHAMK7, SHAMK8, SHAMK9, SHAMK18, SHAMK27, SHARS). Macroscopically, some of these slags can be classified as "flow-type", with external characteristics very similar to the iron slags described above making it difficult to discriminate them based on their external appearance. Furthermore macroscopic characteristics in the form of negative charcoal impressions also indicate that they solidified inside the furnace. However, the majority of copper slags presented here fit in the group of "crushed-type" slags. These copper slags contain macroscopic copper prills and magnetite mineral residues together with occasional green copper tarnish. These fragmented copper slags were strongly magnetic as a result of unreacted magnetite minerals and primary high temperature magnetite spinels. This confirms the observation that magnetism is not always a reliable criterion for distinguishing iron from copper slags in the field identification process (Miller \& Killick 2004, 26). Based on provisional criteria established through initial analyses of a pilot sample, initial screening of copper from iron slags in the laboratory was done qualitatively with the aid of the portable XRF machine. Slag samples with high $\mathrm{TiO}_{2}$ readings were set aside as iron production debris whilst low $\mathrm{TiO}_{2}$ slags were provisionally categorised as copper production debris (see discussion below 6.4.2.3).

Twenty-seven copper smelting slag samples from different contexts at Shankare were subjected to detailed microscopy and chemical investigations. Microscopically, the slags have heterogeneous microstructures but evidently dominated by blocky 
olivines, magnetite spinels $\left(\mathrm{Fe}_{3} \mathrm{O}_{4}\right)$, copper prills and significantly less interstitial glass (Figure 6.31). The silicate crystalline compounds dominating in the microstructure of these slags are significantly different to the magnesian kirschsteinite olivines present in iron slags presented above. Some of these silicate crystalline compounds have the following ratio of ions: $1.2(\mathrm{MgO}), 2.1\left(\mathrm{SiO}_{2}\right), 0.2$ $(\mathrm{CaO})$ and $2.5(\mathrm{FeO})$ consistent with fayalitic olivines but with a one third of forsterite $\left(\left(\mathrm{Fe}_{\mathrm{x}} \mathrm{Mg}_{1-\mathrm{x}}\right)_{2} \mathrm{SiO}_{4}\right)$ component. The documentation of these blocky olivines as the major visible phase microscopically together with the presence of residual minerals further justifies the identification of these slags as smelting debris rather than refining. Fayalitic slags are usually expected to form under relatively reducing atmosphere typical of smelting rather than melting processes. The dominant free iron oxides present in these copper slags are magnetite spinels $\left(\mathrm{Fe}_{3} \mathrm{O}_{4}\right)$ but wüstite dendrites $\left(\mathrm{Fe}_{1-\mathrm{x}} \mathrm{O}\right)$ are sometimes present in relatively small proportions. Three slag samples [SHAMK18(2), SHAMK27(3) \& SMB23(1)] have thin bands or skins of magnetite but these cases are exceptional and rather localised (Figure $6.32 \&$ Figure 6.33), it is unlikely that they represent slag tapping given the high content of residual minerals. The presence of primary magnetite as free iron oxides also suggests relatively less reducing conditions often associated with copper smelting rather than iron smelting. It is important at this juncture to mention that ulvospinels documented in the iron slags were not documented in the copper slags. The absence of ulvospinels in these copper slags is a direct result of the use of titanium-free ores for copper smelting purposes. It has already been pointed out that potential copper ore samples recovered from Shankare are titanium-free. The geological literature also suggests that copper ores in the central carbonatite at Lolwe Hill were associated 
with titanium-free magnetite (Palabora Mining Company Limited Mine Geological and Mineralogical Staff 1976).

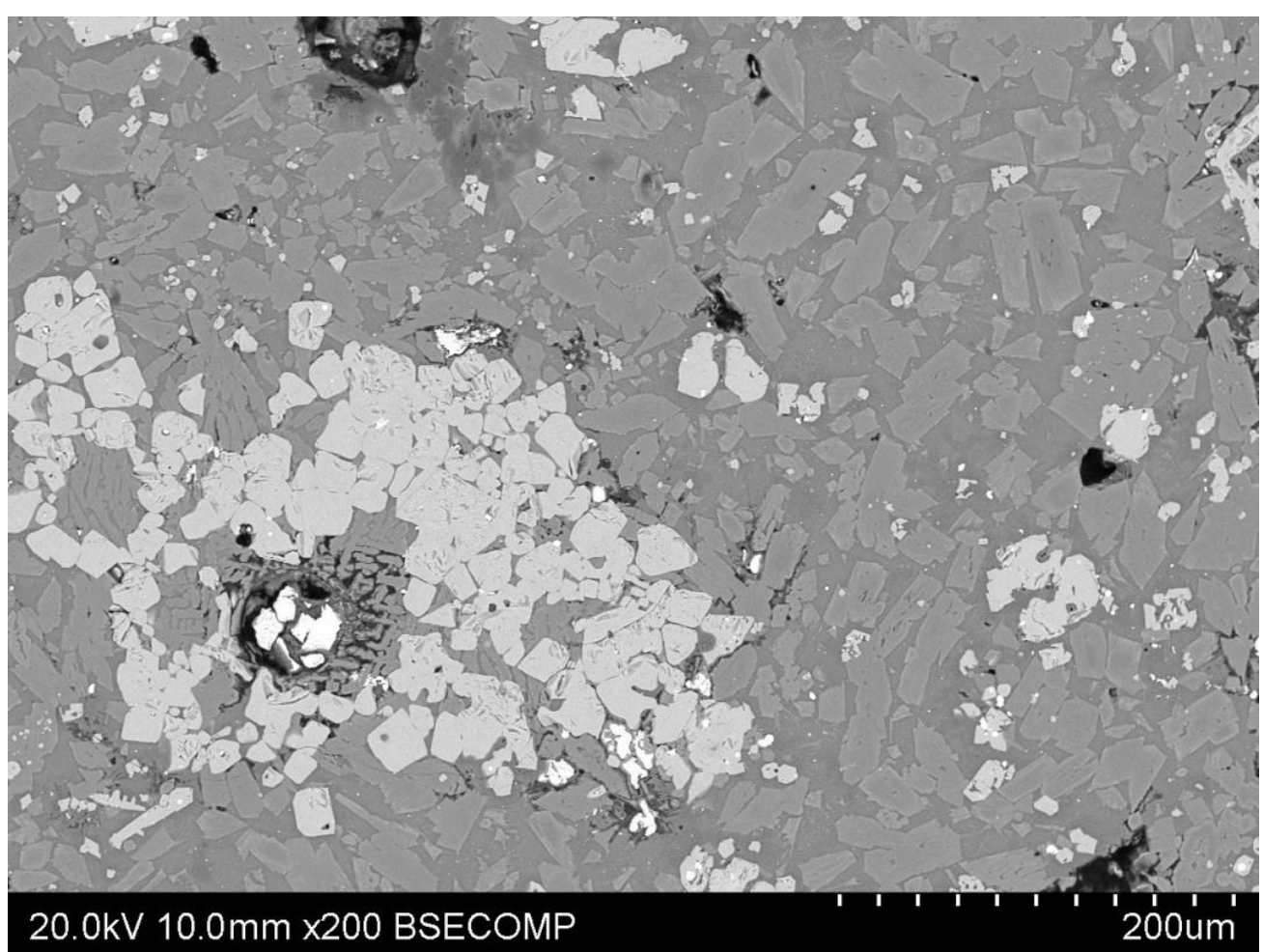

Figure 6.31: SEM-BSE image of copper slag SHA9NWL showing fully crystallised olivines and pseudomorphs of natural magnetite. 


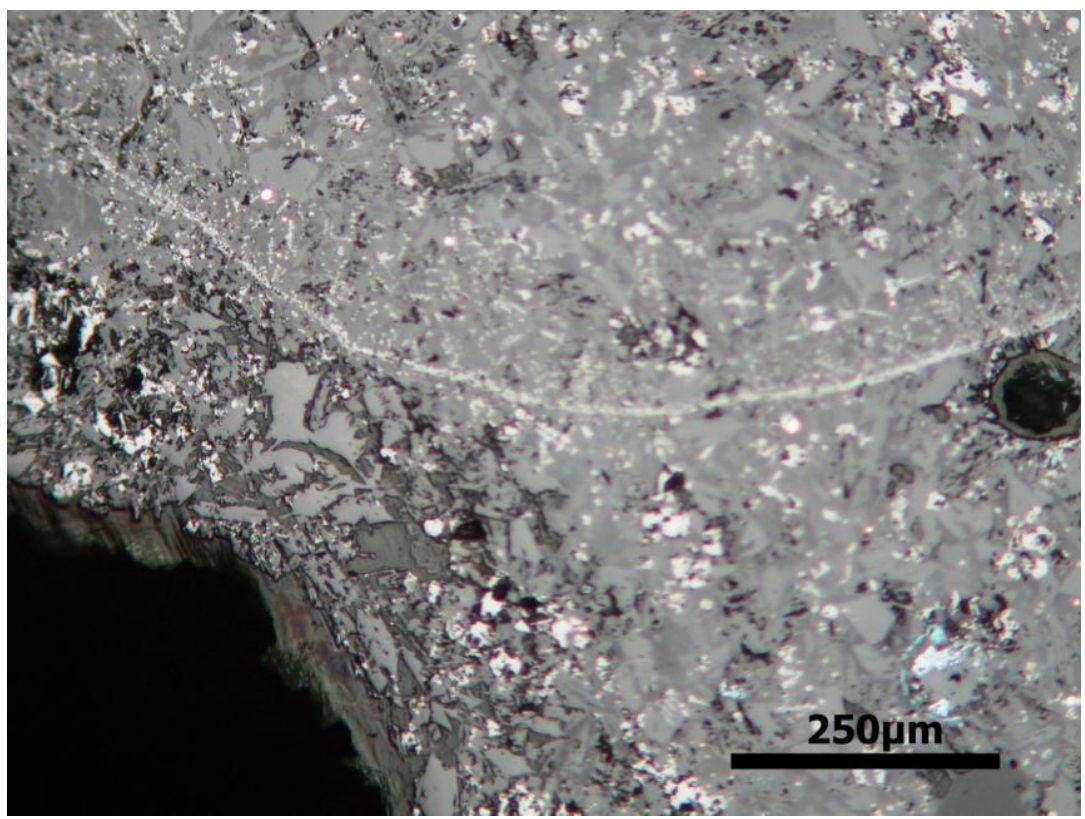

Figure 6.32: Photomicrograph of sample SHAMK27(3) showing magnetite band. Under plane polarised light (100x).

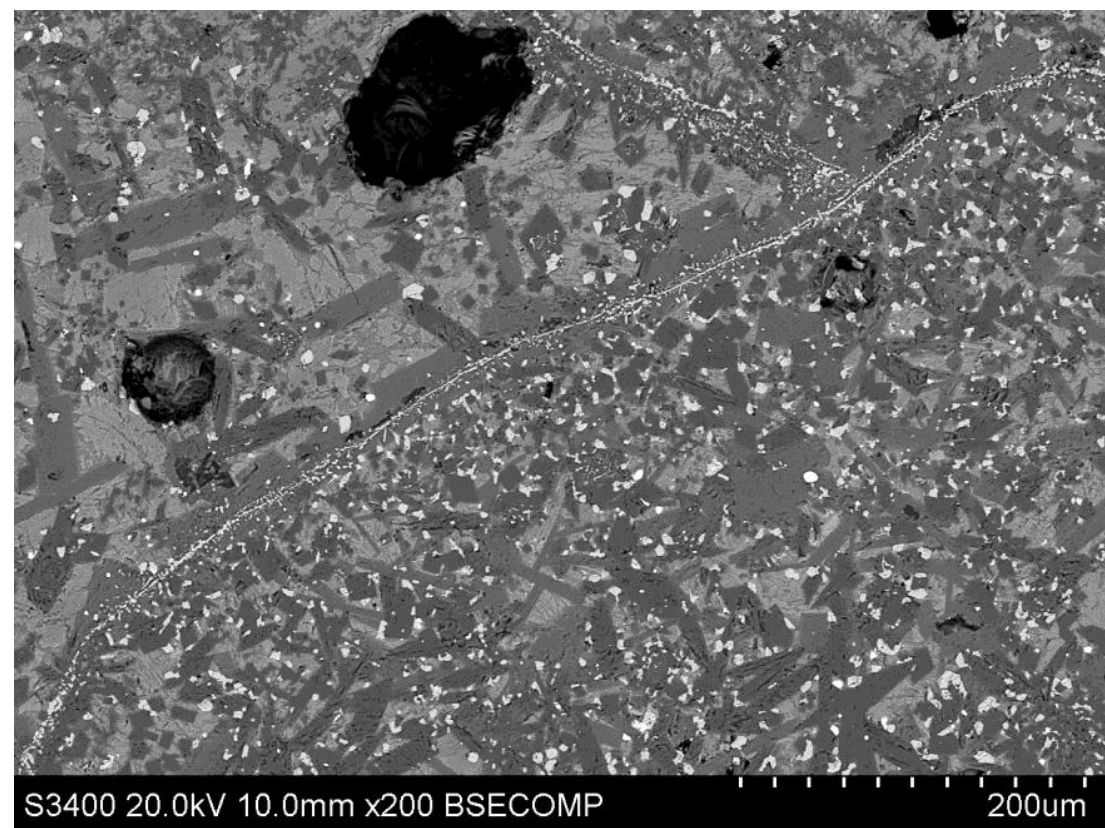

Figure 6.33: SEM-BSE image of sample SHAMK18(2) also showing magnetite bands. 
All titanium-free slags from Shankare had metallic copper inclusions rather than the iron particles documented in titanium-rich iron slags. These slag-entrapped copper prills were mostly spherical in shape with diameters ranging from a few $\mu \mathrm{m}$ up to 2 $\mathrm{mm}$. The shape of these prills indicates that they were once liquid therefore ruling out the possibility that reduction of copper was achieved in solid state, like the counterpart iron bloomery process. During the smelting of copper, certain elements or oxides in the charge contribute to the formation of the slag whilst some are incorporated in the metallic phases as impurities. Quantitative analysis of the metal prills with SEM-EDS revealed that they consist of copper with significant impurities in the form of sulphur and iron. Their chemistry further confirms that copper alloying elements, tin and zinc, prevalent in Southern African Iron Age artefacts, were not present in the copper smelting charge. Copper prills entrapped in slag samples SHA7NWL, SHA8NWL and SHAMK18(3) documented the highest iron levels with a record of up to $30 \mathrm{wt} \% \mathrm{Fe}$. The unusually high iron levels confirmed the microscopic observations that large copper prills $(>1 \mathrm{~mm})$ have exsolved iron and iron oxide $(\mathrm{Fe}-\mathrm{O})$ phases. These iron oxide inclusions represent post-depositional corrosion of exsolved iron. The inclusions appear as various shades of blue under plane polarised light with dark blue reflections under cross polarised light (Figure $6.34 \&$ Figure 6.35). Ferruginous 'black copper' prills further strengthen the identification of these slags as smelting products because they indicate relatively high reducing conditions unlikely to be achieved during the refining process under oxidising conditions. Apart from exsolved iron inclusions, the copper prills entrapped in the slag samples are heavily stained by globules of copper sulphide and copper-iron sulphide inclusions. Some copper prills are also surrounded by blue rims rich in sulphur and iron with dark blue reflections under cross polarised light. 
However, none of the prills entrapped in the copper slags were complete matte prills expected from the smelting of sulphidic ores. 


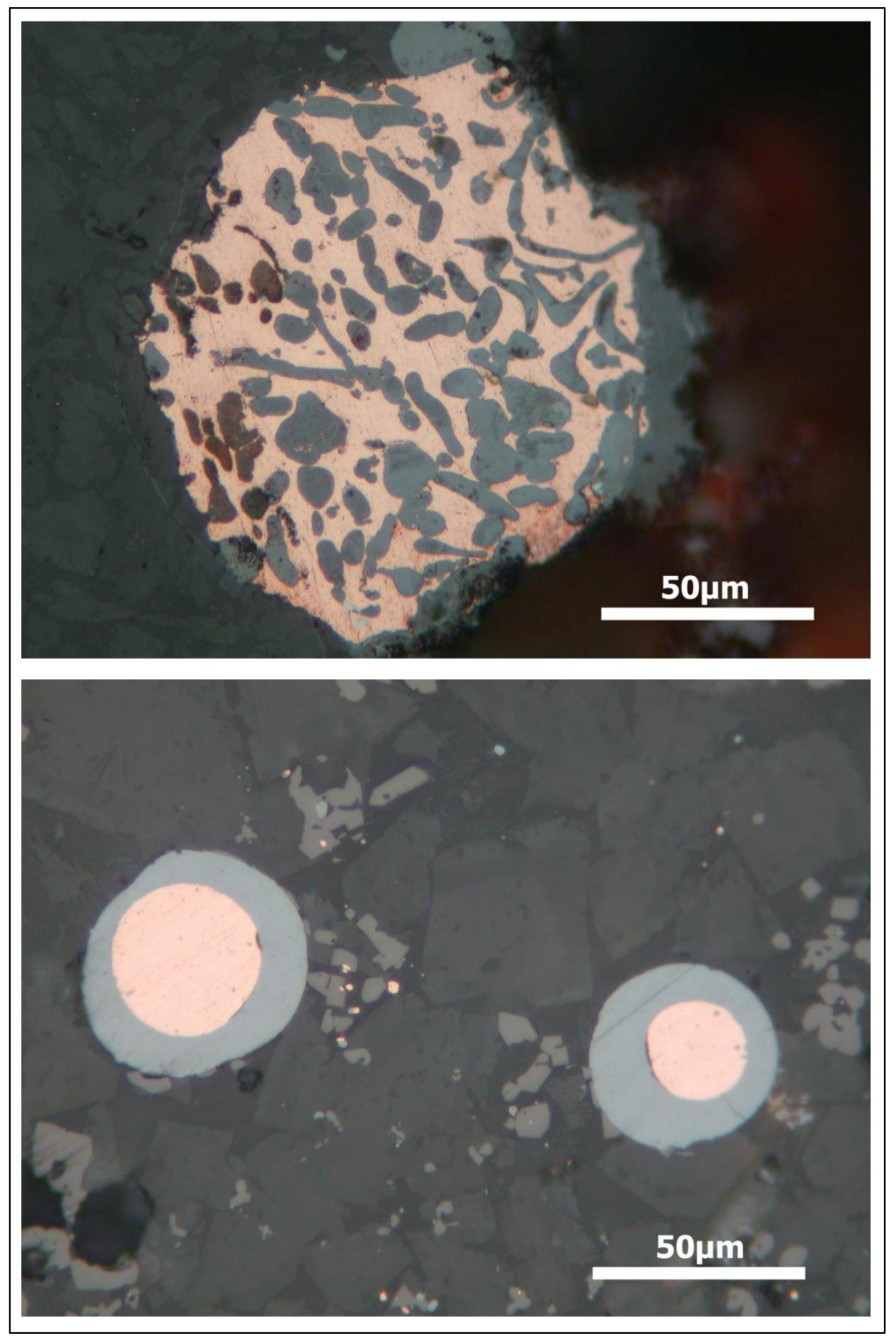

Figure 6.34: Photomicrographs of copper prills trapped inside slag samples SHA7NWL (Top) showing Fe-O phases in copper prill. SHAMK18(3) (Bottom) showing copper sulphide 'rims' surrounding copper prills. Under plane polarised light (500x). 


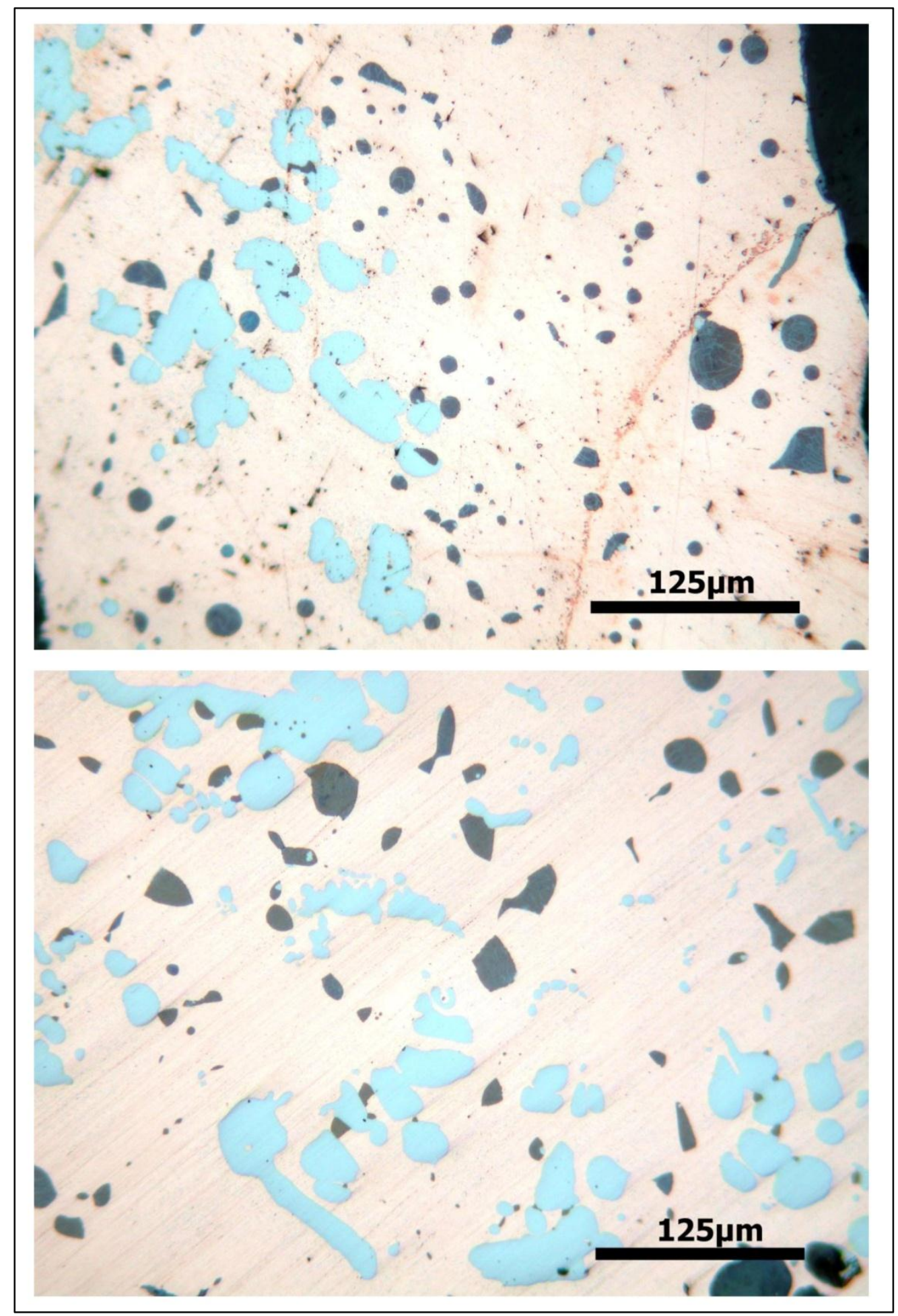

Figure 6.35: Photomicrographs of copper prills trapped inside slag samples SHA8NWL (Top) and SHAMK18(3) (Bottom). Both showing exsolved iron (light blue) and copper sulphide inclusions (dark green). Under plane polarised light (200x). 
Apart from the fully recrystallised slag phases and metallic prills presented above, the majority of copper smelting slags from Shankare Hill contain partially reduced and unreacted mineral inclusions in their matrix (Figure 6.36 \& Figure 6.37). Out of the 27 copper slags prepared as polished blocks, these unreacted minerals were not documented in three samples only [SHAMK7(2), SHAMK9(1) and SHAMK18(4)]. Some of the unreacted materials are about $5 \mathrm{~mm}$ in diameter making them visible macroscopically, but many more become visible under the microscope. Four classes of unreacted or partially reacted materials embedded inside copper smelting slags were documented (Table 6.6). These include magnetite, fluorapatite, quartz and less frequently chalcopyrite, only documented in one sample. The residual magnetite minerals, responsible for the high magnetism in these copper slags, contain magnesia and alumina of up to 3 and $4 \mathrm{wt} \%$ respectively. Noteworthy again is the absence of titania at detectable levels in these residual magnetite minerals. Unreacted fluorapatite minerals (typical composition $\mathrm{P}_{2} \mathrm{O}_{3}-44 \mathrm{wt} \%$; CaO-53 wt $\%$ and $\mathrm{F}-4 \mathrm{wt} \%$ ) are also prevalent. They appeared as dark grey grains during SEM-BSE analysis, whilst the magnetite appeared as bright grains. Unreacted quartz grains are considerably smaller than magnetite and apatite grains but they are present in several copper slags samples. Microscopically, some of the partially reduced minerals have copper prills that failed to separate from the partially dissolved minerals by gravity, suggesting a strong geological association of copper and other minerals. Only one copper smelting slag, SHAMK7(1), contains residual copper-iron sulphide ore fragments (Figure 6.38 Top). This slag sample contained several partially reacted chalcopyrite grains and the bulk chemistry also shows significant $\mathrm{SO}_{3}$ levels $(1.5 \mathrm{wt} \%$ on average, see Table 6.7). Secondary copper carbonates (or chlorides) were also 
redeposited in some porous slag samples due to post depositional corrosion (Figure 6.38 Bottom), but these phases are clearly not original relict minerals.

Table 6.6: Data showing the presence $(\mathscr{})$ and absence of unreacted and partially reduced minerals embedded in the copper smelting slags.

\begin{tabular}{|l|c|c|c|c|}
\hline Sample & Chalcopyrite & Fluorapatite & Magnetite & Quartz \\
\hline SHA1NWL & & $\checkmark$ & & \\
\hline SHA4NWL & & & $\checkmark$ & \\
\hline SHA5NWL & & $\checkmark$ & & \\
\hline SHA6NWL & & & $\checkmark$ & \\
\hline SHA7NWL & & $\checkmark$ & $\checkmark$ & \\
\hline SHA8NWL & & $\checkmark$ & $\checkmark$ & \\
\hline SHA9NEL & & $\checkmark$ & $\checkmark$ & \\
\hline SHA9NWL & & $\checkmark$ & & \\
\hline SHA10NEL & & & & \\
\hline SHA10NWL & & & $\checkmark$ & \\
\hline SHAMK7(1) & $\checkmark$ & & $\checkmark$ & \\
\hline SHAMK8(1) & & & & \\
\hline SHAMK18(1) & & $\checkmark$ & $\checkmark$ & \\
\hline SHAMK18(2) & & $\checkmark$ & & $\checkmark$ \\
\hline SHAMK18(3) & & $\checkmark$ & & \\
\hline SHAMK27(3) & & & & $\checkmark$ \\
\hline SHARS(2) & & $\checkmark$ & & $\checkmark$ \\
\hline SMB21(1) & & & & $\checkmark$ \\
\hline SMB22(1) & & & & \\
\hline SMB22(2) & & & & \\
\hline SMB23(1) & & & & \\
\hline SMB24(1) & & & & \\
\hline SMB26(1) & & & & \\
\hline
\end{tabular}




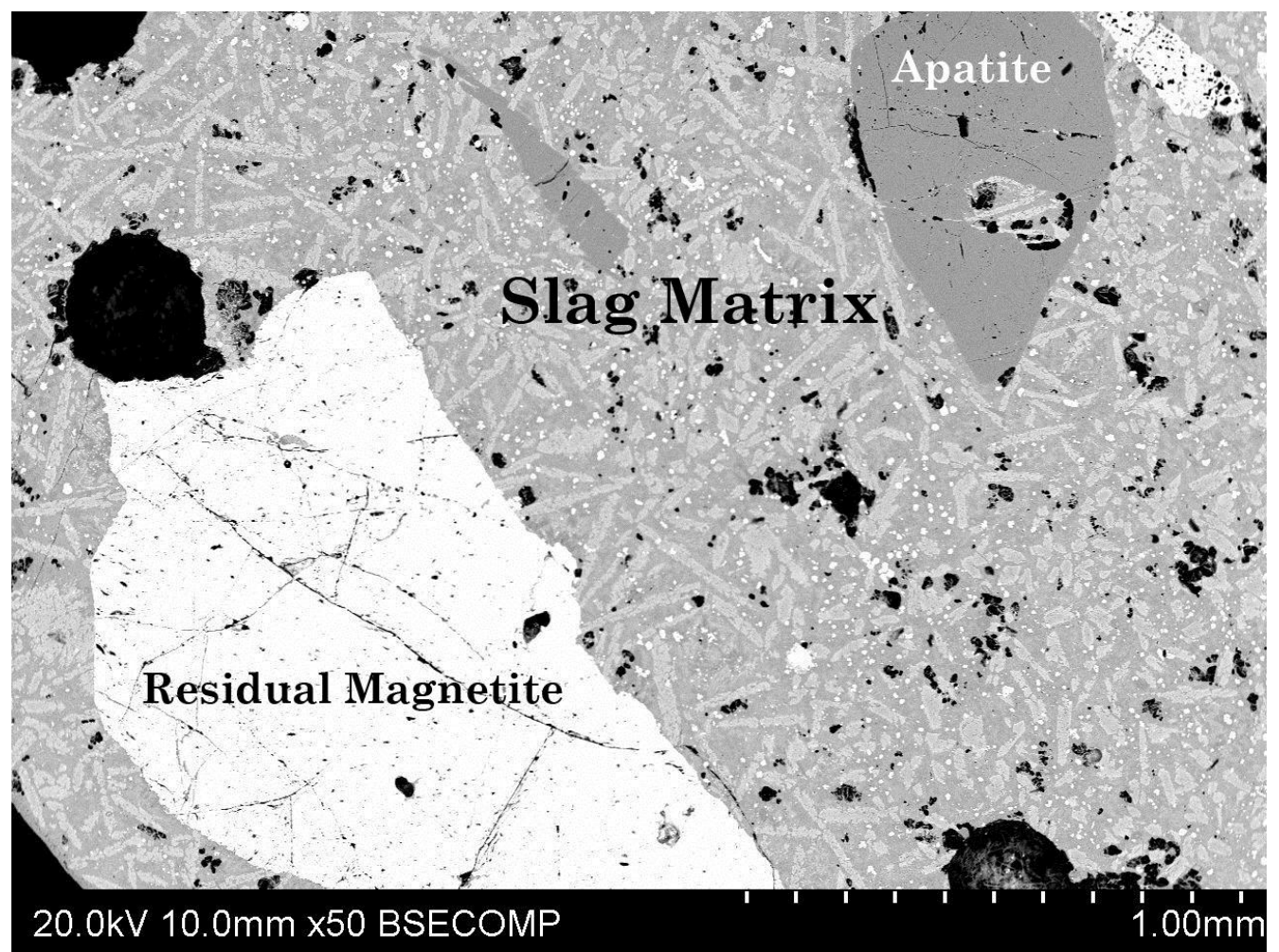

Figure 6.36: SEM-BSE image showing undissolved minerals embedded in the slag matrix of sample SHA8NWL.

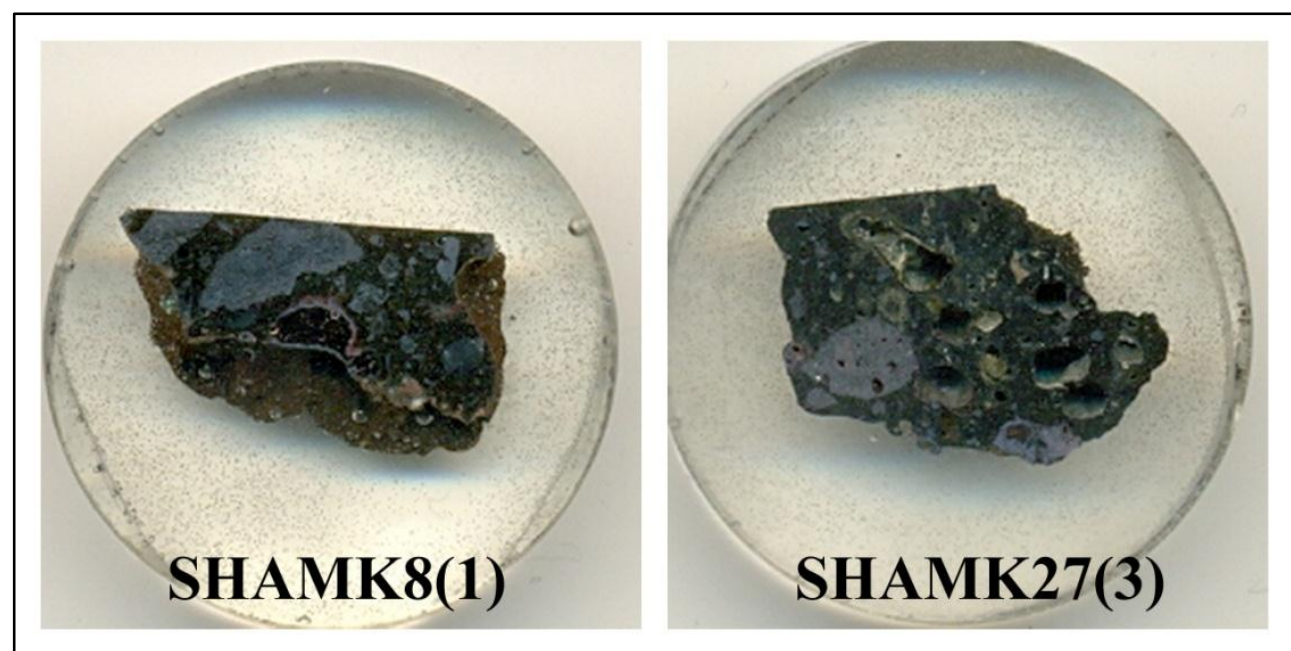

Figure 6.37: Macroscopic residual magnetite fragments in the polished blocks of copper smelting slags from Shankare. 

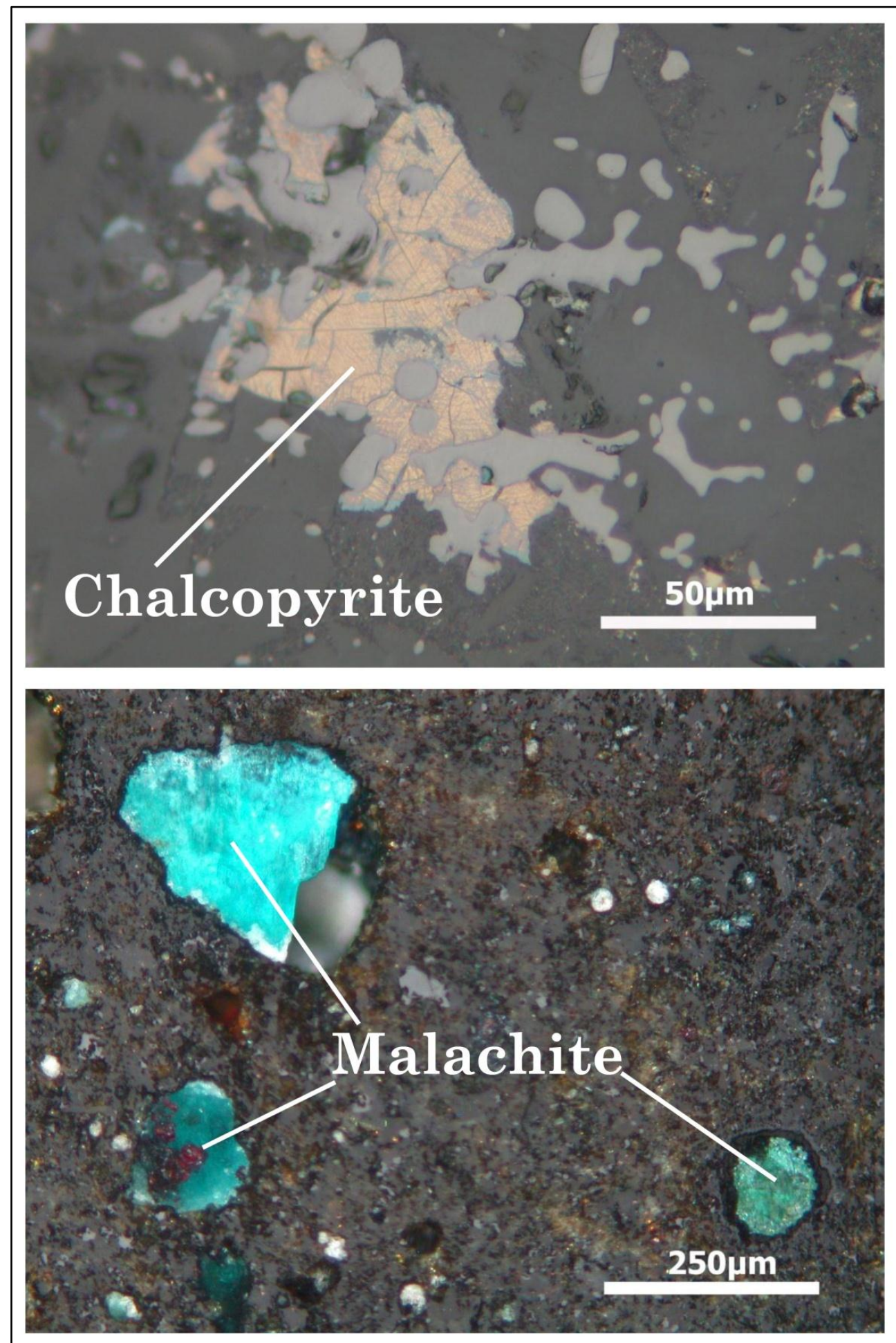

Figure 6.38: Photomicrographs of residual chalcopyrite entrapped in sample SHAMK7(1) (Top) and secondary copper compounds resulting from postdepositional corrosion in sample SHAMK18(1)(Bottom). Under plane and cross polarised light respectively. 
The twenty-seven polished blocks of copper slags were also subjected to 'bulk' chemical analysis with SEM-EDS as outlined in Chapter 5. The three principal oxides in these copper slags are in their order $\mathrm{SiO}_{2}(29-51 \mathrm{wt} \%), \mathrm{FeO}(6-45 \mathrm{wt} \%)$ and $\mathrm{CaO}(8-28 \mathrm{wt} \%)$ (Table 6.7). Just like the iron smelting slags, these copper slags are best presented in the $\mathrm{FeO}-\mathrm{CaO}-\mathrm{SiO}_{2}$ ternary system. However, the average sum of silica, lime and iron oxide in each copper slag is only $87 \mathrm{wt} \%$ with the rest being accounted by magnesia, phosphorous pentoxide and alumina. The silica to alumina ratio in the copper slags varied widely with a range of 9 to 65 . The viscosity index $\left(\mathrm{K}_{\mathrm{v}}\right)$ of the copper slags calculated only from the once molten matrix excluding unreacted minerals ranged from 0.9 to 2.2 with an average of 1.7 . However, the unreacted mineral grains which were avoided during area scans with SEM-EDS would obviously add to viscosity which is thus underestimated by this calculation. The 'bulk' SEM-EDS results obtained through systematic area scans also avoided large metallic inclusions as such they are not useful in the determination of copper losses in the slags. 
Table 6.7: Average SEM-EDS 'bulk' chemical results of copper slags. The results are normalised to 100 \& presented in wt\%.

\begin{tabular}{|c|c|c|c|c|c|c|c|c|c|c|c|c|c|c|}
\hline SAMPLE & Context & $\mathrm{Na}_{2} \mathrm{O}$ & MgO & $\mathrm{Al}_{2} \mathrm{O}_{3}$ & $\mathrm{SiO}_{2}$ & $\mathbf{P}_{2} \mathrm{O}_{5}$ & $\mathrm{SO}_{3}$ & $\mathrm{~K} 2 \mathrm{O}$ & $\mathrm{CaO}$ & $\mathrm{TiO}_{2}$ & MnO & $\mathrm{FeO}$ & $\mathrm{CuO}$ & $\mathrm{SiO}_{2}: \mathrm{Al}_{2} \mathrm{O}_{3}$ \\
\hline SHA1NWL & Surface & 0.5 & 10.2 & 0.8 & 51.4 & 4.7 & 0.1 & 0.7 & 24.9 & 0.4 & 0.1 & 5.8 & 0.3 & 65 \\
\hline SHA4NWL & Surface & 0.4 & 4.2 & 3.2 & 35.2 & 5.7 & 0.1 & 1.1 & 18.8 & 0.5 & 0.1 & 30.3 & 0.3 & 11 \\
\hline SHA5NWL & Surface & 0.5 & 4.1 & 3.1 & 34.7 & 5.9 & 0.0 & 1.2 & 17.4 & 0.7 & 0.2 & 31.5 & 0.6 & 11 \\
\hline SHA6NWL & Surface & 0.5 & 3.7 & 3.7 & 35.1 & 4.9 & 0.1 & 1.3 & 18.9 & 0.6 & 0.2 & 30.8 & 0.3 & 9 \\
\hline SHA7NWL & Surface & 0.3 & 5.6 & 2.4 & 33.0 & 4.5 & 0.0 & 0.8 & 17.0 & 0.5 & 0.2 & 35.4 & 0.3 & 14 \\
\hline SHA8NWL & Surface & 0.5 & 3.5 & 3.1 & 34.7 & 6.2 & 0.1 & 1.0 & 19.3 & 0.7 & 0.2 & 29.9 & 0.7 & 11 \\
\hline SHA9NEL & Surface & 0.5 & 6.0 & 2.3 & 34.3 & 3.3 & 0.1 & 0.8 & 26.6 & 0.5 & 0.2 & 24.9 & 0.5 & 15 \\
\hline SHA9NWL & Surface & 0.5 & 3.4 & 3.1 & 34.6 & 0.9 & 0.1 & 0.9 & 14.7 & 0.3 & 0.1 & 40.4 & 1.0 & 11 \\
\hline SHA10NEL & Surface & 0.7 & 2.9 & 3.1 & 30.4 & 12.4 & 0.1 & 1.0 & 16.8 & 0.9 & 0.3 & 29.5 & 2.1 & 10 \\
\hline SHA10NWL & Surface & 0.4 & 3.7 & 3.4 & 36.1 & 4.6 & 0.0 & 1.3 & 18.0 & 0.6 & 0.1 & 30.8 & 0.8 & 11 \\
\hline SHAMK7(1) & Scatter 7 & 0.5 & 3.8 & 3.1 & 30.0 & 1.9 & 1.5 & 1.4 & 28.1 & 0.2 & 0.2 & 29.0 & 0.4 & 10 \\
\hline SHAMK7(2) & Scatter 7 & 0.4 & 6.6 & 2.8 & 32.3 & 1.8 & 0.2 & 0.9 & 25.9 & 0.1 & 0.3 & 28.3 & 0.5 & 12 \\
\hline SHAMK7(3) & Scatter 7 & 0.2 & 5.7 & 1.2 & 30.7 & 1.5 & 0.1 & 0.4 & 17.8 & 0.1 & 0.3 & 40.0 & 1.8 & 25 \\
\hline SHAMK8(1) & Scatter 8 & 0.2 & 5.8 & 2.1 & 32.6 & 4.7 & 0.1 & 0.5 & 22.1 & 0.5 & 0.2 & 29.2 & 2.0 & 16 \\
\hline SHAMK9(1) & Scatter 9 & 0.7 & 3.4 & 3.2 & 32.1 & 1.7 & 0.1 & 1.0 & 14.8 & 0.6 & 0.1 & 41.5 & 1.0 & 10 \\
\hline SHAMK18(1) & Scatter 18 & 0.1 & 5.3 & 1.1 & 42.7 & 1.7 & 0.0 & 0.3 & 17.2 & 0.5 & 0.3 & 27.9 & 2.9 & 38 \\
\hline SHAMK18(2) & Scatter 18 & 0.2 & 6.9 & 1.6 & 40.6 & 1.7 & 0.1 & 0.5 & 22.7 & 0.3 & 0.3 & 24.0 & 1.2 & 26 \\
\hline SHAMK18(3) & Scatter 18 & 0.5 & 3.4 & 3.2 & 31.7 & 3.6 & 0.2 & 0.8 & 15.6 & 0.1 & 0.2 & 39.8 & 0.9 & 10 \\
\hline SHAMK18(4) & Scatter 18 & 0.3 & 1.4 & 1.8 & 37.3 & 4.3 & 0.0 & 0.7 & 8.2 & 0.3 & 0.2 & 45.0 & 0.5 & 21 \\
\hline SHAMK27(3) & Scatter 27 & 0.4 & 3.4 & 2.4 & 36.6 & 0.9 & 0.0 & 0.7 & 9.0 & 0.3 & 0.2 & 43.9 & 2.2 & 15 \\
\hline SHARS(2) & Road Side & 0.2 & 4.7 & 2.1 & 34.7 & 7.8 & 0.1 & 0.5 & 21.3 & 0.5 & 0.2 & 26.7 & 1.3 & 16 \\
\hline SMB21(1) & SHAM1 & 0.3 & 5.6 & 1.6 & 32.1 & 1.1 & 0.2 & 0.7 & 13.8 & 0.2 & 0.3 & 41.4 & 2.7 & 20 \\
\hline SMB22(1) & SHAM1 & 0.3 & 2.7 & 2.5 & 36.3 & 0.8 & 0.2 & 0.9 & 9.6 & 0.2 & 0.1 & 44.8 & 1.6 & 15 \\
\hline SMB22(2) & SHAM1 & 0.3 & 5.1 & 2.6 & 31.8 & 1.0 & 0.6 & 0.6 & 21.4 & 0.4 & 0.2 & 34.6 & 1.4 & 12 \\
\hline SMB23(1) & SHAM1 & 0.5 & 4.5 & 2.6 & 34.5 & 0.7 & 0.3 & 0.9 & 19.8 & 0.3 & 0.2 & 34.7 & 1.1 & 13 \\
\hline SMB24(1) & SHAM1 & 0.2 & 3.6 & 1.2 & 28.9 & 0.9 & 0.1 & 0.3 & 18.4 & 0.2 & 0.2 & 43.9 & 2.1 & 25 \\
\hline SMB26(1) & SHAM1 & 0.3 & 3.0 & 2.2 & 38.4 & 3.5 & 0.0 & 0.6 & 23.1 & 0.4 & 0.2 & 27.2 & 1.0 & 17 \\
\hline
\end{tabular}


The analytical results of slag sample SHA1NWL deserve further attention because this sample is rather peculiar. Macroscopically this sample has red exterior colour with patches of green stains resulting from corrosion of metal prills. The polished section of the slag matrix is riddled with tiny cavities together with matte and copper prills. However, the surface of the slag sample is covered by iron phosphide prills with average of $18.3 \mathrm{wt} \%$ phosphorus, $80.5 \mathrm{wt} \%$ iron and $1.2 \mathrm{wt} \%$ copper (Figure 6.39). The iron phosphide prills are tiny and not so abundant, which raises questions whether more would have been produced deliberately or not. A single iron phosphide metal fragment with up to $12 \%$ phosphorus from one of the archaeological sites in Phalaborwa was previously analysed (Miller et al. 2001, 409). On the basis of the available evidence these iron phosphide prills should be interpreted as unwanted speiss from copper smelting (c.f. Thorton et al. 2009). The 'bulk' SEM-EDS of this slag is also notably peculiar with very low levels of $\mathrm{FeO}(5.8 \%)$ consistent with the microscopic absence of free iron oxide phases in this sample (Table 6.7). With the present evidence this sample should simply be regarded as an exception. 

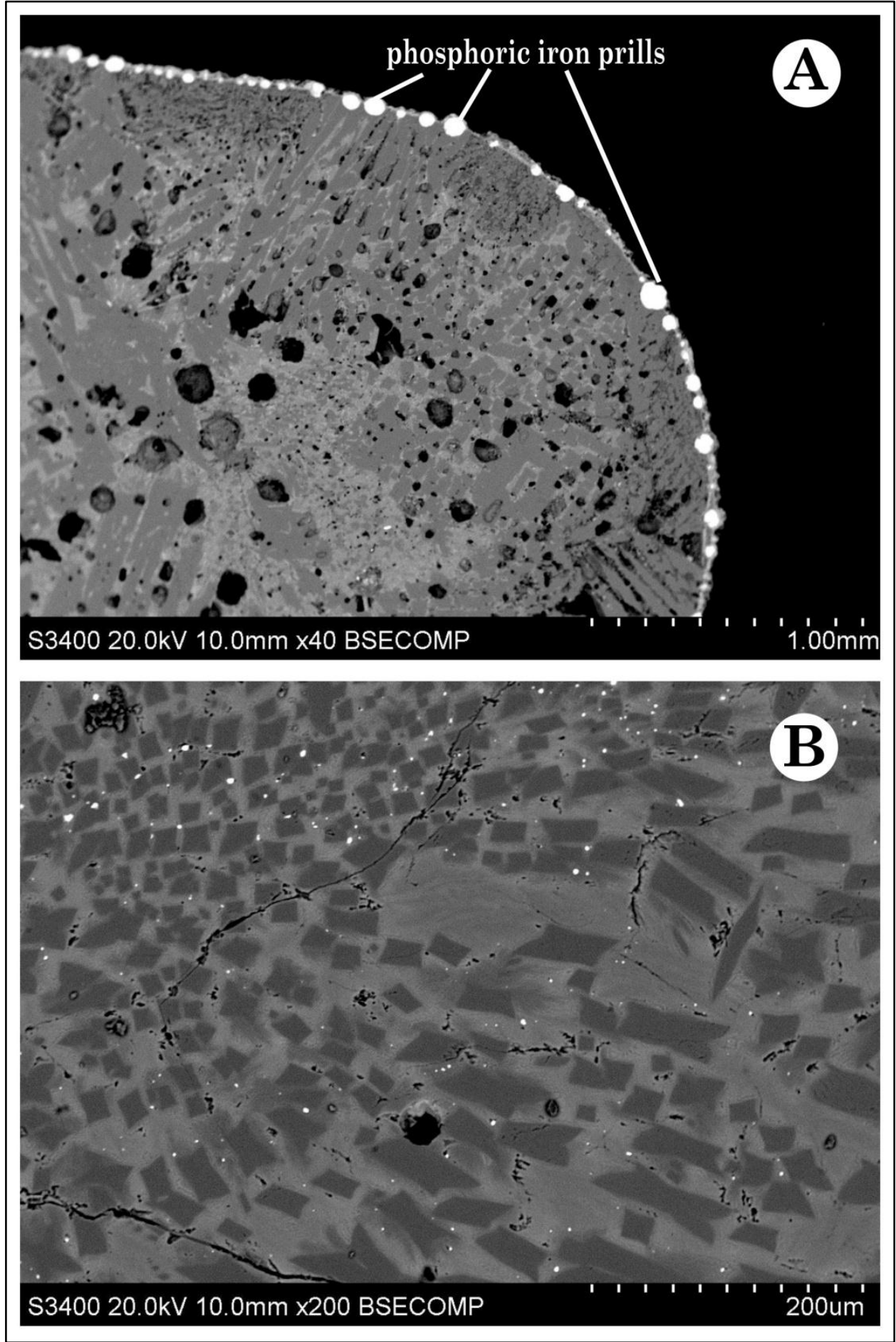

Figure 6.39: SEM-BSE images of slag sample SHAINWL. Image (A) is showing phosphoric iron prills surrounding the slag matrix. Image $(B)$ is showing the micrometric copper and matte prills in the slag matrix. 


\subsubsection{Iron and copper smelting slags: a brief comparison}

The bulk chemical composition of copper slags differs systematically from the composition of iron smelting slags at Shankare. The copper smelting slags are generally enriched in $\mathrm{P}_{2} \mathrm{O}_{5}$ and $\mathrm{CaO}$, but they are notably poor in titania when compared to iron smelting slags (Figure 6.40). Noteworthy also is the inconsistent silica to alumina ratio reported in the copper slags which should be contrasted to the consistent silica to alumina ratio of iron smelting slags (c.f. Table $6.4 \&$ Table 6.7). Copper slags also notably contain more $\mathrm{SiO}_{2}$ than $\mathrm{FeO}$ whereas this is the opposite in iron smelting slags. However, it should be reiterated that $\mathrm{FeO}$ levels are not that useful in discriminating copper from iron smelting slags which usually contain these oxides in varying proportions. Other oxides and microstructural data ought to be considered in distinguishing copper smelting slags from iron slags. The use of magnetic tests to identify copper against iron slags in the field can also be misleading. At Shankare the copper slag samples contain considerable ferromagnetic spinels in the form of magnetite making them highly magnetic.

As pointed out above copper slags from Shankare are significantly enriched in $\mathrm{CaO}$ and $\mathrm{P}_{2} \mathrm{O}_{5}$. The exceptionally high $\mathrm{P}_{2} \mathrm{O}_{5}$ (up to $12 \mathrm{wt} \%$ ) in these slags likely comes from apatite that was charged into the furnace. However, there is too much $\mathrm{CaO}$ in the copper slags to be explained by apatite alone. The $\mathrm{P}_{2} \mathrm{O}_{5}$ to $\mathrm{CaO}$ ratio in the residual apatite is $1: 1.2$ whilst in the molten slag matrices this ratio is approximately 1:5. There was thus an extra source of $\mathrm{CaO}$ most likely fuel ash which would suggest a rather large charcoal to ore ratio possibly explaining exceedingly reducing conditions and occasional presence of exsolved iron inclusions documented in some copper prills. The low titanium levels reported in the copper slags are consistent with 
the bulk chemistry of potential copper ores from Shankare presented in the previous section.

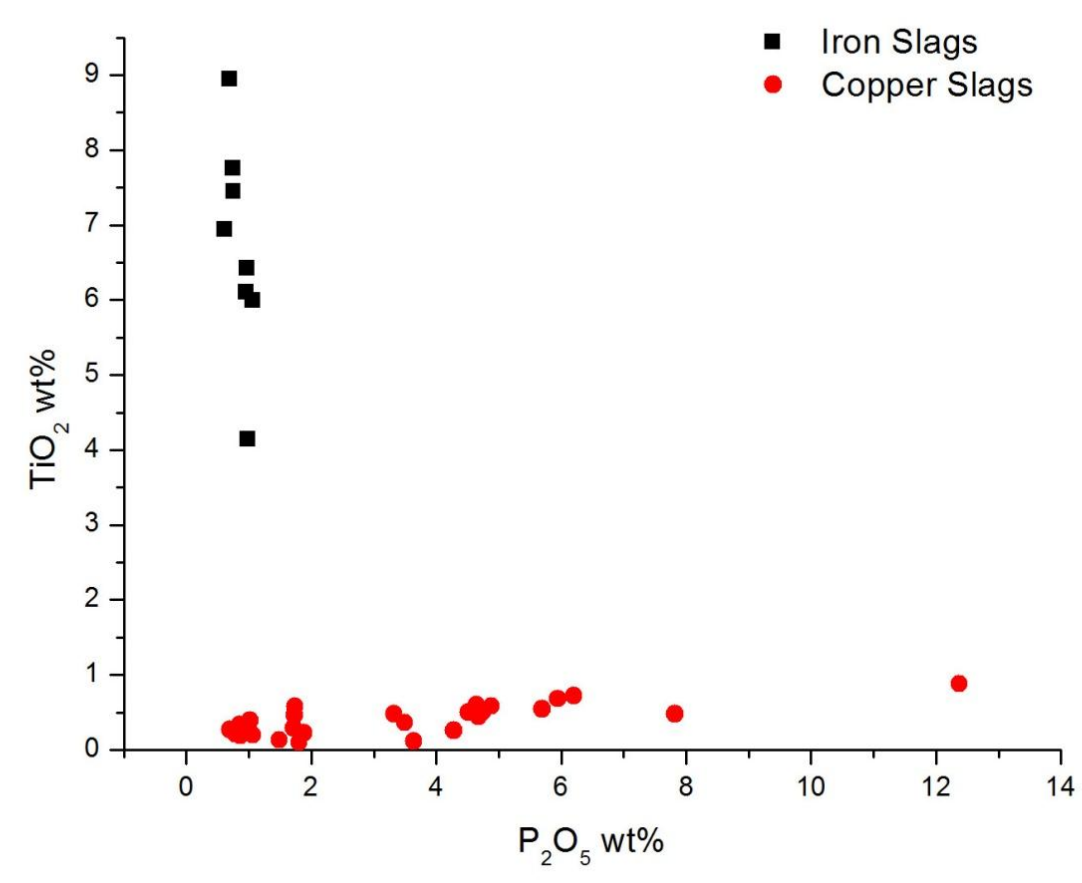

Figure 6.40: Plot of titania against phosphorous pentoxide showing the distinction between $\mathrm{TiO}_{2}$ rich iron slags from $\mathrm{P}_{2} \mathrm{O}_{5}$ rich copper slags. Data based on 'bulk' SEM-EDS area scans.

It is important to highlight that iron smelting slags presented in this section were only recovered from the high density slag scatter (SHASH1) wereas copper slag was recovered from much low density scatters of crushed slags (SHAMK7, SHAMK8, SHAMK9, SHAMK18, SHAMK27 \& SHARS) and from the domestic midden (SHAM1). This information is very crucial in contextualising metallurgical processes that took place at Shankare as will be discussed later in this thesis (see Chapter 8). This combination of fieldwork observations and analytical work shows that sometimes less obtrusive slag scatters can contain equally important technological 
information. However, such low density scatters are usually missed because field workers are generally interested in large slag heaps or high density slag scatters.

To summarise, analytical results of the slags recovered from Shankare confirm that both iron bloomery and copper smelting were practised at the site. The iron slags are characterised microscopically by dominant blocky magnesian kirschsteinite olivines, ulvospinels together with wüstite dendrites and metallic iron particles. On the other hand the once molten parts of copper slags are dominated by fully crystallised olivines suggesting relatively slow cooling process inside the furnace. These olivine (fayalitic) dominated copper slags are usually associated with smelting operations rather than melting. The predominant free iron oxides associated with copper slags from Shankare are magnetite spinels with occasional wüstite dendrites. Although some magnetite skins were noted microscopically in some copper slags there in no evidence of systematic slag tapping at Shankare. Apart from the once molten slag phases copper smelting slags also contain unreacted minerals, mainly magnetite together with some fluorapatite and quartz. Residual copper-iron sulphide ores identified as chalcopyrite were only documented in one copper smelting slag sample. Metallic prills entrapped inside the copper smelting slags are rich in iron and sulphur which occur microscopically in the form of exsolved iron dendrites and globular copper sulphide or copper-iron sulphide inclusions. The copper produced from the smelting process was sometimes impure requiring further refining under less reducing conditions to get rid of the iron and sulphur impurities. The analytical results of crucibles fragments presented in the section next suggest that primary smelted copper was likely subjected to further refining. 


\subsubsection{Technical ceramics}

Extractive metallurgical processes documented at Shankare Hill employed ceramics for various purposes these are presented here as technical ceramics to differentiate them from the ones that were used for domestic purposes. The technical ceramics included tuyères, vital in the air supply system during the smelting or melting processes. The largest concentration of tuyères at Shankare was deposited together with furnace slags at the location where excavation trench SHASH1 was sunk. Another group of technical ceramics recovered at Shankare included at least seventyfour slagged ceramic fragments easily distinct from tuyères. The greater proportion of slagged ceramics was recovered from the domestic midden (SHAM1) together with copper smelting slags. Few slagged crucible fragments were recovered from the lowest levels of trench (SHASH1) whilst others were occasionally recovered during the systematic surface collection process. Similar slagged ceramics have been reported occasionally in archaeological contexts in Southern Africa but little attention has been given to this potentially informative group of artefacts (Calabrase 2000).

Elsewhere dedicated investigations on technical ceramics from archaeological contexts have revealed that they come in various forms and were employed in a wide range of metallurgical processes (see Bayley \& Rehren 2007; Freestone 1989; Freestone \& Tite 1986; Martinon-Torres \& Rehren 2002; Martinon-Torres \& Rehren 2009; Rehren 1999; Rehren 2003). A range of interesting research questions have been formulated concerning crucibles that were used in metallurgy. One of the contentious issues about ancient crucible metallurgy, be it smelting or melting, is whether the source of the heat was internal or external (Bayley \& Rehren 2007; 
Thornton et al. 2010). In non-ferrous metallurgy, crucibles of varying sizes and form were operated under a range of atmospheric conditions. Some crucibles were used for primary smelting of metals from ores whilst some were used to refine, melt, alloy and cast metals. Refining was usually conducted under oxidising conditions, unlike primary smelting which usually required reducing conditions. The appreciation of the role of these technical ceramics to the metallurgical operations often requires further analytical studies. Systematic methods of investigating such technical ceramics have been developed in Europe; however, despite sporadic analyses, this remains a grey area of research in Southern Africa. Usually no further analytical work is carried out on slagged crucibles; as such, their function has been subject of speculation.

Slagged ceramics have previously been interpreted as melting crucibles, metal smelting and slag skimmers without proper analytical work; as such, they remain the most misunderstood category of metallurgical debris in Southern Africa. The scanty analytical literature on crucibles from archaeological sites in the region is frequently limited to the qualitative characterisation of 'glazes'/ 'glasses' on the surface of these crucibles only to identify metals that were processed in these vessels (Friede \& Steel 1975; Hall et al. 2006; Maggs \& Miller 1995; Miller 2001). The slag linings and ceramic fabrics of these slagged crucibles have not been given the attention that they deserve thus there is no baseline data or framework of reference. Recently, Miller (2010) devoted a paper to pre-colonial melting and casting of non-ferrous metals in Southern Africa. However, the paper rather focuses on the metal products that resulted from melting and casting without much consideration of crucibles that were employed in these processes. Complete ceramic crucibles are generally scarce in Southern African archaeological contexts. As a result the general assumption is that 
purpose made crucibles were not manufactured. Based on ethnographic evidence it has often been suggested that Iron Age metallurgists did not manufacture purpose made crucibles but rather prefered to use broken domestic pottery (Calabrase 2000; Miller 2001). On the other hand slagged fragments are also often viewed as skimmers employed to remove slag or dross floating on molten metal during the refining of non-ferrous metals (Calabrase 2000).

Melting and alloying of non-ferrous metals became well established practice in Southern Africa by the early second millennium AD (Miller 2010). Sandstone crucibles employed in the remelting of imported brass have been reported at various Iron Age sites in South Africa (Friede \& Steel 1975, 223; Maggs \& Miller 1995). However, Miller $(2002,1102)$ does not rule out the possibility that crucibles of various forms could be used as smelting vessels for very pure copper carbonate ores. There are indeed references of "crucible smelting furnaces" that were used for copper production during the Iron Age around the Rooiberg area (Friede \& Steel 1975, 226). Iron Age "copper smelting crucibles" are also on display at Foskor Museum in Phalaborwa (Figure 6.44). However, it appears the distinction between primary 'smelting' of metals from their ores and 'melting' of metal in crucibles is not fully comprehended or appreciated in the cases noted above. It should be pointed out that technical ceramics were also employed in other high temperature processes not related to metallurgy, for example the remelting of imported glass beads (Davison 1973; Miller 2001). As a result not all slagged or glazed ceramic fragments were used for metallurgical purposes. It is against this backdrop that technical ceramics were analysed to establish their function and also to create baseline information upon 
which future research can build on. In this section, results of the analytical work on the ceramic fabrics together with the associated metallurgical residues is presented.

\subsubsection{Tuyères}

The fieldwork at Shankare yielded huge quantities of tuyère fragments. Hundreds of tuyère fragments were carried to UCT for macroscopic descriptions and measurement of dimensions whilst the rest were backfilled. Macroscopically these tuyères are orange red to mid-grey in colour without any pronounced longitudinal impressions reported in tuyères from Early Iron Age contexts in other parts of the Northern Lowveld (Klapwijk 1986b; see Chapter 4). The tuyère fragments included flared ends, shafts and nozzles (Figure 6.41). Unfortunately no complete tuyères were recovered but the basic design of the tuyère fragments fits well within the flared or trumpet-shaped tuyères (see Chapter 4). The flared ends are not slagged or vitrified whilst the nozzles are heavily vitrified and in some cases they are sealed with slag. The clogging of some tuyères with slag should not be interpreted as evidence of slag tapping since it has been established in the previous section that this was not common practice. Slag-clogged tuyères together with cylindrical slag plugs are often regarded as positive evidence of smelting rather than smithing or refining (Klapwijk 1986b, 19; Miller 2001, 96). Thus the occurence of slag-clogged tuyères further supports conclusions made in the previous section that the majority of the metallurgical debris at Shankare should be associated with primary smelting operations. The fusion of tuyères as bundles cemented together by slag which highlightes the use of multiple tuyères in the same port, was not documented at Shankare. This usually suggests that natural draft combustion was not employed and 
that single tuyères were used for each furnace port. According to Mapunda (2010, 134) the presence of flared or trumpted-shaped tuyères are usually associated with forced draft. The non-vitrified flared ends were designed to accomodate bellows that provided air to the furnaces. The measurable dimensions of the circular-sectioned tuyère fragments are as follows: the average thickness of the tuyère fabrics is $13 \mathrm{~mm}$ with a range of between $8 \mathrm{~mm}-19 \mathrm{~mm}$, internal diameter is on average $33 \mathrm{~mm}$ (ranging between $26-40 \mathrm{~mm}$ ) whilst their average external diameter is $58 \mathrm{~mm}$ (ranging between 46-64 mm).

Ten tuyère fragments were subjected to reflected light microscopy and SEM-EDS to characterise both the ceramic fabrics and run-back slag. For the purposes of fabric characterisation, non-vitrified and non slagged parts of samples SHA2T, SHA3T, SHA21NEL, SHA22NEL, SHA23NEL, SHA24NEL, SHA25NEL and SHA27NEL were prepared as polished blocks. Microscopically, the selectively sampled non vitrified parts of the tuyères contain intact non-plastic mineral inclusions in the form of quartz and feldspars ranging from medium to coarse grains. The non-plastic inclusions are well-rounded in most cases suggesting that they occurred naturally in the original clay that was used to manufacture the tuyères, or if they were added artificially, sand rather than crushed rocks were used (Figure 6.42). The ceramic fabrics of these tuyères also contain micrometric ilmenite inclusions mostly visible during SEM-BSE imaging. As is expected for non-vitrified parts of tuyère fragments, the porosity of the ceramic fabric is still angular. In line with the recommendations of Freestone and Tite $(1986,39)$ the bulk chemical data of the ceramic fabrics of tuyères from Shankare was determined with multiple SEM-EDS area scans. Large non-plastic inclusions and porosity were carefully avoided during these multiple area 
scans. Chemically, the ceramic fabrics of the tuyères are dominated by silica (ranging 61-71 wt\%) and alumina (ranging 17-21 wt\%) with an average silica to alumina ratio of 3 (Table 6.8). The ceramic fabric also contains significant amounts of iron oxide (ranging 5-9 wt\%). Noteworthy is the comparatively lower amounts of $\mathrm{TiO}_{2}, \mathrm{P}_{2} \mathrm{O}_{5}$ and $\mathrm{CaO}$ in the tuyère samples compared to the smelting slags discussed above. As such the contribution of ceramics tuyères cannot account for the high $\mathrm{TiO}_{2}$, $\mathrm{P}_{2} \mathrm{O}_{5}$ and $\mathrm{CaO}$ in any of the smelting slags presented in the previous sections. However, this does not imply that ceramics did not contribute to the slag composition because some tuyère nozzles show signs of heavy slag attack (Figure 6.41). The few run-back slag samples attached to the tuyères that were analysed were identified as titanium-rich iron smelting slags (see discussion above 6.4.2.3). 


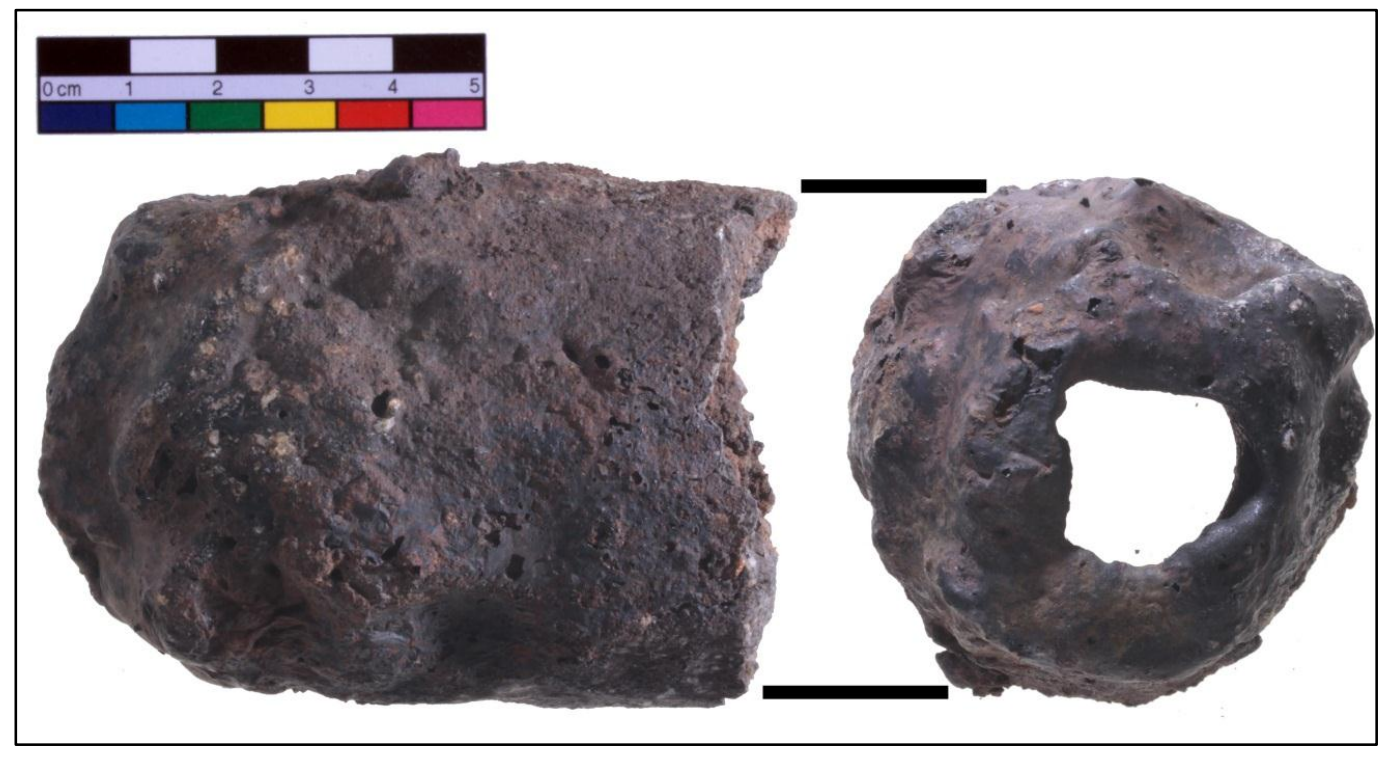

Figure 6.41: Tuyère fragment (nozzle) from trench SHASHI (Image: Author).

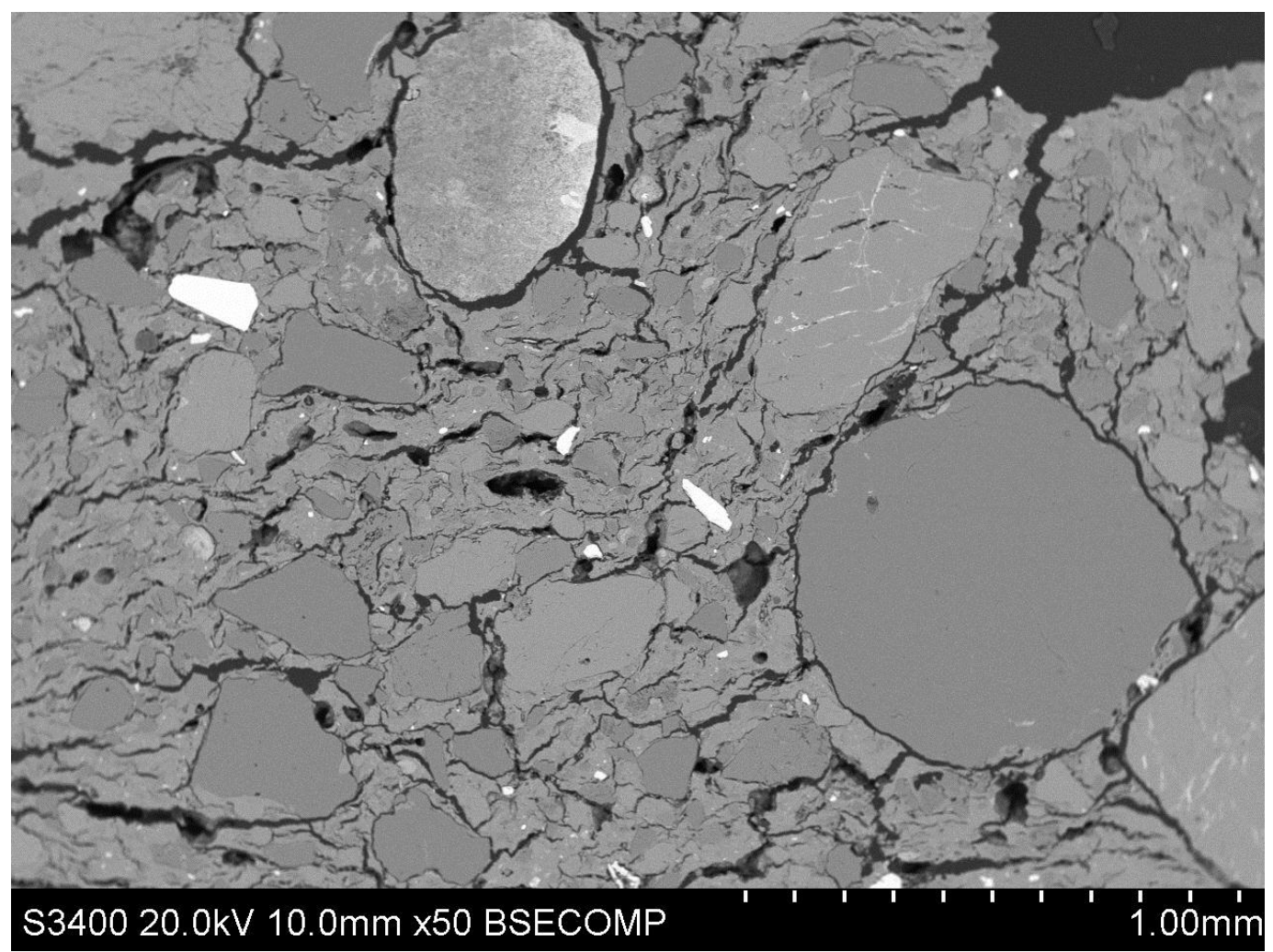

Figure 6.42: SEM-BSE image of the non-vitrified part of tuyère sample SHA25NEL showing the well rounded, unshattered mineral inclusions and bright ilmenite inclusions. 
Table 6.8: Average SEM-EDS results of five area scans of the ceramic fabrics of Shankare tuyères. Reported results in wt\% and normalised to $100 \%$.

\begin{tabular}{|c|c|c|c|c|c|c|c|c|c|c|c|c|c|c|c|}
\hline SAMPLE & Context & Target & $\mathrm{Na}_{2} \mathrm{O}$ & $\mathrm{MgO}$ & $\mathbf{A l}_{2} \mathbf{O}_{3}$ & $\mathrm{SiO}_{2}$ & $\mathbf{P}_{2} \mathrm{O}_{5}$ & $\mathrm{SO}_{3}$ & $\mathrm{~K}_{2} \mathrm{O}$ & $\mathrm{CaO}$ & $\mathrm{TiO}_{2}$ & MnO & $\mathrm{FeO}$ & $\mathrm{CuO}$ & $\mathrm{SiO}_{2}: \mathrm{Al}_{2} \mathrm{O}_{3}$ \\
\hline SHA2T & Surface & Ceramic matrix & 2.3 & 0.9 & 20.3 & 64.7 & 0.0 & 0.1 & 2.9 & 1.6 & 0.7 & 0.1 & 6.4 & 0.0 & 3 \\
\hline SHA3T & Surface & Ceramic matrix & 2.2 & 1.0 & 16.9 & 70.7 & 0.1 & 0.1 & 2.4 & 1.6 & 0.5 & 0.1 & 4.7 & 0.0 & 4 \\
\hline SHA21NEL & Surface & Ceramic matrix & 1.7 & 0.9 & 18.4 & 64.9 & 0.2 & 0.0 & 3.1 & 1.4 & 1.0 & 0.1 & 8.3 & 0.0 & 4 \\
\hline SHA22NEL & Surface & Ceramic matrix & 2.4 & 0.9 & 20.6 & 65.4 & 0.1 & 0.0 & 2.9 & 1.3 & 0.7 & 0.1 & 5.5 & 0.0 & 3 \\
\hline SHA23NEL & Surface & Ceramic matrix & 2.2 & 1.0 & 18.8 & 63.8 & 0.1 & 0.2 & 3.7 & 2.0 & 1.5 & 0.1 & 6.9 & 0.0 & 3 \\
\hline SHA24NEL & Surface & Ceramic matrix & 2.0 & 0.7 & 17.4 & 66.3 & 0.1 & 0.2 & 3.8 & 1.3 & 0.8 & 0.1 & 7.3 & 0.0 & 4 \\
\hline SHA25NEL & Surface & Ceramic matrix & 2.0 & 0.8 & 19.7 & 62.7 & 0.2 & 0.0 & 3.4 & 2.3 & 0.8 & 0.0 & 8.0 & 0.0 & 3 \\
\hline SHA27NEL & Surface & Ceramic matrix & 2.0 & 1.1 & 19.6 & 60.9 & 0.3 & 0.1 & 3.2 & 2.4 & 1.1 & 0.1 & 9.3 & 0.0 & 3 \\
\hline
\end{tabular}




\subsubsection{Slagged ceramics}

From the macroscopic appearence of the crucible fragments from Shankare, showing bloating, there is no doubt that they were exposed to very high temperature regimes. Some of these ceramics have obvious copper prills and copper staining. Unfortunately, due to the fragmentary nature of the Shankare crucible sherds, it is impossible to establish the form and size of complete vessels. As a consequence it was not possible to establish charge holding capacity of the Shankare crucibles. It appears, however, that they do not bear special provisions that usually go together with specialised metallurgical crucibles like handles and pouring lips. The Shankare slagged ceramic fragments include vitrified rims and slightly concave sherds presumably coming from the bottom parts of the vessels. As mentioned earlier on, only two complete crucibles from archeological sites in the research area are on display at the Foskor Museum (Figure 6.44). However, information about their precise context of recovery and age could not be established from the museum officials. The fragmentary nature of these technical ceramics render them inaccessible to traditional typological methods. Despite their fragmentary nature, the characterisation of ceramic fabric and associated metallurgical residues can provide important information upon which some conclusions can be based concerning crucible metallurgical processes, the crucible charges, atmospheric conditions and heat source.

Macroscopically, the ceramic fabrics of slagged cricubles range from dark brown, black or dark grey to reddish in colour. They exhibit some colour changes, from the outer parts to the interior, as a result of exposure to varying redox conditions rather 
than use of different clays. The walls have an average thickness of $7 \mathrm{~mm}$ some with a maximum thickness of $12 \mathrm{~mm}$. Metallurgical residues in the form of slag lining and sound copper metal together with extensive vitrification were restricted to the concave part, presumed interior, of the technical ceramics. They range from 0.6 to 5 $\mathrm{mm}$ in thickness. No vitrification, glaze or slag linings were documented on the exterior parts of the slagged ceramic fragments (Figure 6.43). Six fragments were selected for detailed analytical investigations including two rim fragments [SHA3NWL \& SMB23(2)] and four slightly concave sherds [SMB21(3), SMB27(1), SSHB23(1), SSHB23(3)] (Figure 6.45). The analytical results of the crucible fabrics and metallurgical debris are hereby presented separately to facilitate comparisons.

Mineralogically, the dominant inclusions in the ceramic fabric of these crucibles are quartz and feldspar grains. These are mostly sub-rounded and poorly sorted, and they tend to vary in size from a few micrometres up to coarse grains of about a millimetre. The high temperature to low temperature gradient in the profile of these crucibles indicates that the heat source was inside the vessels. Bloating and rounded porosity reaching up to $200 \mu \mathrm{m}$ was limited to the innermost parts of the ceramic fabrics particularly those parts that were in contact with the molten slag or metal charge. The exterior parts of the crucibles remained intact with the feldspars and quartz grains not showing any signs of stress associated with exposure to high temperature processes (Figure 6.46). Technical ceramics with vitrification restricted to the concave side are consistent with evidence of firing from within the crucible and controlling from above (Rehren 2003). Noteworthy is the presence of occasional slag temper inclusions in the ceramic fabric of three crucible fragments [SMB21(3), SMB27(1), SSHB23(2)] out of the six that were subjected to microscopic analyses. The slag 
temper ranges from $300 \mu \mathrm{m}$ to $1 \mathrm{~mm}$ in size. The composition and phases documented in the slag temper are similar to those of iron smelting slags presented in the previous section. The presence of iron slag tempers in these crucibles possibly highlights the recycling of old slag plus connections between pottery, iron and copper production. Occasional bright mineral inclusions identified as ilmenite $\left(\mathrm{FeTiO}_{3}\right)$ and zirconium $\left(\mathrm{ZrO}_{2}\right)$ minerals were also documented in the ceramic fabric of these crucibles. Chemically, the principal oxides of the ceramic fabrics include silica in the range of 54-67 wt\% and alumina ranging from 13-22 wt\% (Table 6.9) with an average ratio of silica to alumina is 3 . Apart from the alumina and silica, which increase the refractoriness, the crucible fabrics also contain significantly high fluxing oxides such as iron oxide (FeO: 6-13 wt\%), potash $\left(\mathrm{K}_{2} \mathrm{O}: 2-4 \mathrm{wt} \%\right)$ and lime (CaO: 3-5 wt\%). Together with the low-melting feldspar grains, these fluxing oxides would have promoted heavy vitrification of the ceramic fabric once they were exposed to high temperatures. For technical ceramics to be most refractory their fabrics should be high in silica and/or alumina and low in iron, alkalis and alkali earth elements that act as fluxes (Bayley \& Rehren 2007, 47).

The presence of copper metal and copper-green staining on these crucible fragments undoubtedly confirms that they were used for metallurgical purposes. The microstructure and composition of the slag linings attached to these crucibles is consistent with crucible melting slags rather than smelting processes. SEM-EDS area scans revealed that the principal oxides, just like the ceramic fabric, are silica $\left(\mathrm{SiO}_{2}\right.$ : 36-47 wt $\%)$ and alumina $\left(\mathrm{Al}_{2} \mathrm{O}_{3}: 8-11 \mathrm{wt} \%\right)$ (Table 6.10). The average ratio of silica to alumina in the slag linings is 4 . Lime $(\mathrm{CaO}: 16-26 \mathrm{wt} \%)$ is significantly high in the slag linings when compared to the crucible fabrics, possibly highlighting the 
presence of fuel ash from charcoal that will have been charged together with other raw materials inside the crucible. This evidence is also consistent with crucibles that were being fired from within rather than below or externally. Iron oxide also contributed significantly to the composition of the slag linings; however, in comparison to the smelting slags discussed in the previous section, the content of $\mathrm{FeO}$ in the crucible slag is significantly low. The slag linings generally have elevated copper levels with a maximum of $13 \mathrm{wt} \%$. Thus, the bulk composition of the slag linings appears typical of melting of ferruginous copper on the basis of their $\mathrm{CaO}$, $\mathrm{FeO}$ and $\mathrm{CuO}$ concentrations. No residual minerals were present in the slag linings adhering to these fragmented crucible sherds.

The metal prills entrapped inside the crucible slags range from $5 \mu \mathrm{m}$ up to $4 \mathrm{~mm}$ in size. These prills are significantly different from the ones entrapped in the copper smelting slags. They are pure, without exsolved iron or sulphides, thus their iron content is very low. On the other hand copper prills embedded in smelting slags occasionally had exsolved iron and iron copper sulphide inclusions (see above). The only inclusions present in the copper prills associated with crucible fragments are instead cuprite $\left(\mathrm{Cu}_{2} \mathrm{O}\right)$ (Figure 6.47). Otherwise these prills are pure copper, as confirmed by SEM-EDS spot analysis, no tin or zinc. Evidence of thin copper linings together with some macroscopic copper prills attached to the crucible fragments testifies that temperatures above the melting point of copper $\left(1083^{\circ} \mathrm{C}\right)$ were attained inside the crucibles. Cuprite inclusions associated with copper prills adhering to the crucible fragments suggests fairly oxidising conditions. The evidence of an oxidising atmosphere further refutes possibilities that they were employed as smelting vessels. The crucible vessels were likely to be shallow and open in form therefore resulting in 
the oxidising atmosphere. All in all, these vessels were presumably used to refine and consolidate the highly ferruginous and sulphide inclusion-laden copper prills documented in the copper smelting slags. The nature of the refining processes will be further discussed in Chapter 8. 
Table 6.9: Average SEM-EDS results of at least five area scans on the ceramic fabrics of each crucible fragment. Results in wt\% and normalised to $100 \%$.

\begin{tabular}{|c|c|c|c|c|c|c|c|c|c|c|c|c|c|c|}
\hline SAMPLE & Context & Target & $\mathrm{Na}_{2} \mathrm{O}$ & $\mathrm{MgO}$ & $\mathrm{Al}_{2} \mathrm{O}_{3}$ & $\mathrm{SiO}_{2}$ & $\mathrm{P}_{2} \mathrm{O}_{5}$ & $\mathrm{SO}_{3}$ & $\mathrm{~K}_{2} \mathrm{O}$ & $\mathrm{CaO}$ & $\mathrm{TiO}_{2}$ & $\mathrm{MnO}$ & $\mathrm{FeO}$ & $\mathrm{CuO}$ \\
\hline SHA3NWL & Surface & Ceramic matrix & 1.8 & 3.1 & 13.3 & 62.0 & 0.4 & 0.6 & 2.6 & 3.2 & 2.0 & 0.1 & 10.8 & 0.1 \\
\hline SMB21(3) & SHAM1 & Ceramic matrix & 2.3 & 1.8 & 20.6 & 54.4 & 0.4 & 0.1 & 2.2 & 3.3 & 1.6 & 0.1 & 13.1 & 0.1 \\
\hline SMB23(2) & SHAM1 & Ceramic matrix & 2.0 & 1.0 & 15.8 & 67.3 & 0.2 & 0.0 & 3.4 & 2.9 & 1.0 & 0.1 & 6.2 & 0.1 \\
\hline SMB27(1) & SHAM1 & Ceramic matrix & 2.9 & 1.5 & 17.2 & 59.4 & 0.5 & 0.1 & 3.6 & 5.3 & 0.9 & 0.1 & 8.4 & 0.1 \\
\hline SSHB23(1) & SHASH1 & Ceramic matrix & 2.4 & 2.3 & 19.4 & 61.1 & 0.3 & 0.1 & 1.8 & 3.2 & 1.0 & 0.0 & 8.4 & 0.0 \\
\hline SSHB23(2) & SHASH1 & Ceramic matrix & 2.5 & 2.4 & 21.6 & 58.7 & 0.3 & 0.1 & 2.4 & 2.5 & 0.9 & 0.1 & 8.6 & 0.1 \\
\hline
\end{tabular}

Table 6.10: Average SEM-EDS results of five area scans of metallurgical debris attached to Shankare crucible fragments. Results in wt\% and normalised to $100 \%$.

\begin{tabular}{|c|c|c|c|c|c|c|c|c|c|c|c|c|c|c|}
\hline SAMPLE & Context & Target & $\mathrm{Na}_{2} \mathrm{O}$ & $\mathrm{MgO}$ & $\mathrm{Al}_{2} \mathrm{O}_{3}$ & $\mathrm{SiO}_{2}$ & $\mathbf{P}_{2} \mathrm{O}_{5}$ & $\mathrm{SO}_{3}$ & $\mathrm{~K}_{2} \mathrm{O}$ & $\mathrm{CaO}$ & $\mathrm{TiO}_{2}$ & $\mathrm{MnO}$ & $\mathrm{FeO}$ & $\mathrm{CuO}$ \\
\hline SHA3NWL & Surface & Vitrified layer & 1.3 & 3.9 & 10.4 & 46.6 & 1.6 & 0.0 & 2.3 & 23.2 & 2.1 & 0.2 & 8.1 & 0.2 \\
\hline SMB21(3) & SHAM1 & Slag lining & 1.5 & 3.3 & 7.6 & 43.3 & 0.9 & 0.1 & 4.3 & 15.9 & 0.7 & 0.1 & 9.8 & 12.6 \\
\hline SMB23(2) & SHAM1 & Vitrified layer & 0.9 & 3.7 & 10.0 & 35.7 & 15.9 & 0.0 & 1.4 & 26.1 & 0.8 & 0.1 & 5.3 & 0.2 \\
\hline SMB27(1) & SHAM1 & Slag lining & 1.7 & 2.7 & 9.2 & 42.8 & 5.5 & 0.1 & 2.7 & 18.3 & 1.5 & 0.1 & 9.9 & 5.6 \\
\hline SSHB23(1) & SHASH1 & Slag lining & 1.7 & 3.1 & 10.5 & 43.6 & 0.8 & 0.0 & 2.7 & 25.2 & 0.6 & 0.1 & 9.9 & 1.7 \\
\hline SSHB23(2) & SHASH1 & Slag lining & 1.7 & 2.9 & 10.9 & 43.3 & 0.6 & 0.1 & 2.6 & 24.4 & 0.6 & 0.1 & 10.6 & 2.3 \\
\hline
\end{tabular}


To summarise, the crucible fragments recovered from Shankare were not used for copper smelting. The analytical results are consistent with metal melting. The composition of the metal prills and slags associated with these crucible fragments does not suggest the practice of bronze alloying or brass melting. The purpose of subjecting raw smelted copper to re-melting in the crucibles was most likely to refine and consolidate loose copper prills. Copper prills were actually recovered in the same contexts with these crucible fragments in midden SHAM1. The re-melting of raw copper, from smelting, in oxidising conditions was a widely employed practice crossculturally but it posed several challenges (Merkel 1990). In as much as the desire was to oxidise exsolved iron impurities and expel sulphur, inevitably some copper was lost to the crucible slag. The effect of this fire refining is very clear in the large copper prills and coatings attached to the crucible fragments. Their microstructures indicate that the atmosphere inside the crucible vessels was relatively oxidising. The heat source for these crucibles was from the inside, as such charcoal a reducing agent was placed inside the crucibles together with the raw copper prills. To raise the temperatures above the melting point of copper some tuyères and bellows must have been required. By blowing a lot of air during the refining stage, both the operating temperatures and oxidising conditions became high. Probably these crucibles were internally heated perhaps because they were unable to withstand the stress if heated through from the outside. One of the outstanding questions is: where are the complete crucible vessels since all of them are heavily fragmented? It appears that only very thin internal layers of these crucibles are high-fired and thus hardened; whilst the bulk of the ceramic fabrics remain low fired hence friable (M, Martinón- 
Torres 2010, pers. comm.). These crucibles were therefore less likely to stay intact for a long period in the archaeological record. 


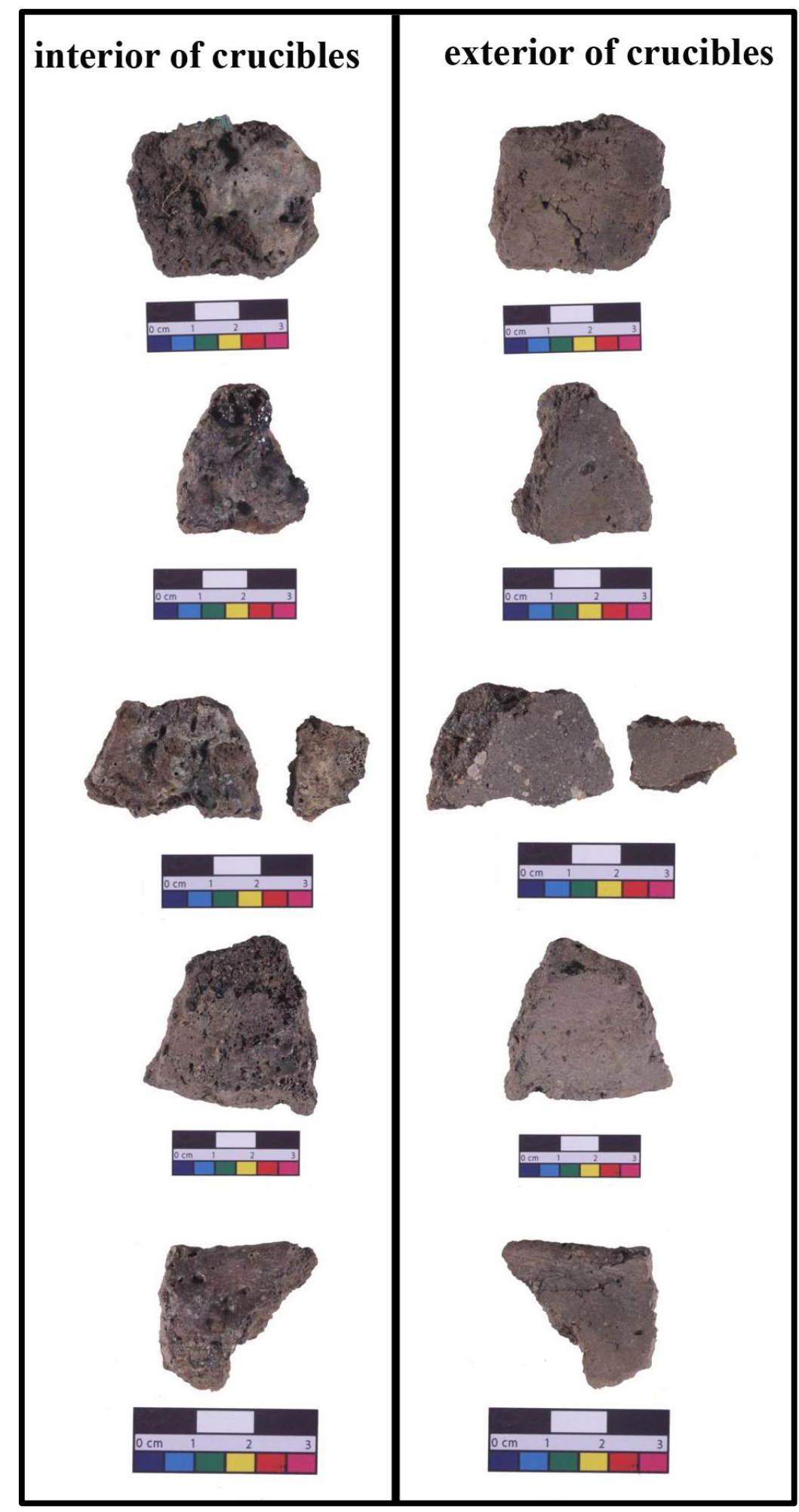

Figure 6.43: Images comparing the slagged and vitrified interiors with the unvitrified exteriors of crucible fragments from Shankare (Image: Author). 


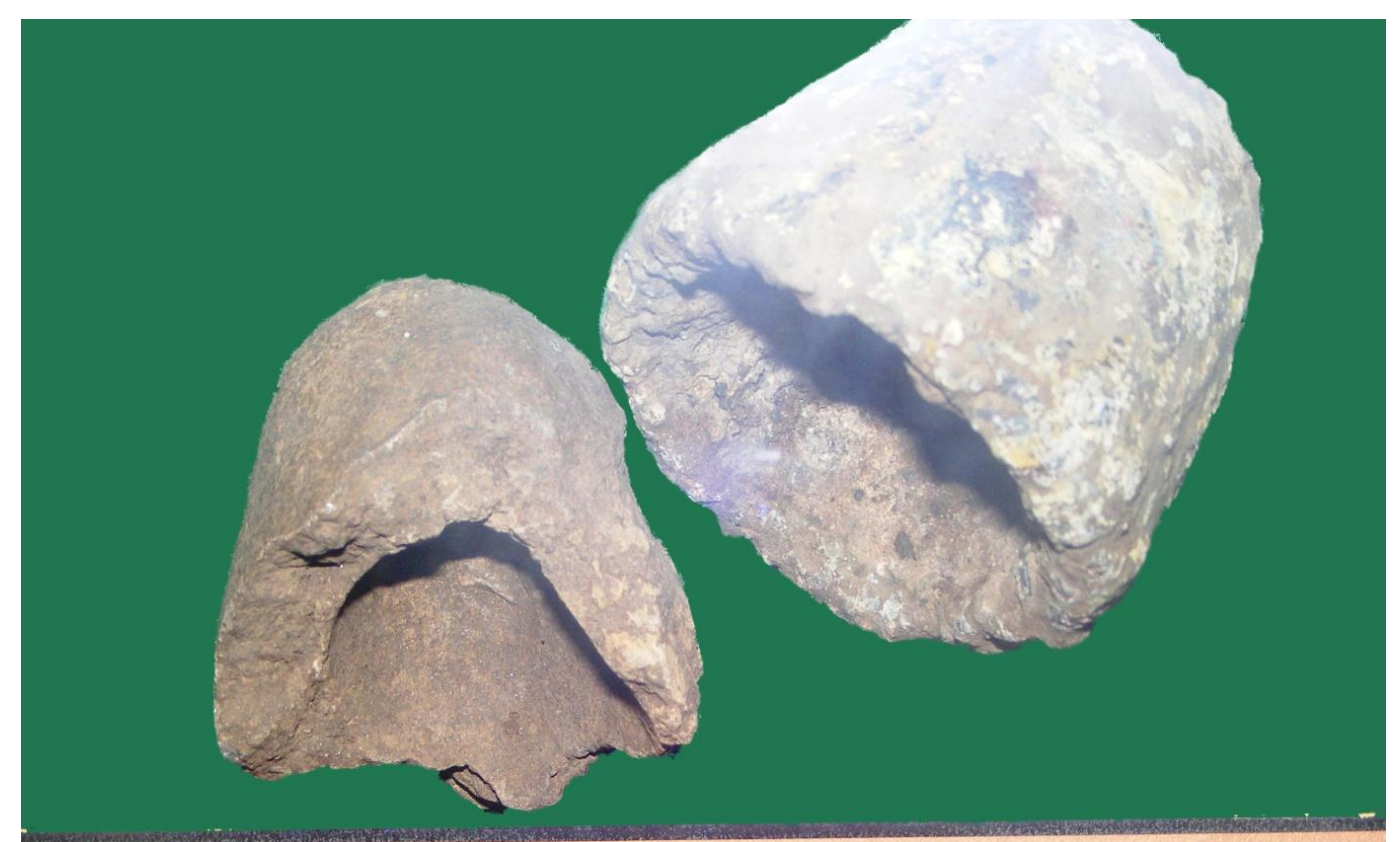

\section{These crucibels were used for the smelting of small quantities of copper}

Figure 6.44: Iron Age clay-based crucibles from Phalaborwa on display at Foskor Museum. Please note that the impression given on the museum label is that these crucibles were used for primary copper smelting (Image: Author). 

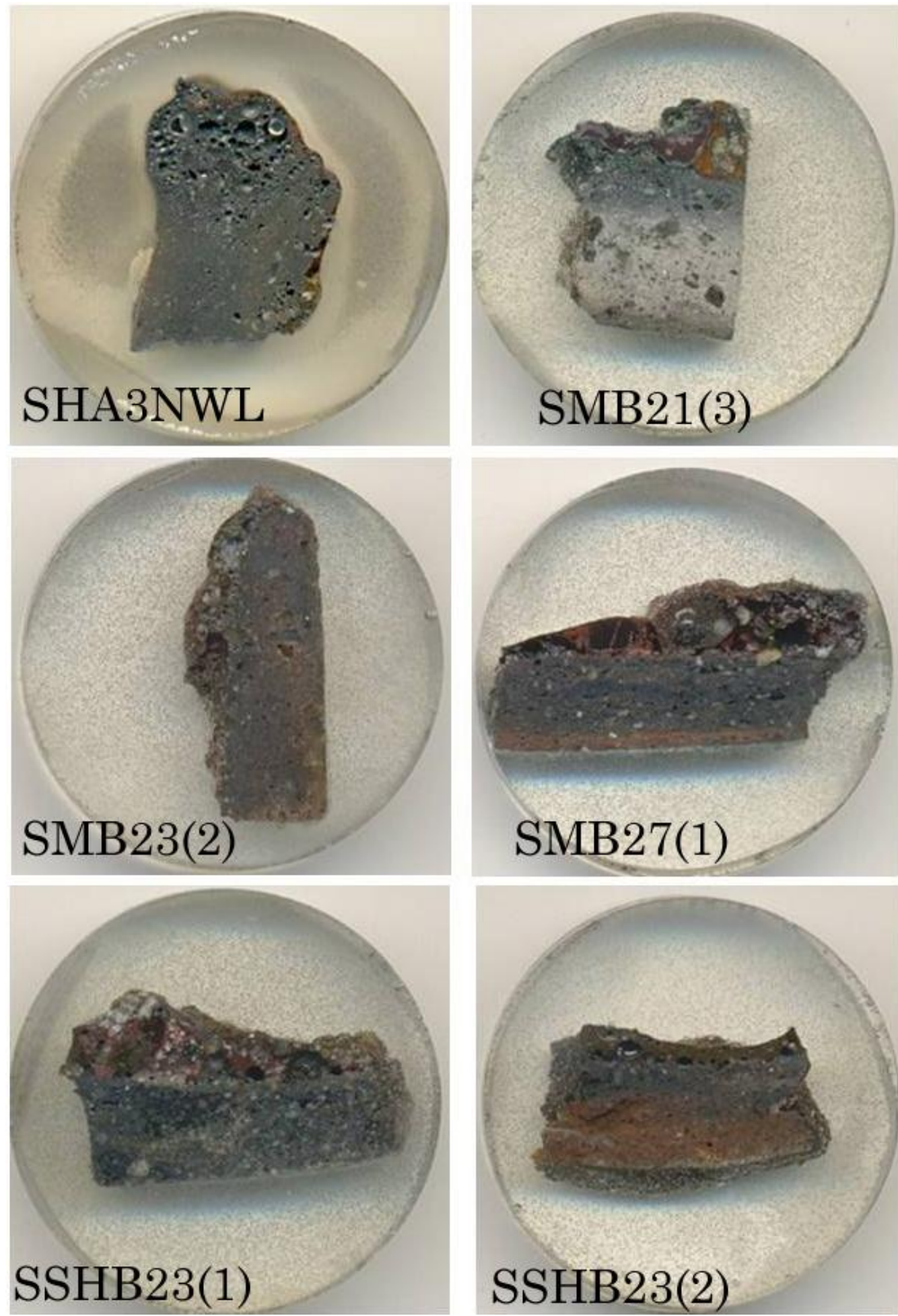

Figure 6.45: Mounted polished blocks of crucible fragments from Shankare Hill (Image: Author). 

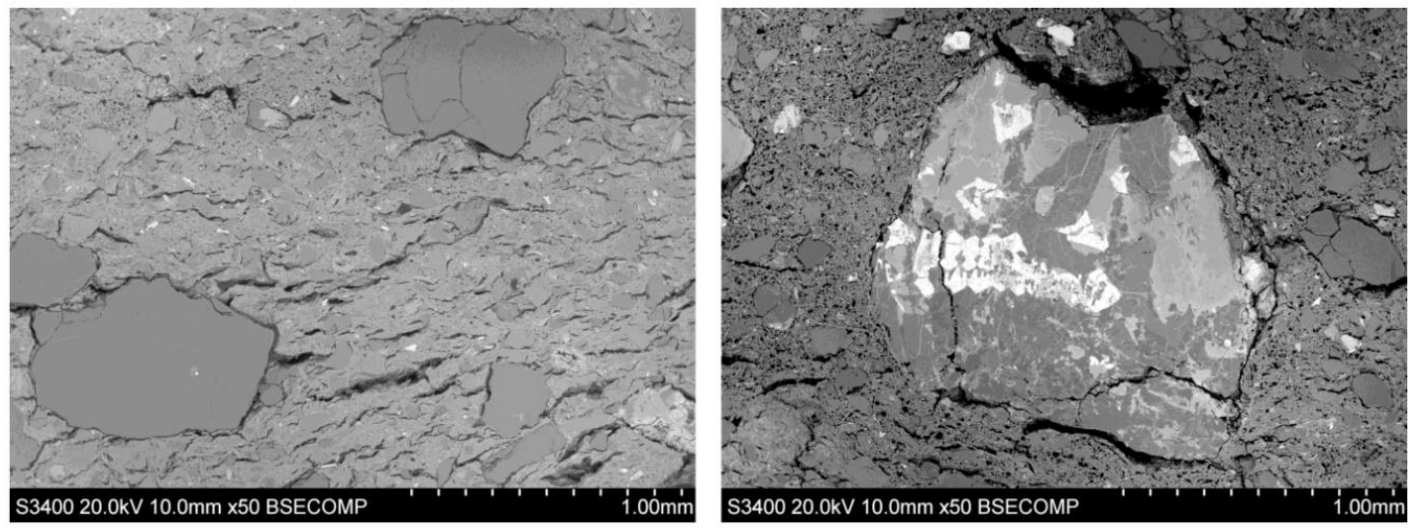

Figure 6.46: SEM-BSE images showing non-shattered quartz inclusion and slag temper in crucible sample SMB21(3).

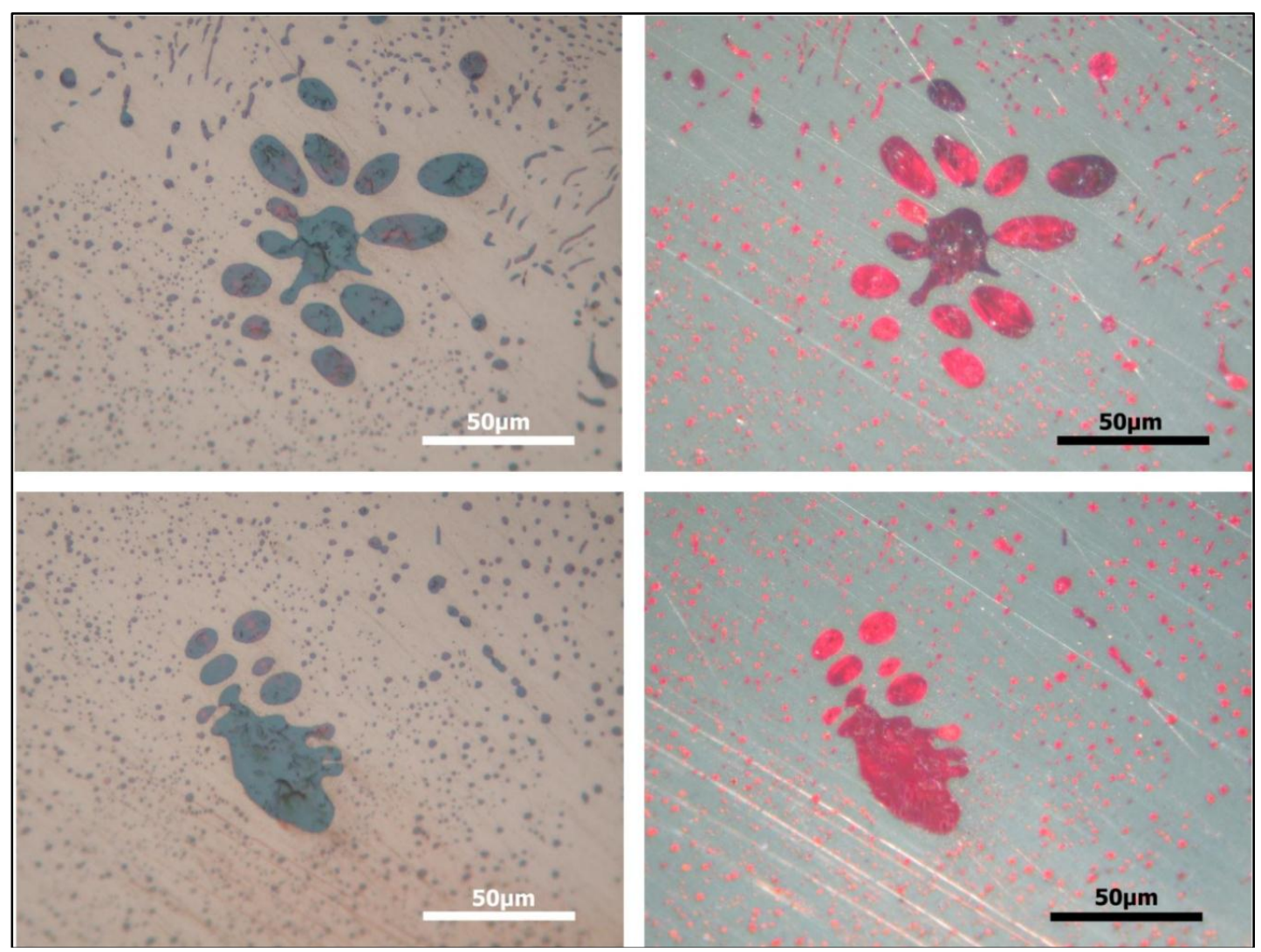

Figure 6.47: Photomicrograph of metal prills adhering to crucible SMB21(3) showing the effects of oxidation during the melting process which resulted in the formation of cuprite. Top left: under plane polarised light (500x), Top right: under cross polarised light (500x), Bottom left: under plane polarised light (500x), Bottom right: under cross polarised light (500x). 


\subsubsection{Metals: copper artefacts, prills and fragments}

Only fourteen copper articles with a total weight of $58 \mathrm{~g}$ were retrieved during the two fieldwork seasons at Shankare (Figure 6.48). These artefacts were in a fairly good state of preservation with only limited and thin layers of green corrosion products on their surface. The limited number of metal artefacts does not seem to suggest high consumption levels of copper artefacts by the residence of Shankare. However, it should be noted that previous excavations in the research area also yielded meagre metal artefacts finds (Miller et al. 2001, 415). It should be acknowledged that large numbers of metal artefacts in the archaeological record usually come from human burials whilst metal production sites and domestic middens targeted in this study usually yield less metallic artefacts. The copper artefacts recovered from Shankare thus represent inevitable occasional losses. Of the fourteen copper objects two were collected from the surface, two from the high density iron smelting slag scatter, with the remaining coming from the domestic midden. Some of these copper artefacts were recovered from the lowest excavation levels at trench SHAM1. Only two copper artefacts from Shankare could be assigned to a proper artefact category. One of them [SSC(1)] was a fragment from a slightly curved heavy copper rod with a circular cross section. This fragment is similar to rigid copper bangles from other archaeological sites in the research area. Examples of these rigid bangles are on display at Foskor and Masorini Museums (Figure 6.49). Artefact SSC(2) is a complete flexible bangle/bracelet/anklet made from a thin wire. These artefacts further confirm that copper was the metal of choice for jewellery production. The rest of the copper artefacts from Shankare cannot be easily assigned to any category; these included three short wires, six tiny lumps/ nodules/ prills and three flat sheets. These artefacts just weigh a few grams and their apparent functional 
purpose is not obvious. These small amorphous articles possibly represent the spillage from raw copper that was re-melted or refined and finally cast or worked into jewellery. One of the slightly concave copper plate [SMB26(2)], possibly represents a layer of metal formed inside the ceramic crucibles discussed above. The absence of obvious copper ingots at Shankare should be highlighted. Having characterised the possible ores, slags and technical ceramics used in the production of copper at Shankare, this section of the chapter briefly presents the analytical results of the copper artefacts. The attempt is to establish the relationship between these metal artefacts and other metallurgical waste at the site. Some ore impurities are likely to enter the metallic phase rather than form slag and they form the key link between our metal artefacts, slags and ores. The copper artefacts will also be compared to metal prills entrapped in the copper smelting slags. The analytical work also sought to determine if copper alloys were present in this limited artefact assemblage. However, detailed metallographic examination of the polished sections, usually involving etching to reveal grain structure or hardness tests to establish the fabrication technology, was beyond the scope of this thesis.

Six copper artefacts that potentially represented various stages of copper processing were prepared as polished sections to establish their bulk and inclusion chemistry. The chemical results are presented in Table 6.11 and more micrographs are found in Appendix 5. Microscopically, only the sub-spherical copper prill [SMB22(3)] contained globular copper sulphide inclusions whilst the rest of the artefacts have cuprite inclusions. Sub-spherical prills similar to sample SMB22(3) have been identified as unrefined products retrieved through slag crushing after primary smelting operations (Miller 2001, 87; Miller 2002, 1102). The presence of copper 
sulphide inclusions in this isolated prill is consistent with sulphide phases present in slag entrapped copper prills. Notably absent in the microstructure of most copper artefacts from Shankare are exsolved iron inclusions prevalent in copper prills entrapped inside smelting slags. The major impurity in these copper artefacts is oxygen, which is present as a network of cuprite surrounding the dendritic copper alpha phase in samples SSC(1) and SMB81(1) (Figure 6.50). Copper artefacts presented in this section are completely different from prills found inside the smelting slags. This discrepancy highlights varying redox conditions in the chaîne opératoire of extractive copper metallurgy that will be further discussed later in this chapter. Significantly, the same cuprite inclusions are prevalent in the metal adhering to the ceramic fragments as presented above. The bulk chemical characterisation of the artefacts with SEM-EDS shows they are largely pure copper. Pure copper artefacts are expected when relatively pure and high grade ores are employed or in cases where thorough refining of the smelted metal was carried out. The typical alloying additives, namely tin, arsenic and zinc were not detected in the metal assemblage, although some tin is present in tiny lead inclusions recorded in sample SMB26(2). 


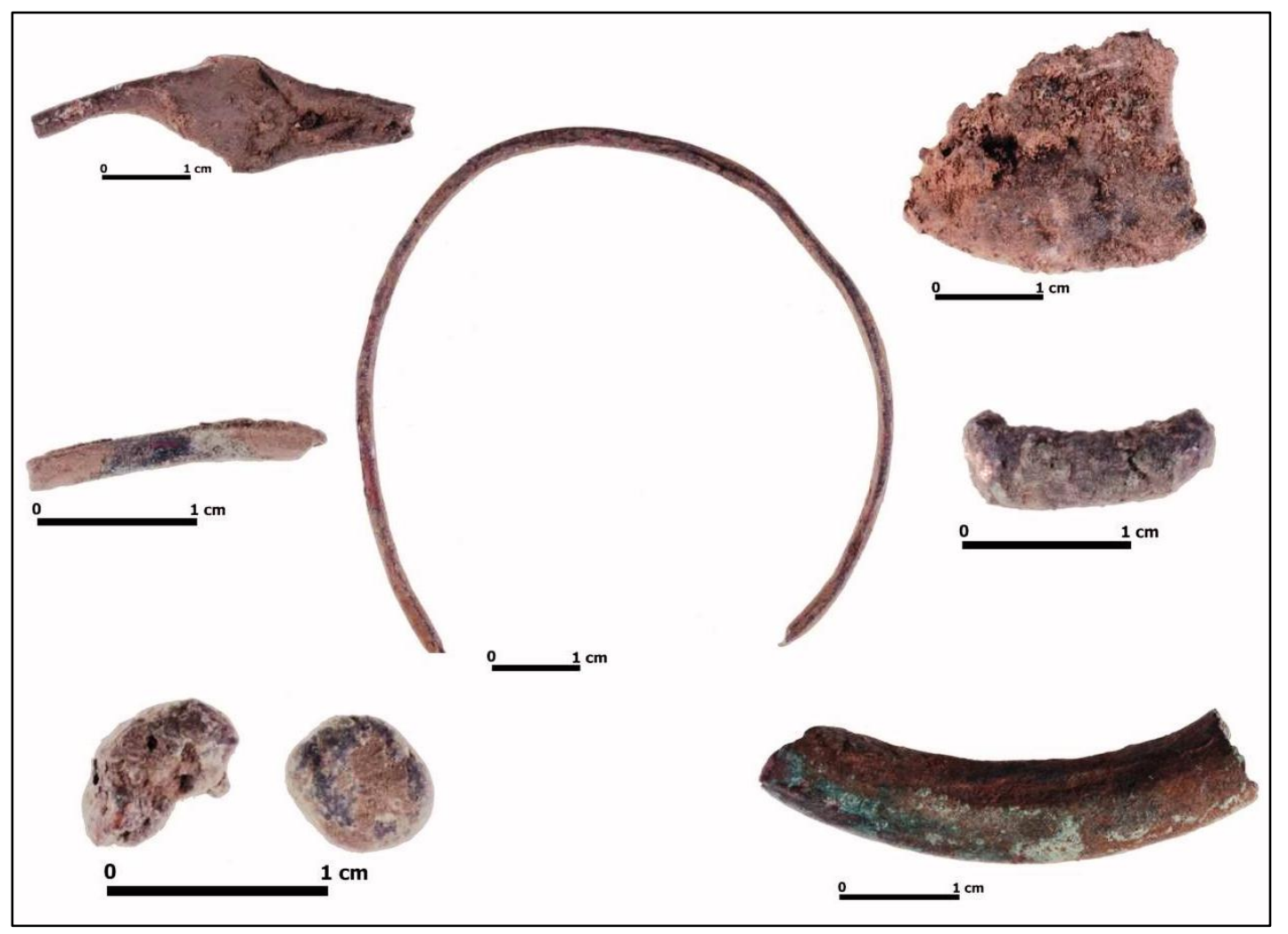

Figure 6.48: Part of the copper metal artefacts recovered from Shankare between 2009 and 2010 (Image: Author). 


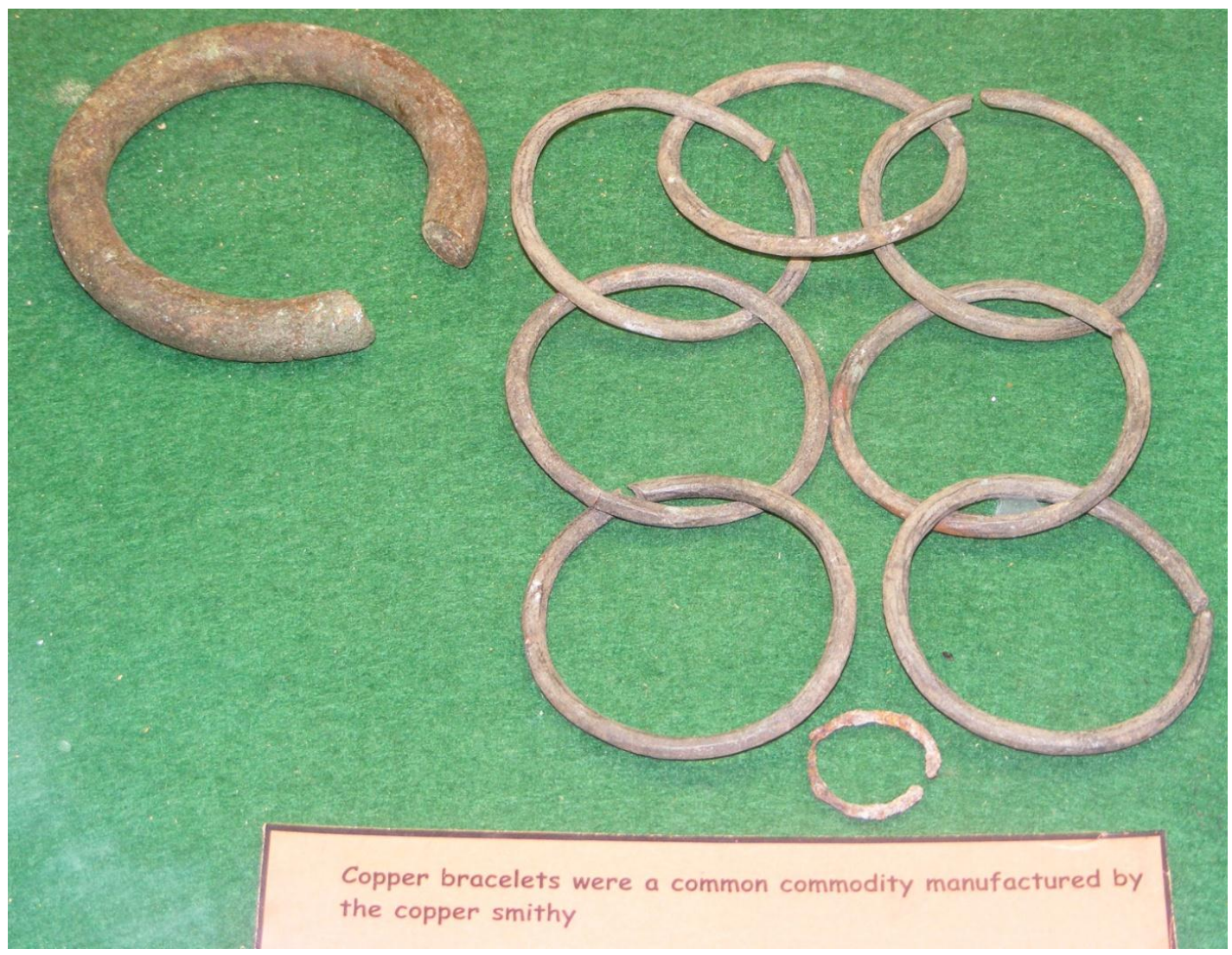

Figure 6.49: Rigid copper bangles from Iron Age sites in the research area. These bangles are on display at Foskor Museum, Phalaborwa (Image: Author). 

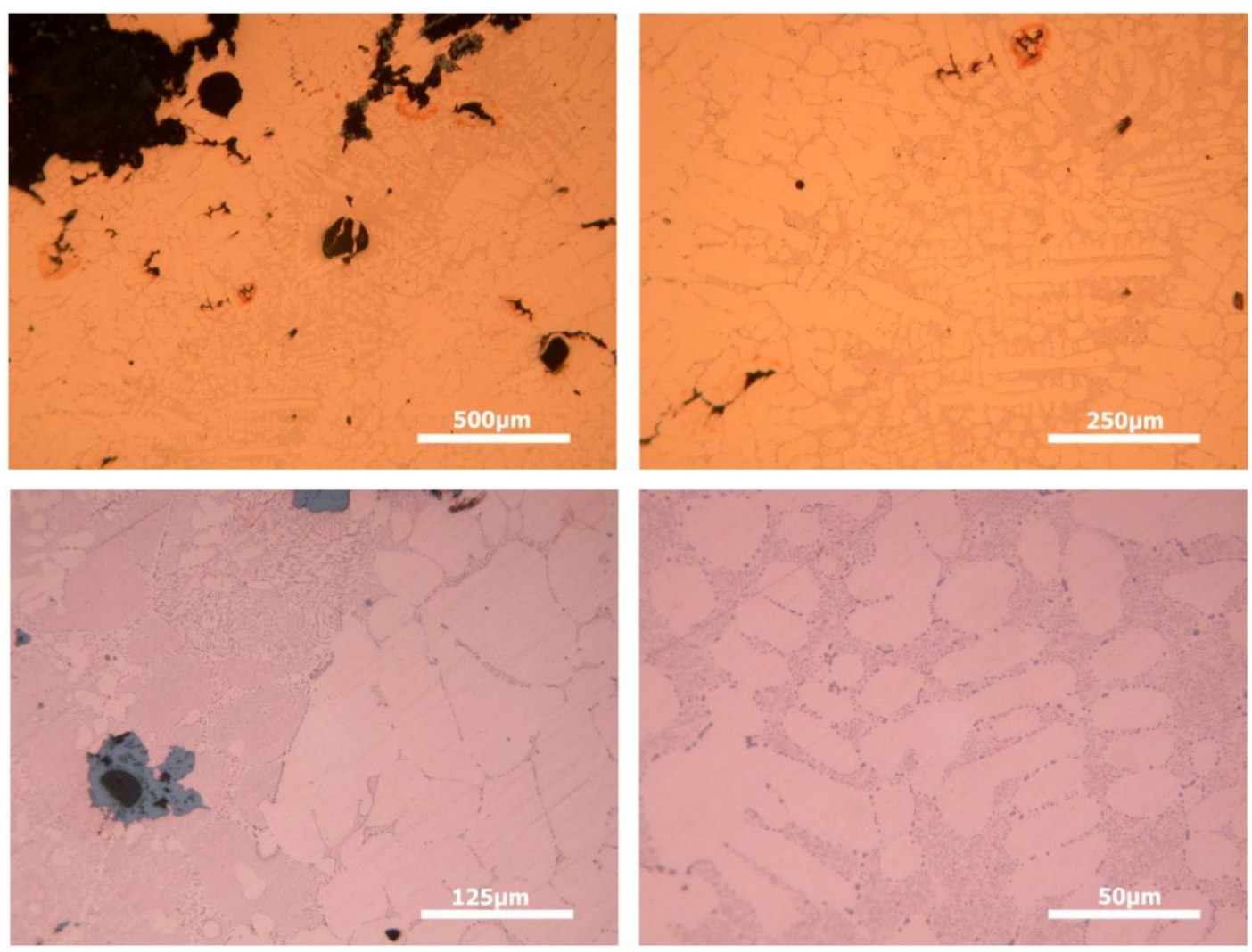

Figure 6.50: Photomicrographs of sample SMB81 showing the copper dendrites together with the network of copper/cuprite eutectic. All images taken under plane polarised light and polished section is not etched (Image: Author). 
Table 6.11: SEM-EDS results of the polished copper artefacts together with their inclusion chemistry. Results are normalised and presented as wt\%.

\begin{tabular}{|c|c|c|c|c|c|c|}
\hline SAMPLE & TARGET & $\mathbf{O}$ & $\mathbf{S}$ & $\mathbf{C u}$ & Sn & $\mathbf{P b}$ \\
\hline $\operatorname{SSC}(1)$ & Area analysis & 0.8 & & 99.2 & & \\
\hline Fragment rigid bangle & Cuprite inclusion & 9.5 & & 90.5 & & \\
\hline \multirow[t]{4}{*}{ Surface collection } & Cuprite inclusion & 9.8 & & 90.2 & & \\
\hline & Cuprite inclusion & 10.3 & & 89.7 & & \\
\hline & Cuprite inclusion & 10.2 & & 89.8 & & \\
\hline & Cuprite inclusion & 10.4 & & 89.6 & & \\
\hline $\operatorname{SSC}(2)$ & Area analysis & & & 100.0 & & \\
\hline Flexible bangle & Cuprite inclusion & 10.3 & & 89.7 & & \\
\hline \multirow[t]{2}{*}{ Surface collection } & Cuprite inclusion & 10.1 & & 89.9 & & \\
\hline & Cuprite inclusion & 10.3 & & 89.6 & & \\
\hline SMB81(1) & Area analysis & 0.7 & & 99.3 & & \\
\hline Copper fragment & Cuprite inclusion & 9.8 & & 90.2 & & \\
\hline \multirow[t]{4}{*}{ Midden Layer 1} & Cuprite inclusion & 10.3 & & 89.6 & & \\
\hline & Cuprite inclusion & 9.7 & & 90.3 & & \\
\hline & Cuprite inclusion & 9.5 & & 90.6 & & \\
\hline & Cuprite inclusion & 8.7 & & 91.3 & & \\
\hline $\begin{array}{l}\text { SMB21(2) } \\
\text { Copper wire } \\
\text { Midden Layer } 1 \\
\end{array}$ & Area analysis & & & 100.0 & & \\
\hline $\operatorname{SMB22(3)}$ & Area analysis & & 0.1 & 99.9 & & \\
\hline Copper Prill & Copper sulphide inclusion & & 20.8 & 79.2 & & \\
\hline \multirow[t]{4}{*}{ Midden Layer 2} & Copper sulphide inclusion & & 21.7 & 78.3 & & \\
\hline & Copper sulphide inclusion & & 21.6 & 78.4 & & \\
\hline & Copper sulphide inclusion & & 22.0 & 78.0 & & \\
\hline & Copper sulphide inclusion & & 21.8 & 78.2 & & \\
\hline $\operatorname{SMB26(2)}$ & Area analysis & & & 100.0 & & \\
\hline Metal Plate & Lead inclusion & & & 23.9 & 12.0 & 64.1 \\
\hline \multirow[t]{2}{*}{ Midden Layer 6} & Lead inclusion & & & 36.8 & 2.0 & 61.2 \\
\hline & Copper sulphide inclusion & & 8.0 & 92.0 & & \\
\hline
\end{tabular}




\subsection{Discussion of the analytical results}

\subsubsection{Establishing the nature of the smelting charge}

The nature of the ores employed in the smelting of metals has a direct impact on the extractive technology and final metal product. By comparing the chemical composition of ores and slags we can begin to have an insight into the nature of the charge that was used by the metal producers at Shankare. The furnace slags resulting from both iron and copper smelting investigated in this thesis are typical ferrous silicates with notable high levels of lime. However, a comparison of the bulk chemical data of the presumed ore samples and copper smelting slag samples highlights some disparities. The majority of the presumed copper ores from Shankare subjected to analysis in this thesis are copper carbonates with low levels of silica. The enhanced silica levels documented in the copper smelting slags are likely to result from the addition of a silica-rich flux to the furnace charge, with some of the silica coming from eroding fabric of the technical ceramics like furnace walls and tuyères.

The presence of millimetric and micrometric unreacted mineral fragments in the copper slags constitutes direct evidence of the minerals charged into the smelting furnace. Relic mineral fragments were not documented in the iron slags; however, the majority of copper furnace slags contained relics of partially dissolved or unreacted fluorapatite, magnetite, quartz and chalcopyrite. It is important to note that apatite in its various forms including fluorapatite, hydroxyapatite and chlorapatite are reported in the geological literature of the Palabora Igneous Complex as accessory minerals occurring together with copper mineralisations (Roux et al. 1989, 130). The 
presence of relict fluorapatite in copper smelting slags at Shankare is therefore consistent with the background geology of copper ores in the Palabora Igneous Complex. The presence of apatite and calcium carbonate in the mineral charge smelted during the extractive copper processes resulted in the enhanced levels of $\mathrm{CaO}$ and $\mathrm{P}_{2} \mathrm{O}_{5}$ in the copper smelting slags. The carbonatite member at Lolwe is known to contain vast reserves of calcite, magnetite and apatite that also occur together with copper ores (van der Merwe \& Killick 1979, 86). However, it must not be overlooked that high $\mathrm{CaO}$ and $\mathrm{P}_{2} \mathrm{O}_{5}$ levels in archaeological slags can also significantly derive from ash from the charcoal fuel (Tylecote et al. 1977, 310). Previous analytical work on ashes from species of trees that possibly provided charcoal for metallurgical purposes in the research area have shown that the ashes have up to $90 \%$ calcium oxide content (van der Merwe \& Killick 1979, 86). Residual magnetite and quartz mineral fragments embedded in slags matrices were partly the source of iron and silica that combined to form ferrous silicate slags (see Chapter 8 for further discussion). One slag sample [SHAMK7(1)] contained residual ore grains that were identified as iron-copper sulphide mineral known as chalcopyrite. As highlighted in Chapter 4 some early literature suggests that sulphidic copper ores were being used by pre-colonial metallurgists in the research area (Cline 1937, 57). However, the evidence at Shankare does not seem to suggest predominant use of sulphide ores went into the charge. The archaeological minerals are mostly secondary copper carbonates whilst the sulphur and sulphide inclusions are low in the copper slags. No complete matte prills were documented in these slag samples, as would have been expected with a sulphur-rich charge. The sulphide inclusions reported in some copper prills show that some limited sulphur was present in the 
smelting system. This sulphur was introduced from predominantly oxidic ores with some residual sulphidic cores (Beyschlag nodules) presented above in section 6.4.1.

The presence of unreacted mineral inclusions in the copper smelting slags raises several interesting issues regarding the beneficiation of ores and efficiency of copper smelting processes represented at Shankare. Killick \& Miller (in press) suggest that the apatite from Phalaborwa is blue-green in colour but that its vitreous lustre and crystalline morphology make it easy to distinguish from blue and green copper carbonates. Apatite as a mineral is known to be highly refractory, therefore unlikely to be used as a flux during the smelting of copper. Quartz is likely to have been used as flux for the malachite and azurite copper ores, thereby potentially improving the yield but it seems there were also present in excess. It can be suggested that the beneficiation and fluxing processes used during the production of copper were poor, resulting in the inclusion of unnecessary apatite, magnetite and quartz in the furnace charge. The presence of unreacted minerals in the copper smelting slags will be further discussed in Chapter 8.

Archaeologists have described the mining of copper ores at Lolwe Hill as a difficult undertaking involving very narrow underground shafts (van der Merwe \& Scully 1971, 181). It has already been postulated that active mining at the Lolwe Hill was largely geared towards the exploitation of copper ores rather than iron ores which occured abundantly on the surface (Killick 1977, 29; van der Merwe \& Scully 1971, 180). Thousands of tons of titanium-rich magnetite ore were still available on the surface of Lolwe Hill just before commercial open pit mining by PMC started in the 1960s (van der Merwe \& Killick 1979, 86). The copper and iron ores from Lolwe Hill described in detail in the geology section of the current thesis highlight the 
unique geochemical signature of magnetite ores (see Chapter 3). The abundant magnetite ores that were situated on the talus slopes of Lolwe Hill, contained only $\mathrm{TiO}_{2}$ in solid solution. On the other hand the magnetite associated with copper mineralisations in the central carbonatite is almost free of $\mathrm{TiO}_{2}$ but also contains $\mathrm{MgO}$ of up to $3 \%$ (Russell et al. 1954, 203). The composition of the residual magnetite embedded in the Shankare copper smelting slags investigated in this thesis is consistent with magnetite ores from the central carbonatite of Lolwe Hill with $\mathrm{TiO}_{2}$ ranging from 0.3 to 0.6 whereas $\mathrm{MgO}$ ranges from 1.0 to $3.3 \mathrm{wt} \%$. There were benefits of using high grade magnetite ores with high $\mathrm{TiO}_{2}$ in bloomery iron production, formation of ulvospinels increases iron yield (see Iles \& Martinon-Torres 2009). However, magnetite from the central carbonatite geologically associated with copper mineralisations would have posed major problems for iron smelters. It was not possible to reduce the magnetite from the central carbonatite to iron without spoiling the iron metal with copper. However, copper contaminated with exsolved iron (black copper) could be refined under oxidising conditions to remove iron as dross, as shown in several experiments on copper refining (Merkel 1990, 117; Tylecote \& Merkel 1985, 7). The evidence of copper refining under oxidising conditions in crucible vessels was documented at Shankare. It is thus consistent with both geological and archaeological evidence that this thesis confirms that copper ores from the central carbonatite of the Palabora Igneous Complex closely associated with apatite, magnetite and calcium carbonate were used for copper smelting at Shankare. In contrast, titanium-rich magnetite ores from Lolwe Hill were used for iron smelting. 


\subsubsection{Establishing the temperature and redox parameters}

Approaches employed to establish the working parameters which prevailed during the production of metals in archaeometallurgical projects have been critically discussed in Chapter 5. The bulk chemical data of Shankare slags is hereby plotted on the $\mathrm{FeO}-\mathrm{CaO}-\mathrm{SiO}_{2}$ ternary system to approximate the furnace working temperature. The challenges associated with the use of phase diagrams of furnace slags which in some cases did not reach free flowing state are fully appreciated. At the core of the use of phase diagrams is the assumption that equilibrium conditions associated with complete melting of the charge prevailed during the smelting process. Reservations have been made regarding the use of equilibrium diagrams to estimate furnace thermodynamics and predict solidification processes with data obtained from furnace slags from non-slag tapping furnaces as was the case at Shankare (Friede et al. 1982; Miller \& Killick 2004). Furnace slags from non-slag tapping furnaces are heterogeneous slags with relic mineral inclusions, a clear indication of unattained equilibria (Miller \& Killick 2004, 24). However, the use of equilibrium diagrams in this thesis is justified because the 'bulk' SEM-EDS data was acquired from completely molten slag matrices excluding large unreacted mineral inclusions.

Despite these reservations, archaeological furnace slags from Southern Africa have previously been represented on a $\mathrm{FeO}-\mathrm{SiO}_{2}-\mathrm{CaAl}_{2} \mathrm{Si}_{2} \mathrm{O}_{8}$ (anorthite) and $\mathrm{FeO}-\mathrm{SiO}_{2}-$ $\mathrm{Al}_{2} \mathrm{O}_{3}$ ternary systems for the purpose of establishing furnace temperature ranges (Miller et al. 1995; Miller \& Sandelowsky 1999) or simply for identifying groups within a slag assemblage (Miller \& Killick 2004). Bachmann $(1982,11)$ argues that the $\mathrm{FeO}-\mathrm{SiO}_{2}-\mathrm{CaAl}_{2} \mathrm{Si}_{2} \mathrm{O}_{8}$ is not suitable for $\mathrm{CaO}$ rich slags like the ones from Shankare. Copper and iron furnace slags from Shankare are thus best represented on 
the $\mathrm{FeO}-\mathrm{CaO}-\mathrm{SiO}_{2}$ ternary system, since these are the three principal oxides. However, the slags have additional major oxides in the form of $\mathrm{Al}_{2} \mathrm{O}_{3}, \mathrm{TiO}_{2}, \mathrm{P}_{2} \mathrm{O}_{5}$ and $\mathrm{MgO}$, capable of influencing the melting point. Recently Iles \& Martinón-Torres (2009) highlighted challenges associated with the interpretation of slags whose bulk chemical composition is composed of more than three major oxides using ternary phase diagrams. The Shankare slags present the same problems because they are not the typical fayalitic slags. It is against the background of all these limitations that 'bulk' SEM-EDS chemical results of Shankare slags were plotted on a $\mathrm{FeO}-\mathrm{SiO}_{2}$ $\left(+\mathrm{Al}_{2} \mathrm{O}_{3}+\mathrm{TiO}_{2}\right)-\mathrm{CaO}\left(+\mathrm{MgO}+\mathrm{P}_{2} \mathrm{O}_{5}\right)$ ternary system to broadly estimate their liquidus temperatures (Figure 6.51). The copper slags plot on the pseudowollastonite and wollastonite regions of the $\mathrm{FeO}-\mathrm{SiO}_{2}-\mathrm{CaO}$ system with liquidus temperatures around $1100-1300{ }^{\circ} \mathrm{C}$. The only exception is slag sample SHA1NWL that stands as an outlier in the higher temperature region above $1400{ }^{\circ} \mathrm{C}$ because it is very low in $\mathrm{FeO}$ at $5.8 \mathrm{wt} \%$. 


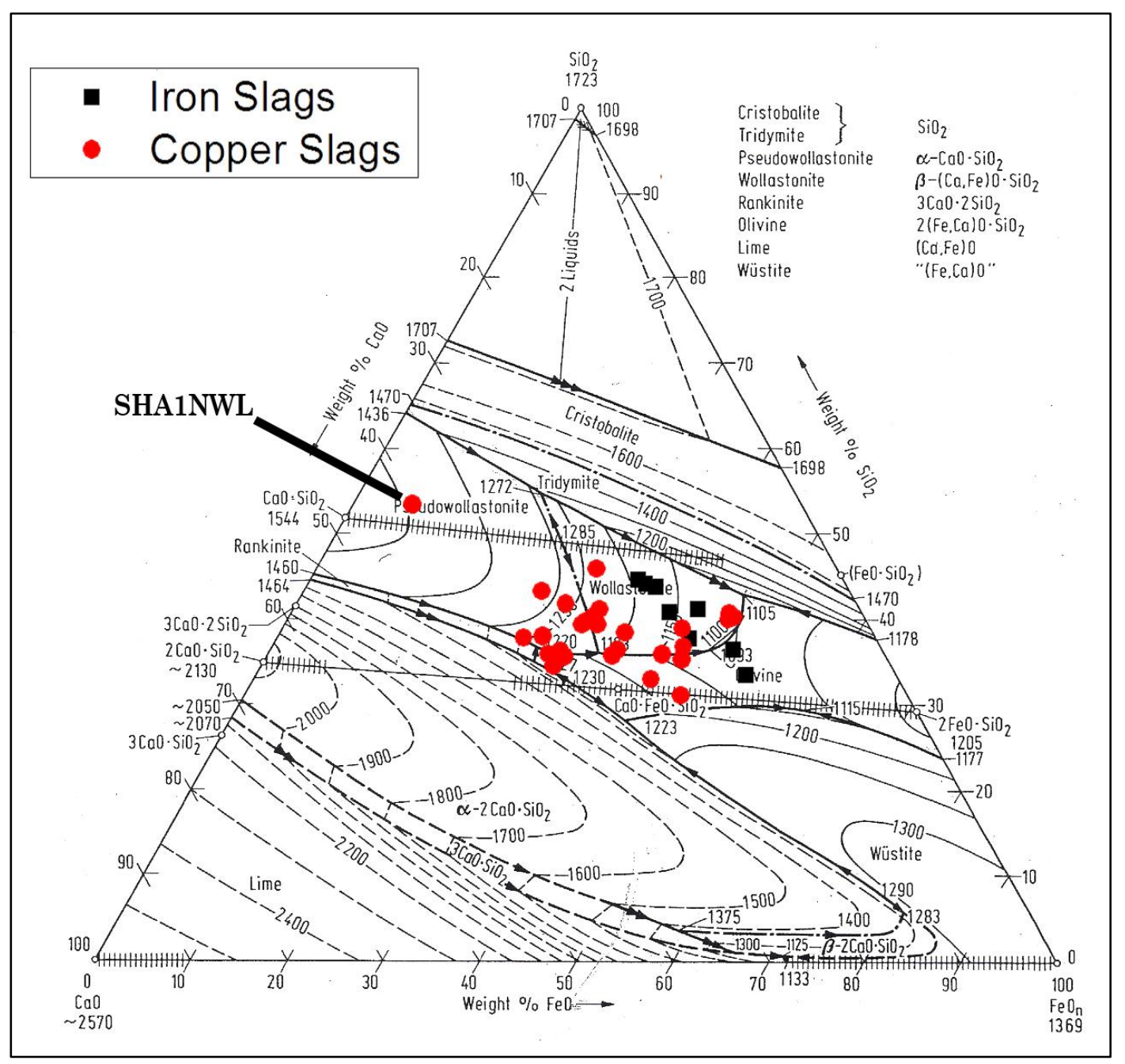

Figure 6.51: Plot of 'bulk' SEM-EDS results of Shankare smelting slag samples on a $\mathrm{FeO}-\mathrm{SiO}_{2} \quad\left(\mathrm{TiO}_{2}+\mathrm{Al}_{2} \mathrm{O}_{3}\right)-\mathrm{CaO} \quad\left(+\mathrm{MgO}+\mathrm{P}_{2} \mathrm{O}_{5}\right)$. (Phase diagram adapted from Kowalski et al. 1995, 126).

The composition and microstructure of slag-entrapped copper prills is another avenue to estimate prevailing furnace thermodynamic ranges. Copper prills embedded in slags as well as isolated copper artefacts can give some indication of the temperatures attained in ancient smelting furnaces provided low sulphur ores were smelted (Cooke \& Aschenbrenner 1975: Craddock \& Meeks 1987). The presence of exsolved iron in primary smelting copper prills or copper artefacts is an indication that temperatures in excess of at least $1250{ }^{\circ} \mathrm{C}$ were attained in the furnace 
(Miller \& van der Merwe 1994b, 112) as well as unnecessarily reducing conditions. Theoretically molten copper can accommodate $2.8 \%$ of dissolved iron at a temperature of $1100{ }^{\circ} \mathrm{C}, 20 \%$ iron at $1400{ }^{\circ} \mathrm{C}$ and up to $70 \%$ iron at $1450{ }^{\circ} \mathrm{C}$ (Craddock \& Meeks 1987, 198). Three slag samples [SHA7NWL, SHA8NWL and SHAMK18(3)] contain millimetric copper prills with iron levels ranging from $15 \%$ and $30 \%$ as obtained by area scans with SEM-EDS. Based on the model provided by Craddock \& Meeks (1987), the 'black copper' prills entrapped inside copper smelting slag samples would have formed at temperatures well above $1400{ }^{\circ} \mathrm{C}$. Technical ceramics capable of handling such high temperatures were probably not available at Shankare; however, such high temperatures could be attained in the reaction zone away from the less refractory furnace walls (Craddock \& Meeks 1987, 200; Childs 1989, 139). The evidence of 'black copper' prills indicates that higher than needed temperatures and reducing conditions prevailed in some cases, leading to the production of highly ferruginous copper. Noteworthy is the fact that one of the copper slags (SHA7NWL) with ferruginous copper is also associated with isolated wüstite dendrites, although magnetite spinels dominate. The combination of isolated wüstite dendrites and ferruginous copper prills corroborates the fact that sometimes unnecessary high temperatures and overly reducing conditions prevailed in the copper smelting process. On the contrary, copper prills adhering to the crucible fragments are pure, notably without any significant iron impurities. However, the lack of iron in these crucible prills reflects more on the redox conditions than on the operating temperature parameters. 


\subsubsection{Quality of the copper products: raw copper vs. finished products}

Ancient copper usually contains ancillary metals in the form of trace or minor elements that are potentially informative about the provenance and nature of ores, and the extractive methods employed. The precise provenancing of the metal debris or artefacts to specific geological ore deposits is beyond the scope and analytical approaches employed in the current thesis. This project sought in a much broader sense to establish the nature of the ores utilised, from the analysis of metallurgical debris and copper artefacts. Copper artefacts have previously been studied with standard archaeometallurgical techniques to establish the nature of the ore. These studies are based on the premises that differences in composition and microstructure of copper artefacts are expected when oxidic or sulphidic ores are used in copper smelting (Pernicka 2004). In the current thesis, slag-entrapped metal prills were investigated to complement information gathered from the mineralogical investigation of presumed ore samples. One of the objectives was to determine whether the copper ores used at Shankare were secondary oxidic, carbonic or primary sulphidic ores. Sulphidic ores are expected to produce matte prills rich in copper and iron sulphides (Craddock 1995, 149-153). In this study the metallographic investigations of large copper prills $(>1 \mathrm{~mm})$ either entrapped in copper slag samples or recovered as isolated metal prills showed the presence of globular sulphide inclusions but complete matte prills were not documented. Such sulphide inclusions are prevalent in copper artefacts that were previously subjected to metallographic studies in Southern Africa. These sulphide inclusions can be produced if secondary copper carbonate ores which contain some residual sulphide minerals are employed (Miller \& van der Merwe 1994b, 112; Miller 2002, 1102). 
Presumed ore fragments from Shankare indeed contain some residual sulphide minerals which can be used to explain the presence of sulphide inclusions documented in the raw smelted copper prills.

Apart from indicating high smelting temperatures, exsolved iron can also suggest the use of an iron-rich ore or addition of iron oxide flux (Miller \& van der Merwe 1994b). Some malachite minerals from Shankare were indeed closely bound to magnetite ores that resulted in production of copper very rich in iron. However, it is important to point out that iron can be present in raw copper or finished objects in different states, for example slag inclusions, oxides, sulphides or metal therefore caution should be taken when reporting or interpreting bulk iron levels in ancient copper (Tylecote et al. 1977, 328). Only metallographic investigations will reveal if the iron is present as a metallic phase, as was the case with some copper prills from Shankare. Evidence of 'black copper' from Shankare reinforces oral traditions claiming that Phalaborwa ores were difficult to work because they produced highly ferruginous copper. It was this problem that forced some miners from Phalaborwa to trek and settle at Musina (about $200 \mathrm{~km}$ north of Phalaborwa) in search of better copper ores during the late second millennium AD (Mamadi 1940; Miller et al. 2001, 409).

The few semi-finished or finished copper artefacts from Shankare are very pure with significant oxidation probably caused by refining process. No 'black copper' artefacts were documented in the meagre collection from Shankare. The high purity of copper artefacts recovered from Phalaborwa has previously been interpreted as evidence that the smelting temperature was fairly low, using remarkably pure copper ores (van der Merwe \& Scully 1971, 182). The research presented here contradicts 
this claim, it has been established that the ores were poorly beneficiated, raw copper was iron-rich and was later refined. The refining process, involving the melting of copper in an open crucible to allow the oxidation of iron on the surface, followed by the sprinkling of clean sand or quartz; was widely practised in many regions during the prehistorical period (Craddock \& Meeks 1987, 192; Craddock 1995, 202-204). The iron oxide and clean sand together with the crucible walls form distinctive crucible slag rich in delafossite $\left(\mathrm{CuFeO}_{2}\right)$ similar to the one documented in one of the slagged crucible fragment from Shankare (Craddock 1995, 204). The evidence of high-purity copper artefacts documented at Shankare highlights the limitation of solely relying on finished products in discussing the nature of ore or smelting technologies that were employed. In the case of Shankare relying on analytical results based on the finished artefacts would have given the false impression that only highly pure secondary ores were exploited during the Iron Age; or at least that temperature and redox were adjusted to avoid the reduction of $\mathrm{FeO}$ to metallic iron.

\subsection{Proposed extractive copper metallurgy chaîne opératoire at}

\section{Shankare}

The survey, excavation and laboratory results presented in this chapter provide important insights upon which the chaîne opératoire of extractive metallurgical processes at Shankare can be reconstructed (Figure 6.52). The analytical work on metallurgical debris confirms that both copper and iron were produced. The analytical results also suggest that at least two stages of pyrometallurgical operations under varying redox conditions, interpreted here as primary smelting and secondary refining processes were carried out to produce copper. Radiometric dates confirmed 
that Shankare Hill was utilised as a habitation site from the early second millennium AD. Evidence of metal production at the site included potential ores, furnace slags, technical ceramics and metal artefacts. Unfortunately the comprehensive fieldwork that was carried out at the site was not fruitful in discovering complete metallurgical installations. Based on the fieldwork data the current thesis cannot establish furnace design details such as the number of tuyère ports, furnace height or capacity. It is against this background that this thesis falls short in addressing a contentious issue regarding the proposed structural differences between iron and copper smelting furnaces although some insights on this issue will be discussed in Chapter 8 (Miller et al. 2001; van der Merwe \& Scully 1971). The location of excavation trench SHASH1 with a considerable amount of metallurgical debris in the north-eastern lowland of Shankare was interpreted as a primary iron smelting precinct. On the other hand, copper smelting slags were documented from the low density scatters, some with just a few handful of metallurgical debris whilst some were recovered in middens together with domestic refuse.

Large copper slag heaps were not documented at Shankare Hill. As pointed out several times in this thesis the use of high grade copper carbonate ores together with low temperature 'slagless' solid-state copper extraction processes can seriously affect the visibility of copper production in the archaeological record. Extraction of high grade ores does not usually promote the accumulation of large slag heaps (see Craddock 1995; Craddock 2009; Craddock \& Craddock 1996, 61; Küsel 1974, 247). However, copper production evidence at Shankare shows that the charge included large proportions of gangue minerals such as magnetite, quartz and apatite. The rounded copper prills and associated exsolved iron also suggest that the reduction 
process did not take place in solid-state at low temperatures. It is in light of this evidence that the verdict of this thesis is that copper smelting represented by slag samples at Shankare was based on a slagging process which would have produced considerable amounts of slag. The apparent scarcity of copper slag is therefore explained as resulting from the further processing of slags after smelting, involving the mechanical crushing of slags to retrieve entrapped prills. The extractive copper metallurgy documented at Shankare fits within the "immature slagging model" (Bourgarit 2007) as represented by relic mineral inclusions in the copper slags which was followed by slag crushing and "prill collection" (Maddin, 1988). This is further supported by the presence of rock surfaces with dolly holes and hammer stones associated with crushed copper smelting slags. However, these dolly holes could be equally used to crush hard magnetite gravel ores present at Shankare. Further detailed fieldwork investigations of the slag crushing activity area will be needed in the future. Slag crushing and prill collection method has been documented at other copper smelting sites in Southern Africa (e.g. Hall et al. 2006, 23). With the available evidence at Shankare it is not possible to categorically deny that planoconvex ingots did not form at the bottom of furnace bottoms. Two bun copper ingots from Kgopolwe, close to Shankare, dating between the $11^{\text {th }}$ and $12^{\text {th }}$ centuries have been described as pure copper with numerous copper sulphide inclusions, with bulk iron content of 0.4 and $0.2 \%$ respectively (Killick \& Miller, in press).

After retrieving prills from the crushed slags, the second phase that combined refining and consolidation of the prills was carried out in crucibles. These crucibles of unknown shape and capacity would have been fired and aerated from above. The oxidizing atmosphere represented by the metallurgical phases adhering to the 
crucible sherds possibly indicates that the refining process did not involve any furnace with a superstructure. The crucibles were possibly placed in a shallow depression in the ground (see further discussion Chapter 8). The same copper refining process was documented from the oral information that was given to Stayt by in Vendaland to the north of Phalaborwa (Anderson 2009, 222; Stayt 1931, 64). The typical copper-based alloys documented elsewhere in Southern Africa; such as, tin-bronzes, zinc brasses and arsenical copper, are not present in the metallurgical assemblage recovered from Shankare during the 2009-2010 fieldwork seasons. Highpurity copper was used to manufacture decorative items similar to the few bangles or anklets that were recovered at Shankare.

Metallurgical debris from contexts not associated with primary smelting, for example from domestic middens, has previously been considered as bearing less information (Miller 2001). However, the results presented in this chapter have highlighted some potential problems of focusing only on in situ smelting precincts with massive slag heaps and other metallurgical debris at the expense of small metallurgical debris scatters.

It is important to situate the proposed chaîne opératoire of extractive copper metallurgy at Shankare within the broad context of Phalaborwa archaeometallurgy. For comparative purposes analytical work was carried out on previously excavated and surface finds from other sites in the research area. The next chapter presents brief site profiles of the archaeological sites where these comparative materials were recovered together with analytical results of limited metallurgical samples from each site. The rest of the analytical and contextual information will then be integrated in the subsequent discussion in Chapter 8. 


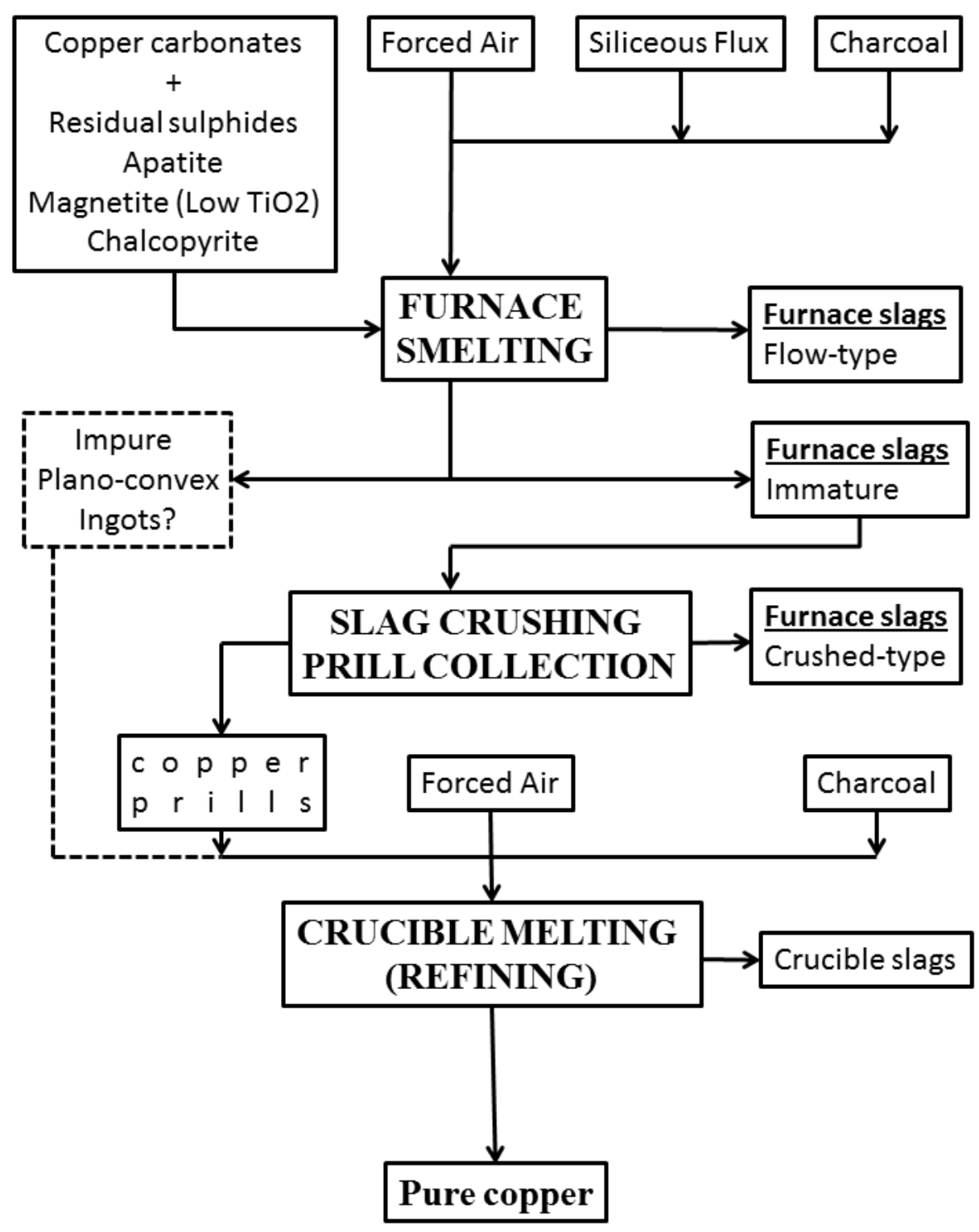

Figure 6.52: Schematic representation of the proposed chaîne opératoire of copper production reconstructed from Shankare metallurgical debris (Image: Author). 


\section{Collection-based investigations: Archaeology and extractive metallurgy processes at Kgopolwe, Molotho, Serotwe, Phutwane and Maranda}

\subsection{Introduction}

Archaeological expeditions carried out since the 1960s around Phalaborwa, including intensive surface surveys together with rescue excavations, resulted in the accumulation of archaeometallurgical materials currently housed in various institutions and private collections in South Africa and abroad. At least a dozen Lolwe type furnaces that were presumably employed exclusively for primary copper smelting were documented during previous archaeological fieldwork campaigns. Van der Merwe's team excavated a total of four Lolwe type furnaces at Nagome, Serotwe (Matsepe) and Molotho during the 1970s. Killick (1977) subsquently conducted extensive surface collections of slag samples from at least twenty archaeometallurgical installations around Phalaborwa. Several Lolwe type furnaces were subsequently excavated in the 1980s by Julius Pistorius, then at the University of Pretoria (Pistorius 1989).

Archaeometallurgical assemblages from the 1960s-1970s fieldwork campaigns by van der Merwe and Killick are currently curated by the Department of Archaeology, UCT. Preliminary analytical work was previously undertaken on limited Phalaborwa archaeometallurgical samples in UCT collection as highlighted in Chapter 4 (Killick \& Miller, in press; Miller 2010; Miller et al. 2001; Miller \& Killick 2004). Although some technical studies were previously carried out on archaeometallurgical collections from the research that are currently housed at UCT, the revisiting of these collections was essential for several reasons. Firstly, previous analytical studies were 
only undertaken on a small number of slags and artefacts with the aid of limited analytical techniques. Hitherto, metallurgical production debris associated with late second millenium AD copper smelting sites of Molotho and Nagome had not been subjected to analytical studies. Secondly, during our fieldwork campaings we were unable to document unequivocal copper smelting installations. As such, the previously collected remains from securely dated copper production contexts at UCT were useful for comparative purposes and also provided the opportunity to explore possible diachronic changes in the extractive metal technology during the second millennium AD. Thirdly, archaeological sites around Phalaborwa were extensively damaged by ongoing mining processes which produce large tailing dumps, slimes and slik dams as alluded to in the previous chapters. Outside the modern mining premises, the ever growing modern town of Phalaborwa has also resulted in the destruction of the previously documented Iron Age metal production sites. However, the major hurdle during the implementation of archaeological fieldwork stage in the current project was the limited access to potentially interesting archaeological sites as a result of land ownership rights. The above factors meant that it was cost-effective to conduct further analytical work on previously excavated archaeometallurgical assemblages from Phalaborwa. The current author was initially granted access to archaeometallurgical materials from Phalaborwa currently housed at UCT to conduct pilot analytical work prior to archaeological fieldwork. More samples were made available for comparative purposes after the fieldwork at Shankare Hill. As mentioned earlier efforts to establish the whereabouts of previously excavated archaeometallurgical assemblages from Phalaborwa by archaeologists from the University of Pretoria (UP) and University of Witwatersrand (Wits) were fruitless. 
This chapter presents analytical results of previously unstudied archaeometallurgical materials from Kgopolwe, Molotho, Serotwe (Matsepe) and Maranda from the UCT archaeometallurgical collection (Figure 7.1). Additional comparative materials were surface-collected at Phutwane Hills during a reconnaissance survey that was conducted by the current author together with colleagues from the Department of Archaeology, UCT in 2009. Brief profiles of the five sites are provided to establish their archaeology, metallurgical evidence and chronology. This information was gathered from unpublished excavation reports and field notes generously provided by the excavators. Results of analytical work carried out on archaeometallurgical assemblages from these sites are presented together with general archaeological information . An attempt is made to relate the ores and slags that were subjected to further studies from the different sites. The mineralogy and chemistry of metallurgical samples from these sites are assessed to establish the metallurgical chaîne opératoire represented at each site. In spite of the potential of these collections for a broader, comparative perspective, it has to be acknowledged that previously excavated materials present their own challenges. The next section of this chapter is dedicated to a brief discussion of these limitations before embarking on the exploitation of their informative potential. 


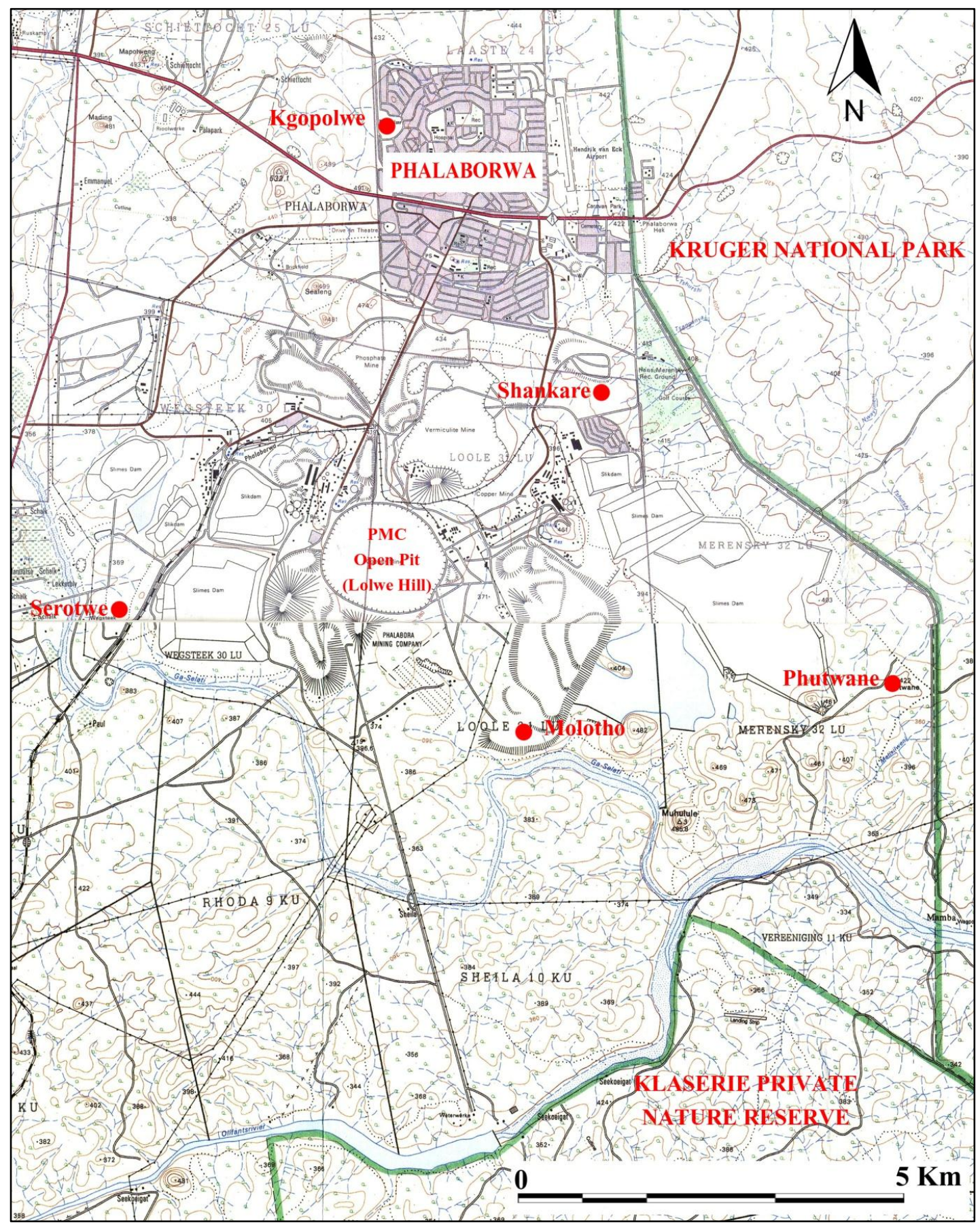

Figure 7.1: Map showing the location of archaeological sites discussed in this chapter (Map adapted from South Africa Map Sheets, 2431AA Grietjie and 2331CC Phalaborwa of 1987). Maranda is further afield, about $60 \mathrm{~km} \mathrm{NW}$ of Phalaborwa (Image: Author). 


\subsection{The Phalaborwa archaeometallurgical collection at UCT}

Collection-based archaeometallurgical studies often have inherent challenges that include lack of detailed description of the context recovery and systematic quantification of metal production debris. As highlighted in Chapter 2, postfieldwork archaeometallurgical studies focusing only on laboratory analyses often lack an appreciation of the social context of production. Part of the Phalaborwa collection resulted from rescue excavations carried out at Molotho and Nagome, which were aimed at salvaging information concerning the chronology of furnace designs and antiquity of metal production activities (van der Merwe 1971; van der Merwe \& Scully 1971). Research objectives, collection policies and excavation strategies differ from one archaeological project to the next. The objectives of previous archaeological investigations of smelting precincts around Phalaborwa did not necessarily seek to obtain the high-resolution technological reconstruction of extractive metallurgy processes placed that is at the core of the present thesis. As such, no attempt was made to describe or quantify the metallurgical debris in both published and unpublished excavation reports and fieldwork notes. It thus seems that the preoccupation of the excavators was the dating and detailed description of furnaces rather than the reconstruction of the smelting technology. The other problem with rescue archaeology programmes is that full excavation reports and analytical results are rarely published. As such, information from the rescue archaeological work that were carried out by van der Merwe in the late 1960s are yet to be published. The sampling methods that were employed in the selection of metallurgical samples eventually transported and kept at UCT are rarely discussed. The samples collected by David Killick during the 1970s came from unstratified archaeological contexts (surface collections). However, the most important issue is 
the certainty that these samples were recovered from positively identified metal production furnaces.

Archaeometallurgical materials from the previous archaeological expeditions in the research area are now housed in several museums, universities and private collections. Complete inventories of these materials are not available as a result it is not always possible to reinvestigate or have access to these materials. In the future, dedicated archaeological site museums like the one at Masorini in the Kruger National Park, which specifically houses and preserves in situ archaeological evidence, should be emulated around Phalaborwa. The Phalaborwa collection at UCT represents an incomplete inventory of the materials that were previously excavated. The absence of some metal production categories in the inventory is an artefact of inconstant surface collection methods over the years (see Table 7.1). In spite of these caveats, this collection presently constitutes the best source material available to initiate a comparative perspective of technological variability in the area, which will no doubt help refine questions and strategies for future work. The following sections present brief backgrounds of the relevant archaeological sites and analytical results obtained from metallurgical debris, before coming to a more integrated discussion in Chapter 8.

Table 7.1: Inventory of metallurgical debris by weight (g) from selected archaeological sites housed at UCT.

\begin{tabular}{|l|c|c|c|c|c|r|}
\hline & Kgopolwe & Molotho & Serotwe & Phutwane & Maranda & Totals \\
\hline Copper ores & 62 & - & - & - & - & $\mathbf{6 2}$ \\
Magnetite & 209 & - & - & 354 & - & $\mathbf{5 6 3}$ \\
Slags & 357 & 411 & 994 & 725 & 86 & $\mathbf{2 5 7 3}$ \\
Tuyères & - & - & - & 279 & 102 & $\mathbf{3 8 1}$ \\
Crucible sherds & - & - & - & - & - & - \\
\hline
\end{tabular}




\subsection{Kgopolwe (SPK): c. $11^{\text {th }}-19^{\text {th }}$ century AD}

\subsubsection{Site profile}

Kgopolwe Hill is located on the northwest part of the modern town of Phalaborwa inside the farm designated Laaste 24 LU owned by Foskor Mining Company (Map Sheet: South Africa 1:50 000 Sheet 2331CC Phalaborwa second edition 1987: Grid Ref: $\left.23^{\circ} 56^{\prime} \mathrm{S} ; 31^{\circ} 07^{\prime} \mathrm{E}\right)$. Kgopolwe Hill, just like Shankare, is a prominent topographical feature that resulted from extinct volcanic activities related to the formation of the Palabora Igneous Complex. Geologically, Kgopolwe Hill is principally composed of syenitic igneous rocks with occasional granites and gneisses. Previous fieldwork campaigns by geologists and archaeologists at Kgopolwe Hill did not document any viable iron and copper resources in the immediate vicinity. Lolwe Hill, the presumed source of most of the copper ores used during the Iron Age, is located approximately $6.4 \mathrm{~km}$ south of Kgopolwe.

Archaeologically, Kgopolwe Hill has yielded the most complete Iron Age sequence in the research area; as such, the site is usually used as the frame of reference for other contemporary sites around Phalaborwa. The site was the main focus of archaeological investigation of the "Phalaborwa Iron Age Project" team directed by Nikolaas van der Merwe during the 1960s-1970s. Due to its archaeological significance, Kgopolwe Hill was instantly declared a National Monument, thus it enjoys the protection accorded to other monuments by the South African Heritage Resources Agency (SAHRA). The archaeological evidence at Kgopolwe Hill includes early second millennium AD occupation settlements, human burials and 
several well-preserved smelting precincts (Evers \& van der Merwe 1987; Rightmire \& van der Merwe 1976; van der Merwe 1971). Under the site designation system developed during the 1960s, archaeological assemblages from Kgopolwe are prefixed SPK. In this system S stands for South Africa, P for Phalaborwa whilst K stands for Kgopolwe. This system will be retained in the thesis for the purposes of consistence.

The archaeological features described at Kgopolwe Hill appear to bear a close resemblance to evidence documented at Shankare Hill discussed in Chapter 6. These features included terraced platforms, large domestic middens and smelting furnaces together with their production debris (Evers \& van der Merwe 1987; van der Merwe 1971). Three exploratory excavation trenches (SPK I, SPK II, SPK III) were sunk at Kgopolwe by Nikolaas van der Merwe from 1965 to 1970. Trenches SPK I and SPK II were sunk on the terraced platform with retaining stone walls on the slopes of Kgopolwe Hill. Noteworthy was the observation that some of the terraced platforms at Kgopolwe were filled with metal production slag (Evers \& van der Merwe 1987, 89). This highlights subsequent reuse of metallurgical debris for building purposes as documented in other regions (Rehren et al. 2007, 215). Trench SPK III was sunk on several hut foundations at the foothill of Kgopolwe Hill. Five radiocarbon dates from

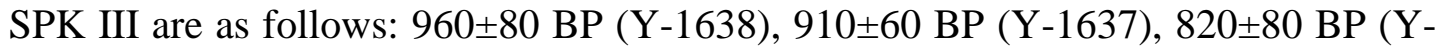

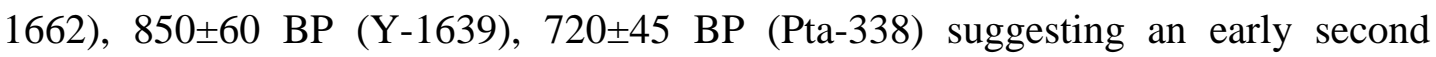
millennium AD occupation history (Evers \& van der Merwe 1987, 88). The pottery collection from Kgopolwe was subjected to preliminary typological and technical studies (Evers \& van der Merwe 1987; Schryver 1970). Pottery from SPK III was recognized as a distinct ceramic entity. The pottery was subsequently named 
Kgopolwe after the type site (Evers \& van der Merwe 1987). Oral traditions identify Kgopolwe as the nineteenth-century residence of the Ba-Phalaborwa royals. According to these traditions, during the nineteenth century the site was also reserved for royal livestock pens and iron production (van der Merwe \& Scully 1971, 191). Kgopolwe Hill thus has a complex occupation history stretching for almost a millennium starting from at least the early second millennium AD.

Two plano-convex copper ingots and a domestic ceramic full of copper slags and prills were recovered below a hut foundation at SPK III, dating to the early second millennium AD (Miller et al. 2001). The plano-convex copper ingots, weighing just above one kilogram each, have since been subjected to metallographic studies (Miller 2010), together with five smelting copper slags from the domestic pot (Miller \& Killick 2004, 41; For illustration of plano-convex ingot see Figure 4.7). It has been suggested that the two plano-convex ingots are products of primary copper smelting. However, it has been proved elsewhere that plano-convex copper ingots can also be produced during copper refining in open pots or large potsherds (Merkel 1990). Copper prills from SPK III were interpreted as products of copper refining since they have copper/cuprite dendrites without any sulphide inclusions (Miller et al. 2001, 409).

Apart from evidence of human settlement in the form of hut foundations and domestic middens, archaeological investigations at Kgopolwe Hill documented at least three (SPK IV, SPK V and SPK VI) intact smelting furnaces (Evers \& van der Merwe 1987; van der Merwe 1971). The furnace installations are described as short shaft furnaces with sub triangular plans and three tuyère port entrances (Miller et al.

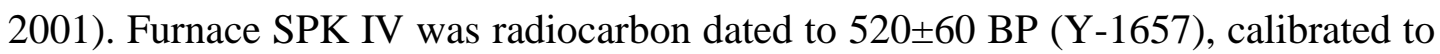


1296 to $1466 \mathrm{AD}$ at 2 sigma, and $280 \pm 60 \mathrm{BP}$ (Y-1658), calibrated to 1450 to 1680 $\mathrm{AD}$ or 1740 to $1800 \mathrm{AD}$ at 2 sigma (Stuiver \& van der Merwe 1968, 56). Noteworthy at this juncture is the occurence of copper and iron smelting slags in slag heaps adjacent to furnaces SPK IV and SPK VI (Evers \& van der Merwe 1987, 92; Miller et al. 2001, 407). This evidence, in the current author's view, casts doubts on the prevailing assumptions that three tuyère port furnaces (Phalaborwa type) were exclusively used for iron smelting.

Altogether previous excavations at Kgopolwe yielded iron slags, copper slags, crucible fragments, copper ingots and finished copper objects. Crucible sherds with slag lining, vitrified and distorted interiors that were also excavated from domestic middens at Kgopolwe (Evers \& van der Merwe 1987, 88). Unfortunately, no metallurgical ceramics, either crucibles or tuyères, were identified in the UCT collection by the current author. The only artefacts from Kgopolwe in this collection include few ore and slag samples. Previous routine archaeometallurgical analysis was carried out on slags and copper artefacts from the early second millennium AD context, SPK III (Miller et al. 2001; Miller \& Killick 2004). In this thesis, potential copper ores samples from the early second millennium SPK III layers and slags from the undated furnace SPK VI were subjected to further laboratory studies. 


\subsubsection{Analytical results}

\subsubsection{Kgopolwe copper ores}

Nine chips of presumed copper ore samples from Kgopolwe (SPK III), radiocarbon dated to the early second millennium AD, were available in the UCT collection. These ore fragments were retrieved from the same context with a domestic pot full of slag and copper prills together with two plano-convex copper ingots. The planoconvex ingots and slags from SPK III were previously subjected to analytical studies (Miller \& Killick 2004, 41; Miller 2010). Hitherto, investigators excluded potential copper ore samples from SPK III in their analytical studies. This is the first time that detailed mineralogical and chemical studies of these potential ore samples are being reported, thus completing the technological sequence from ore to metal.

The rock fragments were initially studied macroscopically and tested for magnetism (Figure 7.2). Externally most of these samples are rusty red in colour with patches or thin layers of oxidised green and blue minerals, which could be classified as malachite and azurite respectively. Macroscopically, they are non-porous, soft without any visible siliceous grains. Only a single sample from this suite of potential ores is characterised by a magnetite host rock with green corrosion layers. Two presumed copper ore samples (SPK3 1 \& SPK3 2) were invasively sampled and subjected to detailed analytical work. Since the number of ore samples subjected to analytical analyses is limited, detailed descriptions of their external characteristics, microstructure and composition will be provided individually. 


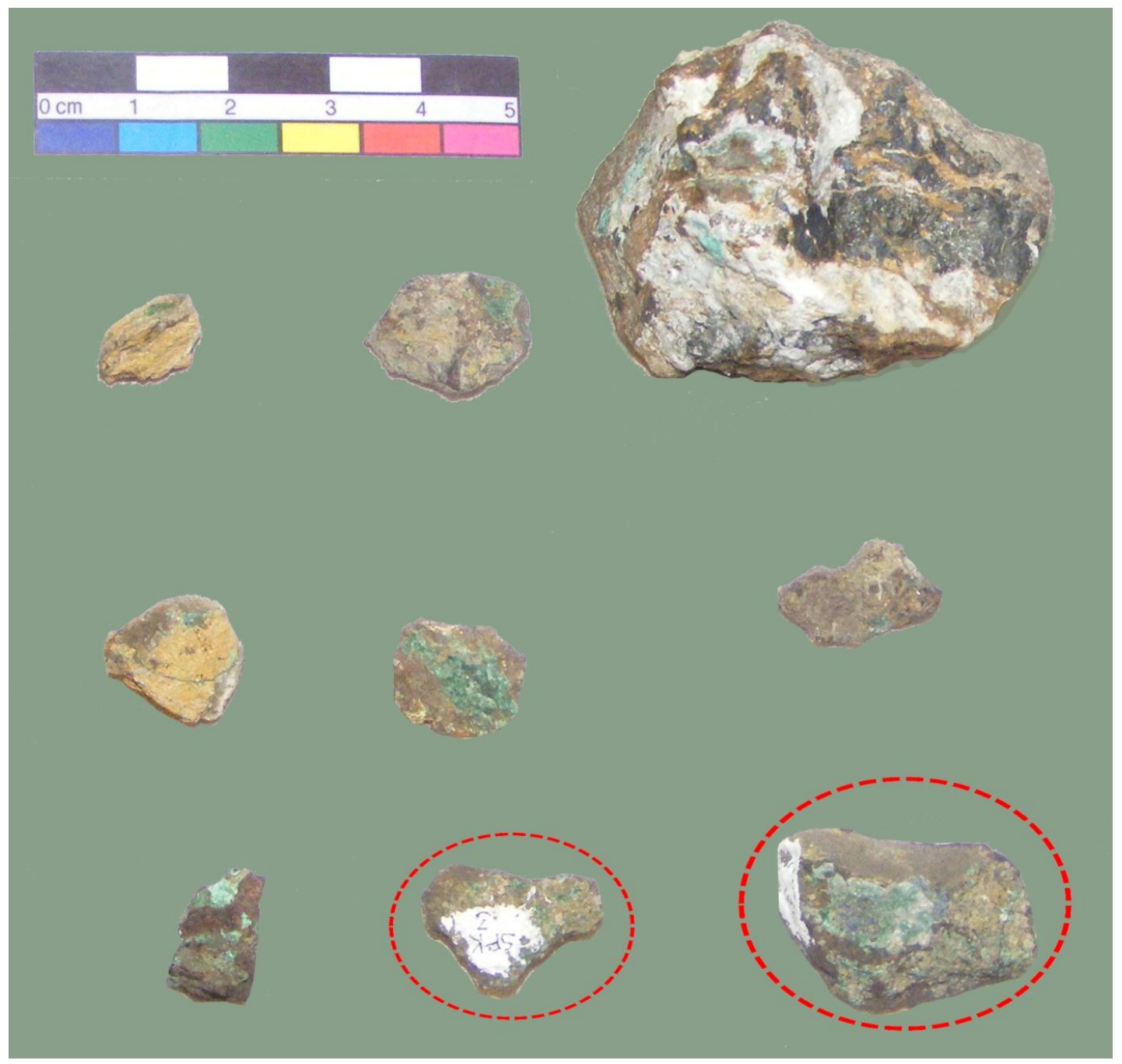

Figure 7.2: Presumed ore samples from Kgopolwe SPK III. Sample SPK3 1 is in the bottom right corner and SPK3 2 is situated in the centre bottom row (Image: Author). 


\section{Copper ore sample (SPK3 1)}

Presumed ore sample SPK3 1, weighing only $7.7 \mathrm{~g}$, is covered externally by greenbluish weathering products. Magnetic tests of the hand specimen were negative indicating the absence of magnetite frequently associated with copper mineralisations of the Palabora Igneous Complex deposit. The resin-mounted section of sample SPK3 1 shows two distinct layers (Figure 7.3). The outer matrix is dominated by blue-green secondary copper minerals whilst the inner layer is dominated by rusty red to black secondary iron and copper minerals. Microscopically, the inner layer contains islands of golden coloured minerals with an approximate atomic ratio of sulphur, iron and copper of 2:1:1 thus corresponding to the mineral chalcopyrite (Figure 7.4). These chalcopyrite islands are embedded in a matrix of oxides, carbonates or hydroxides of iron-copper minerals similar to potential ore samples found at Shankare Hill (see Chapter 6). Occasional narrow veins of green coloured copper minerals penetrated well into the inner red to black layer of sample SPK3 1. However, no visible quartz grains were documented in the inner matrix although few grains were incorporated in the heavily weathered outer matrix possibly as postdepositional products.

The bulk chemistry of ore SPK 31 obtained from systematic area scans of the polished block sample is presented in Table 7.2. The sample is notably rich in $\mathrm{FeO}$ (39-45 wt \%), $\mathrm{CuO}(19-25 \mathrm{wt} \%)$ and $\mathrm{SO}_{3}(6-16 \mathrm{wt} \%)$ with negligible levels of common gangue oxides such as alumina, phosphorus, lime and magnesia typically present in ancient copper smelting slags. These gangue oxides are only confined to the severely weathered outer parts of the sample suggesting that they were only deposited at a much later stage in the geological or archaeological context (Figure 7.1). The sulphur levels in this particular sample are especially high (11 wt\% on 
average) because of the presence of relict chalcopyrite inclusions. The sample is notably undersaturated, containing an average of $4 \mathrm{wt} \%$ silica. The sample thus falls in the same category as the majority of undersaturated copper minerals documented at Shankare Hill. Possible copper alloying elements like arsenic, tin and zinc are all below detection limit of the SEM-EDS. Sample SPK3 1 conspicuously retains its geological microstructure with no signs of heat treatment on the surface.

\section{Copper ore sample (SPK3 2)}

Sample SPK3 2, weighing only $3.8 \mathrm{~g}$, is coated by a thin layer $(\approx 500 \mu \mathrm{m})$ of secondary green copper mineralisations. This sample does not respond to magnetic tests. The cut cross section of this mineral sample reveals a sharp change from green outer layer to a rusty red inner layer with veinlets of green minerals (Figure 7.6). This observation highlights the potential risk of making misleading conclusions when one relies only on external appearance of ore samples for mineral identification.

Microscopically this sample is similar to sample SPK3 1 with notable chalcopyrite inclusions surrounded by secondary iron and copper minerals in the inner matrix (Figure 7.7). Chemically this presumed ore sample is dominated by copper and iron but is rather lean in silica with variable amounts of sulphur and phosphorus (Table 7.2). This ore sample is evidently not self-fluxing; although it is rich in iron, other important slag forming oxides like $\mathrm{Al}_{2} \mathrm{O}_{3}, \mathrm{MnO}, \mathrm{MgO}, \mathrm{CaO}, \mathrm{K}_{2} \mathrm{O}, \mathrm{P}_{2} \mathrm{O}_{5}$ and $\mathrm{TiO}_{2}$ are conspicuously absent or in very low concentrations. None of the typical ancient copper alloying elements were above the detection limits of SEM-EDS. Slag coatings normally observed on archaeological ore samples that were once subjected to pyrotechnological activities or high temperature phases associated with roasting prior to smelting were not observed in sample SPK 32. 
Microscopic and compositional results of samples SPK3 1 and SPK3 2 discussed above suggest close similarities with the majority of presumed ore samples from Shankare Hill. This close similarity, if indeed it can be proved that they were employed in copper smelting process, suggests the exploitation of the same geological deposit at both sites. Several conclusions can be drawn from the analytical results of this rather limited number of samples. First, the results further highlight that iron and copper are geochemically combined in the ore deposit(s) in the research area. This makes it difficult to separate iron from copper production debris in the archaeological record (but see discussion in previous and next chapter). Secondly, these presumed copper ores are not very pure; as such, the extraction of copper from these ores cannot be entirely 'slagless'. Thus previous claims that copper slag heaps are absent due to slagless extractive metallurgy cannot be sustained in the case of Phalaborwa (Küsel 1974a, 247). Thirdly, the undersaturated mineral samples documented at Kgopolwe are consistent with the copper ores from the Palabora Igneous Complex reported in the geological literature (see Chapters 3).

At this stage several questions can be posed concerning these mineral samples. First, can these typically undersaturated samples rich in copper, iron and sulphur be linked to Iron Age copper smelting practices at Kgopolwe or elsewhere around Phalaborwa? Secondly, is it possible to exploit these presumed ore samples economically with the technology that was available? Based on previous observations that no copper mineralisations are in the immediate vicinity of Kgopolwe Hill it is most likely that these samples were carried and deposited by human agents (Schryver 1970, 4). However, they may have been discarded precisely because they were too "dirty" compared to the more weathered ores that were usually exploited. The next section 
gives macrostructural and microstructural descriptions together with chemical data of selected copper slag samples from Kgopolwe. Previously published analytical results will be considered for comparative purposes as well. One of the objectives of analytical work of copper slag samples was to establish their possible link with the presumed ore samples presented in this section.

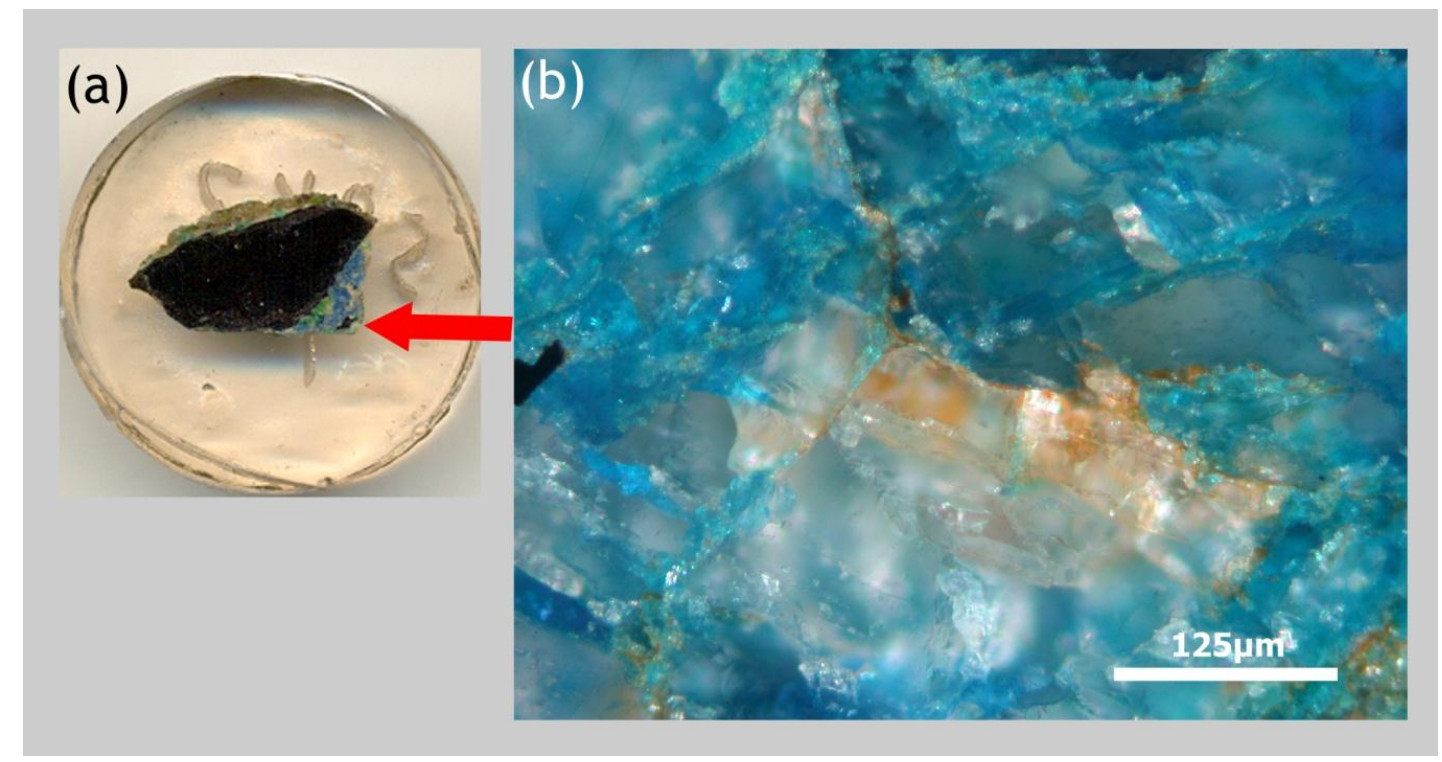

Figure 7.3: (a) Resin mounted section of ore sample SPK3 1 two matrices. (b) Photomicrograph of the outer blue matrix of SPK3 1 presumably azurite. Photomicrograph under cross polarised light (200x magnification) (Image: Author). 


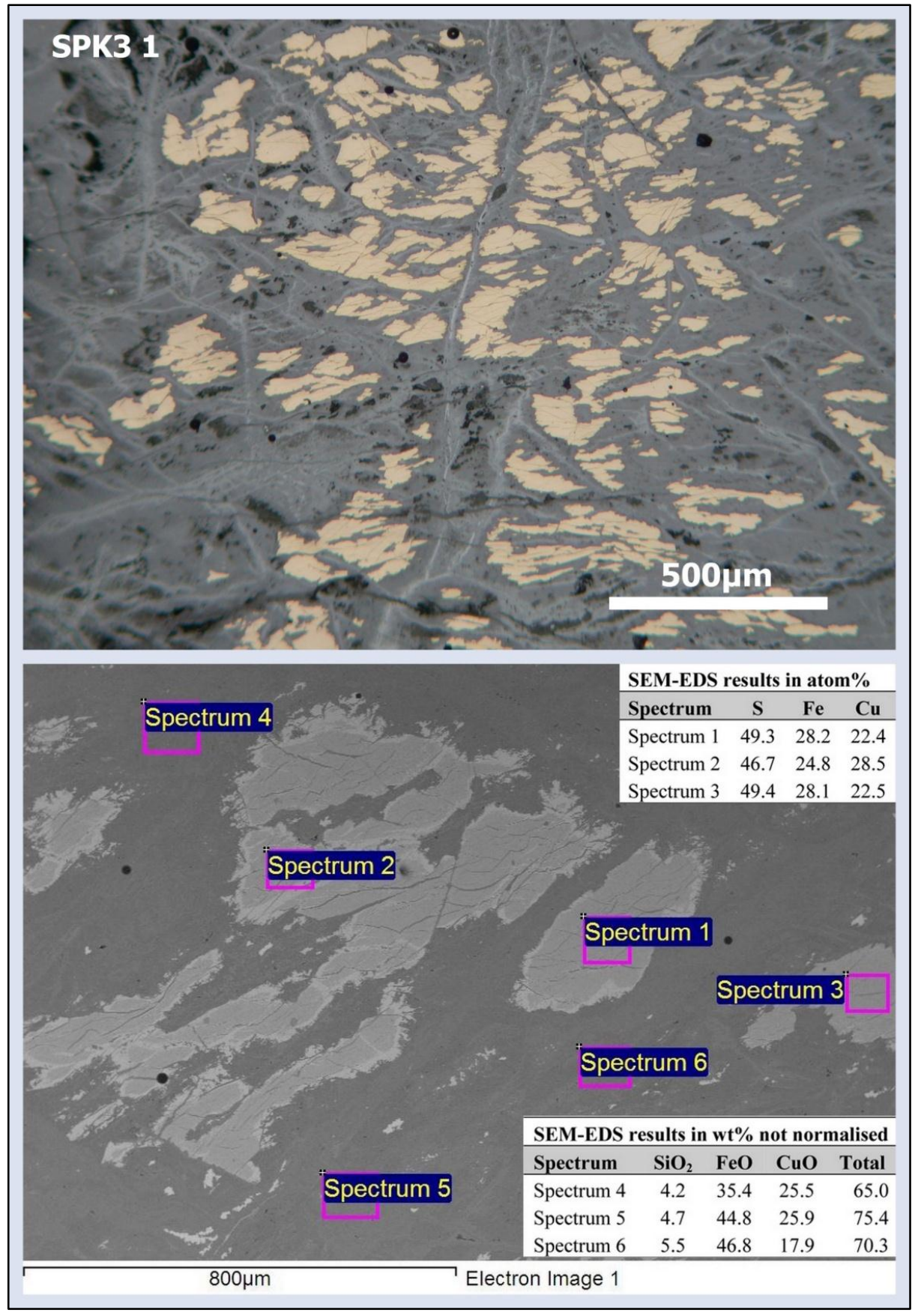

Figure 7.4: (Top) Photomicrograph of sample SPK 31 showing dominant golden coloured chalcopyrite inside an iron-copper secondary mineral matrix. Photomicrograph under plane polarized light at 50x magnification. (Bottom) SEMBSE image of sample SPK3 1 showing the chemistry of chalcopyrite inclusions and surrounding secondary iron-copper matrix (Image: Author). 


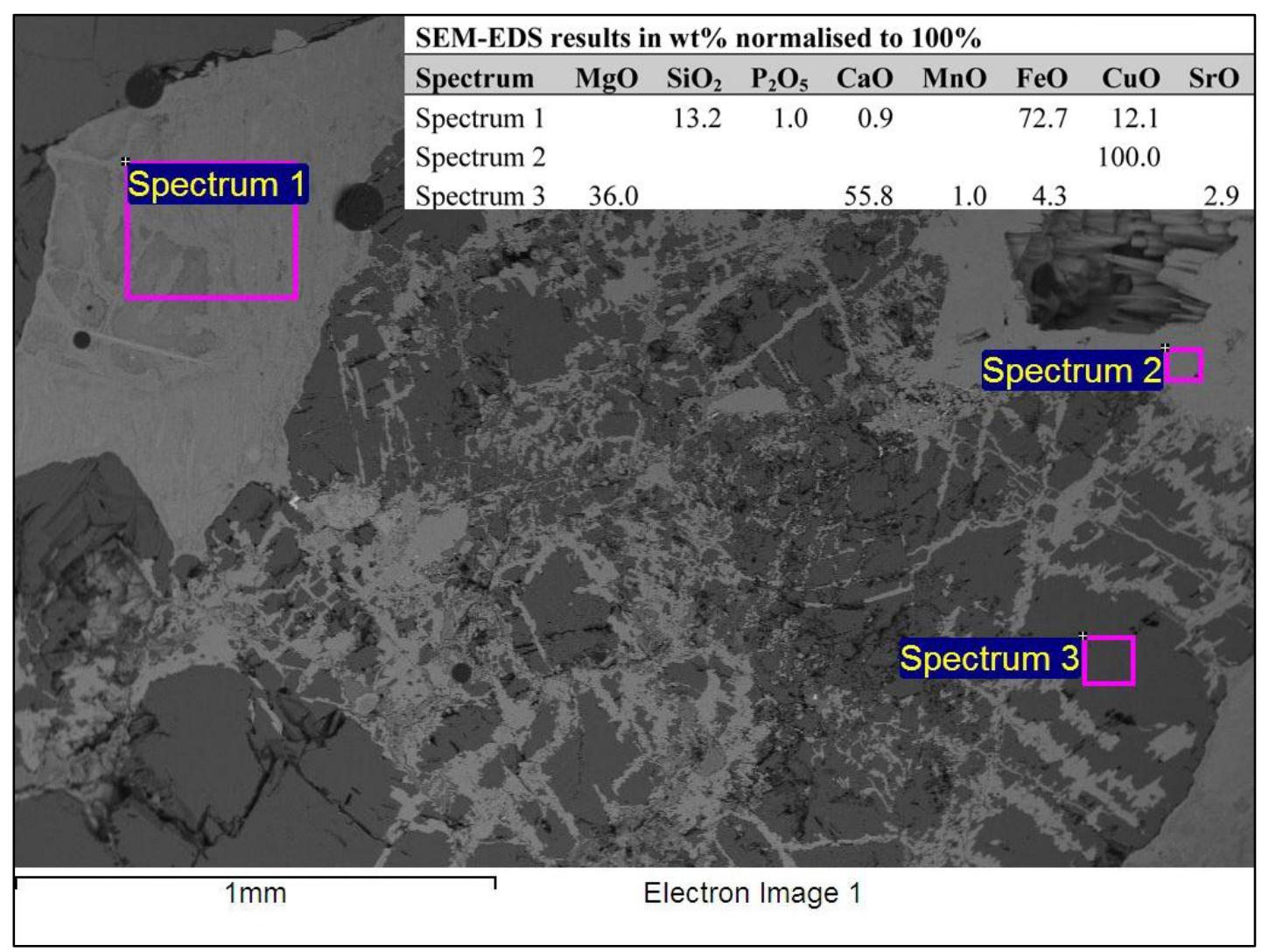

Figure 7.5: SEM-BSE image showing chemistry of the blue-green outer matrix sample SPK3 1(Image: Author). 


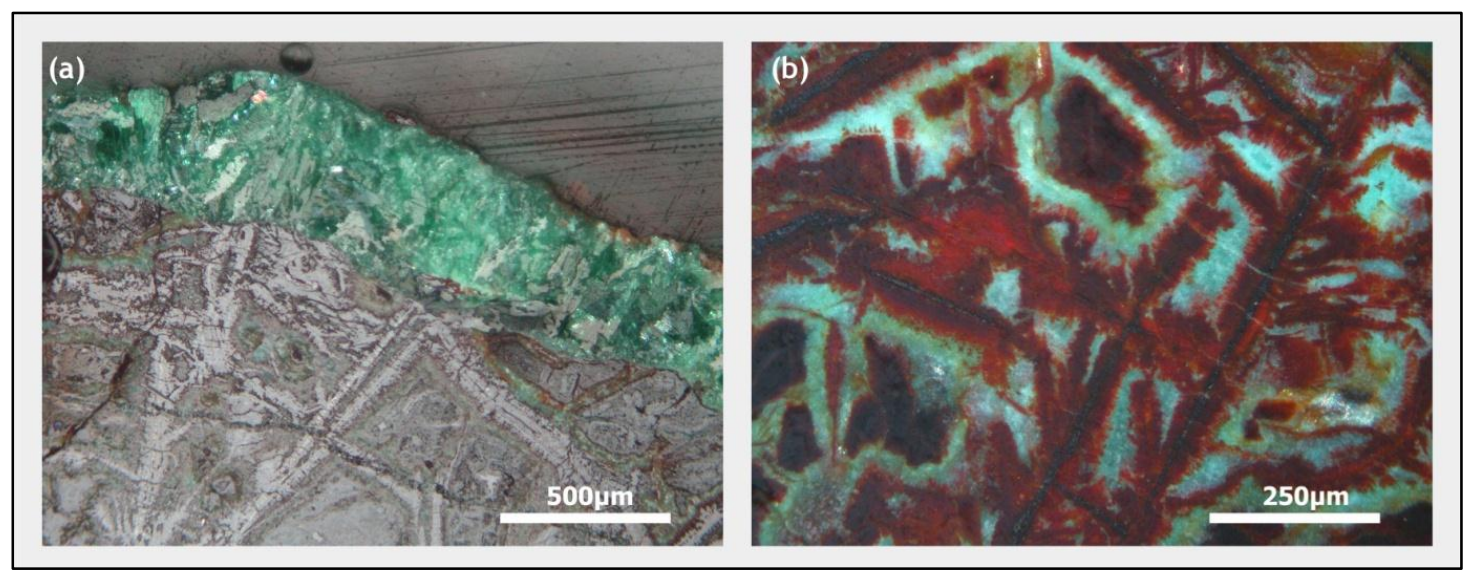

Figure 7.6: Photomicrographs of ore sample SPK3 2, (a) showing an outer thin layer of green copper mineralisation (b) showing the dominant inner secondary iron copper member. Both photomicrographs under cross polarised light (Image: Author).

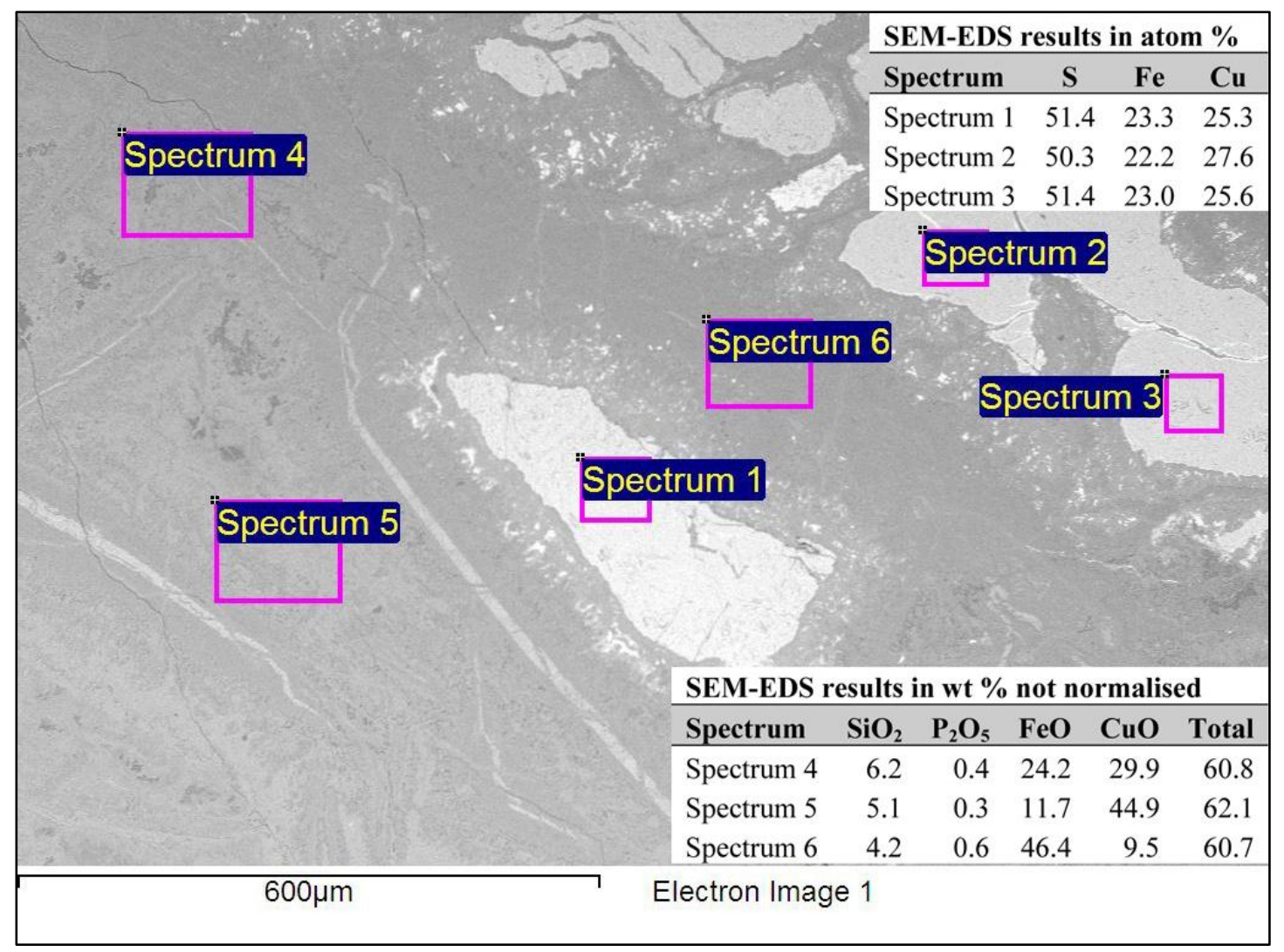

Figure 7.7: SEM-BSE image of sample SPK3 2 showing the chemistry of chalcopyrite inclusions and the surrounding secondary iron-copper matrix (Image: Author). 
Table 7.2: Average SEM-EDS results of at least five area scans of the presumed ore samples from Kgopolwe (SPK III) in wt\%. Results are not normalised due to the presence of structural water and carbonates prevalent in these ores.

\begin{tabular}{|c|c|c|c|c|c|c|c|c|c|c|c|c|c|c|}
\hline Sample & $\mathrm{Na}_{2} \mathrm{O}$ & MgO & $\mathrm{Al}_{2} \mathrm{O}_{3}$ & $\mathrm{SiO}_{2}$ & $\mathbf{P}_{2} \mathbf{O}_{5}$ & $\mathrm{SO}_{3}$ & $\mathrm{~K}_{2} \mathrm{O}$ & $\mathrm{CaO}$ & $\mathrm{TiO}_{2}$ & MnO & $\mathrm{FeO}$ & $\mathrm{CuO}$ & $\mathrm{BaO}$ & Total \\
\hline SPK3 1 & 0.0 & 0.1 & 0.0 & 4.4 & 0.1 & 11.3 & 0.0 & 0.2 & 0.0 & 0.0 & 41.5 & 22.9 & 0.9 & 81.5 \\
\hline SPK3 2 & 0.0 & 0.3 & 0.1 & 7.5 & 0.9 & 1.9 & 0.0 & 0.3 & 0.0 & 0.0 & 29.4 & 32.6 & 0.2 & 73.1 \\
\hline
\end{tabular}




\subsubsection{Kgopolwe copper slags}

Five copper slag samples (SPK6 1F, SPK6 2F, SPK6 3 F, SPK6 4F \& SPK6 5F) associated with a three port Phalaborwa type furnace (SPK VI) were selected for further analysis. Unfortunately, this furnace was not securely dated like other similar furnaces at the site. The copper slags, weighing between $7 \mathrm{~g}$ and $18 \mathrm{~g}$, are irregular in shape and very porous (Figure 7.8). Externally these slags have a grey-brown colouring whilst the crushed and milled powders exhibit a light brown to grey streak as opposed to black streak of Phalaborwa iron slags. None of these slag pieces had macroscopic unreacted minerals comparable to the magnetite prevalent in copper slags from Shankare Hill (cf. Chapter 6). Three of these slag samples (SPK6 1F, SPK6 2F, SPK6 3F) respond strongly to the magnet whilst the remaining two samples (SPK6 4F \& SPK6 5F) are weakly magnetic.

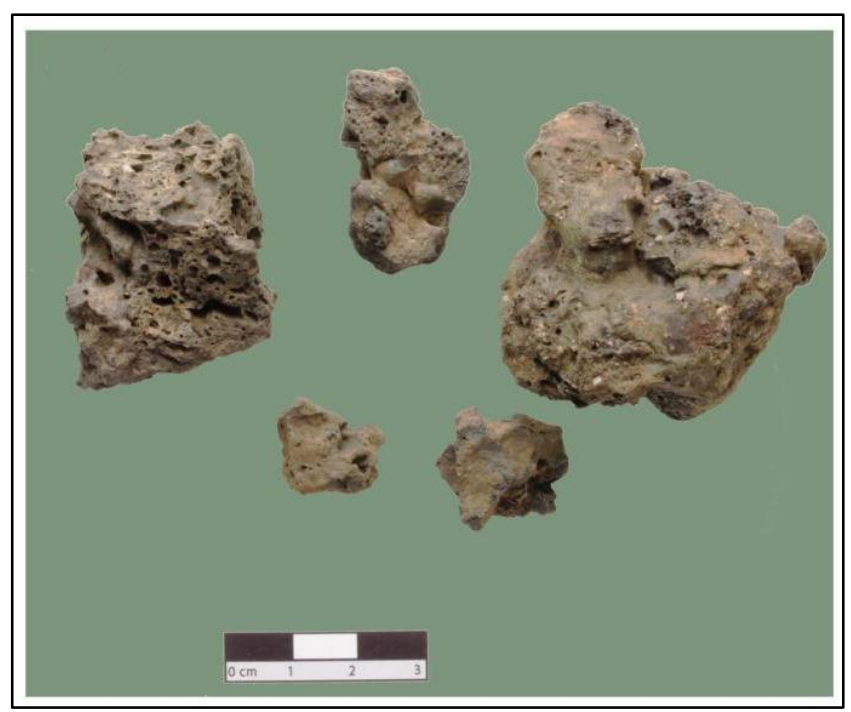

Figure 7.8: Five selected copper slags from Kgopolwe that are notably very porous (Image: Author). 
Copper slags from furnace SPK VI can broadly be subdivided into two groups based on microscopy and phase composition results (Figure 7.9), although they are likely to derive from a similar system because of the similarity in bulk composition. The first group is characterised by slag samples (SPK6 1F, SPK6 2F, SPK6 3F) very rich in magnetite spinels, thus explaining their strongly magnetic nature, together with copper prills and olivines. The second group is characterised by slags (SPK6 4F \& SPK6 5F) with blocky and equiaxed olivines with only a few tiny magnetite crystals on the face boundaries together with occasional copper prills. These fully developed olivines are notably rich in lime and magnesia. Their composition approaches that of a solid solution between montecellite $\left(\mathrm{CaMgSiO}_{4}\right)$ and kirschsteinite $\left(\mathrm{CaFeSiO}_{4}\right)$.

Isolated microscopic residual minerals $(\approx 500 \mu \mathrm{m}$ to $1 \mathrm{~mm})$ identified, with the aid of SEM-EDS analysis, as magnetite, fluorapatite and quartz are present in four Kgopolwe copper slag samples (Figure 7.10). It is interesting to note that unreacted magnetite minerals are rich in iron but are also accompanied by $\mathrm{MgO}(3 \%)$ together with $\mathrm{Al}_{2} \mathrm{O}_{3}$ and $\mathrm{CuO}$ at about one per cent each. $\mathrm{MgO}$ bearing magnetite is present in the carbonatite members at the Palabora Igneous Complex. The average composition of the residual apatite minerals in the copper slags is presented in Table 7.4. The SEM-EDS spectra of the undissolved apatite have a peak for fluorine which identifies them as fluorapatite. The ratio of $\mathrm{P}_{2} \mathrm{O}_{5}$ to $\mathrm{CaO}$ in these undissolved fluorapatite minerals is $1: 1.2$. 
Table 7.3: Average of five SEM-EDS analysis of the dominant olivines in the Kgopolwe copper slags. The results are presented in atomic \% and normalised.

\begin{tabular}{lrrrrrrr}
\hline Sample & Mg & Al & Si & P & Ca & Fe & O \\
\hline SPK6 1F & 3.9 & 1.7 & 17.9 & 0.6 & 10.0 & 6.0 & 59.9 \\
SPK6 2F & 5.4 & 0.0 & 14.7 & 0.2 & 12.9 & 9.4 & 57.5 \\
SPK6 3F & 4.1 & 0.1 & 14.7 & 0.4 & 13.5 & 9.6 & 57.6 \\
SPK6 4F & 7.3 & 0.0 & 14.7 & 0.1 & 6.4 & 14.2 & 57.4 \\
SPK6 5F & 5.1 & 1.0 & 19.4 & 0.1 & 9.3 & 5.0 & 60.0 \\
\hline
\end{tabular}

Table 7.4: Chemistry of some unreduced fluorapatite minerals in the copper slags from Kgopolwe. The results are presented in wt\% and normalised.

\begin{tabular}{lrrr}
\hline SAMPLE & $\mathbf{F}$ & $\mathbf{P}_{\mathbf{2}} \mathbf{O}_{\mathbf{5}}$ & $\mathbf{C a O}$ \\
\hline SPK6 2F & 5.1 & 42.9 & 52.0 \\
SPK3 3F & 3.0 & 44.6 & 52.4 \\
SPK6 5F & 3.3 & 44.3 & 52.5 \\
SPK6 5F & 3.2 & 44.0 & 52.8 \\
SPK6 5F & 3.1 & 44.2 & 52.8 \\
\hline Average & 3.5 & 44.0 & 52.5 \\
Std. deviation & 0.9 & 0.7 & 0.3 \\
Max. & 5.1 & 44.6 & 52.8 \\
Min. & 3.0 & 42.9 & 52.0 \\
\hline
\end{tabular}

Copper prills ranging from a few micrometres up to $700 \mu \mathrm{m}$ in diameter are present in these slag samples. Rounded copper prills embedded in these slag samples are frequently enveloped inside thin copper sulphide rims. The largest slag-entrapped copper prills have microscopic globular sulphide inclusions with a characteristic bluish colour under plane polarised light and dark blue colour under cross polarised light. However, complete matte prills were not documented in the slags. SEM-EDS point analyses of slag-entrapped prills confirmed that they are copper base without alloying elements like tin, zinc or arsenic. Several 'black copper' prills $(\approx 500 \mu \mathrm{m}$ in diameter) are present in sample SPK6 4F. These prills are dominated by exsolved metallic iron appearing as light blue dendrites together with globular dark blue copper sulphide inclusions under the optical microscope. SEM-EDS area scans of 
several of these prills yielded average copper and iron levels of 60 and $40 \mathrm{wt} \%$ respectively (Figure 7.11).

The average bulk chemistry results of Kgopolwe copper slag samples computed from systematic SEM-EDS area scans are presented in Table 7.5. The major oxides in these slag samples are $\mathrm{SiO}_{2}(34-42 \mathrm{wt} \%), \mathrm{FeO}(21-33 \mathrm{wt} \%), \mathrm{CaO}(18-27 \mathrm{wt} \%), \mathrm{MgO}$ (3-5 wt \%) and $\mathrm{Al}_{2} \mathrm{O}_{3}(2-4 \mathrm{wt} \%)$. Silica is always higher in these slags than iron oxide. Relatively higher concentrations of $\mathrm{P}_{2} \mathrm{O}_{5}$ which register up to $2.8 \mathrm{wt} \%$ should also be noted. The elevated levels of $\mathrm{P}_{2} \mathrm{O}_{5}$ in copper slags from Kgopolwe can simply be explained as resulting from the inclusion of gangue mineral fluorapatite in the furnace charge. However, the $\mathrm{P}_{2} \mathrm{O}_{5}$ to $\mathrm{CaO}$ ratio in the once molten slag matrix is much lower than in the undissolved fluorapatite. This issue will be further discussed later in subsequent sections which explore the link between the potential ore samples and slag samples. The copper slags from Kgopolwe are relatively low in $\mathrm{TiO}_{2}$, below $0.5 \mathrm{wt} \%$; an indication that titanium-free ores from the central carbonatite member in the Palabora Igneous Complex were used. The residual $\mathrm{MgO}$ bearing magnetite in these slags further indicates that the ores employed came from the central carbonatite. 
Table 7.5: Average SEM-EDS 'bulk' chemical results of copper smelting slags from Kgopolwe SPK VI. The results are presented in wt\% and normalised to $100 \%$. The last column is showing the silica to alumina ratio.

\begin{tabular}{lrrrrrrrrrrrrr} 
Sample & $\mathbf{N a}_{\mathbf{2}} \mathbf{O}$ & $\mathbf{M g O}$ & $\mathbf{A l}_{\mathbf{2}} \mathbf{O}_{\mathbf{3}}$ & $\mathbf{S i O}_{\mathbf{2}}$ & $\mathbf{P}_{\mathbf{2}} \mathbf{O}_{\mathbf{5}}$ & $\mathbf{S O}_{\mathbf{3}}$ & $\mathbf{K}_{\mathbf{2}} \mathbf{O}$ & $\mathbf{C a O}$ & $\mathbf{T i O}_{\mathbf{2}}$ & $\mathbf{M n O}$ & $\mathbf{F e O}$ & $\mathbf{C u O}$ & $\mathbf{S i O}_{\mathbf{2}}: \mathbf{A l}_{\mathbf{2}} \mathbf{O}_{\mathbf{3}}$ \\
\hline SPK6 1F & 0.4 & 3.2 & 3.3 & 42.1 & 2.7 & 0.1 & 1.0 & 23.9 & 0.1 & 0.2 & 20.8 & 2.3 & $\mathbf{1 3}$ \\
SPK6 2F & 0.5 & 4.5 & 2.7 & 34.3 & 2.8 & 0.1 & 1.1 & 22.8 & 0.2 & 0.2 & 29.5 & 1.2 & $\mathbf{1 3}$ \\
SPK6 3F & 0.2 & 4.1 & 2.1 & 35.6 & 2.2 & 0.2 & 0.7 & 27.0 & 0.2 & 0.2 & 26.7 & 0.9 & $\mathbf{1 7}$ \\
SPK6 4F & 0.6 & 4.3 & 3.5 & 36.9 & 1.6 & 0.2 & 1.1 & 18.0 & 0.4 & 0.2 & 32.9 & 0.3 & $\mathbf{1 1}$ \\
SPK6 5F & 0.5 & 4.3 & 3.4 & 40.8 & 1.9 & 0.1 & 1.0 & 18.6 & 0.4 & 0.2 & 27.8 & 1.0 & $\mathbf{1 2}$ \\
\hline Average & 0.4 & 4.1 & 3.0 & 37.9 & 2.3 & 0.1 & 1.0 & 22.1 & 0.3 & 0.2 & 27.5 & 1.1 & $\mathbf{1 3}$ \\
Std. deviation & 0.2 & 0.5 & 0.6 & 3.4 & 0.5 & 0.0 & 0.2 & 3.8 & 0.1 & 0.0 & 4.4 & 0.7 & $\mathbf{2}$ \\
Max. & 0.6 & 4.5 & 3.5 & 42.1 & 2.8 & 0.2 & 1.1 & 27.0 & 0.4 & 0.2 & 32.9 & 2.3 & $\mathbf{1 7}$ \\
Min. & 0.2 & 3.2 & 2.1 & 34.3 & 1.6 & 0.1 & 0.7 & 18.0 & 0.1 & 0.2 & 20.8 & 0.3 & $\mathbf{1 1}$ \\
\hline
\end{tabular}

Table 7.6: Previously published SEM-EDS bulk chemical results of copper smelting slags from Kgopolwe SPK III (Miller \& Killick 2004, 41).

\begin{tabular}{|c|c|c|c|c|c|c|c|c|c|c|c|c|c|}
\hline Sample & $\mathrm{Na}_{2} \mathrm{O}$ & MgO & $\mathrm{Al}_{2} \mathrm{O}_{3}$ & $\mathrm{SiO}_{2}$ & $\mathbf{P}_{2} \mathrm{O}_{5}$ & $\mathrm{SO}_{3}$ & $\mathrm{~K}_{2} \mathrm{O}$ & $\mathrm{CaO}$ & $\mathrm{TiO}_{2}$ & MnO & $\mathrm{FeO}$ & $\mathrm{Cu}_{2} \mathrm{O}$ & $\mathrm{SiO}_{2}: \mathrm{Al}_{2} \mathrm{O}_{3}$ \\
\hline SPK3.10 & 0.8 & 0.8 & 3.4 & 13.7 & 0.2 & 0.0 & 1.0 & 3.1 & 1.1 & 0.2 & 69.9 & 0.0 & 4 \\
\hline SPK3.10a & 0.0 & 0.6 & 6.1 & 21.2 & 0.0 & 0.0 & 1.8 & 3.2 & 0.8 & 0.0 & 66.3 & 0.0 & 3 \\
\hline SPK3.10c & 0.0 & 1.0 & 7.8 & 26.6 & 0.8 & 0.0 & 2.0 & 4.1 & 0.5 & 0.0 & 57.1 & 0.2 & 3 \\
\hline SPK3.13a & 0.0 & 5.3 & 2.5 & 29.8 & 3.1 & 0.4 & 0.6 & 24.9 & 0.0 & 0.0 & 25.5 & 7.9 & 12 \\
\hline SPK3.Bg & 0.0 & 4.0 & 1.9 & 16.9 & 1.8 & 0.0 & 0.2 & 7.9 & 1.3 & 0.4 & 63.5 & 2.0 & 9 \\
\hline Average & 0.2 & 2.3 & 4.3 & 21.6 & 1.2 & 0.1 & 1.1 & 8.6 & 0.7 & 0.1 & 56.5 & 2.0 & 6 \\
\hline Std. deviation & 0.4 & 2.2 & 2.5 & 6.7 & 1.3 & 0.2 & 0.8 & 9.3 & 0.5 & 0.2 & 17.9 & 3.4 & 4 \\
\hline Max. & 0.8 & 5.3 & 7.8 & 29.8 & 3.1 & 0.4 & 2.0 & 24.9 & 1.3 & 0.4 & 69.9 & 7.9 & 12 \\
\hline Min. & 0.0 & 0.6 & 1.9 & 13.7 & 0.0 & 0.0 & 0.2 & 3.1 & 0.0 & 0.0 & 25.5 & 0.0 & 3 \\
\hline
\end{tabular}




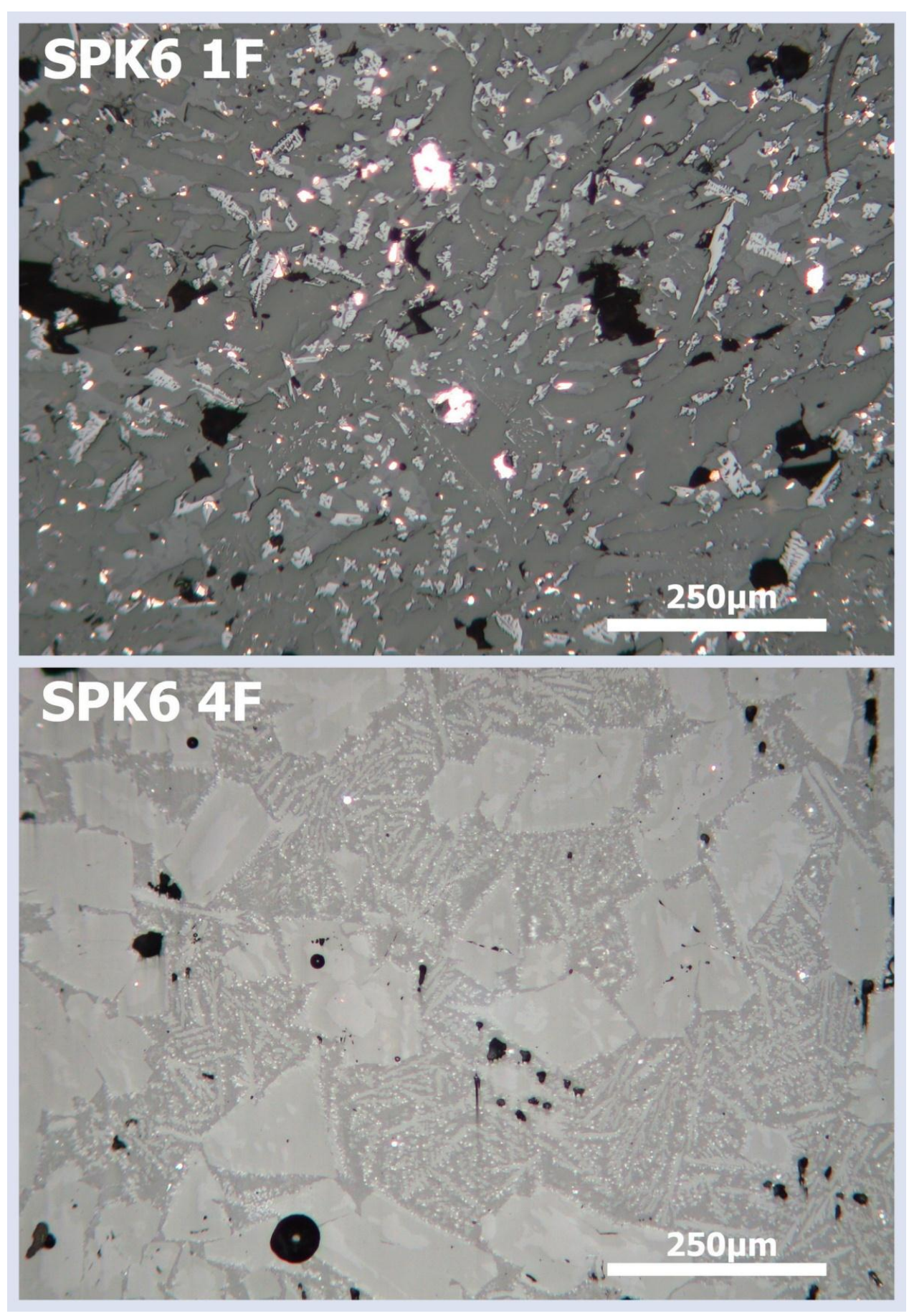

Figure 7.9: Photomicrographs showing magnetite-rich slags (SPK6 1F) against olivine dominated slags (SPK6 4F). Photomicrographs taken under plane polarized light (100x magnification). 


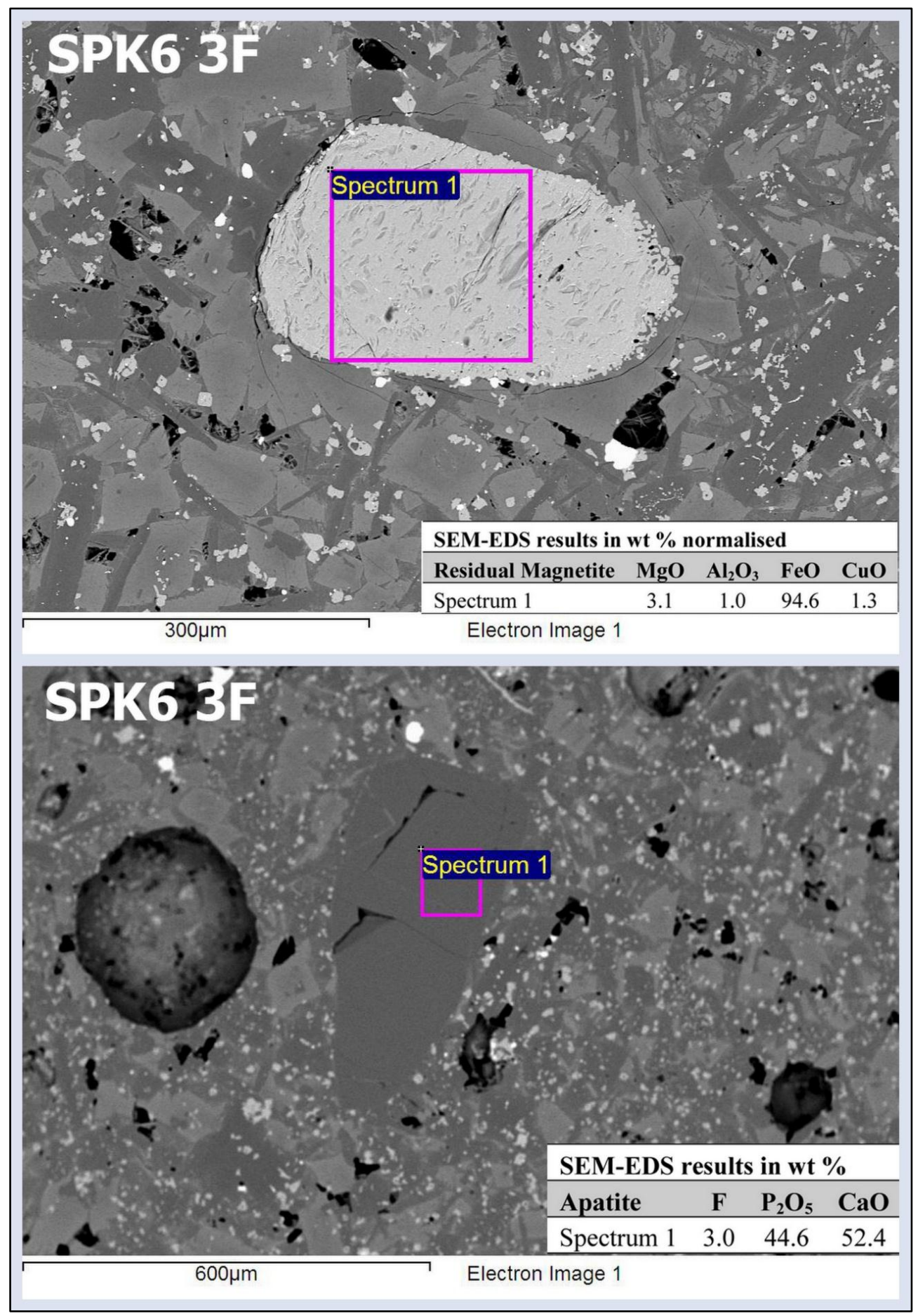

Figure 7.10: SEM-BSE images of sample SPK6 $3 F$ showing some unreacted magnetite and fluorapatite mineral grains embedded in the slag matrix. 

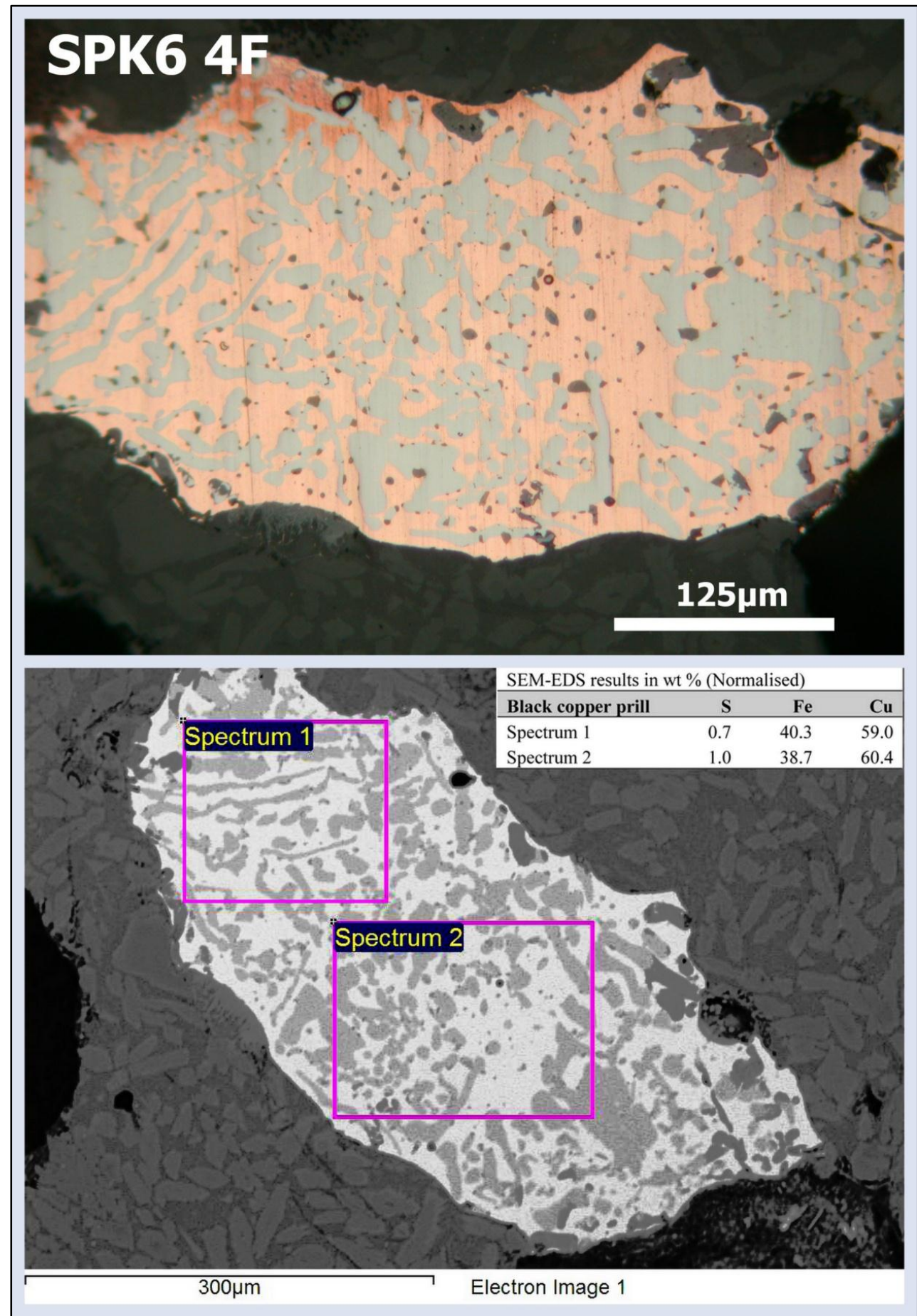

Figure 7.11: Photomicrograph (Top) and SEM-BSE image (Bottom) of one of the several 'black copper' prills entrapped in slag sample SPK6 $4 F$. 


\subsubsection{Brief discussion of Kgopolwe analytical results}

The task of reconstructing the metallurgical chaîne opératoire of copper production activities represented by Kgopolwe debris is adversely affected by the limited number of samples and fragmentary nature of evidence. However, some important aspects of copper smelting processes can be established from these analytical results. The chemistry and mineralogy of Kgopolwe slag samples is consistent with byproducts of smelting operations rather than refining. The absence of delafossite $\left(\mathrm{CuFeO}_{2}\right)$ and presence of olivines as the dominant phases, together with low levels of $\mathrm{CuO}$ and high levels of $\mathrm{FeO}$, support this interpretation.

It is important first to investigate the link between the presumed ore and slag samples recovered from Kgopolwe. There are striking differences in the chemistry of presumed ore samples from SPK III and slag samples from SPK VI presented in this thesis. Archaeological samples from SPK III are securely dated to the early second millennium AD whilst the SPK VI furnace remains undated (Evers \& van der Merwe 1987). Analytical results of copper slags from SPK VI presented in Table 7.5 are also remarkably different from analytical results of copper slags from SPK III previously published by Miller \& Killick $(2004,41)$, also reproduced in Table 7.6 in this chapter. The SPK VI slag samples are rich in silica and calcium whereas the majority of copper slags from SPK III are comparatively low in silica and lime except for slag sample SPK3.13a. The SPK III copper slags are comparatively rich in iron oxide which reaches up to $70 \% \mathrm{FeO}$. The chemistry of SPK III slags tally well with SPK III presumed ore samples, also rich in iron oxide (Figure 7.12). The high $\mathrm{FeO}$ levels in the early copper slags will be discussed further in Chapter 8 . The close association of iron and copper evident in the two potential ores from Kgopolwe is not surprising 
because they originate from chalcopyrite $\left(\mathrm{CuFeS}_{2}\right)$ ores. The smelting of these potential ores would have required significant addition of silica to flux the iron oxide.

The discrepancy in the chemistry of copper ores and slags from SPK III and SPK VI respectively warrants further discussion. The two presumed ore samples from SPK III are devoid of $\mathrm{CaO}$ and $\mathrm{SiO}_{2}$ oxides which dominate in the SPK VI slags. Apatite as documented in copper smelting slags from furnace SPK VI can be used to explain partly the elevated levels of both $\mathrm{P}_{2} \mathrm{O}_{5}$ and $\mathrm{CaO}$ in these slag samples. However the $\mathrm{P}_{2} \mathrm{O}_{5}$ to $\mathrm{CaO}$ ratio of the once molten SPK VI slag matrices is very low $(1: 10)$ compared to their ratio in undissolved fluorapatite $(\approx 1: 1)$. There was thus an additional source of at least $90 \%$ of the $\mathrm{CaO}$ present in SPK VI copper slags. Additional $\mathrm{CaO}$ could have entered the system through the use of lime-rich copper ores, addition of lime as flux, use of calcareous technical ceramics or alternatively ash from charcoal fuel used in the smelting process. The erosion/ slagging of calcareous technical ceramics was identified as the source of additional lime in iron smelting slags at Tell Hammeh (Az-Zarqa) in Jordan (Veldhuijzen 2005). Although analytical data of technical ceramics employed at Kgopolwe is missing we can safely rule out this possibility on the basis of analytical results of technical ceramics from the nearby and contemporary evidence from Shankare Hill presented in Chapter 6. None of the Shankare tuyère ceramic fabrics contains more than $3 \% \mathrm{CaO}$. Limestone chippings frequently embedded in slags where limestone $\left(\mathrm{CaCO}_{3}\right)$ was intentionally added as a flux are absent in the Kgopolwe slags (Morton \& Wingrove 1972). This limits the additional sources of $\mathrm{CaO}$ documented in SPK VI slags to two possible candidates. First, the carbonatite member at Lolwe contains vast reserves of calcite occuring together with copper mineralisations (van der Merwe \& Killick 1979, 86). 
Secondly, ash produced by charcoal fuel can result in significantly high $\mathrm{CaO}$ levels in archaeological slags (Merkel 1990; Tylecote et al. 1977, 310). Indeed preliminary analyses of ashes from hard wood trees in the research area revealed calcium oxide of up to 90\% (Friede et al. 1982, 39; van der Merwe \& Killick 1979, 86).

The bulk chemistry of metallurgical debris from Kgopolwe is plotted on a phase diagram to obtain their liquidus temperature estimates. The ternary system $\mathrm{CaO}-\mathrm{FeO}-$ $\mathrm{SiO}_{2}$ is the most appropriate diagram to plot copper production debris from this site (Figure 7.12). Plots of the Kgopolwe metallurgical debris do not form a tight cluster in the ternary system. However, copper slags plot well within the workable and low melting regions of the phase diagram. From the phase diagram it can be deduced that the silica-rich and lime-rich slags from furnace SPK VI have a liquidus temperature ranging from $1190-1270^{\circ} \mathrm{C}$. On the other hand the iron-rich copper ores and slags from SPK III plot well in the olivine and wüstite regions with a liquidus temperature range between $1115^{\circ} \mathrm{C}$ and $1300^{\circ} \mathrm{C}$. The occurrence of copper prills with exsolved iron in sample SPK6 4F supports the unusually high temperatures or reducing conditions for ancient copper smelting estimated from the phase diagram for the same samples (Cooke \& Aschenbrenner 1975; Craddock \& Meeks 1987).

The copper metal that was produced at Kgopolwe ranged from pure copper and 'black copper' with copper sulphide inclusions. No other base metals accompanied the copper prills besides iron, thus it can be concluded that tin bronzes and brasses were not produced during the primary smelting processes at Kgopolwe. The morphology of SPK VI slags is consistent with crushed slag (see Figure 7.8) although further field evidence and analyses of more copper slags will be required to firmly establish this. It is proposed here that copper smelting slags at Kgopolwe were 
also subjected to crushing to retrieve entrapped prills that were subsequently consolidated and refined in crucibles. Crucible sherds with slag linings, vitrified and distorted interiors were previously excavated from domestic middens at Kgopolwe (Evers \& van der Merwe 1987, 88). The liquation of copper prills to form planoconvex ingots at the bottom of the smelting furnaces cannot be ruled out if the previous interpretations are correct (Miller 2010; Miller et al. 2001). It should be highlighted that the recovery of copper smelting slags associated with Phalaborwa type furnace is contrary to previous suggestions that this furnace design was exclusively used for iron smelting (see Chapter 8 for further discussion). 


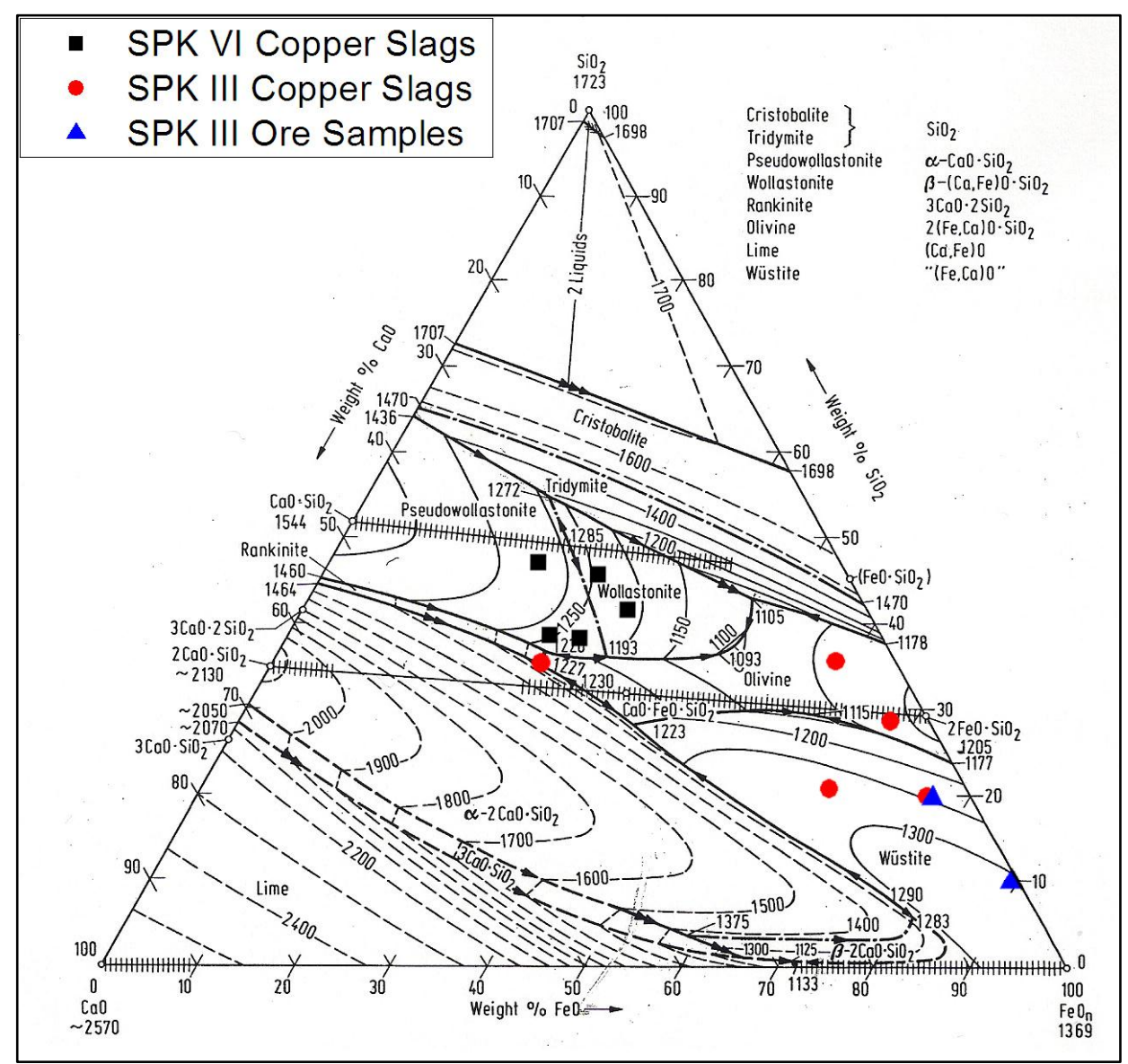

Figure 7.12: Ternary phase diagram showing system $\mathrm{FeO}-\mathrm{SiO}_{2}\left(+\mathrm{TiO}_{2}+\mathrm{Al}_{2} \mathrm{O}_{3}\right)-\mathrm{CaO}$ $\left(\mathrm{MgO}+\mathrm{P}_{2} \mathrm{O}_{5}\right)$, with plots of copper slags and ores from Kgopolwe (phase diagram adapted from Kowalski et al. 1995, 126). Data used in this diagram is present in Table 7.2, Table 7.5 and Table 7.6. 


\subsection{Molotho (MOL): c. $16^{\text {th }}-19^{\text {th }}$ century AD $(60 \pm 120 \mathrm{BP})$}

\subsubsection{Site profile}

Molotho Hill was situated in the Loole farm (31 LU) inside the Palabora Mining Company premises (Map Sheet: South Africa 1:50 000 Sheet 2431AA Grietjie second edition 1986: Grid Ref: $\left.24^{\circ} 00^{\prime} \mathrm{S} ; 31^{\circ} 09^{\prime} \mathrm{E}\right)$. The site was close to rich iron and copper deposit at Lolwe Hill, that was only $3.3 \mathrm{Km}$ away. Unfortunately, the once prominent Molotho Hill is now buried under the heavy tailings resulting from on-going mining operations. Information about the archaeological evidence that was documented at Molotho is available on the Palabora Heritage Committee website (http://www.palabora.com/pmc_cultural_heritage/Moloto.htm).

Archaeologically, the most remarkable evidence at Molotho was a single tuyère port Lolwe type furnace (Figure 7.13). The furnace was initially interpreted as a refining furnace by the geologist Schwellnus $(1937,908-909)$ but was subsequently classified as typical copper smelting furnace by archaeologists (van der Merwe \& Scully 1971, 182). The Lolwe furnace at Molotho was later excavated during the 1970s as part of rescue operations because the site was under imminent threat of destruction from mining operations (van der Merwe 1971). The excavators claim that the furnace structure was excavated and preserved in situ under the custody of Palabora Mining Company. However, it was not possible to trace the whereabouts of this furnace currently. The only published information concerning Molotho is a brief furnace description together with a single radiocarbon date. The furnace was dated to $60 \pm 120$ BP (Y-1661), that is several centuries later than the copper furnace reported at Shankare and the copper production evidence at Kgopolwe (SPK III) (Evers \& van 
der Merwe, 1987, 93; Stuiver \& van der Merwe 1968). Hitherto, materials from Molotho had not been subjected to any archaeometallurgical investigation. Limited slag samples from Molotho were available at UCT Phalaborwa collection. Unfortunately metallurgical ceramics and ores from Molotho were not available for further analysis. The volume of metallurgical debris accompanying the furnace at Molotho was not reported in the unpublished excavation reports. Six slag samples from Molotho were kindly made available for further analysis from UCT.

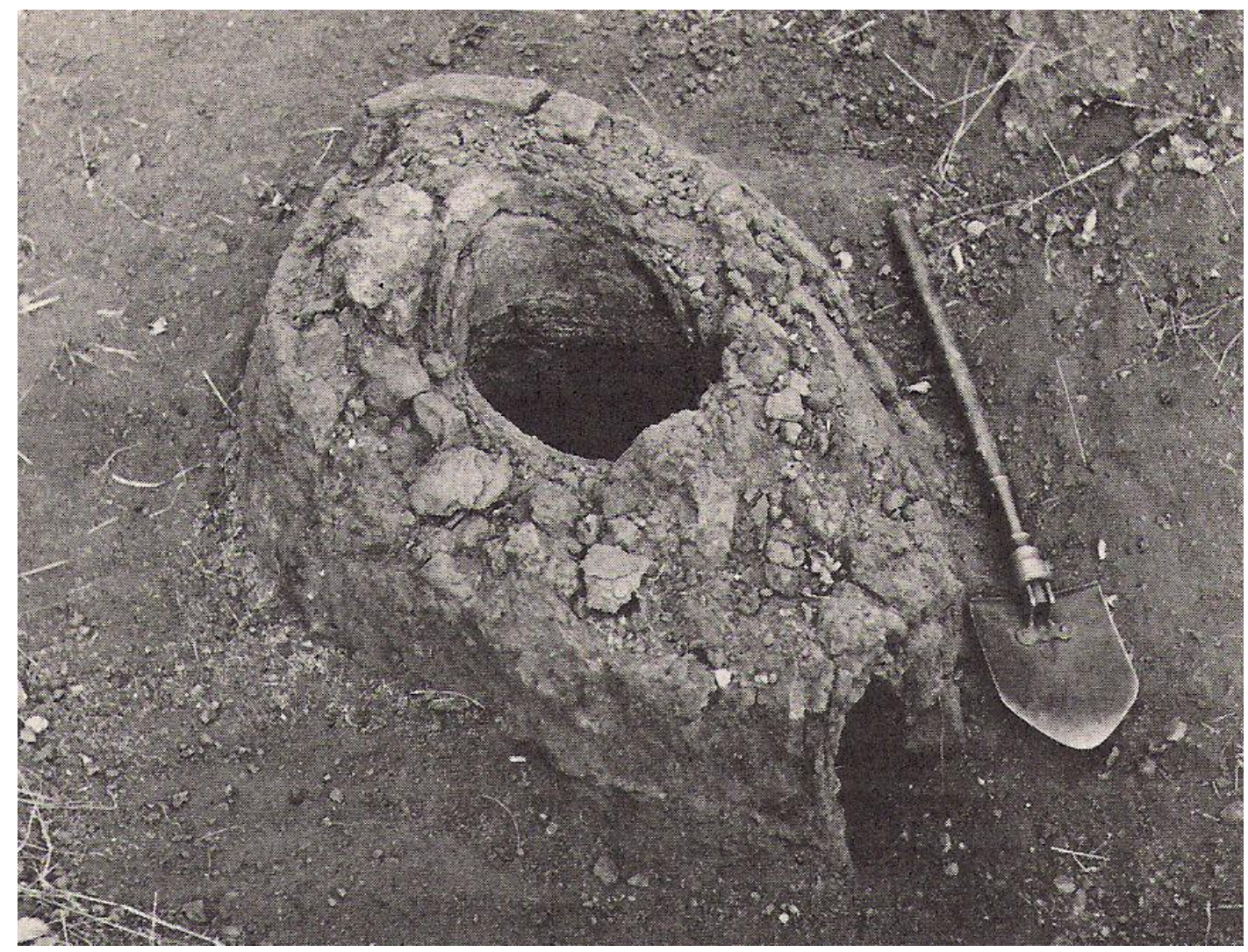

Figure 7.13: Photograph of the Lolwe type furnace at Molotho taken by C. E. More during the 1960s (Image: Reproduced from van der Merwe 1980, 484). 


\subsubsection{Analytical results}

\subsubsection{Molotho copper slags}

The copper slag samples from Molotho presented in this section weigh between $12 \mathrm{~g}$ to $33 \mathrm{~g}$ each. The exterior surfaces of these slags are charcoal-impressed without any macroscopic unreacted or partially decomposed material in their matrices, save for one sample with ceramic fragment adhering (Figure 7.14). The hand specimens of Molotho slags are strongly magnetic suggesting the presence of either ferromagnetic phases or minerals and possibly metallic iron. Due to the inevitable presence of iron oxides the corrosion products of these slags are rusty red in colour. The milled powders of the Molotho slags gave a brown streak easily contrasted with black streak of iron smelting slags presented in this project.

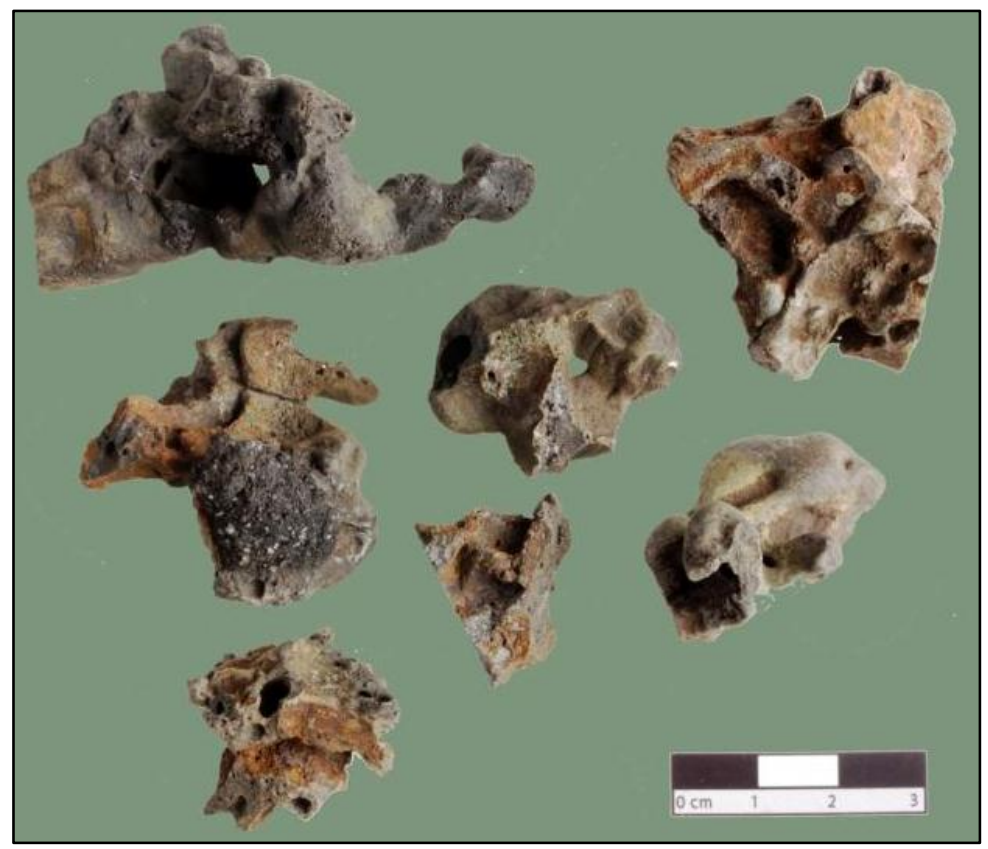

Figure 7.14: Irregular copper slags from Molotho with notable charcoal impressions (Image: Author). 
Microscopically, Molotho slag samples are homogenous, dominated mostly by blocky olivines or pyroxenes and magnetite spinels together with tiny copper prills (Figure 7.15). The microstructure of these slags should be contrasted with the heterogeneous nature of copper smelting slags from Shankare presented in the previous chapter. Occasional wüstite $(\mathrm{FeO})$ globules are also present in slag sample MOL5F. The composition of the individual phases in the slags from Molotho was established with the aid of SEM-EDS analyses. Chemically the blocky olivines and pyroxenes are dominated by $\mathrm{SiO}_{2}(28-39 \mathrm{wt} \%), \mathrm{CaO}$ (28-39 wt\%), $\mathrm{MgO}$ (3-12 wt $\%$ ) and $\mathrm{FeO}(4-22 \mathrm{wt} \%)$. These blocky silicates phases are significantly low FeO (Table 7.7), as a result fayalitic $\left(\mathrm{Fe}_{2} \mathrm{SiO}_{4}\right)$ olivines were not documented in the Molotho slag assemblage. The average atomic ratio between silica, magnesia, calcium and iron oxides in these blocky silicates is 2:1:2:1 for samples MOL2F, MOL5F and MOL6F. The ratio of metal oxides $(\mathrm{MeO})$ to silica $\left(\mathrm{SiO}_{2}\right)$ is $2: 1$; as such, they fit in the group of olivines (Bachmann 1982,14). The composition of these olivines varies but roughly approaches the kirschsteinite and montecellite composition. The other Molotho slags have well crystallised pyroxenes identified as diopside $\left(\mathrm{MgCaSi}_{2} \mathrm{O}_{6}\right)$. The magnetite spinels documented in these slags contain low amounts of $\mathrm{Al}_{2} \mathrm{O}_{3}$ and $\mathrm{MgO}$. Rounded metallic copper prills rarely exceeding $10 \mu \mathrm{m}$ in their diameter are also prevalent in slags samples from Molotho. The majority of these prills are relatively pure with few globular and light blue inclusions. These inclusions were identified by SEM-EDS spot analyses as chalcocite $\left(\mathrm{Cu}_{2} \mathrm{~S}\right)$. Some copper prills recorded up to $2 \% \mathrm{Fe}$, however, none of them showed microscopic evidence of exsolved iron. Hence, the iron levels in these microscopic prills should be accepted with caution since the surrounding matrices of these prills are iron-rich, thus the iron recorded in these small prills may derive from the large interaction volume of the 
SEM-EDS spot analysis. No other base metals were detected in the slag entrapped copper prills suggesting that only unalloyed copper was produced.

Table 7.7: SEM-EDS results of the analysed olivines and pyroxenes associated with copper slags from Molotho. The results are presented in atomic \% and normalised.

\begin{tabular}{llrrrrr}
\hline Sample & Group & Mg & Si & Ca & Fe & O \\
\hline MOL1F & Pyroxenes & 6.7 & 17.2 & 15.9 & 1.3 & 58.7 \\
MOL2F & Olivines & 11.0 & 15.3 & 13.3 & 2.8 & 57.6 \\
MOL3F & Pyroxenes & 1.6 & 20.6 & 14.3 & 3.4 & 60.3 \\
MOL4F & Pyroxenes & 6.7 & 17.8 & 14.2 & 2.3 & 58.9 \\
MOL5F & Olivines & 8.7 & 14.8 & 13.1 & 6.0 & 57.4 \\
MOL6F & Olivines & 8.1 & 14.9 & 11.9 & 7.6 & 57.5 \\
\hline
\end{tabular}

The bulk chemical analyses of six slags from Molotho were also carried out using multiple area scans with SEM-EDS system (Table 7.8). Molotho copper slags are best represented on the $\mathrm{CaO}-\mathrm{FeO}-\mathrm{SiO}_{2}$ ternary system with $\mathrm{SiO}_{2}$ ranging from 33-46 wt $\%, \mathrm{CaO} 23-27 \mathrm{wt} \%$ and $\mathrm{FeO} 18-31 \mathrm{wt} \%$. These slags have remarkably lower levels of iron oxide surpassed by both silica and lime. Apart from these three principal oxides these slags have significant levels of $\mathrm{MgO}, 2-12 \mathrm{wt} \%$. The silica to alumina ratio of these copper slags is exceptionally high in the order of 48 up to 190. These ratios should be contrasted with readings all iron slags from Shankare, Serotwe and Phutwane presented in this thesis. The silica to alumina ratio in the analysed iron slags is consistent at 5:1. The copper content hereby presented as $\mathrm{CuO}$ is between 1-5 wt $\%$. However, it must be highlighted that metallic copper prills were systematically avoided during SEM-EDS area scans. If copper prills were considered in the SEM-EDS area scans the copper content will have been higher than that, indicating higher copper losses. $\mathrm{P}_{2} \mathrm{O}_{5}$ is found in much lower concentrations $(0.7-1.2$ wt $\%)$ in the Molotho slags. 
Table 7.8: Average SEM-EDS 'bulk' chemical results of copper smelting slags from Molotho. The results are presented in wt\% and normalised to $100 \%$. The last column is showing the silica to alumina ratio.

\begin{tabular}{|c|c|c|c|c|c|c|c|c|c|c|c|c|c|}
\hline Sample & $\mathrm{Na}_{2} \mathrm{O}$ & MgO & $\mathrm{Al}_{2} \mathrm{O}_{3}$ & $\mathrm{SiO}_{2}$ & $\mathrm{P}_{2} \mathrm{O}_{5}$ & $\mathrm{SO}_{3}$ & $\mathrm{~K}_{2} \mathrm{O}$ & $\mathrm{CaO}$ & $\mathrm{TiO}_{2}$ & $\mathrm{MnO}$ & $\mathrm{FeO}$ & $\mathrm{CuO}$ & $\mathrm{SiO}_{2}: \mathrm{Al}_{2} \mathrm{O}_{3}$ \\
\hline MOL1F & 0.2 & 11.6 & 0.7 & 39.0 & 1.1 & 0.0 & 0.6 & 26.1 & 0.2 & 0.2 & 17.6 & 2.6 & 54 \\
\hline MOL2F & 0.2 & 10.8 & 0.7 & 38.4 & 1.1 & 0.1 & 0.7 & 26.5 & 0.3 & 0.1 & 17.8 & 3.3 & 59 \\
\hline MOL3F & 0.1 & 1.9 & 0.2 & 46.2 & 1.2 & 0.0 & 0.5 & 22.9 & 0.4 & 0.3 & 22.1 & 4.1 & 190 \\
\hline MOLAF & 0.1 & 9.2 & 0.2 & 36.2 & 1.1 & 0.1 & 0.4 & 24.0 & 0.1 & 0.3 & 23.1 & 5.3 & 162 \\
\hline MOL5F & 0.3 & 7.8 & 0.7 & 33.2 & 0.7 & 0.2 & 1.0 & 23.6 & 0.3 & 0.3 & 31.3 & 0.8 & 48 \\
\hline MOL6F & 0.2 & 8.7 & 1.4 & 40.2 & 0.8 & 0.1 & 0.9 & 23.1 & 0.2 & 0.2 & 23.2 & 1.0 & 30 \\
\hline Average & 0.2 & 8.3 & 0.6 & 38.9 & 1.0 & 0.1 & 0.7 & 24.4 & 0.2 & 0.2 & 22.5 & 2.8 & 90 \\
\hline Std. deviation & 0.1 & 3.4 & 0.4 & 4.4 & 0.2 & 0.1 & 0.2 & 1.5 & 0.1 & 0.1 & 5.0 & 1.7 & 68 \\
\hline Max. & 0.3 & 11.6 & 1.4 & 46.2 & 1.2 & 0.2 & 1.0 & 26.5 & 0.4 & 0.3 & 31.3 & 5.3 & 190 \\
\hline Min. & 0.1 & 1.9 & 0.2 & 33.2 & 0.7 & 0.0 & 0.4 & 22.9 & 0.1 & 0.1 & 17.6 & 0.8 & 30 \\
\hline
\end{tabular}




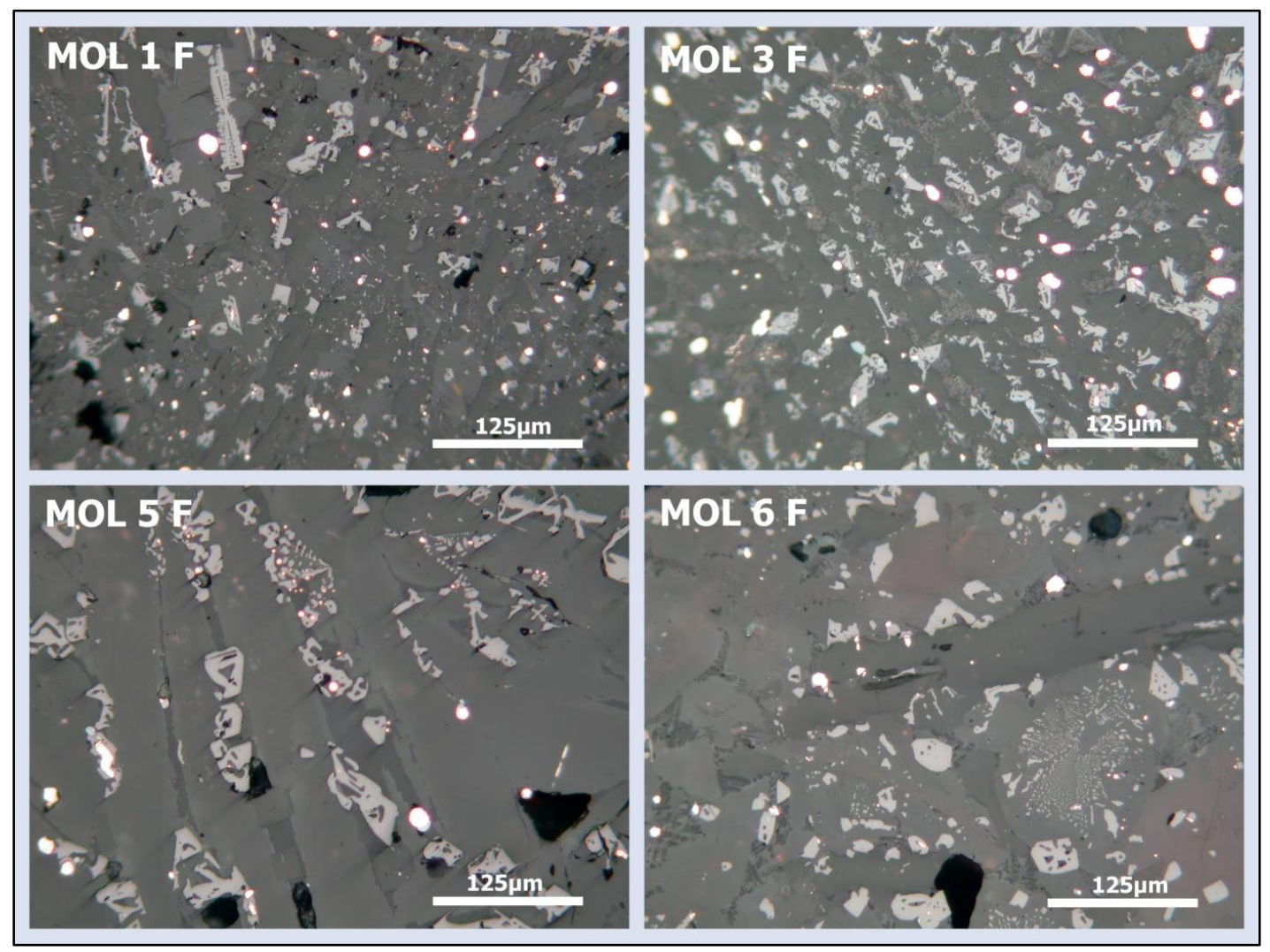

Figure 7.15: Reflected light photomicrographs of copper smelting slags from Molotho. Showing the dominant magnetite spinels embedded in blocky olivines and pyroxenes. Photomicrographs captured under plane polarized light (200x magnification). 


\subsubsection{Brief discussion of Molotho analytical results}

The archaeometallurgical assemblage from Molotho available in the UCT collection was limited to slag samples only. Based on several premises the slag samples from Molotho are positively identified as by-products of copper smelting process. The impressions on the exterior of these samples are consistent with furnace slags that solidified around pieces of charcoal that was used as fuel. The low copper content and iron content noted in the bulk chemistry of these slags, the presence of olivines and the absence of delafossite $\left(\mathrm{CuFeO}_{2}\right)$ or cuprite $\left(\mathrm{Cu}_{2} \mathrm{O}\right)$ altogether confirm they are by-products of smelting rather than melting (Bachmann 1980, 116).

In the absence of presumed ore samples coupled with the virtual absence of unreacted minerals in these slags, the discussion of the nature of ores used is at best speculative. The absence of matte prills together with low sulphur contents in the bulk chemistry of these slags suggests the use of secondary copper ores with only limited residual sulphide minerals. Comparatively low levels of iron oxide together with the absence of exsolved iron in the slag-entrapped copper prills suggests improved furnace charge and/or better extractive technology compared to the ones employed at Shankare and Kgopolwe. The low $\mathrm{P}_{2} \mathrm{O}_{5}$ levels, just above $1 \%$, in the copper slags from Molotho should also be highlighted. Low levels of $\mathrm{P}_{2} \mathrm{O}_{5}$ recorded in these slags should be juxtaposed with high levels of $\mathrm{P}_{2} \mathrm{O}_{5}$, up to 12 wt\%, documented in Shankare copper smelting slags (Chapter 6). It was suggested that the major source of phosphorus reported in Shankare copper slags was fluorapatite. The low levels of phosphorus in Molotho copper slags would thus suggest use of another source of ore or improved beneficiation of ores to get rid of apatite. $\mathrm{TiO}_{2}$ is also conspicuously very low in the bulk chemistry of copper slags from Molotho. The low 
$\mathrm{TiO}_{2}$ and significant levels of $\mathrm{MgO}$ point to the exploitation of ores from the central carbonatite of the Palabora Igneous Complex.

The ternary system $\mathrm{CaO}-\mathrm{FeO}-\mathrm{SiO}_{2}$ is also the most appropriate for the copper smelting slags from Molotho (Figure 7.16). The slags do not plot in a tight cluster in this ternary system, but they all plot well within the low melting pseudowollastonite region of the phase diagram, allowing a liquidus temperature estimate ranging from $1220-1270^{\circ} \mathrm{C}$. The chaîne opératoire represented at Molotho suggests that secondary copper ores were used in single tuyère port furnaces. No evidence was discovered of slag tapping from the macro and microstructural evidence of Molotho slags. Although no ingots or copper artefacts were found at Molotho, it can be safely concluded that the final product was copper of high purity. No additional base metals or exsolved iron, prevalent in copper slags from Shankare and Kgopolwe, were documented in the slag-entrapped copper prills. With the limited evidence it cannot be ascertained if plano-convex ingots formed at the bottom of the furnaces. Neither is there evidence to support the slag crushing and prill collection hypothesis documented at Shankare. 


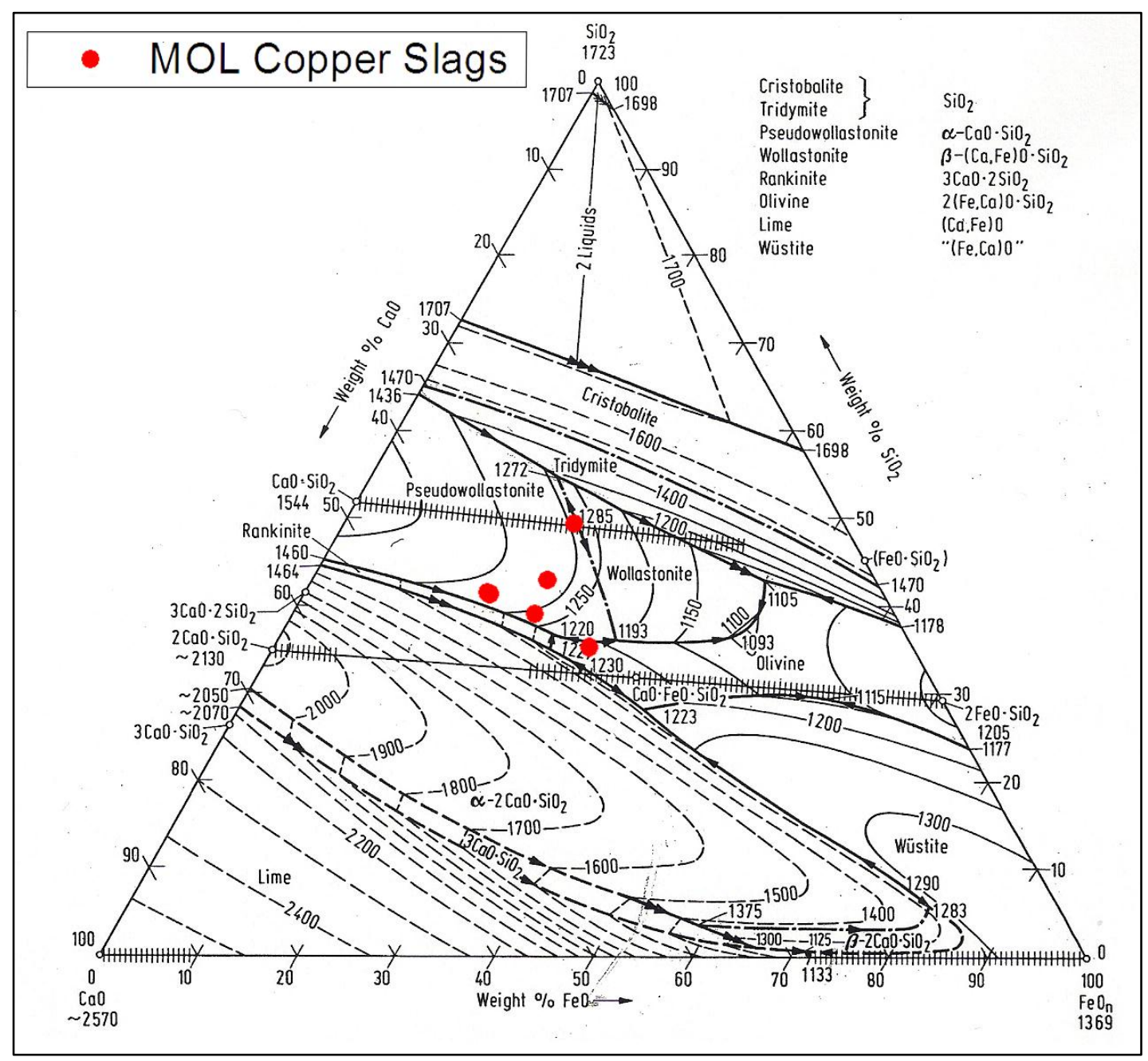

Figure 7.16: Ternary phase diagram showing system $\mathrm{FeO}-\mathrm{SiO}_{2}\left(+\mathrm{TiO}_{2}+\mathrm{Al}_{2} \mathrm{O}_{3}\right)-\mathrm{CaO}$ $\left(\mathrm{MgO}+\mathrm{P}_{2} \mathrm{O}_{5}\right)$, with plots of copper slags from Molotho (Phase diagram adapted from Kowalski et al. 1995, 126). Data used in this diagram is present in Table 7.8. 


\subsection{Serotwe (SPM): c. late $17^{\text {th }}-19^{\text {th }}$ century $\mathrm{AD}(80 \pm 60 \mathrm{BP})$}

\subsubsection{Site profile}

Located in the Wegsteek farm (30LU) is Serotwe Hill, published as Matsepe or Masekekop in previous archaeological reports (Map Sheet: South Africa 1:50 000

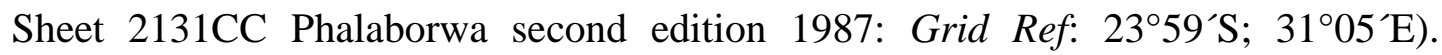
Serotwe Hill is a prominent syenite kopje located approximately $4 \mathrm{~km}$ southwest of the present day PMC copper open pit mine, formerly Lolwe Hill. This syenite hill is also located close to the perennial Ga-Selati River which flows in the easterly direction eventually feeding into the Olifants River.

Several well preserved furnaces representing both sub-triangular Phalaborwa furnaces and single tuyère port Lolwe furnaces were initially reported by Schwellnus on the foothills of Serotwe (Schwellnus 1937). The Lolwe furnace was subsequently excavated by Nikolaas van der Merwe in 1965 (Evers \& van der Merwe 1987), whilst two sub-triangular Phalaborwa furnaces (SERM2M1 \& SER2M3) were excavated by Julius Pistorius during the 1980s (Pistorius 1989). The Lolwe furnace

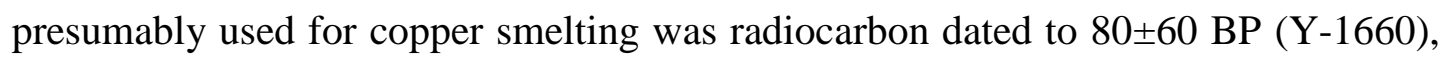
with calibrated dates ranging from the late seventeenth century onwards (Evers \& van der Merwe 1987, 93). The superstructure of this furnace was carefully removed and donated to the National Museum in Bloemfontein for safe keeping after excavation. The volume of production debris associated with the furnaces at Serotwe is not available in the published and unpublished excavation reports. Limited metallurgical debris from these furnaces were collected and deposited at the Department of Archaeology, UCT. Previously a single copper smelting slag sample (SPM1a) was analysed together with seven iron smelting slags to establish their bulk 
chemical composition using XRF methods (Miller \& Killick 2004, 40). Apart from the furnaces, nothing is known about the archaeology around Serotwe Hill. Archaeological materials from Serotwe can be identified by the site code SPM used first in the 1960s site designation system. S stands for South Africa, P for Phalaborwa and $\mathrm{M}$ for Matsepe. This site code system is retained here for the purposes of consistency. A handful of smelting slags from Serotwe were made available for comparative purposes in this thesis.

\subsubsection{Analytical results}

\subsubsection{Serotwe iron slag}

A single iron slag [SPM3C (1)] from Serotwe was subjected to analytical investigations. This particular sample was recovered from a three tuyère port furnace and was only included in this study for comparative purposes. Macroscopically sample SPM3C(1) was once a fully molten slag with notable charcoal impressions clearly suggesting that it solidified inside the furnace. The slag sample is dense with a rusty red external colour but the powder from this sample gave a dark black streak. Unlike most copper slag samples that were investigated in this thesis, sample SPM3C(1) responded negatively to magnetic tests.

Microscopically, the sample is homogeneous and dominated by wüstite dendrites, olivines with isolated metallic iron particles and little interstitial glass (Figure 7.17). The average bulk chemistry of this sample that was gathered using multiple area scans with SEM-EDS is presented in Table 7.10. This sample is best represented on the $\mathrm{CaO}-\mathrm{FeO}-\mathrm{SiO}_{2}$ ternary system because iron oxide, silica and lime are the major oxides. Compared to bulk chemical results of copper smelting slags (see Table 7.11) from the same site sample, $\mathrm{SPM} 3 \mathrm{C}(1)$ is richer in $\mathrm{K}_{2} \mathrm{O}$ and $\mathrm{TiO}_{2}$. It is also 
noteworthy that the silica to alumina ratio $(5: 1)$ of this iron slag sample is also consistent with iron slags from other sites in the research area (cf. $\mathrm{SiO}_{2}: \mathrm{Al}_{2} \mathrm{O}_{3}$ of iron slags from Shankare and Phutwane Table 7.13).

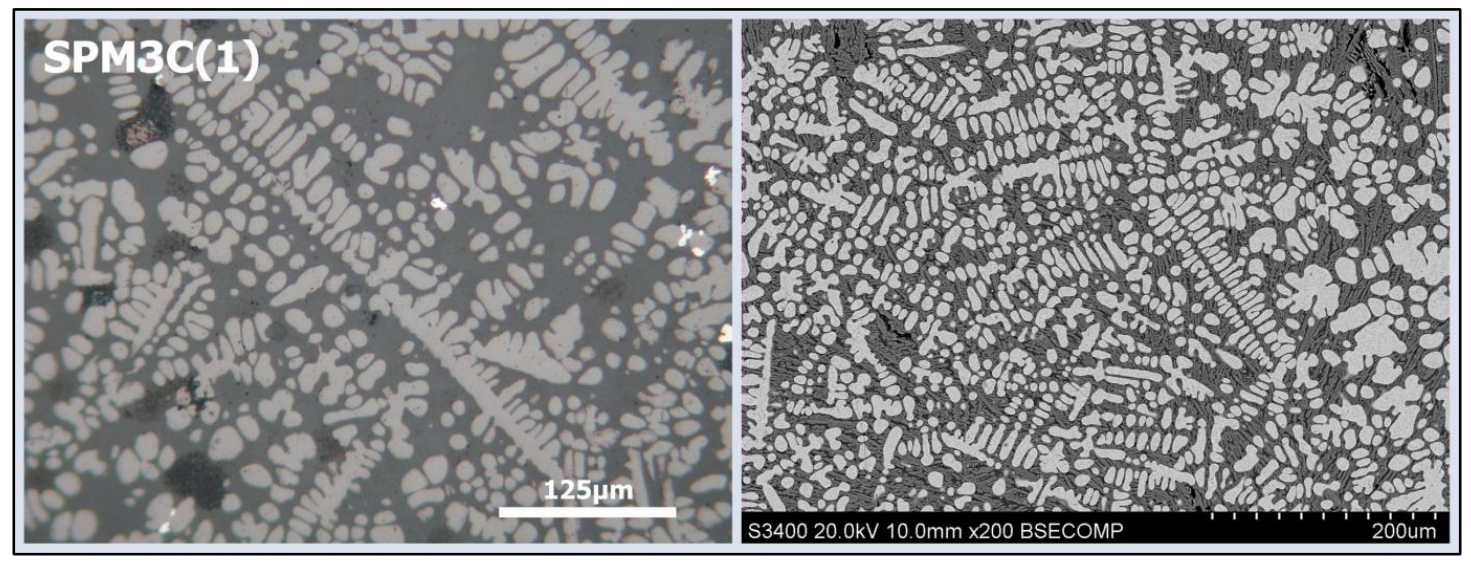

Figure 7.17: Photomicrograph and SEM-BSE image of the wüstite dominated iron slag SPM3C(1) from Serotwe (Image: Author).

\subsubsection{Serotwe copper slags}

Four copper smelting slag samples [SPM1(1), SPM1(2), SPM1(3) \& SPM1(4)] from Serotwe were analysed to establish their mineralogy using optical microscopy and SEM-EDS. These slags are much more dense and compact than others presented in this thesis, weighing between 55 and $80 \mathrm{~g}$ each. They do not exhibit any external porosity like the copper slags from the site of Kgopolwe (see Section 7.3.2.2). Macroscopically, the Serotwe slags are charcoal-impressed without any macroscopic un-decomposed magnetite mineral inclusions embedded in the once liquid slag matrix (Figure 7.18). Externally these slags have brownish corrosion products and once they are crushed and powdered they also produce brown streaks. Serotwe copper slags are strongly magnetic due to the abundance of ferromagnetic phases identified as magnetite spinels in their microstructure. 
Microscopically, Serotwe copper slag samples contain globular metallic copper prills ranging from a few micrometres to $200 \mu \mathrm{m}$ in diameter. Under the optical microscope, these metallic copper prills contain some cuprite phases that appear bluish under plane polarised light and red under cross polarised light. These cuprite phases seem to have been caused by post-depositional corrosion of the metal prills. No exsolved iron phases were documented in the slag-entrapped copper prills. The presence of free iron oxide in the form of magnetite spinels as opposed to wüstite together with dominant copper prills confirms that these are indeed copper smelting slags (Miller \& Killick 2004, 31). The copper slags from Serotwe have blocky olivines or pyroxenes, magnetite spinels and sometimes eutectic olivine-magnetite structures (Figure 7.19). The chemistry of the blocky silicate phases present in these copper slags does not correspond to fayalite $\left(\mathrm{Fe}_{2} \mathrm{SiO}_{4}\right)$. These crystals accommodate significant levels of $\mathrm{CaO}$ and $\mathrm{MgO}$. The ratio of metal oxides to silica in samples SPM1(1) and SPM1(2) is 2:1 which places them in the broad group of olivines. The atomic ratio of metal oxides to silica in the complex silicate phases of samples SPM1(3) and SPM1(4) is 1:1; as such, they should be classified as pyroxenes (Table 7.9). The composition of these pyroxenes approaches that of mineral hedenbergite $\left(\mathrm{MgCaSi}_{2} \mathrm{O}_{6}\right)$.

Table 7.9: SEM-EDS results obtained from the analysis of olivines and pyroxenes documented in Serotwe copper slags. The results are presented in atomic \% and normalised.

\begin{tabular}{llrrrrr}
\hline Sample & Group & Mg & Si & Ca & Fe & O \\
\hline SPM1(1) & Olivines & 4.8 & 14.9 & 11.5 & 11.3 & 57.5 \\
SPM1(2) & Olivines & 2.5 & 15.2 & 4.6 & 20.1 & 57.6 \\
SPM1(3) & Pyroxenes & 5.1 & 19.2 & 9.7 & 6.4 & 59.6 \\
SPM1(4) & Pyroxenes & 4.7 & 19.1 & 9.6 & 7.0 & 59.6 \\
\hline
\end{tabular}


The SEM-EDS bulk chemistry of Serotwe copper slag samples is presented in Table 7.11. These slags are best represented in the $\mathrm{CaO}-\mathrm{FeO}-\mathrm{SiO}_{2}$ ternary system with $\mathrm{SiO}_{2}$ ranging from 40-46 wt $\%, \mathrm{FeO} 22-38 \mathrm{wt} \%$ and $\mathrm{CaO} 15-20 \mathrm{wt} \% . \mathrm{MgO}$ contributes between 4-6 wt\%. The bulk chemistry of these slag samples agree very well with the phases that were documented in these samples. The silica to alumina ratio of these copper slags varies between 34 and 70 . Low $\mathrm{TiO}_{2}$ in these copper slags is also consistent with other copper slags presented in this thesis. Noteworthy in the bulk chemistry of Serotwe copper slags is the lower concentrations of $\mathrm{P}_{2} \mathrm{O}_{5}$, not more than 1 wt\%. This low $\mathrm{P}_{2} \mathrm{O}_{5}$ should be contrasted with higher $\mathrm{P}_{2} \mathrm{O}_{5}$ levels (reaching up to $12 \mathrm{wt} \%)$ in copper smelting slags from Shankare, Kgopolwe and Phutwane. 
Table 7.10: Average SEM-EDS 'bulk' chemical results of iron smelting slag SPM3C(1) from Serotwe. The results are presented in wt\% and normalised to $100 \%$. The last column is showing the silica to alumina ratio.

\begin{tabular}{|c|c|c|c|c|c|c|c|c|c|c|c|c|c|}
\hline Sample & $\mathrm{Na}_{2} \mathrm{O}$ & $\mathrm{MgO}$ & $\mathrm{Al}_{2} \mathrm{O}_{3}$ & $\mathrm{SiO}_{2}$ & $\mathbf{P}_{2} \mathbf{O}_{5}$ & $\mathrm{SO}_{3}$ & $\mathrm{~K}_{2} \mathrm{O}$ & $\mathrm{CaO}$ & $\mathrm{TiO}_{2}$ & MnO & $\mathrm{FeO}$ & $\mathrm{CuO}$ & $\mathrm{SiO}_{2}: \mathrm{Al}_{2} \mathrm{O}_{3}$ \\
\hline SPM3C(1) & 0.8 & 3.6 & 4.3 & 20.3 & 0.8 & 0.1 & 1.5 & 12.5 & 4.3 & 0.2 & 51.5 & 0.1 & 5 \\
\hline
\end{tabular}

Table 7.11: Average SEM-EDS 'bulk' chemical results of copper smelting slags from Serotwe. The results are presented in wt\% and normalised to $100 \%$. The last column is showing the silica to alumina ratio.

\begin{tabular}{|c|c|c|c|c|c|c|c|c|c|c|c|c|c|}
\hline Sample & $\mathrm{Na}_{2} \mathrm{O}$ & MgO & $\mathrm{Al}_{2} \mathrm{O}_{3}$ & $\mathrm{SiO}_{2}$ & $\mathrm{P}_{2} \mathrm{O}_{5}$ & $\mathrm{SO}_{3}$ & $\mathrm{~K}_{2} \mathrm{O}$ & $\mathrm{CaO}$ & $\mathrm{TiO}_{2}$ & $\mathrm{MnO}$ & $\mathrm{FeO}$ & $\mathrm{CuO}$ & $\mathrm{SiO}_{2}: \mathrm{Al}_{2} \mathrm{O}_{3}$ \\
\hline SPM1(1) & 0.3 & 6.4 & 1.2 & 40.7 & 0.6 & 0.1 & 0.4 & 19.9 & 0.2 & 0.2 & 28.5 & 1.5 & 34 \\
\hline SPM1(2) & 0.0 & 3.6 & 0.6 & 39.7 & 0.4 & 0.1 & 0.3 & 14.9 & 0.3 & 0.2 & 38.1 & 1.8 & 70 \\
\hline SPM1(3) & 0.4 & 6.1 & 1.1 & 45.8 & 0.6 & 0.1 & 0.5 & 19.2 & 0.2 & 0.2 & 22.0 & 3.8 & 42 \\
\hline SPM1(4) & 0.3 & 5.7 & 1.2 & 44.9 & 0.7 & 0.0 & 0.5 & 19.0 & 0.2 & 0.1 & 23.3 & 4.2 & 38 \\
\hline Average & 0.3 & 5.4 & 1.0 & 42.8 & 0.6 & 0.1 & 0.4 & 18.3 & 0.2 & 0.2 & 28.0 & 2.8 & 46 \\
\hline Std. deviation & 0.1 & 1.2 & 0.3 & 3.0 & 0.1 & 0.1 & 0.1 & 2.3 & 0.1 & 0.0 & 7.3 & 1.4 & 16 \\
\hline Max. & 0.4 & 6.4 & 1.2 & 45.8 & 0.7 & 0.1 & 0.5 & 19.9 & 0.3 & 0.2 & 38.1 & 4.2 & 70 \\
\hline Min. & 0.0 & 3.6 & 0.6 & 39.7 & 0.4 & 0.0 & 0.3 & 14.9 & 0.2 & 0.1 & 22.0 & 1.5 & 34 \\
\hline
\end{tabular}




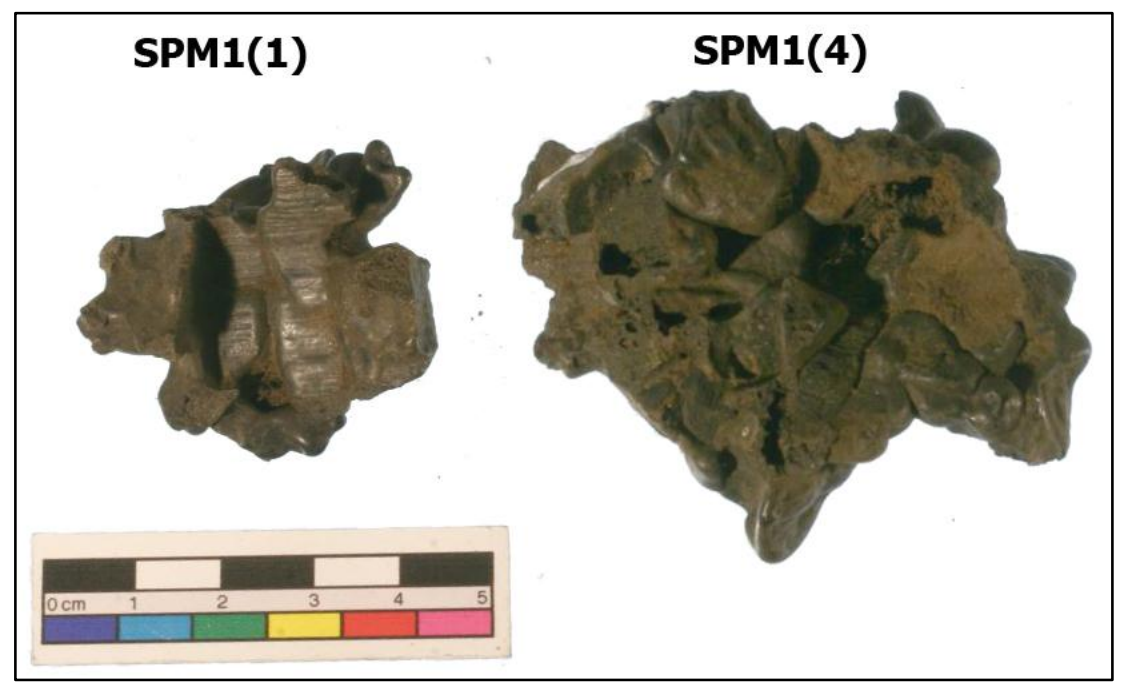

Figure 7.18: Serotwe slag samples SPM1(1) showing charcoal impressions and SPM1(4) with embedded charcoal fragments.
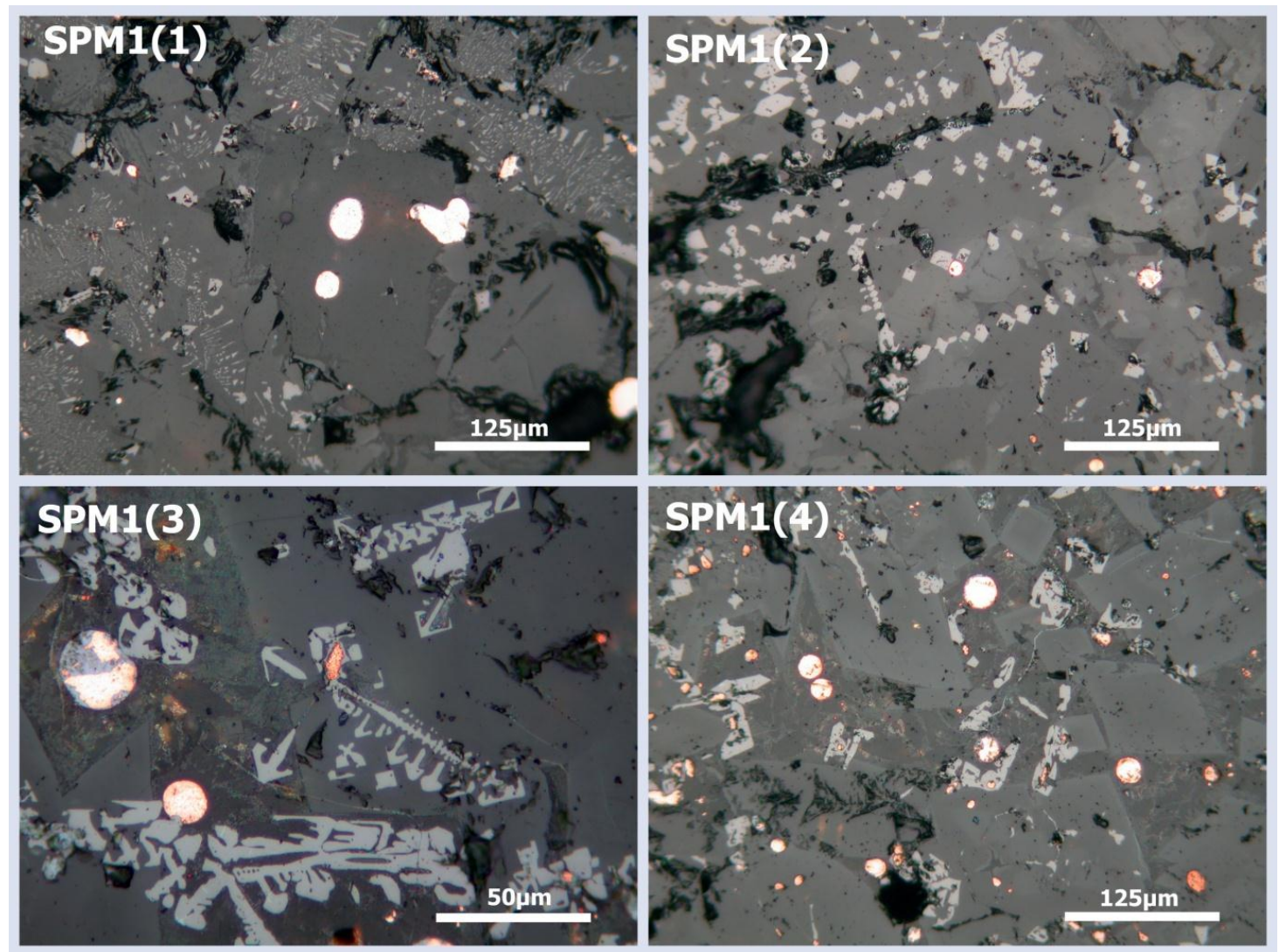

Figure 7.19: Reflected light photomicrographs of copper slags from Serotwe illustrating the presence of blocky olivines and/or pyroxenes, magnetite spinels and copper prills. Under plane polarized light. 


\subsubsection{Brief discussion of Serotwe analytical results}

The Serotwe slags represent by-products of both bloomery iron smelting and copper smelting. The copper smelting slags presented here were recovered from or associated with a Lolwe type furnace. The charcoal impressions and charcoal fragments are characteristic of furnace slags that were not subsequently tapped outside the furnace. The bulk chemistry and mineralogy of the Serotwe samples subjected to further analyses is typical of ancient smelting slags (Bachmann 1982).

Unreacted minerals are virtually absent in both iron and copper slags from Serotwe but the analytical data offers some important insights about the furnace charge. The presence of few copper sulphide inclusions in the slag-entrapped copper prills does not necessarily suggest the use of primary sulphidic copper ores. Exsolved iron inclusions in copper which indicates the use of iron flux or iron-rich ores together with excessively high temperatures are absent in Serotwe slags (Craddock \& Meeks 1987). Serotwe exhibit lower levels of iron oxide but with elevated levels of silica and lime, this might account for the absence of 'black copper' prills. Low $\mathrm{P}_{2} \mathrm{O}_{5}$ levels $(<0.7 \mathrm{wt} \%)$ in the copper slags from Serotwe possibly indicates that fluorapatite was carefully beneficiated or was not an accessory mineral in the copper ores employed at Serotwe. Chemically, Serotwe slags are also consistent with other copper slags from the research area in terms of low levels of $\mathrm{TiO}_{2}$. On the other hand high $\mathrm{TiO}_{2}$ recorded in iron smelting slag SPM3C(1) is consistent with the use of titanium-rich magnetite ores from the foskorite member of the Palabora Igneous Complex.

Both iron and copper slags from Serotwe are best represented in the $\mathrm{CaO}-\mathrm{FeO}-\mathrm{SiO}_{2}$ ternary system (Figure 7.20). The calcium-rich copper slags plot in the wollastonite region with estimated liquidus temperatures ranging from $1150-1270^{\circ} \mathrm{C}$. The 
estimated temperature ranges are much higher than the melting temperature of copper $1083^{\circ} \mathrm{C}$. However, these temperatures were needed to melt the gangue material to form silicate phases. The iron-rich SPM3C(1) bloomery smelting slag plots on the trough between olivine and wüstite on top of the $1177^{\circ} \mathrm{C}$ isotherm. Generally these slags plot well within the workable region of the $\mathrm{CaO}-\mathrm{FeO}-\mathrm{SiO}_{2}$ ternary system.

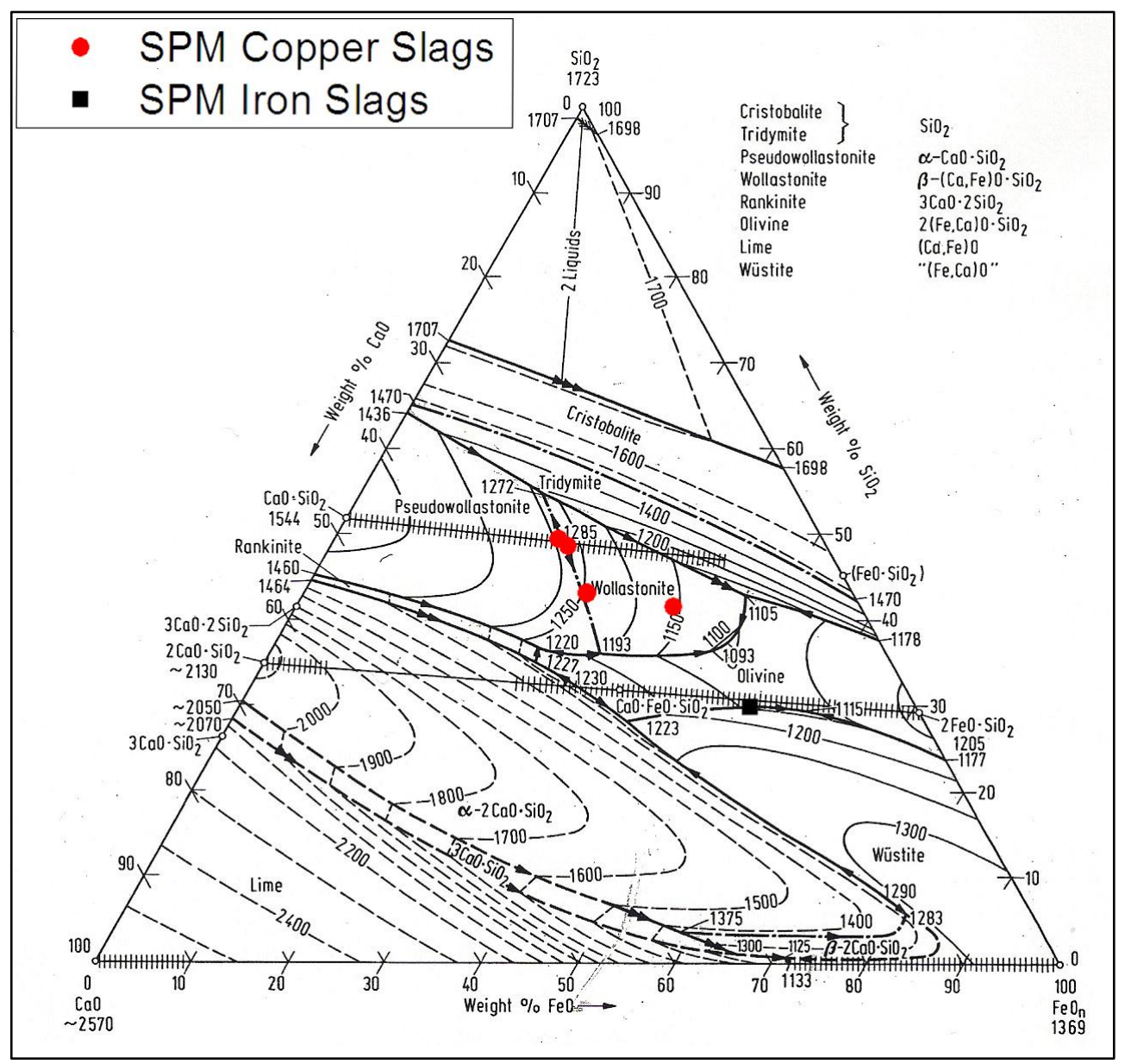

Figure 7.20: Ternary phase diagram showing system $\mathrm{FeO}-\mathrm{SiO}_{2}\left(+\mathrm{TiO}_{2}+\mathrm{Al}_{2} \mathrm{O}_{3}\right)-\mathrm{CaO}$ $\left(\mathrm{MgO}+\mathrm{P}_{2} \mathrm{O}_{5}\right)$, with plots of copper and iron slags from Serotwe (Phase diagram adapted from Kowalski et al. 1995, 126). Data used in this diagram is present in Table 7.10 and Table 7.11. 


\subsection{Phutwane (PHU): Undated}

\subsubsection{Site profile}

During the 2009 fieldwork campaign, our team had the opportunity to conduct a reconnaissance survey at a cluster of koppies known as Phutwane (Putwani) Hills (Map Sheet: South Africa 1:50 000 Sheet 2431AA Grietjie second edition 1986: Grid Ref: $24^{\circ} 00^{\prime} \mathrm{S} ; 31^{\circ} 12^{\prime} \mathrm{E}$ ). Phutwane, which consists of a cluster of three koppies, is located in the original Merensky $32 \mathrm{LU}$ farm within the PMC premises adjacent to the Kruger National Park. The three koppies will be referred in this thesis as koppies A, B and C. Koppie A is found to the east (Grid Ref: 24 $4^{\circ} 00^{\prime} 30.39^{\prime \prime} \mathrm{S}$; $\left.31^{\circ} 12^{\prime} 22.54^{\prime \prime} \mathrm{E}\right)$, Koppie B to the south (Grid Ref: $24^{\circ} 00^{\prime} 34.79^{\prime \prime} \mathrm{S} ; 31^{\circ} 12^{\prime} 21.58^{\prime \prime} \mathrm{E}$ ) and Koppie $\mathrm{C}$ to the west (Grid Ref: $\left.24^{\circ} 00^{\prime} 33.41^{\prime \prime} \mathrm{S} ; 31^{\circ} 12^{\prime} 17.11^{\prime \prime} \mathrm{E}\right)$. The hills can be accessed using vehicles via the south bound dirt mine access road. The distance of Phutwane from PMC open pit mine (formerly Lolwe Hill) is approximately 8 kilometres.

The earliest descriptions of archaeological features at Phutwane are provided by Thorne $(1974,107)$ who noted terraced platforms together with limited cultural materials, mainly potsherds and grinding stones. Similar to Shankare Hill, the archaeological evidence at Phutwane Hills does not show any unequivocal evidence of hut foundations although domestic middens are present. An environmental impact assessment programme during the late 1990s saw the extensive surveying of these koppies by Julius Pistorius on behalf of the Phalaborwa Heritage Committee. This exercise resulted in the determination of the spatial extent of this site with important documentation of archaeometallurgical debris hotspots. A satellite map highlighting the location of archaeological evidence around Phutwane was subsequently produced 
after this environmental impact assessment. This map is currently available online on the Palabora Mining Company (PMC) webpage (http://www.palabora.co.za/pmc_cultural_heritage/Phurwane_Map.htm). The site has not yet been excavated; as such, there are no secure dates from Phutwane. The recent settlement history at this cluster of koppies remains unknown because the site does not feature in the recorded oral traditions of the Ba-Phalaborwa.

A few dedicated slag middens at this site were visited with the assistance of $\mathrm{Mr}$ Johannes Malatji, the game ranger and archaeological tour guide from PMC. In comparison to Shankare Hill, the Phutwane cluster of hills offered very little in terms of cultural materials and metallurgical debris. Systematic pedestrian tactics similar to the ones employed at Shankare were not utilised at Phutwane Hills because of dangers that were posed by wild animals. Our fieldwork at Phutwane only ended with a reconnaissance survey together with some limited collection of surface-finds.

Metallurgical debris in the form of flared tuyères fragments, slags, anvils and hammer stones were documented to the east foothill of Koppie B (Figure 7.21). The archaeological evidence together with the inventory of metallurgical debris present under large rock boulders was interpreted as evidence of metalworking, most likely a forge rather than a primary smelting precinct. Apart from the metal-working inventory, some domestic pottery sherds were also recorded under these rock boulders. Approximately $10 \mathrm{~m}$ from this presumed "forge area" in the south-eastern direction, the survey team encountered scatters of slag and tuyères typical of smelting activities. Based on the cultural material and archaeological features on the surface, the site of Phutwane did not seem to have a great excavation potential. Small domestic middens with significant concentrations pottery were also documented at 
Phutwane Hills. Based on preliminary work on metallurgical debris and scarcity of cultural material a decision was made only to use surface-collected materials for archaeometallurgical investigations in this thesis. 


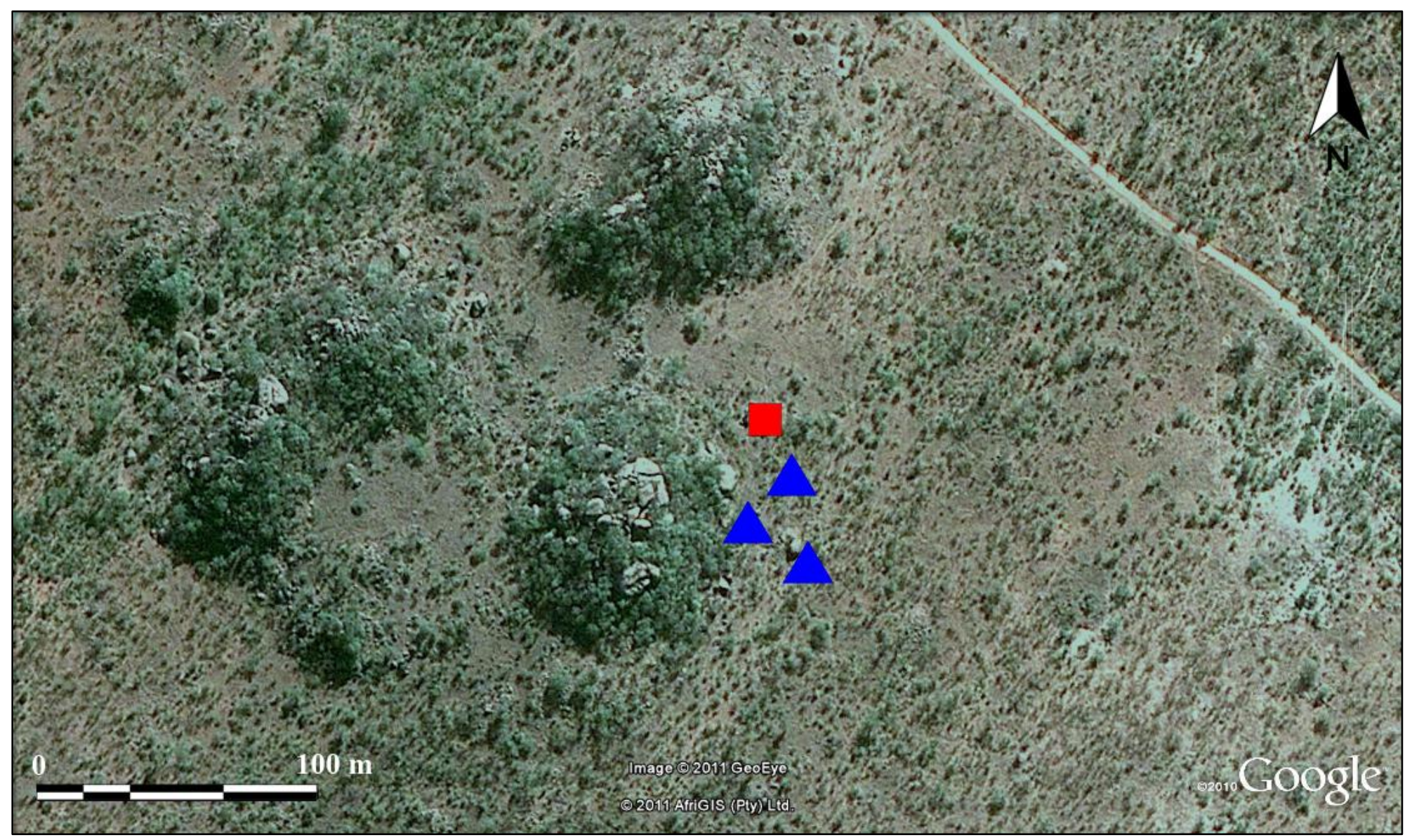

Figure 7.21: Satellite image of the cluster of koppies of Phutwane showing the location of metallurgical debris. The red square shows the location of the forge and the blue triangle represents the dedicated slag scatters (Image: courtesy of Google Earth). 


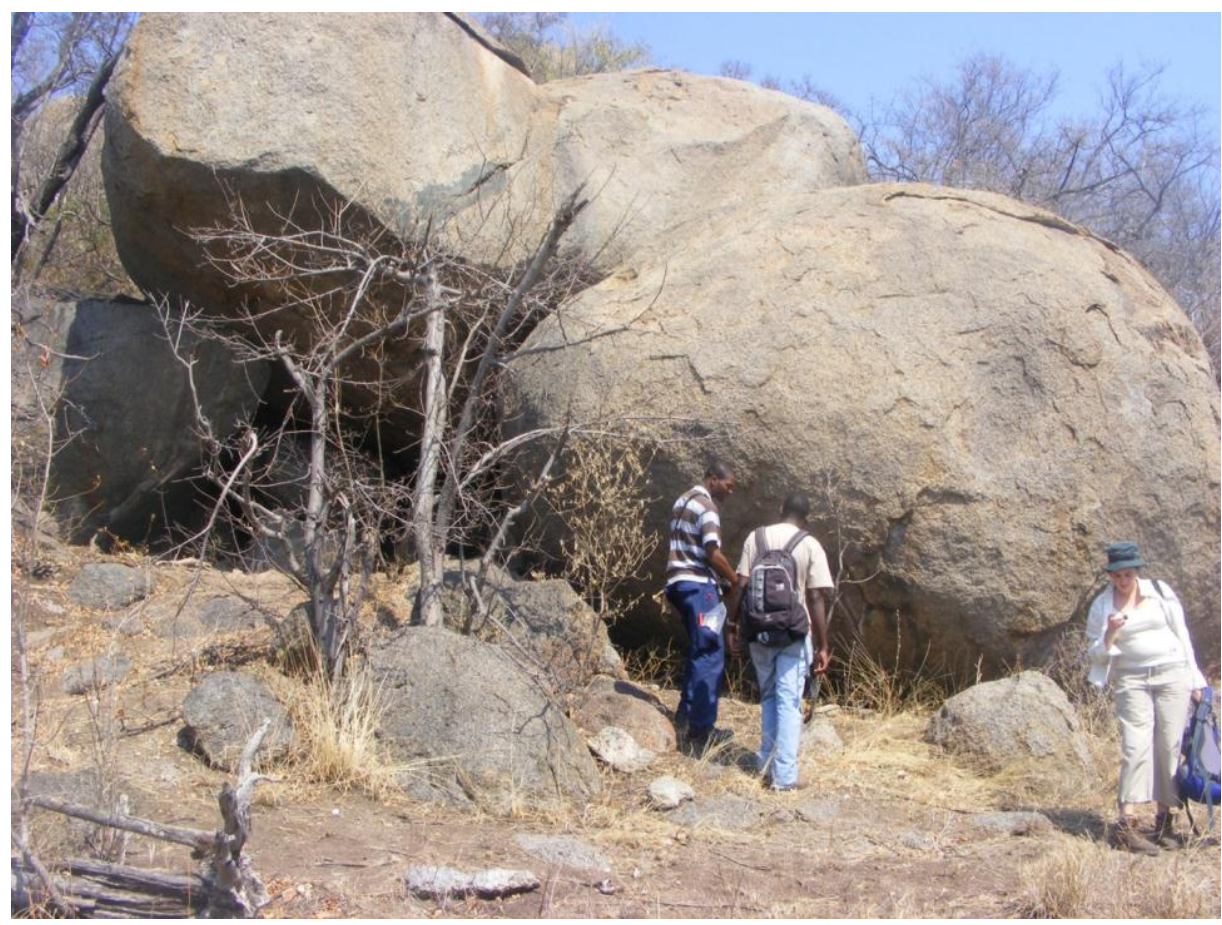

Figure 7.22: The forge site with large hammer stones and few tuyère fragments under large rock boulders at Phutwane Hills (Image: Author).

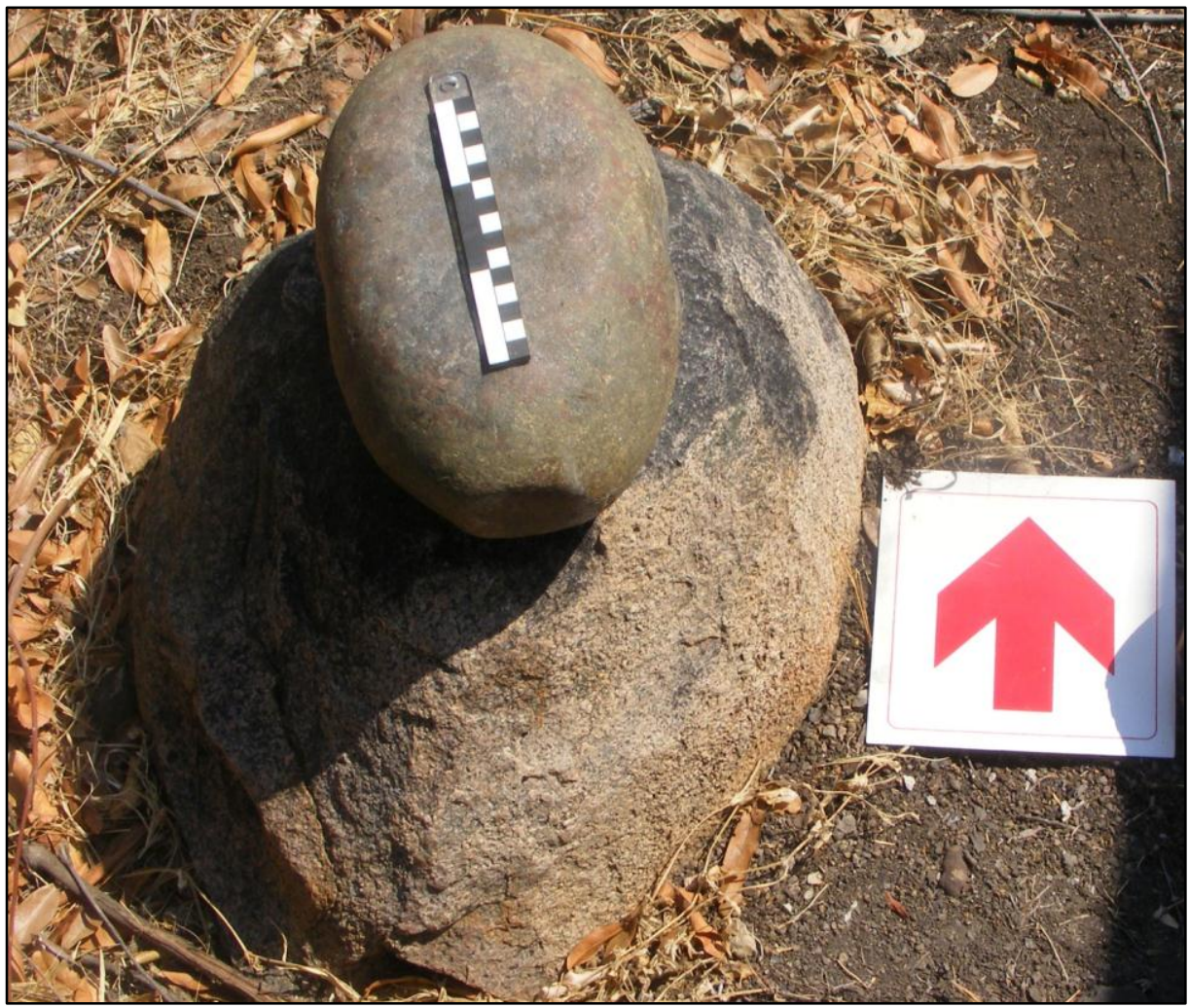

Figure 7.23: A large hammer stone and anvil documented at the forge area at Phutwane Hills (Image: Author). 


\subsubsection{Analytical results}

\subsubsection{Phutwane iron slags}

Iron slags from Phutwane are macroscopically similar to copper smelting slags presented in this thesis. Externally, these slags are charcoal impressed with rusty red corrosion products. Hand specimens of these iron smelting slags were weakly magnetic or non-magnetic. The crushed and milled powders from these iron slags are shiny black in colour.

These slags can be subdivided into two groups based on microstructural and subtle compositional differences. Group 1 (PHU1NL, PHU5NL \& PHU2SM) is composed of microscopically homogenous slags, dominated by blocky olivines, angular ulvospinels with occasional metal iron particles (Figure 7.24). The dominant blocky olivines are magnesian kirschsteinite with the high $\mathrm{CaO}$ levels (Table 7.12). Ulvospinels present in these slags are dominated by $\mathrm{FeO}$ ranging from $60-65 \mathrm{wt} \%$, $\mathrm{TiO}_{2} 28-30 \mathrm{wt} \%, \mathrm{Al}_{2} \mathrm{O}_{3} 4-5 \mathrm{wt} \%$ and $\mathrm{MgO} 3-5 \mathrm{wt} \%$. Group 2 iron production slags (PHU2NL, PHU4NL, PHU1SM \& PHU4SM) are also microscopically homogeneous but dominated by wüstite dendrites, olivines with isolated iron particles and interstitial glass. The wüstite dendrites also contain $\mathrm{TiO}_{2}(1-4 \mathrm{wt} \%)$, $\mathrm{Al}_{2} \mathrm{O}_{3}(1-2 \mathrm{wt} \%)$ and $\mathrm{MgO}(1-2 \mathrm{wt} \%)$. The same broad groups were identified in iron smelting slags from Shankare Hill (Chapter 6). 
Table 7.12: Distribution of major oxides in the iron slag phases. All the remaining oxides are present in the interstitial glass. X: present as a major oxide. -: absent.

\begin{tabular}{lcccccc}
\hline Phase & $\mathrm{MgO}$ & $\mathrm{Al}_{2} \mathrm{O}_{3}$ & $\mathrm{SiO}_{2}$ & $\mathrm{CaO}$ & $\mathrm{TiO}_{2}$ & $\mathrm{FeO}$ \\
\hline magnesian kirschsteinite & $\mathrm{X}$ & - & $\mathrm{X}$ & $\mathrm{X}$ & - & $\mathrm{X}$ \\
ulvospinels & $\mathrm{X}$ & $\mathrm{X}$ & - & - & $\mathrm{X}$ & $\mathrm{X}$ \\
wüstite & $\mathrm{X}$ & $\mathrm{X}$ & - & - & $\mathrm{X}$ & $\mathrm{X}$ \\
\hline
\end{tabular}

In spite of the microstructural differences noted in the iron slags from Shankare, only subtle differences were noted in their bulk chemical composition. Table 7.13 presents the average 'bulk' SEM-EDS results of iron slags computed from at least five area scans of each polished slag sample. These are best represented in the $\mathrm{FeO}-\mathrm{CaO}-\mathrm{SiO}_{2}$ ternary system with $\mathrm{FeO}$ ranging from 34-60 wt $\%, \mathrm{SiO}_{2} 20-31 \mathrm{wt} \%$ and $\mathrm{CaO}$ 6-13 wt\%. It is important to note that iron oxide levels always surpass silica. The magnesian kirschsteinite-dominated slags (Group 1) have the highest $\mathrm{SiO}_{2}$ readings whilst wüstite-dominated iron slags (Group 2) have the highest $\mathrm{FeO}$ levels (Figure 7.26). Other major oxides in these slags include $\mathrm{Al}_{2} \mathrm{O}_{3}$ (4-7 wt $\%$ ), $\mathrm{TiO}_{2}(2-7 \mathrm{wt} \%)$ and $\mathrm{MgO}$ (3-5 wt\%). The $\mathrm{TiO}_{2}$ recorded in the bulk chemical data of the slags in Group 1 and Group 2 is concentrated in angular ulvospinels and wüstite respectively. The $\mathrm{CuO}$ content in these slags is below the detection limits of the SEM-EDS. The silica to alumina ratio of is $5: 1$. This ratio seems to be the norm for all iron slags presented in this thesis. 


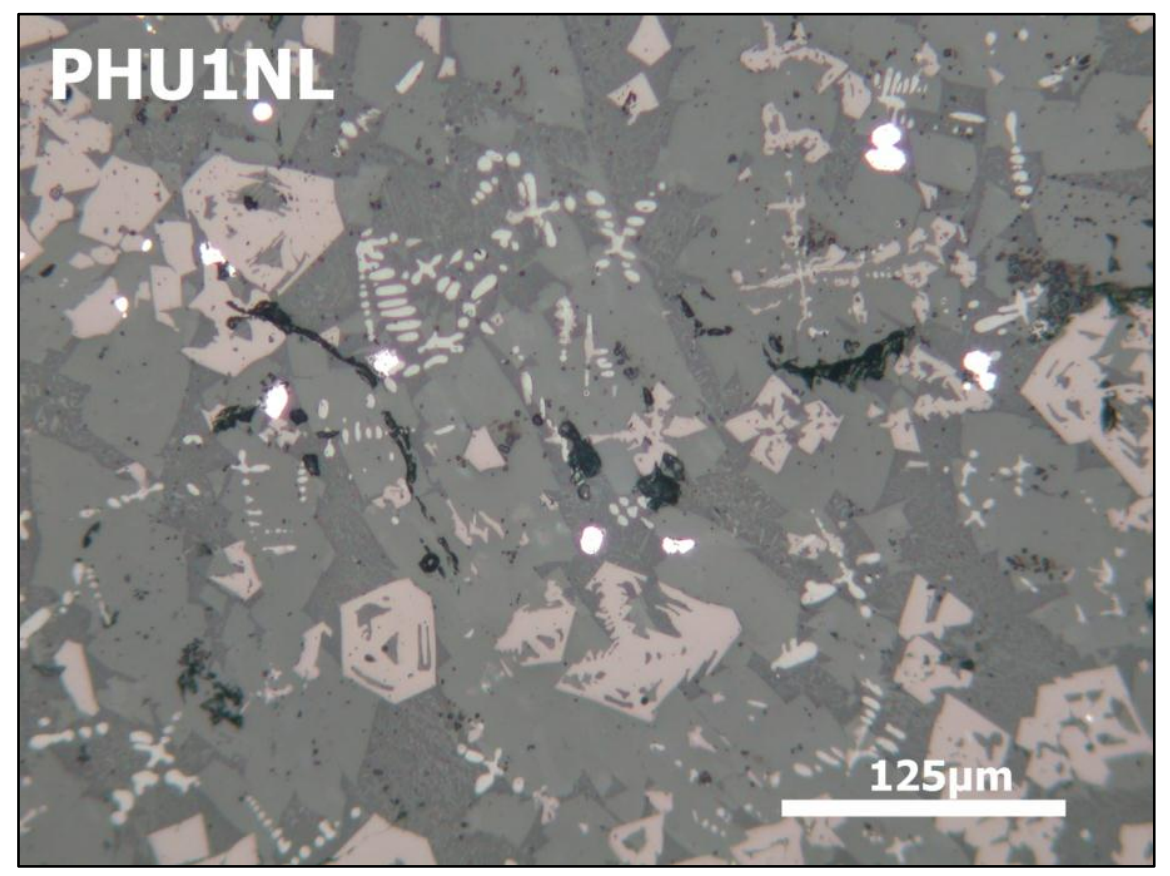

Figure 7.24: Microstructure of iron slags in Group 1. Photomirograph of sample PHU1NL showing blocky olivines, pinkish angular ulvospines and isolated iron particles.

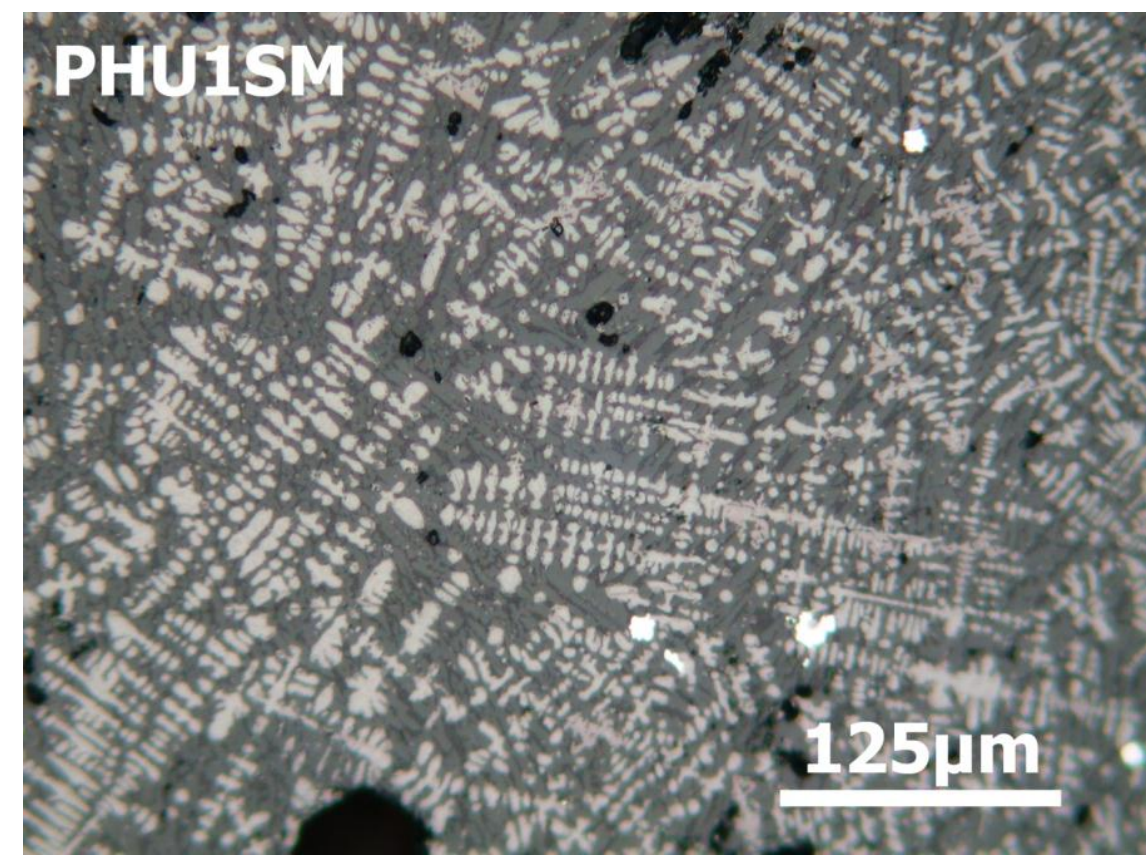

Figure 7.25: Microstructure of iron slag samples in Group 2. Photomicrograph of iron slag sample PHU1SM showing the dominant wüstite dendrites surrounded by olivines with isolated metallic iron particles. 


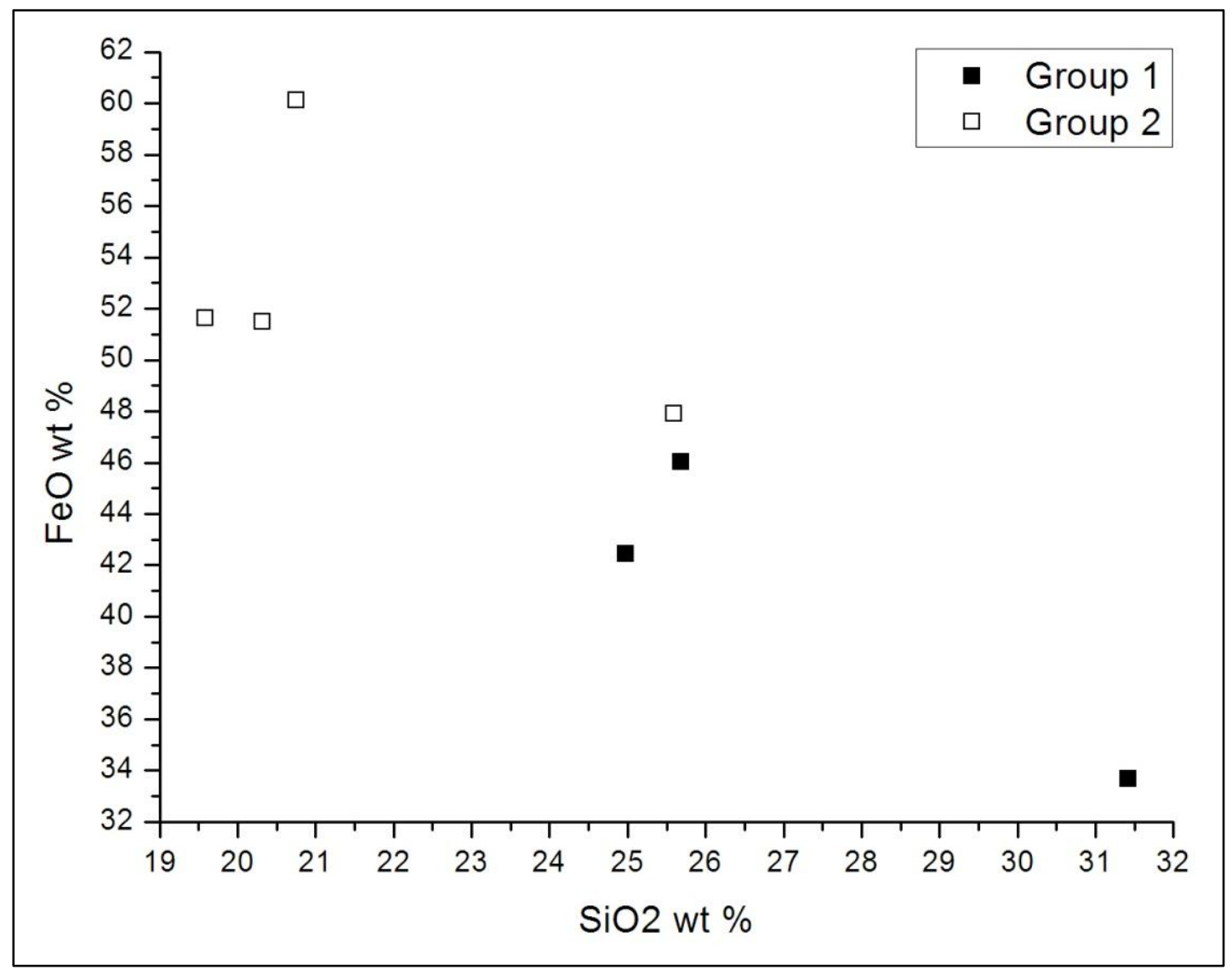

Figure 7.26: Plot of iron oxide against silica showing the silica-rich slags (Group 1) and iron-rich slags (Group 2). Data taken from bulk SEM-EDS results in Table 7.13. 
Table 7.13: Average SEM-EDS 'bulk' chemical results of iron slags from Phutwane. The results are presented in wt\% and normalised to $100 \%$. The last column is showing the silica to alumina ratio.

\begin{tabular}{|c|c|c|c|c|c|c|c|c|c|c|c|c|c|}
\hline Sample & $\mathrm{Na}_{2} \mathrm{O}$ & MgO & $\mathrm{Al}_{2} \mathrm{O}_{3}$ & $\mathrm{SiO}_{2}$ & $\mathbf{P}_{2} \mathbf{O}_{5}$ & $\mathrm{SO}_{3}$ & $\mathrm{~K}_{2} \mathrm{O}$ & $\mathrm{CaO}$ & $\mathrm{TiO}_{2}$ & $\mathrm{MnO}$ & $\mathrm{FeO}$ & $\mathrm{CuO}$ & $\mathrm{SiO}_{2}: \mathrm{Al}_{2} \mathrm{O}_{3}$ \\
\hline PHU1NL & 0.8 & 4.5 & 6.6 & 31.4 & 0.7 & 0.0 & 3.9 & 12.9 & 5.3 & 0.4 & 33.7 & 0.0 & 5 \\
\hline PHU2NL & 1.1 & 3.7 & 5.4 & 25.6 & 0.5 & 0.1 & 2.1 & 10.0 & 3.2 & 0.3 & 47.9 & 0.0 & 5 \\
\hline PHU4NL & 0.5 & 3.3 & 4.2 & 20.8 & 0.3 & 0.1 & 2.3 & 6.0 & 2.1 & 0.3 & 60.1 & 0.1 & 5 \\
\hline PHU5NL & 0.5 & 4.9 & 5.2 & 25.0 & 0.4 & 0.2 & 2.4 & 11.7 & 6.9 & 0.4 & 42.4 & 0.0 & 5 \\
\hline PHU1SM & 0.8 & 3.6 & 4.3 & 21.2 & 0.8 & 0.1 & 1.5 & 12.5 & 4.4 & 0.2 & 50.5 & 0.1 & 5 \\
\hline PHU2SM & 0.7 & 4.1 & 5.4 & 25.7 & 0.5 & 0.1 & 2.7 & 10.1 & 4.4 & 0.3 & 46.0 & 0.0 & 5 \\
\hline PHU4SM & 0.7 & 4.0 & 3.7 & 19.6 & 0.5 & 0.1 & 1.6 & 11.1 & 6.8 & 0.3 & 51.6 & 0.0 & 5 \\
\hline Average & 0.7 & 4.0 & 5.0 & 24.2 & 0.5 & 0.1 & 2.4 & 10.6 & 4.7 & 0.3 & 47.5 & 0.0 & 5 \\
\hline Std. deviation & 0.2 & 0.5 & 1.0 & 4.0 & 0.2 & 0.1 & 0.8 & 2.3 & 1.8 & 0.1 & 8.2 & 0.0 & 0 \\
\hline Max. & 1.1 & 4.9 & 6.6 & 31.4 & 0.8 & 0.2 & 3.9 & 12.9 & 6.9 & 0.4 & 60.1 & 0.1 & 5 \\
\hline Min. & 0.5 & 3.3 & 3.7 & 19.6 & 0.3 & 0.0 & 1.5 & 6.0 & 2.1 & 0.2 & 33.7 & 0.0 & 5 \\
\hline
\end{tabular}




\subsubsection{Phutwane copper slags}

Three out of the ten slag samples (PHU3NL, PHU3SM \& PHU5SM) randomly selected for further analytical studies from the Phutwane assemblage turned out to be copper smelting slags. These copper slags were recovered in the same scatters with iron smelting slags presented above though as surface-collected materials we cannot discuss more about this association. Macroscopically these slags are similar to iron slags making it difficult to distinguish them based on their external features. These copper slags are also weakly magnetic but with a light brown streak and differ significantly from iron slags in their microstructure and chemistry (Figure 7.27).

Microscopically the Phutwane copper slags are mostly homogenous with limited undissolved minerals. Unreacted fluorapatite and magnetite were documented in samples PHU3NL and PHU3SM. Similar undecomposed minerals were documented in copper slags from Shankare and Kgopolwe (cf. Chapter 6 \& the current chapter section 7.3.2.2). The once molten slag matrices are dominated by blocky olivines with occasional magnetite spinels and copper prills (Figure 7.28). The composition of the silicate crystals is provided in Table 7.14. It is important to highlight that magnetite spinels are sparse and tiny. The bulk chemistry of these copper slags is presented in Table 7.15. They are best represented in the $\mathrm{CaO}-\mathrm{FeO}-\mathrm{SiO}_{2}$ ternary system with $\mathrm{SiO}_{2}$ ranging from 35-36 wt\%, $\mathrm{FeO} 25-29$ wt\% and $\mathrm{CaO} 19-22$ wt $\%$. $\mathrm{MgO}$ contributes between 4-7 wt $\%$. The silica to alumina ratio of these copper slags ranges between 10 and 13. Another important aspect of these slags is the high $\mathrm{P}_{2} \mathrm{O}_{5}$ concentrations, varying between $1-9 \mathrm{wt} \%$. $\mathrm{TiO}_{2}$ is low in the bulk chemistry of these copper slags, not exceeding $1 \mathrm{wt} \%$. 
Table 7.14: Average of five SEM-EDS analysis of silicate crystals in the Phutwane copper slags. Results in wt\% and normalised to $100 \%$.

\begin{tabular}{lrrrr}
\hline SAMPLE & $\mathbf{M g O}$ & $\mathrm{SiO}_{2}$ & $\mathbf{C a O}$ & $\mathbf{F e O}$ \\
\hline PHU3SM & 11.7 & 35.9 & 27.2 & 25.1 \\
PHU5SM & 12.4 & 36.3 & 26.7 & 24.6 \\
\hline
\end{tabular}

Table 7.15: Average SEM-EDS 'bulk' chemical results of copper slags from Phutwane. The results are presented in wt\% and normalised to $100 \%$. The last column is showing the silica to alumina ratio.

\begin{tabular}{|c|c|c|c|c|c|c|c|c|c|c|c|c|c|}
\hline Sample & $\mathrm{Na}_{2} \mathrm{O}$ & MgO & $\mathrm{Al}_{2} \mathrm{O}_{3}$ & $\mathrm{SiO}_{2}$ & $\mathrm{P}_{2} \mathrm{O}_{5}$ & $\mathrm{SO}_{3}$ & $\mathbf{K}_{2} \mathbf{O}$ & $\mathrm{CaO}$ & $\mathrm{TiO}_{2}$ & MnO & $\mathrm{FeO}$ & $\mathrm{CuO}$ & $\mathrm{SiO}_{2}: \mathrm{Al}_{2} \mathrm{O}_{3}$ \\
\hline PHU3NL & 0.6 & 4.1 & 3.5 & 35.2 & 8.5 & 0.0 & 1.7 & 18.9 & 0.5 & 0.2 & 25.3 & 1.5 & 10 \\
\hline PHU3SM & 0.4 & 6.2 & 2.8 & 36.2 & 1.2 & 0.0 & 1.0 & 21.6 & 0.3 & 0.3 & 29.2 & 0.8 & 13 \\
\hline PHU5SM & 0.4 & 6.7 & 3.2 & 36.2 & 2.7 & 0.1 & 1.0 & 21.8 & 0.5 & 0.3 & 26.4 & 0.6 & 11 \\
\hline Average & 0.5 & 5.7 & 3.2 & 35.9 & 4.2 & 0.1 & 1.2 & 20.8 & 0.4 & 0.3 & 27.0 & 1.0 & 11 \\
\hline Std. deviation & 0.1 & 1.3 & 0.4 & 0.6 & 3.8 & 0.0 & 0.4 & 1.6 & 0.1 & 0.1 & 2.0 & 0.5 & 1 \\
\hline Max. & 0.6 & 6.7 & 3.5 & 36.2 & 8.5 & 0.1 & 1.7 & 21.8 & 0.5 & 0.3 & 29.2 & 1.5 & 13 \\
\hline Min. & 0.4 & 4.1 & 2.8 & 35.2 & 1.2 & 0.0 & 1.0 & 18.9 & 0.3 & 0.2 & 25.3 & 0.6 & 10 \\
\hline
\end{tabular}




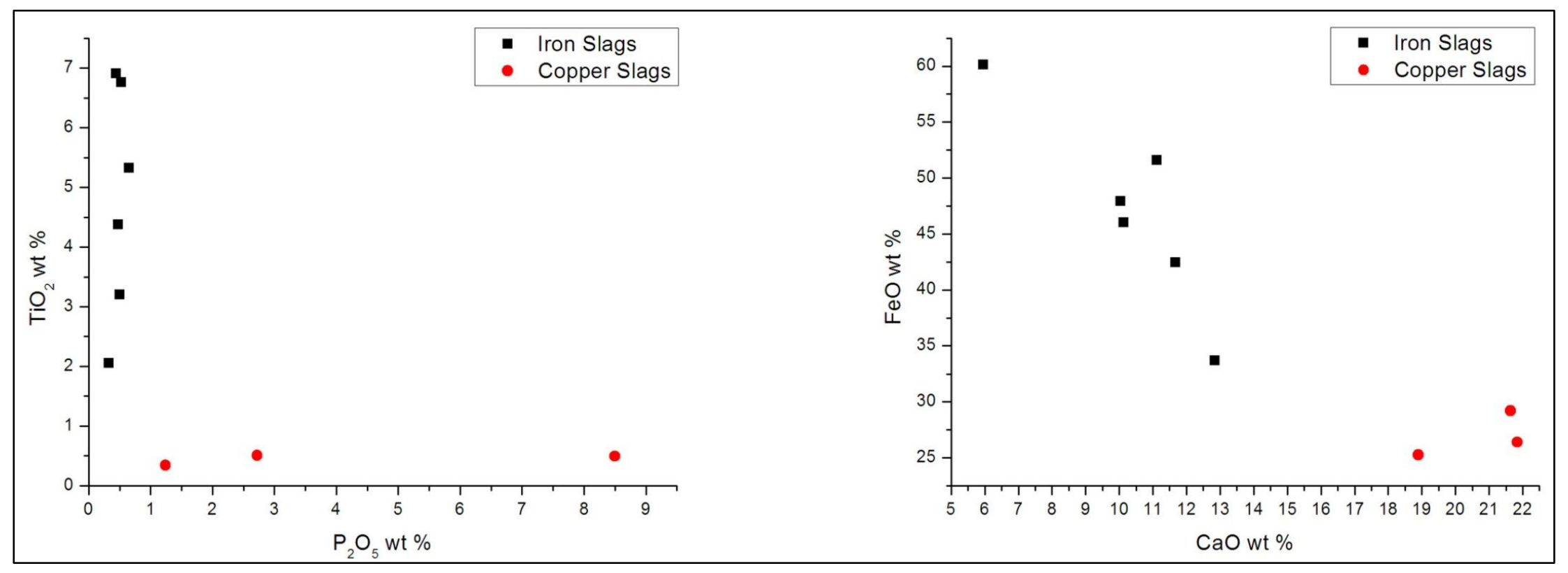

Figure 7.27: Scatter plots of $\mathrm{TiO}_{2}$ against $\mathrm{P}_{2} \mathrm{O}_{5}$ and $\mathrm{FeO}$ against $\mathrm{CaO}$. The scatter plots show differences in the bulk chemistry of copper and iron slags from Phutwane. 

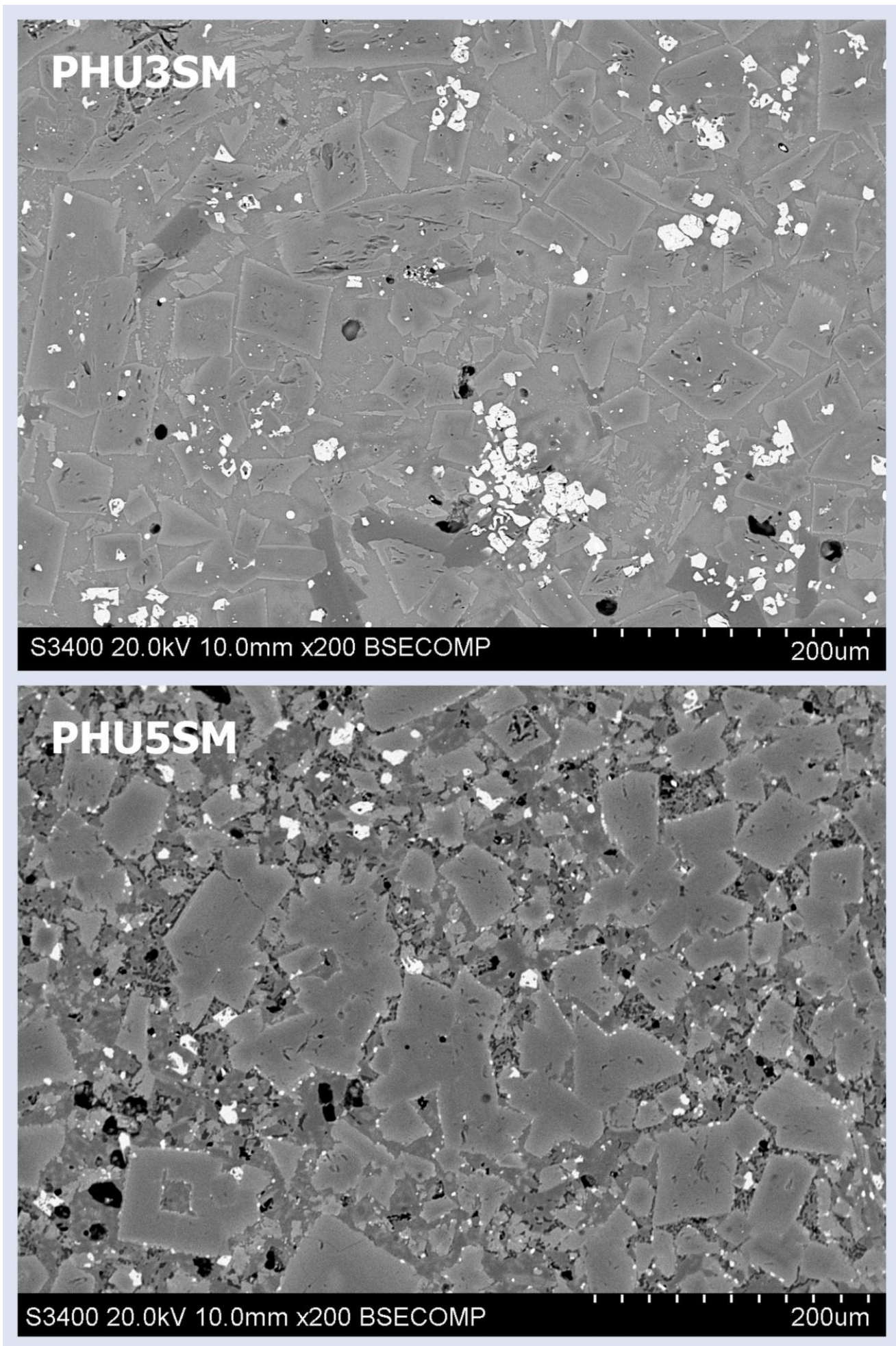

Figure 7.28: SEM-BSE image of copper slags PHU2SM and PHU5SM showing the dominant blocky olivines (midgrey) and sparse magnetite spinels (bright). 


\subsubsection{Brief discussion of Phutwane analytical results}

Ten slags from Phutwane represent by-products of both bloomery iron smelting and copper smelting found in the same metallurgical debris scatters. The external charcoal impressions together with microstructural equiaxed olivine crystals highlight the fact that these samples are furnace slags. Bulk chemistry and mineralogy of the Phutwane slags further confirms that they are smelting slags. Copper slags from Phutwane have elevated levels of $\mathrm{P}_{2} \mathrm{O}_{5}$ and $\mathrm{CaO}$ up to $9 \mathrm{wt} \%$ and $22 \mathrm{wt} \%$ respectively. Elevated levels of phosphorus and lime in the copper slags were partly influenced by fluorapatite gangue minerals which were charged into the furnace. Some unreacted apatite is present in the copper smelting slags from Phutwane. Copper smelting slags have very low levels of $\mathrm{TiO}_{2}$ this further strengthens the conclusion that ores used for copper smelting were mined from the central carbonatite of the Palabora Igneous Complex. On the other hand iron slags from Phutwane have high $\mathrm{TiO}_{2}$ readings suggesting the smelting of titanium-rich ores, the closest source for such ores was the foskorite member at Lolwe Hill (van der Merwe \& Killick 1979). It is also important to highlight the close spatial association of copper and iron smelting slags in the same slag scatters at Phutwane although these are only surface finds.

Copper slags from Phutwane plot inside the pseudowollastonite region in the $\mathrm{CaO}$ $\mathrm{FeO}-\mathrm{SiO}_{2}$ ternary system. This is consistent with high silica and lime levels noted in their bulk chemistry. The estimated liquidus temperatures of these copper slags are between 1220 and $1270^{\circ} \mathrm{C}$. The iron bloomery slags from Phutwane plots in the olivine region of the $\mathrm{CaO}-\mathrm{FeO}-\mathrm{SiO}_{2}$ ternary system, with estimated liquidus 
temperature ranges of between $1100-1200^{\circ} \mathrm{C}$. This indicates a somewhat lower operation temperature for the iron production processes.

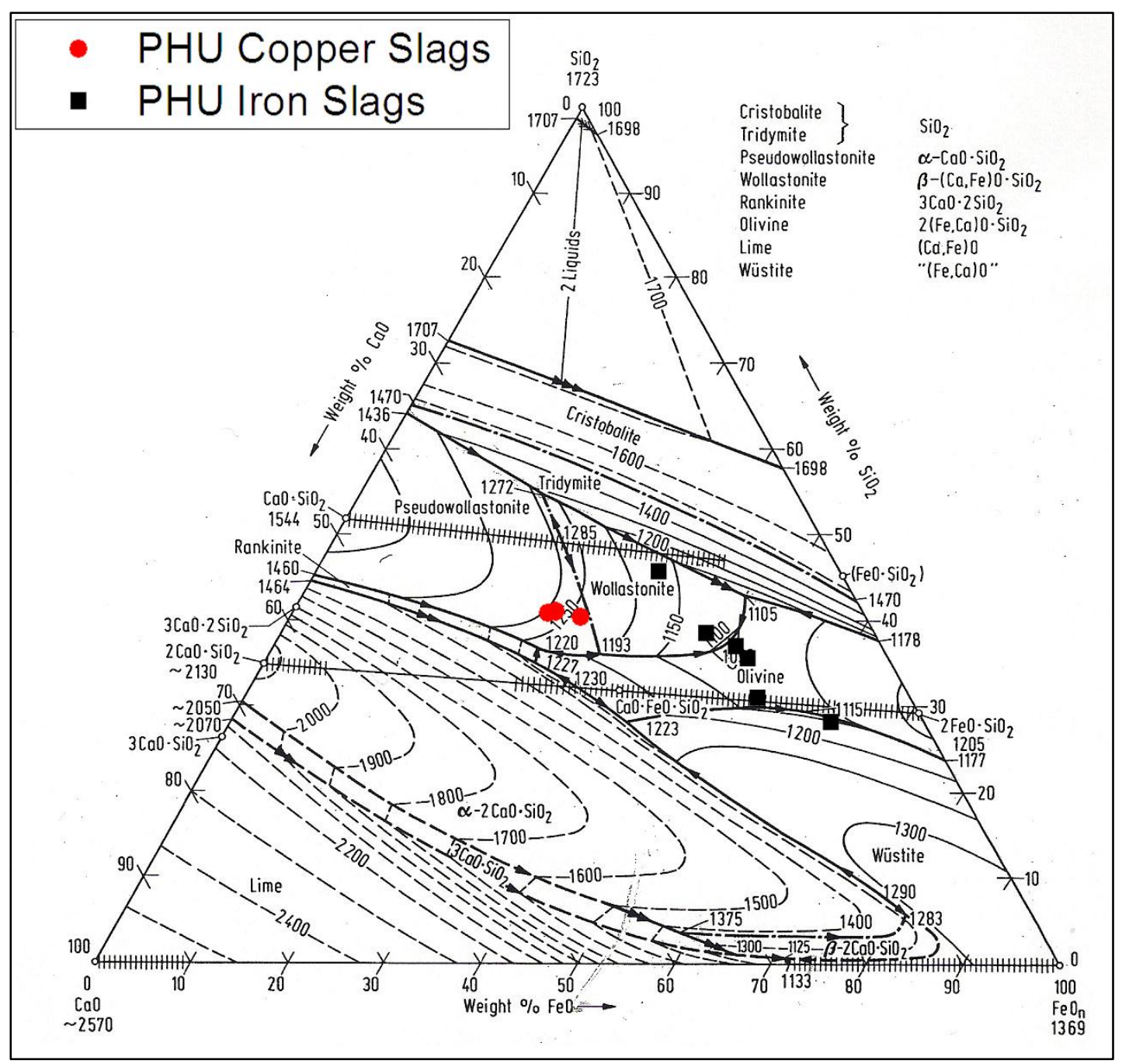

Figure 7.29: Ternary phase diagram showing system $\mathrm{FeO}-\mathrm{SiO}_{2}\left(+\mathrm{TiO}_{2}+\mathrm{Al}_{2} \mathrm{O}_{3}\right)-\mathrm{CaO}$ $\left(\mathrm{MgO}+\mathrm{P}_{2} \mathrm{O}_{5}\right)$, with plots of copper and iron slags from Phutwane (phase diagram adapted from Kowalski et al. 1995, 126). Data used in this diagram is present in Table 7.13 and Table 7.15. 


\subsection{Maranda (GM): Undated}

\subsubsection{Site profile}

Several Iron Age metal production sites were documented in the Gravelotte area by Nikolaas $\mathbf{J}$ van der Merwe and a team of archaeologists from State University of New York (SUNY) in 1972. Isolated slag heaps were documented in the Maranda farm situated about $60 \mathrm{Km}$ North West of Phalaborwa. The archaeometallurgical sites in this farm were later revisited by David Killick in 1977. He managed to record

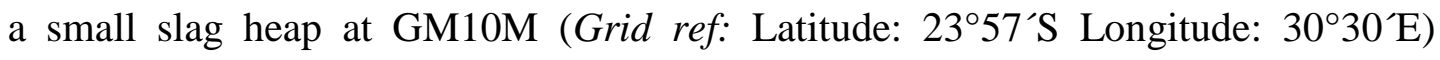
(Killick 1977, 34). The design of smelting furnaces at GM10M and other smelting sites in the Maranda farm could not be ascertained. The metallurgical sites in this farm remain undated and the associated archaeology has not yet been investigated or described in any detail.

Limited slag samples and technical ceramics were surface collected from GM10M by David Killick (1977). The slag samples from this site were described as fluid slag with a grey to green streak powder. Due to limited resources and time it was impossible to carry out further surveys or excavations in this potentially interesting area during the course of the current project. Fortunately some limited metallurgical samples from site GM10M were still available at UCT. These included slags and tuyère fragments. A single slag fragment was made available to the author for use in pilot analytical work. However, the analytical results obtained from this sample were peculiar; as a result, they will be included in this chapter although the site is not situated in the immediate Phalaborwa area, the main focus of this thesis. 


\subsubsection{Analytical results}

\subsubsection{Maranda copper slag}

The copper slag fragment (GM10M1) from Maranda weighed only $17 \mathrm{~g}$. Macroscopically this slag has a smooth surface without any external porosity, suggesting that it was once fluid. Externally the sample has a notable green tarnish resulting from the corrosion of copper. The hand specimen of this sample is weakly magnetic. The polished block of this sample was studied with the aid of optical microscopy and SEM-EDS. The major phase in this slag sample is interstitial glass matrix dissected by elongated and spinifex-textured fayalite crystals (Figure 7.30). According to Bachmann $(1982,15)$, such structures are usually formed if the molten slag is cooled rapidly. However, there was no apparent evidence of slag tapping in the surface texture and microstructure of this slag specimen. The chemical composition of the slag can also influence the formation of large proportions of interstitial glasses in archaeological slags. The fayalite crystals documented in this samples is rich in $\mathrm{FeO}(64 \mathrm{wt} \%)$ and $\mathrm{SiO}_{2}(32 \mathrm{wt} \%)$, but also accommodates $\mathrm{MgO}(2$ $\mathrm{wt} \%)$ and $\mathrm{ZnO}(1 \mathrm{wt} \%)$. Angular magnetite spinels are present in the interstitial glassy matrix together with metallic and non-metallic prills. Rounded prills of varying sizes and colour can be observed under the optical microscope. The prills include larger light blue-coloured matte prills and smaller deep red-coloured pure copper prills (Figure 7.30). Notably matte prills are mostly confined to one section, presumably the upper parts of the slag sample. Area analyses of several matte prills with SEM-EDS revealed significant sulphur levels of up to $23 \mathrm{wt} \%$ with iron of up to $1 \mathrm{wt} \%$ whilst the balance is copper. These matte prills have a composition that approximates chalcocite $\left(\mathrm{Cu}_{2} \mathrm{~S}\right)$. There is a tendency for most copper prills in this 
slag sample to be associated with gas holes. The gas bubbles around metal prills in the middle section probably resulted from the expulsion of gaseous sulphur from the matte prills (Th, Rehren, pers. comm. 2008). The progressive process of desulphurisation of matte prills into pure copper prills is clearly represented in this sample. The other section, presumably the bottom part of the slag contains pure copper prills without any gas bubbles.

SEM-EDS area scans of sample GM10M1 gave bulk chemical results reported in Table 7.16. This slag sample is best represented on the $\mathrm{SiO}_{2}-\mathrm{FeO}-\mathrm{Al}_{2} \mathrm{O}_{3}$ ternary system, with a $\mathrm{SiO}_{2}$ range of 44-46 wt $\%, \mathrm{FeO} 40-44$ wt $\%$ and $\mathrm{Al}_{2} \mathrm{O}_{3}$ 5-6 wt $\%$. Sample GM10M1 thus differs significantly from copper slags from Phalaborwa reported in this thesis. The sample has lower levels of $\mathrm{CaO}$ when compared to both copper and iron smelting slags from Phalaborwa. Another important aspect of the bulk chemistry of this sample is the documentation of $\mathrm{ZnO}$ ranging from 1-1.4 wt\%. 
Table 7.16: Averaged SEM-EDS 'bulk' chemical results of copper slag GM1OM1. The results are presented in wt\% and normalised to $100 \%$. The last column is showing the silica to alumina ratio.

\begin{tabular}{|c|c|c|c|c|c|c|c|c|c|c|c|c|c|c|}
\hline SAMPLE & $\mathrm{Na}_{2} \mathrm{O}$ & MgO & $\mathrm{Al}_{2} \mathbf{O}_{3}$ & $\mathrm{SiO}_{2}$ & $\mathbf{P}_{2} \mathbf{O}_{5}$ & $\mathrm{SO}_{3}$ & $\mathrm{~K}_{2} \mathrm{O}$ & $\mathrm{CaO}$ & $\mathrm{TiO}_{2}$ & MnO & $\mathrm{FeO}$ & $\mathrm{CuO}$ & $\mathrm{ZnO}$ & $\mathrm{SiO}_{2}: \mathrm{Al}_{2} \mathrm{O}_{3}$ \\
\hline GM10M1 & 0.4 & 0.5 & 5.4 & 44.9 & 0.2 & 0.1 & 0.5 & 3.0 & 0.4 & 0.1 & 42.7 & 0.6 & 1.2 & 8 \\
\hline
\end{tabular}
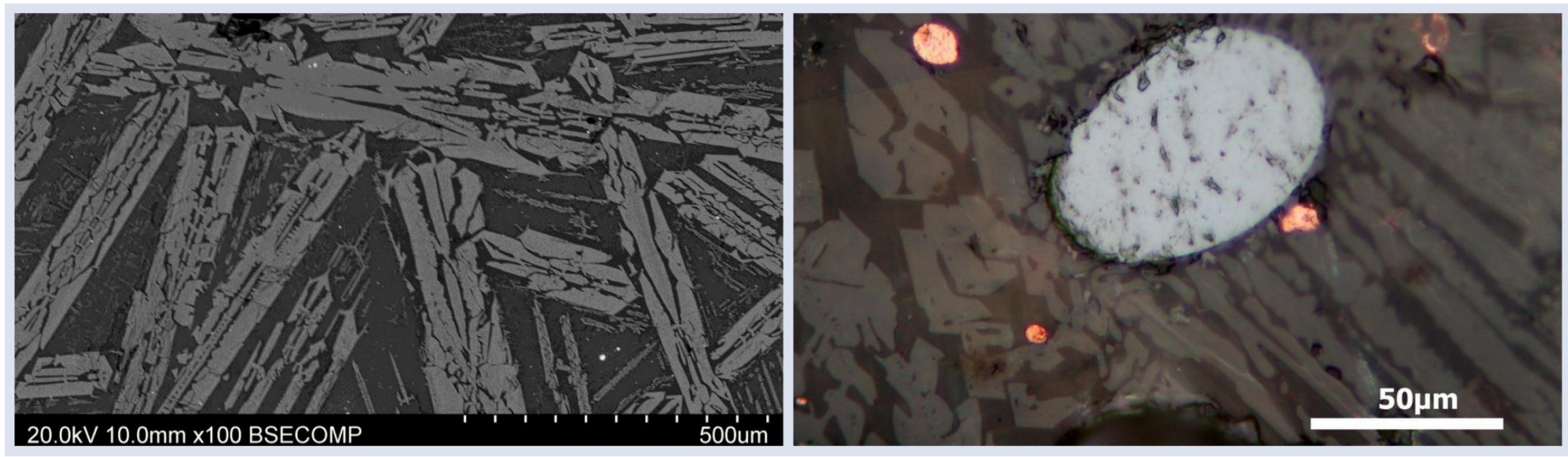

Figure 7.30: Left: BSE image of copper slag sample GMIOM showing spinifex textured fayalite crystals. Right: Photomicrograph of copper slag sample GM10M showing a bluish matte prill together with red copper prills. Under plane polarised light (500x magnifications). 


\subsubsection{Brief discussion of Maranda analytical results}

The single slag sample from Maranda analysed in this thesis adds an important dimension to our knowledge of copper production in the Northern Lowveld. The mineralogy and chemistry of this slag is consistent with smelting slags. The presence of fayalite and high iron oxide in the bulk chemistry identifies this sample as a product of smelting. Analytical results of slag GM10M1 are significantly different from copper slags from Phalaborwa. These differences can be attributed to the use of different ores and possibly differences in smelting technology as well. First, the abundance of matte prills in this sample preliminarily suggests the exploitation of sulphidic ores at Maranda (GM10M). The occurrence of matte and copper prills in this slag sample probably indicates one step smelting processes of sulphidic ores (Georgakopoulou et al. 2011, 139). However, more slag samples together with ore samples from smelting sites around Maranda farm should be analysed first to confirm this and also to get secure dates. More $(1974,230)$ was the first one to suggest that zinc-copper blende ores in the Murchison Schist belt were exploited in the pre-colonial period. The zinc-copper sulphide deposit that is currently mined at Maranda Mine is likely to be the source of ores that were used at GM10M (Viljoen \& Reimold 1999, 111). However, suggestions by More (1974) that these zinc-copper blende ores produced 'natural brasses' during the pre-colonial period cannot be substantiated. A cursory examination of the partitioning of elements in GM10M1 suggests that zinc entered the slag phases rather than matte and copper prills. At high operating temperatures any metallic zinc forming would be eliminated as vapour unless it was 'trapped' in the olivines, since the boiling point of zinc is approximately $900{ }^{\circ} \mathrm{C}$. The author is aware of analytical work that was previously 
carried out to determine the partitioning of zinc the metallic phases and silicates in archaeological slag samples from Maranda Farm. Unfortunately, preliminary results of this analytical work were only given as a conference presentation but the comprehensive results are yet to be published (Fenn et al. 2003). The bulk chemistry the GM10M1 copper slag plots inside the tridymite region of the $\mathrm{SiO}_{2}-\mathrm{FeO}-\mathrm{Al}_{2} \mathrm{O}_{3}$ ternary system (Figure 7.31), with estimated liquidus temperatures of close to $1470{ }^{\circ} \mathrm{C}$. The estimated operating temperature is unrealistically high, but it does indicate very high operating temperatures with a subsequent fast cooling. 


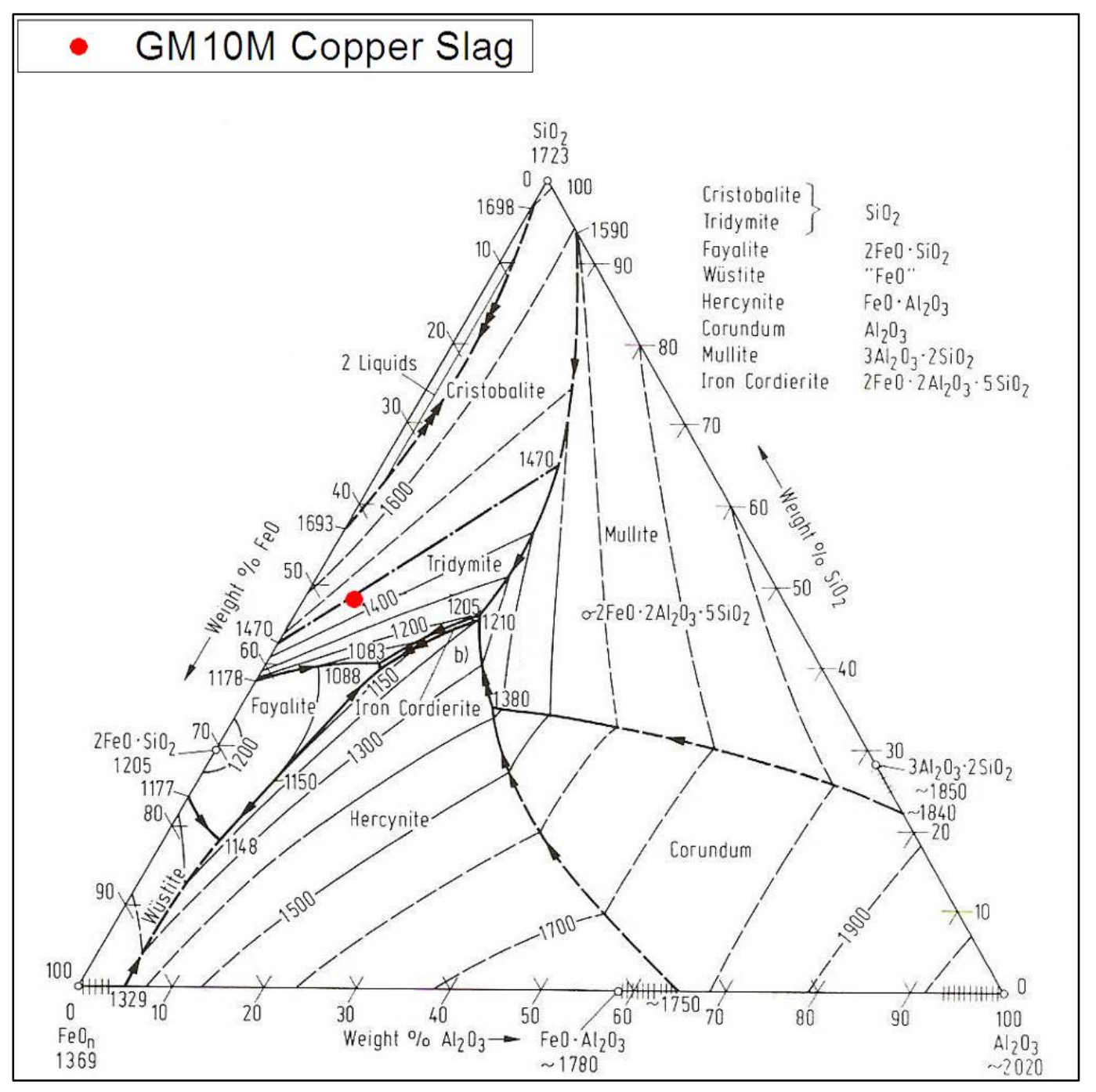

Figure 7.31: Ternary phase diagram showing system $\mathrm{SiO}_{2}-\mathrm{FeO}-\mathrm{Al}_{2} \mathrm{O}_{3}$, with plots of a copper slag from Maranda (Phase diagram adapted from Kowalski et al. 1995, 111). Data used in this diagram is present in Table 7.16. 


\subsection{Summary}

Two potential ore samples and twenty-six slag samples that were previously collected during archaeological expeditions around the Northern Lowveld were subjected to archaeometric approaches for comparative purposes in this thesis. These samples were kindly made available by the Department of Archaeology, UCT. The number of presumed copper ore samples offered for further analysis was rather limited and they only came from Kgopolwe. The unavailability of ore samples from other archaeological sites makes it difficult to account for variations in slag chemistries noted in this chapter. In general terms, it can be concluded that secondary copper ores with some remnant sulphidic minerals were used around Phalaborwa. The potential ores from Kgopolwe indicate a close geochemical association of copper and iron because they evolved from chalcopyrite. The slags from Phalaborwa do not indicate the use of predominantly sulphidic ores. The use of sulphidic copper ores with significant zinc levels for copper smelting was only suggested at Maranda farm.

Slag samples from the five sites presented in this chapter are gravel-sized rarely exceeding $3 \mathrm{~cm}$ in their widest dimension. Morphologically, these slag samples are irregular shaped with notable impressions confirming that they solidified around charcoal fuel inside the furnace. Seven of the slag samples that were selected for further studies turned out to be iron smelting slags again confirming that copper and iron were produced in the region, most likely through selective mining of the same geological deposit. Samples from Molotho and Serotwe were recovered from securely dated and unequivocal smelting precincts with well-preserved furnaces. Regrettably samples from Kgopolwe, Phutwane and Maranda were recovered from 
contexts that were not subsequently dated securely. In spite of these challenges the results presented in this chapter will facilitate further discussions of extractive copper technology in the next chapter. 


\section{Second millennium AD extractive copper metallurgy: Inter-site comparisons and wider regional perspectives}

“...it is hardly conceivable that mining, casting and artistic effort occurred in cultural and economic isolation; the rationale has to be identified in the wider commercial and technological context of the time." (Sutton 1999)

“..., but publications on archaeological metal working frequently are specialist reports that are not easily integrated into wider archaeological analysis and interpretation." (Hall et al. 2006, 4)

\subsection{Introduction}

Reconnaissance and intensive site surveys together with test excavations at Shankare Hill provided important archaeological results together with field evidence of metal production. Subsequent laboratory investigations of metallurgical debris from this site together with materials from other surrounding archaeological sites generated sufficient archaeometallurgical data upon which metal production activities were reconstructed in the previous two chapters. Based on these results and previous work the necessary information to address the aims, objectives and questions initially outlined and posed in the first chapter is now in place. Some of the archaeometallurgical results confirmed previous findings, while some contradict them, hence there is need to highlight and expand more on these issues.

The questions presented at the beginning of this thesis can broadly be divided into two main groups. The first group is comprised of technical questions whose main aim was to enable the detailed reconstruction of extractive copper technologies employed by Iron Age Phalaborwa metallurgists. The first section of this chapter provides in-depth discussion of technical aspects of extractive metallurgy that were 
only highlighted in the previous chapters. Some technical questions were partially addressed in the previous two chapters. However, other aspects that require further discussion arose from the peculiar archaeometallurgical results that were obtained. These peculiar results include the existence of unreacted mineral inclusions in earlier copper smelting slags not documented in later copper and iron slags. This chapter will attempt to establish if there is any discernible pattern, temporal or spatial, in the reconstructed extractive copper technologies employed at archaeological sites presented in this thesis. The variations together with similarities of archaeometallurgical results at inter-site and regional levels will be further identified and explained. As the chapter unfolds, questions that will be addressed include: Are there any socially mediated circumstances or technical requirements that influenced the variations in the reconstructed extractive metallurgy technologies? How does the archaeometallurgical data presented in this thesis compare with contemporary copper production technologies documented in sub-Saharan Africa? Where necessary, the archaeometallurgical results from Phalaborwa will be compared and explained with reference to examples beyond the African context.

The archaeometallurgical results provided in this thesis have hitherto been presented and discussed with superficial reference to the socio-cultural and political contexts within which the extant miners and metallurgists operated. However, a second group of questions posed at the beginning of the thesis sought to address broader issues of archaeological and historical interest or inquiry. Theoretical frameworks outlined in Chapter 2 also emphasise the importance of situating archaeometallurgical results within the broader socio-cultural context. For example it was established that both copper and iron were produced around Phalaborwa, this provides the platform to 
explore differences or similarities in the organisation of production and chaine opératoires of these two crafts.

If the archaeological and archaeometallurgical results from Phalaborwa are not understood at a regional scale a lot of information will be missed. Besides discussing technical aspects emerging from the technological reconstructions proposed in the preceding chapters, the current chapter will thus situate these reconstructions in the socio-cultural and political context of the extant milieu. The exploitation of copper and iron around Phalaborwa took place during a period that is of great importance in Southern African archaeology. Conventional archaeological reconstructions in the region have established that the second millennium AD period was a dynamic period. This period saw the development of the first class-based societies, centralised authority centres, state systems and towns. Secondly, intensive commercial interaction amongst most Southern African communities and beyond the subcontinent commenced during the same period (Mitchell 2005). These fundamental changes are quite evident in the artefact inventory, burial practices and settlement patterns of Iron Age communities in the region. It was highlighted in Chapter 1 that the period also saw mining and production of new metals or alloys, changes in metal extraction and fabrication technologies (also see Miller 2010). Compared to the Early Iron Age the second millennium AD saw increased demand of metals. Thus the second part of this chapter is a general commentary about archaeological evidence and archaeometallurgical reconstructions documented around Phalaborwa (Northern Lowveld) in relation to this dynamic historical and technological background. 


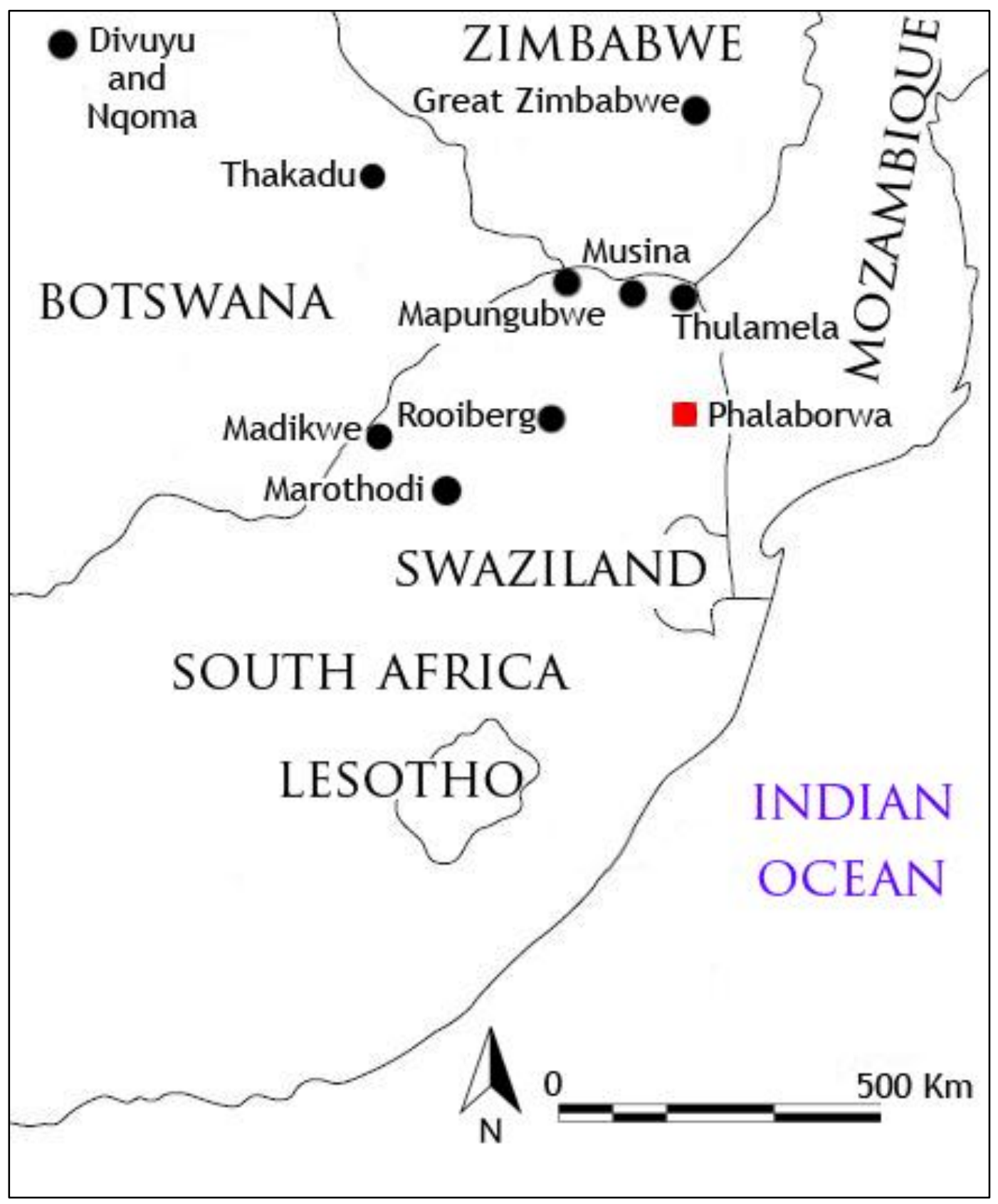

Figure 8.1: Map of some Southern African countries showing the location of relevant archaeological sites mentioned in this chapter (Image: Adapted from Miller 2002, 1084). 


\subsection{Copper and iron metallurgy: technological and regional comparisons}

\subsubsection{The primary smelting furnaces}

Virtually nothing is known about the Early Iron Age extractive copper metallurgy or furnace designs that might have been employed around Phalaborwa. Previous and our recent fieldworks also failed to document copper production debris dating prior to the second millennium AD. As highlighted in Chapter 4, at least three furnace designs were employed for smelting around the Northern Lowveld during the Middle Iron Age and Late Iron Age, namely Lolwe, Phalaborwa and Venda furnaces.

The function of these three major furnace designs has been a subject of academic debate since the 1970s, when Küsel (1974b) proposed that slag samples from a single tuyère port (Lolwe type) furnace which he analysed were by-products of iron smelting. His views did not gain currency with most archaeometallurgy authorities, who believed that there is a strong correlation between three tuyère port (Phalaborwa or Venda type) furnaces and iron smelting. Three tuyère port furnaces, they argue, have the capacity to generate more air from the multiple tuyères and bellows thus have a better heating capacity suitable exclusively for iron smelting (Miller et al. 2001). On the other hand, single tuyère (Lolwe type) furnaces, they propose, were only used for copper smelting. Single tuyère furnaces, for these proponents, represent a technical solution to avoid the co-smelting of iron and copper in the mixed ore deposit at the Palabora Igneous Complex (Miller et al. 2001). One tuyère would have provided less air therefore limited heat capacity and less reducing conditions so that smelters could extract copper without contaminating it with iron. Previous copper smelting experiments using different numbers of tuyères had indeed confirmed that 
the use of multiple tuyères provided higher temperatures with better copper and slag separation; however, they were high risks of iron contamination in the final copper product (Tylecote et al. 1977). Experiments with single tuyère furnaces, on the other hand, did not produce any discrete copper ingots at the bottom of the furnace but instead copper globules and prills were trapped in the slag thus they were retrieved after slag crushing. However, the current prevailing wisdom that one tuyère (Lolwe type) furnaces were used exclusively for copper smelting whilst three tuyère port (Phalaborwa/ Venda type) furnaces were used exclusively for iron smelting should be challenged once again in light of both previous and new data presented in this thesis.

The results of previous analytical work of some slag samples associated with three tuyère furnaces, although authorities do not explicitly acknowledge it, leave no doubt these furnaces could be equally employed for copper production. The association of both copper and iron smelting slags with three port furnaces SPK IV and SPK VI at Kgopolwe is of great interest in this regard (Killick \& Miller, in press; Miller et al. 2001, 408). The presence of copper smelting slags in a slag heap adjacent to a three tuyère port furnace (SPK VI) at Kgopolwe further indicates that copper could be produced in these furnaces (see Chapter 7). The current author thus subscribes to the view that the different furnace designs could be used to smelt copper and iron of course not simultaneously but during different smelting episodes. Having suggested this, it is important to acknowledge that ferruginous copper prills were documented in copper slags associated with a three port (Phalaborwa type) furnace (SPK VI) at Kgopolwe (Chapter 7), indeed confirming the possible risks of producing 'black copper' associated with higher operating temperatures. This also confirms the 
difficulties that were involved in the smelting of iron-rich copper ores. On the other hand, prills embedded in copper slags from single port (Lolwe type) furnaces at Molotho and Serotwe were pure copper without any exsolved iron (Chapter 7). Unfortunately no in situ smelting furnaces were documented during the fieldwork at the few sites that were visited during the course of this project to conclusively confirm that copper could be produced in three port furnaces but indications in this direction appear strong enough. Now that we have established that some three port (Phalaborwa type) furnaces were used for copper smelting, there are several questions to ask: what does the formal variability reflect, if not functional specialisation? Is it differences in the production scale or organisation? Is it a variety of cultural influences or learning traditions? Or perhaps this suggests a combination of these factors and diachronic evolution or specialisation.

Some potentially interesting changes that probably took place in the extraction of metals through the second millennium AD should be highlighted. It seems in the first half of the second millennium $\mathrm{AD}$, the Middle Iron Age, three tuyère port furnaces were equally used both for copper and iron smelting. Slag heaps with a mixture of copper and iron slags have been found adjacent to three tuyère port furnaces at Kgopolwe. Unfortunately, there is no secure date for the copper metallurgical debris associated with furnace SPK VI at Kgopolwe presented in Chapter 7. However, unequivocal copper smelting slags associated with furnace SPK IV at the same site suggest some potentially interesting chronological changes in the use of different furnace designs. The mixed copper and iron slag heap found adjacent to furnace SPK IV was radiocarbon dated to $520 \pm 60 \mathrm{BP}$, calibrated to between AD 1290 and 1470, at 2 sigma (Miller et al. 2001, 405). The use of three port furnaces would have 
resulted in the production of ferruginous copper documented in some slag-embedded copper prills. We can confidently conclude that these slags were associated only with copper because of dominance of magnetite spinels and absence of discrete iron particles. It is also likely that three tuyère port furnaces were used for copper production at Shankare Hill. Three port furnaces were actually documented previously at Shankare (Mason 1986, 114). By the later periods it seems the single tuyère furnaces represented at Molotho, Serotwe and Nagome were exclusively used for copper smelting. Better understanding of smelting together long term experience with copper ores from the Palabora Igneous Complex might have allowed the smelters to adjust their extractive technologies arriving at the seemingly simpler yet more efficient single-port furnace.

The furnaces documented around Phalaborwa did not have copper metal tapping capabilities like primary copper smelting furnaces from Zambia and DRC in Central Africa (Bisson 1997, 129; Miller 1994). The absence of direct metal casting installations together with absence of crucible fragments around furnaces described above is the first indicator that primary smelted copper was taken elsewhere for remelting or further refining. Primary smelted copper was also likely to be re-melted in clay based crucibles for consolidation (Miller 2001a). This takes the current discussion to the nature of copper refining evidence that a field worker should expect in the archaeological record around Phalaborwa. 


\subsubsection{Secondary refining and smithing}

As a way of recapturing, based on the slag embedded copper prills and isolated prills it was suggested that raw copper from some primary smelting around Phalaborwa was impure. Occasionally 'black copper' with exsolved iron and sulphide inclusions was produced during smelting. This 'black copper' would have required several episodes of re-melting to remove the iron and sulphur by oxidation and desulphurization respectively (Davenport et al. 2002, 247-253; Merkel 1990). Analytical results of copper metal attached to crucibles together with few copper artefacts from Shankare indeed showed major discrepancies with copper prills entrapped in the smelting slag (see Chapter 6). No 'black copper' artefacts were documented, suggesting that rigorous refining was carried out after smelting. The subsequent process of copper refining was a very important stage in the chaîne opératoire of copper production around Phalaborwa; and as such, requires further discussion in this section.

Previous intensive archaeological surveys around Phalaborwa failed to locate unequivocal secondary copper refining or melting precincts. The intensive fieldwork around Shankare also gave priority to establishing the location of copper refining precincts but proved fruitless. However, copper refining or melting at Shankare was represented by slagged crucible fragments deposited together with domestic garbage; such as, domestic hearth ash, faunal remains and domestic pottery. These crucibles are the only positive evidence of copper refining or melting documented during the fieldwork. Smithing precincts and forge furnaces with two openings were previously documented at several Iron Age settlements in the research area (Mason 1986, 114121; Thorne 1974, 50). However, none of these forge furnaces were associated with 
evidence expected at copper working precincts, which should usually include crucibles or crucible fragments, therefore the excavators concluded that they were employed exclusively for iron smithing. Therefore some questions remain unanswered concerning copper refining, these are: What are the defining characteristics of Iron Age copper refining precincts around Phalaborwa? What evidence should be expected in the archaeological record for secondary copper refining? A survey of copper refining evidence documented around Southern Africa will help us at least to speculate about the characteristics of structures and accessories that should be expected in the field.

Few ethnographic descriptions of early twentieth century copper refining processes are available. Stayt $(1968,64)$ provides a brief description of a copper refining process of the Musina (BaLemba) copper workers, who used to produce copper for Venda chiefs in the Limpopo Province of South Africa. Their copper refining precincts were hearths comprising of dug-out pit impressions without clay superstructures. These hearths were lined with large domestic potsherds that were recycled and used as crucibles. The refining process started with the hammering of raw smelted copper into small cobbles. The copper cobbles were placed inside the potsherds which were filled with charcoal ready for re-melting. Once the charcoal was ignited air was provided from the bellows via tuyères from above. In Central Africa refining process used by the Kaonde copper workers from Zambia were described (Bisson 1997; Chaplin 1961). Kaonde copper workers used secondary refining furnaces of up to $60 \mathrm{~cm}$ in height, smaller than their smelting furnaces. Ordinary cooking ceramic pots, with raw copper were placed inside these furnaces (Figure 8.2). Subsequently, the furnaces were filled with charcoal and ignited whilst 
the necessary air was supplied from a pair of bellows via a single tuyère placed above the mouth of the clay pot.

Copper refining furnaces have also been documented and excavated by archaeologists around Rooiberg and Marothodi (Friede \& Steel 1975; Hall et al. 2006). These furnaces included rock pillars that were used as props for ceramic crucibles. The archaeological evidence at these furnaces included fragmented but slagged ceramic sherds, tuyères and stones pillars arranged in a circular form (Hall et al. 2006; Miller 2010, 45). No superstructure was documented at these crucible furnaces and bellows were used to supply air. The actual operation of these crucible furnaces is not very clear. More work is required be established if the source of heat was from the outside or inside the clay-based crucibles. From the description of the furnaces it appears the source of the heat was external but this should be augmented by proper analytical studies to positively identify the heat gradient in the ceramic fabric. The limited ethnographic and archaeological descriptions provided above suggest some variations in design of refining furnaces in sub-Saharan Africa. It is not clear whether these variations were conscious results of technical or cultural considerations.

Due to the limited nature of evidence of copper refining encountered, characteristics of the refining precincts presented here are only speculative. The analytical data of fragmented copper refining sherds from Shankare Hill presented in Chapter 6 established that the heat gradient and distortion of ceramic fabrics was from the inside. Both macroscopic and microscopic characteristics of these fragmented crucibles do not conform to the evidence of crucibles that were propped up by rock pillars and fired externally as documented around Rooiberg and Marothodi. Shankare 
crucibles were operated under oxidizing atmospheric conditions as suggested by the conspicuous presence of cuprite inclusions expected from open crucibles. No copper refining furnaces similar to the ones that were used by the Kaonde were documented around Phalaborwa. From the limited archaeological evidence and archaeometallurgical results it seems copper refining processes in the research area have close affinities to the ones that were employed by the Musina (BaLemba). Strong socio-cultural ties between the Ba-Phalaborwa and their northern Musina (BaLemba) neighbours were previously documented (Loubser 1989). Claims of movement of miners and metallurgists from Phalaborwa to Musina in search of copper resources also add more weight the suggestion of close technological similarities between the two Iron Age copper producing areas (Mamadi 1940). The Musina people once mined copper at Phalaborwa before they left under the leadership of Dopokabatho (More 1974, 229). The copper refining process around Phalaborwa was possibly carried out inside open crucibles which were placed in shallow pits without any superstructure. This possibly explains the lack of conspicuous structures that can be associated with copper refining around the research area. Once filled with raw copper nodules and charcoal the crucible was ignited whilst tuyères and bellows were used for air supply from above. Forced air delivery system was required to raise temperatures above the melting point of copper $\left(1084^{\circ} \mathrm{C}\right)$. An open bonfire without forced draft would not have reached high temperatures that were required to melt copper (Killick \& Fenn 2012).

It is not easy to give reasons for the apparent lack of superstructures suggested for the copper refining hearths here. However, this probably highlights a technical solution for the refining of ferruginous copper that was occasionally produced during 
the primary smelting episodes. Once the exsolved iron in the copper was re-melted under oxidising conditions, iron with a higher affinity for oxygen, would have quickly oxidised at high temperatures (Pryce \& Natapintu 2010, 253). The elimination of exsolved iron would have been very difficult if furnaces with substantial superstructures such as the Kaonde refining furnaces were employed (Figure 8.2). For the Kaonde refining furnaces the tuyère would blow air directly onto the mouth of the ceramic pot, thus creating a locally oxidising atmosphere on the surface of the molten metal, while the burning charcoal around would ensure that the metal remained molten throughout. The characteristics of refining precincts provided here remain tentative pending more information that is likely to be gathered with further fieldwork dedicated to this aspect around the research area. Based on the available information the refining precincts should therefore include mostly slagged crucibles and some tuyères. None the less the results gathered from these largely fragmentary crucible sherds are significant; they allow us to get a unique insight into metallurgical refining or melting technologies. This proves that systematic analyses of slagged ceramics should be given equal attention in future archaeometallurgical investigations in the region. 


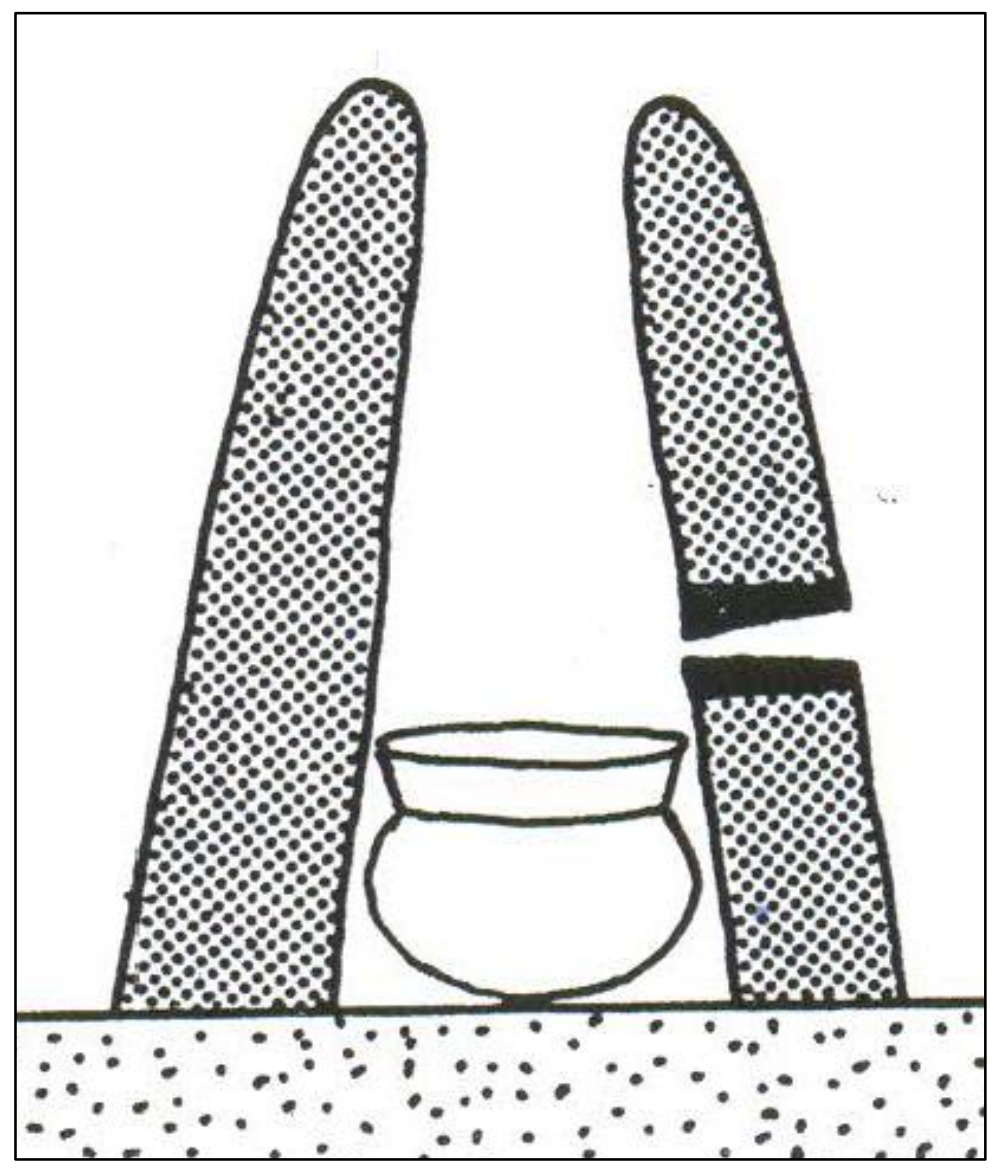

Figure 8.2: Kaonde copper refining furnace with a cooking pot used as a crucible inside (Image: Adapted from Bisson 1997, 129). 


\subsubsection{Spatial location of furnaces}

The investigation of spatial patterning of smelting and smithing activity areas has traditionally been very informative about socio-cultural issues that governed iron production in different parts of sub-Saharan Africa (Greenfield \& Miller 2004; Reid \& MacLean 1995). Iron smelting activities in the sub-continent have largely been viewed as highly ritualised practices that took place in secluded areas away from the habitation sites. However, details are starting to emerge of the stark contrast in the spatial configuration of copper smelting and refining precincts. Recent archaeological work substantiated with archaeometallurgical data at Madikwe (Grant \& Huffman 2007) and Marothodi (Anderson 2009; Hall et al. 2006) highlighted this previously unnoticed spatial patterning of Iron Age copper production in the region (Figure 8.1). Copper production evidence at these two sites, dating to the midseventeenth and nineteenth century respectively, is associated with Western SothoTswana. Primary copper smelting and secondary refining furnaces at these sites are located in residential zones whereas iron smelting was carried out in secluded areas away from the residential zones (Anderson 2009). As a result of this, the evidence of copper smelting and refining at both sites such as smelting slags, crucible fragments and crucible slags is found in domestic middens.

It was not possible to establish with equal certainty whether the same spatial configuration occurred around Phalaborwa, because of the limited evidence of hut foundations and inability to locate copper smelting or refining furnaces. However, we can tentatively conclude that some copper production took place within the residential zones because of the apparent mixing of copper slags and copper crucibles in domestic garbage at Shankare. At Shankare iron production was 
associated with high density metallurgical middens whilst copper slag was mostly found in low density slag scatters. Iron production debris appears to be separate from any domestic refuse whereas sparse copper smelting slags and refining crucibles were found in domestic middens. At Shankare iron production debris was dumped in exclusive metallurgical middens presented in this thesis as dedicated slag middens. These differences are significant because they are in keeping with copper production in domestic contexts. Whilst iron production was carried outside the settlements thus the absence of domestic pottery and faunal food remains in the dedicated iron slag middens. This observation takes us to a related issue regarding the visibility of copper production evidence in the archaeological record.

\subsubsection{Archaeological visibility: slag heaps and slag appearance}

One of the central issues that this thesis aimed to address was the visibility of copper production activities in the archaeological record in comparison to iron production. There is abundant ethnographic information in Central and Southern Africa suggesting that copper furnaces were destroyed after every single smelting episode (Friede \& Steel 1975; Stayt 1968, 64). This practice accounts for the rarity of Iron Age copper furnaces amongst other factors; such as, the use of high grade ores which produce less slag (Craddock \& Craddock 1996). However, previously excavated smelting furnaces, both Phalaborwa type and Lolwe type, were well preserved with signs of relining or re-plastering and repeated use (Miller et al. 2001, 406; Thorne 1974, 40). Besides, slags are usually very durable; as such, if they were produced in great volumes they should be found in the archaeological record. Slags have proved the most important source of information in this thesis. Assuming that copper was smelted at a substantial scale, matching large-scale mining activities around the 
research area, over a period of almost a thousand years it is important to ask the question: what was the fate of the Iron Age copper smelting slags in the research area?

Unequivocal nineteenth century iron smelting furnaces at Square in Phalaborwa included seven three tuyère port furnaces associated with at least 180 tonnes of slag (van der Merwe \& Killick 1979). Another iron smelting furnace excavated at Nareng, a site close to Shankare, was surrounded by at least 30 tonnes of slag (Mason 1965, 262-263). There is no doubt that an enormous quantity of iron slags was deposited next to smelting furnaces around Phalaborwa. On the other hand there is no quantitative information of the volume of slag that was found adjacent to unequivocal copper smelting single tuyère furnaces at Nagome, Molotho and Serotwe, but surely excavators would have mentioned the presence of massive slag heaps at these furnaces. Elsewhere, around Marothodi, it was established that copper smelting furnaces (e.g. furnace SU22A) were not associated with any conspicuous slag heaps, in stark contrast to large slag heaps located adjacent to iron smelting furnaces at the same site (Hall et al. 2006, 23). Accordingly the excavators at Marothodi concluded that the absence of conspicuous slag heaps next to copper smelting furnaces was caused by the subsequent crushing of slags to retrieve copper prills. At Shankare there is evidence that copper smelting slags were subjected to further processing to retrieve prills. The evidence includes crushed-type slags, dimpled hammer stones and dolly holes. Another factor which possesses challenges in the estimation of copper slag volumes in the research area emanates from the occasional occurrence of copper and iron production debris in the same slag heaps. This should be added to the difficulties separating copper from iron production debris macroscopically. To explore further this issue about the visibility of copper 
production in the archaeological record we ought also to acknowledge the limited size of individual slag lumps and fragments around Phalaborwa.

Significantly large slag blocks and cakes reported from the pit furnaces in East Africa have not yet been documented in slag collections or during archaeological field incursions around Phalaborwa (Humphris et al. 2009). Both iron and copper smelting slag samples presented in this thesis are in the form small furnace slag lumps. David Killick who pioneered archaeometallurgy investigations around Phalaborwa also came to the same conclusion that large slag blocks were conspicuously absent (Killick 1977, 44). We can conclude that the methods extracting metals in the research area barely produced large slag blocks or cakes. On top of this, physical crushing copper smelting slags to retrieve prills documented at Shankare reduced the size of the slag pieces. The limited size and subsequent crushing of individual slag pieces provide answers about the fate of slags and slag heaps. After smelting copper slags were removed from the furnaces and carried to domestic contexts where they were subsequently crushed with hammer stones and anvils to mechanically retrieve copper prills. On the other hand iron furnace slags were deposited together with tuyères without further processing therefore allowing them to accumulate as significantly larger slag scatters as documented at Shankare. 


\subsection{Variability and efficiency in copper production technology}

\subsubsection{Residual minerals}

Most copper smelting slags from Shankare, Kgopolwe and Phutwane had ubiquitous magnetite, apatite and quartz as unreacted minerals, with a single occurrence of chalcopyrite. To put this point into perspective, twenty-four out of the twenty-seven copper smelting slags from Shankare Hill presented in this thesis contained macroscopic unreacted residual minerals, mostly magnetite (see Chapter 6). It is appreciated that furnace slags produced by non-slag tapping and short shaft furnaces can contain some unreacted material but the abundance of unreacted minerals presented in this thesis is rather peculiar. The unreacted minerals did not help the smelting process but hindered the process by adding slag viscosity. However, these ubiquitous residual minerals are also informative of the original charge therefore they require further discussion.

The intentional addition of magnetite or iron oxide to the charge during the smelting of copper may offer several benefits depending on the nature of the copper ores employed. Scientific experiments have shown that magnetite can be a source of solid oxygen useful in the evolution of sulphur to $\mathrm{SO}_{2}$ in smelting systems that use predominantly sulphidic ores (Kaiura \& Tohuri 1979 cited in Pryce 2008, 270). The furnace charge which includes massive magnetite chunks together with predominantly sulphidic copper ores provided some advantages for extractive copper processes. Some controlled experiments using crucible furnaces have proved that the co-smelting of sulphidic ores and oxidic ores can produce metallic copper in a single 
step process (Rostoker et al. 1989). Rostoker et al. (1989) thus argue that, with cosmelting stages like ore roasting, matte smelting, final refining could be eliminated.

There is no evidence that the copper ores used around Phalaborwa were predominantly sulphidic. Partially dissolved chalcopyrite $\left(\mathrm{CuFeS}_{2}\right)$ grains occurred together with unreacted magnetite minerals in a single sample SHAMK7(1) from Shankare but as argued in Chapters 6 and 7, analytical data point to the use of oxidic ores. Therefore, intentional co-smelting does not seem to be a convincing explanation here. As an alternative explanation, iron oxide minerals in their various forms could also have been added as a flux in the smelting of high grade secondary copper ores or the usually abundant siliceous copper ores (e.g. chrysocolla) with low iron content (Bachmann 1982). However, the majority of the potential copper ores from various archaeological sites presented in this thesis were found to be rather under saturated (i.e. silica free) and rich in iron. Information provided in the geological literature regarding known copper resources also highlights peculiar under saturation characteristics of minerals from the Palabora Igneous Complex (Groves \& Vielreicher 2001; Russell et al. 1954). Typical copper ore deposits in the research area are thus under saturated and iron-rich, making the addition of magnetite as a flux agent during the extraction of copper an unwise practise. So how then can we account for the ubiquitous presence of residual magnetite minerals?

A small number of case studies of copper smelting slags with evidence of unreacted magnetite comparable to Phalaborwa copper slags are known. Recently, ubiquitous residual magnetite minerals were documented in copper smelting slags from Iron Age (c. 500BC to AD500) sites of Non Pa Wai and Nil Kham Haeng located in the Khao Wong Prachan Valley in Thailand (Pryce 2008; Pryce et al. 2010). Iron Age 
copper metallurgy in the Khao Wong Prachan Valley is known to have employed predominantly sulphidic copper ores. However, the conclusion of the lead investigator was that magnetite fragments found in the copper smelting slags conferred no particular benefit to the extractive process either as a source of solid oxygen or flux (Pryce 2008, 270). It was suggested that the presence of magnetite in these copper slags resulted from the mineralogical misidentification by the metal producers. Magnetite and sulphidic copper minerals employed by Khao Wong Prachan Valley smelters are found in the same geological deposit at Khao Tab Kwai (Pryce 2008; Pryce et al. 2010). The investigators suggest, that due to the similarities in the density and lustre of magnetite and sulphidic copper minerals, these minerals were charged together purely as a result of mineral misidentification. As mentioned earlier, archaeometallurgical results of copper smelting slags presented in this thesis do not suggest the preponderant use of sulphidic minerals in the furnace charge. Besides, chalcopyrite has a golden colour easy to distinguish from back magnetite. Therefore it is unlikely that magnetite was charged unintentionally into the smelting furnaces as a result of misidentification of minerals as is possibly the case in Khao Wong Prachan Valley. The likely explanation of the presence of magnetite in the copper smelting slags is simply poor beneficiation of ores together with smelting processes that were not prolonged or hot enough to reduce the charge (see the discussion in the next section).

The physical properties of magnetite and how it is reduced will help us to establish why so much magnetite remained unreacted in the once molten slag matrices. Iron Age iron bloomery technologies that were employed around the Northern Lowveld are known to have employed the same massive, dense and high grade magnetite ores 
(Killick \& Miller, in press; Miller et al. 2001; van der Merwe \& Killick 1979). In spite of the fact that these are high grade ores it has been established that magnetites provided special challenges to the bloomery smelters during the Iron Age although they were notably high grade ores. Large chunks of magnetite ores, unlike lateritic ores, are known to be notoriously difficult to smelt because they are less permeable which means that they do not readily allow carbon monoxide, the reducing agent, to access the inner parts of massive ores (Killick 2010; Miller et al. 2001, 414). The iron hydroxides typically of the lateritic ores on the other hand are structurally porous compared to magnetite but they are usually low grade (Pryce \& Natapintu 2010). The same challenges would have been encountered by the copper producers who unnecessarily charged these magnetite ores in their furnaces. Their presence as macroscopic unreacted minerals in copper smelting slags from Shankare, Kgopolwe and Phutwane highlights difficulties that were involved in reducing pieces of magnetite. It has been pointed out above that the addition of iron oxide in the form of magnetite as flux for copper ores from the Palabora Igneous Complex is very unlikely. Residual magnetite is the evidence of poor beneficiation; its addition is unlikely to have brought any technical benefit. At present it is difficult to ascertain why so much magnetite was charged during the extraction of copper.

Magnetite is not the only natural mineral identified in the copper smelting slags presented in this thesis. Some unreacted silica grains of smaller size than the magnetite and apatite were also documented. As noted above, the available geological and archaeometallurgical data strongly suggest that both copper and iron mineralisations at the Palabora Igneous Complex are not siliceous. These ores are not naturally self-fluxing thus intentional or unintentional addition of silica into the 
smelting system was required. Technical ceramics always contained a reservoir of silica which could act as flux for under saturated ores (David et al. 1989). However, previous reconstructions of iron smelting technologies around the Northern Lowveld established that high grade magnetite ores were intentionally fluxed with silica-rich material (Miller et al. 2001; van der Merwe \& Killick 1979). Pure silica without fluxing agents requires high temperatures, as its melting point is $1720^{\circ} \mathrm{C}$, not feasibly easy to attain in low shaft furnaces (Pryce \& Natapintu 2010, 256). Blocky quartz rocks, potential choice for siliceous flux, thus would have provided similar problems as massive magnetite chunks discussed above. None of the iron and copper slags that were subjected to archaeometric analysis in this project had conspicuous or macroscopic pieces of unreacted quartz in the same size range as unreacted magnetite pieces. If quartz rocks were employed as a flux, presumably they were meticulously crushed before they could be charged into the furnaces. This painstaking process of crushing quartz was likely avoided, as other scholars have suggested, by using silica-rich river bed sand. Quartz rich sand from the river beds close to the smelting sites was the potential candidate for the fluxing material (Miller et al. 2001, 414). Few samples of river sand from drainage channels that pass through the research area have been subjected to analytical studies to establish if they can be feasibly added fluxes to iron rich smelting systems (Killick \& Miller, in press). The yet unpublished analytical results of the presumed siliceous flux from the river bed are provided in Table 8.1. The sand is rich in silica and alumina with significant levels of soda and potash. It is hereby suggested that the intentional addition of silica-rich material offered benefits to the copper smelting system by combining with iron oxide and lime to form olivines and pyroxenes. However, their residual presence in the slag together with the evidence of slag crushing to retrieve 
metal illustrate that silica fluxing process was not completely successful at some sites.

As for the undissolved fluorapatite grains, these were also quite ubiquitous and large in the copper smelting slags from Shankare, Kgopolwe and Phutwane. Some of the fluorapatite actually dissolved and contributed to the lime and phosphate levels recorded only in copper smelting slags from these sites. The effects of fluorapatite minerals in pyrotechnological copper extraction are not described in the literature known to the author. However, it seems some of the physical properties of this mineral will have negatively affected the copper smelting process. Pure fluorapatite has a high thermal stability with a melting point of $1650^{\circ} \mathrm{C}$ (Lexa 1999, 147). Based on the lower heating capabilities of the furnaces employed during the Iron Age it is not surprising that some of the highly refractory fluorapatite minerals remained unreacted within the molten slag matrices. The geological context of the copper mineralisation in the Palabora Igneous Complex is known to be dominated by calcite, magnetite and apatite (Miller et al. 2001, 406). With the descriptions of Phalaborwa apatite being greenish in colour (Roux et al. 1989), here one could conceive that it was not easy to separate apatite from the secondary copper carbonates. On the other hand magnetite is so different in appearance that it is difficult to believe that early smelters would allow so much to go into the furnace unless they believed there was some advantage in doing so. Some of the minerals discussed above do not seem to have offered benefits to the recovery of copper, again suggesting that they were products of poor ore beneficiation by copper producers of Shankare, Kgopolwe and Phutwane. The mineral charges employed at these sites were not well beneficiated whereas the charge at Molotho and Serotwe was well beneficiated. Alternatively 
thermodynamic conditions in the Molotho and Serotwe smelting furnaces were conducive as will be further discussed below.

Table 8.1: Compositional results of river bed sands from the local river systems that were analysed by David Killick (Killick \& Miller, in press). Sand A was collected from a stream bed near Matsepe (Serotwe) Hill and Sand B from the bed of the GaSelati River.

\begin{tabular}{lrrrrrrrrrrrr}
\hline Sample & $\mathbf{N a}_{2} \mathbf{O}$ & $\mathbf{M g O}$ & $\mathrm{Al}_{2} \mathbf{O}_{3}$ & $\mathbf{S i O}_{2}$ & $\mathbf{P}_{2} \mathbf{O}_{\mathbf{5}}$ & $\mathbf{S O}_{3}$ & $\mathbf{K}_{2} \mathbf{O}$ & $\mathbf{C a O}$ & $\mathbf{T i O}_{2}$ & $\mathbf{M n O}$ & $\mathbf{F e O}$ & $\mathbf{C u O}$ \\
\hline Sand A & 2.41 & 0.29 & 7.57 & 84.69 & 0.02 & 0.00 & 2.16 & 0.92 & 0.14 & 0.01 & 1.29 & 0.00 \\
Sand B & 2.41 & 0.30 & 11.88 & 76.91 & 0.04 & 0.00 & 4.12 & 1.34 & 0.11 & 0.02 & 1.40 & 0.00 \\
\hline
\end{tabular}

\subsubsection{Diachronic variation and regional comparisons}

The range of chemical and mineralogical variation in the slag samples presented in this thesis is worth discussing further. The challenge of distinguishing copper from iron smelting slags noted by previous investigators was settled in this thesis (Miller \& Killick 2004, 29). Although it remains difficult to distinguish copper from iron slags by macroscopic means they differ in their chemistry and microstructure. Iron slags differ significantly from copper slags in their levels of $\mathrm{TiO}_{2}, \mathrm{CaO}$ and $\mathrm{P}_{2} \mathrm{O}_{5}$ (see Chapters $6 \& 7$ for comparisons). Why do we have these major variations in the slag chemistry and mineralogy amongst the archaeological sites around Phalaborwa? Are these slag samples comparable to other archaeological slags known in Southern Africa? The chemical patterning of smelting slags can be caused by the nature of geological deposits, technological constraints or skills and choices of the people who took part in the smelting process. Both iron and copper slags from Phalaborwa presented in this thesis have unusual compositions which separate them from most archaeological slags that have been analysed in sub-Saharan Africa. 
It is not an easy task to pinpoint the reasons behind the variations in slag chemistries noted at inter-site level around Phalaborwa. Archaeologists working around Phalaborwa claim that there was a temporary hiatus in human occupation between the fifteenth and seventeenth centuries AD (Miller et al. 2001; Plug \& Pistorius 1999). The metallurgical debris presented in this thesis was retrieved from contexts linked to these different occupation phases. The lack of secure dates for surface collected materials and some excavated contexts at multi-occupation sites like Shankare and Kgopolwe somehow limits our understanding of diachronic changes that might have occurred in extractive copper technologies. However, if we treat slag assemblages from Shankare and Kgopolwe as representative of earlier material because of some early radiocarbon dates at these sites, but acknowledging this is for convenience sake, and juxtapose them with analytical results of slags from securely dated late second millennium AD sites of Serotwe and Molotho we can identify some trends suggesting changes through time. There is evidence of experimentation during the earlier phase of metal production at Shankare and Kgopolwe. The absence of residual minerals and copper prills with exsolved noted in the Serotwe and Molotho slags would point to refinement of extraction methods; such as, balance in redox and temperature together with use of well beneficiated ores (Figure 8.3). Copper slags from Shankare and Kgopolwe contain more residual minerals, highest levels of iron oxide and phosphate together with some copper prills with exsolved iron. A comparison of some oxides concentrations in the bulk chemistry can also show the differences (Figure 8.4 \& Figure 8.5 ). The majority of earlier copper smelting slags from Shankare have significantly high phosphate and iron oxide levels compared to slags from later periods. The high phosphate documented in Shankare slags likely entered the smelting system from the gangue apatite as discussed above, whilst high 
iron oxide levels together with co-smelting of copper and iron shows unbalanced redox and temperature regimes.

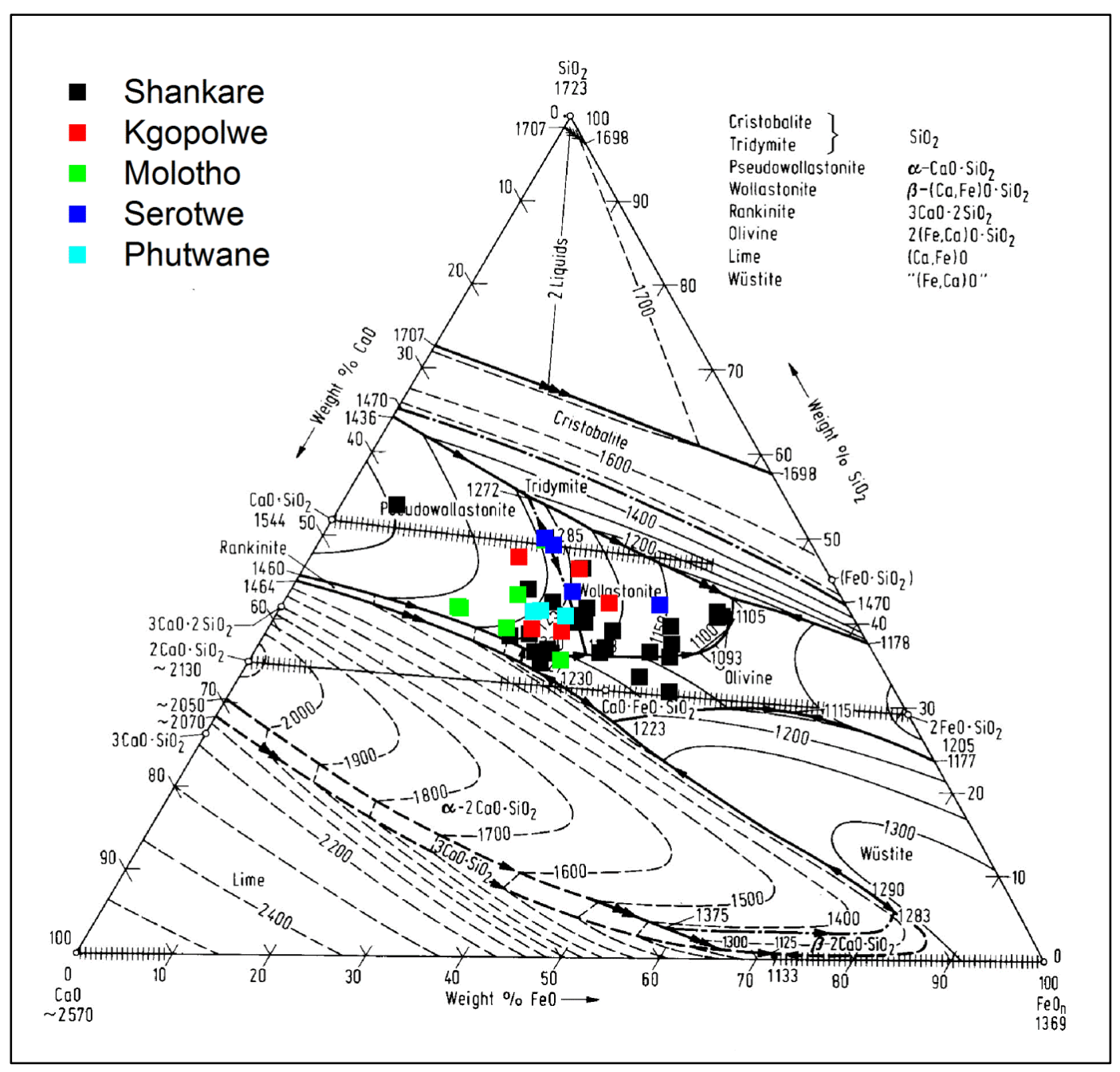

Figure 8.3: Plot of 'bulk' SEM-EDS results of copper smelting slag samples from Phalaborwa on a $\mathrm{FeO}-\mathrm{SiO}_{2}\left(\mathrm{TiO}_{2}+\mathrm{Al}_{2} \mathrm{O}_{3}\right)-\mathrm{CaO}\left(+\mathrm{MgO}+\mathrm{P}_{2} \mathrm{O}_{5}\right)$. (Phase diagram adapted from Kowalski et al. 1995, 126). 


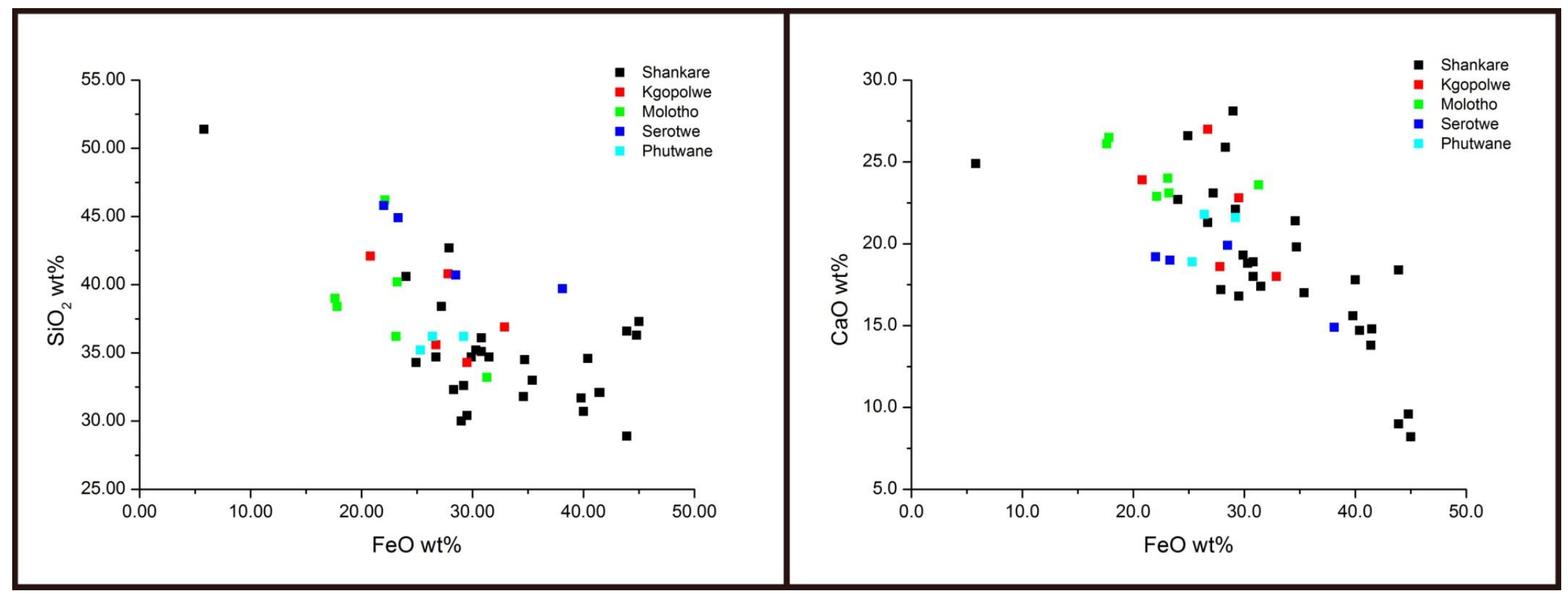

Figure 8.4: Scatter plots showing the relationship between $\mathrm{FeO}, \mathrm{SiO}_{2}$ and $\mathrm{CaO}$ in the copper smelting slags from various sites around Phalaborwa . 


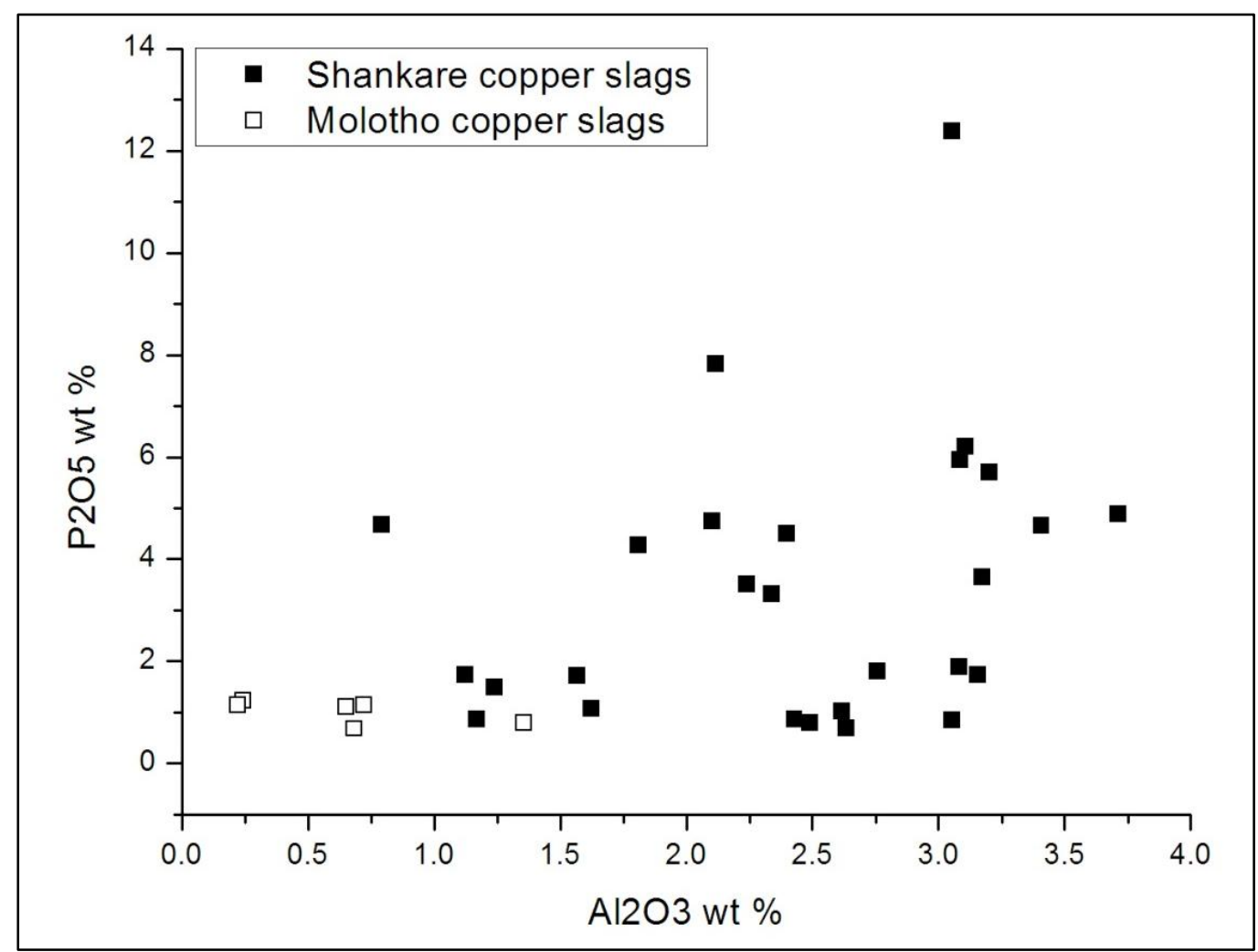

Figure 8.5: Scatter plot showing concentration of $\mathrm{P}_{2} \mathrm{O}_{5}$ against $\mathrm{Al}_{2} \mathrm{O}_{3}$ of copper smelting slags from Molotho and Shankare.

While the previous paragraphs addresses possible diachronic variation within Phalaborwa slag assemblages, it is also interesting to investigate how this technological tradition fits in the broader region. Few copper smelting slags have been subjected to acceptable standards of archaeometallurgical investigations in Southern Africa. Notable well studied copper slag assemblages in the region include Marothodi, Kleinfontein and Rehoboth (Hall et al. 2006; Miller et al. 1995; Miller \& Killick 2004; Sandelowsky \& Miller 1999). The copper slags from these sites fit in the iron-alumino-silicate systems and are microstructurally dominated by well crystallised fayalite olivines. Tabulated bulk chemical averages of copper slags from these three areas show some variations (Figure 8.6). Copper smelting slags from 
Phalaborwa are notably characterised by highest levels of $\mathrm{CaO}$ and $\mathrm{P}_{2} \mathrm{O}_{5}$ compared to slags from others areas. The regional variations in the copper slag chemistry provided here probably reflect little about the technological differences. These high lime and phosphate readings result first from the unique geochemistry of the Palabora Igneous Complex ores together with high fuel to ore ratio employed around Phalaborwa.

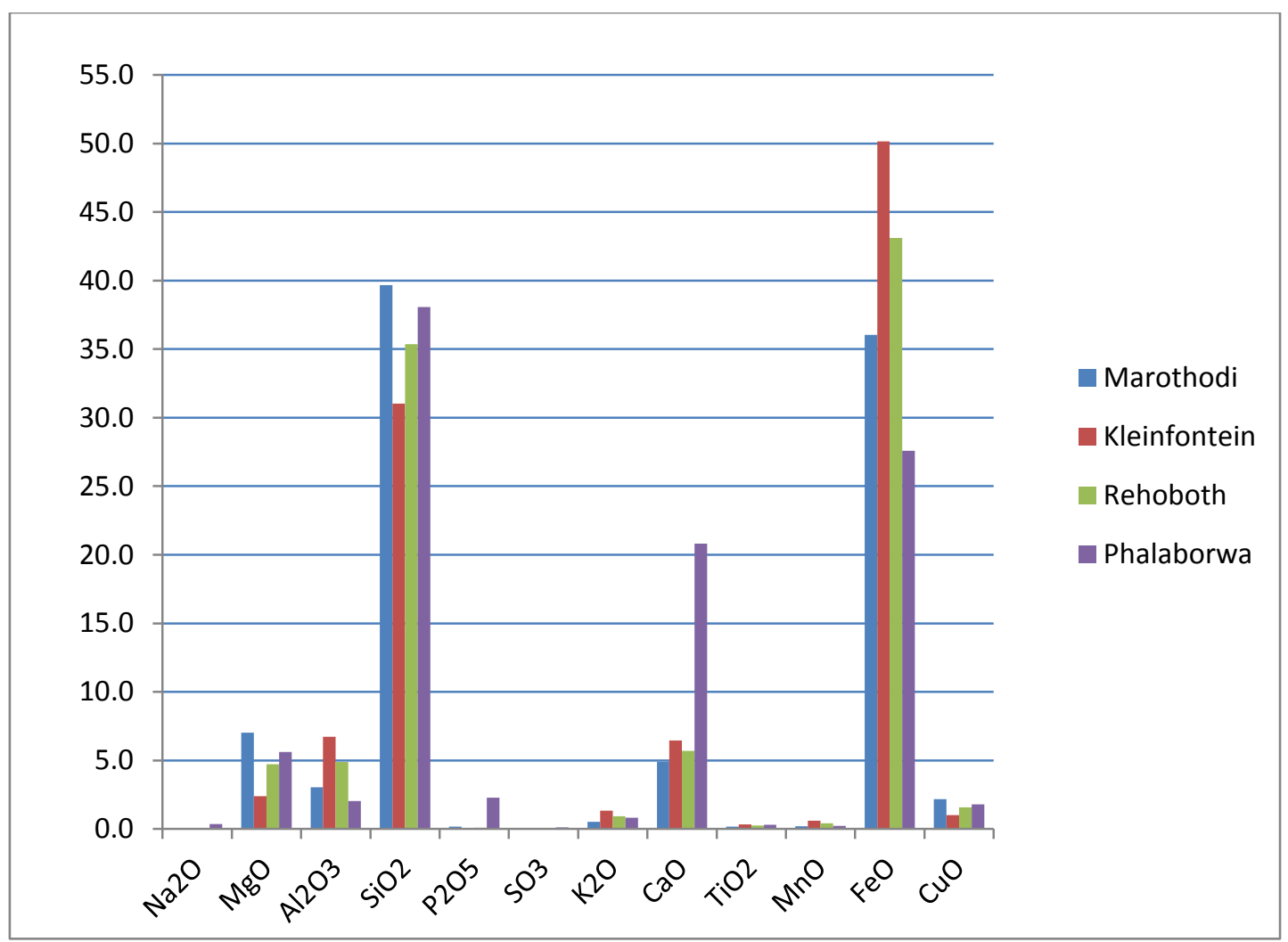

Figure 8.6: Comparisons of the averages major oxides of bulk chemistry of copper slags from Southern African archaeological sites. For the Marothodi data see Hall et al. 2006; Kleinfontein data see Miller et al. 1995 or Miller \& Killick 2004; Rehoboth data see Sandelowsky \& Miller 1999. 


\subsubsection{Efficiency}

A number of archaeometallurgical projects have attempted to discuss the issue of efficiency or compare the efficiency of various extractive technologies. Efficiency as a parameter can be measured or discussed at various scales subject to the limitations of archaeological data (Chirikure \& Rehren 2006, 49). Efficiency in copper extractive technologies has previously been discussed in terms of labour and time needed to produce the copper (Shennan 1999). It is not possible to establish the amount of labour or time that was put to produce a certain quantity of copper around Phalaborwa though one can infer that proper beneficiation may be more costbeneficial than poor beneficiation followed by slag crushing and re-melting as documented at Shankare Hill. Other scholars have previously measured efficiency based on the content of copper content in the slags (Pryce et al. 2010, 258). Extractive technologies that produced slags which retained high copper content are interpreted as inefficient technologies, while low copper content in the smelting slags is a sign of efficient extractive technologies.

The measurement of copper content that remained entrapped in the copper slags from Phalaborwa was compromised by the problems that occurred during the (P)ED-XRF analysis (see Chapter 5). On the other hand, bulk SEM-EDS results do not reflect the true picture of copper that was lost to the slag since the multiple area scans employed here excluded large metallic prills. Reliable bulk (P)ED-XRF show that up to $5 \mathrm{wt} \%$ of $\mathrm{CuO}$ was lost in the copper slags at Shankare (Appendix 6). The copper losses in these slags are much lower than the ones reported in Central Africa where up to 36 wt\% $\mathrm{CuO}$ was lost to the slag (Friede \& Steel 1975, 222). The Central African extractive technologies used high grade ores but did not employ any fluxing agents, 
resulting in high copper losses in the slag (Chaplin 1961; Cline 1937), whilst it has been established that Phalaborwa smelters added silica-rich flux. The low copper content in the Phalaborwa slags can also represent successive iterations of slag resmelting.

\subsection{Copper-base products: a general commentary on cultural preferences}

There is not much ethnographic information about the use of copper and copper alloy objects around Phalaborwa. The collections of copper artefacts available are in the form of rings that could be employed as anklets or bracelets, without any copper tools as typically found in Bronze Age Eurasia. Those subjected to metallographic analyses were comprised of some unalloyed copper, brass and tin bronzes (Miller et al. 2001). It cannot be established with any certainty whether there were temporary changes in preference or availability of one metal (alloy) over another around Phalaborwa as was documented in other parts of sub-Saharan Africa (see Thondhlana \& Martinón-Torres 2009). With the limited number of copper-based artefacts from Phalaborwa the trends in copper alloy preference and use through time cannot be established. However, there is no doubt that the brasses and possibly tin bronzes were not produced locally in the research area. The ore deposits that characterise the Palabora Igneous Complex do not contain tin and copper smelting slags presented in this thesis do not contain detectable tin levels. Having said this, the possibility that there was access to tin is demonstrated by the presence of a tin lerale typically Lowveld in form (Killick 1991a). So far there is no direct evidence suggesting that copper alloying was actually carried out around Phalaborwa. 
The consumption levels of copper around the research area must have been very low. To date, the excavations around Phalaborwa have only produced a meagre collection of copper artefacts, suggesting most of the copper was exchanged. Not a single complete copper artefact was actually recovered during our recent excavations at Shankare Hill. The metal artefacts that were retrieved represented various stages of copper production, including raw copper prills, fragments and possible offcuts. If copper was produced intensively around the Northern Lowveld, as has been assumed by many scholars, the majority of it was exchanged to meet high regional demands of the metal. It seems copper was valued more as an unalloyed product because there is no evidence of attempts to increase value by turning it into an alloy.

Ethnographic information which associates pure copper use or production with women in pre-colonial South Africa deserves to be mentioned. Amongst the Venda people, the red colour of unalloyed copper is always associated with women whilst the white colour of iron symbolise male. According to the Venda myths of human conception, the child receives its flesh and red blood from the mother whilst the white bones and teeth are from the father (Stayt 1968, 210). Stayt $(1968,210)$ goes on to suggest that this concept comes from the colours of women's menstrual flow and men's semen, which are red and white respectively. Amongst the Tswana people who occupy the Northern Highveld of South Africa, copper is also gendered female due to its red and soft nature (Hall et al. 2006, 31). The copper that was produced around Phalaborwa was probably valued as a metal of choice for women as well, justifying its exclusive use for manufacturing personal adornments. 


\subsection{Phalaborwa metallurgists: Their socio-cultural and economic roles and status}

Archaeologists and ethnographers have long been interested in the social roles and political positions that metal workers played or held in the societies within which they operated in (Rowlands 1971). Ethnographic evidence from sub-Saharan Africa offers several examples of highly skilled metal workers who subsequently became privileged specialists, wealthy elites and founders of important chiefdoms or states (Chirikure 2010, 66). Access to and control of vital ore resources, production and exchange of metals are also usually regarded as some of the key ingredients for the development of socio-political inequality. The theme of metallurgists as political leaders or close associates of the ruling elite recurrent in the ethnographic record has been adapted, sometimes uncritically, by archaeologists. Some archaeologists have argued that the ability to extract metals or control their production contributed to the development of earliest state systems in Southern Africa, like Mapungubwe and Great Zimbabwe as suggested at the beginning of this thesis (Calabrase 2000; Herbert 1996). However, contrary to the more popular stories, there are ethnographic examples in sub-Saharan Africa of metal smelters and workers who were (are) actually feared, despised and occupy low status in their societies (Haaland 2004; Haaland et al. 2004). It is thus important to discuss the role and status of Phalaborwa metal workers in their societies and beyond. This issue has not received attention from the more technically oriented scholars interested in the metallurgical practises around the Northern Lowveld, possibly because this information is hardly obtained from archaeometric data available from production debris alone (Miller et al. 2001). In order to address this issue there is need to establish the general historical trends in Southern Africa during the second millennium AD. As the ensuing discussion shows, 
this thesis contends that by placing the technical data in its context it is indeed possible to inform about socio-economic matters.

The period of copper and iron production around the Northern Lowveld coincides with some important regional developments. The second millennium $\mathrm{AD}$ is associated with increased social complexity and development of elaborate political institutions in Southern Africa (Huffman 1972; 2000; 2005; 2009). One of the hallmarks of increased social complexity in this area, though not universally acceptable, is the intensive long distance commercial interaction (Manyanga 2006). Interaction between Southern Africa and the Muslim World flourished between the eighth and sixteenth centuries before it was surpassed by interactions with the Christian World post-dating the fifteenth century (Killick 2009a). According to Manyanga $(2006,139)$ long distance exchange networks required administration and organisation to monitor procurement, production and distribution of exchange and trade goods. For these networks to avoid dissociation they required some form of central authority. In Southern Africa, this long distance commercial interaction is attested in the archaeological record by the presence of substantial quantities of oriental ceramics (Garlake 1968), glass beads (Wood 2000) and exotic metals (Miller 2002). Other important changes that occurred during the second millennium AD include elaborate mortuary practices and settlement patterns which for the first time suggested the presence of class-based societies and unequal access to resources (Huffman 2005). The presence of elite classes also saw the construction of extravagant monumental structures such as Great Zimbabwe. Important archaeological sites associated with these new elite classes in Southern Africa include Mapungubwe, Great Zimbabwe and Thulamela, to mention just a few 
(Figure 8.1). What was the role of metallurgy in the evolution of socio-political institutions in Southern Africa? It has already been pointed out that some scholars are of the opinion that the production of iron, copper and gold at Mapungubwe and Great Zimbabwe played a critical role in their social and political evolution (Calabrase 2000; Herbert 1996). Phalaborwa is well known as the centre for both iron and copper production during the Iron Age period (Evers 1974). Where do the renowned metallurgists of Phalaborwa fit in the whole puzzle of political evolution in Northern Lowveld and the broader Southern African region?

In light of the dynamic developments that took place during the second millennium $\mathrm{AD}$ it is relevant to establish the social standing and role of the Phalaborwa metal producers in their societies and beyond. Oral and ethnohistorical sources cited in Chapter 3 suggest that Malatji rulers with the title Kgoshi (Kriege 1937; Scully 1979; van der Merwe \& Scully 1971). Archaeologists Plug and Pistorius (1999) identify the archaeological settlements of Kgopolwe, Shankare, Nagome and Sealeng Hill as some of the residences of ruling Malatji elites. The criteria used by Plug \& Pistorius (1999) to identify these settlements as elite class are not very clear and will not easily enable us to address the issue of the role and status of the Phalaborwa metal producers. This issue is not easy to address, particularly given the paucity of ethnographic information concerning the metal producers of Phalaborwa. Neither can we find the answers from the archaeometallurgical data presented in the previous chapters alone. Once again we are forced to look for evidence which suggests the presence of elite or non-elite metal producers in the archaeological record. According to Rowlands $(1971,216)$ the principal source of direct archaeological evidence concerning social status of metal producers comes from their burials and associated 
grave goods. Two Iron Age burials at Kgopolwe (SPK3) and Nagome (MN5), radiocarbon dated to the thirteenth and eighteenth centuries respectively, have been previously excavated (Rightmire \& van der Merwe 1976). No notable grave goods suggesting elite consumption or involvement in long distance trade were documented in these two burials. During the excavations at Shankare Hill, we partly excavated a human burial (see Chapter 6); again no evidence of elite class consumption was present, presumably suggesting that the burials belonged to low status individuals. However, some concern should be raised whether these excavated Phalaborwa graves can be positively related with the skilled metal producers or workers.

Exotic artefacts usually associated with elite consumption are equally scarce among the Iron Age settlements around Phalaborwa, as suggested by the excavations at Shankare Hill. It should be understood that the few glass beads that we recovered from Shankare represent occasional losses rather than intentional deposits in graves or hoards. However, the majority of personal adornments that were retrieved from the middens at Shankare Hill were shell beads, presumably manufactured from local and few exotic raw materials (Figure 8.7). There is no doubt that Phalaborwa metal producers had access to exotic goods, for example glass beads, brass and bronzes. However, the volume of direct trade with the outside world seems limited. If exotic goods can be used as a universal hallmark of wealth or status, then the current archaeological evidence indicates that the metal producers of Phalaborwa must have been poorer. There seems to be no evidence of elite class or consumption amongst the Iron Age Phalaborwa metal miners and producers. The picture around Phalaborwa should be contrasted with contemporary rich graves and settlements associated with elites who resided at Mapungubwe (thirteenth century AD), Great 
Zimbabwe (thirteenth to fifteenth century AD) and Thulamela (fifteenth to sixteenth century AD) to the North (Fouché 1937; Gardner 1963; Huffman 2009; Oddy 1984; 1991; Steyn et al. 1998; Steyn \& Nienaber 2000). These elite settlements and burials are endowed with status items such as gold adornments together with a high frequency of exotic goods, mostly glasses beads and oriental ceramics. The lack of large volumes of exotic goods suggests that the metal producers did not produce metals to meet demand of the Indian Ocean trade system. Exotic goods are mostly present in major gold producing areas that had contact with Eurasia. This reminds us of the fact that gold was produced mostly for overseas traders whereas copper and iron would have been produced to meet local or regional demands (Swan 1994). The excavations in north-western Zambia one of the major producers of copper also failed to yield significant quantities of foreign trade goods (Bisson 1982). 


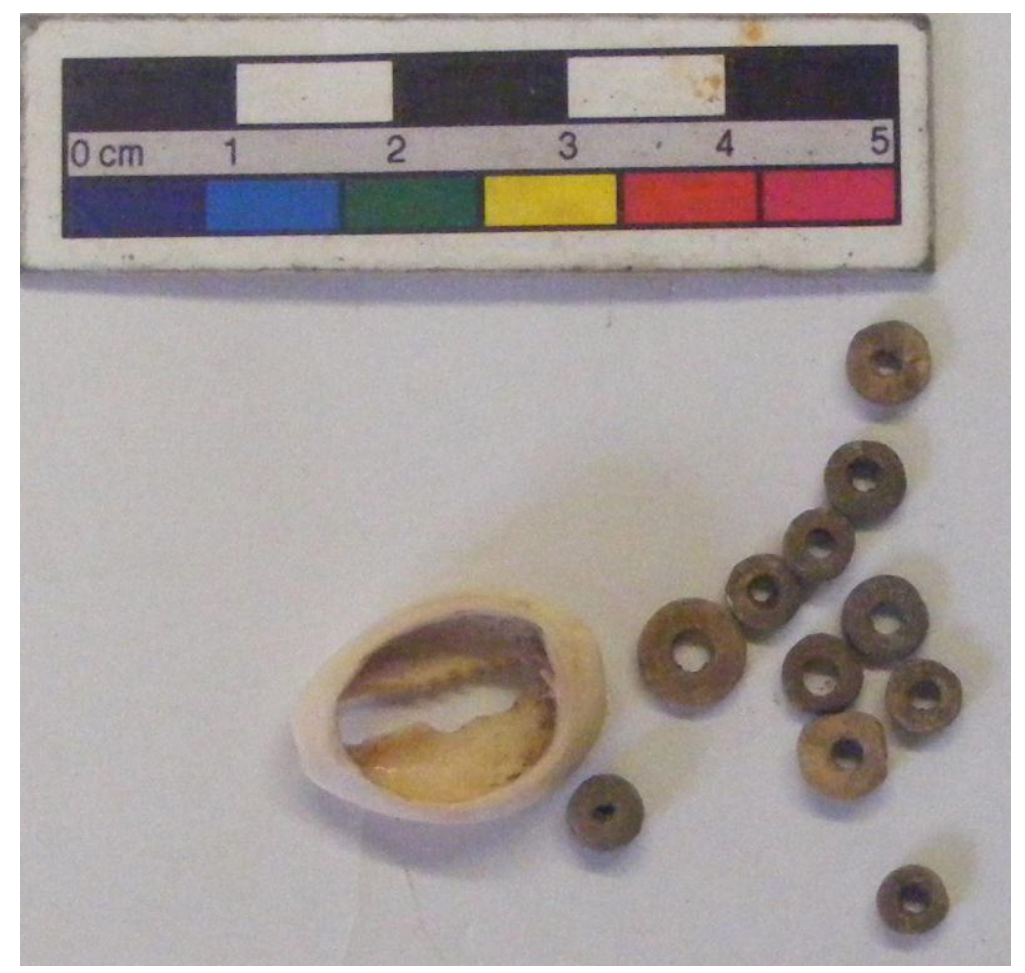

Figure 8.7: Part of the personal adornments from Shankare (SHAM1) made from locally available shell and a single East African coast conus shell.

If the suggestion that the social standing of Phalaborwa metal producers at a regional level was comparatively lower than that of their contemporaries holds water, several questions and issues should be discussed further. What was the contribution of Lowveld metallurgists to the regional and long distance commercial interaction? Was Phalaborwa integrated into the Southern African regional trade system? What did they receive in return for their metal products or raw materials? What would have compelled these metal producers to put up in the supposedly hostile region if they did not benefit much from their produce? The answer to these questions are rather complex but some inspiration may be drawn from case studies of prehistoric metal producers outside the African continent while remaining aware of the risks of uncritical universal parallels. Examples of low status metal producers who resiliently 
occupied agriculturally marginal areas have been documented in prehistoric Eurasia. Two good examples include the Bronze Age copper producers of the Mitterberg region, Eastern Alps Valley in Austria (Shennan 1998; 1999) and Iron Age copper producers of the Khao Wong Prachan Valley in Thailand (Pryce et al. 2010). Excavations at St Veit-Klinglberg, a settlement associated with specialised copper producers in the Mitterberg region, did not show much evidence of elite consumption similar to Phalaborwa. Shennan $(1998 ; 1999)$ thus argued that copper producers who occupied the mining areas had a peripheral status even though they were producing a commodity that was highly sought after during the European Bronze Age. The archaeological record of the poor St Veit-Klinglberg copper producers was also contrasted with that of the nearby Dürnberg salt miners who had large volumes of elite consumption in their burial grave goods. The contrast between the archaeological records from Iron Age sites in the north and contemporary sites in Phalaborwa is also extremely remarkable. The "world-systems" approaches might be an important avenue to explore if core-periphery relations existed between the mining/metal producing regions and their neighbours during the Iron Age period (Killick 2009a).

Archaeologists working in the Northern Lowveld have a strong conviction that Iron Age miners and metallurgists were not self-sufficient; given the supposedly hostile ecological conditions (see Chapter 3). The archaeological scarcity of metal consumption evidence also indicates that metals were materials for interaction with other areas. Nineteenth century ethnographic evidence suggests that these metal producers heavily depended on their agropastoral neighbours for their foodstuffs which they exchanged for both ores and metals (Miller et al. 2002). Surplus iron 
production to cater for the regional markets was documented at several sites around Phalaborwa (Miller et al. 2001; van der Merwe \& Killick 1979). The low levels of copper consumption around the research area show that the metal was produced in surplus for exchange. The two occupational phases of Phalaborwa, i.e. 1000-1400 $\mathrm{AD}$ and 1600-1900 AD, during the second millennium AD coincide with commercial interaction of the greater Southern African region with the Muslim World and Christian World (Plug \& Pistorius 1999, 178). However, as pointed out above the scarcity of exotic goods around Phalaborwa would suggest that metal production practices in this region were not geared towards an overseas market.

\subsection{Summary}

This chapter has highlighted further the peculiar attributes of the chaîne opératoire of extractive copper metallurgy activities practised around Phalaborwa and the diachronic changes of this technological tradition. Some previous assumptions about the differences between copper and iron smelting furnace designs were questioned. A refinement of the extractive methods through time has been suggested, although more temporal resolved data will be required to make a case for this. Challenges that were posed by the smelting of copper ores from the Palabora Igneous Complex were further explained. Extractive metallurgy technologies of Northern Lowveld were compared to technologies employed by contemporary copper producers in Southern Africa. The archaeological evidence from Phalaborwa was also placed in the broader framework of the Southern African archaeology. This regional perspective suggests that Phalaborwa metalworkers, despite producing metals that were important in the regional market, remained comparatively less privileged. Some contemporary 
archaeological sites to the north of the research area have overwhelming evidence of interaction with overseas markets. This commercial interaction is archeologically represented by luxury oriental goods which are very scarce around Phalaborwa. Long distance exchange played only a peripheral role in the day to day life of second millennium AD metallurgists of Phalaborwa. 


\section{Conclusions and Recommendations}

"Indeed, this paper, as a philosopher would have predicted, raises as many new questions as it settles old ones." (Craddock 1980, 165)

\subsection{Introduction}

The first part of this chapter provides a summary of the main conclusions of this thesis concerning extractive copper technologies around Phalaborwa during the second millennium AD. For any research project of this magnitude the ability to undertake some critical self-evaluation or stocktaking at the end is essential. For this reason, the limitations that were faced during the processes of data collection, analyses and interpretation which rendered some of the conclusions tentative or speculative will be pointed out to assist investigators who wish to undertake similar research. It is acknowledged that this thesis is certainly not the final statement on the theme of extractive copper technologies in the research area or the wider Southern African region but it is also hoped that some questions have been answered and there is now firmer ground for further work in this field. As suggested in the citation provided above, as the questions and objectives outlined at the beginning of this thesis were being resolved, 'new' research problems also aroused. These 'new' research questions could not be addressed within the limited scope of this thesis. As such, this chapter concludes by outlining avenues that future investigations can engage with concerning not only copper production but the general archaeology of Phalaborwa and the wider geographical scope of the Northern Lowveld. It is hoped that this thesis will stimulate further investigation of extractive copper production; this is an area that has hitherto received very little attention. After a hiatus of more than two decades, it is also hoped that revisiting Phalaborwa will revitalise fieldwork archaeology in this interesting region. Phalaborwa was the cradle of systematic Iron 
Age research by professionally-trained archaeologists during the time when it was more of a taboo to study the Iron Age period because of apartheid policies in South Africa. However, little follow up has been done to this once promising region in the post liberation period.

\subsection{Conclusions drawn}

The primary concern of this thesis was to reconstruct extractive copper production technologies in the research area from the early second millennium AD. The inspiration to undertake this investigation was drawn from the chaîne opératoire approach which is both a theoretical and methodological framework popular with archaeologists and anthropologists interested in ancient technologies. The approach entails detailed reconstructions of the stages of production as the foundation of understanding technologies in their social contexts. In order to reconstruct the extinct extractive copper pyrotechnologies, some archaeological surveys, test excavations and subsequent archaeometric analyses of potential ore samples, slags, technical ceramics and metal artefacts were undertaken. The reconstructions that were presented in this thesis are by no means complete due to the nature of archaeological evidence, which is always incomplete. However, the key features of extractive copper metallurgies that were practised during the second millennium AD period around Phalaborwa can be summarised as follows:

Copper extraction required intensive human labour together with a range of raw materials and specialised knowledge. Copper ores were available in variable quantities at different locations around the research area but the chief source was Lolwe Hill. When systematic archaeological research was initiated during the 1970s this hill was riddled with pits and shafts resulting from previous copper mining 
activities and the study presented here confirm geochemical links between this deposit and the slag. The ores from this geological deposit included copper-iron secondary ores resulting from the decomposition of chalcopyrite, which is the dominant primary ore. The copper-iron sulphides (chalcopyrite) at Lolwe have remained of economic importance; to date they continue to be exploited by the Phalaborwa Mining Company (PMC), one of the major copper producers in South Africa today. The majority of potential ore samples from the archaeological contexts presented in this thesis are copper-iron secondary minerals with residual chalcopyrite islands in the matrix. It has been established that the ores from the Palabora Igneous Complex are characterised by a strong co-existence of copper and iron in both primary and secondary ores. Unlike copper ores that were exploited in other regions both primary and secondary ores from the Palabora Igneous Complex are notably under saturated with very low levels of silica. Magnetite is another mineral of economic interest to the Iron Age metallurgists that was found in abundant quantities. There was no need of underground mining to obtain high grade magnetite ores at Lolwe Hill during the Iron Age period. Accessory minerals with no metallurgical value to the Iron Age metallurgists like apatite and calcite also occurred in the same geological deposit with the copper and iron ores and during the earlier phases a substantial amount of these entered the furnace charge. The very nature of the geological deposit provided challenges for both iron and copper producers. It is for this reason that archaeometric analysis of copper production debris from different sites presented in this thesis suggests an initial phases of experimentation with these complex ores that was followed by progressive mastering of copper smelting processes through time. 
Secure evidence of copper smelting around Phalaborwa dates to the beginning of the second millennium AD, although mining activities at Lolwe Hill seem to precede these dates by at least two centuries. Nothing is known about the methods of copper extraction that were used prior to the second millennium $\mathrm{AD}$ in the research area. Copper smelting activities in the research area are thought to have ceased way before 1890 whereas iron continued into the early years of European colonisation (Miller et al. 2002). Commencing from the early second millennium $\mathrm{AD}$, furnace-based metallurgies which utilised three distinct furnace designs were available. The furnace designs that were employed for primary smelting purposes included the Phalaborwa and Venda furnaces with typical three tuyère ports and the Lolwe furnaces equipped with one tuyère port entrance. Both types of furnaces fit well in the family of short shaft furnaces with no slag or metal tapping capabilities. However, the differences in their size together with the number of tuyères had an impact on several furnace operation parameters. The larger furnaces with three tuyère port provisions presumably provided more draft air and thus could attain higher temperatures and more reducing conditions than single tuyère port furnaces. Based on this reasoning, previous informed assumptions were that three tuyère port furnaces were used exclusively in smelting iron operations whilst the smaller single tuyère port furnaces were used for copper production (Miller et al. 2001). However, it was proposed in this thesis that during the first half of the second millennium AD copper was actually smelted in three tuyère port furnaces. Some three tuyère port furnaces dating to the first half of the second millennium AD were accompanied by both copper and iron smelting slags. The three tuyère port furnaces should thus be added to the chaîne opératoire of the initial primary copper smelting activities that took place during the early second millennium AD around Phalaborwa. The results 
of extracting copper from iron-rich copper ores in these furnaces were the occasional, but accidental, production of 'black copper'. Despite the presumed high temperatures and reducing conditions that were attained in these three port furnaces, the copper smelting slags from early contexts have ubiquitous unreacted minerals in the form of quartz, magnetite and apatite. The conclusion that can be drawn from this evidence is that the charge that went into the furnace was not well beneficiated; as a result, gangue material entered the charge in proportionately large quantities. Separation of copper from the slag was not very efficient; as such a prill collection technology that involved mechanical crushing of slags to retrieve slag embedded prills was employed.

Single tuyère port furnaces provided the technical solution to extract copper without contaminating it with iron (Miller et al. 2001, 414). The single tuyère furnaces presumably provided limited air supply thus lower temperatures which selectively reduced copper with very limited levels of iron. The copper smelting slags from single tuyère furnaces dating to the late second millennium AD sites at Serotwe and Molotho contain copper prills of high purity. However, the copper smelting slags from these furnaces though small in size are comparably quite dense without macroscopic unreacted materials typically found in copper smelting slags from presumed earlier contexts at Kgopolwe and Shankare. The once highly fluid, well reacted and dense slags from single tuyère furnaces testifies the attainment of high temperatures. The copper ores that were charged into these furnaces were likely thoroughly sorted out to remove most of the gangue material prior to smelting. It is therefore tempting to conclude that there was progressive refinement of ore selection or beneficiation and extractive techniques with time and experience. The timing of these supposed shifts in procedures is not yet clear due to lack of secure dates for 
some of the metallurgical debris presented in this thesis. This limits our understanding of the temporal changes that occurred in the smelting technologies through time. None-the-less this evidence would suggest an initial phase of experimentation with the particular regional ores that was later superseded by mastering of the extractive methods. It is acknowledged that more archaeometallurgical samples from securely dated contexts and furnaces will be required to support firmly the proposed temporal changes in smelting techniques.

It is noteworthy that none of the finished copper artefacts from archaeological sites around Phalaborwa or adjacent areas has the notably high iron contents (up to 40 wt\%) registered in some of the slag-entrapped copper prills (Miller 2002). Subsequent to smelting, the primary copper was subjected to further processing as documented at Shankare Hill, so that copper products were of remarkable and enhanced purity and quality. The refining of copper under oxidising conditions is part of the crucible-based metallurgy documented at archaeological sites around Southern Africa. The analysis of slagged ceramic fragments suggested the use of open crucibles for refining of copper was well established by the early second millennium $\mathrm{AD}$. No evidence of copper alloying activities or potential alloying materials was retrieved around Phalaborwa, suggesting that unalloyed copper remained the preferred metal.

One key contribution of the investigation of metallurgical ceramics in this thesis was to demonstrate that these crucibles were fired from within or above. This is a significant discovery because it explains why the majority of slagged crucible fragments in the region are heat distorted from the inside whilst external surfaces are always intact. This new evidence challenges suggestions that these ceramic 
fragments were used as slag skimmers during refining processes (Calabrase 2000). Further analytical work should be carried out on slagged crucible sherds from contexts with different dates to establish if they were consistently fired from within or above throughout the Iron Age. In other World regions, over time high temperature resistant metallurgical ceramics were developed that could eventually be fired from the outside (Bayley \& Rehren 2007; Rehren 2003). Further systematic studies of refining crucible sherds will be able to establish if the same trend actually was attained in the manufacturing of specialised metallurgical ceramics in Southern Africa. Reconstruction of crucible-based metallurgy in Southern Africa should be given more priority in the future. Such investigations are likely to expose some important innovations that took place in the manufacturing ceramics that were used in pyrometallurgical processes. These ceramics are vital pieces of evidence in the reconstruction of ancient pyrotechnologies just like the slags and finished artefacts.

The proposed temporal changes can give some important insights into the changes that occurred in the organisation of production through time. It seems during the first half of the second millennium $\mathrm{AD}$ there was no difference between copper and iron producers. The same metallurgists would have engaged in both copper and iron smelting in the same type of furnaces of course during different smelting episodes. However, with time the two crafts were separated with copper smelters specialising on copper only whilst iron producers did the same. For this reason it has been suggested before that some historic groups of Phalaborwa, like the Maseke-Malatji were exclusively copper producers whilst their neighbours the Majaji-Malatji and Makusane were iron producers (Plug \& Pistorius 1999, 156). Apart from purely technical aspects it will be of interest to establish if the same craftsmen were actually 
involved in all the stages of the reconstructed chaînes opératoires of Phalaborwa copper production that is from mining, smelting to refining from the scant ethnographic information available.

It has been difficult to ascertain the value attached to the finished copper products produced in the research area. It is also difficult to establish trends in the scale of production based on the limited evidence that was gathered in this thesis. The volume of finished copper objects that has so far been recovered from the area remains modestly low, which suggests that most of their copper products would have been exchanged. The principal products after copper fabrication were mainly bangles, which is in agreement with findings from other parts of sub-Sahara that copper was a metal of choice for personal adornments rather than making utilitarian tools (Herbert 1984; Killick 2009b). In the future, systematic work should be conducted to quantify and characterise the copper artefacts that have been excavated to date from Phalaborwa. The quantification of finished artefacts will shed more light on the scale of local consumption and value whilst raw copper artefacts will help establish more about production of copper. In the future lead isotope analysis would also help to trace the exchange of Phalaborwa in the region. 


\subsection{Lessons and directions for future research}

The search for archaeological evidence of copper production and the subsequent reconstruction of typical characteristics of extractive copper technologies around Phalaborwa has offered lessons for future research in copper-base metallurgy in subSaharan Africa. The first lesson is concerned with distinguishing metallurgical debris produced by ferrous and cuprous extractive technologies. In sub-Saharan Africa wherever copper was being produced during the Iron Age it is likely that some smelting of iron was also taking place since iron was required for several agricultural activities. This thesis has highlighted the fact that debris from iron and copper smelting can be hard to distinguish in the archaeological record, requiring not only bulk chemical analysis but also microscopic investigations of slags. This point just reiterates previous calls by other specialists who have noted that field approaches alone often result in erroneous interpretations of metallurgical debris (van der Merwe 1978; Miller \& Killick 2004; Severin et al. 2011). It was also established that furnace charges for both copper and iron smelting processes around Phalaborwa included magnetite. Therefore fieldwork evidence of unreacted magnetite embedded in smelting slags is not always positive evidence of iron smelting. The current author indeed initially dismissed slags with unreacted magnetite as products of iron smelting before further laboratory analyses actually confirmed that they were by-products of inefficient copper smelting episodes. The use of magnetic tests in the field can also be misleading because copper smelting slags invariably contain ferromagnetic magnetite spinels. The majority of the copper smelting slags that were presented in this thesis were actually strongly magnetic compared to iron smelting slags. The ultimate answer for separating copper from iron production slags will be microscopic analytical methods. 
Another lesson that can be drawn from the fieldwork experience is that archaeometallurgists should not only target impressive slag heaps without paying attention to small scatters. It is rather ironic that the most important evidence of copper production at Shankare Hill was actually obtained from low density scatters with a handful of crushed slags and not the impressive slag heaps. These less obtrusive slag scatters can provide the key information particularly for non-ferrous metallurgical activities. In most cases, scatters of slag associated with settlements or domestic contexts are simply assigned to iron smithing without further analysis and this thesis has shown that such assumptions impose a strong bias in our ability to reconstruct ancient metallurgical technologies.

There are also challenges with the methods of estimating furnace operating parameters such as temperature ranges. The occurrence of unreacted materials together with unusual slag chemistries compromises the estimation of furnace temperatures using traditional ternary phase diagrams. In future, experiments should be carried out by archaeometallurgists to device new approaches to establish more reliable furnace temperature estimates. The choice of phase diagrams is usually based on modern laboratory metallurgical and chemical principles and reaction in equilibrium that were not necessarily achieved in most ancient furnaces (Iles \& Martinon-Torres 2009). More investigations should be done to highlight the major short falls of phase diagrams that continue to be used with indiscretion in archaeometallurgy. But if these diagrams are used critically and in combination with microscopy they can be useful as was the case in this thesis.

Some conclusions reached in this thesis are still tentative because of the small numbers of samples that were analysed at particular sites. The single slag sample 
from Maranda farm suggests a unique extraction process that would have utilised sulphidic copper zinc blende ores to produce copper metal in a single-step process. This slag sample has crucial evidence which shows the co-existence of pure copper and large matte prills with definite evidence of progressive reduction of matte prills to copper. With several claims that extraction of copper from sulphidic ores did not always require complex treatment before smelting it is worth investigating if this was the case around Maranda farm (Georgakopoulou 2004, 6; Georgakopoulou et al. 2011; Rostoker et al. 1989). Further archaeometallurgical investigations should include focused surveys and excavations should be carried out in the farm of Maranda to establish more about this rather peculiar smelting process. The reconstruction of extractive copper metallurgy following the field and laboratory standards that were set at Shankare in this thesis will provide fresh information about the possibility of sulphidic copper ores having been used in Iron Age sub-Saharan Africa, a hypothesis generally dismissed by many scholars.

This thesis has largely succeeded in the reconstruction of the extractive copper technologies from a metallurgical point of view but there is still potential for investigations concerning the socio-political impacts of metallurgy in the Northern Lowveld. Future investigations can benefit from economic models that have been proposed for other parts of Africa (e.g. Killick 2009a) to establish if the interaction between Phalaborwa metallurgists and their neighbours or beyond affected their methods of producing metals. Future archaeometallurgy work around Phalaborwa would also benefit from more investigations of issues of traditional archaeological interest. The last dedicated archaeology investigations around were carried out almost two decades ago. Since then a lot has changed in the discipline of archaeology 
and research priorities in the region. Some dedicated paleobotanical investigations will likely yield new information about the agricultural practices that probably sustained the Lowveld societies throughout the Iron Age. Most studies around Phalaborwa have been preoccupied with the role of mining and metal production largely undermining other research avenues. Apart from mining and metallurgy we still know very little about the socio-political organisation of second millennium AD societies who occupied Phalaborwa. Little archaeological attention has been given to establishing political evolution processes that took place during the Iron Age in the Northern Lowveld. Shallow understanding of political evolution processes in the research area from an archaeological perspective has adversely affected our sociocultural interpretation of mining and metallurgy in the area.

In South Africa the pre-colonial centre of copper mining of Musina should be surveyed intensively for evidence of copper smelting since no archaeometric analysis has been done on copper production debris from this region. It is understandable that most of the evidence around Musina, just like around Phalaborwa, was destroyed by modern mining but some vital insights can still be gathered as this project has shown. South Africa has enjoy some growth of archaeometallurgical studies that routinely involve copper production (Friede \& Steel 1975; Friede et al. 1982; Hall et al. 2006; Grant \& Huffman 2007; Miller 2001a), while little or virtually nothing is known about copper metallurgy in neighbouring countries (Eric et al. 1995; Miller \& Sandelowsky 1999). Broadening the geographical scope in search of archaeological evidence of copper production should include countries like Democratic Republic of Congo (DRC), Zambia and Zimbabwe. Central African countries have to date provided important ethnographic information on Iron Age copper mining and 
smelting however dedicated archaeometric analysis of the production debris is yet to be undertaken. Virtually nothing is known about furnace designs or copper production activities on the Zimbabwe plateau despite the overwhelming evidence of copper mining and copper artefacts (Summers 1969; Swan 2002; 2007). Almost three decades ago Herbert $(1984,26)$ lamented that no information was available about the smelting technologies in the copper mining areas of Zimbabwe. The state of affairs remains the same with no single publication of a copper smelting site from the large copper mining regions of Zimbabwe to date.

The final remark for future research in the field of African metallurgy is that investigators should contribute to sustainable development issues. In order to justify their existence, Africanists interested in archaeology or metallurgy should attempt to solve some of these contemporary social problems. Reconstruction of extinct pyrotechnologies should not be seen as an end in itself. Research in African metallurgies has been able to challenge some of the negative perceptions about the continent by showing some of its past achievements and therefore restore lost pride (see Chapter 2). On this front, archaeometallurgy has provided useful approaches that have been developed over the years. However, these studies have failed to address the challenges which continue to affect present day African societies. One of the notable challenges to which these studies can contribute is poverty alleviation. The revival and encouragement of indigenous technological systems like copper or iron smelting after successful archaeometallurgical projects is one way of contributing positively. There are good examples where traditional African crafts have been revived for the benefits of local communities in the research areas. Good examples include the revival of traditional stone sculpturing in the country of Zimbabwe which 
resulted from studies of art historians (Winter-Irving 1993). In the twenty-first century, where studies of the African past including archaeology are fighting for relevance there should be active promotion of mining and metallurgical heritage awareness. Archaeometallurgists are in a better position to engage with indigenous societies to promote spin-off projects like the revival of traditional hand-craft production for tourist markets thereby addressing immediate societal needs like jobs. Ethno-experimental reconstructions that put indigenous people at the centre would benefit both local communities and academics. 


\section{References}

Alpern, S., 2005. Did they or didn't they invent it? Iron in sub-Saharan Africa. History in Africa 32, 41-94.

Anderson, M. S., 2009. Marothodi: The Historical Archaeology of an African Capital. Northamptonshire: Atikkam Media Limited.

Austen, R. A. \& Headrick, D., 1983. The role of technology in the African past. African Studies Review 26(3/4), 163-184.

Bachmann, H.-G., 1980. Early copper smelting techniques in Sinai and Negev as deduced from slag investigations. In: P. T. Craddock (ed.), Scientific Studies in Early Mining and Extractive Metallurgy. London: The British Museum Occasional Paper No. 48, 103-134.

Bachmann, H.-G., 1982. The Identification of Slags from Archaeological Sites. London: University of London, Institute of Archaeology Occasional Publication No. 6.

Banning, E. B., 2002. Archaeological Survey. New York: Kluwer Academic/ Plenum Publishers.

Barndon, R., 2004. An Ethnoarchaeological Study of Iron-Smelting Practices Among the Pangwa and Fipa in Tanzania (Cambridge Monographs in African Archaeology 61), BAR International Series 1308. Oxford: Archaeopress.

Barton, J. M., Bristow, J. W. \& Venter, F. J., 1986. A summary of the Precambrian granitoid rocks of the Kruger National Park. Koedoe 29(1), 39-44.

Bassiakos, Y. \& Catapotis, M., 2006. Reconstruction of the copper smelting process based on the analysis of ore and slag samples. Hesperia Supplements 36 The Chrysokamino Metallurgy Workshop and Its Territory, 329-353.

Baumann, M., 1919. Ancient tin mines of the Transvaal. Journal of the Chemical, Metallurgical and Mining Society of South Africa 19, 120-132.

Bayley, J. \& Rehren, Th., 2007. Towards a functional and typological classification of crucibles. In: S. La Niece, D. Hook \& P. Craddock (eds.), Metals and Mines: Studies in Archaeometallurgy. London: Archaetype Publications (in association with the British Museum), 46-55. 
Bernhard, F. O., 1962. Two types of iron smelting furnaces on Ziwa farm (Inyanga). South African Archaeological Bulletin 17(68), 235-236.

Bisson, M. S., 1974. Prehistoric copper mining in northwestern Zambia. Archaeology 27(4), 242-247.

Bisson, M. S., 1975. Copper currency in central Africa: the archaeological evidence. World Archaeology 6(3), 276-292.

Bisson, M. S., 1976. The prehistoric copper mines of Zambia. Unpublished Ph.D. thesis, University of California.

Bisson, M. S., 1982. Trade and tribute. archaeological evidence for the origin of States in south central Africa. Cahiers d'Etudes Africaines 22(87/88), 343-361.

Bisson, M. S., 1997. Copper metallurgy. In: J. O. Vogel (ed.), Encyclopedia of Precolonial Africa: Archaeology, History, Languages, Cultures and Enviroments. Walnut Creek: Altamira Press, 125-132.

Bisson, M. S., 2000. Precolonial copper metallurgy: sociopolitical context. In: J. O. Vogel (ed.), Ancient African Metallurgy. Walnut Creek: Altamira Press, 83-146.

Bourgarit, D., 2007. Chalcolithic copper smelting. In: S. La Niece, D. Hook \& P. Craddock (eds.), Metals and Mines: Studies in Archeometallurgy. London: Archaetype Publications (in association with the British Museum), 3-14.

Bowen, R. \& Gunatilaka, A., 1977. Copper: Its Geology and Economics. London: Applied Science Publishers.

Bray, F., 2007. Gender and technology. Annual Review of Anthropology 36, 37-53.

Calabrase, J. A., 2000. Metals, ideology and power: the manufacture and control of materialised ideology in the area of Limpopo-Shashe confluence, c. AD 900 to 1300. Goodwin Series 8, 100-111.

Caple, C., 2006. Objects: Reluctant Witnesses to the Past. London: Routledge.

Carruthers, J., 1995. The Kruger National Park: A Social and Politcal History. Pietermaritzburg: University of Natal Press.

Cartwright, A. P., 1974. By the Waters of Letaba: A History of the Transvaal Lowveld. Cape Town: Purnell.

Caton-Thompson, G., 1931. The Zimbabwe Culture: Ruins and Reactions. Oxford: The Claredon Press. 
Chaplin, J. H., 1961. Notes on traditional smelting in Northern Rhodesia. South African Archaeological Bulletin 16(62), 53-60.

Chikwendu, V. E., Craddock, P. T., Farquhar, R. M., Shaw, T. \& Umeji, A C., 1989. Nigerian sources of copper, lead and tin for the Igbo-Ukwu Bronzes. Archaeometry 31(1), 27-36.

Childs, S. T., 1989. Clays to artifacts: resources selection in African Early Iron Age iron making technologies. In: G. Bronitsky (ed.), Pottery Technology, Ideas and Approaches. Boulder: Westview Press, 139-164.

Childs, S. T., 1991. Iron as utility or expression: reforging function in Africa. In: R. M. Ehrenreich (ed.), Metals in Society: Theory Beyond Analysis. Pennsylvannia: MASCA, The University Museum, University of Pennsylvannia, 57-67.

Childs, S. T., 1994. Society, culture and technology in Africa: An introduction. In: S. T. Childs, (ed.), Society, Culture and Technology in Africa. Pennsylvania: MASCA Research Papers in Science and Archaeology. Supplement to Volume II, 7-14.

Childs, S. T. \& Dewey, W. J., 1996. Forging symbolic meaning in Zaire and Zimbabwe. In: P. R. Schmidt (ed.), The Culture and Technology of African Iron Production. Gainesville: University Press of Florida, 145-171.

Childs, S. T. \& Herbert, E. W., 2005. Metallurgy and its concequences. In: A. B. Stahl (ed.), African Archaeology: A Critical Introduction. Oxford: Blackwell Publishing, 276300 .

Childs, S. T. \& Killick, D., 1993. Indigenous African metallurgy: nature and culture. Annual Review of Anthropology 22, 317-337.

Chirikure, S., 2005. Iron production in Iron Age Zimbabwe: stagnation or innovation. Unpublished Ph.D. thesis, University College London, Institute of Archaeology.

Chirikure, S., 2006. New light on Njanja iron working: towards a systematic encounter between ethnohistory and archaeometallurgy. South African Archaeological Bulletin 61(184), 142-151.

Chirikure, S., 2007. Metals in society: iron production and its position in Iron Age communities of southern Africa. Journal of Social Archaeology 7(1), 72-100.

Chirikure, S., 2010. Indigenous Mining and Metallurgy in Africa. Cambridge: Cambridge University Press. 
Chirikure, S., Burrett, R. \& Heimann, R. B., 2009. Beyond furnaces and slags: a review study of bellows and their role in indigenous African metallurgical processes. Azania 44(2), 195-215.

Chirikure, S., Hall, S. \& Maggs, T., 2008. Metals beyond frontiers: a study of the production and distribution of metals in the Free State Grasslands. In: A. Esterhuysen, N. Swanepoel \& P. Bonner (eds.), Five Hundred Years Rediscovered: Southern African Precedents and Prospects. Johannesburg: Witswatersrand University Press, 88-102.

Chirikure, S., Hall, S. \& Miller, D., 2007. One hundred years on: what do we know about tin and bronze production in southern Africa?. In: S. La Niece, D. Hook \& P. Craddock (eds.), Metals and Mines: Studies in Archeometallurgy. London: Archetype Publications, 112-119.

Chirikure, S., Heimann, R. B. \& Killick, D., 2010. The technology of tin smelting in the Rooiberg Valley, Limpopo Province, South Africa ca. 1650-1850. Journal of Archaeological Science 37, 1656-1669.

Chirikure, S. \& Rehren, Th., 2004. Ores, furnaces, slags and prehistoric societies: aspects of iron working in the Nyanga agricultural complex, AD 1300-1900. African Archaeological Review 21(3), 135-152.

Chirikure, S. \& Rehren, Th., 2006. Iron smelting in pre-colonial Zimbabwe: evidence for diachronic change from Swart Village and Baranda, northern Zimbabwe. Journal of African Archaeology 4(1), 37-53.

Cleere, H., 1993. Archaeometallurgy comes of age. Antiquity 67(254), 175-178.

Cline, W., 1937. Mining and Metallurgy in Negro Africa. Menasha: George Banta Publishing Company.

Cooke, K., 1959. An iron smelting site in the Matopo Hills, Southern Rhodesia. South African Archaeological Bulletin 14(55), 118-120.

Cooke, S. R. B. \& Aschenbrenner, S., 1975. The occurence of metallic iron in ancient copper. Journal of Field Archaeology 2(3), 251-266.

Costin, C. L., 1991. Craft specialization: Issues in defining, documenting and expalining the organisation of production. Archaeological Method and Theory 3, 1-56.

Craddock, P. T., 1980. The composition of copper produced at the ancient smelting camps in the Wadi Timna, Israel. In: P. T. Craddock (ed.), Scientific Studies in Early Mining and Extractive Metallurgy. London: The British Museum Occasional Paper No. 20, 165-174. 
Craddock, P. T., 1985. Medieval copper alloy production and West African bronze analyses- Part I. Archaeometry 27(1), 17-41.

Craddock, P. T., 1995. Early Metal Mining and Production. Edinburgh: Edinburgh University Press.

Craddock, P. T., 2009. Evidences for the earliest smelting processes in western Europe, In: Archaeometallurgy in Europe: 2nd International Conference (24th-26th September 2003). Milano, Associazione Italian di Metalugia, 3-11.

Craddock, P. T., Ambers, J., Hook, D. R., Farquhar, R. M., Chikwendu, V. E. \& Umeji, D. C., 1997. Metal sources and the bronzes from Igbo-Ukwu, Nigeria. Journal of Field Archaeology 24(4), 405-429.

Craddock, P. T. \& Craddock, B. R., 1996. The beginings of metallurgy in south-west Britain: hypothesis and evidence. The Bulletin of the Peak District Mines Historical Society 13(2), 52-63.

Craddock, P. T., Freestone, I. C., Gurjar, L. K., Middleton, A. P. \& Willies, L., 1998. Zinc in India. In: P. T. Craddock (ed.), 2000 Years of Zinc and Brass. London: The British Museum Occasional Paper No. 50, 27-72.

Craddock, P. T. \& Meeks, N. D., 1987. Iron in ancient copper. Archaeometry 2(3), 187204.

Craddock, P. T. \& Picton, J., 1986. Medieval copper alloy production and West African Bronze analyses- Part II. Archaeometry 28(1), 3-32.

Crew, P., 1991. The iron and copper slags at Baratti, Populonia, Italy. Journal of Historical Metallurgy Society 25(2), 109-115.

Davenport, W. G., King, M., Schlesinger, M. \& Biswas, A. K., 2002. Extractive Metallurgy of Copper. 4th ed. Oxford: Elsevier Science Ltd.

David, D., Heimann, R., Killick, D. \& Wayman, M., 1989. Between bloomery and blast furnace: Mafa iron-smelting technology in North Cameroon. African Archaeological Review 7(1), 183-208.

David, N., 2001. Lost in the Third Hermeneutic? Theory and metholodogy objects and representations in the ethnoarchaeology of African Metallurgy. Mediterranean Archaeology 14, 49-72.

Davison, C. C., 1973. Chemical resemblance of garden roller and M1 glass beads. African Studies 32(4), 247-257. 
de Barros, P., 1988. Societal repercussions of the rise of traditional iron production: a West African example. African Archaeological Review 6(1), 91-115.

de Maret, P., 1999. The power of symbols and symbols of power through time: probing the Luba past. In: S. K. McIntosh (ed.), Beyond Chiefdoms: Pathways to Complexity in Africa. Cambridge: Cambridge University Press, 151-165.

Dobres, M.-A., 1995. Gender and prehistoric technology: on the social agency of technical studies. World Archaeology 27(1), 25-49.

Dobres, M.-A., 2000. Technology and Social Agency: Outlining Practice Framework for Archaeology. Oxford: Blackwell.

Doonan, R. C. P. \& Day, P. M., 2007. Mixed origins and the origins of mixing: Alloys and provenance in the Early Bronze Age Aegean. In: P. M. Day \& R. C. P. Doonan (eds.), Metallurgy in the Early Bronze Age Aegean (Sheffield Studies in Aegean Archaeology). Oxford: Oxbow Books, 1-18.

Dunnel, R., 1993. Why archaeologists don't care about archaeometry. Archaeomaterials 7(1), 161-165.

Edmonds, M., 1990. Description, understanding and the chaîne opératoire- technology and the humanities. Archaeological Review from Cambridge 9(1), 55-70.

Eglash, R., 2006. Technology as material culture. In: C. Tilley., W. Keane., S. Küchler., M. Rowlands \& P. Spyer (eds.), Handbook of Material Culture. London: SAGE Publications, 329-340.

Eglington, B. M. \& Armstrong, R. A., 2004. The Kaapvaal craton and adjacent oregens, southern Africa: a geochronological database and overview of the geological development of the craton. South African Journal of Geology 107(1-2), 13-32.

Ellert, H., 1984. The Material Culture of Zimbabwe. Harare: Longman Zimbabwe.

Eric, H., Stirling, P., Huffman, T. \& Grant, M. R., 1995. An SEM-EDX study of residues from Iron Age copper furnaces in Botswana. South African Journal of Science 91(6), 312-314.

Ericksson, S. C., 1984. Age of carbonatite and phoscorite magmatism of the Phalaborwa Complex (South Africa). Isotope Geoscience 2, 291-299.

Eriksson, S. C., 1985. Oscillatory zoning in clinopryoxenes from the Guide Copper Mine Phalaborwa, South Africa. American Mineralogist 70(1-2), 74-79. 
Espelund, A., 1997. An attempt to define archaeo-metallurgy. In: L. C. Nørbach (ed.), Early Iron Production: Archaeology, Technology and Experiments (Technical Report Number 3). Lejre: Historical-Archaeological Experimental Centre, 7-14.

Evers, T. M., 1974. Iron Age trade in the eastern Transvaal, South Africa. South African Archaeological Bulletin 29(113/114), 33-37.

Evers, T. M., 1975. Recent Iron Age research in the eastern Transvaal, South Africa. South African Archaeological Bulletin 30(119/120), 71-83.

Evers, T. M., 1981. The Iron Age in the eastern Transvaal, South Africa. In: E. A. Voigt (ed.), Guide to Archaeological Sites in the Northern and Eastern Transvaal. Pretoria: Transvaal Museum, 64-108.

Evers, T. M., 1982. Two Later Iron Age sites on Mabete, Hans Merensky Nature Reserve, Letaba District, N. E. Transvaal. South African Archaeological Bulletin 37(136), 63-67.

Evers, T. M. \& van der Berg, R. P., 1974. Ancient mining in southern Africa, with reference to a copper mine in the Harmony Block, North-Eastern Transvaal. Journal of the South African Institute of Mining and Metallurgy 74(6), 217-226.

Evers, T. M. \& van der Merwe, N. J., 1987. Iron Age ceramics from Phalaborwa north eastern Transvaal Lowveld, South Africa. South African Archaeological Bulletin 146(42), 87-106.

Fagan, B. M., Phillipson, D. W. \& Daniels, S. G. H., 1969. Iron Age Cultures in Zambia (Dambwa, Ingombe Illede and the Tonga). London: Chatto \& Windus.

Fenn, T. R., 2006. Ancient trans-Saharan commerce and the role of copper metallurgy. West African Research Association Newsletter 12-13.

Fenn, T. R., Miller, D. \& Killick, D., 2003. Partitioning of zinc between metallic, silicate and oxide phases in the smelting of oxidized copper-zinc ore: an archaeological example from the Lowveld, South Africa, In: Archaeometallurgy in Europe:2nd International Conference (24th-26th September 2003). Milan, Unpublished Paper.

Fouché, L., 1937. Mapungubwe: Ancient Bantu Civilization on the Limpopo, Reports on Excavations at Mapungubwe (Northern Transvaal) from February 1933 to June 1935. Cambridge: Cambridge University Press.

Fraser, S. W., van Rooyen, T. H. \& Verster, E., 1987. Soil-plant relationships in the central Kruger National Park. Koedoe 30(1), 19-34. 
Freestone, I. C., 1988. Melting points and viscosities of ancient slags: a contribution to the discussion. Journal of the Historical Metallurgy Society 22(1), 49-51.

Freestone, I. C., 1989. Refractory materials and their procurement. In: A. Hauptmann, E. Penicka \& G. A. Wagner (eds.), Old World Archaeometallurgy: Proceedings of the International Symposium 'Old World Archaeometallurgy', Heidelberg 1987, Der Anschnitt Beineft 7. Bochum: Deutschen Bergbau-Museums, 155-161.

Freestone, I. \& Tite, M. S., 1986. Refractories in the ancient and preindustrial world. In: W. D. Kingery \& E. Lense (eds.), High Technology Ceramics: Past, Present and Future. The Nature of Innovation and Change in Ceramic Technology. Westerville, OH: The American Ceramic Society, 35-63.

Frick, C., 1986. The Phalaborwa Syenite intrusions along the west-central boundary of the Kruger National Park. Koedoe 29(1), 45-48.

Friede, H. M., 1975. Notes on the composition of pre-European copper and copper alloy artefacts from the Transvaal. Journal of the South African Institute of Mining and Metallurgy 75(7), 185-191.

Friede, H. M., 1980. Iron Age mining in the Transvaal. Journal of the South African Institute of Mining and Metallurgy 80(4), 156-165.

Friede, H. M., Hejja, A. A. \& Koursaris, A., 1982. Archaeometallurgical studies of iron smelting slags from prehistoric sites in southern Africa. Journal of the South African Institute of Mining and Metallurgy 82(2), 38-48.

Friede, H. M. \& Steel, R., 1986. Traditional wooden drum bellows of south-western Africa. South African Archaeological Bulletin 41(143), 12-16.

Friede, H. M. \& Steel, R. H., 1975. Notes on Iron Age copper smelting technology in the Transvaal. Journal of the South African Institute of Mining and Metallurgy 76(4), 221231.

Friede, H. M. \& Steel, R. H., 1976. Tin mining and smelting in the Transvaal during the Iron Age. Journal of the South African Institute of Mining and Metallurgy 76(12), 461470.

Gardner, G. A., 1963. Mapungubwe Volume II: Report on Excavations at Mapungubwe and Bambandyanalo in Northern Transvaal from 1935 to 1940. Pretoria: J L van Schaik Limited. 
Garenne-Marot, L., Wayman, M. L. \& Pigott, V. C., 1994. Early copper and brass in Senegal. In: S. T. Childs (ed.), Society, Culture and Technology in Africa Phialadelphia: MASCA Papers in Science and Archaeology. Supplement to Volume II, 45-62.

Garlake, P. S., 1968. The value of imported ceramics in the dating and interpretation of the Rhodesian Iron Age. Journal of African History, 9(1), 13-33.

Garrison, E. G., 2003. Techniques in Archaeological Geology. Verlag Berlin Heidelberg: Springer.

Georgakopoulou, M., 2004. Examination of copper slags from the Early Bronze Age site of Daskaleio-Kavos on the island of Keros (Cyclades, Greece). Institute of ArchaeoMetallurgical Studies 24, 3-12.

Georgakopoulou, M., Bassiakos, Y. \& Philaniotou, O., 2011. Seriphos surfaces: a study of copper slag heaps and copper sources in the context of Early Bronze Age Aegean metal production. Archaeometry 53(1), 123-145.

Gertenbach, W. P. D., 1980. Rainfall patterns in the Kruger National Park. Koedoe 23(1), 35-43.

Goodway, M., 1991. Archaeometallurgy: evidence of a paradigm shift?. In: P. B. Vandiver, J. Druzik \& G. S. Wheeler (eds.), Material Issues in Art and Archaeology II. Pittsburgh: Materials Research Society, 705-712.

Goody, J., 1971. Technology, Tradition and the State in Africa. Oxford: Oxford University Press.

Gordon, R. B. \& van der Merwe, N. J., 1984. Metallographic study of iron artefacts from eastern Transvaal, South Africa. Archaeometry 26(1), 108-127.

Goucher, C., Teillhet, J. H., Wilson, K. R. \& Chow, T. J., 1976. Lead isotope studies in metal sources from ancient Nigerian 'bronzes'. Nature 262(5564), 130-131.

Grant, M. \& Huffman, T. N., 2007. The extractive metallurgy of copper at Iron Age Madikwe. South African Journal of Science 103(9-10), 403-408.

Grant, M. R., 1990. A radiocarbon date on a tin artefact from Rooiberg. South African Journal of Science 86(2), p. 63.

Grant, M. R., 1999. The sourcing of southern African tin artefacts. Journal of Archaeological Science 26(8), 1111-1117. 
Grant, M. R., Huffman, T. N. \& Watterson, J. I. W., 1994. The role of copper smelting in precolonial exploitation of the Rooiberg tin field. South African Journal of Science 90(2), 85-90.

Grébénart, D., 1987. Characteristics of the final Neolithic and Metal Ages in the region of Agadez (Niger). In: A. E. Close (ed.), Prehistory of Arid North Africa: Essays in Honour of Fred Wendorf. Dallas: Southern Methodist University Press, 287-316.

Greenfield, H. \& Miller, D., 2004. Spatial patterning of Early Iron Age metal production at Ndondondwane, South Africa: The question of cultural continuity between the Early and Late Iron Ages. Journal of Archaeological Science 31(11), 1511-1533.

Grigorova, B., Smith, W., Stülpner, K., Tumilty, J A. \& Miller, D., 1998. Fingerprinting of gold artefacts from Mapungubwe, Bosutswe and Thulamela. Gold Bulletin 31(3), 99-102.

Groves, D. I. \& Vielreicher, M. N., 2001. The Palaborwa (Palabora) carbonatite-hosted magnetite-copper-sulphide deposit, South Africa: an end member of iron-oxide coppergold-rare earth element deposit group?. Mineral Deposita 36(2), 189-194.

Haaland, G., Haaland, R. \& Dea, D., 2004. Furnace and pot: why the iron smelter is a big pot maker, a case study from south-western Ethiopia. Azania 39, 146-165.

Haaland, R., 2004. Iron smelting- a vanishing tradition: ethnographic study of this craft in south-west Ethiopia. Journal of African Archaeology 2(1), 65-79.

Haddon, A. C., 1908. Copper rod currency from Transvaal. Man 8(65), 121-122.

Hall, A. L., 1912. The Geology of the Murchison Range and District (Geology Survey Memoir 6). Pretoria: Union of South Africa, Mines Department.

Hall, M., 1987. Archaeology and modes of production in pre-colonial southern Africa. Journal of Southern African Studies 14(1), 1-17.

Hall, S., Miller, D., Anderson, M. \& Boeyens, J., 2006. An exploratory study of copper and iron production at Marathodi, an early 19th century Tswana Town, Rustenburg District, South Africa. Journal of African Archaeology 4(1), 3-35.

Hammel, A., White, C., Pfeiffer, S. \& Miller, D., 2000. Pre-colonial mining in southern Africa. Journal of the South African Institute of Mining and Metallurgy 100(1), 49-56.

Hanisch, E. O. M., 1974. Copper working in the Messina district. Journal of South African Institute of Mining and Metallurgy 74(6), 250-253. 
Hauptmann, A., 2007. The Archaeometallurgy of Copper: Evidence from Faynan, Jordan. New York: Springer.

Heimann, R. B., Chirikure, S. \& Killick, D., 2010. Mineralogical study of precolonial (1650-1850 CE) tin smelting slags from Rooiberg, Limpopo Province, South Africa. European Journal of Mineralogy 22(5), 751-761.

Heirich, E. W., 1970. The Palabora carbonititic complex: a unique copper deposit. Canadian Mineralogist 10(3), 585-598.

Hemsworth, H. D., 1908. Note on marali currency. Man 8(66), p. 122.

Herbert, E. W., 1973. Aspects of the use of copper in pre-colonial west Africa. Journal of African History 24(2), 179-194.

Herbert, E. W., 1984. Red Gold of Africa: Copper in Precolonial History and Culture. Madison: University of Wisconsin Press.

Herbert, E. W., 1996. Metals and power at Great Zimbabwe. In: G. Pwiti \& R. C. Soper (eds.), Aspects of African Archaeology: Papers from the 10th Congress of the Pan African Association for Prehistory and Related Studies. Harare: University of Zimbabwe Publications, 641-647.

Herbert, E. W., 2001. African metallurgy: the historian's dilemma. Meditarch 14, 41-48.

Hoffman, M. T., 1997. Human impacts on vegitation. In: R. M. Cowling, D. M. Richardson \& S. M. Pierce (eds.), Vegetation of Southern Africa. Cambridge: Cambridge University Press, 507-534.

Holl, A. F. C., 2009. Early West African metallurgies: new data and old orthodoxy. Journal of World Prehistory 22(4), 415-438.

Huffman, T. N., 1972. The rise and fall of Great Zimbabwe. Journal of African History 13(3), 353-366.

Huffman, T. N., 1986a. Archaeological evidence and conventional explanations of southern Bantu settlement patterns. Journal of the International African Institute 56(3), 280-298.

Huffman, T. N., 1986b. Iron Age settlement patterns and the origins of class distinction in southern Africa. Advances in World Archaeology 5, 291-338.

Huffman, T. N., 1998. The antiquity of lobola. South African Archaeological Bulletin 53(168), 57-62. 
Huffman, T. N., 2000. Mapungubwe and the origins of the zimbabwe culture. Goodwin Series 8, 14-29.

Huffman, T. N., 2005. Mapungubwe: Ancient Civilization on the Limpopo. Johannesburg: Witwatersrand University Press.

Huffman, T. N., 2007. Handbook to the Iron Age: The Archaeology of Pre-Colonial Farming Societies in Southern Africa. Pietermaritzburg: University of KwaZulu-Natal Press.

Huffman, T. N., 2009. Mapungubwe and Great Zimbabwe: The origins and spread of social complexity in southern Africa. Journal of Anthropological Archaeology 28(1), $37-54$.

Huffman, T. N. \& Herbert, R. K., 1994-1995. New perspectives on the eastern Bantu. Azania, 29-30(1), 27-36.

Huffman, T. N., van der Merwe, H. D., Grant, M. R. \& Kruger, G. S., 1995. Early copper mining at Thakadu, Botswana. Journal of the South African Institute of Mining and Metallurgy 95(2), 53-61.

Humphris, J. E., 2010. An archaeometallurgical investigation of iron smelting traditions in southern Rwanda. Unpublished Ph.D. thesis, University College London, Institute of Archaeology.

Humphris, J., Martinon-Torres, M., Rehren, Th. \& Reid, A., 2009. Variability in single smelting episodes-pilot study using iron slag from Uganda. Journal of Archaeological Science 36(2), 359-369.

Ige, A. \& Rehren, Th., 2003. Black sand and iron stone: iron smelting in Modakeke, Ife, south western Nigeria. Institute of Archaeo-Metallurgical Studies 23, 15-20.

Iles, L. \& Martinon-Torres, M., 2009. Pastoralist iron production on the Laikipia Plateau, Kenya: wider implications for archaeometallurgical studies. Journal of Archaeological Science 36(10), 2314-2326.

Ineson, P. R., 1989. Introduction to Practical Ore Microscopy. Essex: Longman Group UK Limited.

Ingold, T., 1990. Society, nature and concept of technology- technology and the humanities. Archaeological Review from Cambridge 9(1), 5-17. 
Ingold, T., 2001. Beyond art and technology: the anthropology of skill. In: M. B. Schiffer (ed.), Anthropological Perspectives on Technology. Alburquerque: University of New Mexico Press, 17-32.

Joel, E. C., Sayre, E. V., Vocke, R. D. \& Willett, F., 1995. Stable lead isotope characterization of various copper alloys used in West Africa: an interim report. Historical Metallurgy 29(1), 25-33.

Jones, A., 2004. Archaeometry and materiality: materials-based analysis in theory and practice. Archaeometry 46(3), 327-338.

Joosten, I., 2004. Technology of Early Historical Iron Production in the Netherlands (Geoarchaeological and Biological Studies Volume 2). Amsterdam: Institute for Geo-\& Bioarchaeology, Vrije Universiteit.

Kaiura, G. H. \& Tohuri, J. M., 1979. Natural convective mass transfer rates between solid magnetite and molten mattes. Metallurgical Transactions 10B, 595-606.

Killick, D., 1977. An attempt to trace the movement of the ores in the Transvaal Lowveld by XRF analysis of slags. Unpublished BA (Hons) thesis, University of Cape Town.

Killick, D., 1987. On the dating of African metallurgical sites. Nyame Akuma 28, 29-30.

Killick, D., 1991a. A tin lerale from Soutpansberg, northern Transvaal, South Africa. South African Archaeological Bulletin 46(154), 137-141.

Killick, D., 1991b. The relevance of recent African iron-smelting practice to reconstructions of prehistoric smelting technology. In: P. D. Glumac (ed.), Recent Trends in Archaeometallurgical Research. Philadelphia: MASCA, The University Museum, University of Pennsylvannia, Research Papers in Science and Anthropology 8(1), 47-54.

Killick, D., 2004a. Social constructionist approaches to the study of technology. World Archaeology 36(4), 571-578.

Killick, D., 2004b. What do we know about African iron working?. Journal of African Archaeology 2(1), 97-112.

Killick, D., 2009a. Agency, dependency and long distance trade: East Africa and the Islamic world 700-1500CE. In: S. E. Falconer \& C. L. Redman (eds.), Polities and Power: Archaeological Perspectives on the Landscapes of Early States. Tucson: University of Arizona Press, 179-207. 
Killick, D., 2009b. Cairo to Cape: the spread of metallurgy through eastern and southern Africa. Journal of World Prehistory 22(4), 399-414.

Killick, D., 2010. Use of magnetite ore in bloomery iron smelting: kinetic and chemical considerations (Poster Presented at the 38th International Symposium on Archaeometry, May 10-14, 2010). Tampa, University of Florida Tampa, p. 125.

Killick, D. \& Fenn, T., 2012. Archaeometallurgy: The study of preindustrial mining and metallurgy. Annual Review of Anthropology 41, 559-575.

Killick, D. \& Miller, D., in press. Late Iron Age metallurgical technology at Phalaborwa (Northern Lowveld, South Africa). Journal of Archaeological Science.

Killick, D., van der Merwe, N. J., Gordon, R. B. \& Grébénart, D., 1988. Reassessment of the evidence for early metallurgy in Niger, West Africa. Journal of Archaeological Science 15(4), 367-394.

Killick, D. \& Young, S. M. M., 1997. Archaeology and archaeometry: from casual dating to meaningful relationship?. Antiquity 71(273), 518-524.

Kiriama, H. O., 1987. Archaeo-metallurgy of iron smelting slags from Mwitu Tradition site in Kenya. South African Archaeological Bulletin 42(146), 125-130.

Klapwijk, M., 1974. An analysis of Bantu-made iron implements from the Letaba District. Journal of the South African Institute of Mining and Metallurgy 74(6), 265-268.

Klapwijk, M., 1986a. A Late Iron Age furnace excavation on the farm Longridge, Agatha, north-eastern Transvaal, South Africa. South African Archaeological Bulletin 41(143), 22-26.

Klapwijk, M., 1986b. Some notes on the tuyères from smelting sites in the north-eastern Transvaal, South Africa. The South African Archaeological Bulletin 41(143), 17-21.

Knapp, A. B., 2000. Archaeology, science-based archaeology and the Mediterranean Bronze Age metals trade. European Journal of Archaeology 3(1), 31-56.

Kowalski, M., Spences, P. J. \& Neuschutz, D., 1995. Phase diagrams. In: Eisenhuttenleute Verein Deutshcher (ed.), Slag Atlas. Second Edition. Dussteldoff: Verlag Stahleisen GmbH, 21-214.

Kresten, P., 1986. Melting points and viscosities of ancient slags: a discussion. Journal of the Historical Metallurgy Society 20(1), 43-45. 
Kriege, E. J., 1937. Notes on the Phalaborwa and their Morula complex. Bantu Studies 11(1), 357-366.

Kriege, E. J., 1938. The place of the north-eastern Transvaal Sotho in the South Bantu Complex. Journal of the International African Institute 21(3), 265-293.

Kriege, J. D., 1937. Traditional origins and tribal relations of the Sotho of the Northern Transvaal. Bantu Studies 11(1), 321-356.

Krige, E. J., 1938. The place of North-Eastern Transvaal Sotho in the Bantu Complex. Journal of the International African Institute 11(3), 265-293.

Kruger, A. C., Makamo, L. B. \& Shongwe, S., 2001. An analysis of Skukuza climate data. Koedoe 45(1), 1-7.

Küchler, S., 2006. Processes and transformations. In: C. Tilley, W. Keane., S. Küchler., M. Rowlands \& P. Spyer (eds.), Handbook of Material Culture. London: SAGE Publications, 325-328.

Kuhn, S. L., 2004. Evolutionary perspectives on technology and technological change. World Archaeology 36(4), 561-570.

Kuper, A., 1982. Wives for Cattle: Bridewealth and Marriage in Southern Africa. London: Routledge \& Kegan Paul.

Kuschke, O. H. \& Tonking, M. J., 1971. Geology and mining operations at Palabora Mining Company Limited, Phalaborwa, N-E Transvaal. Journal of the South African Institute of Mining and Metallurgy 71(1), 12-22.

Küsel, M. M., 1992. A preliminary report on settlement layout and gold melting at Thula Mela, a Late Iron Age site in the Kruger National Park. Koedoe 35(1), 55-64.

Küsel, U. S., 1974a. Extractive metallurgy in Iron Age South Africa. Journal of the South African Institute of Mining and Metallurgy 74(6), 246-249.

Küsel, U. S., 1974b. Primitive Iron Smelting in the Transvaal. Pretoria: Studies by the National Cultural History and Open-Air Museum No. 3.

Kusimba, C. M., Killick, D. J. \& Cresswell, R. G., 1994. Indigenous and imported metals at Swahili sites on the coast. In: S. T. Childs (ed.), Society, Culture and Technology in Africa Philadelphia, P A: MASCA Supplement to Volume II, 63-78. 
Lane, P., Reid, A. \& Segobye, A., 1998. Introduction. In: P. Lane, A. Reid \& A. Segobye (eds.), Ditswa Mmung the Archaeology of Botswana. Gaborone: Pula Press and the Botswana Society, 13-23.

Lemonnier, P., 1986. The study of material culture today: toward an anthropology of technical systems. Journal of Anthropological Archaeology 5(2), 147-186.

Lexa, D., 1999. Preparation and characteristics of a lithium beryllium-substituted fluorapatite. Metallurgical and Materials Transaction 30A(1), 147-153.

Lindblom, G., 1926. Copper rod "currency" from Palabora, N. Transvaal. Man 26(90), 144-147.

Loubser, J. H. N., 1989. Archaeology and early Venda history. Goodwin Series 6, 54-61.

Maddin, R., 1988. Technical studies-early use of metals. In: E. V. Sayre, P. Vandiver, J. Druzik \& C. Steveson (eds.), Materials Issues in Art and Archaeology: Materials Research Society Symposium Proceedings. Pittsburg PA: Materials Research Society, 171-181.

Maggs, T. \& Miller, D., 1995. Sandstone crucibles from Mhlopeni, KwaZulu-Natal: evidence of precolonial brassworking. Natal Museum Journal of Humanities 7, 1-16.

Maggs, T. \& Whitelaw, G., 1991. A review of recent archaeological research on foodproducing communities in southern Africa. The Journal of African History 32(1), 3-24.

Makhado, R. A., Potgieter, M. J. \& Wessels, D. C. J., 2009. Colophospermum mopane wood utilisation in the northeast of the Limpopo Province, South Africa. Ethnobotanical Leaflets 13, 921-945.

Mamadi, M., 1940. The copper miners of Musina. In: N. J. van Warmelo (ed.), The Copper Miners of Musina and the Early History of the Zoutpansberg. Pretoria: South African Ethnological Publications, 81-87.

Manyanga, M., 2006. Resilient Landscapes: Socio-Enviromental Dynamics in the Shashe-Limpopo Basin, Southern Zimbabwe c. AD 800 to the Present. Uppsala: Department of Archaeology and Ancient History.

Mapunda, B., 2010. Contemplating the Fipa Ironworking. Kampala: Fountain Publishers.

Mapunda, B., 2002. Iron metallurgy along the Tanzania coast. In: F. Chami \& G. Pwiti (eds.), Southern Africa and the Swahili World. Dar es Salaam: Dar es Salaam University Press Ltd, 76-88. 
Martinón-Torres, M., 2002. Chaîne opératoire: the concept and it applications within the study of technology. Gallaecia 21, 29-43.

Martinón-Torres, M., 2008. Why should archaeologists take history and science seriously?. In: M. Martinón-Torres \& Th. Rehren (eds.), Archaeology, History and Science. Walnut Creek, L A: Left Coast Press, 15-36.

Martinón-Torres, M. \& Rehren, Th., 2002. Agricola and Zwickau: theory and practice of Renaissance brass production in SE Germany. Historical Metallurgy 36(2), 95-111.

Martinón-Torres, M. \& Rehren, Th., 2009. Post-medieval crucible production and distribution: a study of materials and materialities. Archaeometry 51(1), 49-74.

Marx, L., 2010. Technology: The emergence of a hazardous concept. Technology and Culture 51(3), 561-577.

Mason, R. J., 1965. The origin of South African society. South African Journal of Science 61(7), 255-267.

Mason, R. J., 1982. Prehistoric mining in South Africa and Iron Age copper mines in the Dwarsberg, Transvaal. Journal of the South African Institute of Mining and Metallurgy 82(5), 134-144.

Mason, R. J., 1986. Origins of Black People of Johannesburg and the Southern Western Central Transvaal AD 350-1880. Johannesburg: University of the Witwatersrand Archaeological Research Unit Occasional Paper No. 16.

Mason, R. J., Brown, A. J. V., Fatti, L. P. \& Beardall, G., 1983. Cluster and correspondance analysis of Iron Age faunal assemblages, circa AD 350-510 and AD 1550-1850 from Southern, Western and Eastern Transvaal. South African Journal of Science 79, 182-203.

Mei, J. \& Rehren, Th., 2005. Copper smelting from Xinjiang, NW China. Part I: Kangcun village, Kuche county, c 18th century AD. Historical Metallurgy 39(2), 96105.

Merkel, J. F., 1990. Experimental reconstruction of Bronze Age copper smelting based on archaeological evidence from Timna. In: B. Rothenberg (ed.), The Ancient Metallurgy of Copper: Archaeology-Experiment-Theory. London: Institute for ArchaeoMetallurgical Studies, 78-122.

Miller, D., 1992. Iron Age metal working at Tsodilo Hills north-western Botswana. Unpublished Ph.D. thesis, University of Cape Town. 
Miller, D., 1994. Kaonde copper smelting: technical versatility and the ethnographic record. In: S. T. Childs (ed.), Society, Culture and Technology in Africa. Philadelphia, PA: MASCA Research Papers in Science and Archaeology. Supplement to Volume II, 79-85.

Miller, D., 1995. 2000 years of indigenous mining and metallurgy in southern Africa- a review. South African Journal of Geology 98(2), 232-238.

Miller, D., 1996. The Tsodilo Jewellery: Metal Work from Northern Botswana. Cape Town: UCT Press (Pty).

Miller, D., 2001a. Metal assemblages from Greesfwald area K2, Mapungubwe Hill and Mapungubwe south terrace. South African Archaeological Bulletin 56(173/174), 83-103.

Miller, D., 2001b. Indigenous iron production in southern Africa: archaeological observations and interpretation. Meditarch 14, 229-234.

Miller, D., 2002. Smelter and smith: Iron Age metal fabrication technology in southern Africa. Journal of Archaeological Science 29(10), 1083-1131.

Miller, D., 2003. Indigenous copper mining and smelting in pre-colonial southern Africa. In: P. T. Craddock \& J. Lang (eds.), Mining and Metal Production Through the Ages. London: The British Museum Press, 101-110.

Miller, D., 2010. Indigenous metal melting and casting in southern Africa. South African Archaeological Bulletin 65(191), 45-57.

Miller, D., Boeyens, J. \& Kusel, M., 1995. Metallurgical analyses of slags, ores, and metal artefacts from archaeological sites in the North-West Province and northern Transvaal. The South African Archaeological Bulletin 50(161), 39-54.

Miller, D. \& Hall, S., 2008. Rooiberg revisited- the analysis of tin and copper smelting debris. Historical Metallurgy 42(1), 23-38.

Miller, D. \& Killick, D., 2004. Slag identification at southern African archaeological sites. Journal of African Archaeology 2(1), 23-47.

Miller, D., Killick, D. \& van der Merwe, N. J., 2001. Metal working in the northern Lowveld, South Africa, A.D. 1000-1890. Journal of Field Archaeology 28(3/4), 401417.

Miller, D., Mulaudzi, M. \& Killick, D., 2002. An historical account of iron smelting in the Lowveld, South Africa. Historical Metallurgy 36(2), 112-121. 
Miller, D. \& Sandelowsky, B., 1999. Smelting without ceramics: the Drierivier copper smelting site near Rehoboth, Namibia. The South African Archaeological Bulletin 54(169), 28-37.

Miller, D. \& van der Merwe, N. J., 1994a. Early metal working in sub-Saharan Africa: a review of recent research. Journal of African History 35(1), 1-36.

Miller, D. \& van der Merwe, N. J., 1994b. Early Iron Age metal working at the Tsodilo Hills, northwestern Botswana. Journal of Archaeological Science 21(1), 101-115.

Miller, H. M.-L., 2007. Archaeological Approaches to Technology. London: Elsevier/ Academic Press.

Mitchell, P., 2002. The Archaeology of Southern Africa. Cambridge: Cambridge University Press.

Mitchell, P., 2005. African Connections: Archaeological Perspectives on Africa and the Wider World. Walnut Creek: AltaMira Press.

Moens, L., Bohlen, A. V. \& Vandenabeele, P., 2000. X-Ray Florescence. In: E. Ciliberto \& G. Spoto (eds.), Modern analytical methods in Art and Archaeology. New York: John Willey \& Sons, Inc., 55-63.

Molofsky, L. J., 2009. A novel approach to lead isotope provenance studies of tin and bronze, Tucson: Prepublication Manuscript Submitted to the Department of Geosciences, The University of Arizona.

Molyneux, T. G. \& Reinecke, T., 1983. Ancient ruins and mines of the Tati region of north-east Botswana. South African Archaeological Bulletin 38(138), p. 99.

More, C. E., 1974. Some observations on 'ancient' mining at Phalaborwa. Journal of the South African Institute of Mining and Metallurgy 74(6), 227-232.

Morton, G. R. \& Wingrove, J., 1969. Constitution of bloomery slags. Part I: Roman. Journal of the Iron and Steel Institute 207, 1556-1564.

Morton, G. R. \& Wingrove, J., 1972. Constitution of bloomery slags. Part II: Medieval. Journal of the Iron and Steel Institute 210, 478-488.

Muller, R., Rehren, Th. \& Rovira, S., 2004. Almizaraque and the early copper metallurgy of southeast Spain: new data. Madrider Mutteilungen 45, 33-56.

Ndoro, W., 1991. Why decorate her? Zimbabwea 3(1), 60-65. 
Nesse, W. D., 2004. Introduction to Optical Mineralogy. Oxford: Oxford University Press.

Nixon, S., Rehren, Th. \& Filomena Guerra, M., 2011. New light on early Islamic West Africa gold trade: coin moulds from Tadmekka, Mali. Antiquity 85(330), 1353-1368.

Oddy, A., 1984. Gold in the southern African Iron Age: a technological investigation of Mapungubwe and other finds. Gold Bulletin 17(2), 70-78.

Oddy, A., 1991. Gold foil, strip and wire in the Iron Age of southern Africa. In: D. A. Scott, J. Podany \& B. B. Considine (eds.), Ancient and Historic Metals Conservation and Scientific Research. Los Angeles: The Getty Conservation Institute, 183-196.

Orton, C., 2000. Sampling in Archaeology. Cambridge: Cambridge University Press.

Ottaway, B. S., 2001. Innovation, production and specialization in early prehistoric copper metallurgy. European Journal of Archaeology 4(1), 87-112.

Palabora Heritage Committee, n.d. http://www.palabora.com/pmc_cultural_heritage/index.asp. [Online] Available at: http://www.palabora.com/pmc_cultural_heritage/index.asp

[Accessed 15 August 2008].

Palabora Mining Company Limited Mine Geological and Mineralogical Staff, 1976. The geology and economic deposits of copper, iron and vermiculite in the Palabora Igneous Complex: A brief review. Economic Geology 71, 177-192.

Pernicka, E., 2004. Archaeometallurgy: Examples of the application of scientific methods to provenance of archaeological metal objects. In: M. Martini, M. Milazoo \& M. Placentini (eds.), Physics Methods in Archaeometry: Proceedings of the International School of Physics 'Enrico Fermi' Villa Monastero, 17-27 June 2003 (International School of Physics Enrico Fermi). Amsterdam: IOS Press, 309-329.

Pfaffenberger, B., 1988. Fetishised objects and humanised nature: towards an anthropology of technology. Man 23(2), 236-252.

Pfaffenberger, B., 1992. Social anthropology of technology. Annual Review of Anthropology 21, 491-516.

Pikirayi, I., 2001. The Zimbabwe Culture: Origins and Decline of Southern Zambezian States. New York: Altamira Press.

Pistorius, J. C. C., 1989. Die metaalbewerkers van Phalaborwa. Unpublished Ph.D. thesis, University of Pretoria. 
Plug, I., 1989. Notes on distribution and relative abundances of some species and on climate in the Kruger National Park during prehistoric times. Koedoe 32(1), 101-120.

Plug, I. \& Pistorius, J. C. C., 1999. Animal remains from the industrial Iron Age communities in Phalaborwa, South Africa. African Archaeological Review 16(3), 155184.

Plug, I. \& Skelton, P., 1991. Fish and other faunal remains from a Late Iron Age site on the Letaba River, Kruger National Park. Koedoe 34(1), 1-6.

Pollard, A. M., Batt, C. M., Stern, B. \& Young, S. M. M., 2007. Analytical Chemistry in Archaeology. Cambridge: Cambridge University Press.

Pollard, A. M. \& Bray, P., 2007. A bicycle made for two? The intergration of scientific techniques into archaeological interpretation. Annual Review of Anthropology 36, $245-$ 259.

Pollard, A. M. \& Heron, C., 2008. Archaeological Chemistry. Cambridge: The Royal Society of Chemistry.

Ponting, M., 2004. The scanning electron microscope and the archaeologist. Physics Education 39(2), 166-170.

Prendergast, M. D., 1979. Cornucopia: phase 1 zimbabwe stone buildings associated with an Iron Age tin mine?. Rhodesian Prehistory 19, 1-13.

Pringle, H., 2009. Seeking Africa's first iron men. Science 232(5911), 200-202.

Prior, J. \& Culter, D., 1992. Trees to fuel Africa's fire: trees are a vital source of firewood in rural Africa but the wrong ones turn savannas into desert. New Scientiest $1836,35-39$.

Pryce, T. O., 2008. Prehistoric copper production and technological reproduction in the Khao Wong Pranchan Valley of Central Thailand. Unpublished Ph.D. thesis, University College London, Institute of Archaeology.

Pryce, T. O. \& Natapintu, S., 2010. Smelting iron from laterite: technical possibility or ethnographic aberration?. Asian Perspectives 48(2), 249-264.

Pryce, T. O., Pigott, V. C., Martinon-Torres, M. \& Rehren, Th., 2010. Prehistoric copper production and technological reproduction in the Khao Wong Prachan Valley. Archaeological and Anthropological Sciences 2(4), 237-264. 
Pwiti, G., 1996. Continuity and Change: An Archeological Study of Farming Communities in Northern Zimbabwe AD 500-1700 (Studies in African Archaeology 13). Uppsala: Societas Archaeologica Upsaliensis.

Radivojević, M., Rehren, Th., Pernicka, E., Šljivar, D., Brauns, M. \& Borić, D., 2010. On the origins of extractive metallurgy: new evidence from Europe. Journal of Archaeological Science 37(11), 2775-2787.

Rapp, G., 2002. Archaeomineralogy. Verlag Berlin Heidelberg: Springer.

Redman, C. L., 1987. Surface collection, sampling and research design: a retrospective. American Antiquity 52(2), 249-265.

Reed, S. J. B., 1996. Electron Microprobe Analysis and Scanning Electron Microscopy in Geology. Cambridge: Cambridge University Press.

Rehren, Th., 1999. Small size, large scale Roman brass production in Germania Inferior. Journal of Archaeological Science 26(8), 1083-1087.

Rehren, Th., 2000. Archaeometallurgy-an island?. Antiquity 74(286), 964-967.

Rehren, Th., 2003. Crucibles as reaction vessels in ancient metallurgy. In: P. T. Craddock \& J. Lang (eds.), Mining and Metal Production Through the Ages. London: The British Museum Press, 2007-215.

Rehren, Th., 2009. From mine to microbe-the Neolithic copper melting crucibles from Switzerland. In: A. J. Shortland, I. Freestone \& Th. Rehren (eds.), From Mine to Microscope: Advances in the Study of Ancient Technology. Oxford: Oxbow, 155-162.

Rehren, Th., Charlton, M., Chirikure, S., Humphris, J., Ige, A. \& Veldhuijzen, H. A., 2007. Decisions set in slag: the human factor in Africa iron smelting. In: S. La Niece, D. R. Hook \& P. T. Craddock (eds.), Metals and Mines: Studies in Archaeometallurgy. London: British Museum Press, 211-218.

Rehren, Th. \& Pernicka, E., 2008. Coins, artefacts and isotopes- archaeometallurgy and archaeometry. Archaeometry 50(2), 232-248.

Reid, A. \& MacLean, R., 1995. Symbolism and the social contexts of iron production in Karagwe. World Archaeology 27(1), 144-161.

Renfrew, C. \& Bahn, P., 2004. Archaeology, Theory, Methods and Practice. 4th ed. London: Thames \& Hudson. 
Revenko, A. G., 2009. Estimation and account for matrix effects in studying glass materials of cultural heritage by x-ray spectral analysis. X-Ray Spectrometry 39(1), 6369.

Rightmire, G. P. \& van der Merwe, N. J., 1976. Two burials from Phalaborwa and the association of race and culture in the Iron Age of southern Africa. The South African Archaeological Bulletin 31(123/124), 147-152.

Rostoker, W., Pigott, V. C. \& Dvorak, J. R., 1989. Direct reduction to copper metal by oxide-sulfide mineral interaction. Archeomaterials 3(1), 69-87.

Roux, E. H., de Jager, D. H., du Plooy, J. H., Nicotra, A., van der Linde, G. J. \& de Waal, P., 1989. Phosphates in South Africa. Journal of the South African Institute of Mining and Metallurgy 89(5), 129-139.

Roux, V., 2003. Ceramic standardization and intensity of production: quantifying degrees of specialisation. American Antiquity 68(4), 768-782.

Rowlands, M. J., 1971. The archaeological interpretation of prehistoric metalworking. World Archaeology 3(2), 210-224.

Russell, H. D., Hiemstra, S. A. \& Groeneveld, D., 1954. The mineralogy and petrology of the carbonatite at Loolekop, Eastern Transvaal. Transactions of the Geological Society of South Africa 57, 197-208.

Salomon, J.-J., 1984. What is technology? the issue of its origins and definitions. History and Technology 1(2), 113-156.

Sandelowsky, B. \& Miller, D., 1999. Smelting without ceramics: the Drierivier copper smelting site near Rehoboth, Namibia. South African Archaeological Bulletin 54(169), 28-37.

Schatzberg, E., 2006. Technik comes to America: changing meanings of technology before 1930. Technology and Culture 47(3), 486-512.

Schiffer, M. B., 1986. Radiocarbon dating and the 'wood' problem: the case of the Hohokam chronology. Journal of Archaeological Science 13(1), 13-30.

Schiffer, M. B., 2002. Studying technological differentiation: the case of 18th- century electrical technology. American Anthrologist 104(4), 1148-1161.

Schiffer, M. B., Sullivan, A. P. \& Klinger, T. C., 1978. The design of archaeological surveys. World Archaeology 10(1), 1-28. 
Schlüter, T. \& Trauth, M. H., 2006. Geological Atlas of Africa. Verlag Berlin Heidelberg: Springer.

Schryver, J., 1970. A Preliminary Descripition and Typology of Pottery of Kgopolwe Hill of Palabora Area, Northern Transvaal, New York: Unpublished MA Dissertation, State University of New York at Binghamton.

Schwellnus, C. M., 1937. Short notes on the Palabora smelting ovens. South African Journal of Science 33, 904-912.

Scott, D. A., 1991. Metallography and Microstructure of Ancient and Historic Metals. Los Angeles: The J Paul Getty Conservation Institute in association with Archetype Books.

Scully, R. T. K., 1979. The lists of Phalaborwa Rulers: A comparison of varient 'fixed' sources. History in Africa 6, 209-224.

Severin, T., Rehren, Th. \& Schleicher, H., 2011. Early metal smelting in Aksum, Ethiopia: copper or iron?. European Journal of Mineralogy 23(6), 981-992.

Shand, S. J., 1931. The granite-syenite-limestone complex of Palabora, Eastern Transvaal and the associated apatite deposits. Transactions of the Geological Society of South Africa 31, 81-105.

Shaw, T., 1969. Further spectrographic analyses of Nigerian bronzes. Archaeometry 11(1), 85-93.

Shennan, S., 1999. Cost, benefit and value in the organisation of early European copper production. Antiquity 73(280), 352-363.

Shennan, S. J., 1998. Producing copper in the eastern Alps during the second millenium BC. In: A. B. Knapp, V. C. Pigott \& E. W. Herbert (eds.), Social Approaches to An Industrial Past: The Archaeology and Anthropology of Mining. London: Routledge, 191-204.

Shepherd, N., 2003. State of the discipline: science, culture and identity in South African Archaeology 1870-2003. Journal of Southern African Studies 29(4), 823-844.

Sigaut, F., 1994. Technology. In: T. Ingold (ed.), Companion Encyclopedia of Anthropology: Humanity, Culture and Social Life. London: Routledge, 420-459.

Sillar, B. \& Tite, M. S., 2000. The challenge of 'technological choices' for material science approaches in archaeology. Archaeometry 42(1), 2-20. 
Stanley, G. H., 1929a. The composition of some prehistoric South African bronzes with notes on the methods of analysis. South African Journal of Science 26, 44-49.

Stanley, G. H., 1929b. Primitive metallurgy in South Africa: some products and their significance. South African Journal of Science 26, 732-748.

Stayt, H., 1968. The BaVenda. London: Oxford University Press.

Stevenson-Hamilton, J., 1974. South Africa Eden: From Sabi Game Reserve to Kruger National Park. London: William Collins Sons \& Co Ltd.

Steyn, M., Miller, S., Nienaber, W. C. \& Loots, M., 1998. Late Iron Age gold burials from Thulamela (Pafuri Region, Kruger National Park). South African Archaeological Bulletin 53(168), 73-85.

Steyn, M. \& Nienaber, W. C., 2000. Iron Age human skeletal remains from the Limpopo Valley and Soutpansberg. South African Archaeological Society Goodwin Series 8, $112-$ 116.

Stuiver, M. \& van der Merwe, N. J., 1968. Radiocarbon chronology of the Iron Age in sub-Saharan Africa. Current Anthropology 9(1), 54-58.

Summers, R., 1969. Ancient Mining in Rhodesia and Adjacent Areas. Salisbury: The Trustees of the National Museums of Rhodesia. Museum Memoria No. 3.

Sutton, J. E. G., 1983. West African metals and the ancient Mediterranean. Oxford Journal of Archaeology 2(2), 181-188.

Sutton, J. E. G., 1999. African metal and the wider world before 1500 AD. (Unpublished Papers from World Archaeological Congress 4, 10th-14th January), University of Cape Town.

Swan, L., 1994. Early Gold Mining on the Zimbabwean Plateau. Uppsala: Societas Archaeologica Upsaliensis.

Swan, L., 2002. Excavations at Copper Queen Mine, northwestern Zimbabwe. South African Archaeological Bulletin 57(176), 64-79.

Swan, L., 2007. Economic and ideological roles of copper ingots in prehistoric Zimbabwe. Antiquity 81(314), 999-1012.

Thondhlana, T. P. \& Martinón-Torres, M., 2009. Small size, high value: composition and manufacture of second millenium AD copper-based beads from northern Zimbabwe. Journal of African Archaeology 7(1), 79-97. 
Thorne, R. M., 1974. Archaeological survey in South Africa: conceptual, methodological and practical problems. The Phalaborwa Complex- a case study. Unpublished Ph.D. thesis, University of Missouri .

Thornton, C. P., 2009. Archaeometallurgy: evidence of a paradigm shift?. In: T. Kienlin \& B. W. Roberts (eds.), Metals and Societies: Studies in Honour of Barbara S. Ottaway. Verlag: Dr. Rudolf Habelt GmbH, Bonn, 25-33.

Thornton, C. P., Golden, J. M., Killick, D. J., Pigott, V. C., Rehren, Th. \& Roberts, B. W., 2010. A Chalcolithic error: rebuttal to Amzallag 2009. American Journal of Archaeology 114(2), 305-315.

Thorton, C. P., Rehren, Th. \& Pigott, V. C., 2009. The production of speiss (iron arsenide) during the Early Bronze Age in Iran. Journal of Archaeological Science 36(2), 308-316.

Tilley, C., Keane, W., Küchler, S., Rowlands, M. \& Spyer, P., 2006. Introduction. In: C. Tilley, W. Keane., S. Küchler., M. Rowlands \& P. Spyer (eds.), Handbook of Material Culture. London: Sage Publications, 1-6.

Tite, M. S., 1972. Methods of Physical Examination in Archaeology. London: Seminar Press.

Trevor, T. G., 1912. Some observations on ancient mine workings in Transvaal. Journal of the Chemical, Metalurgical and Mining Society of South Africa 12, 267-275.

Trevor, T. G., 1930. Some observations on the relics of pre-European culture in Rhodesia and South Africa. Journal of the Royal Anthropological Institute of Great Britain and Ireland 60(33), 389-399.

Tylecote, R. F., Ghaznavi, H. A. \& Boydell, P. J., 1977. Partitioning of trace elements between ores, fluxes, slags and metal during the smelting of copper. Journal of Archaeological Sciences 4(4), 305-333.

Tylecote, R. F. \& Merkel, J. F., 1985. Experimental smelting techniques: achievements and future. In: P. T. Craddock \& M. J. Hughes (eds.), Furnaces and Smelting Technology in Antiquity. London: The British Museum Occasional Paper No. 48, 3-20.

van der Merwe, N. J., 1971. An interim reports to the National Monuments Council of South Africa on archaeological investigations at Phalaborwa, Unpublished Report to the National Monuments Council of South Africa. 
van der Merwe, N. J., 1978. Field methodology and Iron Age metallurgy at Buhwa, Rhodesia. In: Occasional Papers of the National Museums and Monuments of Rhodesia 4(6), 101-105.

van der Merwe, N. J., 1980. The advent of iron in Africa. In: T. A. Wertime (ed.), The Coming of the Age of Iron. New Haven: Yale University Press, 463-506.

van der Merwe, N. J. \& Killick, D., 1979. Square: an iron smelting site near Phalaborwa. Goodwin Series 3, 86-193.

van der Merwe, N. J. \& Scully, R. T. K., 1971. The Phalaborwa story: archaeological and ethnographic investigation of a South African Iron Age group. World Archaeology 3(2), 178-196.

Veldhuijzen, H. A., 2003. 'Slag_Fun'- a new tool for archaeometallurgy: development of an analytical (P) ED-XRF method for iron-rich materials. Papers from the Institute of Archaeology 14, 102-118.

Veldhuijzen, H. A., 2005. Technical ceramics in early iron smelting: the role of ceramics in the early first millenium BC iron production at Tell Hammeh (Az-Zarqa), Jordan. In: M. I. Prudêncio (ed.), Understanding People Through Their Pottery: Procedings of the 7th European Meeting on Ancient Ceramics (EMAC 03). Lisbon: Instituto Postugues de Arqueologia (IPA), 294-302.

Venter, F. J., 1986. Soil patterns associated with the major geological units of the Kruger National Park. Koedoe 29(1), 125-138.

Venter, F. J. \& Bristow, J. W., 1986. An account of the geomorphology and drainage of the Kruger National Park. Koedoe 29(1), 117-124.

Verhoef, J., 1986. Notes on the archaeology and prehistoric mining in Kruger National Park. Koedoe 29(1), 149-156.

Viljoen, M. J. \& Reimold, W. U., 1999. An Introduction to South Africa's Geological and Mining Heritage. Randburg: Mintek.

Walker, N. J., 1995. Late Pleistocene and Holocene Hunter-Gatherers of the Matopos: An Archaeological Study of Change and Continuity in Zimbabwe (Studies in African Archaeology 10). Uppsala: Societas Archaeologica Upsaliensis.

Willett, F. \& Sayre, E. V., 2006. Lead Isotopes in West African copper alloys. Journal of African Archaeology 4(1), 55-90. 
Winter-Irving, C., 1993. Stone Sculpture in Zimbabwe. Harare: Modus Publications Pvt. Ltd..

Woodhouse, J., 1998. Iron in Africa: metal from nowhere. In: G. Connah (ed.), Transformations in Africa: Essays on Africa's Later Past. London: Leicester University Press, 160-185.

Wood, M., 2000. Making connections: relationships between international trade and glass beads from the Shashe-Limpopo area. South African Archaeological Society Goodwin Series 8, 78-90.

Zangato, E. \& Holl, A. F. C., 2010. On the iron front: new evidence from north-central Africa. Journal of African Archaeology 8(1), 7-23. 


\section{Appendix 1: Precision and accuracy of instrumental methods}

Accuracy and precision tests of the instrumental methods were carried out on several certified reference materials (CRMs). Efforts were made to select CRMs with comparable compositions to the various archaeometallurgical samples from Phalaborwa. However, it was not always possible to find CRMs that perfectly matched the wide range of samples analysed in this project. For example the CRMs collection at the Wolfson Archaeological Science Laboratories does not have references materials similar to the potential copper ores presented in this thesis. None the less the available CRMs allowed the precision and accuracy of the instrumental methods to be assessed. To establish the precision of the instrumental methods coefficients of variation ( $\mathrm{CVs} \%$ ) were calculated. Whilst the assessment of instrumental accuracy was calculated in terms of absolute and relative differences (errors) hereby presented as $\delta$ absolute and $\delta$ relative $(\%)$ respectively.

Three CRMs (BIR-1, BCR-2 and BIR-1) of geological origin were used to test the accuracy and precision the Hitachi S-3400 employed for SEM-EDS analytical work. These CRMs are the most appropriate match for both slag samples and technical ceramics presented in this thesis. These CRMs were run at different dates prior, during and after the analytical work, results of these tests are presented below in Tables 1 to 6 . The discussion of the accuracy and precision of the Hitachi is provided in the main thesis (Chapter 5).

Three CRMs (BCS 301, ECRM 681/1 \& W-25R) in the form of iron ores and slags were also run concurrent with Phalaborwa slags to test precision and accuracy of the Spectro X-Lab Pro 2000 instrument employed for (P)ED-XRF analysis in this project. The test results gathered from these CRMs are presented in Tables 7 to 9. The discussion of the precision and accuracy of the Spectro X-Lab Pro 2000 instrument is provided in Chapter 5. 
List of CRMs analysed to test instrumental accuracy and precision

\begin{tabular}{|l|l|l|}
\hline CRM No. & Description & Method tested \\
\hline BIR-1 & Icelandic basalt & SEM-EDS \\
\hline BCR-2 & Basalt from Columbia River & SEM-EDS \\
\hline BHVO-2 & Basalt from Hawaiian Volcanic Observatory & SEM-EDS \\
\hline BCS 301 & Lincolnshire iron ore & (P)ED-XRF \\
\hline ECRM 681/1 & Iron ore & (P)ED-XRF \\
\hline W-25R & Swedish slag & (P)ED-XRF \\
\hline
\end{tabular}

Table 1: SEM-EDS results of sample BIR-1. Results in wt\% and not normalised to $100 \%$.

\begin{tabular}{|l|r|r|r|r|r|r|r|r|r|r|r|}
\hline BIR-1 & $\mathbf{N a}_{2} \mathbf{O}$ & $\mathbf{M g O}$ & $\mathbf{A l}_{2} \mathbf{O}_{\mathbf{3}}$ & $\mathbf{S i O}_{\mathbf{2}}$ & $\mathbf{P}_{\mathbf{2}} \mathbf{O}_{\mathbf{5}}$ & $\mathbf{K}_{\mathbf{2}} \mathbf{O}$ & $\mathbf{C a O}$ & $\mathbf{T i O}_{2}$ & $\mathbf{M n O}$ & $\mathbf{F e O}$ & Total \\
\hline Analysis 1 & 1.9 & 10.7 & 16.2 & 55.1 & 0.0 & 0.0 & 14.2 & 1.0 & 0.2 & 10.8 & 110.1 \\
\hline Analysis 2 & 1.8 & 10.4 & 16.6 & 54.7 & 0.2 & 0.0 & 14.2 & 1.0 & 0.3 & 10.9 & 110.1 \\
\hline Analysis 3 & 1.7 & 10.5 & 16.1 & 54.2 & 0.0 & 0.0 & 14.1 & 1.0 & 0.3 & 10.9 & 108.8 \\
\hline Analysis 4 & 1.6 & 10.4 & 15.7 & 53.1 & 0.0 & 0.1 & 14.0 & 0.9 & 0.0 & 10.1 & 105.9 \\
\hline Analysis 5 & 1.8 & 9.7 & 15.4 & 52.2 & -0.1 & 0.0 & 13.3 & 0.9 & 0.2 & 10.3 & 103.7 \\
\hline
\end{tabular}

Table 2: SEM-EDS results of sample BIR-1. Results in wt\% with totals normalised to $100 \%$.

\begin{tabular}{|c|c|c|c|c|c|c|c|c|c|c|c|}
\hline BIR-1 & $\mathrm{Na}_{2} \mathrm{O}$ & MgO & $\mathrm{Al}_{2} \mathrm{O}_{3}$ & $\mathrm{SiO}_{2}$ & $\mathbf{P}_{2} \mathbf{O}_{5}$ & $\mathbf{K}_{2} \mathrm{O}$ & $\mathrm{CaO}$ & $\mathrm{TiO}_{2}$ & $\mathrm{MnO}$ & $\mathrm{FeO}$ & Total \\
\hline Analysis 1 & 1.7 & 9.7 & 14.7 & 50.1 & 0.0 & 0.0 & 12.9 & 0.9 & 0.2 & 9.8 & 100.0 \\
\hline Analysis 2 & 1.6 & 9.4 & 15.1 & 49.7 & 0.2 & 0.0 & 12.9 & 0.9 & 0.2 & 9.9 & 100.0 \\
\hline Analysis 3 & 1.6 & 9.7 & 14.8 & 49.8 & 0.0 & 0.0 & 12.9 & 0.9 & 0.2 & 10.0 & 100.0 \\
\hline Analysis 4 & 1.5 & 9.8 & 14.8 & 50.2 & 0.0 & 0.1 & 13.2 & 0.8 & 0.0 & 9.6 & 100.0 \\
\hline Analysis 5 & 1.7 & 9.4 & 14.8 & 50.3 & 0.0 & 0.0 & 12.8 & 0.9 & 0.2 & 10.0 & 100.0 \\
\hline Mean & 1.6 & 9.6 & 14.9 & 50.0 & 0.0 & 0.0 & 13.0 & 0.9 & 0.2 & 9.8 & \\
\hline Std. deviation & 0.1 & 0.2 & 0.2 & 0.3 & 0.1 & 0.0 & 0.1 & 0.0 & 0.1 & 0.2 & \\
\hline CVs (\%) & 6 & 2 & 1 & 1 & & & 1 & $\mathbf{0}$ & 50 & 2 & \\
\hline Given CRM & 1.8 & 9.7 & 15.5 & 48.0 & 0.0 & 0.0 & 13.3 & 1.0 & 0.2 & 10.2 & \\
\hline$\delta$ Absolute & -0.2 & -0.1 & -0.6 & 2.0 & 0.0 & 0.0 & -0.3 & -0.1 & 0.0 & -0.4 & \\
\hline$\delta$ Relative (\%) & -11.1 & -1.0 & -3.9 & 4.2 & 0.0 & 0.0 & -2.3 & -10.0 & 0.0 & -3.9 & \\
\hline
\end{tabular}


Table 3: SEM-EDS results of sample BCR-2. Results in wt\% and not normalised to $100 \%$.

\begin{tabular}{|l|r|r|r|r|r|r|r|r|r|r|}
\hline $\mathbf{B C R}-2$ & $\mathbf{N a}_{\mathbf{2}} \mathbf{O}$ & $\mathbf{M g O}$ & $\mathbf{A l}_{2} \mathbf{O}_{\mathbf{3}}$ & $\mathbf{S i O}_{\mathbf{2}}$ & $\mathbf{P}_{\mathbf{2}} \mathbf{O}_{\mathbf{5}}$ & $\mathbf{K}_{\mathbf{2}} \mathbf{O}$ & $\mathbf{C a O}$ & $\mathbf{T i O}$ & $\mathbf{F e O}$ & Total \\
\hline Analysis 1 & 2.6 & 3.1 & 11.5 & 50.4 & 0.3 & 1.7 & 6.1 & 2.2 & 11.0 & 88.9 \\
\hline Analysis 2 & 2.6 & 3.2 & 11.4 & 49.8 & 0.3 & 1.6 & 6.3 & 2.1 & 10.5 & 87.9 \\
\hline Analysis 3 & 2.7 & 3.0 & 11.0 & 48.4 & 0.3 & 1.6 & 6.1 & 2.0 & 10.4 & 85.4 \\
\hline Analysis 4 & 2.6 & 3.0 & 10.8 & 47.1 & 0.3 & 1.5 & 6.0 & 2.0 & 10.0 & 83.1 \\
\hline Analysis 5 & 2.4 & 2.7 & 10.5 & 46.3 & 0.3 & 1.6 & 5.5 & 2.0 & 9.9 & 81.2 \\
\hline
\end{tabular}

Table 4: SEM-EDS results of sample BCR-2, reported in wt\% with totals normalised to $100 \%$.

\begin{tabular}{|c|c|c|c|c|c|c|c|c|c|c|}
\hline BCR-2 & $\mathrm{Na}_{2} \mathrm{O}$ & MgO & $\mathrm{Al}_{2} \mathrm{O}_{3}$ & $\mathrm{SiO}_{2}$ & $\mathbf{P}_{2} \mathrm{O}_{5}$ & $\mathrm{~K}_{2} \mathrm{O}$ & $\mathrm{CaO}$ & $\mathrm{TiO}_{2}$ & $\mathrm{FeO}$ & Total \\
\hline Analysis 1 & 3.0 & 3.5 & 12.9 & 56.7 & 0.4 & 1.9 & 6.8 & 2.4 & 12.4 & 100.0 \\
\hline Analysis 2 & 3.0 & 3.7 & 13.0 & 56.7 & 0.4 & 1.8 & 7.1 & 2.4 & 12.0 & 100.0 \\
\hline Analysis 3 & 3.1 & 3.5 & 12.9 & 56.7 & 0.4 & 1.9 & 7.1 & 2.3 & 12.2 & 100.0 \\
\hline Analysis 4 & 3.1 & 3.6 & 13.0 & 56.6 & 0.3 & 1.8 & 7.2 & 2.4 & 12.0 & 100.0 \\
\hline Analysis 5 & 3.0 & 3.4 & 12.9 & 57.0 & 0.4 & 1.9 & 6.7 & 2.5 & 12.2 & 100.0 \\
\hline Mean & 3.0 & 3.5 & 13.0 & 56.7 & 0.4 & 1.8 & 7.0 & 2.4 & 12.1 & \\
\hline Std. deviation & 0.1 & 0.1 & 0.1 & 0.1 & 0.0 & 0.1 & 0.2 & 0.1 & 0.2 & \\
\hline CVs (\%) & 3 & 3 & 1 & $\mathbf{0}$ & $\mathbf{0}$ & 6 & 3 & 4 & 2 & \\
\hline Given CRM & 3.2 & 3.6 & 13.5 & 54.1 & 0.4 & 1.8 & 7.1 & 2.3 & 12.4 & \\
\hline$\delta$ Absolute & -0.2 & -0.1 & -0.5 & 2.6 & 0.0 & $\mathbf{0 . 0}$ & -0.1 & 0.1 & -0.3 & \\
\hline$\delta$ Relative (\%) & -6.3 & -2.8 & -3.7 & 4.8 & 0.0 & 0.0 & -1.4 & 4.3 & -2.4 & \\
\hline
\end{tabular}


Table 5: SEM-EDS results of sample BHVO-2, reported in wt\%. Results are not normalised to $100 \%$.

\begin{tabular}{|l|r|r|r|r|r|r|r|r|r|r|r|}
\hline BHVO-2 & $\mathbf{N a}_{2} \mathbf{O}$ & $\mathbf{M g O}$ & $\mathbf{A l}_{2} \mathbf{O}_{\mathbf{3}}$ & $\mathbf{S i O}_{\mathbf{2}}$ & $\mathbf{P}_{\mathbf{2}} \mathbf{O}_{\mathbf{5}}$ & $\mathbf{K}_{\mathbf{2}} \mathbf{O}$ & $\mathbf{C a O}$ & $\mathbf{T i O}_{\mathbf{2}}$ & $\mathbf{M n O}$ & $\mathbf{F e O}$ & $\mathbf{T o t a l}$ \\
\hline Analysis 1 & 2.1 & 7.3 & 13.0 & 53.2 & 0.2 & 0.5 & 11.3 & 2.7 & 0.3 & 10.8 & 101.2 \\
\hline Analysis 2 & 2.2 & 7.1 & 12.9 & 52.4 & 0.2 & 0.5 & 10.9 & 2.6 & 0.0 & 10.4 & 99.2 \\
\hline Analysis 3 & 1.9 & 6.7 & 12.5 & 50.4 & 0.3 & 0.5 & 10.8 & 2.6 & 0.1 & 10.7 & 96.6 \\
\hline Analysis 4 & 1.9 & 6.9 & 12.3 & 49.1 & 0.1 & 0.5 & 10.6 & 2.7 & 0.2 & 10.0 & 94.1 \\
\hline Analysis 5 & 2.1 & 6.3 & 11.9 & 48.3 & 0.2 & 0.5 & 10.0 & 2.6 & 0.1 & 9.9 & 91.9 \\
\hline
\end{tabular}

Table 6: SEM-EDS results of sample BHVO-2, reported in wt\% with totals normalised to $100 \%$.

\begin{tabular}{|c|c|c|c|c|c|c|c|c|c|c|c|}
\hline BHVO-2 & $\mathrm{Na}_{2} \mathrm{O}$ & $\mathrm{MgO}$ & $\mathrm{Al}_{2} \mathrm{O}_{3}$ & $\mathrm{SiO}_{2}$ & $\mathbf{P}_{2} \mathrm{O}_{5}$ & $\mathrm{~K}_{2} \mathrm{O}$ & $\mathrm{CaO}$ & $\mathrm{TiO}_{2}$ & $\mathrm{MnO}$ & $\mathrm{FeO}$ & Total \\
\hline Analysis 1 & 2.0 & 7.2 & 12.8 & 52.5 & 0.2 & 0.5 & 11.1 & 2.7 & 0.3 & 10.7 & 100.0 \\
\hline Analysis 2 & 2.2 & 7.2 & 13.0 & 52.8 & 0.2 & 0.5 & 11.0 & 2.6 & 0.0 & 10.5 & 100.0 \\
\hline Analysis 3 & 2.0 & 6.9 & 13.0 & 52.2 & 0.3 & 0.6 & 11.1 & 2.7 & 0.2 & 11.0 & 100.0 \\
\hline Analysis 4 & 2.0 & 7.3 & 13.0 & 52.1 & 0.1 & 0.5 & 11.3 & 2.8 & 0.2 & 10.6 & 100.0 \\
\hline Analysis 5 & 2.3 & 6.9 & 12.9 & 52.5 & 0.2 & 0.5 & 10.9 & 2.8 & 0.1 & 10.8 & 100.0 \\
\hline Average & 2.1 & 7.1 & 12.9 & 52.4 & 0.2 & 0.5 & 11.1 & 2.7 & 0.2 & 10.7 & \\
\hline Std. deviation & 0.1 & 0.2 & 0.1 & 0.3 & 0.1 & 0.0 & 0.1 & 0.1 & 0.1 & 0.2 & \\
\hline CVs (\%) & 5 & 3 & 1 & 1 & $\mathbf{5 0}$ & 0 & 1 & 4 & $\mathbf{5 0}$ & 2 & \\
\hline Given CRM & 2.2 & 7.2 & 13.5 & 49.9 & 0.3 & 0.5 & 11.4 & 2.7 & 0.1 & 11.1 & \\
\hline$\delta$ Absolute & -0.1 & -0.1 & -0.6 & 2.5 & -0.1 & 0.0 & -0.3 & 0.0 & 0.1 & -0.4 & \\
\hline$\delta$ Relative (\%) & -4.5 & -1.4 & -4.4 & 5.0 & -33.3 & 0.0 & -2.6 & 0.0 & 100.0 & -3.6 & \\
\hline
\end{tabular}


Table 7: (P)ED-XRF results of CRM sample BCS301 analysed together with slag samples from Phalaborwa.

\begin{tabular}{|c|c|c|c|c|c|c|c|c|c|c|c|c|c|c|}
\hline BCS 301 & Analysis date & $\mathrm{Na}_{2} \mathrm{O}$ & MgO & $\mathrm{Al}_{2} \mathrm{O}_{3}$ & $\mathrm{SiO}_{2}$ & $\mathbf{P}_{2} \mathbf{O}_{5}$ & $\mathrm{SO}_{3}$ & $\mathrm{~K}_{2} \mathrm{O}$ & $\mathrm{CaO}$ & $\mathrm{TiO}_{2}$ & $\mathrm{~V}_{2} \mathrm{O}_{5}$ & $\mathrm{Cr}_{2} \mathrm{O}_{3}$ & $\mathrm{MnO}$ & $\mathrm{FeO}$ \\
\hline Run 1 & $12 / 03 / 2010$ & 0.04 & 1.02 & 4.53 & 7.99 & 0.54 & 0.45 & 0.41 & 27.40 & 0.21 & 0.15 & 0.03 & 1.30 & 37.08 \\
\hline Run 2 & $12 / 03 / 2010$ & 0.11 & 0.98 & 4.55 & 7.87 & 0.52 & 0.46 & 0.40 & 27.02 & 0.21 & 0.14 & 0.02 & 1.28 & 36.66 \\
\hline Run 3 & $12 / 03 / 2010$ & 0.05 & 1.03 & 4.55 & 7.97 & 0.54 & 0.45 & 0.41 & 27.37 & 0.21 & 0.14 & 0.03 & 1.30 & 37.02 \\
\hline Run 2 & $21 / 03 / 2010$ & 0.05 & 1.21 & 4.25 & 9.30 & 0.69 & 0.60 & 0.34 & 21.25 & 0.13 & 0.09 & 0.02 & 1.16 & 30.68 \\
\hline Run 3 & $21 / 03 / 2010$ & 0.05 & 1.22 & 4.14 & 9.34 & 0.71 & 0.61 & 0.34 & 21.37 & 0.13 & 0.09 & 0.02 & 1.17 & 30.72 \\
\hline Run 3 & $14 / 09 / 2011$ & 0.05 & 1.01 & 4.56 & 8.05 & 0.54 & 0.45 & 0.41 & 27.73 & 0.21 & 0.14 & 0.02 & 1.31 & 37.30 \\
\hline \multicolumn{2}{|l|}{ Mean } & 0.05 & 1.08 & 4.45 & 8.43 & 0.59 & 0.50 & 0.39 & 25.37 & 0.18 & 0.12 & 0.02 & 1.25 & 34.91 \\
\hline \multicolumn{2}{|c|}{ Std. deviation } & 0.02 & 0.10 & 0.19 & 0.66 & 0.08 & 0.08 & $\mathbf{0 . 0 3}$ & 3.08 & 0.04 & 0.03 & 0.01 & 0.07 & 3.16 \\
\hline \multicolumn{2}{|l|}{ CVs (\%) } & 39 & 9 & 4 & 8 & 13 & 15 & 9 & 12 & 24 & 21 & 21 & 5 & 9 \\
\hline \multicolumn{2}{|c|}{ Given CRM } & 0.07 & 1.73 & 4.26 & 7.40 & 0.80 & 1.00 & 0.32 & 22.60 & 0.16 & 0.00 & 0.00 & 1.25 & 35.10 \\
\hline \multicolumn{2}{|c|}{$\boldsymbol{\delta}$ Absolute } & -0.02 & -0.65 & 0.19 & 1.03 & -0.21 & -0.50 & $\mathbf{0 . 0 7}$ & 2.77 & 0.02 & 0.12 & 0.02 & 0.00 & -0.19 \\
\hline
\end{tabular}


Table 8: (P)ED-XRF results of CRM sample ECRM 681/1 analysed together with slag samples from Phalaborwa.

\begin{tabular}{|c|c|c|c|c|c|c|c|c|c|c|c|c|c|c|}
\hline ECRM 681/1 & Analysis date & $\mathrm{Na}_{2} \mathrm{O}$ & MgO & $\mathrm{Al}_{2} \mathrm{O}_{3}$ & $\mathrm{SiO}_{2}$ & $\mathbf{P}_{2} \mathbf{O}_{5}$ & $\mathrm{SO}_{3}$ & $\mathrm{~K}_{2} \mathrm{O}$ & $\mathrm{CaO}$ & $\mathrm{TiO}_{2}$ & $\mathrm{~V}_{2} \mathrm{O}_{5}$ & $\mathrm{Cr}_{2} \mathrm{O}_{3}$ & MnO & $\mathrm{FeO}$ \\
\hline Run 1 & $12 / 03 / 2010$ & 0.05 & 0.97 & 14.86 & 22.24 & 1.76 & 0.26 & 0.70 & 5.48 & 0.57 & 0.20 & 0.09 & 0.28 & 49.68 \\
\hline Run 2 & $12 / 03 / 2010$ & 0.05 & 0.95 & 15.06 & 22.63 & 1.75 & 0.25 & 0.71 & 5.48 & 0.57 & 0.20 & 0.09 & 0.28 & 49.19 \\
\hline Run 3 & $12 / 03 / 2010$ & 0.06 & 0.98 & 14.88 & 22.38 & 1.75 & 0.26 & 0.71 & 5.48 & 0.58 & 0.20 & 0.09 & 0.28 & 49.53 \\
\hline Run 1 & $21 / 03 / 2010$ & 0.30 & 1.07 & 12.12 & 21.62 & 2.05 & 0.36 & 0.56 & 3.85 & 0.41 & 0.14 & 0.07 & 0.29 & 40.89 \\
\hline Run 2 & $21 / 03 / 2010$ & 0.25 & 1.04 & 12.18 & 21.68 & 2.07 & 0.38 & 0.57 & 3.86 & 0.41 & 0.14 & 0.07 & 0.29 & 40.93 \\
\hline Run 3 & $21 / 03 / 2010$ & 0.24 & 1.03 & 12.23 & 21.76 & 2.09 & 0.37 & 0.57 & 3.88 & 0.42 & 0.14 & 0.07 & 0.29 & 41.12 \\
\hline Run 1 & $14 / 09 / 2011$ & 0.05 & 0.95 & 14.67 & 22.31 & 1.76 & 0.27 & 0.70 & 5.50 & 0.58 & 0.20 & 0.09 & 0.29 & 49.76 \\
\hline Run 2 & $14 / 09 / 2011$ & 0.05 & 1.00 & 14.67 & 22.28 & 1.73 & 0.26 & 0.71 & 5.49 & 0.58 & 0.20 & 0.09 & 0.29 & 49.79 \\
\hline Run 3 & $14 / 09 / 2011$ & 0.05 & 0.99 & 14.55 & 22.24 & 1.75 & 0.27 & 0.70 & 5.50 & 0.57 & 0.20 & 0.09 & 0.29 & 49.91 \\
\hline \multicolumn{2}{|l|}{ Mean } & 0.12 & 1.00 & 13.91 & 22.13 & 1.86 & 0.30 & 0.66 & 4.95 & 0.52 & 0.18 & 0.08 & 0.29 & 46.76 \\
\hline \multicolumn{2}{|l|}{ Std. deviation } & 0.11 & 0.04 & 1.31 & 0.35 & 0.16 & 0.05 & 0.07 & 0.81 & 0.08 & 0.03 & 0.01 & 0.00 & 4.34 \\
\hline \multicolumn{2}{|l|}{ CVs (\%) } & $\mathbf{8 8}$ & 4 & 9 & 2 & 9 & 18 & 11 & 16 & 16 & 17 & 12 & 2 & 9 \\
\hline \multicolumn{2}{|l|}{ Given CRM } & 0.09 & 1.48 & 10.62 & 17.8 & 2.02 & 0.65 & 0.59 & 3.92 & 0.48 & 0.14 & 0.06 & 0.28 & 42.72 \\
\hline \multicolumn{2}{|l|}{$\delta$ Absolute } & 0.03 & -0.48 & 3.29 & 4.33 & -0.16 & -0.35 & 0.07 & 1.03 & 0.04 & 0.04 & 0.02 & 0.01 & 4.04 \\
\hline \multicolumn{2}{|l|}{$\delta$ Relative (\%) } & 35.80 & -32.58 & 31.01 & 24.31 & -8.09 & -54.19 & 11.68 & 26.19 & 8.56 & 28.57 & 38.89 & 2.38 & 9.45 \\
\hline
\end{tabular}


Table 9: (P)ED-XRF results of CRM sample W-25R analysed together with slag samples from Phalaborwa.

\begin{tabular}{|c|c|c|c|c|c|c|c|c|c|c|c|c|c|c|}
\hline W-25R & Analysis date & $\mathrm{Na}_{2} \mathrm{O}$ & $\mathrm{MgO}$ & $\mathrm{Al}_{2} \mathrm{O}_{3}$ & $\mathrm{SiO}_{2}$ & $\mathbf{P}_{2} \mathbf{O}_{5}$ & $\mathrm{SO}_{3}$ & $\mathrm{~K}_{2} \mathrm{O}$ & $\mathrm{CaO}$ & $\mathrm{TiO}_{2}$ & $\mathbf{V}_{2} \mathbf{O}_{5}$ & $\mathrm{Cr}_{2} \mathrm{O}_{3}$ & MnO & $\mathrm{FeO}$ \\
\hline Run 1 & $12 / 03 / 2010$ & 0.60 & 0.25 & 7.49 & 24.33 & 0.20 & 0.15 & 1.12 & 1.76 & 0.35 & 0.05 & 0.00 & 2.62 & 57.50 \\
\hline Run 3 & $12 / 03 / 2010$ & 0.58 & 0.26 & 7.39 & 24.37 & 0.20 & 0.15 & 1.13 & 1.79 & 0.35 & 0.05 & 0.00 & 2.62 & 57.53 \\
\hline Run 2 & $21 / 03 / 2010$ & 0.62 & 0.20 & 7.88 & 30.65 & 0.13 & 0.27 & 1.17 & 1.55 & 0.23 & 0.00 & 0.02 & 2.93 & 61.05 \\
\hline Run 3 & $21 / 03 / 2010$ & 0.68 & 0.14 & 7.71 & 30.29 & 0.14 & 0.26 & 1.15 & 1.52 & 0.23 & 0.00 & 0.01 & 2.90 & 60.48 \\
\hline Run 1 & $14 / 09 / 2011$ & 0.56 & 0.22 & 7.40 & 24.39 & 0.20 & 0.15 & 1.11 & 1.79 & 0.35 & 0.05 & 0.00 & 2.63 & 57.55 \\
\hline \multicolumn{2}{|l|}{ Mean } & 0.59 & 0.23 & 7.50 & 26.36 & 0.18 & 0.19 & 1.13 & 1.70 & 0.31 & 0.03 & 0.00 & 2.72 & 58.60 \\
\hline \multicolumn{2}{|c|}{ Std. deviation } & 0.06 & 0.04 & 0.20 & 3.00 & 0.04 & 0.06 & 0.02 & 0.13 & 0.06 & $\mathbf{0 . 0 3}$ & 0.01 & 0.14 & 1.60 \\
\hline \multicolumn{2}{|c|}{ CVs $(\%)$} & 10 & 19 & 3 & 11 & 20 & 30 & 2 & 8 & 19 & 75 & 163 & 5 & 3 \\
\hline \multicolumn{2}{|c|}{ Given CRM } & 0.61 & 0.41 & 7.43 & 24.73 & 0.26 & 0.04 & 0.99 & 1.46 & 0.31 & 0.03 & 0.01 & 3.13 & 57.28 \\
\hline \multicolumn{2}{|c|}{$\delta$ Absolute } & -0.02 & -0.18 & 0.07 & 1.63 & -0.08 & 0.15 & 0.14 & 0.24 & 0.00 & 0.00 & -0.01 & -0.41 & 1.32 \\
\hline
\end{tabular}




\section{Appendix 2: Inventory of samples subjected to analytical work}

\begin{tabular}{|l|l|l|}
\hline INVENTORY No & SITE & SAMPLE TYPE \\
\hline SHA1T & Shankare & Potential ore \\
\hline SHA2NWL & Shankare & Potential ore \\
\hline SHA13NEL & Shankare & Potential ore \\
\hline SHA14NEL & Shankare & Potential ore \\
\hline SHA15NEL & Shankare & Potential ore \\
\hline SMB22(4) & Shankare & Potential ore \\
\hline SMB22(5) & Shankare & Potential ore \\
\hline SMB26(2) & Shankare & Potential ore \\
\hline SMB26(3) & Shankare & Potential ore \\
\hline SMB26(4) & Shankare & Potential ore \\
\hline SMB27(1) & Shankare & Potential ore \\
\hline SHA1NEL & Shankare & Iron smelting slag \\
\hline SHA2NEL & Shankare & Iron smelting slag \\
\hline SHA3NEL & Shankare & Iron smelting slag \\
\hline SHA4NEL & Shankare & Iron smelting slag \\
\hline SHA5NEL & Shankare & Iron smelting slag \\
\hline SHA6NEL & Shankare & Iron smelting slag \\
\hline SHA7NEL & Shankare & Iron smelting slag \\
\hline SHA8NEL & Shankare & Iron smelting slag \\
\hline SHA1NWL & Shankare & Copper smelting slag \\
\hline SHA4NWL & Shankare & Copper smelting slag \\
\hline SHA5NWL & Shankare & Copper smelting slag \\
\hline SHA6NWL & Shankare & Copper smelting slag \\
\hline SHA7NWL & Shankare & Copper smelting slag \\
\hline SHA8NWL & Shankare & Copper smelting slag \\
\hline SHA9NWL & Shankare & Copper smelting slag \\
\hline SHA10NWL & Shankare & Copper smelting slag \\
\hline SHA9NEL & Shankare & Copper smelting slag \\
\hline SHA10NEL & Shankare & Copper smelting slag \\
\hline SHAMK8(1) & Shankare & Copper smelting slag \\
\hline SHAMK9(1) & Shankare & Copper smelting slag \\
\hline SHAMK18(3) & Shankare & Copper smelting slag \\
\hline & & \\
\hline
\end{tabular}




\begin{tabular}{|l|l|l|}
\hline INVENTORY No & SITE & SAMPLE TYPE \\
\hline SHAMK18(4) & Shankare & Copper smelting slag \\
\hline SHAMK27(3) & Shankare & Copper smelting slag \\
\hline SMB21(1) & Shankare & Copper smelting slag \\
\hline SMB22(1) & Shankare & Copper smelting slag \\
\hline SMB22(2) & Shankare & Copper smelting slag \\
\hline SMB23(1) & Shankare & Copper smelting slag \\
\hline SMB24(1) & Shankare & Copper smelting slag \\
\hline SMB26(1) & Shankare & Copper smelting slag \\
\hline SHA21NEL & Shankare & Tuyère fragment \\
\hline SHA22NEL & Shankare & Tuyère fragment \\
\hline SHA23NEL & Shankare & Tuyère fragment \\
\hline SHA24NEL & Shankare & Tuyère fragment \\
\hline SHA25NEL & Shankare & Tuyère fragment \\
\hline SHA26NEL & Shankare & Tuyère fragment \\
\hline SHA27NEL & Shankare & Tuyère fragment \\
\hline SHA28NEL & Shankare & Tuyère fragment \\
\hline SHA3NWL & Shankare & Crucible fragment \\
\hline SMB21(3) & Shankare & Crucible fragment \\
\hline SMB23(2) & Shankare & Crucible fragment \\
\hline SMB27(1) & Shankare & Crucible fragment \\
\hline SSHB23(1) & Shankare & Crucible fragment \\
\hline SSHB23(2) & Shankare & Crucible fragment \\
\hline SMB21(2) & Shankare & Copper artefact \\
\hline SMB22(3) & Shankare & Copper artefact \\
\hline SMB26(2) & Shankare & Copper artefact \\
\hline SMB81(1) & Shankare & Copper artefact \\
\hline SSC(1) & Shankare & Copper artefact \\
\hline SSC(2) & Shankare & Copper artefact \\
\hline SPK3 1 & Kgopolwe & Potential ore \\
\hline SPK3 2 & Kgopolwe & Potential ore \\
\hline SPK6 1 & Kgopolwe & Copper smelting slag \\
\hline SPK62 & Kgopolwe & Copper smelting slag \\
\hline SPK63 & Kgopolwe & Copper smelting slag \\
\hline SPK6 4 & Kgopolwe & Copper smelting slag \\
\hline SPK6 5 & Kgopolwe & Copper smelting slag \\
\hline MOL1F & Copper smelting slag \\
\hline MOL2F & Copper smelting slag \\
\hline MOL3F & Copper smelting slag \\
\hline & \\
\hline
\end{tabular}




\begin{tabular}{|l|l|l|}
\hline INVENTORY No & SITE & SAMPLE TYPE \\
\hline MOL4F & Molotho & Copper smelting slag \\
\hline MOL5F & Molotho & Copper smelting slag \\
\hline MOL6F & Molotho & Copper smelting slag \\
\hline SPM1(1) & Serotwe & Copper smelting slag \\
\hline SPM1(2) & Serotwe & Copper smelting slag \\
\hline SPM1(3) & Serotwe & Copper smelting slag \\
\hline SPM1(4) & Serotwe & Copper smelting slag \\
\hline SPM3C(1) & Serotwe & Iron smelting slag \\
\hline PHU1NL & Phutwane & Iron smelting slag \\
\hline PHU2NL & Phutwane & Iron smelting slag \\
\hline PHU4NL & Phutwane & Iron smelting slag \\
\hline PHU5NL & Phutwane & Iron smelting slag \\
\hline PHU2SM & Phutwane & Iron smelting slag \\
\hline PHU4SM & Phutwane & Iron smelting slag \\
\hline PHU3NL & Phutwane & Copper smelting slag \\
\hline PHU3SM & Phutwane & Copper smelting slag \\
\hline PHU5SM & Phutwane & Copper smelting slag \\
\hline GM10M(1) & Maranda & Copper smelting slag \\
\hline
\end{tabular}




\section{Appendix 3: The presumed ore samples}

This appendix contains a catalogue of the presumed ore samples subjected to further analytical studies in this thesis. The catalogue includes brief macroscopic and microscopic description of the ores. This brief catalogue is followed up by analytical results of individual samples documented in the form of photomicrographs or back scatter electron images and bulk chemistry. These analytical results are presented as summaries in the main thesis document. Please note that the 'bulk' SEM-EDS results presented here are in wt $\%$ and not normalised to $100 \%$ as a result of the presence of carbonates and hydroxides. 


\section{Catalogue of presumed ore samples subjected to analytical work}

\begin{tabular}{|c|c|c|c|c|c|}
\hline Sample No & Site & Context & Weight (g) & Brief macroscopic description & Brief microscopic description \\
\hline SHA1T & Shankare & Surface Terraces & 114.36 & $\begin{array}{l}\text { Highly magnetic black iron ore partially } \\
\text { covered with a thick speck of green } \\
\text { copper compounds on the surface. }\end{array}$ & $\begin{array}{l}\text { Microstructure contains assorted mineral grains ranging from } \\
\text { magnetite, malachite, calcium carbonate, apatite and uranothorite. }\end{array}$ \\
\hline SHA2NWL & Shankare & Surface NW of the Hill & 13.27 & $\begin{array}{l}\text { Non-magnetic, sugary grained siliceous } \\
\text { host rock mixed with green copper } \\
\text { compounds. }\end{array}$ & $\begin{array}{l}\text { Quartz dominated sample containing occasionally apatite grains, the } \\
\text { grain boundaries are filled by barite and copper compounds. }\end{array}$ \\
\hline SHA11NEL & Shankare & Surface NE of the Hill & 7.68 & $\begin{array}{l}\text { Non-magnetic, green malachite } \\
\text { attached to a brown to red mineral. }\end{array}$ & $\begin{array}{l}\text { The outer most part of the sample is green malachite enclosing iron and } \\
\text { copper rich carbonates/hydroxides with unique chalcopyrite inclusions } \\
\text { also containing occasionally rare earth phosphates }\end{array}$ \\
\hline SHA12NEL & Shankare & Surface NE of the Hill & 5.04 & $\begin{array}{l}\text { Non-magnetic, sample composed of red } \\
\text { calcium carbonate and green copper } \\
\text { compounds. }\end{array}$ & $\begin{array}{l}\text { The outer layer is malachite with isolated rare earth oxides. The red } \\
\text { matrix is dominated by grains of calcium carbonate cemented together } \\
\text { by copper compounds. }\end{array}$ \\
\hline SHA13NEL & Shankare & Surface NE of the Hill & 3.85 & $\begin{array}{l}\text { Half green malachite sample combined } \\
\text { with a brown to red mineral. }\end{array}$ & $\begin{array}{l}\text { The outer part of the sample is green malachite, followed by iron and } \\
\text { copper rich carbonates/hydroxides with unique chalcopyrite inclusions } \\
\text { with chalcocite rims, occasional rare earth oxides towards the centre. }\end{array}$ \\
\hline SHA14NEL & Shankare & Surface NE of the Hill & 2.36 & $\begin{array}{l}\text { Non-magnetic ore sample combining } \\
\text { red calcium carbonate and green copper } \\
\text { compounds. }\end{array}$ & $\begin{array}{l}\text { The outer layer is malachite with isolated calcium carbonate grains and } \\
\text { rare earth oxides, the red matrix is calcium carbonate with veins of } \\
\text { copper and iron oxide. }\end{array}$ \\
\hline SHA15NEL & Shankare & Surface NE of the Hill & 1.16 & Tiny green malachite mineral sample & Dominated by green copper carbonates and isolated rare earth oxides \\
\hline $\operatorname{SMB} 22(4)$ & Shankare & Trench SHAM1-Layer 2 & 8.49 & $\begin{array}{l}\text { Magnetic black iron ore with a thick } \\
\text { speck of green copper compounds and } \\
\text { reddish iron oxide }\end{array}$ & The outer layer is green but contains residual chalcopyrite \\
\hline SMB22(5) & Shankare & Trench SHAM1-Layer 2 & 3.43 & $\begin{array}{l}\text { Non-magnetic, siliceous host rock } \\
\text { stained with green copper compounds }\end{array}$ & The green matrix contains chalcopyrite, silica and apatite grains \\
\hline SMB26(2) & Shankare & Trench SHAM1-Layer 6 & 8.16 & $\begin{array}{l}\text { Non-magnetic, siliceous mineral } \\
\text { combine with reddish matrix also } \\
\text { stained with green malachite }\end{array}$ & $\begin{array}{l}\text { The sample is fine grained with green copper oxides but lacks any } \\
\text { sulphide inclusions. }\end{array}$ \\
\hline SMB26(3) & Shankare & Trench SHAM1-Layer 6 & 1.59 & $\begin{array}{l}\text { Non-magnetic, reddish ore sample } \\
\text { stained with green malachite and blue } \\
\text { azurite }\end{array}$ & $\begin{array}{l}\text { The sample contains sulphide inclusions of barite very bright under } \\
\text { BSE imaging. }\end{array}$ \\
\hline SMB26(4) & Shankare & Trench SHAM1-Layer 6 & 0.59 & $\begin{array}{l}\text { Non-magnetic, deep green malachite } \\
\text { sample with visible blue azurite matrix. }\end{array}$ & $\begin{array}{l}\text { Microscopically dominated by copper carbonates with very few } \\
\text { magnetite and zirconium grains. }\end{array}$ \\
\hline $\operatorname{SMB} 27(1)$ & Shankare & Trench SHAM1-Layer 7 & 9.29 & $\begin{array}{l}\text { Non-magnetic, green and reddish } \\
\text { mineral sample with visible yellow } \\
\text { residual sulphides. }\end{array}$ & $\begin{array}{l}\text { Copper carbonates with residual sulphide inclusions namely } \\
\text { chalcopyrite and chalcocite with limited calcium carbonate grains. }\end{array}$ \\
\hline
\end{tabular}




\section{Catalogue of presumed ore samples subjected to analytical work}

\begin{tabular}{|l|l|l|c|l|l|}
\hline Sample No & Site & Context & Weight $(\mathbf{g})$ & Brief macroscopic description & Brief microscopic description \\
\hline SPK3 1 & Kgopolwe & SPK III (HUT FLOOR) & 7.7 & $\begin{array}{l}\text { Non-magnetic, with green blue external } \\
\text { colour likely malachite and azurite. }\end{array}$ & $\begin{array}{l}\text { Dominated by residual sulphide inclusions in the form of chalcopyrite } \\
\text { in a matrix of secondary copper-iron carbonates or hydroxides. }\end{array}$ \\
\hline SPK3 2 & Kgopolwe & SPK III (HUT FLOOR) & 3.8 & $\begin{array}{l}\text { Non-magnetic, sugary grained siliceous } \\
\text { host rock mixed with green copper } \\
\text { compounds. }\end{array}$ & $\begin{array}{l}\text { Contains some residual sulphide inclusions in the form of chalcopyrite } \\
\text { in a matrix of secondary copper-iron carbonates or hydroxides. }\end{array}$ \\
\hline
\end{tabular}




\section{SHA1T}
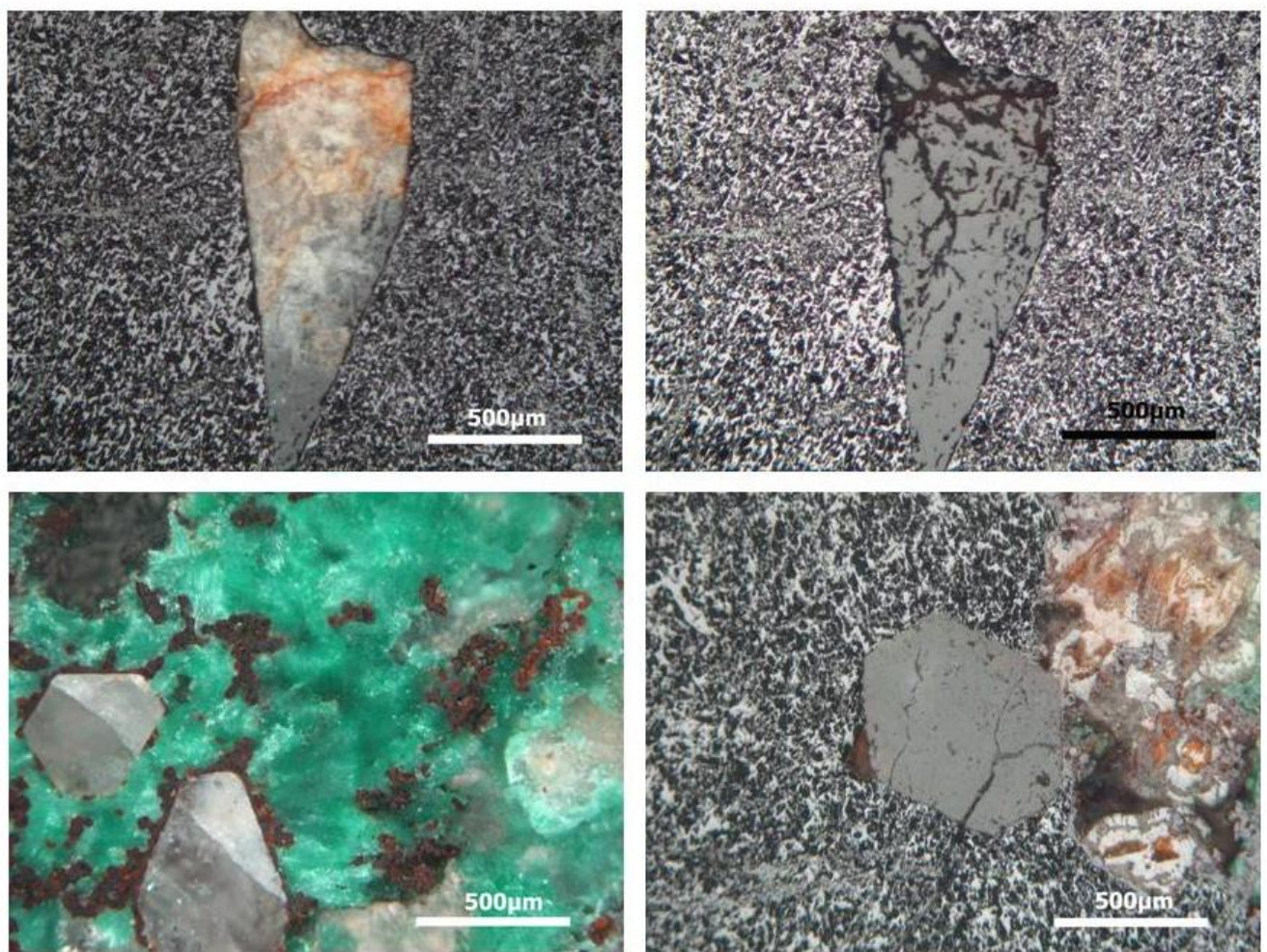

Photomicrographs of sample SHA1T: Top left, showing apatite grain in a magnetite matrix. Under cross polarized light (50x). Top right, same apatite grain. Under plane polarized light (50x). Bottom left, showing the green malachite matrix together with apatite grains. Under cross polarized light (50x. Bottom right, showing magnetite matrix with grains of apatite. Under cross polarized light (50x).

Multiple SEM-EDS area scan results of presumed ore sample SHA1T

\begin{tabular}{lrrrrrrrrrrrr}
\hline SHA1T & Na2O & MgO & Al2O3 & SiO2 & P2O5 & SO3 & K2O & CaO & TiO2 & MnO & FeO & CuO \\
\hline Area 1 & 0.0 & 0.3 & 0.0 & 1.8 & 8.3 & 0.2 & 0.0 & 8.6 & 0.0 & 0.0 & 26.2 & 11.4 \\
Area 2 & 0.0 & 0.3 & 0.1 & 1.2 & 8.9 & 0.0 & 0.0 & 15.7 & 0.0 & 0.0 & 14.1 & 22.5 \\
Area 3 & 0.0 & 0.5 & 0.1 & 1.0 & 5.9 & 0.0 & 0.1 & 22.6 & 0.0 & 0.1 & 15.6 & 9.0 \\
Area 4 & 0.0 & 0.3 & 0.3 & 1.6 & 0.3 & 0.1 & 0.0 & 19.5 & 0.1 & 0.2 & 16.7 & 13.7 \\
Area 5 & 0.0 & 0.2 & 0.0 & 1.0 & 6.5 & 0.1 & 0.0 & 25.4 & 0.0 & 0.0 & 11.0 & 6.9 \\
Average & $\mathbf{0 . 0}$ & $\mathbf{0 . 3}$ & $\mathbf{0 . 1}$ & $\mathbf{1 . 3}$ & $\mathbf{6 . 0}$ & $\mathbf{0 . 1}$ & $\mathbf{0 . 0}$ & $\mathbf{1 8 . 3}$ & $\mathbf{0 . 0}$ & $\mathbf{0 . 1}$ & $\mathbf{1 6 . 7}$ & $\mathbf{1 2 . 7}$ \\
\hline
\end{tabular}




\section{SHA2NWL}
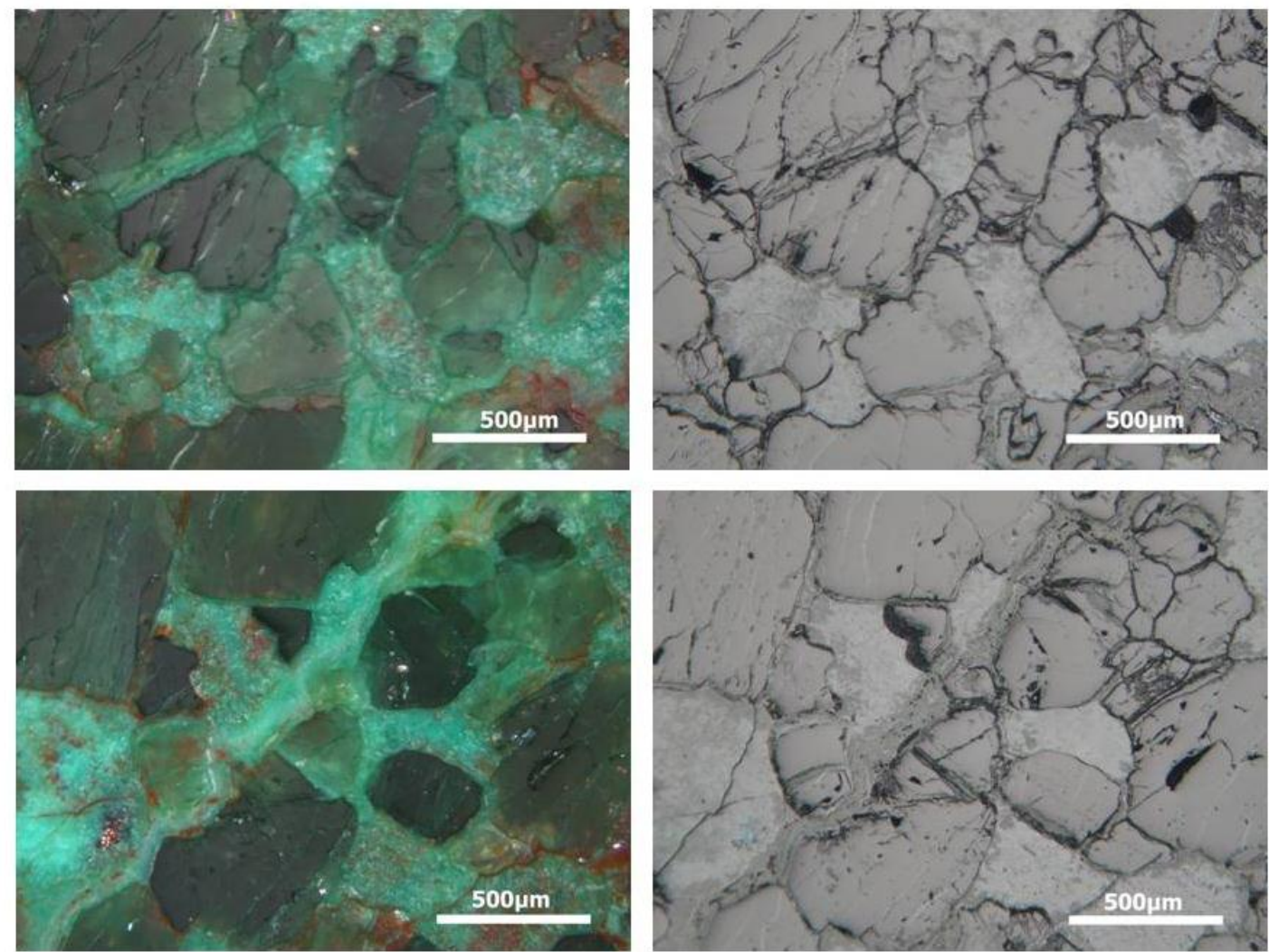

Photomicrographs of sample SHA2NWL: All of the showing grains of quartz associated with green copper compounds. Top left, under cross polarized light (50x). Top right, under plane polarized light (50x). Bottom left, under cross polarized light (50x). Bottom right, under plane polarized light (50x).

Multiple SEM-EDS area scan results of presumed ore sample SHA2NWL

\begin{tabular}{lrrrrrrrrrrrrr}
\hline SHA2NWL & Na2O & MgO & Al2O3 & SiO2 & P2O3 & SO3 & K2O & CaO & TiO2 & MnO & FeO & CuO & BaO \\
\hline Area 1 & 0.0 & 12.2 & 0.0 & 49.6 & 0.1 & 1.5 & 0.1 & 15.7 & 0.2 & 0.1 & 4.8 & 19.8 & 2.3 \\
Area 2 & 0.0 & 11.6 & 0.0 & 50.1 & 0.2 & 1.1 & 0.1 & 15.4 & 0.1 & 0.1 & 5.6 & 17.2 & 1.6 \\
Area 3 & 0.0 & 10.1 & 0.0 & 40.3 & 1.8 & 0.6 & 0.1 & 14.0 & 0.2 & 0.0 & 4.3 & 24.9 & 0.8 \\
Area 4 & 0.1 & 9.7 & 0.0 & 38.8 & 1.3 & 0.9 & 0.0 & 12.4 & 0.1 & 0.1 & 4.4 & 24.3 & 1.3 \\
Area 5 & 0.0 & 8.7 & 0.0 & 35.3 & 0.3 & 2.0 & 0.0 & 9.9 & 0.0 & 0.1 & 3.7 & 24.7 & 3.7 \\
Average & $\mathbf{0 . 0}$ & $\mathbf{1 0 . 5}$ & $\mathbf{0 . 0}$ & $\mathbf{4 2 . 8}$ & $\mathbf{0 . 7}$ & $\mathbf{1 . 2}$ & $\mathbf{0 . 1}$ & $\mathbf{1 3 . 5}$ & $\mathbf{0 . 1}$ & $\mathbf{0 . 1}$ & $\mathbf{4 . 5}$ & $\mathbf{2 2 . 2}$ & $\mathbf{1 . 9}$ \\
\hline
\end{tabular}




\section{SHA11NEL}
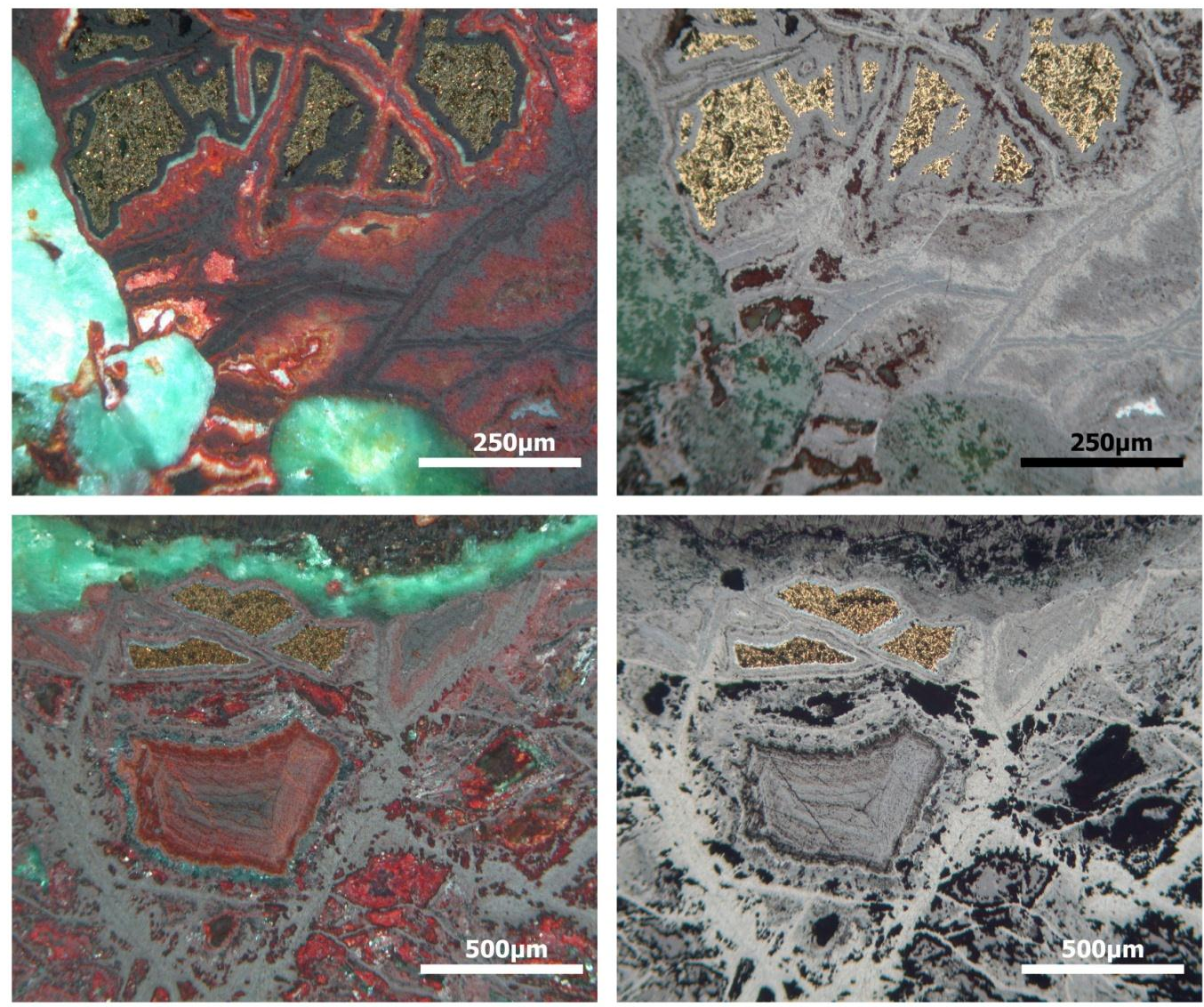

Photomicrographs of sample SHA11NEL: Showing green malachite, red matrix rich in copper and iron carbonates and hydroxides together with residual sulphides with a brassy colour. Top left, under cross polarized light (100x). Top right, under plane polarized light (100x). Bottom left, under cross polarized light (50x) Bottom right, under plane polarized light (50x).

Multiple SEM-EDS area scan results of presumed ore sample SHA11NEL

\begin{tabular}{lrrrrrrrrrrrrr}
\hline SHA11NEL & Na2O & MgO & Al2O3 & SiO2 & P2O5 & SO3 & K2O & CaO & TiO2 & MnO & FeO & CuO & BaO \\
\hline Area 1 & 0.0 & 0.2 & 0.1 & 2.3 & 0.6 & 0.2 & 0.0 & 4.4 & 0.0 & 0.0 & 39.8 & 29.2 & 0.1 \\
Area 2 & 0.0 & 0.1 & 0.2 & 2.7 & 0.5 & 0.8 & 0.0 & 6.7 & 0.0 & 0.1 & 39.9 & 26.1 & 0.2 \\
Area 3 & 0.0 & 0.1 & 0.2 & 2.6 & 0.2 & 2.1 & 0.0 & 2.1 & 0.0 & 0.0 & 40.2 & 32.0 & 0.2 \\
Area 4 & 0.0 & 0.1 & 0.0 & 2.0 & 0.3 & 2.3 & 0.0 & 0.6 & 0.0 & 0.1 & 23.4 & 47.8 & 0.1 \\
Area 5 & 0.0 & 0.1 & 0.2 & 1.6 & 0.4 & 0.5 & 0.0 & 0.5 & 0.1 & 0.0 & 21.8 & 48.0 & 0.0 \\
Area 6 & 0.0 & 0.1 & 0.2 & 2.3 & 0.8 & 0.7 & 0.0 & 0.5 & 0.0 & 0.0 & 39.5 & 32.2 & 0.2 \\
Average & $\mathbf{0 . 0}$ & $\mathbf{0 . 1}$ & $\mathbf{0 . 1}$ & $\mathbf{2 . 3}$ & $\mathbf{0 . 5}$ & $\mathbf{1 . 1}$ & $\mathbf{0 . 0}$ & $\mathbf{2 . 4}$ & $\mathbf{0 . 0}$ & $\mathbf{0 . 0}$ & $\mathbf{3 4 . 1}$ & $\mathbf{3 5 . 9}$ & $\mathbf{0 . 1}$ \\
\hline
\end{tabular}


SHA12NEL

Multiple SEM-EDS area scan results of presumed ore sample SHANEL

\begin{tabular}{lrrrrrrrrrrrrr}
\hline SHA12NEL & Na2O & MgO & Al2O3 & SiO2 & P2O5 & SO3 & K2O & CaO & TiO2 & MnO & FeO & CuO & BaO \\
\hline Area 1 & 0.0 & 0.2 & 0.1 & 1.3 & 0.0 & 0.2 & 0.0 & 4.3 & 0.0 & 0.1 & 8.2 & 55.2 & 0.0 \\
Area 2 & 0.0 & 0.0 & 0.2 & 0.9 & 0.2 & 0.3 & 0.1 & 4.4 & 0.0 & 0.0 & 5.3 & 59.6 & 0.0 \\
Area 3 & 0.0 & 0.1 & 0.2 & 0.9 & 0.0 & 0.0 & 0.0 & 6.8 & 0.0 & 0.0 & 9.7 & 53.8 & 0.3 \\
Area 4 & 0.0 & 0.3 & 0.0 & 1.9 & 0.5 & 0.2 & 0.0 & 30.8 & 0.0 & 0.0 & 29.9 & 4.7 & 0.0 \\
Area 5 & 0.0 & 0.3 & 0.2 & 2.1 & 0.5 & 0.3 & 0.0 & 24.3 & 0.0 & 0.2 & 35.0 & 2.3 & 0.0 \\
Area 6 & 0.0 & 0.4 & 0.1 & 2.2 & 0.4 & 0.2 & 0.0 & 27.9 & 0.2 & 0.1 & 34.2 & 3.0 & 0.1 \\
Average & $\mathbf{0 . 0}$ & $\mathbf{0 . 2}$ & $\mathbf{0 . 1}$ & $\mathbf{1 . 5}$ & $\mathbf{0 . 3}$ & $\mathbf{0 . 2}$ & $\mathbf{0 . 0}$ & $\mathbf{1 6 . 4}$ & $\mathbf{0 . 0}$ & $\mathbf{0 . 1}$ & $\mathbf{2 0 . 4}$ & $\mathbf{2 9 . 7}$ & $\mathbf{0 . 1}$ \\
\hline
\end{tabular}




\section{SHA13NEL}
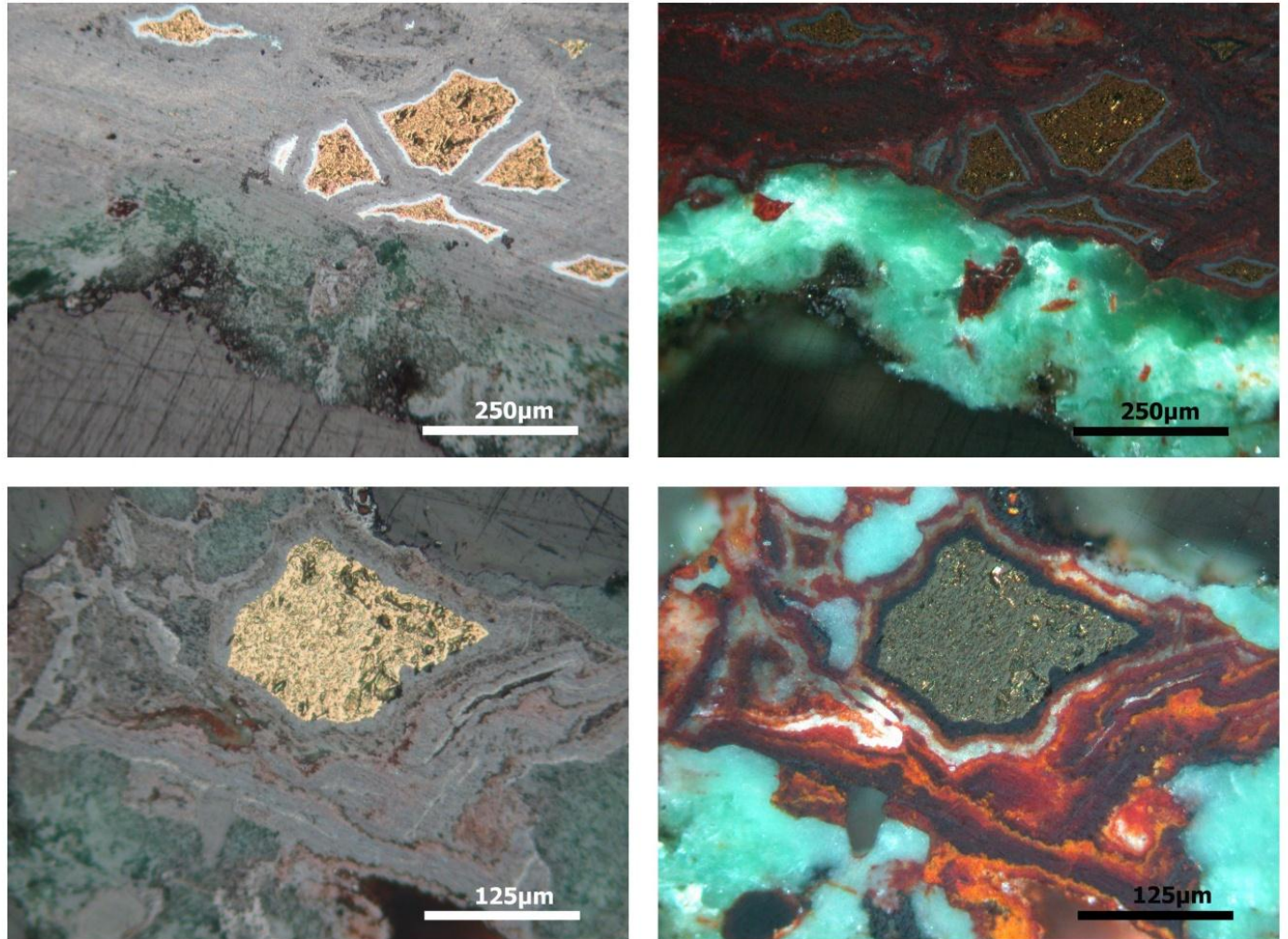

Photomicrographs of sample SHA13NEL: Showing green malachite, red matrix rich in copper and iron carbonates and hydroxides together with residual sulphides with a brassy colour. Top left, under plane polarized light (100x). Top right, under cross polarized light (100x). Bottom left, under plane polarized light (200x) Bottom right, under cross polarized light (200x).

Multiple SEM-EDS area scan results of presumed ore sample SHA13NEL

\begin{tabular}{lrrrrrrrrrrrrr}
\hline SHA13NEL & Na2O & MgO & Al2O3 & SiO2 & P2O5 & SO3 & K2O & CaO & TiO2 & MnO & FeO & CuO & BaO \\
\hline Area 1 & 0.0 & 0.2 & 0.1 & 0.0 & 0.4 & 0.0 & 0.1 & 0.0 & 0.2 & 0.0 & 2.1 & 67.2 & 0.0 \\
Area 2 & 0.0 & 0.0 & 0.1 & 0.2 & 0.3 & 0.0 & 0.0 & 0.0 & 0.0 & 0.0 & 0.4 & 67.2 & 0.0 \\
Area 3 & 0.0 & 0.2 & 0.4 & 0.9 & 0.2 & 0.0 & 0.0 & 0.1 & 0.0 & 0.0 & 11.5 & 56.5 & 0.1 \\
Area 4 & 0.0 & 0.2 & 0.0 & 0.2 & 0.1 & 0.3 & 0.0 & 0.1 & 0.1 & 0.1 & 0.4 & 65.4 & 0.0 \\
Area 5 & 0.0 & 0.1 & 0.3 & 2.0 & 0.7 & 0.1 & 0.0 & 0.3 & 0.0 & 0.1 & 27.0 & 41.5 & 0.0 \\
Average & $\mathbf{0 . 0}$ & $\mathbf{0 . 2}$ & $\mathbf{0 . 2}$ & $\mathbf{0 . 7}$ & $\mathbf{0 . 3}$ & $\mathbf{0 . 1}$ & $\mathbf{0 . 0}$ & $\mathbf{0 . 1}$ & $\mathbf{0 . 1}$ & $\mathbf{0 . 0}$ & $\mathbf{8 . 3}$ & $\mathbf{5 9 . 6}$ & $\mathbf{0 . 0}$ \\
\hline
\end{tabular}




\section{SHA14NEL}

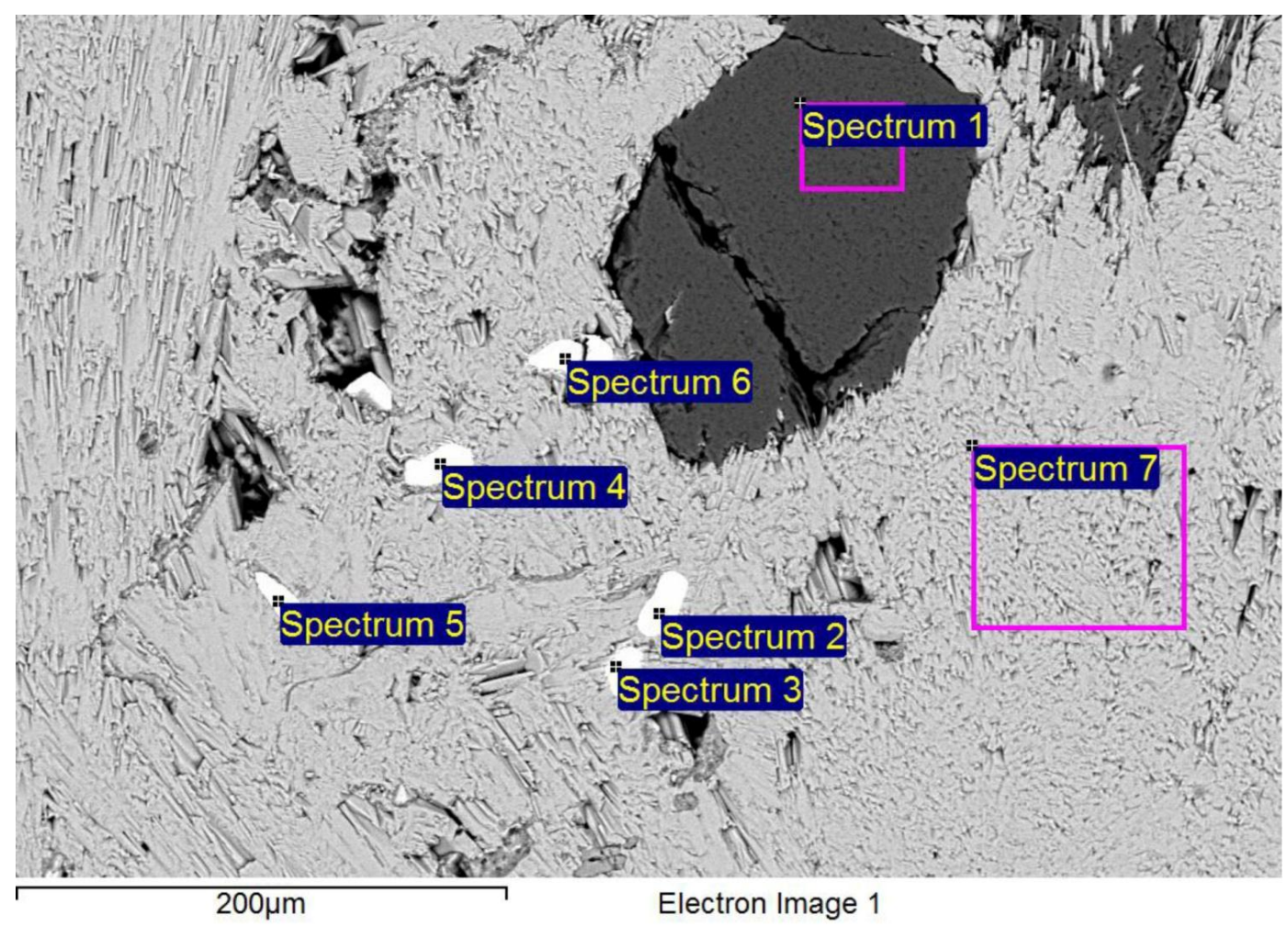

\begin{tabular}{lrrrrrrrr}
\hline \multicolumn{1}{l}{ SEM-EDS results of sample SHA14NEL. Results in w\% \& } & normalised to 100\%. & \\
\hline SHA14NEL & P2O5 & CaO & FeO & CuO & La2O3 & Ce2O3 & Pr2O3 & Nd2O3 \\
\hline Spectrum 1 & & 95.5 & & 4.5 & & & & \\
Spectrum 2 & 29.8 & & 4.1 & 20.1 & 33.5 & 3.7 & 8.8 \\
Spectrum 3 & 31.1 & & 4.0 & 19.1 & 33.6 & 3.4 & 8.9 \\
Spectrum 4 & 28.4 & & 3.6 & 21.0 & 34.2 & 3.4 & 9.4 \\
Spectrum 5 & 28.4 & & 5.1 & 20.9 & 34.7 & 2.9 & 7.9 \\
Spectrum 6 & 29.0 & & 4.2 & 19.7 & 35.2 & 3.2 & 8.7 \\
Spectrum 7 & & 0.5 & 99.5 & & & & \\
\hline
\end{tabular}

Multiple SEM-EDS area scan results of presumed ore sample SHA14NEL

\begin{tabular}{lrrrrrrrrrrrrr}
\hline SHA14NEL & Na2O & MgO & Al2O3 & SiO2 & P2O5 & SO3 & K2O & CaO & TiO2 & MnO & FeO & CuO & BaO \\
\hline Area 1 & 0.0 & 0.0 & 0.1 & 0.6 & 0.0 & 0.2 & 0.0 & 5.5 & 0.0 & 0.0 & 4.5 & 59.1 & 0.0 \\
Area 2 & 0.0 & 0.1 & 0.0 & 0.5 & 0.1 & 0.0 & 0.1 & 3.4 & 0.0 & 0.1 & 2.5 & 63.3 & 0.2 \\
Area 3 & 0.0 & 0.1 & 0.2 & 0.1 & 0.0 & 0.2 & 0.0 & 1.6 & 0.0 & 0.0 & 1.2 & 66.0 & 0.0 \\
Area 4 & 0.1 & 0.0 & 0.2 & 0.1 & 0.1 & 0.1 & 0.0 & 3.5 & 0.2 & 0.0 & 2.2 & 62.0 & 0.0 \\
Area 5 & 0.0 & 0.0 & 0.0 & 0.2 & 0.1 & 0.0 & 0.0 & 0.5 & 0.1 & 0.0 & 3.5 & 64.4 & 0.0 \\
Area 6 & 0.0 & 0.2 & 0.2 & 1.8 & 0.3 & 0.1 & 0.0 & 29.0 & 0.0 & 0.0 & 31.6 & 2.5 & 0.0 \\
Area 7 & 0.1 & 0.3 & 0.1 & 2.1 & 0.4 & 0.3 & 0.0 & 25.0 & 0.0 & 0.1 & 31.9 & 2.1 & 0.0 \\
Average & $\mathbf{0 . 0}$ & $\mathbf{0 . 1}$ & $\mathbf{0 . 1}$ & $\mathbf{0 . 8}$ & $\mathbf{0 . 2}$ & $\mathbf{0 . 1}$ & $\mathbf{0 . 0}$ & $\mathbf{9 . 8}$ & $\mathbf{0 . 1}$ & $\mathbf{0 . 0}$ & $\mathbf{1 1 . 0}$ & $\mathbf{4 5 . 6}$ & $\mathbf{0 . 0}$ \\
\hline
\end{tabular}




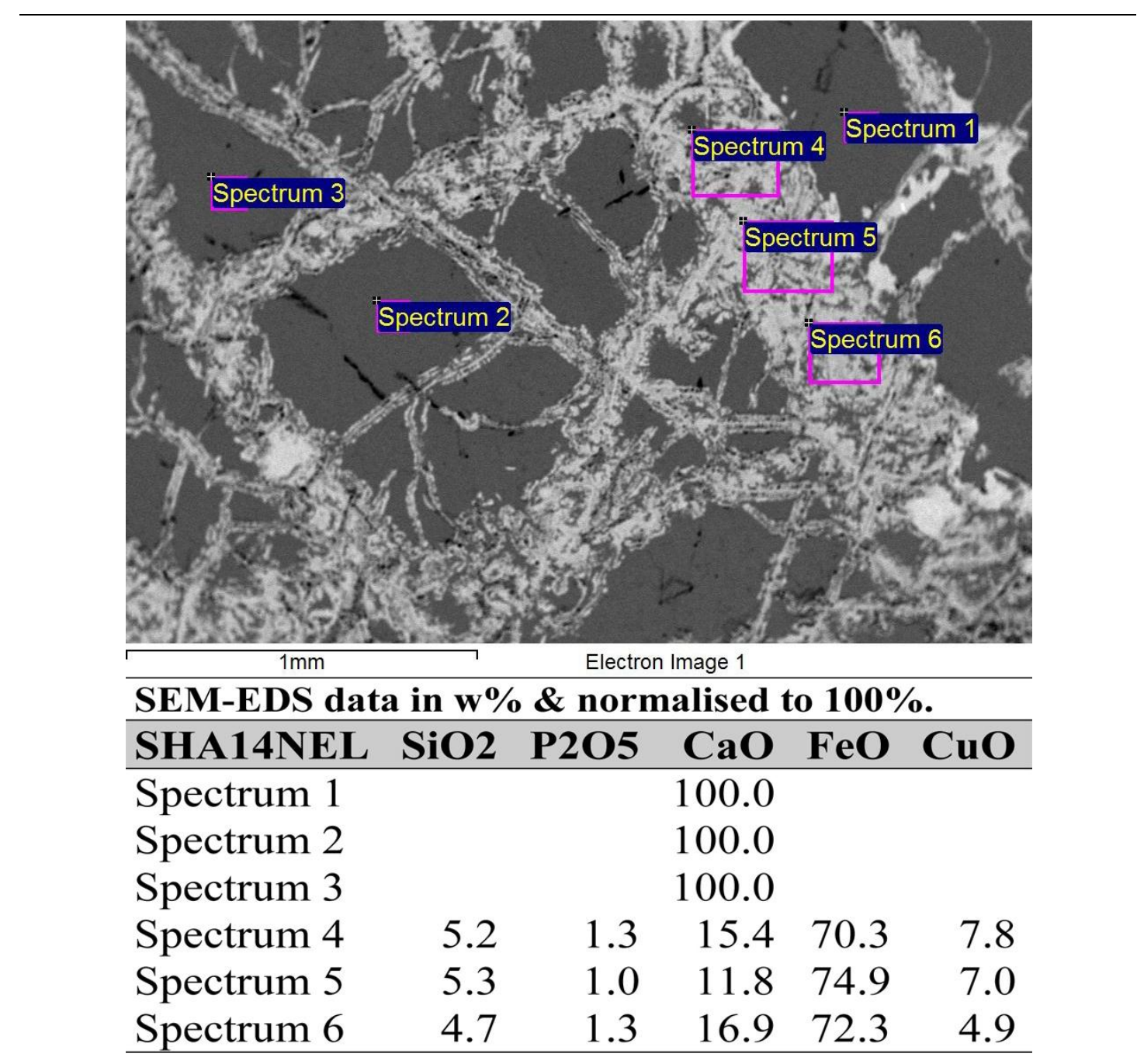




\section{SHA15NEL}
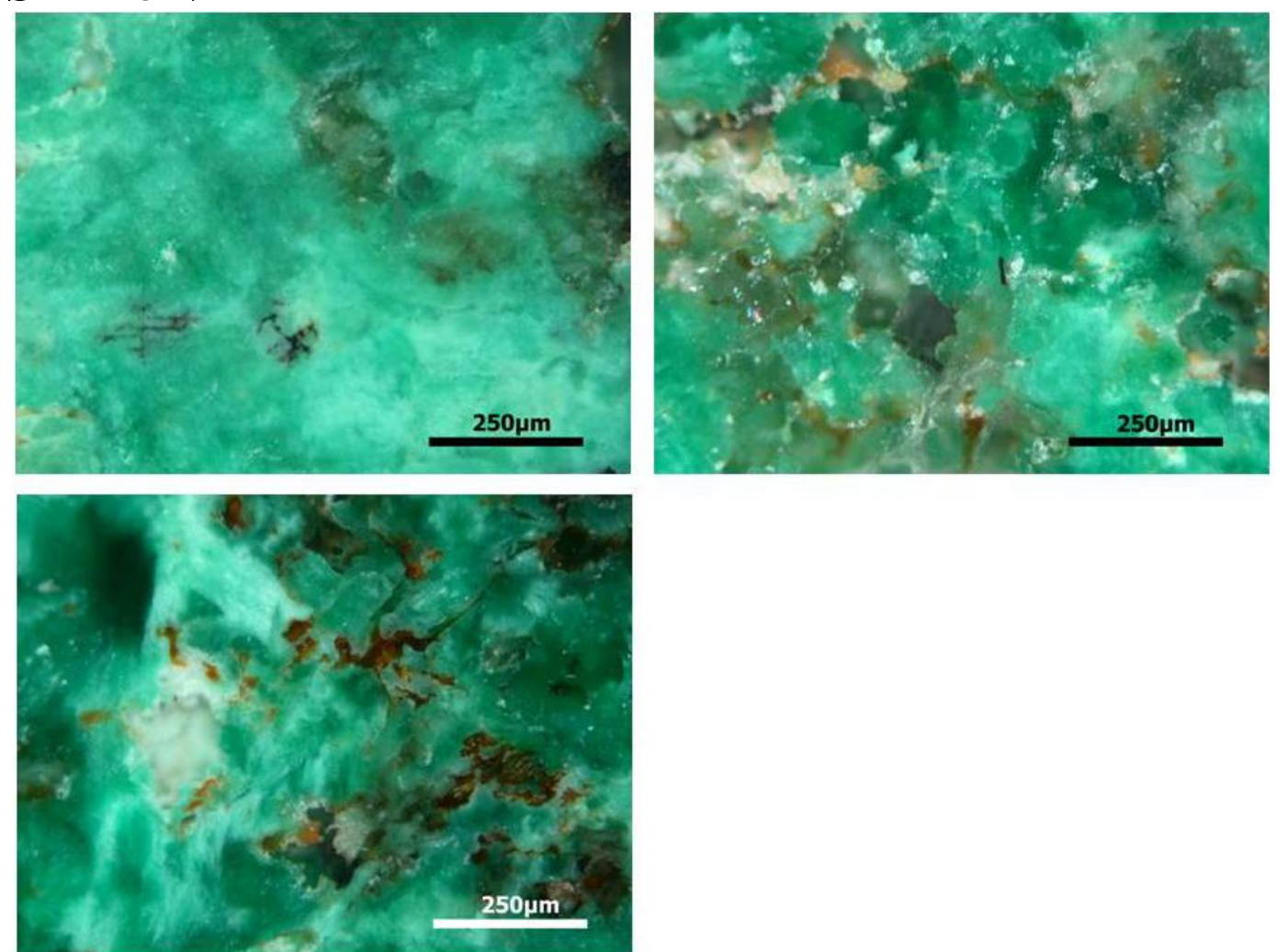

Photomicrographs of sample SHA15NEL: Showing the dominant malachite free of other gangue material. All micrographs are taken under cross polarized light (100x).

Multiple SEM-EDS area scan results of presumed ore sample SHA15NEL

\begin{tabular}{lrrrrrrrrrrrrr}
\hline SHA15NEL & Na2O & MgO & Al2O3 & SiO2 & P2O5 & SO3 & K2O & CaO & TiO2 & MnO & FeO & CuO & BaO \\
\hline Area 1 & 0.0 & 0.3 & 0.8 & 2.7 & 0.2 & 0.3 & 0.1 & 0.9 & 0.0 & 0.0 & 0.4 & 57.7 & 0.0 \\
Area 2 & 0.0 & 0.4 & 0.4 & 0.7 & 0.4 & 0.0 & 0.0 & 0.7 & 0.0 & 0.0 & 0.2 & 59.3 & 0.0 \\
Area 3 & 0.0 & 0.3 & 0.5 & 0.8 & 0.2 & 0.0 & 0.1 & 1.7 & 0.0 & 0.0 & 0.1 & 59.0 & 0.1 \\
Area 4 & 0.0 & 0.5 & 0.9 & 5.4 & 0.4 & 0.0 & 0.0 & 1.3 & 0.0 & 0.3 & 0.4 & 54.8 & 0.0 \\
Area 5 & 0.0 & 0.3 & 0.3 & 0.9 & 0.4 & 0.0 & 0.0 & 0.2 & 0.0 & 0.0 & 0.2 & 59.0 & 0.2 \\
Average & $\mathbf{0 . 0}$ & $\mathbf{0 . 4}$ & $\mathbf{0 . 6}$ & $\mathbf{2 . 1}$ & $\mathbf{0 . 3}$ & $\mathbf{0 . 0}$ & $\mathbf{0 . 0}$ & $\mathbf{1 . 0}$ & $\mathbf{0 . 0}$ & $\mathbf{0 . 1}$ & $\mathbf{0 . 3}$ & $\mathbf{5 7 . 9}$ & $\mathbf{0 . 1}$ \\
\hline
\end{tabular}




\section{SHA16NEL}
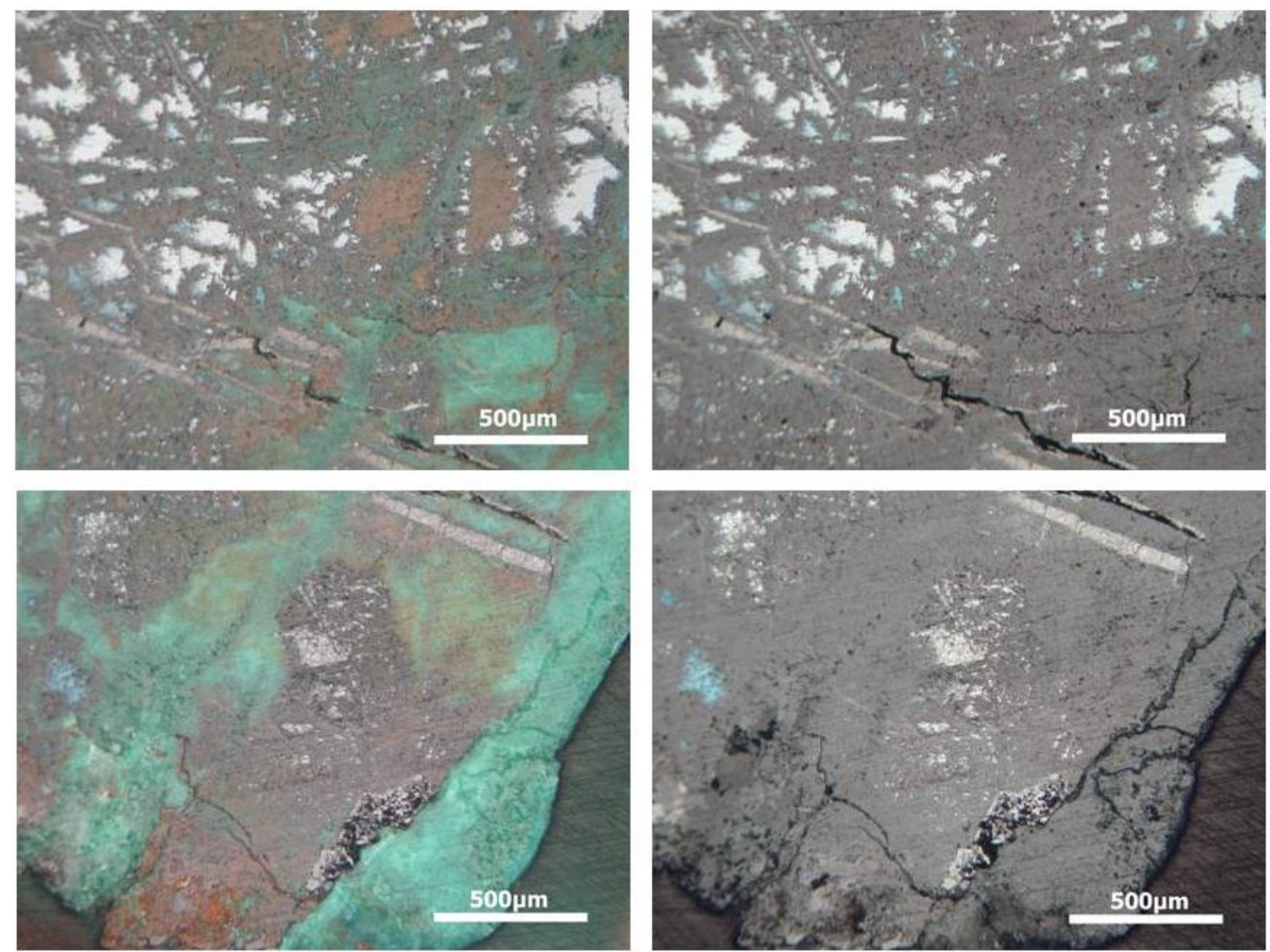

Photomicrographs sample SHA16NEL: Showing chalcocite appearing as bright phase together with the green copper mineral. Top left \& Bottom left: under cross polarized light (50x). Top right \& Bottom right: under plane polarised light (50x).

Multiple SEM-EDS area scan results of presumed ore sample SHA16NEL

\begin{tabular}{lrrrrrrrrrrrrr}
\hline SHA16NEL & Na2O & MgO & Al2O3 & SiO2 & P2O5 & SO3 & K2O & CaO & TiO2 & MnO & FeO & CuO & BaO \\
\hline Area 1 & 0.0 & 0.3 & 0.1 & 0.8 & 0.5 & 6.1 & 0.1 & 0.2 & 0.0 & 0.1 & 3.4 & 58.6 & 0.0 \\
Area 2 & 0.0 & 0.3 & 0.1 & 3.0 & 0.0 & 4.2 & 0.0 & 0.1 & 0.1 & 0.1 & 4.7 & 53.8 & 0.0 \\
Area 3 & 0.0 & 0.4 & 0.1 & 0.8 & 0.4 & 4.7 & 0.0 & 0.5 & 0.3 & 0.0 & 6.2 & 52.6 & 0.0 \\
Area 4 & 0.0 & 0.0 & 0.0 & 1.1 & 0.1 & 4.2 & 0.0 & 0.1 & 0.0 & 0.1 & 3.1 & 55.8 & 0.0 \\
Area 5 & 0.0 & 0.4 & 0.0 & 1.1 & 0.2 & 3.2 & 0.1 & 0.2 & 0.0 & 0.0 & 4.7 & 52.9 & 0.2 \\
Average & $\mathbf{0 . 0}$ & $\mathbf{0 . 3}$ & $\mathbf{0 . 1}$ & $\mathbf{1 . 3}$ & $\mathbf{0 . 2}$ & $\mathbf{4 . 5}$ & $\mathbf{0 . 0}$ & $\mathbf{0 . 2}$ & $\mathbf{0 . 1}$ & $\mathbf{0 . 1}$ & $\mathbf{4 . 4}$ & $\mathbf{5 4 . 7}$ & $\mathbf{0 . 1}$ \\
\hline
\end{tabular}




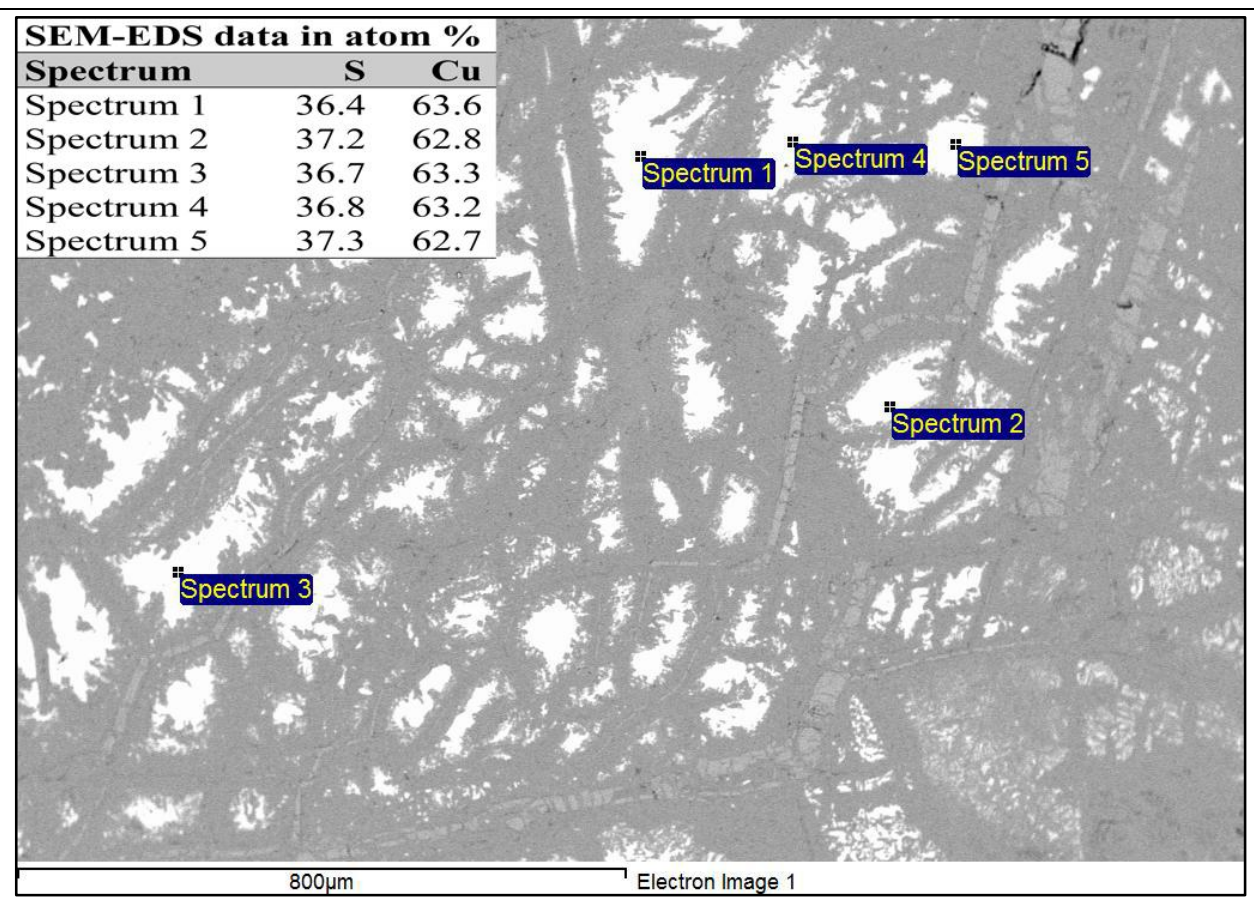

SEM-BSE image showing the prevalent chalcocite in sample SHA16NEL. 


\section{SMB22(4)}
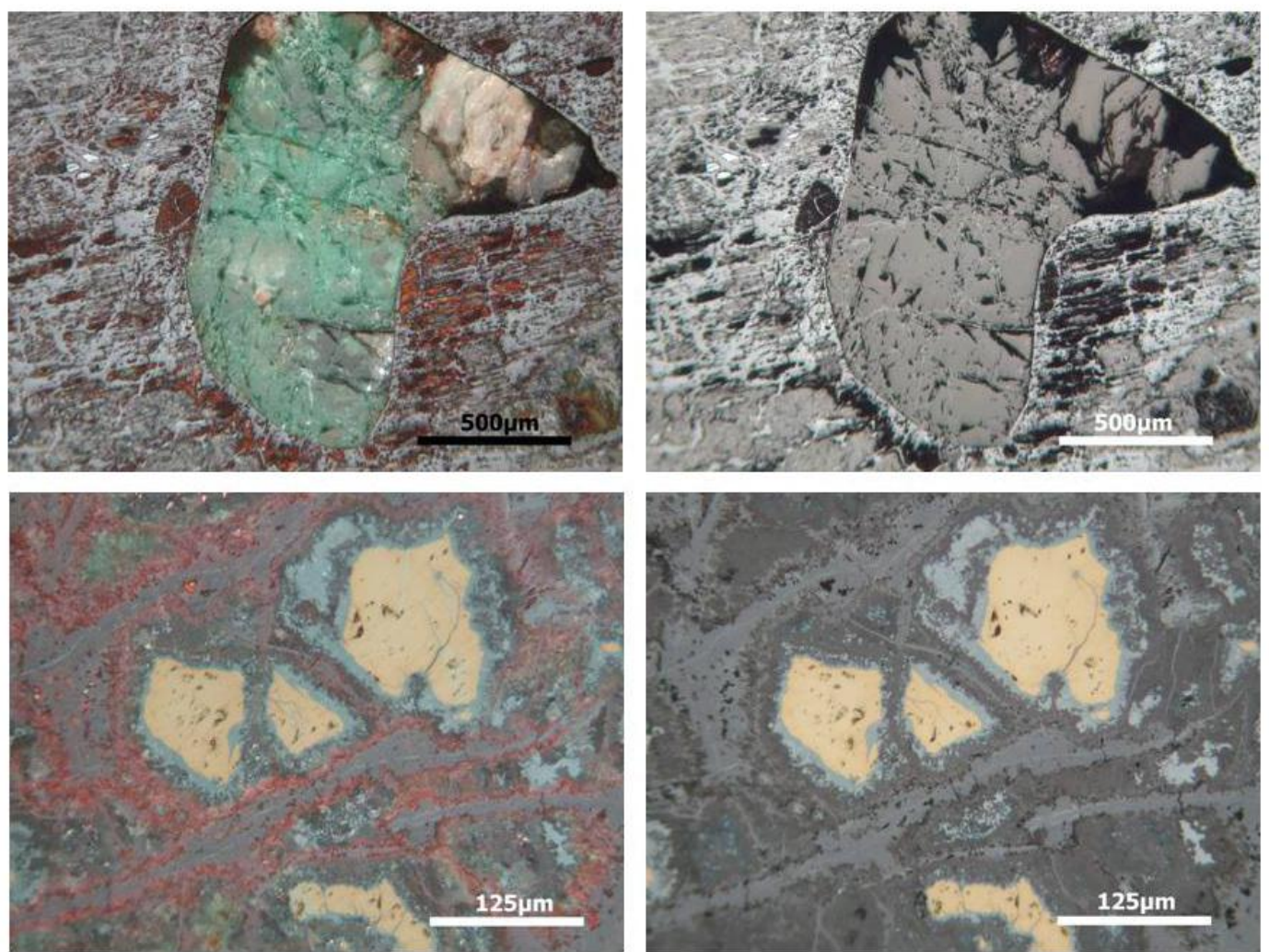

Photomicrographs sample SMB22(4): Showing green malachite, red matrix rich in copper and iron carbonates and hydroxides together with residual sulphides with a brassy colour. Top left, under cross polarized light (50x). Top right, under plane polarized light (50x). Bottom left, under cross polarized light (200x). Bottom right, under plane polarized light (200x).

Multiple SEM-EDS area scan results of presumed ore sample SMB22(4)

\begin{tabular}{lrrrrrrrrrrrrr}
\hline SMB22(4) & Na2O & MgO & Al2O3 & SiO2 & P2O5 & SO3 & K2O & CaO & TiO2 & MnO & FeO & CuO & BaO \\
\hline Area 1 & 0.0 & 2.1 & 1.6 & 0.2 & 0.0 & 0.1 & 0.1 & 0.0 & 0.0 & 0.1 & 79.0 & 0.1 & 0.0 \\
Area 2 & 0.0 & 2.4 & 2.2 & 0.2 & 0.2 & 0.0 & 0.0 & 0.3 & 0.0 & 0.1 & 77.1 & 0.2 & 0.0 \\
Area 3 & 0.2 & 2.3 & 2.2 & 0.4 & 0.0 & 0.0 & 0.0 & 1.0 & 0.1 & 0.1 & 76.4 & 0.3 & 0.0 \\
Area 4 & 0.0 & 0.2 & 0.3 & 2.7 & 0.7 & 0.1 & 0.0 & 0.4 & 0.0 & 0.1 & 38.2 & 18.9 & 0.0 \\
Area 5 & 0.0 & 0.1 & 0.1 & 2.4 & 0.7 & 0.0 & 0.0 & 0.5 & 0.0 & 0.1 & 43.3 & 18.1 & 0.0 \\
Average & $\mathbf{0 . 0}$ & $\mathbf{1 . 4}$ & $\mathbf{1 . 3}$ & $\mathbf{1 . 2}$ & $\mathbf{0 . 3}$ & $\mathbf{0 . 0}$ & $\mathbf{0 . 0}$ & $\mathbf{0 . 4}$ & $\mathbf{0 . 0}$ & $\mathbf{0 . 1}$ & $\mathbf{6 2 . 8}$ & $\mathbf{7 . 5}$ & $\mathbf{0 . 0}$ \\
\hline
\end{tabular}




\section{SMB22(5)}

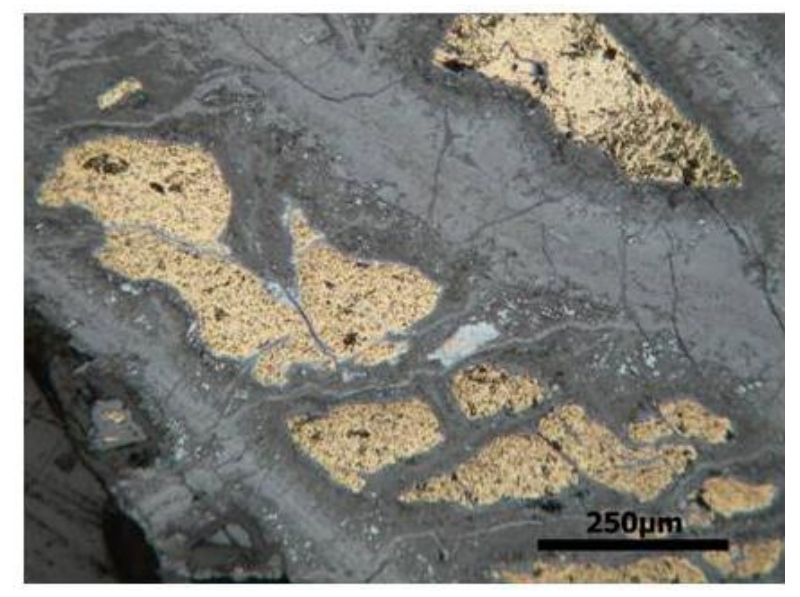

Photomicrograph of sample SMB22(5) showing some residual chalcopyrite with a brassy colour. Under plane polarized light (100x).

Multiple SEM-EDS area scan results of presumed ore sample SMB22(5)

\begin{tabular}{lrrrrrrrrrrrrr}
\hline SMB22(5) & Na2O & MgO & Al2O3 & SiO2 & P2O5 & SO3 & K2O & CaO & TiO2 & MnO & FeO2 & CuO & BaO \\
\hline Area 1 & 0.0 & 0.2 & 0.0 & 7.4 & 1.3 & 2.8 & 0.0 & 0.3 & 0.0 & 0.0 & 32.0 & 32.8 & 0.0 \\
Area 2 & 0.0 & 0.4 & 0.1 & 7.0 & 1.0 & 6.0 & 0.0 & 0.3 & 0.1 & 0.0 & 31.3 & 32.7 & 0.0 \\
Area 3 & 0.0 & 0.5 & 0.0 & 7.1 & 0.3 & 0.1 & 0.0 & 0.4 & 0.1 & 0.0 & 28.0 & 33.7 & 0.0 \\
Area 4 & 0.0 & 0.4 & 0.2 & 7.5 & 0.9 & 0.2 & 0.0 & 0.3 & 0.0 & 0.0 & 23.6 & 36.5 & 0.0 \\
Area 5 & 0.0 & 0.3 & 0.0 & 8.3 & 0.8 & 0.2 & 0.0 & 0.3 & 0.0 & 0.1 & 31.8 & 27.4 & 0.0 \\
Area 6 & 0.0 & 12.5 & 0.0 & 5.5 & 0.3 & 0.0 & 0.1 & 15.0 & 0.0 & 0.4 & 5.8 & 16.4 & 0.0 \\
Average & $\mathbf{0 . 0}$ & $\mathbf{2 . 4}$ & $\mathbf{0 . 1}$ & $\mathbf{7 . 1}$ & $\mathbf{0 . 8}$ & $\mathbf{1 . 6}$ & $\mathbf{0 . 0}$ & $\mathbf{2 . 8}$ & $\mathbf{0 . 0}$ & $\mathbf{0 . 1}$ & $\mathbf{2 5 . 4}$ & $\mathbf{2 9 . 9}$ & $\mathbf{0 . 0}$ \\
\hline
\end{tabular}




\section{$\operatorname{SMB26}(2)$}
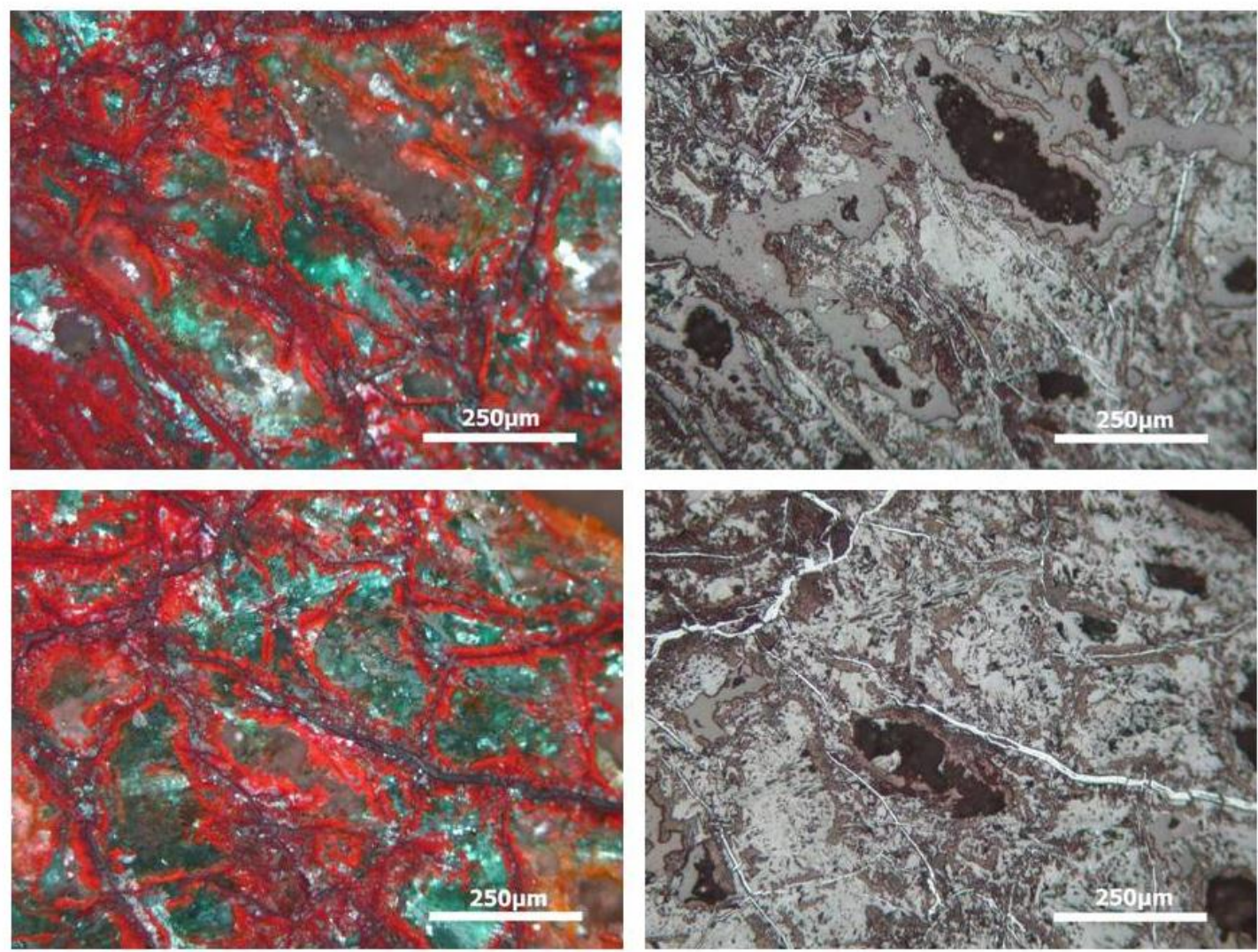

Photomicrographs of sample SMB26(2): Showing the fine grained sample with green copper carbonates. Top left, under cross polarized light (100x). Top right, under plane polarized light (100x). Bottom left, under cross polarized light (100x). Bottom right, under plane polarized light (100x).

Multiple SEM-EDS area scan results of presumed ore sample SMB26(2)

\begin{tabular}{lrrrrrrrrrrrrr}
\hline SMB26(2) & Na2O & MgO & Al2O3 & SiO2 & P2O5 & SO3 & K2O & CaO & TiO2 & MnO & FeO & CuO & BaO \\
\hline Area 1 & 0.0 & 0.1 & 0.0 & 58.8 & 0.0 & 0.0 & 0.0 & 0.3 & 0.0 & 0.0 & 11.0 & 24.8 & 0.0 \\
Area 2 & 0.0 & 0.1 & 0.0 & 54.6 & 0.0 & 0.3 & 0.1 & 0.3 & 0.0 & 0.1 & 13.7 & 24.3 & 0.0 \\
Area 3 & 0.0 & 0.2 & 0.0 & 59.4 & 0.1 & 0.1 & 0.0 & 0.3 & 0.0 & 0.0 & 14.6 & 20.1 & 0.0 \\
Area 4 & 0.0 & 0.0 & 0.0 & 47.3 & 0.2 & 0.2 & 0.0 & 0.3 & 0.0 & 0.0 & 14.5 & 25.4 & 0.0 \\
Area 5 & 0.0 & 0.1 & 0.0 & 58.0 & 0.1 & 0.1 & 0.0 & 1.5 & 0.0 & 0.0 & 14.2 & 19.7 & 0.0 \\
Area 6 & 0.0 & 0.1 & 0.0 & 31.3 & 0.3 & 0.1 & 0.0 & 1.4 & 0.1 & 0.0 & 17.6 & 34.2 & 0.0 \\
Area 7 & 0.0 & 0.0 & 0.0 & 5.6 & 0.0 & 0.2 & 0.0 & 0.0 & 0.0 & 0.0 & 16.1 & 47.5 & 0.0 \\
Average & $\mathbf{0 . 0}$ & $\mathbf{0 . 1}$ & $\mathbf{0 . 0}$ & $\mathbf{4 5 . 0}$ & $\mathbf{0 . 1}$ & $\mathbf{0 . 1}$ & $\mathbf{0 . 0}$ & $\mathbf{0 . 6}$ & $\mathbf{0 . 0}$ & $\mathbf{0 . 0}$ & $\mathbf{1 4 . 5}$ & $\mathbf{2 8 . 0}$ & $\mathbf{0 . 0}$ \\
\hline
\end{tabular}




\section{$\operatorname{SMB26(3)}$}
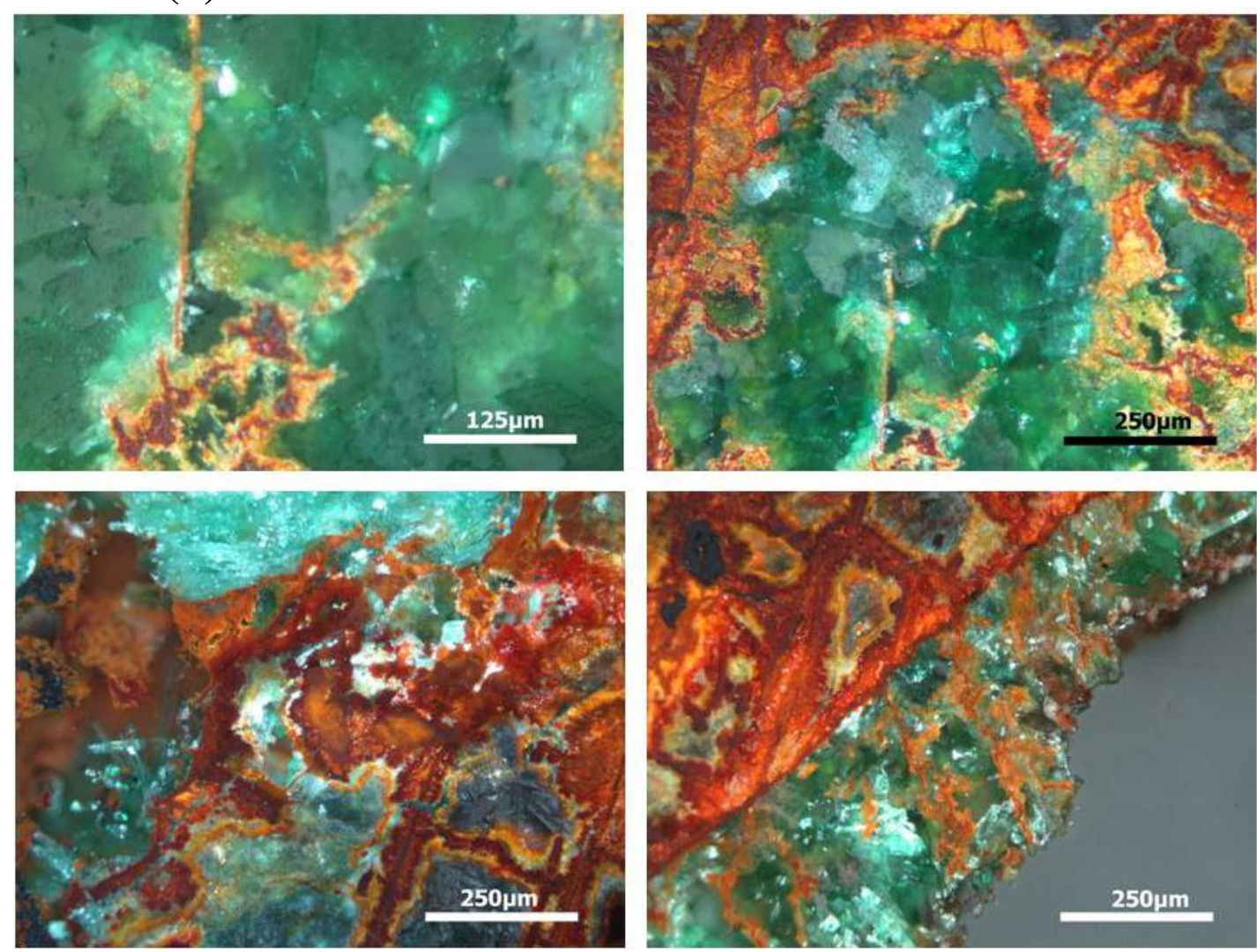

Photomicrographs of sample SMB26(3): showing the dominant green copper carbonates together with the reddish iron hydroxides. All photographs taken under cross polarized light (x100) except for top left taken at (200x).

Multiple SEM-EDS area scan results of presumed ore sample SMB26(3)

\begin{tabular}{lrrrrrrrrrrrrr}
\hline SMB26(3) & Na2O & MgO & Al2O3 & SiO2 & P2O5 & SO3 & K2O & CaO & TiO2 & MnO & FeO & CuO & BaO \\
\hline Area 1 & 0.1 & 0.2 & 0.0 & 2.9 & 0.1 & 0.2 & 0.0 & 0.2 & 0.0 & 0.0 & 31.0 & 28.2 & 0.0 \\
Area 2 & 0.0 & 0.2 & 0.0 & 3.3 & 0.1 & 0.1 & 0.0 & 0.3 & 0.0 & 0.1 & 29.7 & 27.0 & 0.0 \\
Area 3 & 0.0 & 0.1 & 0.2 & 3.6 & 0.0 & 0.1 & 0.0 & 0.2 & 0.0 & 0.2 & 25.4 & 29.1 & 0.0 \\
Area 4 & 0.0 & 0.1 & 0.1 & 2.6 & 0.0 & 0.0 & 0.0 & 0.3 & 0.0 & 0.1 & 25.1 & 28.1 & 0.0 \\
Area 5 & 0.0 & 0.2 & 0.1 & 2.9 & 0.0 & 0.4 & 0.0 & 0.2 & 0.1 & 0.1 & 28.2 & 23.7 & 0.0 \\
Average & $\mathbf{0 . 0}$ & $\mathbf{0 . 2}$ & $\mathbf{0 . 1}$ & $\mathbf{3 . 1}$ & $\mathbf{0 . 0}$ & $\mathbf{0 . 2}$ & $\mathbf{0 . 0}$ & $\mathbf{0 . 2}$ & $\mathbf{0 . 0}$ & $\mathbf{0 . 1}$ & $\mathbf{2 7 . 9}$ & $\mathbf{2 7 . 2}$ & $\mathbf{0 . 0}$ \\
\hline
\end{tabular}




\section{$\operatorname{SMB26(4)}$}
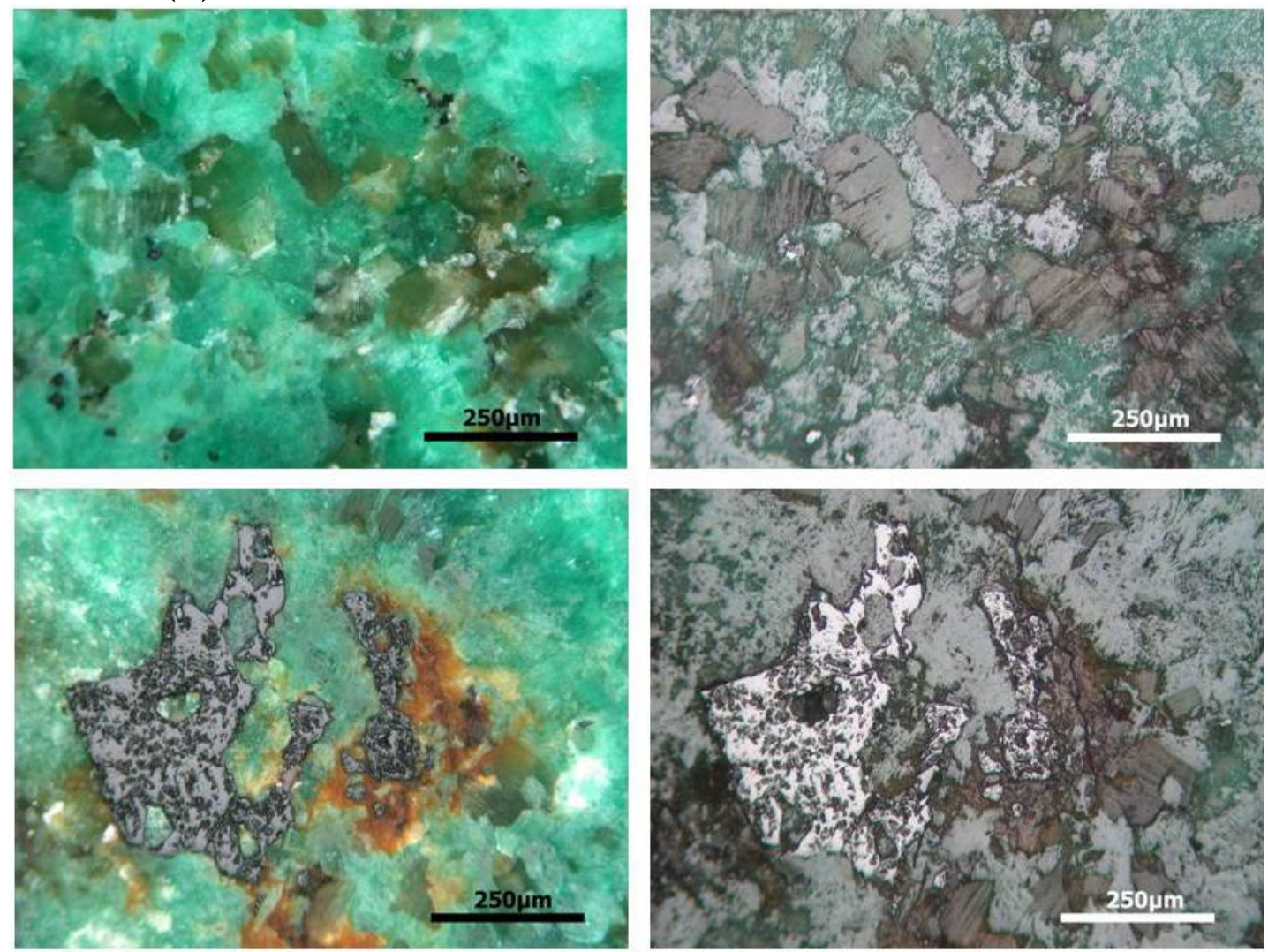

Photomicrographs of sample SMB26(4): showing the dominant green copper carbonates which sometimes encompassed iron oxides magnetite appearing greyish under cross polarized light. Top left, under cross polarized light (100x), Top right, under plane polarized light (100x). Bottom left, under cross polarized light (100x). Bottom right, under plane polarized light (100x).

Multiple SEM-EDS area scan results of presumed ore sample SMB26(4)

\begin{tabular}{lrrrrrrrrrrrrr}
\hline SMB26(4) & Na2O & MgO & Al2O3 & SiO2 & P2O5 & SO3 & K2O & CaO & TiO2 & MnO & FeO & CuO & BaO \\
\hline Area 1 & 0.0 & 4.9 & 1.6 & 5.4 & 0.1 & 0.0 & 0.1 & 0.6 & 0.0 & 0.0 & 0.9 & 59.1 & 0.0 \\
Area 2 & 0.0 & 7.2 & 2.8 & 7.9 & 0.2 & 0.1 & 0.1 & 1.1 & 0.1 & 0.0 & 1.5 & 52.6 & 0.0 \\
Area 3 & 0.0 & 5.3 & 2.2 & 6.3 & 0.2 & 0.0 & 0.0 & 0.6 & 0.0 & 0.0 & 1.7 & 55.6 & 0.0 \\
Area 4 & 0.0 & 8.0 & 2.3 & 8.0 & 0.3 & 0.0 & 0.0 & 0.7 & 0.1 & 0.0 & 0.5 & 54.2 & 0.0 \\
Area 5 & 0.0 & 4.4 & 1.4 & 4.2 & 0.4 & 0.0 & 0.0 & 0.5 & 0.0 & 0.1 & 0.7 & 59.5 & 0.0 \\
Average & $\mathbf{0 . 0}$ & $\mathbf{6 . 0}$ & $\mathbf{2 . 1}$ & $\mathbf{6 . 4}$ & $\mathbf{0 . 2}$ & $\mathbf{0 . 0}$ & $\mathbf{0 . 0}$ & $\mathbf{0 . 7}$ & $\mathbf{0 . 0}$ & $\mathbf{0 . 0}$ & $\mathbf{1 . 1}$ & $\mathbf{5 6 . 2}$ & $\mathbf{0 . 0}$ \\
\hline
\end{tabular}




\section{$\operatorname{SMB27(1)}$}
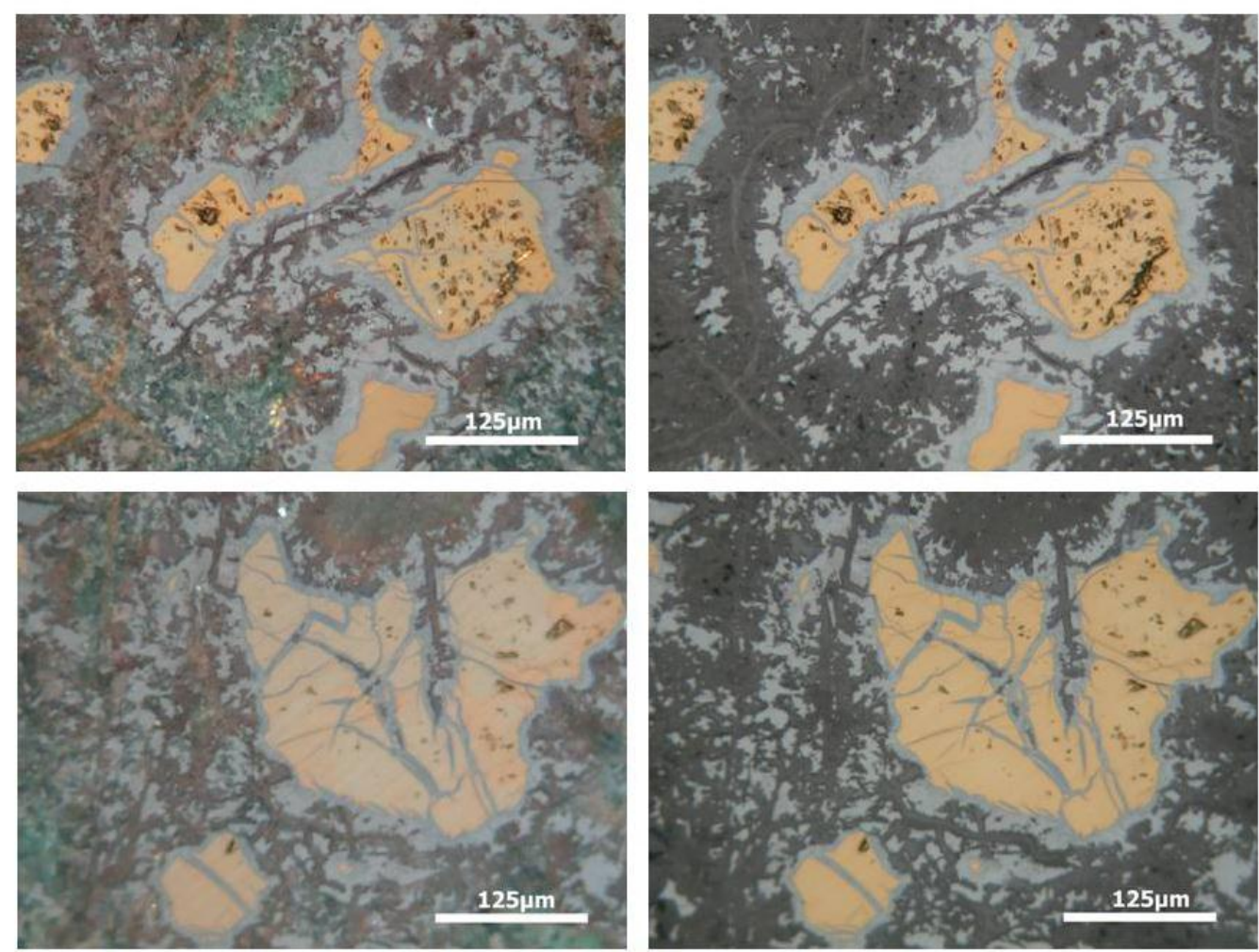

Photomicrographs of sample SMB27(1): All the micrographs are showing the residual chalcopyrite with a brassy colour surrounded by light blue chalcocite. The pictures were taken at 200x magnification. Top left and bottom left, under cross polarized light. Top right and bottom, right under plane polarized light.

Multiple SEM-EDS area scan results of presumed ore sample SMB27(1)

\begin{tabular}{lrrrrrrrrrrrrr}
\hline SMB27(1) & Na2O & MgO & Al2O3 & SiO2 & P2O5 & SO3 & K2O & CaO & TiO2 & MnO & FeO & CuO & BaO \\
\hline Area 1 & 0.0 & 0.3 & 0.2 & 1.1 & 0.0 & 2.6 & 0.0 & 6.3 & 0.0 & 0.0 & 5.4 & 52.3 & 0.0 \\
Area 2 & 0.0 & 0.3 & 0.1 & 0.5 & 0.0 & 4.2 & 0.0 & 0.1 & 0.0 & 0.0 & 3.4 & 62.4 & 0.0 \\
Area 3 & 0.0 & 0.4 & 0.3 & 0.6 & 0.1 & 3.7 & 0.0 & 1.6 & 0.1 & 0.0 & 2.4 & 59.9 & 0.0 \\
Area 4 & 0.0 & 0.1 & 0.2 & 1.6 & 0.2 & 1.2 & 0.0 & 5.8 & 0.1 & 0.0 & 10.0 & 44.6 & 0.0 \\
Area 5 & 0.0 & 0.3 & 0.0 & 2.1 & 0.2 & 0.9 & 0.1 & 8.3 & 0.0 & 0.0 & 9.5 & 44.2 & 0.0 \\
Average & $\mathbf{0 . 0}$ & $\mathbf{0 . 3}$ & $\mathbf{0 . 2}$ & $\mathbf{1 . 2}$ & $\mathbf{0 . 1}$ & $\mathbf{2 . 5}$ & $\mathbf{0 . 0}$ & $\mathbf{4 . 4}$ & $\mathbf{0 . 0}$ & $\mathbf{0 . 0}$ & $\mathbf{6 . 2}$ & $\mathbf{5 2 . 7}$ & $\mathbf{0 . 0}$ \\
\hline
\end{tabular}


SPK 31

Multiple SEM-EDS area scan results of presumed ore sample SPK3 1

\begin{tabular}{lrrrrrrrrrrrrr}
\hline SPK3 1 & Na2O & MgO & Al2O3 & SiO2 & P2O5 & SO3 & K2O & CaO & TiO2 & MnO & FeO & CuO & BaO \\
\hline Area 1 & 0.0 & 0.1 & 0.0 & 5.1 & 0.2 & 13.0 & 0.0 & 0.2 & 0.0 & 0.0 & 45.1 & 19.3 & 1.1 \\
Area 2 & 0.0 & 0.1 & 0.0 & 4.3 & 0.0 & 16.3 & 0.0 & 0.2 & 0.1 & 0.1 & 42.9 & 23.6 & 0.9 \\
Area 3 & 0.0 & 0.0 & 0.1 & 4.1 & 0.1 & 10.3 & 0.0 & 0.1 & 0.1 & 0.0 & 39.9 & 24.7 & 0.9 \\
Area 4 & 0.0 & 0.0 & 0.1 & 4.7 & 0.1 & 6.3 & 0.0 & 0.2 & 0.0 & 0.0 & 40.9 & 21.6 & 1.1 \\
Area 5 & 0.0 & 0.2 & 0.1 & 4.1 & 0.0 & 10.4 & 0.0 & 0.2 & 0.0 & 0.0 & 38.9 & 25.3 & 0.6 \\
Average & $\mathbf{0 . 0}$ & $\mathbf{0 . 1}$ & $\mathbf{0 . 0}$ & $\mathbf{4 . 4}$ & $\mathbf{0 . 1}$ & $\mathbf{1 1 . 3}$ & $\mathbf{0 . 0}$ & $\mathbf{0 . 2}$ & $\mathbf{0 . 0}$ & $\mathbf{0 . 0}$ & $\mathbf{4 1 . 5}$ & $\mathbf{2 2 . 9}$ & $\mathbf{0 . 9}$ \\
\hline
\end{tabular}


SPK3 2

Multiple SEM-EDS area scan results of presumed ore sample SPK3 2

\begin{tabular}{lrrrrrrrrrrrrr}
\hline SPK3 2 & Na2O & MgO & Al2O3 & SiO2 & P2O5 & SO3 & K2O & CaO & TiO2 & MnO & FeO & CuO & BaO \\
\hline Area 1 & 0.0 & 0.2 & 0.0 & 7.4 & 1.3 & 2.8 & 0.0 & 0.3 & 0.0 & 0.0 & 32.0 & 32.7 & 0.3 \\
Area 2 & 0.0 & 0.4 & 0.1 & 7.0 & 1.0 & 6.0 & 0.0 & 0.3 & 0.0 & 0.0 & 31.4 & 32.7 & 0.3 \\
Area 3 & 0.0 & 0.5 & 0.0 & 7.1 & 0.3 & 0.1 & 0.0 & 0.4 & 0.0 & 0.0 & 28.0 & 33.7 & 0.2 \\
Area 4 & 0.0 & 0.4 & 0.2 & 7.5 & 0.9 & 0.2 & 0.0 & 0.3 & 0.0 & 0.0 & 23.6 & 36.5 & 0.1 \\
Area 5 & 0.0 & 0.3 & 0.0 & 8.3 & 0.8 & 0.2 & 0.0 & 0.3 & 0.0 & 0.1 & 31.8 & 27.4 & 0.0 \\
Average & $\mathbf{0 . 0}$ & $\mathbf{0 . 3}$ & $\mathbf{0 . 1}$ & $\mathbf{7 . 5}$ & $\mathbf{0 . 9}$ & $\mathbf{1 . 9}$ & $\mathbf{0 . 0}$ & $\mathbf{0 . 3}$ & $\mathbf{0 . 0}$ & $\mathbf{0 . 0}$ & $\mathbf{2 9 . 4}$ & $\mathbf{3 2 . 6}$ & $\mathbf{0 . 2}$ \\
\hline
\end{tabular}


Appendix 4: The slagged crucible fragments from Shankare Hill

\begin{tabular}{|l|l|l|}
\hline Sample No & Context of recovery & Brief macroscopic description \\
\hline SHA3NWL & Surface find NW of the Hill & $\begin{array}{l}\text { This is a rim part of a ceramic (12mm wall thickness) heavily vitrified with a very thin layer of } \\
\text { slag }(0.5 \mathrm{~mm}) \text {. The ceramic fabric is dark black to brown in colour. }\end{array}$ \\
\hline SMB21(3) & Trench SHAM1/Layer 1 & $\begin{array}{l}\text { This is a thick ceramic fragment (11mm wall thickness) with a light grey fabric. The profile has } \\
\text { two colours dark grey and light grey exterior. A layer of copper and red slag is attached to this } \\
\text { crucible fragment. }\end{array}$ \\
\hline SMB23(2) & Trench SHAM1/Layer 3 & $\begin{array}{l}\text { This is a rim part of ceramic vessel (7mm wall thickness) dark brown in colour with a layer of } \\
\text { black slag (2mm). The ceramic fabric contains large quartz grains. }\end{array}$ \\
\hline SMB27(1) & Trench SHAM1/Layer 7 & $\begin{array}{l}\text { Black ceramic fragment (7mm wall thickness) devoid of large quartz inclusions. Layer of slag } \\
\text { (5mm thick) with visible copper prills (4mm diameter) is attached to this crucible. }\end{array}$ \\
\hline SSHB23(1) & Trench SHASH1/Layer 3 & $\begin{array}{l}\text { Ceramic fragment (7mm wall thickness) with a grey fabric, visible quartz inclusions and a layer } \\
\text { of greenish to grey slag (6mm). }\end{array}$ \\
\hline SSHB23(2) & Trench SHASH1/Layer 3 & Ceramic fragment brown exterior with a grey interior layer (7mm) with a layer of slag (1mm). \\
\hline
\end{tabular}




\section{Appendix 5: The metal artefacts}

This appendix contains a catalogue of copper objects subjected to further analytical studies in this project. The catalogue includes brief macroscopic and microscopic description of the artefacts. Analytical results of individual samples documented in the form of photographs and photomicrographs of the polished sections are also presented. 


\section{Catalogue of copper artefacts subjected to analytical work}

\begin{tabular}{|c|c|c|c|c|c|}
\hline Sample No & Site & Context & Weight (g) & Brief macroscopic description & Brief microscopic description \\
\hline SMB21(2) & Shankare & Trench SHAM1- Layer 1 & 0.53 & $\begin{array}{l}\text { Non-magnetic copper wire c. } 20 \mathrm{~mm} \\
\text { in length. }\end{array}$ & $\begin{array}{l}\text { The wire has been affected by selective corrosion along the } \\
\text { grain boundaries. The microstructure suggests intensive } \\
\text { working. Chemically this sample is pure copper. }\end{array}$ \\
\hline $\operatorname{SMB} 22(3)$ & Shankare & Trench SHAM1- Layer 2 & 0.74 & $\begin{array}{l}\text { Non-magnetic, rounded copper prill } \\
\text { with a green tarnish on the surface } \\
\text { c. } 7 \mathrm{~mm} \text { in diameter. }\end{array}$ & $\begin{array}{l}\text { The fresh metal matrix has limited porosity. The sample } \\
\text { possibly contained slag inclusions which were scratching the } \\
\text { sample during polishing. The only artefact with rounded CuS } \\
\text { inclusions. These inclusions contain } 20 \mathrm{wt} \% \text { sulphur. }\end{array}$ \\
\hline SMB26(2) & Shankare & Trench SHAM1- Layer 6 & 4.03 & $\begin{array}{l}\text { Non-magnetic, fragment of copper } \\
\text { plate not finished artefact. From the } \\
\text { lowest levels of the excavation unit. }\end{array}$ & $\begin{array}{l}\text { Pure copper sample, very porous with a clean microscopical } \\
\text { matrix. Tiny inclusions rich in lead and tin were noted during } \\
\text { the SEM-EDS session. }\end{array}$ \\
\hline SMB81(1) & Shankare & Trench SHAM1- Layer 1 & 1.06 & $\begin{array}{l}\text { Non-magnetic, tiny fragment of } \\
\text { copper from the burial context. } \\
15 \mathrm{~mm} \text { in length. }\end{array}$ & $\begin{array}{l}\text { The metal matrix is very porous. Corrosion from the outside } \\
\text { Composition, pure copper with dendrites of alpha } \mathrm{Cu}, \mathrm{Cu}-\mathrm{O} \\
\text { eutectic, on average the cuprite contains } 10 \mathrm{wt} \% \text { oxygen. }\end{array}$ \\
\hline $\operatorname{SSC}(1)$ & Shankare & Surface NE of the Hill & 18.09 & $\begin{array}{l}\text { Non-magnetic, fragment of a heavy } \\
\text { bangle. } 40 \mathrm{~mm} \text { in length. }\end{array}$ & $\begin{array}{l}\text { Homogenous microstructure. Composition is pure copper with } \\
\text { cuprite inclusions, dendrite } \mathrm{Cu} \text { alpha phase and } \mathrm{Cu}-\mathrm{O} \text { eutectic. } \\
\text { The cuprite contains } \mathrm{c} 10 \mathrm{wt} \% \text { oxygen. }\end{array}$ \\
\hline $\operatorname{SSC}(2)$ & Shankare & Surface NE of the Hill & 3.76 & $\begin{array}{l}\text { Non-magnetic, complete copper } \\
\text { bangle made from thin wire. } \\
150 \mathrm{~mm} \text { in length. }\end{array}$ & $\begin{array}{l}\text { The sample is not porous and contains squashed inclusions, most } \\
\text { likely cuprite, suggesting hammering into shape or wire } \\
\text { drawing. The sample is pure copper. }\end{array}$ \\
\hline
\end{tabular}




\section{SMB21(2) : COPPER WIRE}
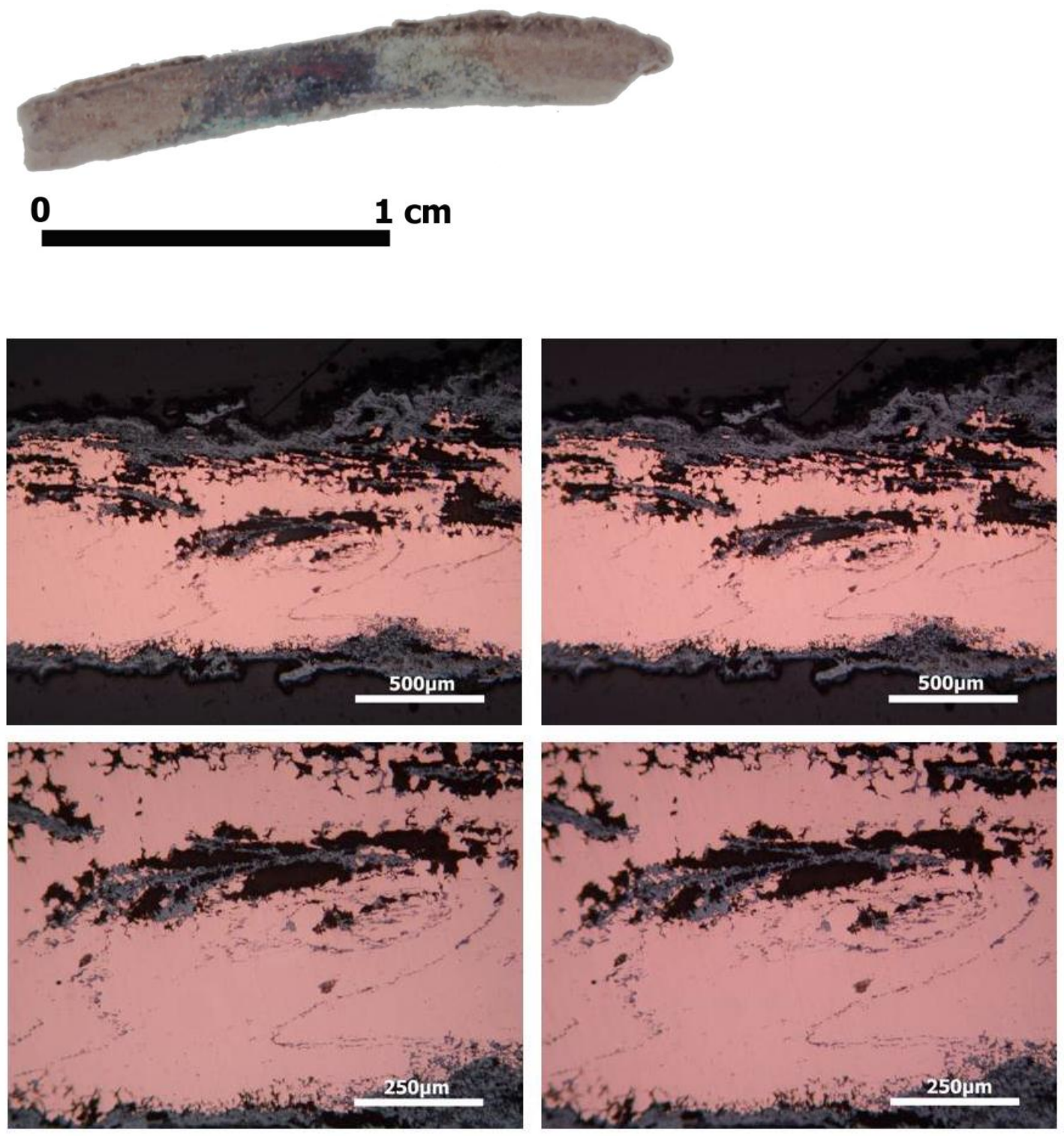

Photomicrographs of sample SMB21(2): Showing selective corrosion and squashed inclusions. Top left, under plane polarized light (50x). Top right, under cross polarized light (50x). Bottom left, under plane polarized light (100x). Bottom right, under cross polarized light (100x). 


\section{SMB22(3): COPPER PRILLS}

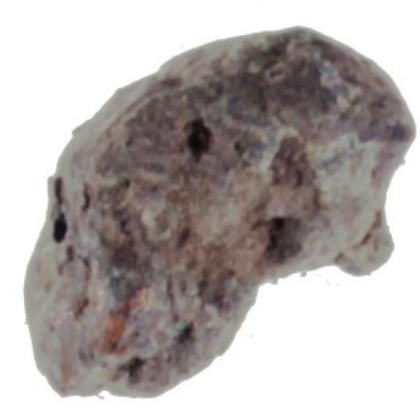

$\mathbf{0}$

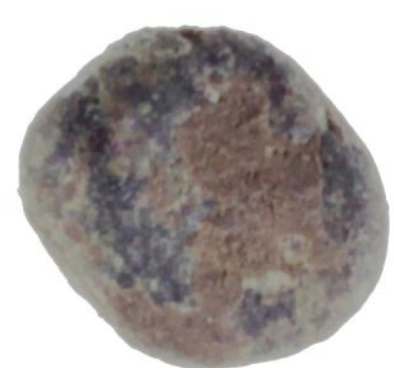

$1 \mathrm{~cm}$
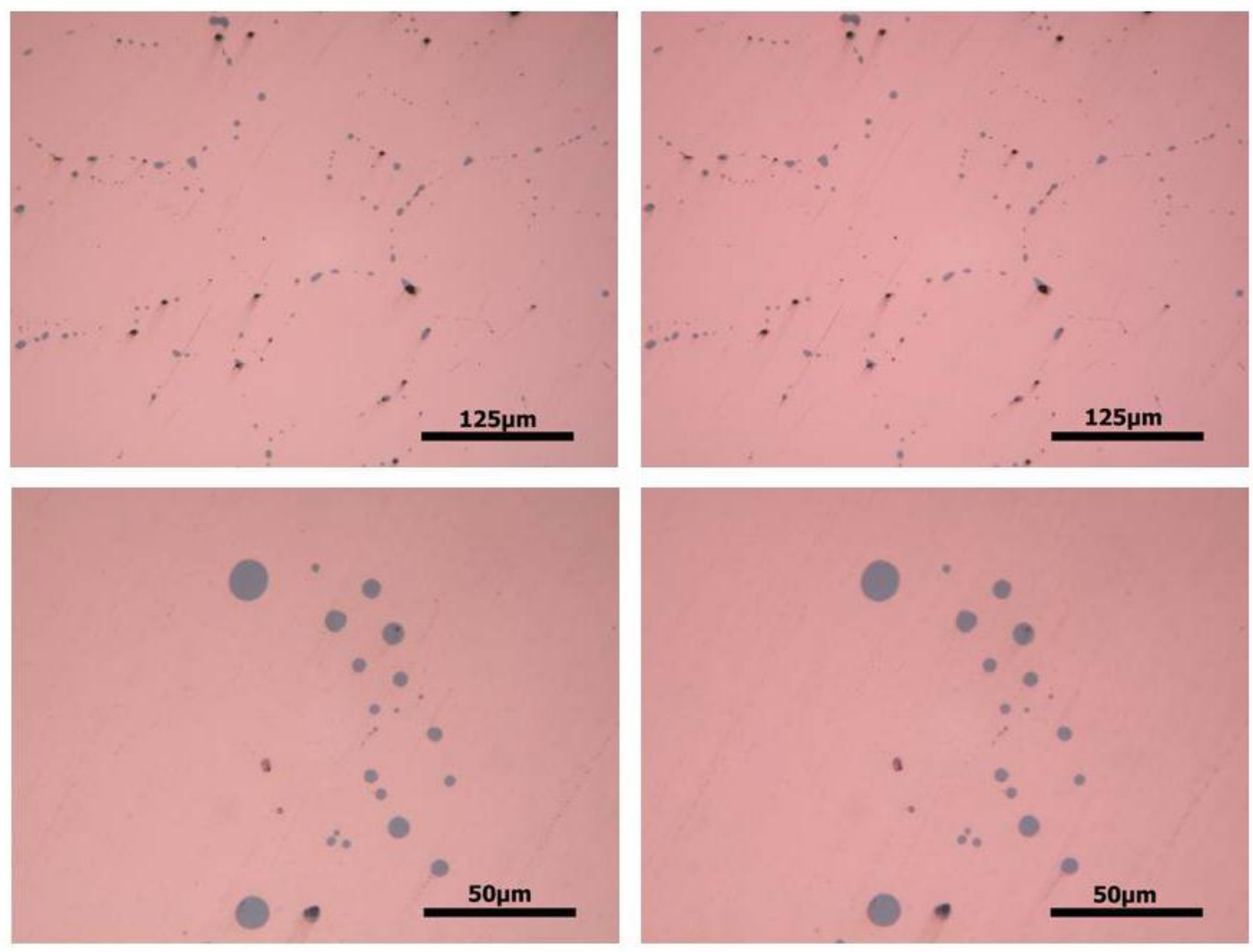

Photomicrographs of sample SMB22(3): Showing globular copper sulphide inclusions on the grain boundaries. Top left, under plane polarized light (200x). Top right, under cross polarized light (200x). Bottom left, under plane polarized light (500x). Bottom right, under cross polarized light (500x). 


\section{SMB26(2): COPPER PLATE}
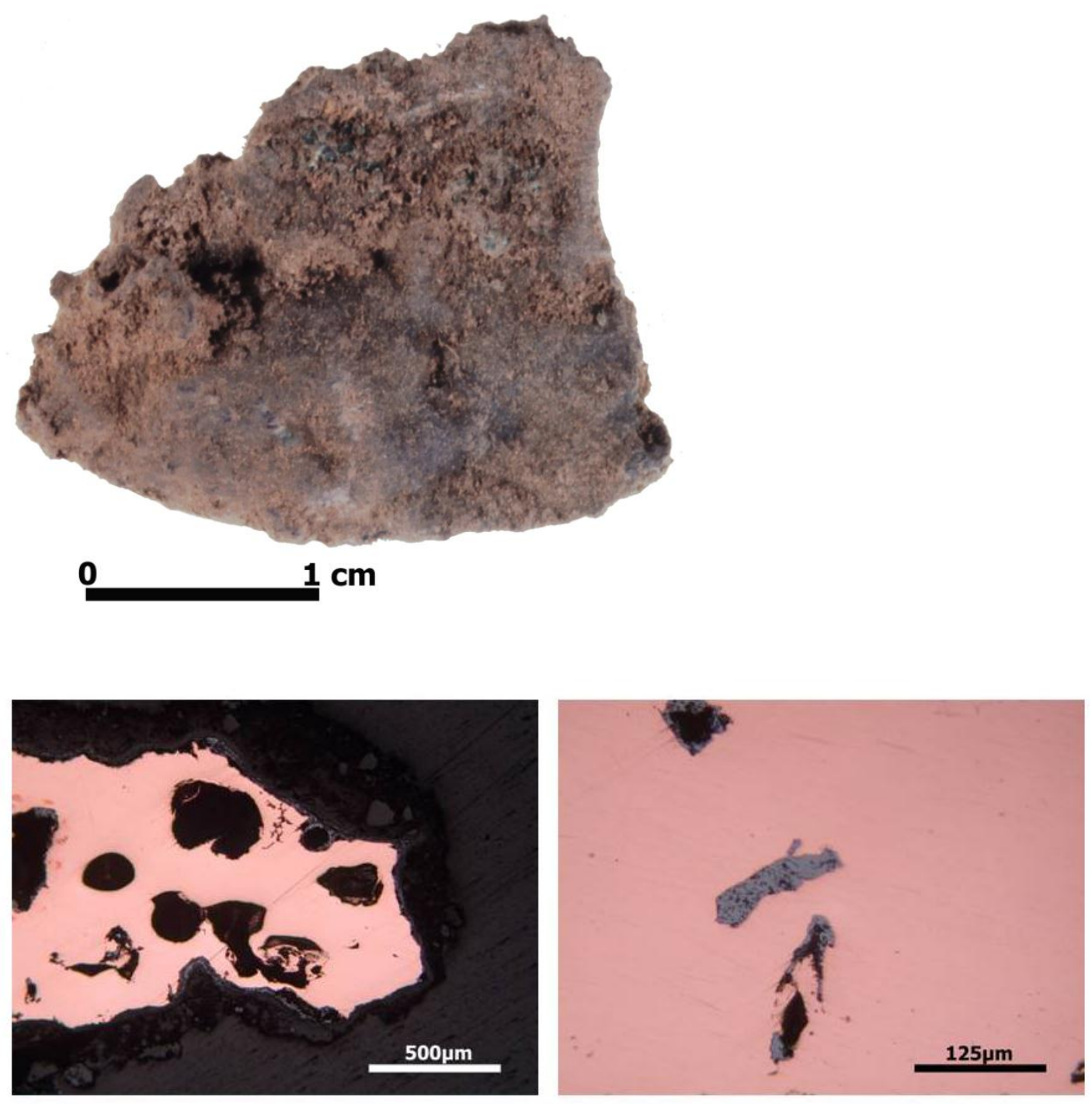

Photomicrographs of sample SBM26(2): Showing casting porosity. Left, under plane polarized light (50x). Right, under plane polarized light (200x). 


\section{SMB81(1): COPPER FRAGMENT}
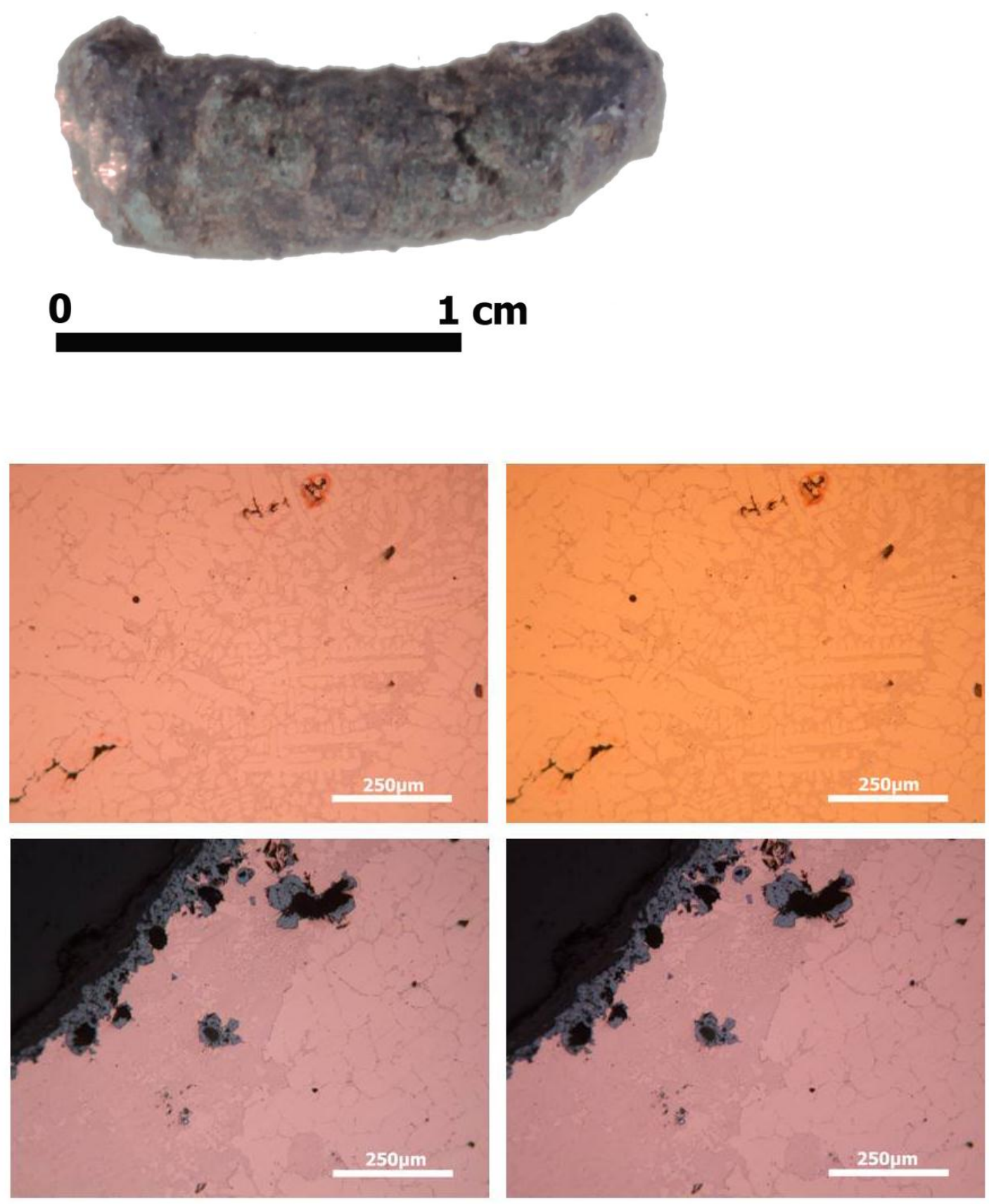

Photomicrographs of sample SMB81(1): Showing copper dendrites and coppercuprite eutectics. Top left, under plane polarized light (100x). Top right, under cross polarized light (100x). Bottom left, under plane polarized light (100x). Bottom right, under cross polarized light (100x). 


\section{SSC(1): HEAVY COPPER BANGLE FRAGMENT}
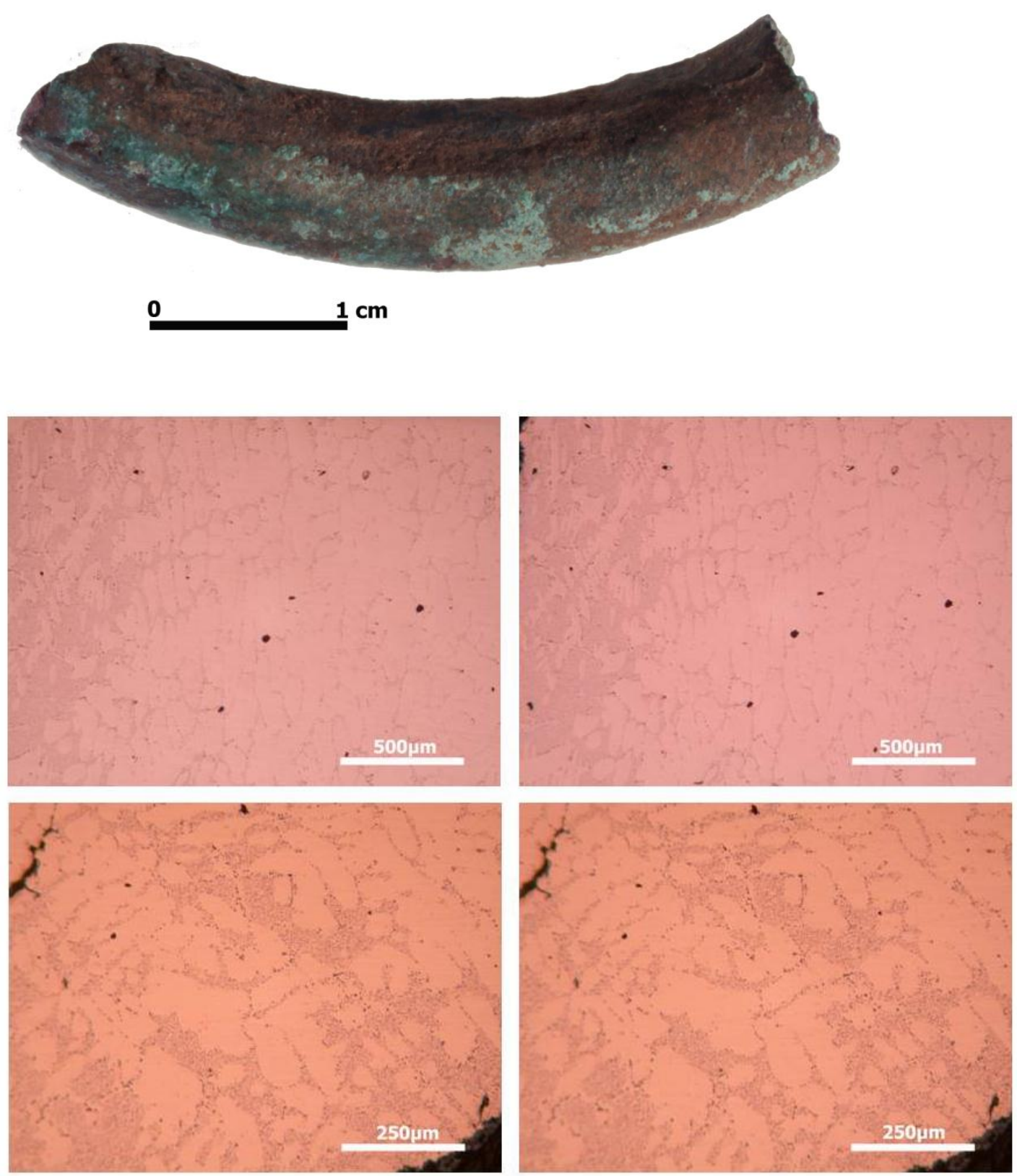

Photomicrographs of sample SSC(1): Showing copper dendrites and copper-cuprite eutectics. Top left, under plane polarized light (50x). Top right, under cross polarized light (50x). Bottom left, under plane polarized light (100x). Bottom right, under cross polarized light (100x). 


\section{SSC(2): COPPER WIRE BANGLE}
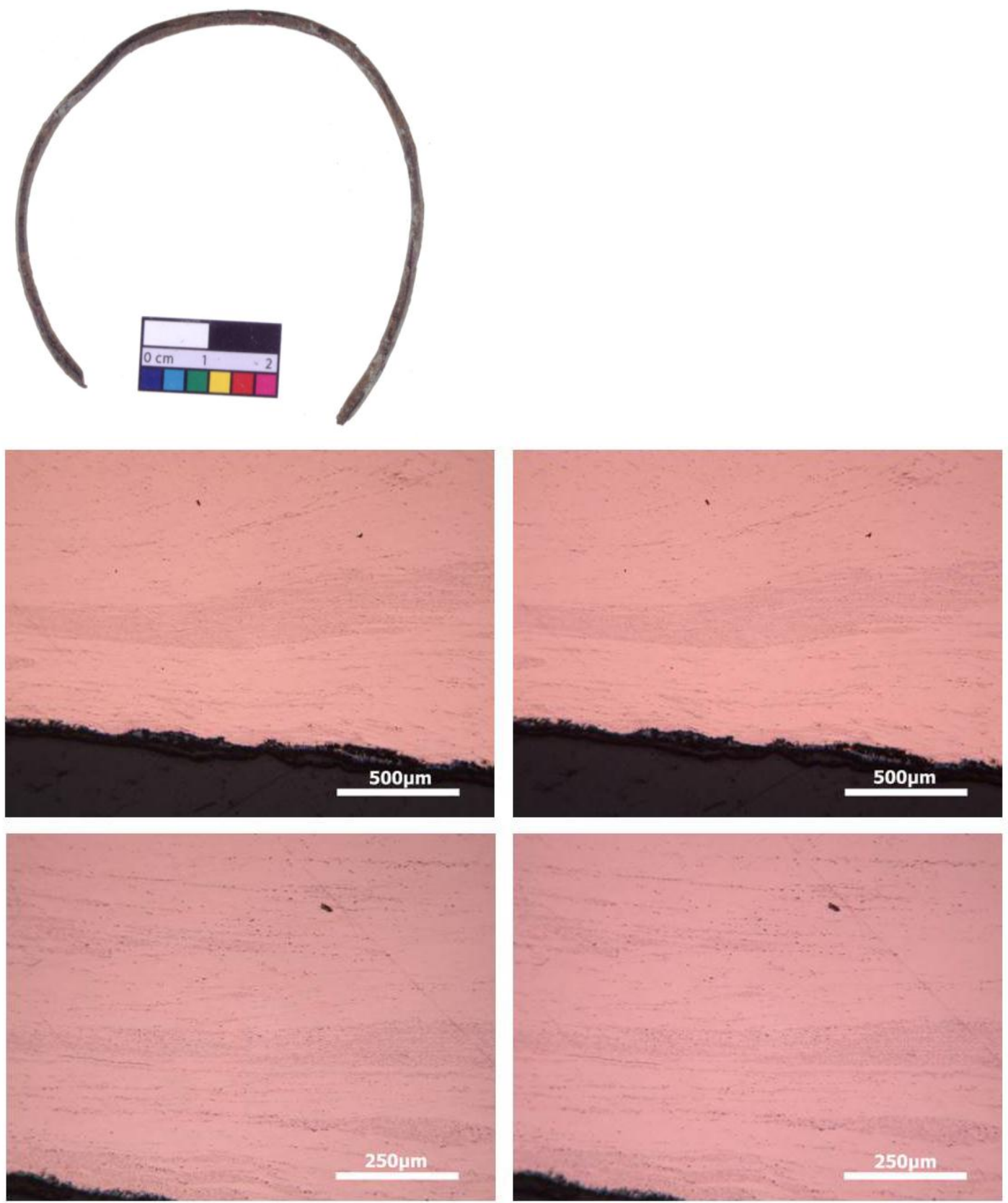

Photomicrographs of sample SSC(2): Showing elongated or heavy squashed inclusions. Top left, under plane polarized light (50x). Top right, under cross polarized light (50x). Bottom left, under plane polarized light (100x). Bottom right, under cross polarized light (100x). 
Appendix 6: Full (P)ED-XRF bulk composition data of slag samples from Shankare Hill 
Table 1: Full (P)ED-XRF results of selected iron smelting slags from Shankare Hill. Results presented in weight $\%$ and totals not normalised.

\begin{tabular}{|c|c|c|c|c|c|c|c|c|c|c|c|c|c|}
\hline SAMPLE & $\mathrm{Na2O}$ & $\mathrm{MgO}$ & Al2O3 & $\mathrm{SiO2}$ & P2O5 & SO3 & K2O & $\mathrm{CaO}$ & TiO2 & V2O5 & $\mathrm{Cr} 2 \mathrm{O3}$ & MnO & $\mathrm{FeO}$ \\
\hline & $\%$ & $\%$ & $\%$ & $\%$ & $\%$ & $\%$ & $\%$ & $\%$ & $\%$ & $\%$ & $\%$ & $\%$ & $\%$ \\
\hline SHA4NEL & 0.35 & 3.95 & 5.06 & 32.16 & 0.85 & 0.17 & 2.53 & 14.54 & 6.67 & 0.09 & 0.01 & 0.36 & 38.98 \\
\hline SHA4NEL & 0.51 & 4.16 & 5.11 & 32.53 & 0.88 & 0.17 & 2.57 & 14.73 & 6.84 & 0.13 & 0.02 & 0.38 & 39.72 \\
\hline SHA4NEL & 0.70 & 4.15 & 5.19 & 32.50 & 0.89 & 0.18 & 2.58 & 14.76 & 6.81 & 0.09 & 0.01 & 0.37 & 39.56 \\
\hline Average & 0.52 & 4.09 & 5.12 & 32.40 & 0.87 & 0.17 & 2.56 & 14.68 & 6.77 & 0.10 & 0.01 & 0.37 & 39.42 \\
\hline SHA6NEL & 0.65 & 3.76 & 4.82 & 31.66 & 0.98 & 0.18 & 2.73 & 12.19 & 6.40 & 0.11 & 0.01 & 0.34 & 44.80 \\
\hline SHA6NEL & 0.60 & 3.80 & 4.86 & 31.51 & 0.97 & 0.18 & 2.73 & 12.19 & 6.40 & 0.11 & 0.01 & 0.34 & 44.87 \\
\hline SHA6NEL & 0.66 & 3.91 & 4.95 & 31.74 & 0.98 & 0.19 & 2.74 & 12.27 & 6.46 & 0.11 & 0.01 & 0.35 & 45.27 \\
\hline Average & 0.64 & 3.82 & 4.88 & 31.64 & 0.98 & 0.19 & 2.73 & 12.22 & 6.42 & 0.11 & 0.01 & 0.34 & 44.98 \\
\hline SHA7NEL & 0.58 & 3.82 & 4.53 & 29.91 & 0.54 & 0.12 & 1.96 & 14.02 & 9.14 & 0.11 & 0.02 & 0.37 & 43.27 \\
\hline SHA7NEL & 0.63 & 3.70 & 4.56 & 30.02 & 0.55 & 0.12 & 1.98 & 14.04 & 9.06 & 0.07 & 0.02 & 0.37 & 43.20 \\
\hline SHA7NEL & 0.71 & 3.78 & 4.57 & 29.69 & 0.54 & 0.12 & 1.94 & 13.95 & 9.11 & 0.10 & 0.02 & 0.37 & 43.10 \\
\hline Average & 0.64 & 3.77 & 4.56 & 29.87 & 0.54 & 0.12 & 1.96 & 14.00 & 9.10 & 0.09 & 0.02 & 0.37 & 43.19 \\
\hline SHA8NEL & 0.46 & 3.46 & 3.81 & 26.96 & 0.90 & 0.21 & 2.38 & 10.30 & 4.21 & 0.11 & 0.02 & 0.33 & 57.86 \\
\hline SHA8NEL & 0.46 & 3.42 & 3.79 & 26.89 & 0.90 & 0.21 & 2.37 & 10.30 & 4.21 & 0.11 & 0.02 & 0.33 & 57.84 \\
\hline SHA8NEL & 0.64 & 3.38 & 3.92 & 27.09 & 0.90 & 0.21 & 2.40 & 10.40 & 4.23 & 0.11 & 0.02 & 0.33 & 58.21 \\
\hline Average & 0.52 & 3.42 & 3.84 & 26.98 & 0.90 & 0.21 & 2.38 & 10.33 & 4.21 & 0.11 & 0.02 & 0.33 & 57.97 \\
\hline SHA10NEL & 0.12 & 1.42 & 1.57 & 24.28 & 9.42 & 0.10 & 0.69 & 13.03 & 0.92 & 0.06 & 0.04 & 0.30 & 47.55 \\
\hline SHA10NEL & 0.60 & 1.68 & 1.75 & 25.04 & 9.62 & 0.10 & 0.71 & 13.41 & 0.94 & 0.07 & 0.04 & 0.30 & 48.77 \\
\hline SHA10NEL & 0.76 & 1.70 & 1.69 & 24.39 & 9.49 & 0.10 & 0.69 & 13.16 & 0.93 & 0.06 & 0.04 & 0.30 & 48.09 \\
\hline Average & 0.49 & 1.60 & 1.67 & 24.57 & 9.51 & 0.10 & 0.70 & 13.20 & 0.93 & 0.06 & 0.04 & 0.30 & 48.14 \\
\hline
\end{tabular}


Table 1: continued from previous page.

\begin{tabular}{|c|c|c|c|c|c|c|c|c|c|c|c|c|c|c|c|c|c|c|}
\hline SAMPLE & $\mathrm{Co3O4}$ & $\mathrm{NiO}$ & $\mathrm{CuO}$ & $\mathrm{ZnO}$ & Ga2O3 & Rb2O & SrO & Y2O3 & $\mathrm{ZrO2}$ & $\mathrm{Nb2O5}$ & $\mathrm{SnO2}$ & $\mathrm{BaO}$ & $\mathrm{La2O3}$ & $\mathrm{Ce} 2 \mathrm{O3}$ & WO3 & ThO2 & U308 & TOTAL \\
\hline & ppm & ppm & ppm & ppm & ppm & ppm & ppm & ppm & ppm & ppm & ppm & ppm & ppm & ppm & ppm & ppm & ppm & \\
\hline SHA4NEL & 498 & 0 & 234 & 43 & 17 & 30 & 1363 & 13 & 892 & 1 & 12 & 1298 & 102 & 228 & 10 & 0 & 8 & 106.21 \\
\hline SHA4NEL & 357 & 0 & 244 & 48 & 15 & 31 & 1389 & 10 & 933 & 4 & 12 & 1295 & 114 & 239 & 12 & 0 & 8 & 108.21 \\
\hline SHA4NEL & 452 & 0 & 249 & 45 & 17 & 31 & 1383 & 14 & 954 & 6 & 12 & 1315 & 118 & 231 & 12 & 0 & 6 & 108.27 \\
\hline Average & 436 & $\mathbf{0}$ & 242 & 45 & 16 & 31 & 1378 & 12 & 926 & 3 & 12 & 1302 & 111 & 233 & 11 & 0 & 7 & 107.56 \\
\hline SHA6NEL & 541 & 0 & 107 & 45 & 13 & 25 & 1121 & 16 & 835 & 6 & 15 & 1653 & 32 & 172 & 12 & 0 & 7 & 109.11 \\
\hline SHA6NEL & 439 & 0 & 98 & 45 & 15 & 25 & 1112 & 10 & 833 & 2 & 14 & 1656 & 76 & 212 & 11 & 0 & 4 & 109.03 \\
\hline SHA6NEL & 457 & 0 & 96 & 43 & 14 & 27 & 1128 & 9 & 880 & 7 & 14 & 1657 & 61 & 125 & 12 & 0 & 2 & 110.08 \\
\hline Average & 479 & 0 & 100 & 44 & 14 & 26 & 1120 & 12 & 849 & 5 & 14 & 1655 & 56 & 170 & 11 & 0 & 5 & 109.41 \\
\hline SHA7NEL & 480 & 0 & 67 & 63 & 13 & 22 & 1394 & 11 & 934 & 4 & 13 & 2024 & 30 & 76 & 7 & 0 & 5 & 108.90 \\
\hline SHA7NEL & 530 & 0 & 60 & 60 & 13 & 20 & 1395 & 8 & 922 & 0 & 13 & 2050 & 66 & 0 & 10 & 0 & 5 & 108.83 \\
\hline SHA7NEL & 479 & 0 & 64 & 62 & 15 & 20 & 1386 & 9 & 919 & 6 & 12 & 2033 & 0 & 88 & 9 & 0 & 0 & 108.52 \\
\hline Average & 496 & $\mathbf{0}$ & 64 & 62 & 14 & 21 & 1392 & 10 & 925 & 3 & 12 & 2036 & 32 & 55 & 9 & 0 & 3 & 108.75 \\
\hline SHA8NEL & 568 & 0 & 273 & 44 & 10 & 0 & 947 & 15 & 580 & 0 & 14 & 1248 & 117 & 296 & 5 & 0 & 7 & 111.42 \\
\hline SHA8NEL & 559 & 0 & 269 & 44 & 8 & 0 & 947 & 15 & 637 & 0 & 15 & 1239 & 74 & 259 & 5 & 0 & 6 & 111.26 \\
\hline SHA8NEL & 697 & 0 & 282 & 42 & 16 & 0 & 946 & 12 & 631 & 0 & 13 & 1252 & 97 & 247 & 7 & 0 & 6 & 112.27 \\
\hline Average & 608 & $\mathbf{0}$ & 275 & 44 & 11 & $\mathbf{0}$ & 947 & 14 & 616 & $\mathbf{0}$ & 14 & 1246 & 96 & 267 & 6 & o & 6 & 111.65 \\
\hline SHA10NEL & 1131 & 243 & 49030 & 1143 & 7 & 9 & 2231 & 113 & 724 & 0 & 18 & 1404 & 3052 & 4479 & 0 & 127 & 26 & 105.87 \\
\hline SHA10NEL & 1153 & 243 & 50420 & 1185 & 9 & 8 & 2280 & 112 & 714 & 37 & 18 & 1451 & 3089 & 4518 & 0 & 122 & 33 & 109.57 \\
\hline SHA10NEL & 985 & 251 & 49350 & 1192 & 7 & 0 & 2237 & 109 & 728 & 0 & 17 & 1406 & 3069 & 4521 & 0 & 115 & 32 & 107.82 \\
\hline Average & 1090 & 246 & 49600 & 1173 & 8 & 6 & 2249 & 111 & 722 & 12 & 17 & 1420 & 3070 & 4506 & 0 & 121 & 30 & 107.75 \\
\hline
\end{tabular}


Table 2: Full (P)ED-XRF results of copper smelting slags from Shankare Hill. Results presented in weight \% and totals not normalised.

\begin{tabular}{|c|c|c|c|c|c|c|c|c|c|c|c|c|c|}
\hline SAMPLE & $\mathrm{Na} 2 \mathrm{O}$ & $\mathrm{MgO}$ & Al2O3 & $\mathrm{SiO} 2$ & $\mathbf{P 2 O 5}$ & SO3 & K2O & $\mathrm{CaO}$ & TiO2 & V2O5 & $\mathrm{Cr} 203$ & MnO & $\mathrm{FeO}$ \\
\hline & $\%$ & $\%$ & $\%$ & $\%$ & $\%$ & $\%$ & $\%$ & $\%$ & $\%$ & $\%$ & $\%$ & $\%$ & $\%$ \\
\hline SHA4NWL(R1) & 0.41 & 3.29 & 2.67 & 37.56 & 4.71 & 0.14 & 1.06 & 18.78 & 0.40 & 0.01 & 0.03 & 0.22 & 32.36 \\
\hline SHA4NWL(R2) & 0.00 & 3.09 & 2.63 & 37.72 & 4.67 & 0.14 & 1.07 & 18.94 & 0.40 & 0.02 & 0.03 & 0.22 & 32.56 \\
\hline SHA4NWL(R3) & 0.46 & 3.41 & 2.66 & 38.13 & 4.79 & 0.14 & 1.09 & 19.22 & 0.41 & 0.02 & 0.03 & 0.22 & 33.23 \\
\hline Average & 0.29 & 3.26 & 2.66 & 37.80 & 4.72 & 0.14 & 1.07 & 18.98 & 0.40 & 0.02 & $\mathbf{0 . 0 3}$ & 0.22 & 32.72 \\
\hline SHA5NWL(R1) & 0.07 & 3.15 & 2.74 & 38.78 & 4.55 & 0.12 & 1.16 & 16.99 & 0.42 & 0.02 & 0.03 & 0.21 & 32.52 \\
\hline SHA5NWL(R2) & 0.11 & 3.20 & 2.77 & 38.68 & 4.56 & 0.12 & 1.15 & 16.94 & 0.41 & 0.02 & 0.03 & 0.21 & 32.42 \\
\hline SHA5NWL(R3) & 0.63 & 3.41 & 2.83 & 39.02 & 4.58 & 0.12 & 1.17 & 17.17 & 0.41 & 0.02 & 0.03 & 0.21 & 32.56 \\
\hline Average & 0.27 & 3.25 & 2.78 & 38.83 & 4.56 & 0.12 & 1.16 & 17.03 & 0.41 & 0.02 & $\mathbf{0 . 0 3}$ & 0.21 & 32.50 \\
\hline SHA6NWL(R1) & 0.50 & 2.95 & 3.03 & 36.97 & 3.90 & 0.13 & 1.27 & 18.94 & 0.36 & 0.01 & 0.03 & 0.21 & 31.47 \\
\hline SHA6NWL(R2) & 0.19 & 3.00 & 3.03 & 38.11 & 4.05 & 0.14 & 1.28 & 19.45 & 0.37 & 0.02 & 0.03 & 0.21 & 32.16 \\
\hline SHA6NWL(R3) & 0.22 & 2.78 & 2.96 & 37.11 & 3.90 & 0.14 & 1.25 & 19.03 & 0.36 & 0.02 & 0.03 & 0.21 & 31.64 \\
\hline Average & 0.30 & 2.91 & 3.01 & 37.40 & 3.95 & 0.13 & 1.27 & $\mathbf{1 9 . 1 4}$ & 0.36 & 0.02 & $\mathbf{0 . 0 3}$ & 0.21 & 31.76 \\
\hline SHA8NWL(R1) & 0.67 & 2.89 & 2.79 & 35.36 & 5.77 & 0.18 & 0.98 & 18.64 & 0.44 & 0.02 & 0.04 & 0.21 & 31.14 \\
\hline SHA8NWL(R2) & 0.62 & 2.83 & 2.80 & 35.68 & 5.83 & 0.19 & 0.97 & 18.73 & 0.44 & 0.02 & 0.04 & 0.22 & 31.33 \\
\hline SHA8NWL(R3) & 0.43 & 2.79 & 2.73 & 35.16 & 5.73 & 0.20 & 0.97 & 18.58 & 0.45 & 0.02 & 0.04 & 0.21 & 31.03 \\
\hline Average & 0.57 & 2.84 & 2.77 & 35.40 & 5.78 & 0.19 & 0.97 & 18.65 & 0.44 & 0.02 & 0.04 & 0.21 & 31.17 \\
\hline SHA9NWL(R1) & 0.41 & 1.42 & 0.46 & 14.48 & 0.25 & 0.19 & 0.23 & 4.08 & 0.09 & 0.04 & 0.03 & 0.21 & 78.28 \\
\hline SHA9NWL(R2) & 0.23 & 1.49 & 0.46 & 14.73 & 0.24 & 0.19 & 0.22 & 4.17 & 0.09 & 0.04 & 0.04 & 0.22 & 78.99 \\
\hline SHA9NWL(R3) & 0.25 & 1.50 & 0.49 & 14.96 & 0.24 & 0.20 & 0.23 & 4.21 & 0.10 & 0.04 & 0.04 & 0.22 & 79.34 \\
\hline Average & 0.30 & 1.47 & 0.47 & 14.72 & 0.24 & 0.19 & 0.23 & 4.15 & 0.09 & 0.04 & 0.04 & 0.22 & 78.87 \\
\hline SHA10NWL(R1) & 0.24 & 4.14 & 2.26 & 35.91 & 3.98 & 0.15 & 1.01 & 18.85 & 0.36 & 0.02 & 0.04 & 0.22 & 31.50 \\
\hline SHA10NWL(R2) & 0.55 & 4.06 & 2.27 & 35.34 & 3.95 & 0.15 & 0.98 & 18.65 & 0.36 & 0.01 & 0.04 & 0.21 & 31.09 \\
\hline SHA10NWL(R3) & 0.16 & 3.99 & 2.31 & 36.13 & 4.04 & 0.16 & 1.01 & 19.09 & 0.36 & 0.02 & 0.04 & 0.22 & 31.87 \\
\hline Average & 0.32 & 4.06 & 2.28 & 35.79 & 3.99 & 0.15 & 1.00 & 18.86 & 0.36 & 0.02 & 0.04 & 0.22 & 31.49 \\
\hline
\end{tabular}


Table 2: continued from previous page.

\begin{tabular}{|c|c|c|c|c|c|c|c|c|c|c|c|c|c|c|c|c|c|c|c|c|}
\hline SAMPLE & $\mathrm{Co3O4}$ & $\mathrm{NiO}$ & $\mathrm{CuO}$ & $\mathrm{ZnO}$ & Ga2O3 & Rb2O & SrO & $\mathrm{Y2O3}$ & $\mathrm{ZrO2}$ & $\mathrm{Nb2O5}$ & Ag & $\mathrm{SnO2}$ & $\mathrm{BaO}$ & $\mathrm{La2O3}$ & $\mathrm{Ce} 2 \mathrm{O3}$ & $\mathrm{Nd} 2 \mathrm{O3}$ & WO3 & ThO2 & U308 & TOTAL \\
\hline & ppm & ppm & ppm & ppm & ppm & ppm & ppm & ppm & ppm & ppm & ppm & ppm & ppm & ppm & ppm & ppm & ppm & ppm & ppm & \\
\hline SHA4NWL(R1) & 849 & 49 & 8291 & 177 & 17 & 26 & 1941 & 84 & 4454 & 6 & 0 & 8 & 2706 & 1447 & 2277 & 1244 & 11 & 177 & 29 & 104.03 \\
\hline SHA4NWL(R2) & 797 & 46 & 8398 & 180 & 17 & 24 & 1938 & 83 & 4588 & 7 & 0 & 7 & 2750 & 1450 & 2271 & 1210 & 11 & 179 & 37 & 103.88 \\
\hline SHA4NWL(R3) & 605 & 65 & 8647 & 176 & 19 & 24 & 1992 & 85 & 4750 & 14 & 0 & 8 & 2787 & 1488 & 2368 & 1276 & 12 & 183 & 29 & 106.26 \\
\hline Average & 750 & 54 & 8445 & 177 & 18 & 24 & 1957 & 84 & 4597 & 9 & $\mathbf{0}$ & 8 & 2748 & 1462 & 2306 & 1243 & 11 & 180 & 32 & 104.72 \\
\hline SHA5NWL(R1) & 758 & 160 & 22370 & 236 & 20 & 29 & 1754 & 80 & 4965 & 7 & 0 & 10 & 2451 & 1372 & 2175 & 1134 & 10 & 161 & 29 & 104.54 \\
\hline SHA5NWL(R2) & 852 & 156 & 22380 & 232 & 20 & 30 & 1756 & 83 & 4908 & 7 & 0 & 10 & 2470 & 1345 & 2135 & 1309 & 8 & 162 & 27 & 104.40 \\
\hline SHA5NWL(R3) & 843 & 153 & 22410 & 236 & 17 & 27 & 1757 & 79 & 4924 & 10 & 0 & 10 & 2462 & 1386 & 2163 & 1117 & 13 & 164 & 27 & 105.94 \\
\hline Average & 818 & 156 & 22387 & 235 & 19 & 29 & 1756 & 81 & 4932 & 8 & $\mathbf{0}$ & 10 & 2461 & 1368 & 2158 & 1187 & 10 & 162 & 28 & 104.96 \\
\hline SHA6NWL(R1) & 714 & 102 & 12940 & 169 & 17 & 31 & 1863 & 79 & 3678 & 15 & 0 & 6 & 2317 & 1326 & 2146 & 1107 & 13 & 160 & 25 & 102.44 \\
\hline SHA6NWL(R2) & 803 & 97 & 13290 & 178 & 19 & 30 & 1901 & 81 & 3720 & 13 & 0 & 6 & 2398 & 1443 & 2255 & 1171 & 12 & 161 & 25 & 104.79 \\
\hline SHA6NWL(R3) & 846 & 96 & 13100 & 165 & 17 & 30 & 1879 & 80 & 3691 & 19 & 0 & 5 & 2358 & 1424 & 2261 & 1411 & 13 & 161 & 27 & 102.40 \\
\hline Average & 788 & 98 & 13110 & 171 & 18 & 31 & 1881 & 80 & 3696 & 16 & $\mathbf{0}$ & 6 & 2358 & 1398 & 2220 & 1230 & 13 & 161 & 26 & 103.21 \\
\hline SHA8NWL(R1) & 697 & 89 & 13810 & 194 & 25 & 21 & 1979 & 83 & 6210 & 11 & 0 & 6 & 2148 & 1499 & 2341 & 1249 & 12 & 126 & 21 & 102.20 \\
\hline SHA8NWL(R2) & 761 & 86 & 13780 & 208 & 17 & 22 & 1999 & 84 & 6256 & 18 & 0 & 5 & 2199 & 1495 & 2378 & 1298 & 10 & 127 & 21 & 102.77 \\
\hline SHA8NWL(R3) & 743 & 82 & 13750 & 194 & 22 & 23 & 1973 & 83 & 6193 & 11 & 0 & 6 & 2181 & 1463 & 2408 & 1502 & 13 & 123 & 25 & 101.42 \\
\hline Average & 734 & 86 & 13780 & 199 & 21 & 22 & 1984 & 83 & 6220 & 13 & $\mathbf{0}$ & 6 & 2176 & 1486 & 2376 & 1350 & 12 & 125 & 22 & 102.13 \\
\hline SHA9NWL(R1) & 1303 & 0 & 48820 & 212 & 0 & 0 & 663 & 24 & 62 & 0 & 8 & 18 & 2194 & 507 & 875 & 275 & 0 & 0 & 15 & 105.68 \\
\hline SHA9NWL(R2) & 1296 & 0 & 49000 & 216 & 20 & 0 & 663 & 24 & 25 & 0 & 10 & 18 & 2222 & 533 & 852 & 602 & 0 & 0 & 18 & 106.65 \\
\hline SHA9NWL(R3) & 1198 & 0 & 48850 & 208 & 24 & 0 & 669 & 27 & 61 & 0 & 13 & 17 & 2215 & 477 & 842 & 323 & 0 & 0 & 17 & 107.31 \\
\hline Average & 1266 & $\mathbf{0}$ & 48890 & 212 & 15 & 0 & 665 & 25 & 49 & $\mathbf{0}$ & 10 & 17 & 2210 & 506 & 856 & 400 & $\mathbf{0}$ & $\mathbf{0}$ & 17 & 106.54 \\
\hline SHA10NWL(R1) & 796 & 155 & 32020 & 219 & 19 & 26 & 1999 & 74 & 4641 & 11 & 0 & 8 & 2132 & 1308 & 2107 & 1171 & 0 & 122 & 24 & 103.34 \\
\hline SHA10NWL(R2) & 1108 & 144 & 31840 & 222 & 19 & 25 & 1985 & 74 & 4673 & 15 & 2 & 8 & 2139 & 1404 & 2139 & 1203 & 4 & 123 & 24 & 102.37 \\
\hline SHA10NWL(R3) & 762 & 179 & 32420 & 217 & 24 & 27 & 2026 & 77 & 4798 & 22 & 0 & 8 & 2190 & 1372 & 2183 & 1126 & 4 & 125 & 25 & 104.15 \\
\hline Average & 889 & 159 & 32093 & 219 & 21 & 26 & 2003 & 75 & 4704 & 16 & 1 & 8 & 2154 & 1361 & 2143 & 1167 & 3 & 123 & 24 & 103.28 \\
\hline
\end{tabular}


